
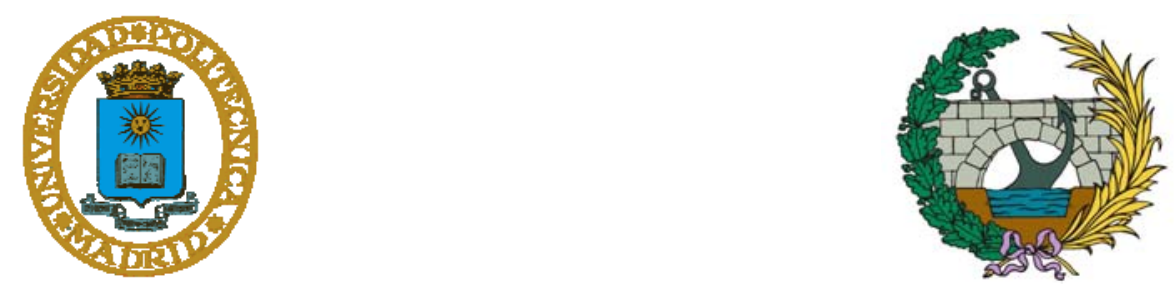

UNIVERSIDAD POLITÉCNICA DE MADRID

E.T.S. INGENIEROS DE CAMINOS, CANALES Y PUERTOS

TESIS DOCTORAL

OPTIMIZACIÓN DE CIMENTACIONES DIRECTAS DE MEDIANERÍA Y ESQUINA MEDIANTE MODELOS DE ELEMENTOS FINITOS

Pablo Galletero Montero

Arquitecto

Madrid 2016 


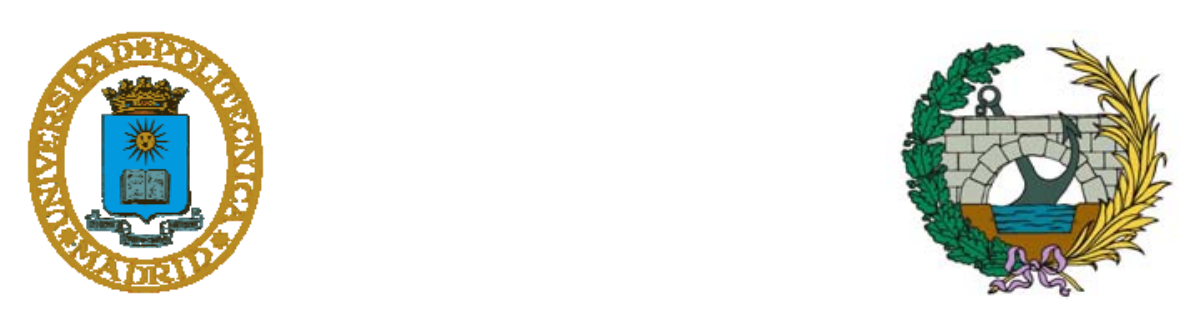

DEPARTAMENTO DE INGENIERÍA CIVIL - CONSTRUCCIÓN

E.T.S. INGENIEROS DE CAMINOS, CANALES Y PUERTOS

TESIS DOCTORAL

\title{
OPTIMIZACIÓN DE CIMENTACIONES DIRECTAS DE MEDIANERÍA Y ESQUINA MEDIANTE MODELOS DE ELEMENTOS FINITOS
}

\author{
Autor: Pablo Galletero Montero \\ Arquitecto \\ Directores: D. Jaime Fernández Gómez \\ Dr. Ingeniero de Caminos, Canales y Puertos \\ D. Bernardo Perepérez Ventura \\ Dr. Arquitecto
}




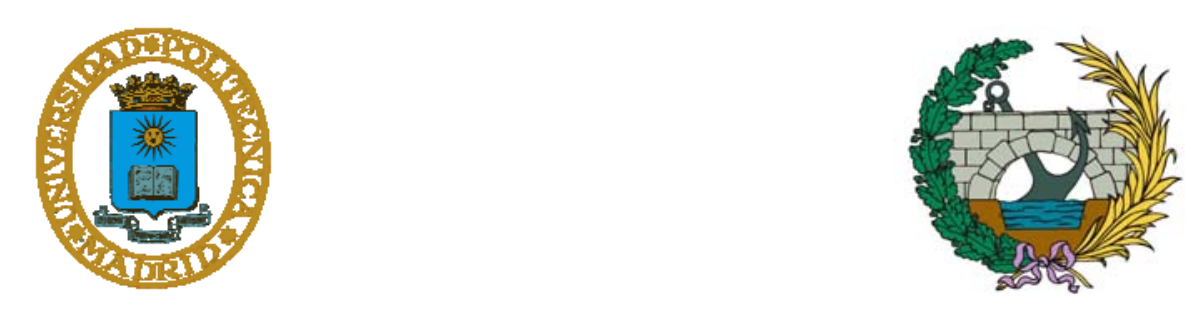

TESIS DOCTORAL

\title{
OPTIMIZACIÓN DE CIMENTACIONES DIRECTAS DE MEDIANERÍA Y ESQUINA MEDIANTE MODELOS DE ELEMENTOS FINITOS
}

\begin{abstract}
Autor:
Pablo Galletero Montero

Tribunal nombrado por el Magnífico y Excelentísimo Sr. Rector de la Universidad Politécnica de Madrid, el día de de 2015 para juzgar la Tesis Doctoral arriba citada, compuesto de la siguiente manera:
\end{abstract}

Presidente:

Vocal:

Vocal:

Vocal:

Vocal Secretario:

Acuerda otorgarle la calificación de:

EL PRESIDENTE/A EL SECRETARIO/A LOS VOCALES

Madrid, de de 2016 

A Santos Galletero, mi padre, que me ha transmitido el amor por la construcción y por el trabajo bien hecho 



\section{AGRADECIMIENTOS}

En primer lugar quisiera mostrar mi agradecimiento a mis directores de tesis D. Jaime Fernández Gómez y D. Bernardo Perepérez Ventura, por el tiempo que me han dedicado, por los consejos y orientaciones que de ellos he recibido a lo largo del proceso de elaboración de la tesis, y por el apoyo que, muy cordialmente, me han proporcionado en todo momento.

Aprovecho asimismo la ocasión para reconocer los años previos de aprendizaje en la E.T.S. de Arquitectura de Valencia junto a mi, hoy director, D. Bernardo Perepérez Ventura. Siempre tuve una predisposición, casi innata, hacia el mundo de la construcción y del cálculo de estructuras, pero esa inclinación se ve siempre reforzada cuando en tu camino se cruzan profesores con un marcado carisma, como Bernardo.

Quiero también tener un agradecimiento especial para Carlos Neumeister Peguero, compañero y amigo en la E.T.S.I. Agrónomos y de Montes de Albacete. Su apoyo con los medios informáticos y sus conocimientos en el manejo de las herramientas de cálculo mediante elementos finitos, han sido de inestimable valor en el desarrollo y evolución de esta tesis doctoral.

Y por último, y no por ello menos importante, un merecido agradecimiento a Manoli, mi mujer y a mis hijos Marcos y Pablo. Junto con esta profesión que me apasiona, ellos llenan mi vida y son uno de los principales motivos para seguir siempre adelante.

A todos ellos, mi más sincero agradecimiento. 



\section{RESUMEN}

Existe un amplio catálogo de posibles soluciones para resolver la problemática de las zapatas de medianería así como, por extensión, las zapatas de esquina como caso particular de las anteriores. De ellas, las más habitualmente empleadas en estructuras de edificación son, por un lado, la utilización de una viga centradora que conecta la zapata de medianería con la zapata del pilar interior más próximo y, por otro, la colaboración de la viga de la primera planta trabajando como tirante.

En la primera solución planteada, el equilibrio de la zapata de medianería y el centrado de la respuesta del terreno se consigue gracias a la colaboración del pilar interior con su cimentación y al trabajo a flexión de la viga centradora. La modelización clásica considera que se logra un centrado total de la reacción del terreno, con distribución uniforme de las tensiones de contacto bajo ambas zapatas. Este planteamiento presupone, por tanto, que la viga centradora logra evitar cualquier giro de la zapata de medianería y que el pilar puede, por ello, considerarse perfectamente empotrado en la cimentación. En este primer modelo, el protagonismo fundamental recae en la viga centradora, cuyo trabajo a flexión conduce frecuentemente a unas escuadrías y a unas cuantías de armado considerables.

La segunda solución, plantea la colaboración de la viga de la primera planta, trabajando como tirante. De nuevo, los métodos convencionales suponen un éxito total en el mecanismo estabilizador del tirante, que logra evitar cualquier giro de la zapata de medianería, dando lugar a una distribución de tensiones también uniforme.

Los modelos convencionales existentes para el cálculo de este tipo de cimentaciones presentan, por tanto, una serie de simplificaciones que permiten el cálculo de las mismas, por medios manuales, en un tiempo razonable, pero presentan el inconveniente de su posible alejamiento del comportamiento real de la cimentación, con las consecuencias negativas que ello puede suponer en el dimensionamiento de estos elementos estructurales. 
La presente tesis doctoral desarrolla un contraste de los modelos convencionales de cálculo de cimentaciones de medianería y esquina, mediante un análisis alternativo con modelos de elementos finitos, con el objetivo de poner de manifiesto las diferencias entre los resultados obtenidos con ambos tipos de modelización, analizar cuáles son las variables que más influyen en el comportamiento real de este tipo de cimentaciones y proponer un nuevo modelo de cálculo, de tipo convencional, más ajustado a la realidad.

El proceso de investigación se desarrolla mediante una etapa experimental virtual que utiliza como modelo un pórtico tipo de edificación, ortogonal, de hormigón armado, con dos vanos y número variable de plantas.

Tras identificar el posible giro de la cimentación como elemento clave en el comportamiento de las zapatas de medianería y de esquina, se adoptan como variables de estudio aquellas que mayor influencia puedan tener sobre el citado giro de las zapatas y sobre la rigidez del conjunto del elemento estructural. Así, se han estudiado luces de $3 \mathrm{~m}$ a $7 \mathrm{~m}$, diferente número de plantas desde baja+1 hasta baja+4, resistencias del terreno desde $100 \mathrm{kN} / \mathrm{m}^{2}$ hasta $300 \mathrm{kN} / \mathrm{m}^{2}$, relaciones de forma de la zapata de medianería de $1,5: 1$ y $2: 1$, aumento y reducción de la cuantía de armado de la viga centradora y variación del canto de la viga centradora desde el mínimo canto compatible con el anclaje de la armadura de los pilares hasta un incremento del $75 \%$ respecto del citado canto mínimo.

El conjunto de pórticos generados al aplicar las variables indicadas, se ha calculado tanto por métodos convencionales como por el método de los elementos finitos. Los resultados obtenidos ponen de manifiesto importantes discrepancias entre ambos métodos que conducen a importantes diferencias en el dimensionamiento de este tipo de cimentaciones. El empleo de los métodos tradicionales da lugar, por un lado, a un sobredimensionamiento de la armadura de la viga centradora y, por otro, a un infradimensionamiento, tanto del canto de la viga centradora, como del tamaño de la zapata de medianería y del armado de la viga de la primera planta.

Finalizado el análisis y discusión de resultados, la tesis propone un nuevo método alternativo, de carácter convencional y, por tanto, aplicable a un cálculo manual en un tiempo razonable, que permite obtener los parámetros clave que regulan el comportamiento de las zapatas de medianería y esquina, conduciendo a un dimensionamiento más ajustado a las necesidades reales de este tipo de cimentación. 


\section{ABSTRACT}

There is a wide catalogue of possible solutions to solve the problem of party shoes and, by extension, corner shoes as a special case of the above. From all of them, the most commonly used in building structures are, on one hand, the use of a centering beam that connects the party shoe with the shoe of the nearest interior pillar and, on the other hand, the collaboration of the beam of the first floor working as a tie rod.

In the first proposed solution, the balance of the party shoe and the centering of the ground response is achieved thanks to the collaboration of the interior pillar with his foundation along with the bending work of the centering beam. Classical modeling considers that a whole centering of the ground reaction is achieved, with uniform contact stress distribution under both shoes. This approach to the issue presupposes that the centering beam manages to avoid any rotation of the party shoe, so the pillar can be considered perfectly embedded in the foundation. In this first model, the leading role lies in the centering beam, whose bending work usually leads to important section sizes and high amounts of reinforced.

The second solution, consideres the collaboration of the beam of the first floor, working as tie rod. Again, conventional methods involve a total success in the stabilizing mechanism of the tie rod, that manages to avoid any rotation of the party shoe, resulting in a stress distribution also uniform.

Existing conventional models for calculating such foundations show, therefore, a series of simplifications which allow calculation of the same, by manual means, in a reasonable time, but have the disadvantage of the possible distance from the real behavior of the foundation, with the negative consequences this could bring in the dimensioning of these structural elements. 
The present thesis develops a contrast of conventional models of calculation of party and corner foundations by an alternative analysis with finite element models with the aim of bring to light the differences between the results obtained with both types of modeling, analysis which are the variables that influence the real behavior of this type of foundations and propose a new calculation model, conventional type, more adjusted to reality.

The research process is developed through a virtual experimental stage using as a model a typical building frame, orthogonal, made of reinforced concrete, with two openings and variable number of floors.

After identifying the possible spin of the foundation as the key element in the behavior of the party and corner shoes, it has been adopted as study variables, those that may have greater influence on the spin of the shoes and on the rigidity of the whole structural element. So, it have been studied lights from $3 \mathrm{~m}$ to $7 \mathrm{~m}$, different number of floors from lower floor +1 to lower floor +4 , máximum ground stresses from $100 \mathrm{kN} / \mathrm{m}^{2} 300 \mathrm{kN} / \mathrm{m}^{2}$, shape relationships of party shoe 1,5:1 and 2:1, increase and decrease of the amount of reinforced of the centering beam and variation of the height of the centering beam from the minimum compatible with the anchoring of the reinforcement of pillars to an increase of $75 \%$ from the minimum quoted height.

The set of frames generated by applying the indicated variables, is calculated both by conventional methods such as by the finite element method. The results show significant discrepancies between the two methods that lead to significant differences in the dimensioning of this type of foundation. The use of traditional methods results, on one hand, to an overdimensioning of the reinforced of the centering beam and, on the other hand, to an underdimensioning, both the height of the centering beam, such as the size of the party shoe and the reinforced of the beam of the first floor.

After the analysis and discussion of results, the thesis proposes a new alternative method, conventional type and, therefore, applicable to a manual calculation in a reasonable time, that allows to obtain the key parameters that govern the behavior of party and corner shoes, leading to a dimensioning more adjusted to the real needings of this type of foundation. 
ÍNDICE 



\section{ÍNDICE GENERAL}

AGRADECIMIENTOS

RESUMEN

iii

ABSTRACT

CAPÍTULO 1. INTRODUCCIÓN

1

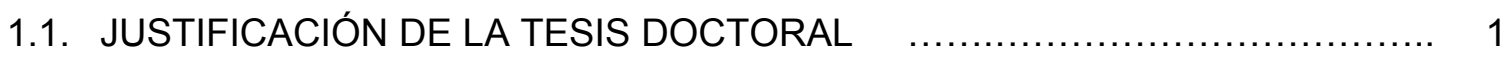

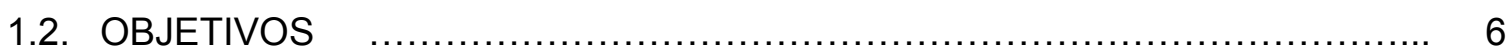

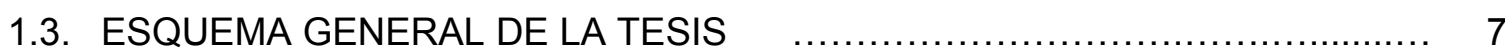

CAPÍTULO 2. ESTADO ACTUAL DEL CONOCIMIENTO

2.1. ZAPATAS DE MEDIANERÍA Y ESQUINA. CONCEPTO Y TIPOLOGÍA $\quad \ldots \ldots . . \quad 9$

2.2. ZAPATA DE MEDIANERÍA CON VIGA CENTRADORA $\quad \ldots \ldots \ldots \ldots \ldots \ldots \ldots \ldots \ldots \ldots \ldots \ldots \ldots$

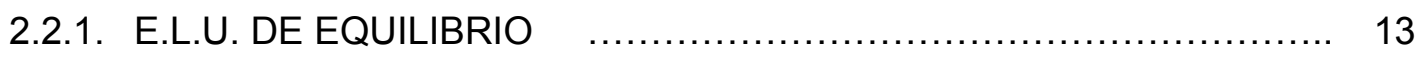

2.2.2. CÁlCULO DE ESFUERZOS EN LA VIGA CENTRADORA $\quad \ldots \ldots \ldots \ldots . . .16$

2.3. ZAPATA DE MEDIANERIA CON COLABORACIÓN DE LA

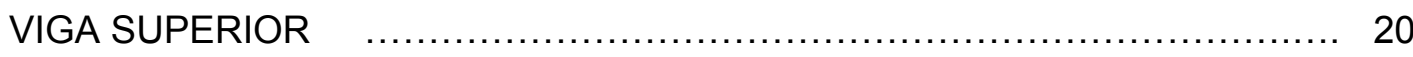

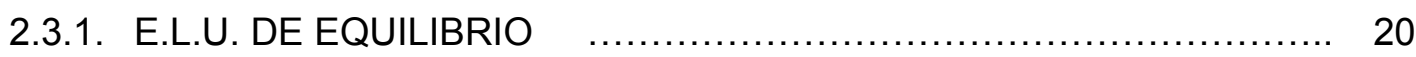

2.3.2. CÁLCULO DE ESFUERZOS EN LA VIGA Y EN EL PILAR $\quad \ldots \ldots \ldots \ldots . . \ldots 24$

2.4. ZAPATA DE ESQUINA CON DOS VIGAS CENTRADORAS $\quad \ldots \ldots \ldots \ldots \ldots \ldots . . . \ldots \ldots$

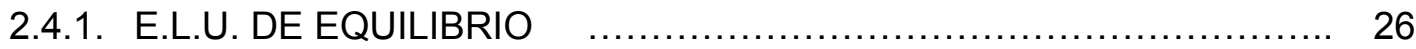

2.4.2. CÁlCULO DE ESFUERZOS EN LAS VIGAS CENTRADORAS $\quad \ldots \ldots .31$

2.5. VALORACIÓN CRÍTICA DE LOS MODELOS CONVENCIONALES $\quad \ldots \ldots \ldots \ldots . . . . .37$

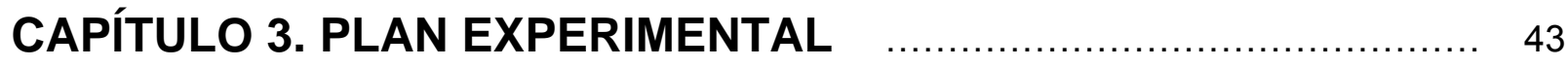

3.1. PLANTEAMIENTO GENERAL. DISEÑO EXPERIMENTAL $\quad \ldots \ldots \ldots \ldots \ldots \ldots \ldots . . \ldots \ldots$

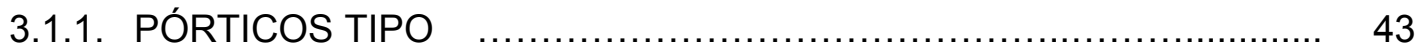

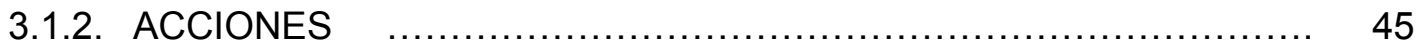

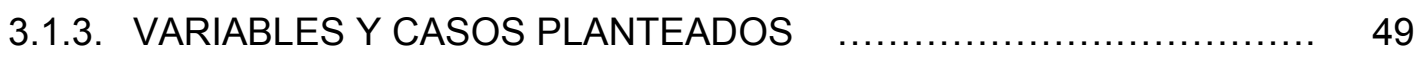

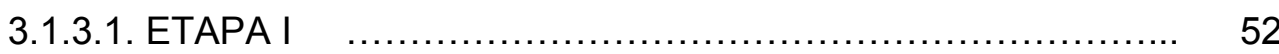




\section{ÍNDICE GENERAL}

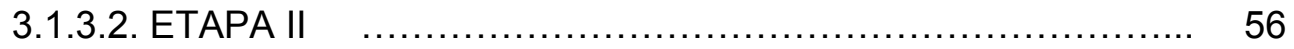

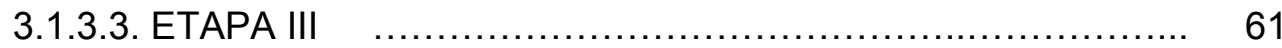

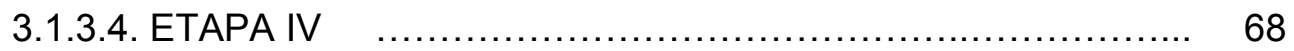

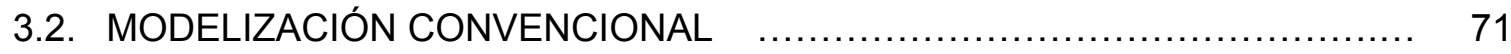

3.2.1. CÁLCULO DE ESFUERZOS EN LOS PÓRTICOS $\quad \ldots \ldots \ldots \ldots \ldots \ldots \ldots . . \ldots 1$

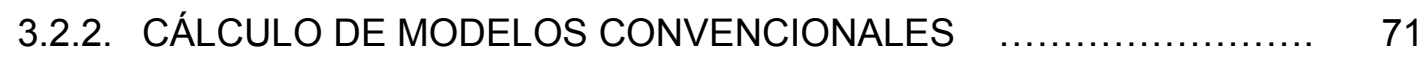

3.2.2.1. ZAPATA DE MEDIANERÍA CON VIGA CENTRADORA $\quad \ldots . .72$

3.2.2.2. ZAPATA DE MEDIANERÍA CON COLABORACIÓN DE VIGA SUPERIOR $\quad$................................................... 73

3.2.2.3. ZAPATA DE ESQUINA CON VIGAS CENTRADORAS $\quad \ldots . . . \quad 74$

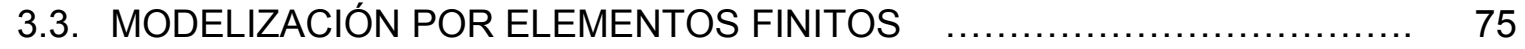

3.3.1. MODELOS DE ELEMENTOS FINITOS. ETAPA I $\quad$.................... 76

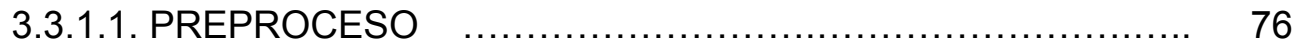

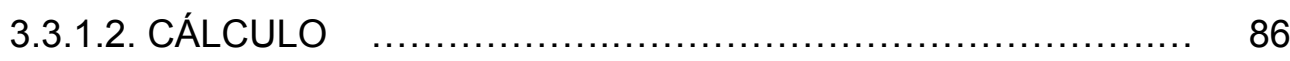

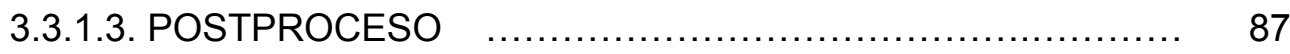

3.3.2. MODELOS DE ELEMENTOS FINITOS. ETAPAS II Y III $\quad$............ 91

3.3.2.1. PREPROCESO. DEFINICIÓN DE MATERIALES $\quad \ldots \ldots \ldots \ldots . . . . .91$

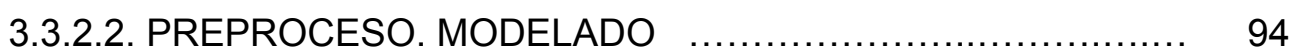

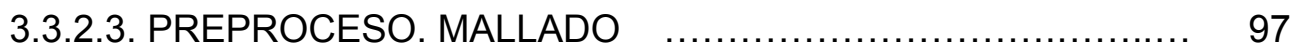

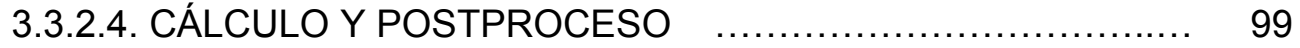

3.3.3. MODELOS DE ELEMENTOS FINITOS. ETAPA IV $\quad \ldots \ldots \ldots \ldots \ldots \ldots \ldots . . . \ldots 101$

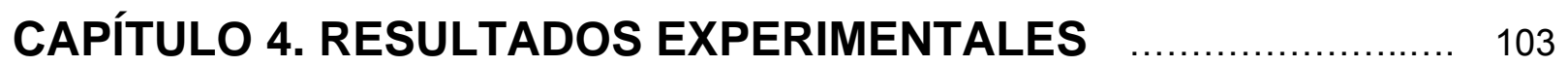

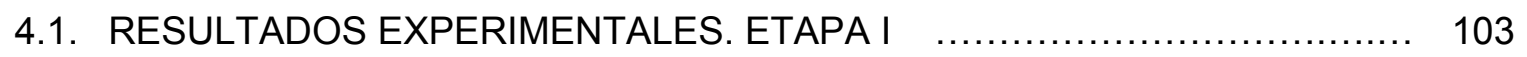

4.1.1. RESULTADOS DE LOS MODELOS CONVENCIONALES $\ldots \ldots \ldots \ldots$

4.1.1.1. ZAPATA DE MEDIANERÍA CON VIGA CENTRADORA $\ldots . .103$

4.1.1.2. ZAPATA DE MEDIANERÍA CON COLABORACIÓN

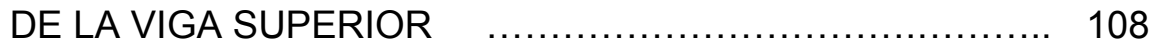

4.1.2. RESULTADOS DE LOS MODELOS DE ELEMENTOS FINITOS $\ldots 112$ 


\section{ÍNDICE GENERAL}

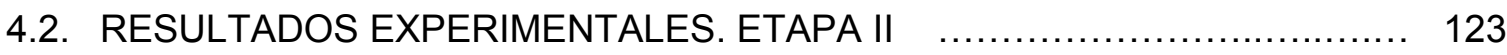

4.2.1. RESULTADOS DE LOS MODELOS CONVENCIONALES _.......... 123

4.2.1.1. ZAPATA DE MEDIANERÍA CON VIGA CENTRADORA $\ldots . .123$

4.2.1.2. ZAPATA DE MEDIANERÍA CON COLABORACIÓN

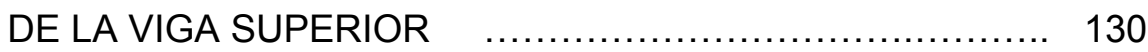

4.2.2. RESULTADOS DE LOS MODELOS DE ELEMENTOS FINITOS $\quad \ldots . \quad 137$

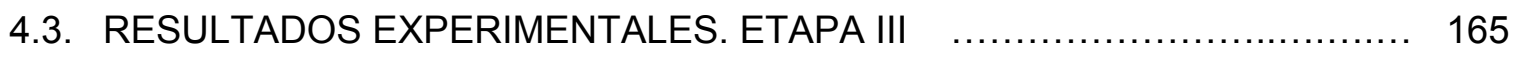

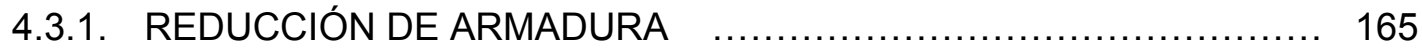

4.3.2. ELIMINACIÓN DE LA VIGA CENTRADORA $\ldots \ldots \ldots \ldots \ldots \ldots \ldots \ldots . \ldots \ldots$

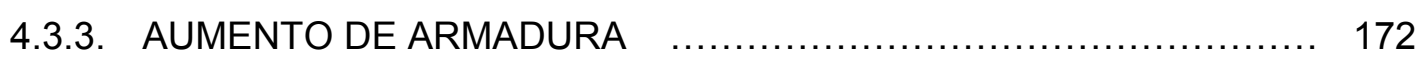

4.3.4. INCREMENTO DEL CANTO DE LA VIGA CENTRADORA .......... 176

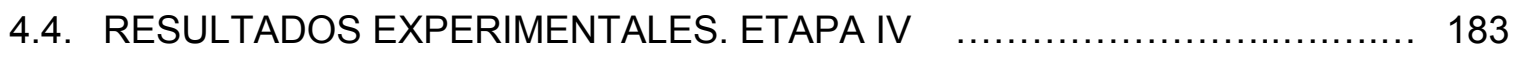

4.4.1. RESULtAdOS DE LOS MODELOS CONVENCIONALES .......... 183

4.4.2. RESULTADOS DE LOS MODELOS DE ELEMENTOS FINITOS $\quad \ldots \quad 185$

CAPÍTULO 5. ANÁLISIS Y DISCUSIÓN DE RESULTADOS

5.1. ANÁLISIS Y DISCUSIÓN DE RESULTADOS. ETAPA I $\quad \ldots \ldots \ldots \ldots \ldots \ldots \ldots \ldots . \ldots \ldots$

5.1.1. ESFUERZOS EN LA VIGA CENTRADORA $\ldots \ldots \ldots \ldots \ldots \ldots \ldots \ldots \ldots \ldots \ldots$

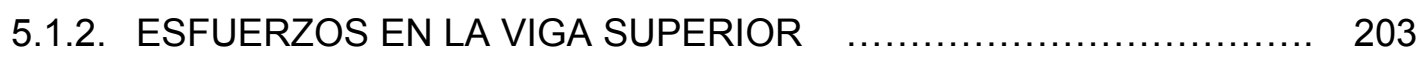

5.1.3. DISTRIBUCIÓN DE TENSIONES DE CONTACTO $\ldots \ldots \ldots \ldots \ldots \ldots . . . \ldots 207$

5.2. ANÁLISIS Y DISCUSIÓN DE RESULTADOS. ETAPA II $\quad \ldots \ldots \ldots \ldots \ldots \ldots \ldots . . \ldots \ldots \ldots \ldots$

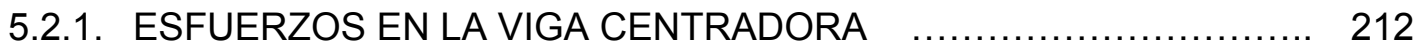

5.2.2. DISTRIBUCIÓN DE TENSIONES DE CONTACTO $\ldots \ldots \ldots \ldots \ldots \ldots . . \ldots 215$

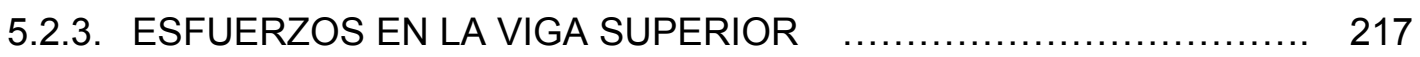

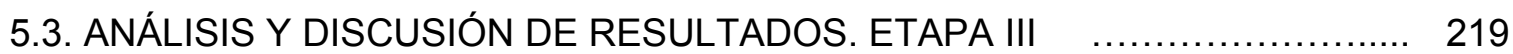

5.3.1. AUMENTO DE ARMADURA DE LA VIGA CENTRADORA $\ldots \ldots \ldots \ldots . .219$

5.3.2. REDUCCIÓN DE ARMADURA DE LA VIGA CENTRADORA $\ldots \ldots \ldots .221$

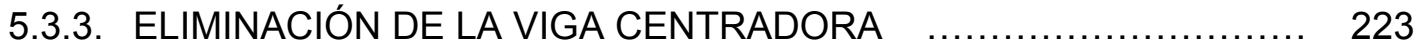

5.3.4. AUMENTO DEL CANTO DE LA VIGA CENTRADORA ............... 225 


\section{ÍNDICE GENERAL}

5.4. ANÁLISIS Y DISCUSIÓN DE RESULTADOS. ETAPA IV $\ldots \ldots \ldots \ldots \ldots \ldots \ldots \ldots . . . . . . . . . . . .228$

5.5. PROPUESTA DE MEJORA DEL MÉTODO CONVENCIONAL $\quad \ldots \ldots \ldots \ldots \ldots \ldots . . . . . .231$

5.5.1. ZAPATA DE MEDIANERÍA CON VIGA CENTRADORA $\ldots \ldots \ldots \ldots \ldots . . .231$

5.5.2. ZAPATA DE ESQUINA CON DOS VIGAS CENTRADORAS $\quad \ldots \ldots \ldots . \quad 243$

5.6. RECOMENDACIONES DE RELACIÓN LUZ - CANTO $\ldots \ldots \ldots \ldots \ldots \ldots \ldots \ldots \ldots . . . . \ldots \ldots$

CAPÍTULO 6. CONCLUSIONES Y FUTURAS LÍNEAS DE

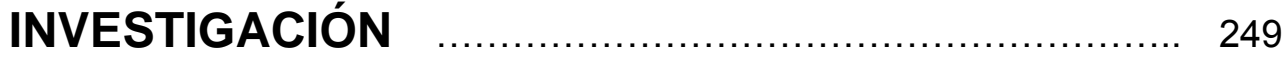

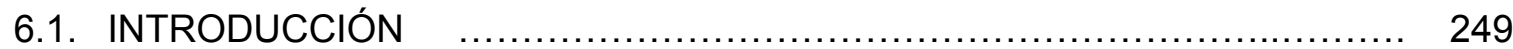

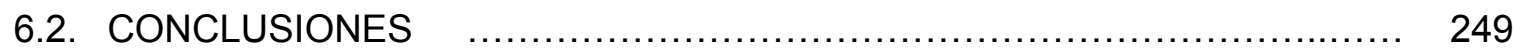

6.2.1. CONCLUSIONES DE LA ETAPA I .................................. 249

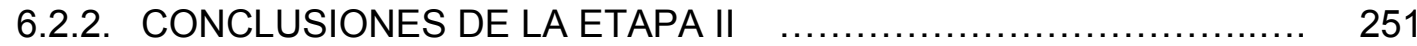

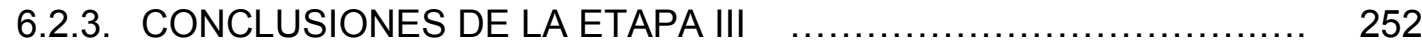

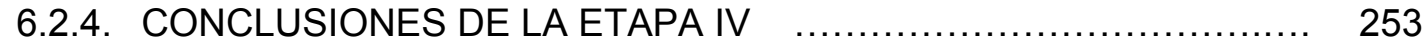

6.2.5. PROPUESTA DE MEJORA DEL MÉTODO CONVENCIONAL _.... 254

6.2.6. RECOMENDACIONES DE RELACIÓN LUZ - CANTO _............... 256

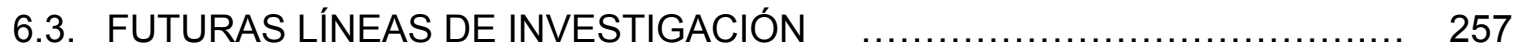

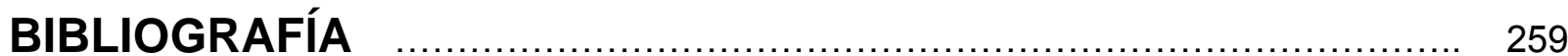

\section{ANEJOS}

ANEJO I. MODELO DE ELEMENTOS FINITOS

ANEJO II. PARÁMETROS DE CONFIGURACIÓN DEL MATERIAL HORMIGÓN 


\section{ÍNDICE DE TABLAS}

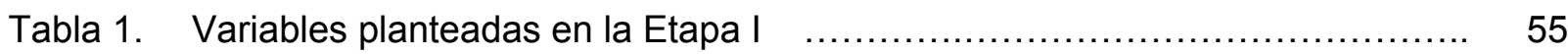

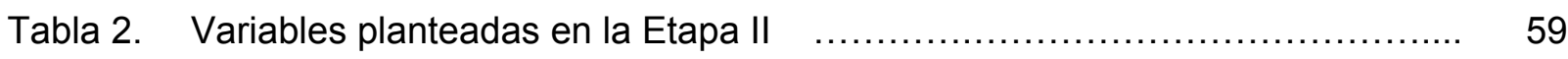

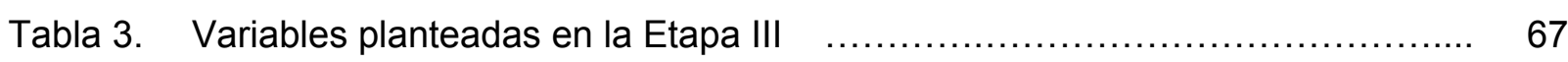

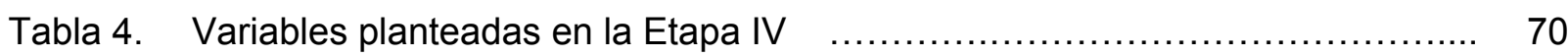

Tabla 5. Hoja de cálculo para resolución de zapata de medianería con viga centradora

Tabla 6. Hoja de cálculo para resolución de zapata de medianería con colaboración de la viga superior

Tabla 7. Hoja de cálculo para resolución de zapata de esquina

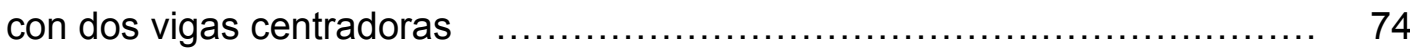

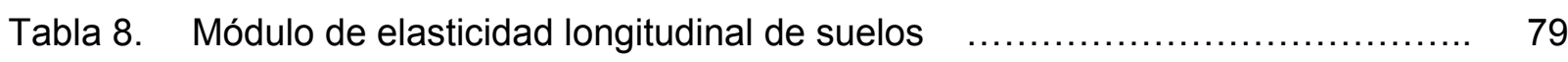

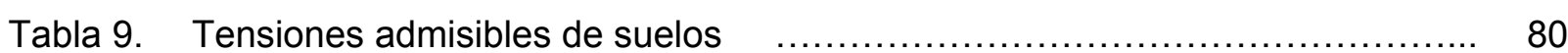

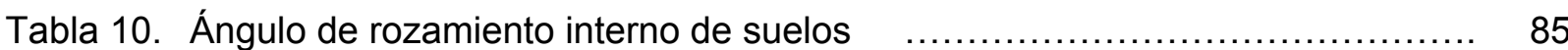

Tabla 11. Zapata de medianería con viga centradora. Modelo convencional. Etapa I Resultados para nivel de rigidez de pórtico tipo $\mathrm{h}=300$ 105

Tabla 12. Zapata de medianería con viga centradora. Modelo convencional. Etapa I Resultados para nivel de rigidez de pórtico tipo $h=450$ 106

Tabla 13. Zapata de medianería con viga centradora. Modelo convencional. Etapa I Resultados para nivel de rigidez de pórtico tipo $\mathrm{h}=600$

Tabla 14. Zapata de medianería con colaboración de viga superior. M. convencional. Etapa I. Resultados para nivel de rigidez de pórtico tipo $\mathrm{h}=300$

Tabla 15. Zapata de medianería con colaboración de viga superior. M. convencional. Etapa I. Resultados para nivel de rigidez de pórtico tipo $h=450$

Tabla 16. Zapata de medianería con colaboración de viga superior. M. convencional.

Etapa I. Resultados para nivel de rigidez de pórtico tipo $\mathrm{h}=600$

Tabla 17. Modelo de elementos finitos. Etapa I. Resultantes tensiones terreno.

Esfuerzos en vigas centradora y superior. Pórtico tipo $\mathrm{h}=300$

Tabla 18. Modelo de elementos finitos. Etapa I. Resultantes tensiones terreno.

Esfuerzos en vigas centradora y superior. Pórtico tipo $\mathrm{h}=450$

Tabla 19. Modelo de elementos finitos. Etapa I. Resultantes tensiones terreno.

Esfuerzos en vigas centradora y superior. Pórtico tipo $h=600$

Tabla 20. Distribución de tensiones de contacto en modelo de elementos finitos.

Etapa I. Pórtico tipo $\mathrm{h}=300$ 


\section{ÍNDICE DE TABLAS}

Tabla 21. Distribución de tensiones de contacto en modelo de elementos finitos.

Etapa I. Pórtico tipo $\mathrm{h}=450$

Tabla 22. Distribución de tensiones de contacto en modelo de elementos finitos.

Etapa I. Pórtico tipo $\mathrm{h}=600$

Tabla 23. Zapata de medianería con viga centradora. Modelo convencional. Etapa II Resultados para $\sigma_{\text {adm. }}=100 \mathrm{kN} / \mathrm{m}^{2}$ y relación de forma $1,5: 1$

Tabla 24. Zapata de medianería con viga centradora. Modelo convencional. Etapa II Resultados para $\sigma_{\text {adm. }}=200 \mathrm{kN} / \mathrm{m}^{2}$ y relación de forma 1,5:1

Tabla 25. Zapata de medianería con viga centradora. Modelo convencional. Etapa II Resultados para $\sigma_{\text {adm. }}=300 \mathrm{kN} / \mathrm{m}^{2}$ y relación de forma 1,5:1

Tabla 26. Zapata de medianería con viga centradora. Modelo convencional. Etapa II Resultados para $\sigma_{\mathrm{adm} .}=100 \mathrm{kN} / \mathrm{m}^{2}$ y relación de forma $2: 1$

Tabla 27. Zapata de medianería con viga centradora. Modelo convencional. Etapa II Resultados para $\sigma_{\mathrm{adm}}=200 \mathrm{kN} / \mathrm{m}^{2}$ y relación de forma $2: 1$

Tabla 28. Zapata de medianería con viga centradora. Modelo convencional. Etapa II Resultados para $\sigma_{\text {adm. }}=300 \mathrm{kN} / \mathrm{m}^{2}$ y relación de forma $2: 1$

Tabla 29. Zapata de medianería con colaboración de viga superior. M. convencional.

Etapa II. Resultados para $\sigma_{\text {adm. }}=100 \mathrm{kN} / \mathrm{m}^{2}$ y relación de forma 1,5:1

Tabla 30. Zapata de medianería con colaboración de viga superior. M. convencional.

Etapa II. Resultados para $\sigma_{\text {adm. }}=200 \mathrm{kN} / \mathrm{m}^{2}$ y relación de forma 1,5:1

Tabla 31. Zapata de medianería con colaboración de viga superior. M. convencional.

Etapa II. Resultados para $\sigma_{\text {adm. }}=300 \mathrm{kN} / \mathrm{m}^{2}$ y relación de forma 1,5:1

Tabla 32. Zapata de medianería con colaboración de viga superior. M. convencional.

Etapa II. Resultados para $\sigma$ adm. $=100 \mathrm{kN} / \mathrm{m}^{2}$ y relación de forma $2: 1$

Tabla 33. Zapata de medianería con colaboración de viga superior. M. convencional.

Etapa II. Resultados para $\sigma_{\mathrm{adm}}=200 \mathrm{kN} / \mathrm{m}^{2}$ y relación de forma $2: 1$

Tabla 34. Zapata de medianería con colaboración de viga superior. M. convencional.

Etapa II. Resultados para $\sigma_{\text {adm. }}=300 \mathrm{kN} / \mathrm{m}^{2}$ y relación de forma $2: 1 \ldots \ldots$.

Tabla 35. Dimensionamiento y armado de pórticos con Baja +1 plantas.

Modelos de elementos finitos. Etapa II

Tabla 36. Dimensionamiento y armado de pórticos con Baja +2 plantas.

Modelos de elementos finitos. Etapa II 


\section{ÍNDICE DE TABLAS}

Tabla 37. Dimensionamiento y armado de pórticos con Baja +3 plantas.

Modelos de elementos finitos. Etapa II

Tabla 38. Dimensionamiento y armado de pórticos con Baja +4 plantas.

Modelos de elementos finitos. Etapa II

Tabla 39. Dimensionamiento cimentación para $\sigma_{\mathrm{adm} .}=100 \mathrm{kN} / \mathrm{m}^{2}$ y relación

de forma $1,5: 1$. Modelos de elementos finitos. Etapa II

Tabla 40. Dimensionamiento cimentación para $\sigma_{\mathrm{adm}}=200 \mathrm{kN} / \mathrm{m}^{2}$ y relación de forma $1,5: 1$. Modelos de elementos finitos. Etapa II

Tabla 41. Dimensionamiento cimentación para $\sigma_{\text {adm. }}=300 \mathrm{kN} / \mathrm{m}^{2}$ y relación de forma $1,5: 1$. Modelos de elementos finitos. Etapa II

Tabla 42. Dimensionamiento cimentación para $\sigma_{\mathrm{adm} .}=100 \mathrm{kN} / \mathrm{m}^{2}$ y relación de forma $2: 1$. Modelos de elementos finitos. Etapa II

Tabla 43. Dimensionamiento cimentación para $\sigma_{\text {adm. }}=200 \mathrm{kN} / \mathrm{m}^{2}$ y relación de forma $2: 1$. Modelos de elementos finitos. Etapa II

Tabla 44. Dimensionamiento cimentación para $\sigma_{\text {adm. }}=300 \mathrm{kN} / \mathrm{m}^{2}$ y relación de forma $2: 1$. Modelos de elementos finitos. Etapa II

Tabla 45. Resultantes tensiones terreno y esfuerzos en vigas centradora y superior. M.E.F. Etapa II. $\sigma_{\text {adm. }}=100 \mathrm{kN} / \mathrm{m}^{2}$ y relación de forma $1,5: 1$

Tabla 46. Distribución de tensiones de contacto. Modelo de elementos finitos. Etapa II. $\sigma_{\text {adm. }}=100 \mathrm{kN} / \mathrm{m}^{2}$ y relación de forma $1,5: 1$

Tabla 47. Resultantes tensiones terreno y esfuerzos en vigas centradora y superior.

M.E.F. Etapa II. $\sigma_{\text {adm. }}=200 \mathrm{kN} / \mathrm{m}^{2}$ y relación de forma $1,5: 1$

Tabla 48. Distribución de tensiones de contacto. Modelo de elementos finitos. Etapa II. $\sigma_{\text {adm. }}=200 \mathrm{kN} / \mathrm{m}^{2}$ y relación de forma $1,5: 1$

Tabla 49. Resultantes tensiones terreno y esfuerzos en vigas centradora y superior.

M.E.F. Etapa II. $\sigma_{\text {adm. }}=300 \mathrm{kN} / \mathrm{m}^{2}$ y relación de forma $1,5: 1$

Tabla 50. Distribución de tensiones de contacto. Modelo de elementos finitos. Etapa II. $\sigma_{\text {adm. }}=300 \mathrm{kN} / \mathrm{m}^{2}$ y relación de forma 1,5:1

Tabla 51. Resultantes tensiones terreno y esfuerzos en vigas centradora y superior.

M.E.F. Etapa II. $\sigma_{\text {adm. }}=100 \mathrm{kN} / \mathrm{m}^{2}$ y relación de forma $2: 1$

Tabla 52. Distribución de tensiones de contacto. Modelo de elementos finitos. Etapa II. $\sigma_{\mathrm{adm} .}=100 \mathrm{kN} / \mathrm{m}^{2} \mathrm{y}$ relación de forma $2: 1$ 


\section{ÍNDICE DE TABLAS}

Tabla 53. Resultantes tensiones terreno y esfuerzos en vigas centradora y superior.

M.E.F. Etapa II. $\sigma_{\text {adm. }}=200 \mathrm{kN} / \mathrm{m}^{2}$ y relación de forma $2: 1$

Tabla 54. Distribución de tensiones de contacto. Modelo de elementos finitos. Etapa II.

$\sigma_{\text {adm. }}=200 \mathrm{kN} / \mathrm{m}^{2} \mathrm{y}$ relación de forma $2: 1$

Tabla 55. Resultantes tensiones terreno y esfuerzos en vigas centradora y superior.

M.E.F. Etapa II. $\sigma_{\text {adm. }}=300 \mathrm{kN} / \mathrm{m}^{2}$ y relación de forma $2: 1$

Tabla 56. Distribución de tensiones de contacto. Modelo de elementos finitos. Etapa II.

$\sigma_{\text {adm. }}=300 \mathrm{kN} / \mathrm{m}^{2}$ y relación de forma $2: 1$

Tabla 57. Dimensionamiento cimentación. Reducción de armadura. M.E.F. Etapa III $\sigma_{\text {adm. }}=200 \mathrm{kN} / \mathrm{m}^{2}$ y relación de forma $2: 1$

Tabla 58. Resultantes tensiones terreno y esfuerzos en vigas centradora y superior.

M.E.F. Red. Arm. Etapa III. $\sigma_{\text {adm. }}=200 \mathrm{kN} / \mathrm{m}^{2}$ y relación de forma $2: 1$

Tabla 59. Distribución de tensiones de contacto. M.E.F. Red. Armadura. Etapa III.

$\sigma_{\text {adm. }}=200 \mathrm{kN} / \mathrm{m}^{2}$ y relación de forma $2: 1$

Tabla 60. Resultantes tensiones terreno y esfuerzos en viga superior.

M.E.F. Sin V.CEN.. Etapa III. $\sigma_{\text {adm. }}=200 \mathrm{kN} / \mathrm{m}^{2}$ y relación de forma $2: 1 \quad \ldots \quad 170$

Tabla 61. Distribución de tensiones de contacto. M.E.F. Sin V. Centradora. Etapa III.

$\sigma_{\text {adm. }}=200 \mathrm{kN} / \mathrm{m}^{2}$ y relación de forma $2: 1$

Tabla 62. Dimensionamiento cimentación. Incremento de armadura. M.E.F. Etapa II

$\sigma_{\text {adm. }}=200 \mathrm{kN} / \mathrm{m}^{2}$ y relación de forma $2: 1$

Tabla 63. Resultantes tensiones terreno y esfuerzos en vigas centradora y superior.

M.E.F. Inc. Arm. Etapa III. $\sigma_{\text {adm. }}=200 \mathrm{kN} / \mathrm{m}^{2}$ y relación de forma $2: 1$

Tabla 64. Distribución de tensiones de contacto. M.E.F. Inc. Armadura. Etapa III.

$\sigma_{\text {adm. }}=200 \mathrm{kN} / \mathrm{m}^{2}$ y relación de forma $2: 1$

Tabla 65. Resultantes tensiones terreno y esfuerzos en vigas centradora y superior.

M.E.F. $\mathrm{H}=1,25 \cdot \mathrm{H}$ II. Etapa III. $\sigma_{\mathrm{adm} .}=200 \mathrm{kN} / \mathrm{m}^{2}$ y relación de forma $2: 1 . .177$

Tabla 66. Distribución de tensiones de contacto. M.E.F. H=1,25 · H II. Etapa III.

$\sigma_{\text {adm. }}=200 \mathrm{kN} / \mathrm{m}^{2}$ y relación de forma $2: 1$

Tabla 67. Resultantes tensiones terreno y esfuerzos en vigas centradora y superior.

M.E.F. $\mathrm{H}=1,50 \cdot \mathrm{H}$ II. Etapa III. $\sigma_{\mathrm{adm}}=200 \mathrm{kN} / \mathrm{m}^{2}$ y relación de forma $2: 1 . .179$

Tabla 68. Distribución de tensiones de contacto. M.E.F. H=1,50 $\cdot$ H II. Etapa III.

$\sigma_{\text {adm. }}=200 \mathrm{kN} / \mathrm{m}^{2}$ y relación de forma $2: 1$ 180 


\section{ÍNDICE DE TABLAS}

Tabla 69. Resultantes tensiones terreno y esfuerzos en vigas centradora y superior.

M.E.F. $H=1,75 \cdot H$ II. Etapa III. $\sigma_{\text {adm. }}=200 \mathrm{kN} / \mathrm{m}^{2}$ y relación de forma $2: 1 . .181$

Tabla 70. Distribución de tensiones de contacto. M.E.F. H = 1,75 · H II. Etapa III.

$\sigma_{\text {adm. }}=200 \mathrm{kN} / \mathrm{m}^{2}$ y relación de forma $2: 1$

Tabla 71. Zapata de esquina con vigas centradoras. Modelo convencional. Etapa IV Resultados para $\sigma_{\text {adm. }}=200 \mathrm{kN} / \mathrm{m}^{2}$ y relación de forma $2: 1$

Tabla 72. Resultantes tensiones terreno y esfuerzos en vigas centradoras.

Zapata de esquina. M.E.F. $\mathrm{H}=\mathrm{H}$ min (I). Etapa IV.

$\sigma_{\mathrm{adm}}=200 \mathrm{kN} / \mathrm{m}^{2} \mathrm{y}$ relación de forma $2: 1$

Tabla 73. Resultantes tensiones terreno y esfuerzos en vigas centradoras.

Zapata de esquina. M.E.F. $\mathrm{H}=\mathrm{H}$ min (II). Etapa IV.

$\sigma_{\text {adm. }}=200 \mathrm{kN} / \mathrm{m}^{2}$ y relación de forma $2: 1$

Tabla 74. Distribución de tensiones de contacto. Zapata de esquina. M.E.F.

$\mathrm{H}=\mathrm{H}$ min. Etapa IV. $\sigma_{\text {adm. }}=200 \mathrm{kN} / \mathrm{m}^{2}$ y relación de forma $2: 1$

Tabla 75. Resultantes tensiones terreno y esfuerzos en vigas centradoras.

Zapata de esquina. M.E.F. $\mathrm{H}=1,75 \cdot \mathrm{H}$ min (I). Etapa IV.

$\sigma_{\text {adm. }}=200 \mathrm{kN} / \mathrm{m}^{2}$ y relación de forma $2: 1$

Tabla 76. Resultantes tensiones terreno y esfuerzos en vigas centradoras.

Zapata de esquina. M.E.F. $\mathrm{H}=1,75 \cdot \mathrm{H}$ min. (II). Etapa IV.

$\sigma_{\text {adm. }}=200 \mathrm{kN} / \mathrm{m}^{2}$ y relación de forma $2: 1$

Tabla 74. Distribución de tensiones de contacto. Zapata de esquina. M.E.F.

$\mathrm{H}=1,75 \cdot \mathrm{H}$ min. Etapa IV. $\sigma_{\text {adm. }}=200 \mathrm{kN} / \mathrm{m}^{2}$ y relación de forma $2: 1$

Tabla 75. Resultados M.E.F. Baja+1. Posición y Resultantes

Tabla 76. Resultados M.E.F. Baja+2. Posición y Resultantes 234

Tabla 77. Resultados M.E.F. Baja+3. Posición y Resultantes 235

Tabla 78. Resultados M.E.F. Baja+4. Posición y Resultantes 236

Tabla 79. Resultados M.E.F. zapata de esquina. Posiciones y Resultantes 243 



\section{ÍNDICE DE FIGURAS}

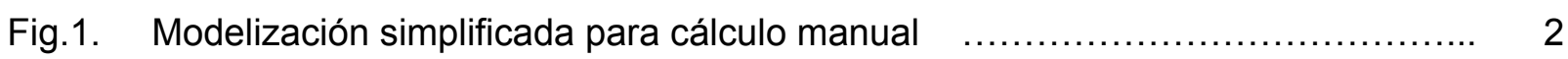

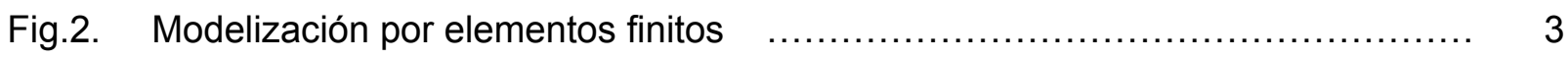

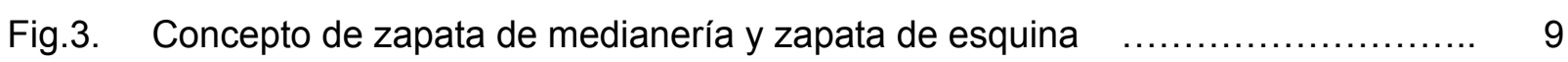

Fig.4. Soluciones más frecuentes para las de zapatas de medianería $\quad$................. 10

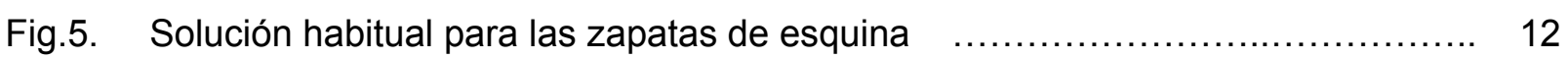

Fig.6. Zapata de medianería con viga centradora. Modelización convencional $\quad \ldots . . . . . \quad 15$

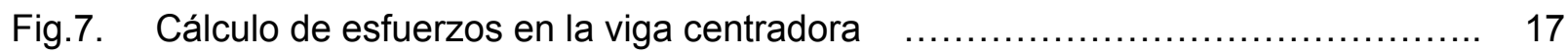

Fig.8. Zapata de medianería con colaboración de la viga superior.

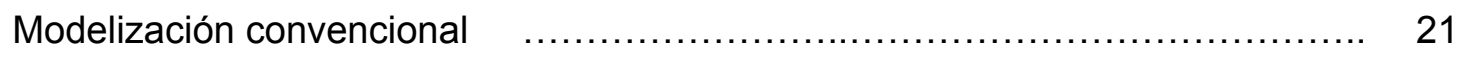

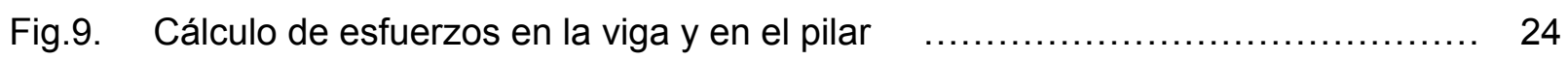

Fig.10. Esquema de la cimentación en el entorno de una zapata de esquina $\quad \ldots \ldots \ldots \ldots . . \ldots 27$

Fig.11. Zapata de esquina con vigas centradoras. Modelización convencional $\quad \ldots \ldots \ldots . . .28$

Fig.12. Zapata de esquina con vigas centradoras. Acciones y reacciones $\quad \ldots \ldots \ldots \ldots \ldots . \ldots . \ldots 29$

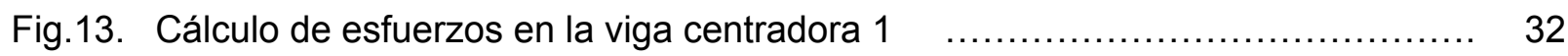

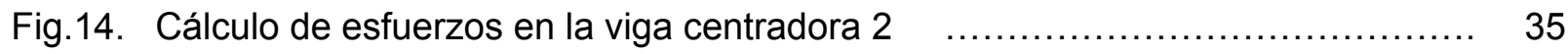

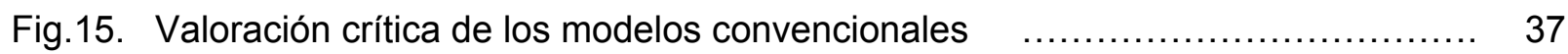

Fig.16. Zapata de medianería con colaboración de la viga superior

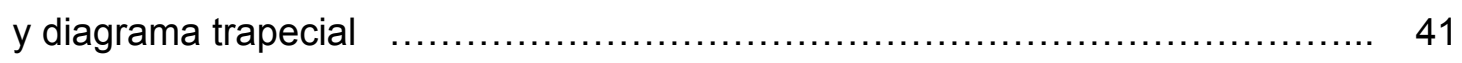

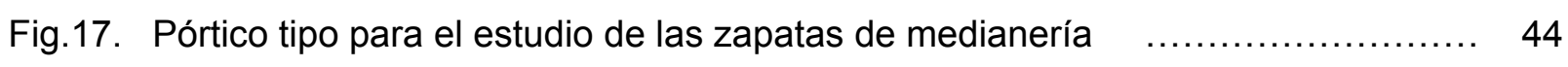

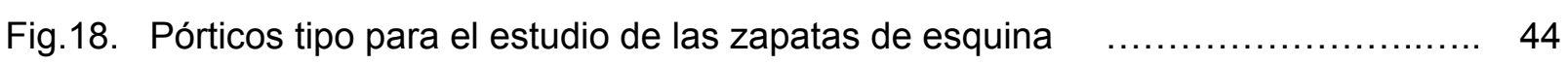

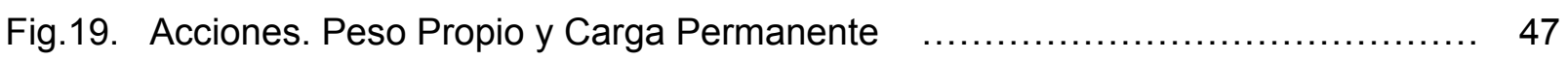

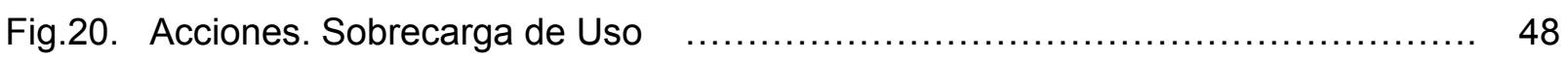

Fig.21. Deformada de una zapata de medianería con viga centradora $\quad \ldots \ldots \ldots \ldots \ldots \ldots \ldots . . . \ldots 1$

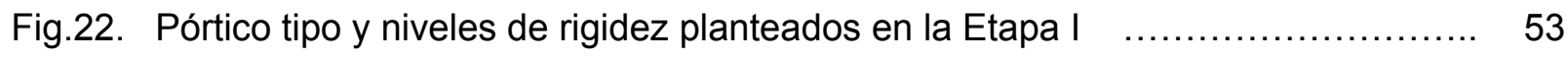

Fig.23. Relaciones de forma consideradas en la zapata de medianería $\quad . . \ldots \ldots \ldots \ldots \ldots \ldots . . . . . .55$

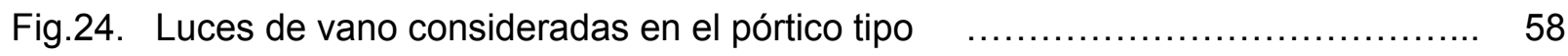

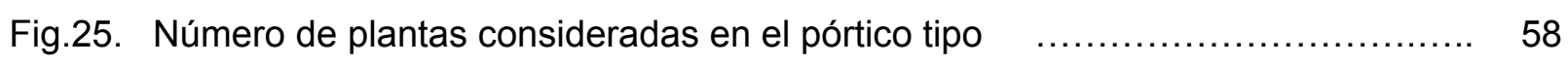

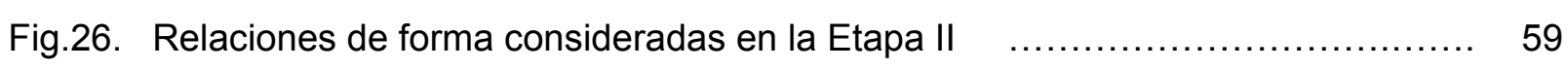

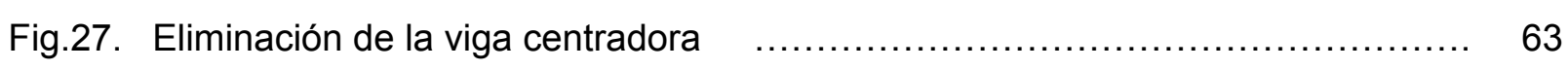

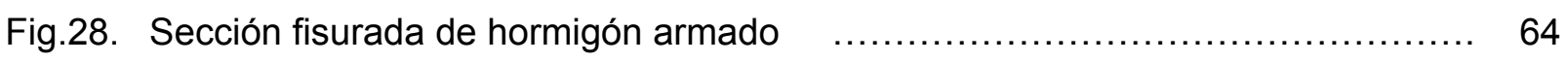

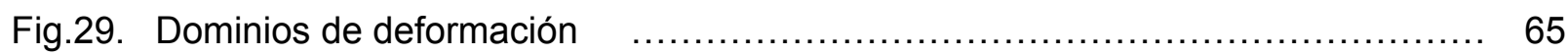

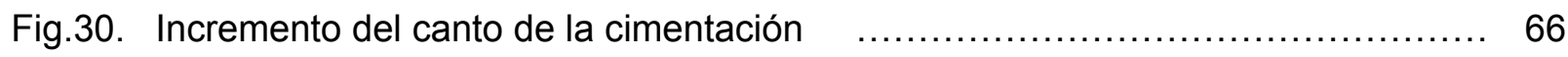

Fig.31. Luces y número de plantas consideradas en el pórtico tipo $\quad$..................... 69

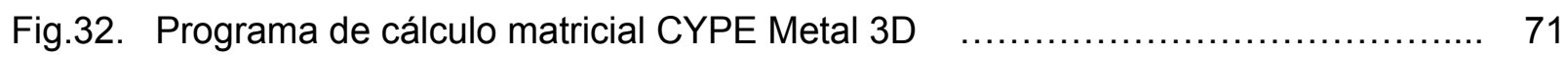




\section{ÍNDICE DE FIGURAS}

Fig.33. Esquema de cálculo de zapata de medianería con viga centradora 72

Fig.34. Esquema de cálculo de zapata de medianería con colaboración de la viga superior 73

Fig.35. Esquema de cálculo de zapata de esquina con dos vigas centradoras $\ldots \ldots \ldots \ldots . . . .74$

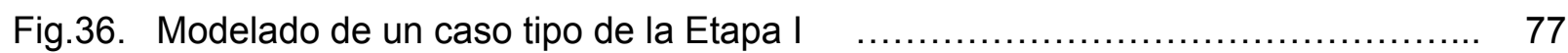

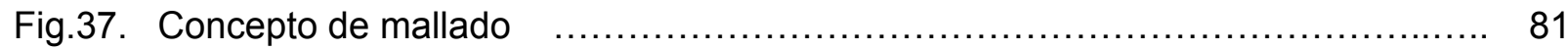

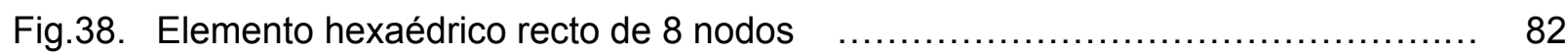

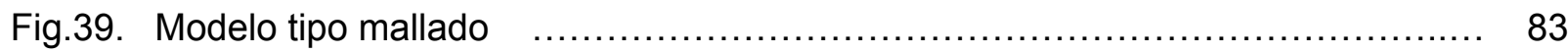

Fig.40. Método de cálculo numérico de Newton - Raphson $\quad$.......................... 86

Fig.41. Salida gráfica de resultados con indicación de valor por escala cromática $\quad \ldots . . \quad 87$

Fig.42. Listado con relación de tensiones correspondientes a diferentes nodos $\quad \ldots \ldots \ldots . . .88$

Fig.43. Sección transversal y relación de elementos y nodos que la componen $\quad$.......... 89

Fig.44. Proceso de integración de tensiones para una sección $\quad \ldots \ldots \ldots \ldots \ldots \ldots \ldots \ldots \ldots . . . \ldots \ldots$

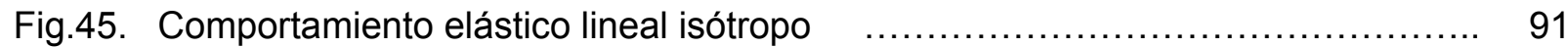

Fig.46. Diagrama parabólico rectangular del hormigón

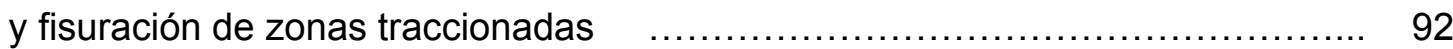

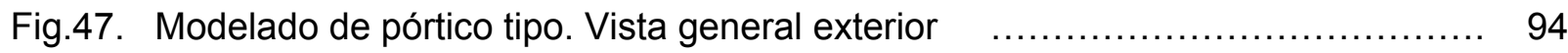

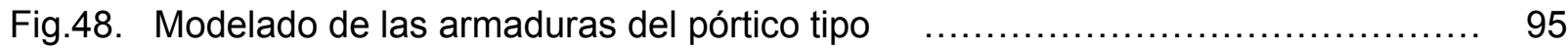

Fig.49. Detalle del modelado de las armaduras de vigas y pilares $\quad$..................... 95

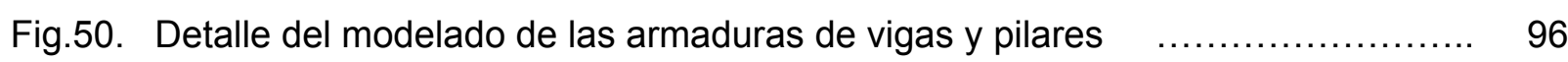

Fig.51. Detalle del modelado de las armaduras de la cimentación $\quad \ldots \ldots \ldots \ldots \ldots \ldots \ldots \ldots . . . \ldots 6$

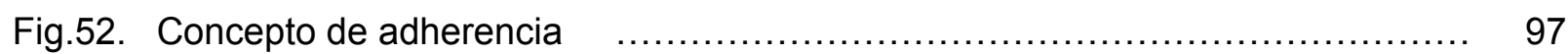

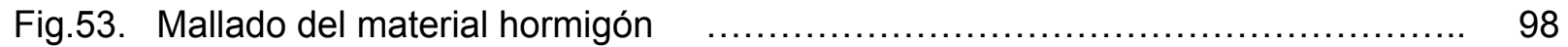

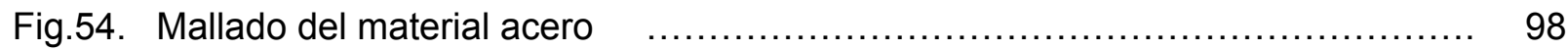

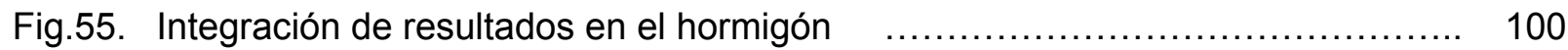

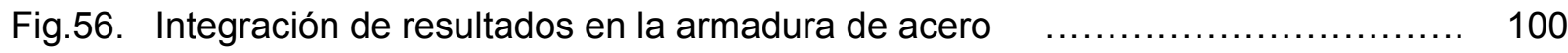

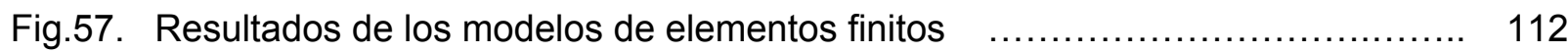

Fig.58. Distribución de tensiones de contacto en modelo de elementos finitos $\quad \ldots \ldots \ldots \ldots . . .117$

Fig.59. Posición absoluta y relativa de la resultante de la zapata de medianería $\quad \ldots . . . \quad 118$

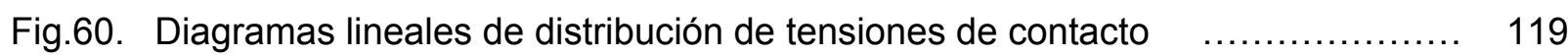

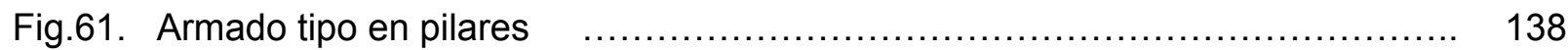

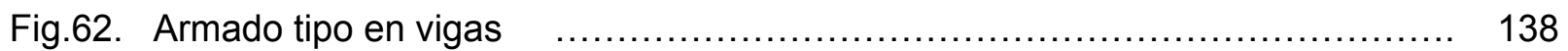

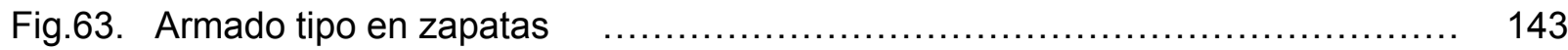

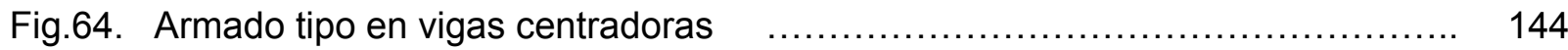




\section{ÍNDICE DE FIGURAS}

Fig.65. Contraste del valor del momento flector en la viga centradora en función de la rigidez del pórtico

Fig.66. Contraste del valor del momento flector en la viga centradora en función de la tensión admisible del terreno

Fig.67. Contraste del valor del momento flector en la viga centradora en función de la relación de forma 195

Fig.68. Giro de la cimentación según el modelo de elementos finitos 196

Fig.69. Modelo convencional de zapata de medianería con viga centradora 197

Fig.70. Variación de la excentricidad y valor de la resultante de la zapata de medianería en función del nivel de rigidez del pórtico

Fig.71. Variación de la excentricidad y valor de la resultante de la zapata de medianería en función de la tensi ón admisible del terreno

Fig.72. Variación de la excentricidad y valor de la resultante de la zapata de medianería en función de la relación de forma

Fig.73. Desplazamiento de la resultante de tensiones de la zapata de medianería

Fig.74. Reducción de eficacia de las zonas de la zapata de medianería próximas al centro del vano

Fig.75. Variación del esfuerzo axil en la viga de la primera planta en función de la rigidez del pórtico

Fig.76. Variación del esfuerzo axil en la viga de la primera planta en función de la tensión admisible del terreno

Fig.77. Variación del esfuerzo axil en la viga de la primera planta en función de la relación de forma

Fig.78. Distribución de tensiones de contacto en modelos de elementos finitos 207

Fig.79. Diagrama de distribución de tensiones lineal equivalente 207

Fig.80. Verificación de tensiones de contacto con modelo de elementos finitos

Fig.81. Contraste de resultantes de tensiones de contacto en zapata de medianería y viga centradora

Fig.82. Relación resultante viga centradora - resultante zapata 210

Fig.83. Viga centradora como viga de cimentación

Fig.84. Contraste del valor del momento flector en la viga centradora en función de la relación de forma y de la tensión admisible del terreno

Fig.85. Contraste del valor del momento flector en la viga centradora en función de la luz y el número de plantas del pórtico 


\section{ÍNDICE DE FIGURAS}

Fig.86. Excentricidades relativas de la resultante de la zapata de medianería. Etapa II .. 213

Fig.87. Aumento de la excentricidad de la resultante de la zapata de medianería $\ldots . . . .214$

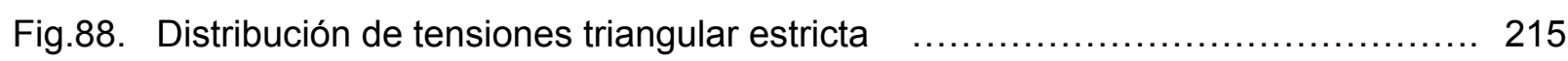

Fig.89. Relación resultante viga centradora - resultante zapata medianería. Etapa II .... 215

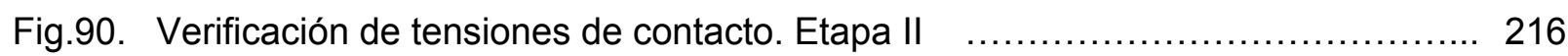

Fig.91. Contraste del esfuerzo axil en la viga superior en función de la relación de forma y de la tensión admisible del terreno

Fig.92. Contraste del axil en la viga superior en función de la luz y el número de plantas del pórtico

Fig.93. Excentricidades relativas de la resultante de la zapata de medianería con aumento de armadura. Contraste Etapa II - Etapa III

Fig.94. Verificación de tensiones de contacto con aumento de armadura.

Contraste Etapa II - Etapa III

Fig.95. Excentricidades relativas de la resultante de la zapata de medianería con reducción de armadura. Contraste Etapa II - Etapa III

Fig.96. Excentricidades relativas de la resultante de la zapata de medianería sin viga centradora. Contraste Etapa II - Etapa III

Fig.97. Contraste del axil en la viga superior en función de la luz y el número de plantas del pórtico

Fig.98. Excentricidades relativas de la resultante de la zapata de medianería. $\mathrm{H}=1,75 \cdot \mathrm{H}$ min 225

Fig.99. Verificación de tensiones de contacto. $\mathrm{H}=1,75 \cdot \mathrm{H}$ min 226

Fig.100. Contraste del valor del momento flector en la viga centradora 227

Fig.101. Excentricidades relativas de la resultante de la zapata de esquina 228

Fig.102. Verificación de tensiones de contacto en la zapata de esquina 229

Fig.103. Contraste del valor del momento flector en las vigas centradoras 230

Fig.104. Comparación método convencional - resultados M.E.F. 231

Fig.105. Posición de la resultante de la zapata de medianería en función de la rigidez ... 237

Fig.106. Gráfico de ajuste por mínimos cuadrados 238

Fig.107. Resultantes de tensiones de contacto en zapata de medianería y viga centradora 239

Fig.108. Evolución del porcentaje de área de la viga centradora 240

Fig.109. Resultante en la viga centradora en función de su rigidez 240

Fig.110. Correlación del ajuste de la resultante de la viga centradora 242 


\section{ÍNDICE DE FIGURAS}

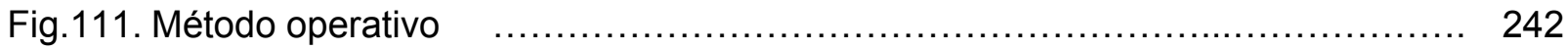

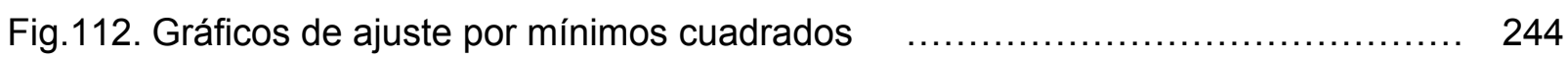

Fig.113. Correlación de los ajustes de las resultantes de las vigas centradoras $\quad \ldots \ldots \ldots . . .245$

Fig.114. Recomendación de relación luz canto en zapatas de medianería $\quad$.............. 246

Fig.115. Recomendación de relación luz canto en zapatas de esquina $\quad \ldots \ldots \ldots \ldots \ldots \ldots . . . \ldots 246$ 



\section{SÍMBOLOS}

\begin{tabular}{|c|c|}
\hline$\phi$ & Ángulo de rozamiento interno del terreno \\
\hline$\gamma_{\text {ho }}$ & Peso específico del hormigón armado \\
\hline$\gamma_{\text {so }}$ & Peso específico de la solera \\
\hline$\gamma_{\text {su }}$ & Peso específico del suelo \\
\hline$\mu$ & Coeficiente de rozamiento \\
\hline$v_{c}$ & Coeficiente de Poisson del hormigón armado \\
\hline$v_{\text {su }}$ & Coeficiente de Poisson del suelo \\
\hline$\sigma_{\mathrm{adm}}$ & Tensión admisible en el terreno \\
\hline$\sigma_{\mathrm{e}}$ & Tensión de contacto en la zapata de esquina \\
\hline$\sigma_{(\mathrm{e}-1)}$ & $\begin{array}{l}\text { Fracción de la tensión de contacto de la zapata de esquina correspondiente a } \\
\text { la viga centradora } 1\end{array}$ \\
\hline$\sigma^{\prime}(e-1)$ & $\begin{array}{l}\text { Fracción de la tensión de contacto reducida de la zapata de esquina } \\
\text { correspondiente a la viga centradora } 1\end{array}$ \\
\hline$\sigma_{(\mathrm{e}-2)}$ & $\begin{array}{l}\text { Fracción de la tensión de contacto de la zapata de esquina correspondiente a } \\
\text { la viga centradora } 2\end{array}$ \\
\hline$\sigma^{\prime}(e-2)$ & $\begin{array}{l}\text { Fracción de la tensión de contacto reducida de la zapata de esquina } \\
\text { correspondiente a la viga centradora } 2\end{array}$ \\
\hline$\sigma_{\mathrm{i}}$ & Tensión de contacto en la zapata interior \\
\hline$\sigma_{i}^{\prime}$ & Tensión de contacto reducida en la zapata interior \\
\hline$\sigma_{\mathrm{m}}$ & Tensión de contacto en la zapata de medianería \\
\hline$\sigma_{m}^{\prime}$ & Tensión de contacto reducida en la zapata de medianería \\
\hline$\sigma_{\mathrm{m} 1}$ & Tensión de contacto en la zapata de medianería 1 \\
\hline$\sigma_{m 1}^{\prime}$ & Tensión de contacto reducida en la zapata de medianería 1 \\
\hline$\sigma_{\mathrm{m} 2}$ & Tensión de contacto en la zapata de medianería 2 \\
\hline$\sigma_{m 2}^{\prime}$ & Tensión de contacto reducida en la zapata de medianería 2 \\
\hline$\sigma_{\max }$ & Tensión de contacto máxima \\
\hline$\sigma_{\text {med. }}$ & Tensión de contacto media \\
\hline$\sigma_{\min }$ & Tensión de contacto mínima \\
\hline a & Dimensión de la zapata paralela al pórtico \\
\hline $\mathrm{a}_{\mathrm{c}}$ & Dimensión de la viga centradora paralela al pórtico \\
\hline$a_{c 1}$ & Dimensión de la viga centradora 1 en dirección $x$ \\
\hline$a_{c 2}$ & Dimensión de la viga centradora 2 en dirección x \\
\hline
\end{tabular}




\section{SímBOLOS}

\begin{tabular}{|c|c|}
\hline$a_{e}$ & Dimensión de la zapata de esquina en dirección x \\
\hline$a_{i}$ & Dimensión de la zapata interior paralela al pórtico \\
\hline$a_{m}$ & Dimensión de la zapata de medianería paralela al pórtico \\
\hline$a_{m 1}$ & Dimensión de la zapata de medianería 1 en dirección x \\
\hline$a_{m 2}$ & Dimensión de la zapata de medianería 2 en dirección x \\
\hline$a^{\prime}{ }_{i}$ & Dimensión del pilar interior paralela al pórtico \\
\hline$a_{m}^{\prime}$ & Dimensión del pilar de medianería paralela al pórtico \\
\hline$a_{R}$ & Posición de la resultante respecto del extremo de la zapata \\
\hline$b_{e}$ & Dimensión de la zapata de esquina en dirección y \\
\hline$b_{c}$ & Dimensión de la viga centradora perpendicular al pórtico \\
\hline$b_{c 1}$ & Dimensión de la viga centradora 1 en dirección y \\
\hline $\mathrm{b}_{\mathrm{c} 2}$ & Dimensión de la viga centradora 2 en dirección y \\
\hline$b_{i}$ & Dimensión de la zapata interior perpendicular al pórtico \\
\hline$b_{m}$ & Dimensión de la zapata de medianería perpendicular al pórtico \\
\hline$b_{m 1}$ & Dimensión de la zapata de medianería 1 en dirección y \\
\hline$b_{m 2}$ & Dimensión de la zapata de medianería 2 en dirección y \\
\hline$b^{\prime}{ }_{i}$ & Dimensión del pilar interior perpendicular al pórtico \\
\hline$b^{\prime} m$ & Dimensión del pilar de medianería perpendicular al pórtico \\
\hline c.d.g. & Centro de gravedad \\
\hline d & Canto útil de una sección de hormigón armado \\
\hline e & Excentricidad \\
\hline$e_{i}$ & Excentricidad de la resultante de tensiones de la zapata interior \\
\hline$e_{m}$ & Excentricidad de la resultante de tensiones de la zapata de medianería \\
\hline$e_{v}$ & Excentricidad de la resultante de tensiones de la viga centradora \\
\hline E & Módulo de elasticidad longitudinal \\
\hline$E_{c m}$ & Módulo de deformación longitudinal secante a 28 días de edad \\
\hline $\mathrm{E}_{\mathrm{su}}$ & Módulo de elasticidad longitudinal del suelo \\
\hline$f_{c k}$ & Resistencia característica a compresión del hormigón a 28 días de edad \\
\hline$f_{c m}$ & Resistencia media a compresión del hormigón a 28 días de edad \\
\hline $\mathrm{F}_{\mathrm{r}}$ & Fuerza de rozamiento \\
\hline $\mathrm{h}$ & Canto de un elemento de hormigón armado \\
\hline $\mathrm{h}_{\mathrm{so}}$ & Espesor de la solera \\
\hline $\mathrm{I}_{\mathrm{b}}$ & Inercia bruta de una sección de hormigón armado \\
\hline $\mathrm{I}_{\mathrm{e}}$ & Inercia equivalente de una sección de hormigón armado \\
\hline
\end{tabular}




\title{
SÍMBOLOS
}

\author{
I $\quad$ Inercia fisurada de una sección de hormigón armado \\ L Luz del pórtico \\ $\mathrm{L}_{\mathrm{c}} \quad$ Distancia del centro de la viga centradora al centro de la zapata interior \\ $L_{\text {ex }} \quad$ Distancia del eje del pilar de esquina al centro de la zapata de medianería 2 en \\ dirección $\mathrm{x}$ \\ $\mathrm{L}_{\mathrm{ey}} \quad$ Distancia del eje del pilar de esquina al centro de la zapata de medianería 1 en \\ dirección y \\ $\mathrm{L}_{\text {c1y }} \quad$ Distancia del centro de la viga centradora 1 al centro de la zapata de \\ medianería 1 en dirección y \\ $\mathrm{L}_{\text {c1y }} \quad$ Distancia del centro de la viga centradora 1 al centro de la zapata de \\ medianería 2 en dirección $\mathrm{x}$ \\ $\mathrm{L}_{\mathrm{c} 2 \mathrm{x}} \quad$ Distancia del centro de la viga centradora 2 al centro de la zapata de \\ medianería 2 en dirección $\mathrm{x}$ \\ $\mathrm{L}_{c 2 \mathrm{y}} \quad$ Distancia del centro de la viga centradora 2 al centro de la zapata de \\ medianería 1 en dirección y \\ $\mathrm{L}_{\mathrm{m}} \quad$ Distancia del centro de la zapata de medianería al centro de la zapata interior \\ $\mathrm{L}_{\mathrm{m} 1 \mathrm{x}} \quad$ Distancia del eje del pilar de medianería 1 al centro de la zapata de medianería \\ 2 en dirección $x$ \\ $\mathrm{L}_{\mathrm{m} 2 \mathrm{y}} \quad$ Distancia del eje del pilar de medianería 2 al centro de la zapata de medianería \\ 1 en dirección y \\ $\mathrm{L}_{\text {zex }} \quad$ Distancia del centro de la zapata de esquina al centro de la zapata de \\ medianería 2 en dirección $\mathrm{x}$ \\ $\mathrm{L}_{\text {zey }} \quad$ Distancia del centro de la zapata de esquina al centro de la zapata de \\ medianería 1 en dirección y \\ $\mathrm{L}_{\mathrm{zm1x}} \quad$ Distancia del centro de la zapata de medianería 1 al centro de la zapata de \\ medianería 2 en dirección $x$ \\ $\mathrm{L}_{\text {zm2y }} \quad$ Distancia del centro de la zapata de medianería 2 al centro de la zapata de \\ medianería 1 en dirección y \\ $\mathrm{M}_{\mathrm{a}} \quad$ Momento flector aplicado en una sección de hormigón armado \\ $M_{\text {ex }} \quad$ Momento flector en la base del pilar de esquina respecto del eje $x$ \\ $M_{\text {ey }} \quad$ Momento flector en la base del pilar de esquina respecto del eje y \\ $\mathrm{M}_{\mathrm{f}} \quad$ Momento de fisuración de una sección de hormigón armado \\ $\mathrm{M}_{\mathrm{i}} \quad$ Momento flector en la base del pilar interior \\ $\mathrm{M}_{\mathrm{m}} \quad$ Momento flector en la base del pilar de medianería
}




\section{SímBOLOS}

\begin{tabular}{|c|c|}
\hline$M_{m 1 x}$ & Momento flector en la base del pilar de medianería 1 respecto del eje $\mathrm{x}$ \\
\hline $\mathrm{M}_{\mathrm{m} 1 \mathrm{y}}$ & Momento flector en la base del pilar de medianería 1 respecto del eje y \\
\hline $\mathrm{M}_{\mathrm{m} 2 \mathrm{x}}$ & Momento flector en la base del pilar de medianería 2 respecto del eje $\mathrm{x}$ \\
\hline $\mathrm{M}_{\mathrm{m} 2 \mathrm{y}}$ & Momento flector en la base del pilar de medianería 2 respecto del eje y \\
\hline $\mathrm{M}_{\mathrm{ms}}$ & Momento flector en la cabeza del pilar de medianería \\
\hline$M_{v \max }$ & Momento máximo en la viga de cimentación imaginaria \\
\hline$M_{1 v}$ & Momento flector en la sección inicial de la viga centradora \\
\hline $\mathrm{M}_{1 \mathrm{c} 1}$ & Momento flector en la sección inicial de la viga centradora 1 \\
\hline $\mathrm{M}_{1 \mathrm{c} 2}$ & Momento flector en la sección inicial de la viga centradora 2 \\
\hline $\mathrm{N}_{\mathrm{e}}$ & Esfuerzo axil en la base del pilar de esquina \\
\hline $\mathrm{N}_{(\mathrm{e}-1)}$ & $\begin{array}{l}\text { Fracción del esfuerzo axil del pilar de esquina correspondiente a la viga } \\
\text { centradora } 1\end{array}$ \\
\hline $\mathrm{N}_{(\mathrm{e}-2)}$ & $\begin{array}{l}\text { Fracción del esfuerzo axil del pilar de esquina correspondiente a la viga } \\
\text { centradora } 2\end{array}$ \\
\hline $\mathrm{N}_{\mathrm{i}}$ & Esfuerzo axil en la base del pilar interior \\
\hline $\mathrm{N}_{\mathrm{m}}$ & Esfuerzo axil en la base del pilar de medianería \\
\hline $\mathrm{N}_{\mathrm{m} 1}$ & Esfuerzo axil en la base del pilar de medianería 1 \\
\hline $\mathrm{N}_{\mathrm{m} 2}$ & Esfuerzo axil en la base del pilar de medianería 2 \\
\hline $\mathrm{N}_{\mathrm{ms}}$ & Esfuerzo axil en la cabeza del pilar de medianería \\
\hline $\mathrm{P}_{\mathrm{pm}}$ & Peso del pilar de medianería \\
\hline$P_{s c}$ & Peso de la solera sobre la viga centradora \\
\hline$P_{\text {sc1 }}$ & Peso de la solera sobre la viga centradora 1 \\
\hline $\mathrm{P}_{\mathrm{sc} 2}$ & Peso de la solera sobre la viga centradora 2 \\
\hline $\mathrm{P}_{\mathrm{se}}$ & Peso de la solera sobre la zapata de esquina \\
\hline$P_{s(e-1)}$ & $\begin{array}{l}\text { Fracción del peso de la solera sobre la zapata de esquina correspondiente a la } \\
\text { viga centradora } 1\end{array}$ \\
\hline$P_{s(e-2)}$ & $\begin{array}{l}\text { Fracción del peso de la solera sobre la zapata de esquina correspondiente a la } \\
\text { viga centradora } 2\end{array}$ \\
\hline $\mathrm{P}_{\mathrm{si}}$ & Peso de la solera sobre la zapata interior \\
\hline $\mathrm{P}_{\mathrm{sm}}$ & Peso de la solera sobre la zapata de medianería \\
\hline$P_{\mathrm{sm} 1}$ & Peso de la solera sobre la zapata de medianería 1 \\
\hline $\mathrm{P}_{\mathrm{sm} 2}$ & Peso de la solera sobre la zapata de medianería 2 \\
\hline$P_{\mathrm{vc}}$ & Peso de la viga centradora \\
\hline $\mathrm{P}_{\mathrm{vc} 1}$ & Peso de la viga centradora 1 \\
\hline
\end{tabular}




\section{SíMBOLOS}

\begin{tabular}{|c|c|}
\hline $\mathrm{P}_{\mathrm{vc2}}$ & Peso de la viga centradora 2 \\
\hline $\mathrm{P}_{\mathrm{ze}}$ & Peso de la zapata de esquina \\
\hline$P_{z(e-1)}$ & $\begin{array}{l}\text { Fracción del peso de la zapata de esquina correspondiente a la viga } \\
\text { centradora } 1\end{array}$ \\
\hline$P_{z(e-2)}$ & $\begin{array}{l}\text { Fracción del peso de la zapata de esquina correspondiente a la viga } \\
\text { centradora } 2\end{array}$ \\
\hline$P_{z i}$ & Peso de la zapata interior \\
\hline$P_{z m}$ & Peso de la zapata de medianería \\
\hline$P_{z m 1}$ & Peso de la zapata de medianería 1 \\
\hline $\mathrm{P}_{\mathrm{zm} 2}$ & Peso de la zapata de medianería 2 \\
\hline$q_{p}$ & Carga de peso propio y carga permanente \\
\hline$q_{s}$ & Carga de sobrecarga de uso \\
\hline $\mathrm{R}_{\mathrm{e}}$ & Resultante de las tensiones de contacto en la zapata de esquina \\
\hline$R_{(e-1)}$ & $\begin{array}{l}\text { Fracción de la resultante de las tensiones de contacto de la zapata de esquina } \\
\text { correspondiente a la viga centradora } 1\end{array}$ \\
\hline$R^{\prime}(e-1)$ & $\begin{array}{l}\text { Fracción de la resultante de las tensiones de contacto reducidas de la zapata } \\
\text { de esquina correspondiente a la viga centradora } 1\end{array}$ \\
\hline $\mathrm{R}_{(\mathrm{e}-2)}$ & $\begin{array}{l}\text { Fracción de la resultante de las tensiones de contacto de la zapata de esquina } \\
\text { correspondiente a la viga centradora } 2\end{array}$ \\
\hline$R^{\prime}(e-2)$ & $\begin{array}{l}\text { Fracción de la resultante de las tensiones de contacto reducidas de la zapata } \\
\text { de esquina correspondiente a la viga centradora } 2\end{array}$ \\
\hline $\mathrm{R}_{\mathrm{i}}$ & Resultante de las tensiones de contacto en la zapata interior \\
\hline $\mathrm{R}_{\mathrm{m}}$ & Resultante de las tensiones de contacto en la zapata de medianería \\
\hline $\mathrm{R}_{\mathrm{m} 1}$ & Resultante de las tensiones de contacto en la zapata de medianería 1 \\
\hline$R^{\prime}{ }_{m}$ & $\begin{array}{l}\text { Resultante de las tensiones de contacto reducidas en la zapata de } \\
\text { medianería } 1\end{array}$ \\
\hline $\mathrm{R}_{\mathrm{m} 2}$ & Resultante de las tensiones de contacto en la zapata de medianería 2 \\
\hline $\mathrm{R}_{\mathrm{m} 2}^{\prime}$ & $\begin{array}{l}\text { Resultante de las tensiones de contacto reducidas en la zapata de } \\
\text { medianería } 2\end{array}$ \\
\hline$R_{v}$ & Resultante de las tensiones de contacto en la viga centradora \\
\hline $\mathrm{T}$ & Esfuerzo axil de tracción en la viga de la primera planta \\
\hline $\mathrm{V}_{\mathrm{ex}}$ & Esfuerzo cortante en la base del pilar de esquina en dirección $x$ \\
\hline $\mathrm{V}_{\text {ey }}$ & Esfuerzo cortante en la base del pilar de esquina en dirección y \\
\hline$V_{i}$ & Esfuerzo cortante en la base del pilar interior \\
\hline
\end{tabular}




\section{SímBOLOS}

$V_{m} \quad$ Esfuerzo cortante en la base del pilar de medianería

$V_{\text {m1x }}$

Esfuerzo cortante en la base del pilar de medianería 1 en dirección $\mathrm{x}$

$V_{m 1 y}$

Esfuerzo cortante en la base del pilar de medianería 1 en dirección y

$V_{m 2 x}$

Esfuerzo cortante en la base del pilar de medianería 2 en dirección $x$

$V_{\text {m2y }}$

Esfuerzo cortante en la base del pilar de medianería 2 en dirección y

$\mathrm{V}_{\mathrm{ms}}$

Esfuerzo cortante en la cabeza del pilar de medianería

$\mathrm{V}_{1 \mathrm{v}}$

Esfuerzo cortante en la sección inicial de la viga centradora

$\mathrm{V}_{1 \mathrm{c} 1}$

Esfuerzo cortante en la sección inicial de la viga centradora 1

$\mathrm{V}_{1 \mathrm{c} 2}$

Esfuerzo cortante en la sección inicial de la viga centradora 2

$\mathrm{V}_{2 \mathrm{v}}$

Esfuerzo cortante a un canto útil del pilar de medianería

$\mathrm{X}$

Profundidad de la fibra neutra 


\section{ABREVIATURAS}

C.T.E. Código Técnico de la Edificación

DB SE - AE Documento Básico. Seguridad Estructural: Acciones en la Edificación

DB SE - C Documento Básico. Seguridad Estructural: Cimientos

D.E.A. $\quad$ Diploma de Estudios Avanzados

EHE Instrucción de Hormigón Estructural

E.L.U. Estado Límite Último

Fig. Figura

M.E.F. Método de Elementos Finitos 

CAPÍTULO 1

INTRODUCCIÓN 



\section{INTRODUCCIÓN}

\subsection{JUSTIFICACIÓN DE LA TESIS DOCTORAL}

Desde tiempos remotos la humanidad ha tenido la aspiración de llegar a apropiarse de la complejidad de los procesos naturales y su comportamiento real, mediante algoritmos de cálculo que simulen y reproduzcan fielmente dicho comportamiento.

Ante el hecho constatado de lo utópico del planteamiento, llega el momento de la humildad, del reconocimiento de las limitaciones propias y, como consecuencia, del planteamiento de algoritmos o modelos de cálculo simplificados, que aspiran a aproximarse lo más posible a la realidad, dentro de las posibilidades de las herramientas de cálculo disponibles.

Como caso particular de lo comentado, el proceso de cálculo de una estructura comienza por una fase inicial consistente en la definición de un modelo teórico que se asemeja, todo lo posible, a la estructura real y cuyo cálculo arroja resultados que se aproximan, todo lo posible, al comportamiento real de la estructura.

La modelización o idealización que se adopta para una estructura supone una solución de compromiso entre diversos factores:

- Precisión deseada en el resultado

- Potencia de las herramientas de cálculo disponibles

- Tiempo de cálculo disponible

La precisión del resultado va asociada al proceso de decisiones a tomar en el dimensionamiento de la estructura. Si el resultado es muy grosero, será preciso adoptar planteamientos muy conservadores en el dimensionamiento para quedar del lado de la seguridad. Por el contrario, alcanzado un determinado nivel de precisión, no compensa incrementar la precisión del resultado, si las decisiones de dimensionamiento a las que conduce son las mismas. En cuanto a la potencia de las herramientas de cálculo, evidentemente las aspiraciones de modelización deben ser muy diferentes si se trabaja con cálculo estrictamente manual, regla de cálculo, calculadora u ordenador. Finalmente, los dos parámetros anteriores vienen condicionados por el tiempo de cálculo disponible para realizar el proyecto estructural, que queda limitado por los plazos de entrega. Conviene comentar, en este sentido, que el progresivo incremento de la potencia de las herramientas de cálculo, en muchos casos se ha invertido solamente en reducir los plazos de entrega y no en mejorar las modelizaciones utilizadas. 
El objetivo es, por tanto, lograr los resultados más precisos posibles, en un tiempo razonable, en función de las herramientas de cálculo disponibles.

Si el proceso de cálculo ha de ser manual (entendiendo por tal el que se realiza hoy en día con calculadoras) la modelización debe ser necesariamente simplificada, pues de lo contrario será imposible alcanzar resultados prácticos en un tiempo razonable. Este tipo de cálculos suele estar plagado de modelos sencillos, lineales, isostáticos o hiperestáticos con un grado de hiperestaticidad muy reducido. A modo de ejemplo, en la Fig.1.a se muestra una clásica modelización de un pórtico de edificación de nudos rígidos, planteado como un conjunto de vigas continuas apoyadas sobre pilares. Dicha modelización puede abordarse manualmente en un tiempo razonable con el empleo de prontuarios. Una modelización clásica más compleja, considerando propiamente el pórtico de nudos rígidos (Fig.1.b), solo es abordable de forma manual (por ejemplo por el método de Cross) si el número de plantas y vanos es reducido, en caso contrario, la única solución viable es el empleo de otros métodos de cálculo, pero ya no manualmente, sino mediante el uso de ordenadores.
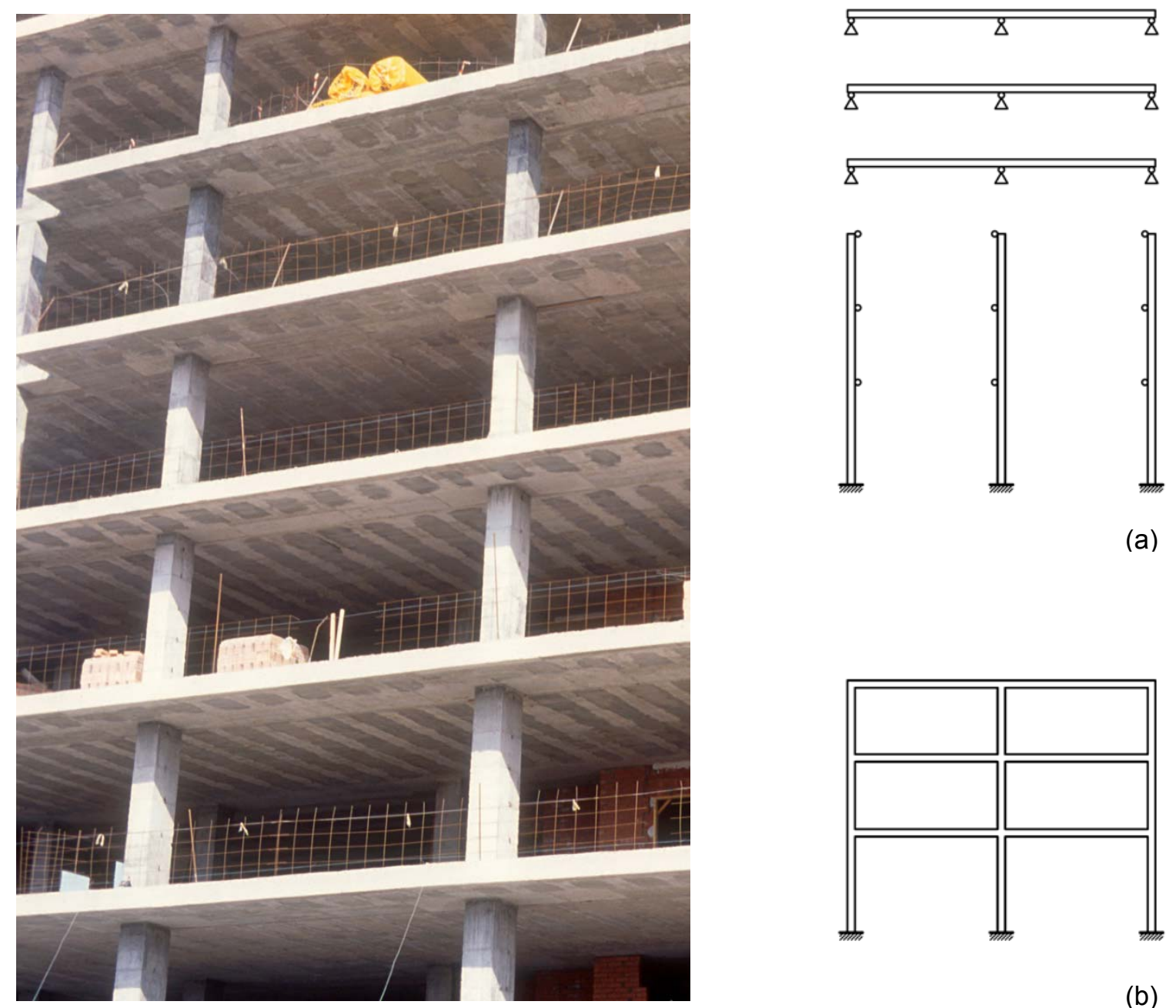

(a)

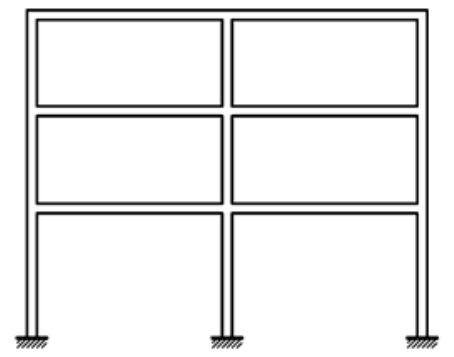

(b)

Fig.1. Modelización simplificada para cálculo manual 
La aparición de los ordenadores y el progresivo incremento de su potencia de cálculo ha permitido el empleo de métodos de cálculo cada vez más complejos, hasta llegar al Método de Elementos Finitos (M.E.F.) que aproxima el viejo sueño de llegar a calcular los elementos estructurales con toda la complejidad de la estructura real (Cervenka, V., 2002). En la Fig.2 puede observarse una modelización por elementos finitos de un pórtico de edificación junto con su cimentación y el terreno que la recibe.

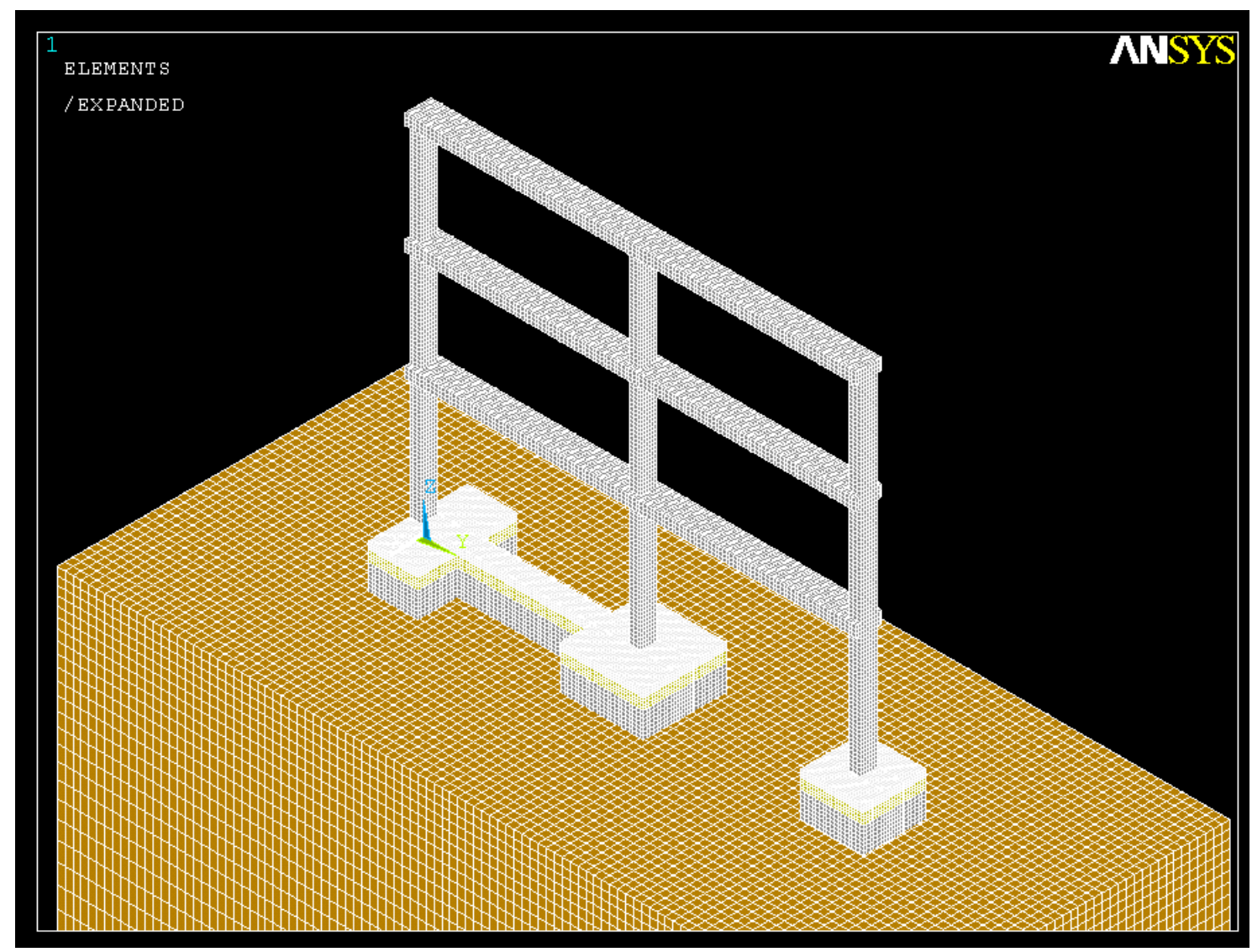

Fig.2. Modelización por elementos finitos

No obstante, a fecha de hoy, incluso con ordenadores muy potentes, una modelización por elementos finitos tan precisa como la representada en la Fig.2 (con elementos de pequeño tamaño, considerando todos los materiales implicados con sus correspondientes contactos y con programas informáticos de elementos finitos que aún deben mejorar su facilidad de manejo) puede llegar a suponer un tiempo de cálculo considerable y, por ello, es preciso seguir haciendo un ejercicio de racionalidad y encontrar el punto óptimo de equilibrio entre precisión en el resultado, tiempo de cálculo necesario para alcanzarla y repercusiones reales del incremento de la precisión sobre las decisiones de dimensionamiento del proyecto estructural. 
Las modelizaciones empleadas en cada momento han de ir evolucionando al ritmo que se incrementa la potencia de las herramientas de cálculo. No tiene sentido seguir empleando modelizaciones de la época del cálculo estrictamente manual con ordenadores de última generación. El momento actual puede considerarse como un momento de transición. Los métodos clásicos o convencionales resultan hoy excesivamente simplificados y poco ajustados a la realidad, pero la alternativa del cálculo por elementos finitos todavía no es de aplicación práctica, de forma generalizada, en la vida cotidiana del ejercicio profesional del cálculo de estructuras. El pasado parece quedar muy atrás, pero el futuro todavía no ha llegado.

En este momento de transición, el empleo de modelizaciones por elementos finitos es perfectamente aplicable en el ámbito de la investigación y ello permite utilizar el método de elementos finitos, con todas sus posibilidades, para contrastar los métodos convencionales (llenos de simplificaciones) y deducir ajustes de los mismos que les acerquen más al comportamiento real de los elementos estructurales, optimizando así el dimensionamiento de éstos. Se trata de seguir disfrutando de la sencillez de los métodos tradicionales mejorando la precisión de sus resultados y su ajuste a la realidad, gracias a un proceso de investigación con elementos finitos, mientras llega el momento (tal vez no muy lejano) de trabajar directamente y de forma cómoda y práctica con modelos de elementos finitos en el ejercicio profesional cotidiano del cálculo de estructuras, momento que supondrá el abandonando definitivo de los métodos clásicos.

La presente tesis doctoral pretende realizar una aplicación concreta de este planteamiento. Se ha elegido como tema de estudio un caso de cimentaciones superficiales, las zapatas de medianería y esquina con viga centradora. La modelización de este tipo de cimentación por métodos convencionales presenta una serie de simplificaciones que permiten el cálculo de las mismas, por medios manuales, en un tiempo razonable, pero que claramente la alejan del comportamiento real de las mismas, con las consecuencias negativas que ello puede suponer en el dimensionamiento de estos elementos estructurales.

Constituye, por ello, un interesante ejemplo para un proceso de investigación, que desarrolla un contraste de los modelos convencionales de cálculo de cimentaciones de medianería y esquina, mediante un análisis alternativo con modelos de elementos finitos. Los resultados obtenidos ponen de manifiesto importantes discrepancias entre ambos métodos que conducen a importantes diferencias en el dimensionamiento de este tipo de cimentaciones. El empleo de los métodos tradicionales da lugar, por un lado, a un sobredimensionamiento de 
la armadura de la viga centradora y, por otro, a un infradimensionamiento, tanto del canto de la viga centradora, como del tamaño de la zapata de medianería y del armado de la viga de la primera planta.

Asimismo, los resultados obtenidos evidencian el papel protagonista del giro de la zapata de medianería como elemento clave en el comportamiento de este tipo de cimentación y la necesidad de disponer de un suficiente canto en la viga centradora, como único recurso realmente eficaz para lograr la rigidización del conjunto del elemento estructural, como mecanismo para conseguir un correcto funcionamiento de las zapatas de medianería y esquina, limitando los giros excesivos de las mismas.

Finalmente, la tesis propone un nuevo método alternativo, de carácter convencional y, por tanto, aplicable a un cálculo manual, que permite obtener de forma sencilla los párametros clave que regulan el comportamiento de las zapatas de medianería y esquina, conduciendo a un dimensionamiento más ajustado a las necesidades reales de este tipo de cimentación.

Todo ello constituye una aportación práctica de gran utilidad en el ejercicio profesional del cálculo de estructuras, ya que permite la optimización del dimensionamiento de un elemento estructural que se presenta habitualmente en los proyectos de edificación en ámbito urbano, donde el caso de las medianerías es muy frecuente. 


\subsection{OBJETIVOS}

El objetivo general de esta tesis doctoral es la optimización de los actuales métodos de cálculo de zapatas de medianería y esquina, con el fin de lograr una optimización de los dimensionamientos obtenidos para las mismas con el empleo de los citados métodos.

Este objetivo general se desarrolla mediante los siguientes objetivos específicos:

- Contrastar los modelos convencionales de cálculo de cimentaciones superficiales de medianería y esquina, con un análisis alternativo realizado mediante modelos de elementos finitos, con el fin de poner de manifiesto las diferencias entre los resultados obtenidos con ambos tipos de modelización.

- Identificar las variables que presentan mayor influencia sobre el comportamiento real de este tipo de cimentación.

- Proponer un nuevo método alternativo, de carácter convencional y, por tanto, aplicable a un cálculo manual, que permita obtener los parámetros clave que regulan el comportamiento de las zapatas de medianería y esquina y que conduzca, por tanto, a un dimensionamiento más ajustado a las necesidades reales de este tipo de cimentación. 


\subsection{ESQUEMA GENERAL DE LA TESIS}

La presentación de este trabajo de investigación se ha organizado siguiendo el esquema clásico de una tesis doctoral, con 6 capítulos principales y 1 anejo, cuyo contenido se describe a continuación:

\section{- CAPÍTULO 1. INTRODUCCIÓN}

En este capítulo se presentan la justificación de la tesis doctoral y los objetivos de la misma.

\section{- CAPÍtUlo 2. ESTAdo ACTUAL DEL CONOCIMIENTO}

En este capítulo se describe en primer lugar el concepto de zapata de medianería y zapata de esquina, indicando las soluciones más habitualmente empleadas para abordar la problemática que implican. A continuación, se analizan detalladamente los métodos de cálculo convencionales actualmente empleados para el cálculo y dimensionamiento de este tipo de cimentaciones. Finalmente, se realiza una valoración crítica de los citados modelos convencionales, identificando las principales simplificaciones que podrían ponerse en tela de juicio, así como las consecuencias que pueden suponer para el dimensionamiento de la cimentación.

\section{- CAPÍTULO 3. PLAN EXPERIMENTAL}

En este capítulo se define el plan de trabajo llevado a cabo en la fase experimental de la tesis doctoral. En primer lugar, se describen los pórticos tipo empleados en el proceso de investigación, así como las cargas contempladas en el estudio. A continuación se realiza un análisis del comportamiento real de las zapatas de medianería y esquina para seleccionar las variables que mayor influencia tienen sobre dicho comportamiento, que definen el conjunto de casos a ensayar. Por último, se describe el método experimental (virtual en este caso) empleado en el ensayo del conjunto de casos definido por las variables seleccionadas.

\section{- CAPÍTULO 4. RESULTADOS EXPERIMENTALES}

En este capítulo se exponen los resultados obtenidos en los ensayos realizados. Dichos resultados se han organizado en una serie de tablas, en función de las variables analizadas y de forma independiente para los modelos convencionales, por un lado, y para los modelos de elementos finitos, tanto de las zapatas de medianería como las de esquina, por otro. 


\section{- CAPÍTULO 5. ANÁLISIS Y DISCUSIÓN DE RESULTADOS}

En este capítulo se procede al análisis de los resultados obtenidos en los ensayos realizados. Se aborda, en primer lugar, el estudio de los esfuerzos obtenidos en la viga centradora, especialmente el momento flector en la misma. A continuación, se analizan las distribuciones de tensiones de contacto obtenidas en los modelos de elementos finitos, incidiendo especialmente en la excentricidad de la resultante de las mismas, asociada al giro de las zapatas y analizando la influencia de las distintas variables estudiadas sobre dicha excentricidad. Seguidamente se estudia la colaboración portante de la viga centradora y su influencia sobre el comportamiento del conjunto del elemento de cimentación. Por último, se discuten los efectos que genera la cimentación sobre la viga de la primera planta. Concluido el análisis de resultados $y$, a partir de ellos, se propone una alternativa a los métodos convencionales tradicionales, con el fin de obtener resultados más ajustados al comportamiento real de la cimentación.

\section{- CAPÍTULO 6. CONCLUSIONES Y FUTURAS LÍNEAS DE INVESTIGACIÓN}

En este capítulo se describen las conclusiones de la tesis doctoral, basadas en los objetivos que se habían marcado para el trabajo de investigación abordado y se plantean ciertas cuestiones de interés para futuras líneas de investigación.

- ANEJOS

Se incorporan dos anejos que incluyen los listados de programación de los modelos de elementos finitos empleados en la fase experimental virtual de la tesis doctoral. 
CAPÍTULO 2

ESTADO ACTUAL DEL CONOCIMIENTO 



\section{ESTADO ACTUAL DEL CONOCIMIENTO}

\subsection{ZAPATAS DE MEDIANERÍA Y ESQUINA. CONCEPTO Y TIPOLOGÍA}

La zapata de medianería es un tipo de cimentación superficial o directa, que se presenta cuando el edificio proyectado se sitúa junto a alguno de los límites de la parcela disponible, ya sea medianería (límite con otra propiedad) o fachada (límite con la vía pública). En tal situación (Fig.3), al encontrarse los pilares extremos o de fachada tangentes al límite de la propiedad y no poder invadir con la cimentación terreno ajeno ni público, la correspondiente zapata quedará geométricamente desplazada respecto del eje del pilar y la reacción del terreno lógicamente descentrada. La zapata de esquina puede entenderse como un caso particular de la anterior, que se presenta en aquellos pilares de esquina en los que confluyen dos medianerías o límites de propiedad mutuamente perpendiculares.
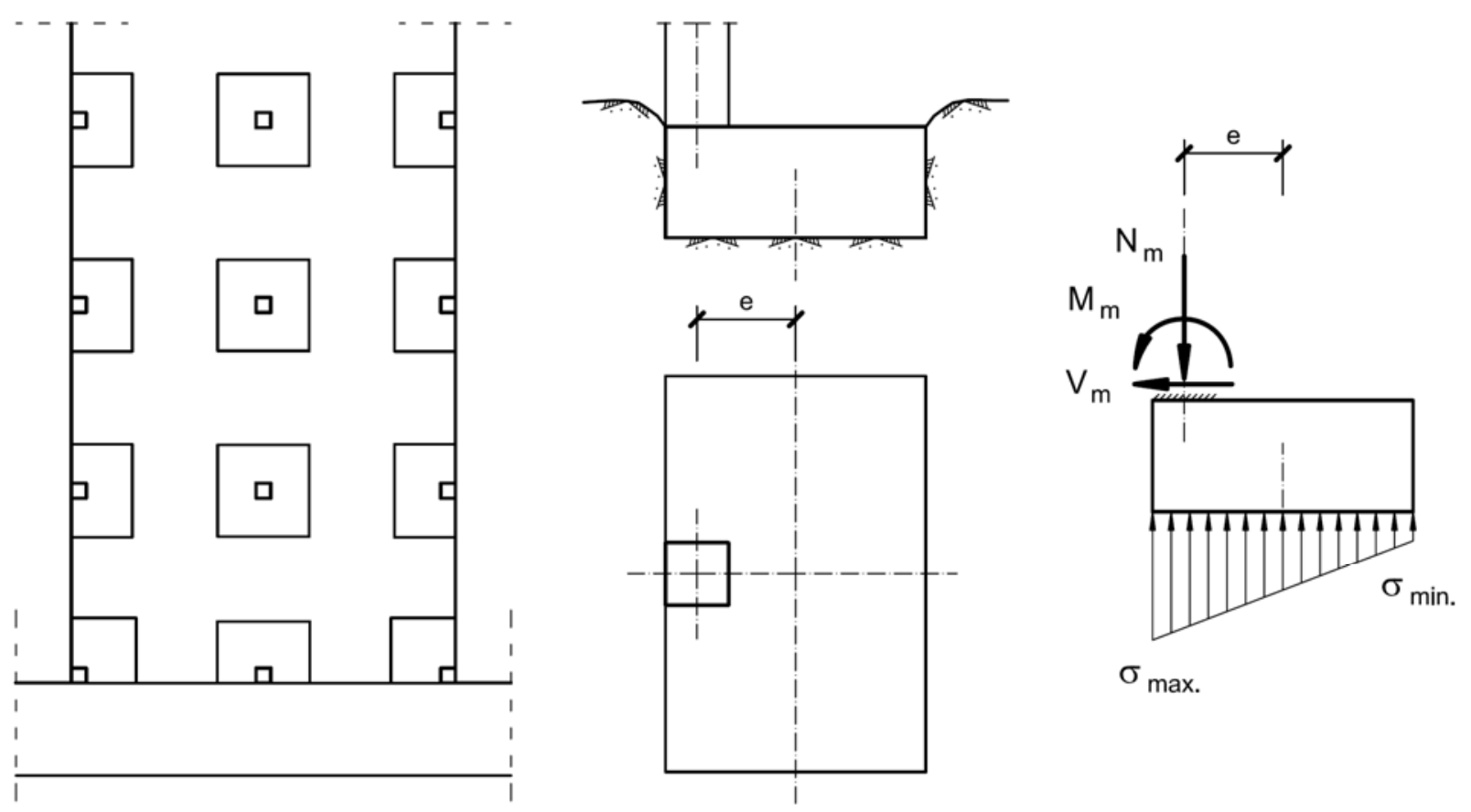

Fig.3. Concepto de zapata de medianería y zapata de esquina

La solución de este caso como zapata aislada solamente es posible en edificios muy reducidos, de planta baja o, a lo sumo, baja más una. Debido a la excentricidad (e) del esfuerzo axil $\left(\mathrm{N}_{\mathrm{m}}\right)$, si se proyectase una zapata aislada (Fig. 3), la distribución de tensiones de contacto con el terreno sería trapecial o incluso triangular, según los casos, produciendo un incremento de tensión hacia el borde de la zapata que recibe el pilar (con valor máximo 
$\sigma_{\max }$ bajo dicho borde) y asientos diferenciales entre ambos extremos, con los consiguientes giros de la zapata y las consecuencias perjudiciales que ello puede acarrear. Si los esfuerzos transmitidos por el pilar son importantes (especialmente el esfuerzo axil $\mathrm{N}_{\mathrm{m}}$ que aumenta considerablemente con el número de plantas), el volumen de zapata aislada necesario para equilibrar la cimentación y evitar los efectos negativos descritos resulta excesivo, por lo cual, el planteamiento de zapatas de medianería o esquina aisladas es inviable en la inmensa mayor parte de las estructuras de edificación habituales, siendo necesario recurrir a otro tipo de soluciones que se describen a continuación.

( a )
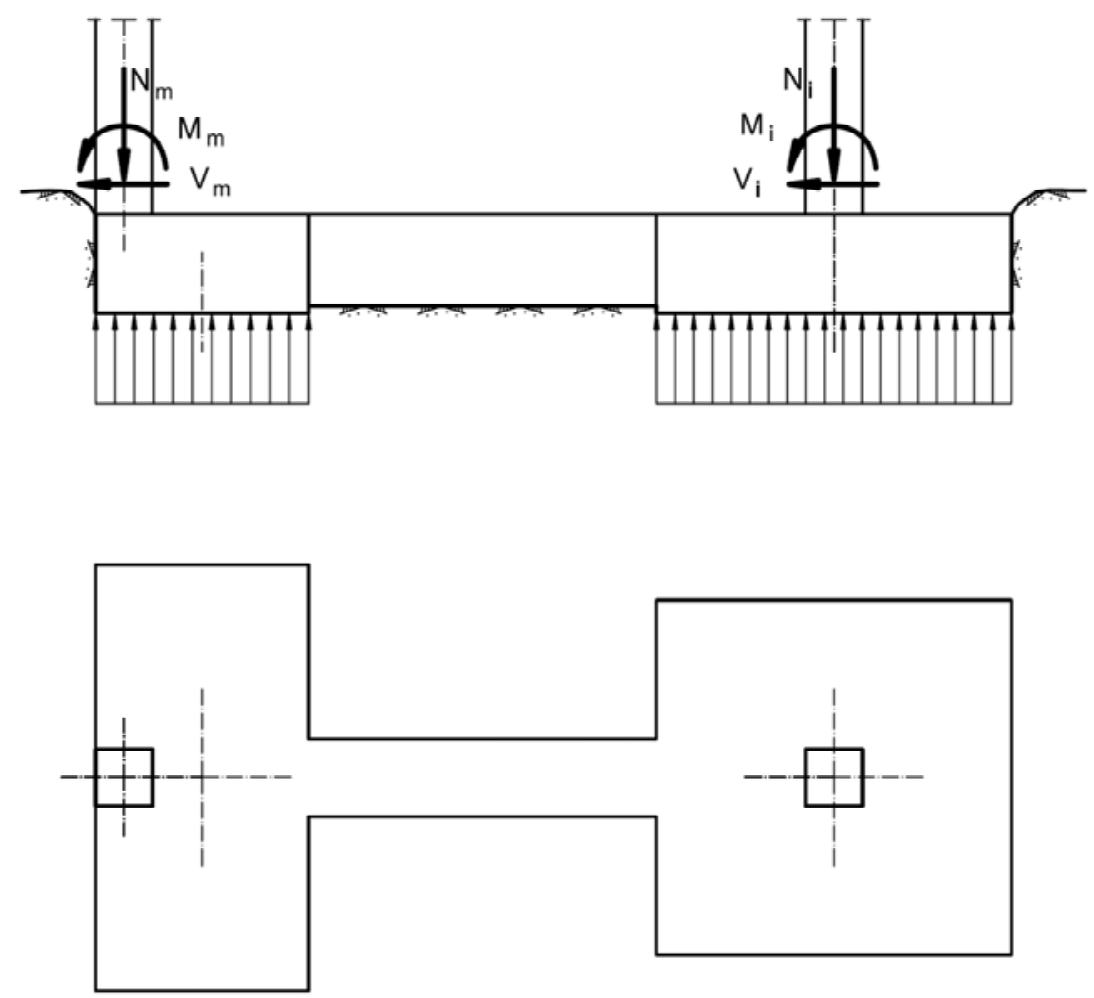
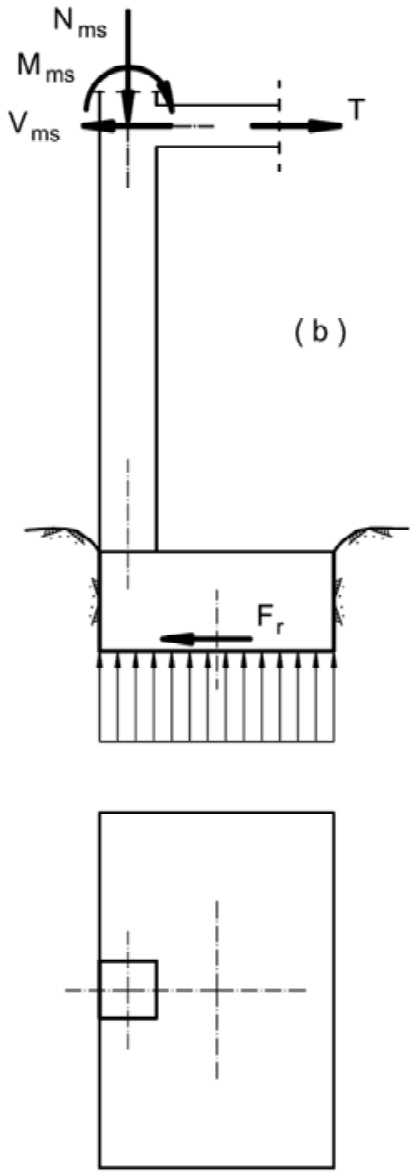

Fig.4. Soluciones más frecuentes para las de zapatas de medianería

Existe un amplio catálogo de posibles soluciones para el caso de la zapata de medianería (Calavera, J. 2000, Perepérez, B. 2005 y Rodríguez, J.M. 1982). De ellas, las más utilizadas habitualmente en estructuras de edificación son las que se recogen en la Fig.4.

La primera solución que se plantea (Fig.4.a), tal vez con diferencia la más empleada como solución al problema de la medianería, es la utilización de una viga centradora que conecta la zapata de medianería con la zapata del pilar interior más próximo. De esta manera, el 
equilibrio de la zapata de medianería y el centrado de la respuesta del terreno se consigue gracias a la colaboración del pilar interior con su cimentación y al trabajo a flexión de la viga centradora. En caso de no disponer de un pilar interior a una distancia razonable, la misión del citado pilar interior con su cimentación puede ser desarrollada por un contrapeso. La modelización clásica considera un éxito completo en la misión de la viga centradora, que logra un centrado total de la reacción del terreno, con distribución de tensiones uniforme tanto en la zapata de medianería como en la interior. Este planteamiento presupone, por tanto, que la viga centradora logra evitar cualquier giro de la zapata de medianería y que el pilar puede, por ello, considerarse perfectamente empotrado en la cimentación, sin ningún incremento adicional de la flexión en el mismo debido al comportamiento de la cimentación. En este primer modelo, el protagonismo fundamental recae en la viga centradora, cuyo trabajo a flexión conduce frecuentemente a unas escuadrías y a unas cuantías de armado bastante considerables.

La segunda solución (Fig.4.b.), no tan empleada como la anterior, plantea la colaboración de la viga de la primera planta (o en su caso el forjado de la misma), trabajando como tirante a flexotracción. La fuerza de tracción en la viga de la primera planta $(T)$ encuentra su equilibrio horizontal gracias al rozamiento entre la zapata y el terreno $\left(F_{r}\right)$. Dicho par de fuerzas genera un momento estabilizador que equilibra al producido por la excentricidad del esfuerzo axil $\left(\mathrm{N}_{\mathrm{ms}}\right)$ logrando centrar la reacción del terreno y dando lugar a una distribución de tensiones también uniforme. En este caso, la fuerza estabilizadora que resuelve el problema se introduce en la cabeza del pilar de la planta baja, por lo cual, esta solución implica un incremento en la flexión del pilar al encontrarse físicamente colocado en una posición intermedia entre el origen del problema y la solución del mismo.

En el caso de la zapata de esquina, como generalización tridimensional de la zapata de medianería, también son aplicables las dos soluciones indicadas, es decir, el empleo de vigas centradoras, por un lado, o la colaboración de la viga y el forjado de la primera planta trabajando a flexotracción, por otro.

En este caso, tal vez de forma más acentuada que en la zapata de medianería, la solución más ampliamente empleada es el uso de vigas centradoras, que conectan la zapata de esquina, habitualmente cuadrada, con las dos zapatas vecinas, previsiblemente dos zapatas de medianería, dada la confluencia de dos límites de la propiedad en la esquina. Al ser un problema tridimensional, la zapata de esquina presenta una doble excentricidad del pilar respecto de la zapata, que requiere una viga centradora por cada una de las dos direcciones implicadas. 


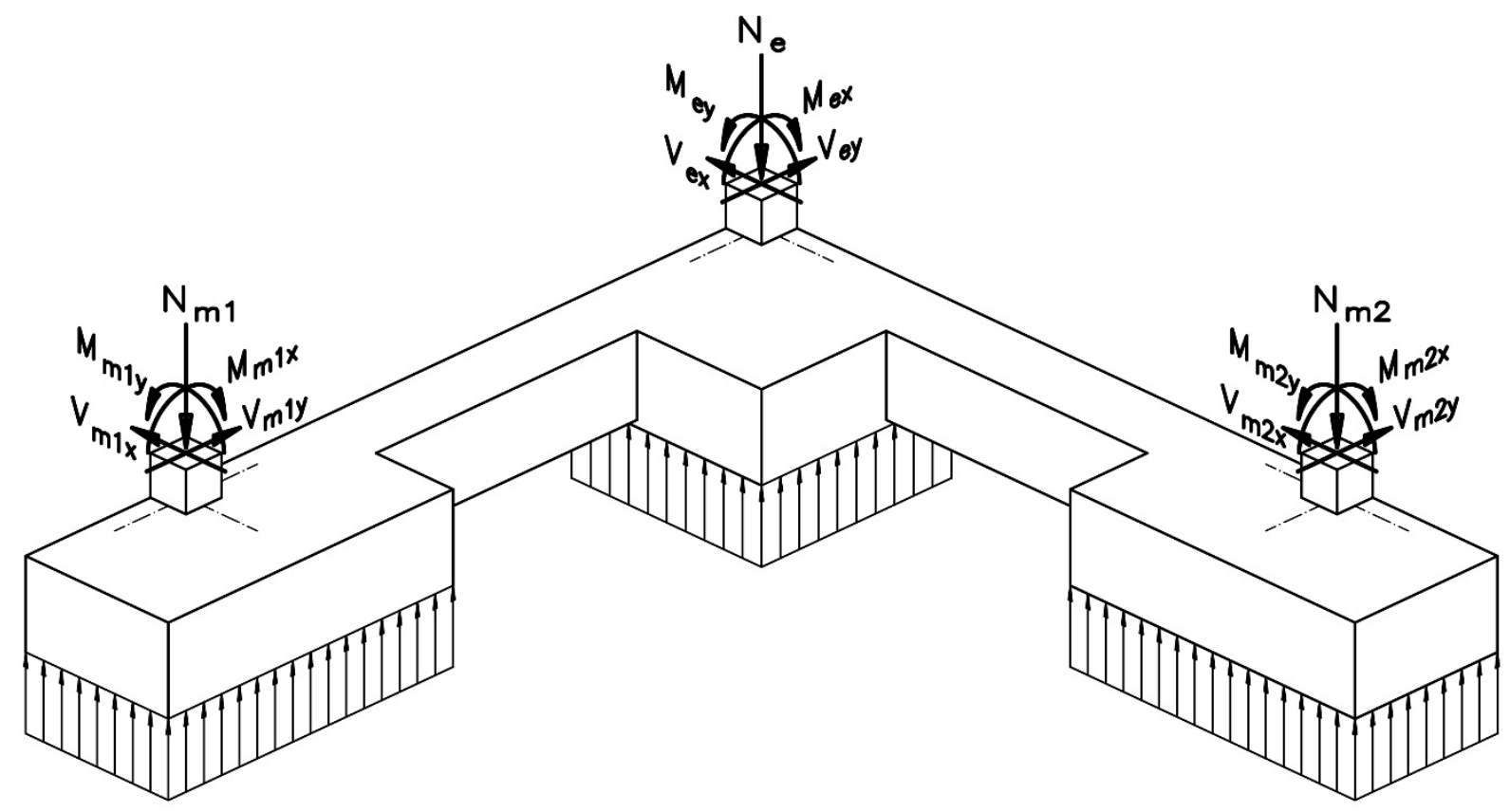

Fig.5. Solución habitual para las zapatas de esquina 


\subsection{ZAPATA DE MEDIANERÍA CON VIGA CENTRADORA}

La solución más frecuente al problema de la medianería es la utilización de una viga centradora que conecta la zapata de medianería con la zapata del pilar interior más próximo. De esta manera, el equilibrio de la zapata de medianería y el centrado de la respuesta del terreno se consigue gracias a la colaboración del pilar interior con su cimentación y al trabajo a flexión de la viga centradora (Fig.4.a).

En el cálculo y dimensionamiento de una zapata de medianería con viga centradora pueden distinguirse tres fases:

- Verificación del Estado Límite Último (E.L.U.) de Equilibrio

- Cálculo de esfuerzos en la viga centradora

- Armado de las zapatas y de la viga centradora

La presente tesis doctoral de investigación se centra en el estudio de las posibles modelizaciones de las zapatas de medianería y su influencia sobre los esfuerzos que se generan, tanto en el contacto zapata terreno, como en la viga centradora. Por ello, se van a abordar los contrastes de modelizaciones respecto de las dos primeras fases y no se va a entrar en los métodos de cálculo del armado, si bien se incidirá en las consecuencias que tienen sobre el armado de la viga centradora los esfuerzos obtenidos con las distintas modelizaciones.

\subsubsection{E.L.U. DE EQUILIBRIO}

La verificación del E.L.U. de Equilibrio supone la comprobación de la estabilidad del conjunto del elemento de cimentación (zapata de medianería, zapata interior y viga centradora), que implica la ausencia global en la misma de giros y desplazamientos (tanto horizontales como verticales). En el caso de estructuras de edificación con varias plantas de forjados, los esfuerzos axiles transmitidos por los pilares a la cimentación suelen ser considerables y muy superiores a los momentos flectores y a los esfuerzos cortantes, por lo cual, las comprobaciones de ausencia de vuelco y de desplazamiento horizontal no suelen plantear ningún problema, siendo la comprobación relativa a los posibles desplazamientos verticales la que determina el tamaño de la cimentación. La comprobación de equilibrio en dirección vertical consiste, en esencia, en verificar que las tensiones de contacto transmitidas por la 
cimentación al terreno sean inferiores a la tensión admisible de éste, para lo cual, han de disponerse unas zapatas de suficiente tamaño y adecuada proporción. Por tratarse de una comprobación geotécnica, la verificación de tensiones de contacto ha de realizarse a partir de las cargas con su valor de servicio o característico.

En la Fig.6 se muestra detalladamente la modelización convencional que permite el cálculo de la tensión transmitida al terreno. Se parte de un determinado predimensionamiento de las zapatas, de dimensiones $a_{m} \cdot b_{m} \cdot h$ para la de medianería y $a_{i} \cdot b_{i} \cdot h$ para la interior. La zapata de medianería suele disponerse de forma rectangular con lado menor $\mathrm{a}_{\mathrm{m}}$ paralelo al plano principal de cargas, para reducir al máximo la excentricidad de la misma y la flexión en la viga centradora. Se predimensiona también la viga centradora, de dimensiones $a_{c} \cdot b_{c} \cdot h_{c}$. Dada la importante flexión que soporta la viga centradora, suele aprovecharse al máximo el canto de la cimentación, haciendo la viga centradora solamente con $50 \mathrm{~mm}$ menos de canto para facilitar el cruce de la ferralla en el encuentro entre las zapatas y la viga.

Las acciones incluyen, por un lado, los pesos propios de los elementos de cimentación y su entorno y, por otro lado, las cargas transmitidas por los pilares. Se ha considerado en la Fig.6 tanto el peso propio de ambas zapatas como el de la viga centradora $\left(\mathrm{P}_{\mathrm{zm}}, \mathrm{P}_{\mathrm{zi}}, \mathrm{P}_{\mathrm{vc}}\right)$. Asimismo, se ha tenido en cuenta el peso de las tierras o soleras que gravitan sobre la cimentación ( $\left.P_{s m}, P_{s i}, P_{s c}\right)$ que incluyen, en su caso, las posibles sobrecargas de uso sobre la solera. Por lo que respecta a las cargas transmitidas por los pilares, se contemplan tanto el esfuerzo axil como el momento flector y el esfuerzo cortante de ambos pilares, calculados previamente a partir del análisis del pórtico en cuestión con la hipótesis de pilares perfectamente empotrados en la cimentación. Ciertos autores (Calavera, J. 2000, Rodríguez,J.M. 1982) plantean únicamente los esfuerzos axiles como carga transmitida por los pilares, argumentando que el valor de los momentos flectores y esfuerzos cortantes es reducido y, por tanto, despreciable. No obstante, la inclusión de dichos momentos y cortantes aumenta la precisión del modelo sin un incremento considerable en su complejidad.

Las cargas descritas se equilibran gracias a las tensiones que se generan en el contacto entre la cimentación y el terreno. Todos los autores que describen la modelización clásica de este tipo de cimentación (Calavera, J. 2000, Perepérez, B. 2005 y Rodríguez, J.M. 1982), coinciden en plantear una distribución de tensiones uniformemente repartida, tanto bajo la zapata de medianería como en la interior, considerando nula la tensión de contacto bajo la viga centradora. Como consecuencia de ello, el modelo clásico presente solamente dos incógnitas a resolver, las resultantes $R_{m}$ y $R_{i}$ de los diagramas uniformes de tensiones de contacto que, lógicamente, están aplicadas en el centro de las respectivas zapatas. 

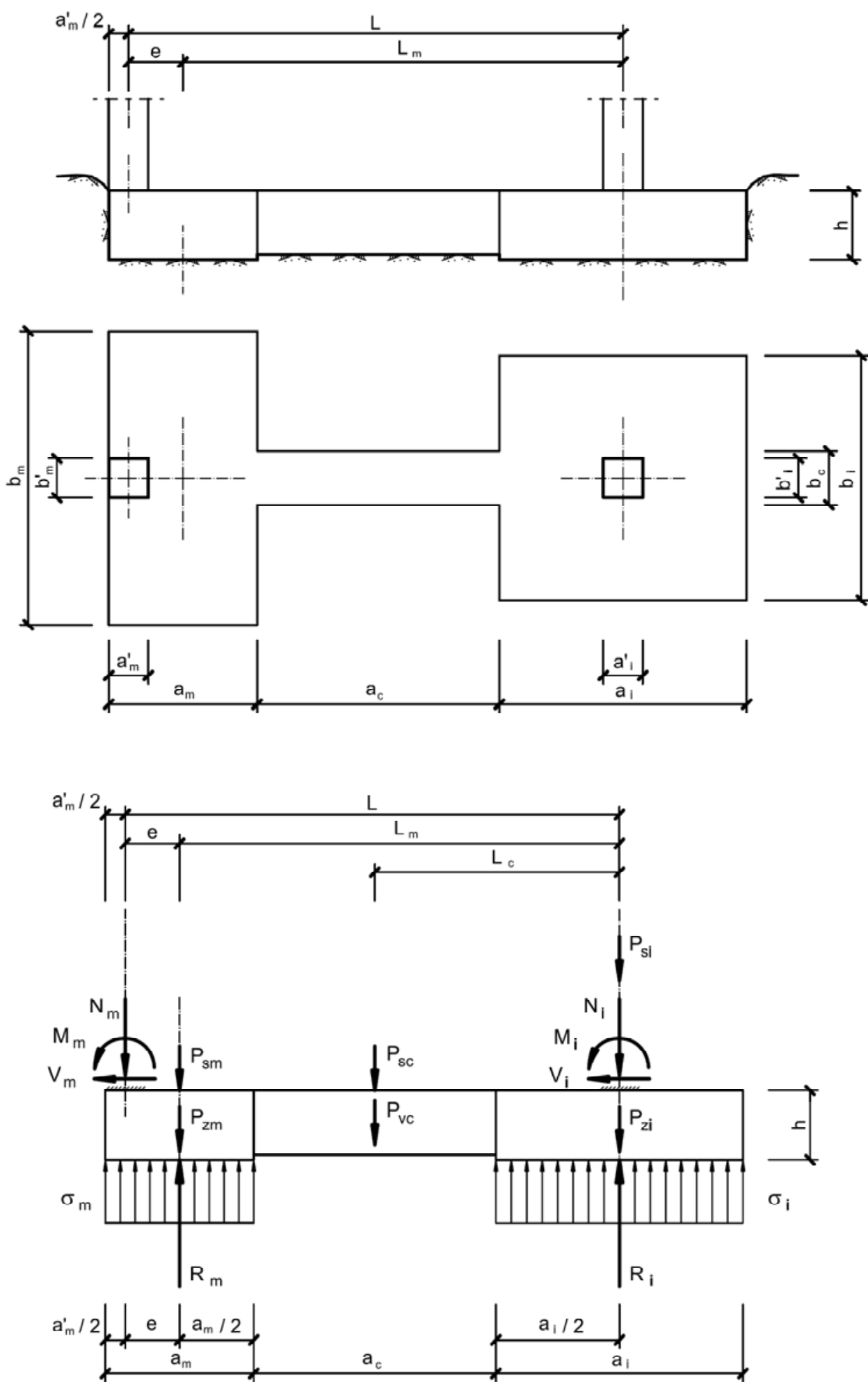

Fig.6. Zapata de medianería con viga centradora. Modelización convencional

Para la resolución de las dos incógnitas que presenta el modelo $\left(R_{m}\right.$ y $\left.R_{i}\right)$ es preciso plantear dos ecuaciones, que se obtienen de aplicar las condiciones de equilibrio estático de fuerzas en el eje vertical y de momentos, al sólido representado en la Fig.6, resultando las siguientes expresiones: 


$$
\begin{array}{ll}
\Sigma \mathrm{F}_{\mathrm{y}}=0 & \mathrm{R}_{\mathrm{m}}+\mathrm{R}_{\mathrm{i}}-\mathrm{N}_{\mathrm{m}}-\mathrm{N}_{\mathrm{i}}-\mathrm{P}_{\mathrm{zm}}-\mathrm{P}_{\mathrm{sm}}-\mathrm{P}_{\mathrm{vc}}-\mathrm{P}_{\mathrm{sc}}-\mathrm{P}_{\mathrm{zi}}-\mathrm{P}_{\mathrm{si}}=0 \\
\Sigma \mathrm{M}_{\mathrm{i}}=0 & -\mathrm{N}_{\mathrm{m}} \cdot \mathrm{L}+\left(\mathrm{R}_{\mathrm{m}}-\mathrm{P}_{\mathrm{zm}}-\mathrm{P}_{\mathrm{sm}}\right) \cdot \mathrm{L}_{\mathrm{m}}-\left(\mathrm{P}_{\mathrm{vc}}+\mathrm{P}_{\mathrm{sc}}\right) \cdot \mathrm{L}_{\mathrm{c}}- \\
& -\left(\mathrm{V}_{\mathrm{m}}+\mathrm{V}_{\mathrm{i}}\right) \cdot \mathrm{h}-\mathrm{M}_{\mathrm{m}}-\mathrm{M}_{\mathrm{i}}=0
\end{array}
$$

Sistema de dos ecuaciones con dos incógnitas cuya solución es:

$$
\begin{aligned}
& R_{m}=N_{m} \cdot \frac{L}{L_{m}}+P_{z m}+P_{s m}+\left(P_{v c}+P_{s c}\right) \cdot \frac{L_{c}}{L_{m}}+\left(V_{m}+V_{i}\right) \cdot \frac{h}{L_{m}}+\frac{\left(M_{m}+M_{i}\right)}{L_{m}} \\
& R_{i}=N_{i}-N_{m} \cdot\left(\frac{L}{L_{m}}-1\right)+P_{z i}+P_{s i}+\left(P_{v c}+P_{s c}\right) \cdot\left(1-\frac{L_{c}}{L_{m}}\right)-\left(V_{m}+V_{i}\right) \cdot \frac{h}{L_{m}}-\frac{\left(M_{m}+M_{i}\right)}{L_{m}}
\end{aligned}
$$

Solución que pone de manifiesto que la reacción resultante para la zapata de medianería es superior a la que tendría si trabajase como zapata aislada, mientras que la correspondiente a la zapata interior es inferior.

Conocidas las reacciones $R_{m}$ y $R_{i}$, las tensiones transmitidas al terreno por cada una de las zapatas serán:

$$
\sigma_{m}=\frac{R_{m}}{a_{m} \cdot b_{m}} \quad \sigma_{i}=\frac{R_{i}}{a_{i} \cdot b_{i}}
$$

La verificación de tensiones de contacto se cumplirá siempre y cuando:

$$
\sigma_{m} \leq \sigma_{\text {adm }} \quad \sigma_{i} \leq \sigma_{\text {adm }}
$$

En caso contrario será preciso incrementar la superficie de contacto entre la cimentación y el terreno, con el fin de reducir las tensiones transmitidas al suelo hasta que cumplan.

\subsubsection{CÁLCULO DE ESFUERZOS EN LA VIGA CENTRADORA}

Calculadas las tensiones transmitidas al terreno y determinado el tamaño de la cimentación, se procede al cálculo de esfuerzos internos o solicitaciones en la viga centradora, de cara al dimensionamiento y armado de la misma. En la Fig.7.(a) se representa el esquema de la cimentación como sólido libre, con las acciones y reacciones que actúan sobre ella. Por ser el cálculo y dimensionamiento del armado de la viga centradora una comprobación estructural, 
las solicitaciones a emplear en dicho cálculo deberán estar mayoradas, con los correspondientes coeficientes de seguridad. Como notación se ha empleado el subíndice $d$ para indicar que se trata de valores mayorados. Dado que la actual normativa EHE 08 plantea distintos valores del coeficiente de seguridad para las diferentes hipótesis de carga según sean permanentes o variables, habrá que recalcular las tensiones mayoradas aplicando, con las cargas mayoradas, el mismo procedimiento planteado en el apartado 2.2.1.
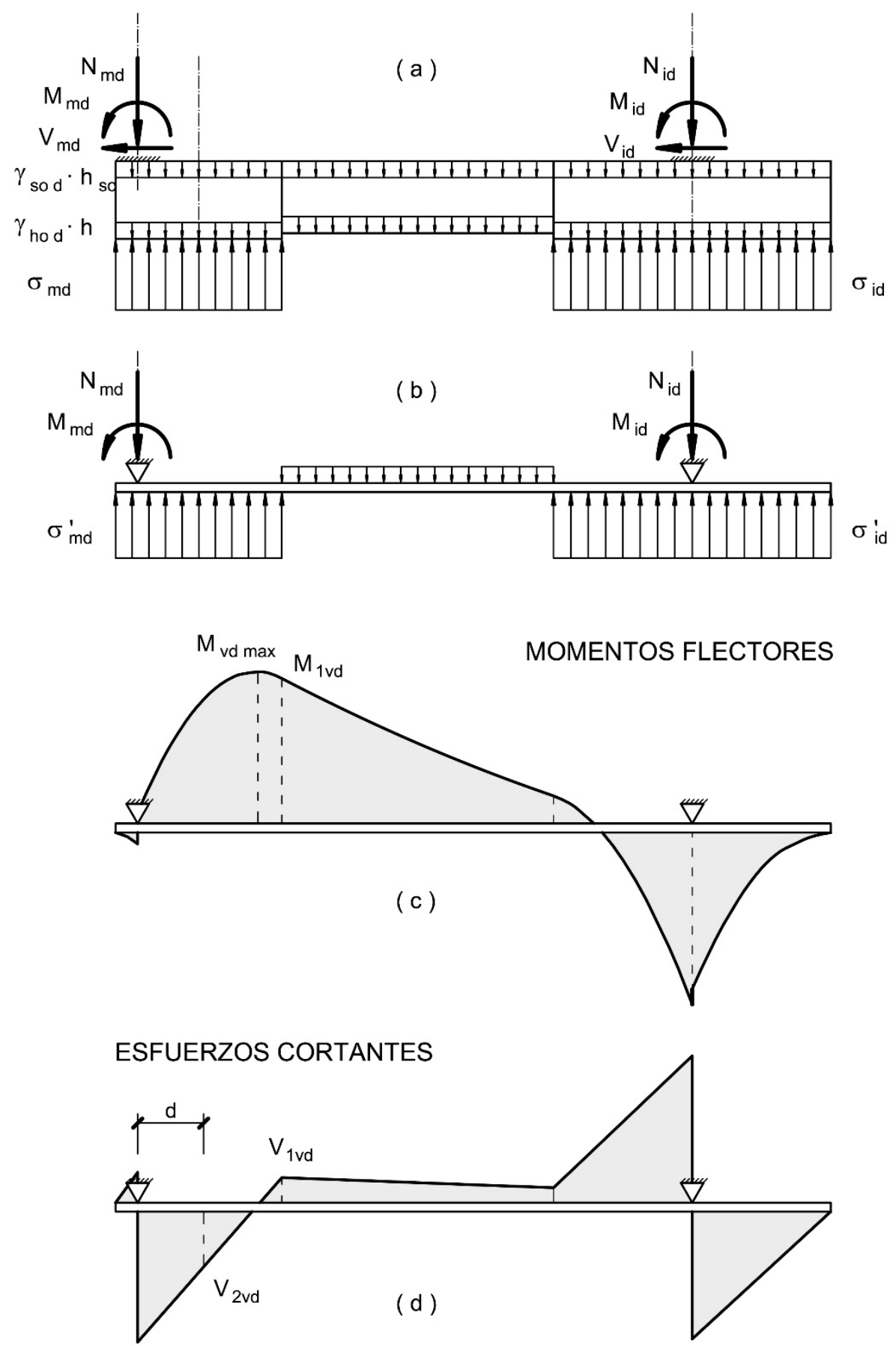

Fig.7. Cálculo de esfuerzos en la viga centradora 
El cálculo de solicitaciones en la viga centradora implica un nuevo proceso de modelización que se representa en la Fig.7.(b). El modelo convencional asimila el conjunto formado por las dos zapatas y la viga centradora a una única viga que va de extremo a extremo de la cimentación y que se encuentra apoyada en la base de los respectivos pilares. Con este planteamiento se entiende el conjunto de la cimentación como un único elemento lineal, en el que se invierte el punto de vista acción - reacción, al considerar la respuesta del terreno como la carga y los esfuerzos en la base de los pilares como las reacciones.

Planteado el modelo de la forma indicada, se obtienen los diagramas de esfuerzos internos de la viga en cuestión, representados en la Fig.7.(c y d). Dado el reducido valor que presentan habitualmente los cortantes de los pilares, su efecto puede considerarse equilibrado directamente por el rozamiento entre la respectiva zapata y el terreno, por lo cual, los axiales en la viga centradora serán nulos o despreciables y la viga, en su conjunto, podrá considerarse como un elemento trabajando a flexión simple, solicitado solamente por esfuerzos cortantes y momentos flectores.

A la hora de calcular la armadura longitudinal de la viga centradora, es preciso tener en cuenta la distribución de momentos de la viga imaginaria conjunta y los cambios de sección reales que se producen a lo largo de la misma. Ciertamente el máximo momento suele producirse en una posición que se corresponde con la zapata de medianería, cuya sección transversal es considerablemente superior a la de la viga centradora. Por ello, la sección realmente más desfavorable es aquella que presenta mayor momento flector dentro de las que pertenecen propiamente a la viga centradora, lo cual se produce en la sección de contacto de la viga centradora con la zapata de medianería. A partir de los esquema de la Fig.7.( $a$ y $b$ ) se deduce que el momento flector mayorado en dicha sección ( $\left.\mathrm{M}_{1 \mathrm{vd}}\right)$ viene dado por la expresión:

$$
M_{1 v d}=\left(\sigma_{m d}-\gamma_{h o d} \cdot h-\gamma_{s o d} \cdot h_{s o}\right) \cdot b_{m} \cdot \frac{a_{m}^{2}}{2}-N_{m d} \cdot\left(a_{m}-\frac{a_{m}^{\prime}}{2}\right)-V_{m d} \cdot h-M_{m d}
$$

Por su parte, para el esfuerzo cortante habrá que considerar el valor del mismo en dos secciones de referencia. La primera, al inicio propiamente dicho de la viga centradora en el contacto de ésta con la zapata de medianería $\left(V_{1 v d}\right)$ y, la segunda, al plantear el modelo el conjunto de la cimentación como un único elemento lineal, a un canto útil de la zapata de medianería medido a partir del borde del pilar de medianería $\left(\mathrm{V}_{2 \mathrm{vd}}\right)$. El valor de dichos esfuerzos cortantes será: 


$$
\begin{gathered}
\mathrm{V}_{\text {1vd }}=\left(\sigma_{\mathrm{md}}-\gamma_{\mathrm{hod}} \cdot \mathrm{h}-\gamma_{\mathrm{sod}} \cdot \mathrm{h}_{\mathrm{so}}\right) \cdot \mathrm{b}_{\mathrm{m}} \cdot \mathrm{a}_{\mathrm{m}}-\mathrm{N}_{\mathrm{md}} \\
\mathrm{V}_{2 \mathrm{vd}}=\left(\sigma_{\mathrm{md}}-\gamma_{\mathrm{hod}} \cdot \mathrm{h}-\gamma_{\mathrm{sod}} \cdot \mathrm{h}_{\mathrm{so}}\right) \cdot \mathrm{b}_{\mathrm{m}} \cdot\left(\mathrm{a}_{\mathrm{m}}^{\prime}+\mathrm{d}\right)-\mathrm{N}_{\mathrm{md}}
\end{gathered}
$$

De forma parecida a lo que ocurría con el momento flector, en muchos casos puede ser mayor el esfuerzo cortante $V_{2 v d}$, pero al ser la sección transversal en dicho punto la de la zapata de medianería (de considerable tamaño) no suele demandar armadura transversal o, en su caso, la demanda de pequeña cuantía. Por ello, la sección realmente más desfavorable es la del inicio de la viga centradora, calculando con la propia sección de la viga centradora y el esfuerzo cortante $V_{1 \mathrm{vd}}$.

Es preciso llamar la atención, de manera especial, sobre la considerable escuadría que suele requerir la viga centradora y la elevada cuantía que resulta para la armadura de tracción situada en la cara superior de la misma, debido todo ello, al enorme momento flector que soporta dicha viga en su función de centrado, de acuerdo con el modelo convencional. 


\subsection{ZAPATA DE MEDIANERÍA CON COLABORACIÓN DE LA VIGA SUPERIOR}

La segunda solución al problema de la medianería (Fig.4.b.), no tan empleada como la anterior, plantea la colaboración de la viga de la primera planta (o en su caso el forjado de la misma), trabajando como tirante a flexotracción. La fuerza de tracción en la viga de la primera planta encuentra su equilibrio horizontal gracias al rozamiento entre la zapata y el terreno. Dicho par de fuerzas genera un momento estabilizador que equilibra al producido por la excentricidad del esfuerzo axil y que logra centrar la reacción del terreno, dando lugar a una distribución de tensiones de contacto uniforme.

Al igual que en el caso de la zapata de medianería con viga centradora, cuando el equilibrio se logra gracias a la colaboración de la viga superior, el cálculo y dimensionamiento de los elementos estructurales implicados para por tres fases:

- Verificación del E.L.U. de Equilibrio

- Cálculo de esfuerzos en la viga superior y en el pilar

- Armado de la zapata, de la viga superior y del pilar

Tal y como ya se ha planteado en el apartado 2.2. es objeto de esta tesis doctoral el estudio de la influencia de las posibles modelizaciones sobre las dos primeras fases, por lo cual, no se abordan cuestiones relativas a métodos de cálculo de armado.

\subsubsection{E.L.U. DE EQUILIBRIO}

La verificación del E.L.U. de Equilibrio implica la comprobación de la ausencia de giros y desplazamientos (tanto horizontales como verticales) de valor inadmisible en la cimentación. En este segundo tipo de solución, debido a que la tracción de la viga superior se equilibra gracias al rozamiento entre la zapata y el terreno, además de la evidente comprobación de validez de las tensiones de contacto, resulta importante la comprobación de ausencia de desplazamientos horizontales o deslizamiento en el plano de contacto cimentación-suelo. Por lo que respecta a la comprobación de giro o vuelco, no suele ser decisiva en estructuras de edificación con sucesivas plantas de forjados que transmiten a la cimentación importantes esfuerzos axiles que se oponen al vuelco. Las comprobaciones en cuestión se realizan con cargas en valor de servicio o característico; la de tensiones de contacto por ser una comprobación geotécnica que incorpora el coeficiente de seguridad en el valor de la tensión admisible y la de deslizamiento porque introduce la seguridad en el término de comparación de la misma, tal y como se expone más adelante. 
En la Fig.8 se representa el modelo convencional que permite calcular la distribución de tensiones transmitida al terreno, la fuerza de tracción adicional que se produce en la viga superior y la fuerza horizontal generada en la cara de contacto zapata-suelo para equilibrar a la anterior.

Se parte de un predimensionamiento de la zapata de medianería, de dimensiones $a_{m} \cdot b_{m} \cdot h$. Es recomendable disponer la menor dimensión en planta de la zapata $\left(a_{m}\right)$ paralela al plano de las cargas, con el fin de reducir la excentricidad del esfuerzo axil del pilar respecto del centro de la zapata y, por tanto, el momento de desequilibrio que se genera en la medianería.

Por lo que respecta a las acciones (Fig.8), se consideran tanto los pesos de los distintos elementos implicados, como las acciones transmitidas por el pilar. Los pesos en cuestión son el peso propio de la zapata $\left(P_{z m}\right)$, el del pilar $\left(P_{p m}\right) y$ la carga permanente debida a las tierras o soleras que gravitan sobre la zapata $\left(P_{\mathrm{sm}}\right)$. Por su parte, han de tenerse en cuenta como acciones tanto el esfuerzo axil como el momento flector y el esfuerzo cortante recibidos por el pilar de medianería en su nudo superior $\left(\mathrm{N}_{\mathrm{ms}}, \mathrm{M}_{\mathrm{ms}}, \mathrm{V}_{\mathrm{ms}}\right)$. Dichos esfuerzos se habrán obtenido previamente a partir del análisis del pórtico en cuestión (supuestamente también por métodos convencionales) bajo la hipótesis de pilares perfectamente empotrados en la cimentación.
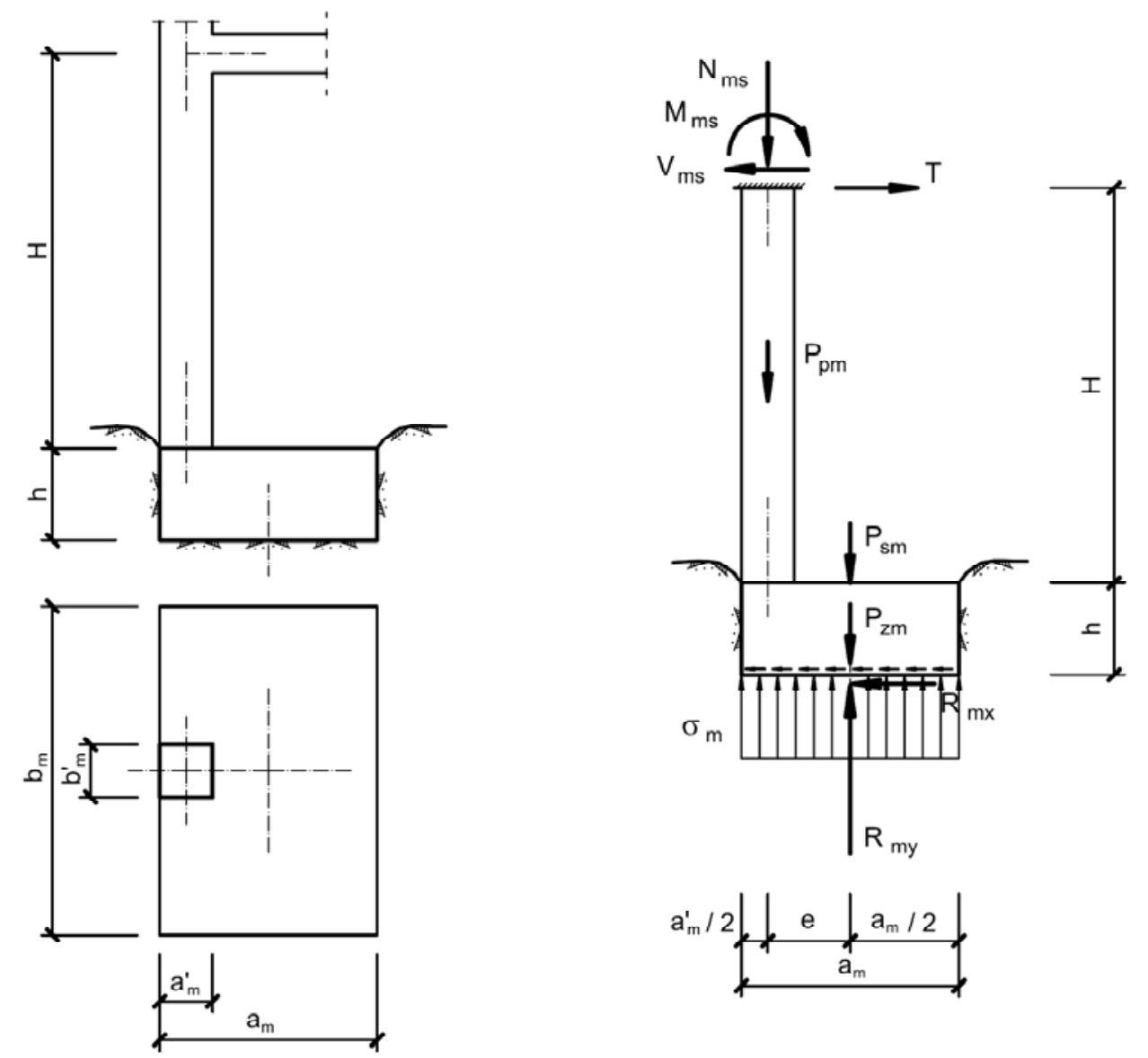

Fig.8. Zapata de medianería con colaboración de la viga superior. Modelización convencional 
Como respuesta a las acciones planteadas surgen las reacciones del modelo, constituidas por las presiones y el rozamiento en el contacto zapata-suelo, así como por la tracción en la viga superior actuando como tirante. El modelo convencional plantea una distribución de tensiones de contacto con el terreno uniformemente repartida, lo cual implica un éxito completo de la viga superior en su misión de equilibrado y centrado de la respuesta del terreno y una confirmación de la hipótesis de pilares perfectamente empotrados en la cimentación.

Como consecuencia de ello, el modelo clásico presente tres incógnitas a resolver, la resultante del diagrama uniforme de tensiones de contacto $\left(R_{\text {my }}\right)$ aplicada en el centro de la cara inferior de la zapata de medianería, la reacción horizontal por rozamiento en la cara de contacto zapata suelo $\left(R_{m x}\right)$ y la fuerza de tracción $(T)$ generada en la viga superior para equilibrar los efectos de la excentricidad del esfuerzo axil del pilar de medianería. Para resolver estas tres incógnitas, es preciso plantear tres ecuaciones, que se obtienen de aplicar las condiciones de equilibrio estático de momentos y de fuerzas, tanto en el eje horizontal como vertical, al sólido representado en la Fig.7, resultando las siguientes expresiones:

$$
\begin{aligned}
& \Sigma \mathrm{M}_{\mathrm{M}}=0 \quad\left(\mathrm{~T}-\mathrm{V}_{\mathrm{ms}}\right) \cdot(\mathrm{H}+\mathrm{h})+\mathrm{M}_{\mathrm{ms}}-\left(\mathrm{N}_{\mathrm{ms}}+\mathrm{N}_{\mathrm{pm}}\right) \cdot\left(\frac{\mathrm{a}_{\mathrm{m}}-\mathrm{a}_{\mathrm{m}}^{\prime}}{2}\right)=0 \\
& \Rightarrow \quad T=\frac{\left(N_{m s}+N_{p m}\right) \cdot\left(\frac{a_{m}-a_{m}^{\prime}}{2}\right)-M_{m s}}{(H+h)}+V_{m s}=0 \\
& \Sigma \mathrm{F}_{\mathrm{x}}=0 \quad \mathrm{~T}-\mathrm{V}_{\mathrm{ms}}-\mathrm{R}_{\mathrm{mx}}=0 \quad \Rightarrow \quad \mathrm{R}_{\mathrm{mx}}=\mathrm{T}-\mathrm{V}_{\mathrm{ms}} \\
& \Sigma F_{y}=0 \quad R_{m y}-N_{m s}-P_{p m}-P_{z m}-P_{s m}=0 \\
& \Rightarrow \quad R_{m y}=N_{m s}+P_{p m}+P_{z m}+P_{s m}
\end{aligned}
$$

Conocida la reacción vertical $\mathrm{R}_{\text {my }}$, la tensión transmitida al terreno por la zapata de medianería vendrá dada por:

$$
\sigma_{m}=\frac{R_{m y}}{a_{m} \cdot b_{m}}
$$


La comprobación de tensiones de contacto del E.L.U. de Equilibrio se cumplirá siempre y cuando:

$$
\sigma_{m} \leq \sigma_{\text {adm }}
$$

En caso contrario será preciso incrementar la superficie de contacto entre la cimentación y el terreno, con el fin de reducir las tensiones transmitidas al suelo hasta que cumplan.

Por su parte, la comprobación de deslizamiento del E.L.U. de Equilibrio vendrá dada por la expresión:

$$
\frac{F_{\text {Antidesliantes }}}{F_{\text {Deslizante }}} \geq 1,5 \Rightarrow \frac{F_{\text {Roz Disponible }}}{F_{\text {Roz Demandada }}} \geq 1,5 \Rightarrow \frac{\mu \cdot N}{R_{m x}} \geq 1,5
$$

Se cumplirá la comprobación de deslizamiento si la máxima fuerza de rozamiento que es capaz de proporcionar el suelo ( $F_{\text {Roz. Disponible }}$ ) supera en un $50 \%$ a la fuerza de rozamiento demandada para lograr el equilibrio del sistema $R_{m x}$, siendo $\mu$ el coeficiente de rozamiento entre zapata y suelo y $\mathrm{N}$ el valor de la normal o fuerza con la que se comprimen ambas superficies. El valor 1,5 es el coeficiente de seguridad establecido por el Código Técnico de la Edificación (C.T.E.) en el DB SE - C. Expresando el coeficiente de rozamiento en función del ángulo de rozamiento interno del suelo $(\phi)$ y desarrollando el término de la normal, queda finalmente la comprobación de deslizamiento del siguiente modo:

$$
\frac{\operatorname{tg}\left(\frac{2}{3} \cdot \phi\right) \cdot\left(\mathrm{N}_{\mathrm{ms}}+\mathrm{P}_{\mathrm{pm}}+\mathrm{P}_{\mathrm{zm}}+\mathrm{P}_{\mathrm{sm}}\right)}{\mathrm{R}_{\mathrm{mx}}} \geq 1,5
$$

En caso de no cumplirse la expresión anterior será preciso, o bien aumentar el tamaño de la cimentación con el fin de lograr mayor fuerza de rozamiento aumentando el peso, tanto de la zapata como de la tierra o solera que gravita sobre ella, o bien cambiar la proporción de la zapata disminuyendo la dimensión en el plano de las cargas con el fin de reducir la excentricidad del esfuerzo axil del pilar y la tracción T en la viga superior. 


\subsubsection{CÁlCULO DE ESFUERZOS EN LA VIGA Y EN EL PILAR}

Si bien en este caso la cimentación propiamente dicha está integrada por un único elemento (la zapata de medianería), tanto el pilar de medianería de la planta baja como la viga superior desempeñan un papel protagonista en el modelo conjunto para estabilizar la zapata de medianería. La viga superior, actuando como tirante, es la encargada de desarrollar la fuerza de tracción que equilibra la excentricidad del esfuerzo axil del pilar, centrando la distribución de tensiones que se transmite al terreno (Fig.9). Por su parte, el pilar de medianería de la planta baja, al encontrarse físicamente en una posición intermedia entre el origen del problema (zapata de medianería) y la solución del mismo (viga superior), actúa como intermediario, transmitiendo mediante su trabajo a flexión, el efecto estabilizador de la viga superior. Por ello, en el cálculo del armado de la viga y del pilar deberán tenerse en cuenta tanto la tracción inducida en la viga como el incremento de momento flector en el pilar. Dichos esfuerzos han de calcularse mayorados, con los correspondientes coeficientes de seguridad.

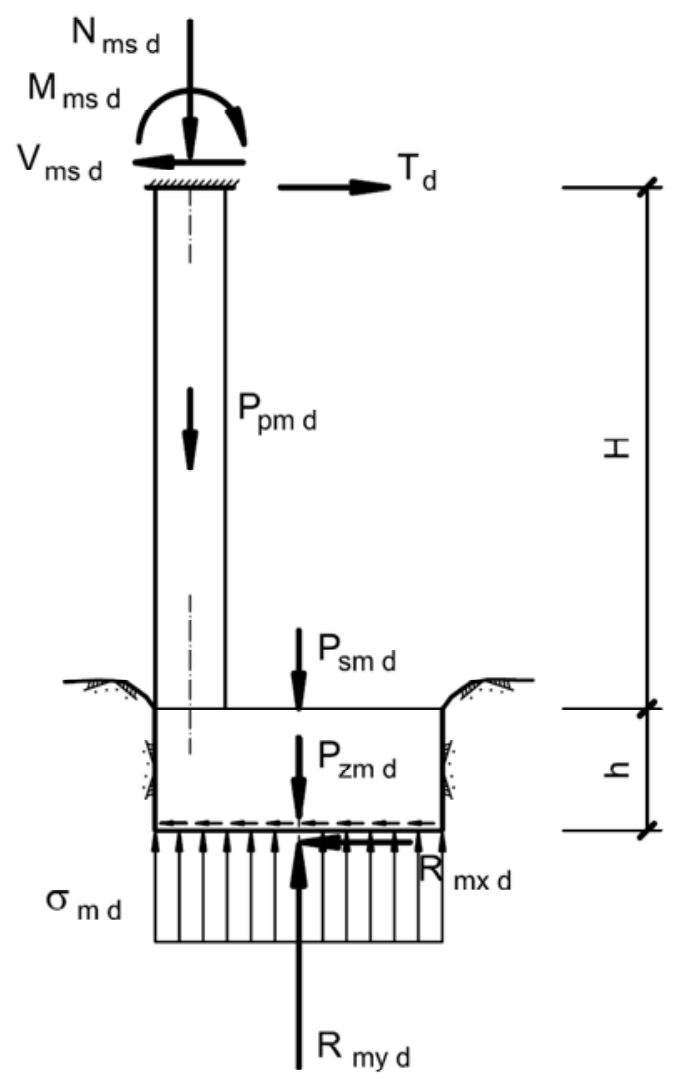

Fig.9. Cálculo de esfuerzos en la viga y en el pilar 
La viga superior combina, por tanto, la doble función de viga propiamente dicha y de tirante. Por ello, la armadura resultante de su habitual trabajo a flexión como viga, tendrá que incrementarse con una sección adicional, que le permita soportar la solicitación conjunta a flexotracción.

Por su parte el pilar, además de hacer frente a los esfuerzos correspondientes a su pertenencia al pórtico en cuestión, tendrá que soportar el momento flector originado por la tracción en la viga superior (Fig.9), que vendrá dado por:

$$
\mathrm{M}_{\mathrm{d}}=\mathrm{T}_{\mathrm{d}} \cdot \mathrm{H}
$$

A pesar de que el momento en cuestión es de signo contrario al habitualmente generado por las cargas gravitatorias, el reducido valor de éste último hace que la combinación de ambos momentos suponga un considerable incremento neto de la magnitud de la flexión en el pilar. 


\subsection{ZAPATA DE ESQUINA CON DOS VIGAS CENTRADORAS}

La solución más habitualmente empleada en el caso de las zapatas de esquina es el empleo de dos vigas centradoras que conectan la zapata de esquina con las dos zapatas más próximas (Fig. 5). Al confluir en la esquina dos medianerías o líneas de fachada, lo normal es que las dos zapatas auxiliares sean dos zapatas de medianería. El equilibrio de la zapata de esquina y el centrado de la respuesta del terreno se logra gracias a la colaboración de los pilares de medianería indicados junto con su cimentación y al trabajo a flexión de las dos vigas centradoras.

En el cálculo y dimensionamiento de una zapata de esquina con vigas centradoras pueden distinguirse tres fases:

- Verificación del E.L.U. de Equilibrio

- Cálculo de esfuerzos en las vigas centradoras

- Armado de las zapatas y de las vigas centradoras

Tal y como ya se ha indicado en los dos casos anteriores, el objetivo de la presente tesis doctoral es el estudio de las posibles modelizaciones sobre las dos primeras fases, por lo cual, no se abordan cuestiones relativas a métodos de cálculo de armado.

\subsubsection{E.L.U. DE EQUILIBRIO}

Tal y como se indicó para la zapata de medianería con viga centradora, en el caso de estructuras de edificación con varias plantas de forjados, los esfuerzos axiles transmitidos por los pilares a la cimentación suelen ser muy superiores a los momentos flectores y a los esfuerzos cortantes, por lo cual, es la verificación relativa al equilibrio vertical la que determina el tamaño de la cimentación. La comprobación de equilibrio en dirección vertical (estado límite último de hundimiento) consiste en verificar que las tensiones de contacto transmitidas por la cimentación al terreno sean inferiores a la tensión admisible de éste, para lo cual, han de disponerse unas zapatas de suficiente tamaño y adecuada proporción. Por tratarse de una comprobación geotécnica, la verificación de tensiones de contacto se realiza a partir de las cargas con su valor de servicio o característico.

El estudio en profundidad del caso de una zapata de esquina equilibrada gracias a la colaboración de dos zapatas de medianería auxiliares, mediante las correspondientes vigas centradoras, es realmente complejo. Al desequilibrio de la zapata de esquina por la doble excentricidad respecto de su pilar se le añade, a su vez, el desequilibrio de las dos zapatas de medianería auxiliares, que requieren la colaboración de un cuarto pilar interior mediante 
otras dos vigas centradoras (Fig.10). Se genera así un conjunto de cimentación integrado por cuatro pilares y cuatro vigas centradoras.

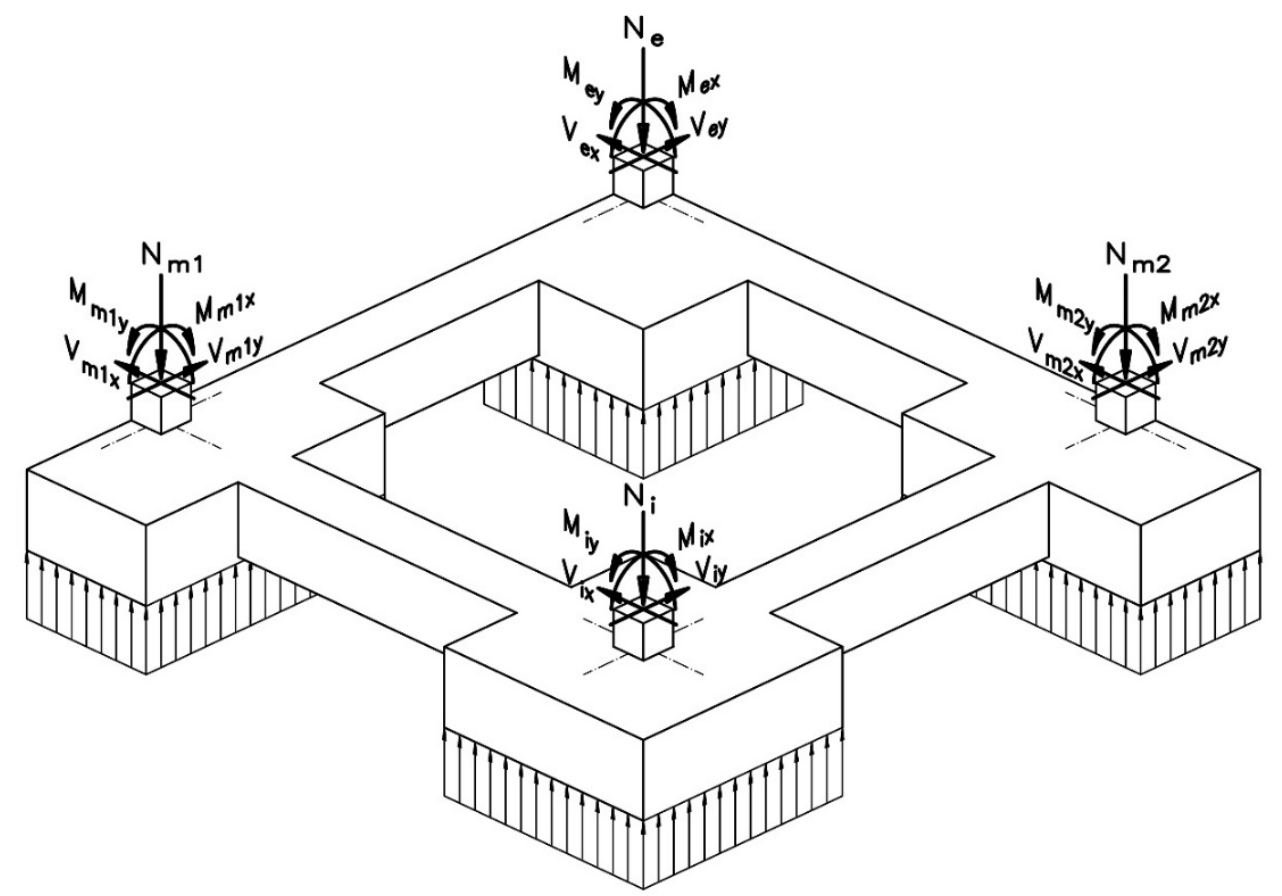

Fig.10. Esquema de la cimentación en el entorno de una zapata de esquina

Los autores que describen la modelización clásica de este tipo de cimentación (Calavera, J. 2000, Perepérez, B. 2005), plantean la separación, por superposición, de los dos problemas implicados en la Fig.10, estudiando, por un lado, la zapata de esquina con sus dos vigas centradoras y, por otro lado, de forma independiente, las zapatas de medianería equilibradas con la cuarta zapata interior. De este modo, el equilibrio de las zapatas de medianería es responsabilidad exclusiva de la cuarta zapata interior y su viga centradora, sin ninguna participación por torsión de las vigas centradoras de la zapata de esquina (Fig.11).

En las Fig. 11 y 12 se muestra detalladamente la modelización convencional de la zapata de esquina y sus vigas centradoras. Se parte de un predimensionamiento de las zapatas, de dimensiones $a_{e} \cdot b_{e} \cdot h$ para la de esquina y $a_{m 1} \cdot b_{m 1} \cdot h$ y $a_{m 2} \cdot b_{m 2} \cdot h$ para las dos zapatas de medianería auxiliares. Al presentar dos excentricidades con magnitudes habitualmente similares en ambas direcciones, la zapata de medianería suele disponerse de forma cuadrada, mientras que las dos zapatas de medianería suelen proyectarse de forma rectangular con lado menor perpendicular a la alineación medianera, para reducir al máximo la excentricidad de la misma. Se predimensionan también las dos vigas centradoras, de dimensiones $\mathrm{b}_{\mathrm{c} 1} \cdot \mathrm{a}_{\mathrm{c} 1} \cdot \mathrm{h}_{\mathrm{c}}$ y $\mathrm{a}_{\mathrm{c} 2} \cdot \mathrm{b}_{\mathrm{c} 2} \cdot \mathrm{h}_{\mathrm{c}}$ respectivamente. Dada la importante flexión que soporta la viga centradora, suele aprovecharse al máximo el canto de la cimentación, haciendo la viga centradora solamente con $50 \mathrm{~mm}$ menos de canto para facilitar el cruce de la ferralla en el encuentro entre las zapatas y las vigas. 

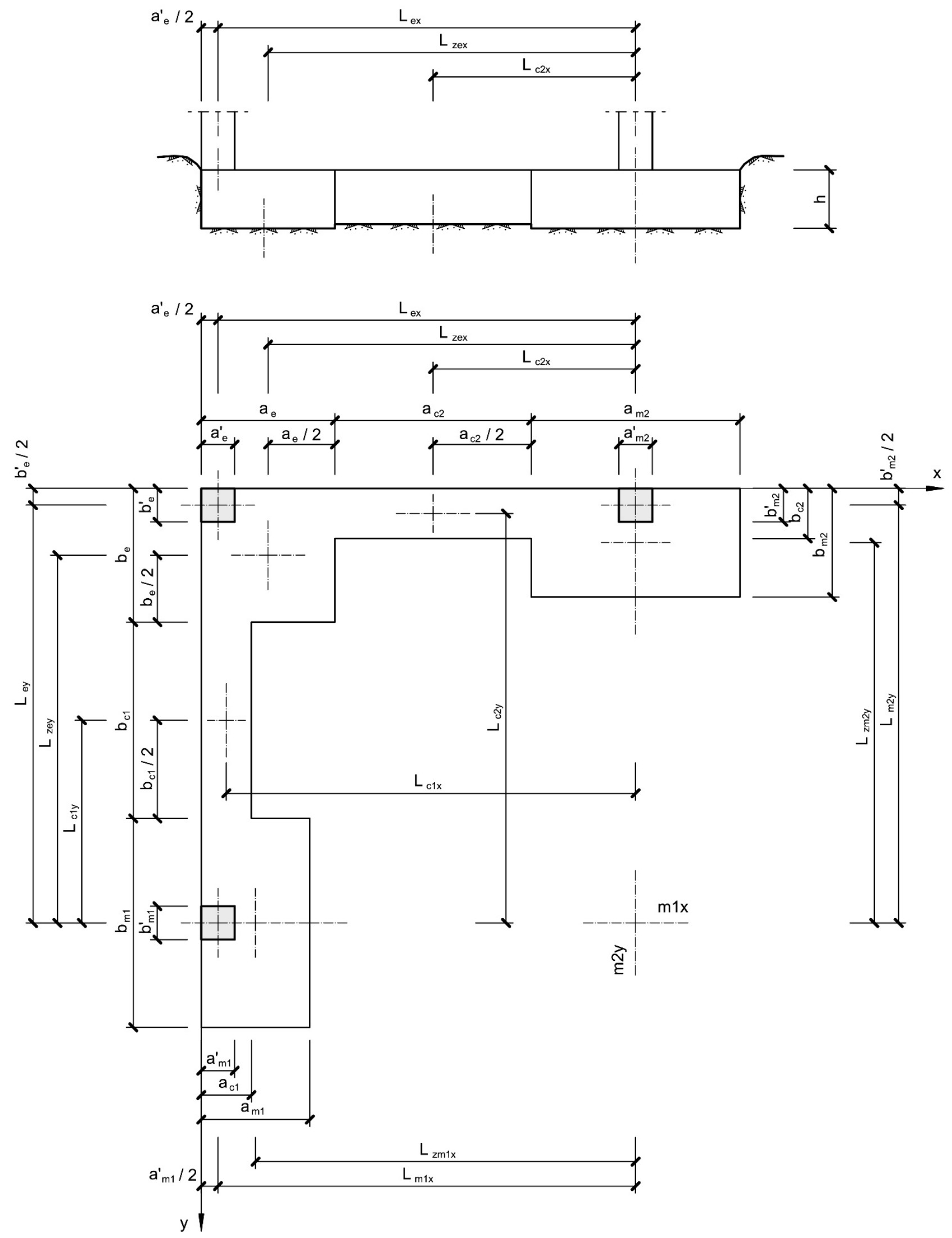

Fig.11. Zapata de esquina con vigas centradoras. Modelización convencional 
Las acciones incluyen, por un lado, los pesos propios de los elementos de cimentación y, por otro, las cargas transmitidas por los pilares. Se ha considerado en la Fig.12, el peso propio de la zapata de esquina $\left(P_{z e}\right)$ y el de las dos vigas centradoras $\left(P_{v c 1}, P_{v c 2}\right)$. Asimismo, se ha tenido en cuenta el peso de las tierras o soleras que gravitan sobre la cimentación $\left(P_{\text {se }}, P_{s c 1}\right.$, $\mathrm{P}_{\mathrm{sc} 2}$ ) que incluyen, en su caso, las posibles sobrecargas de uso sobre la solera. Por lo que respecta a la carga transmitida por el pilar de esquina, se contemplan tanto el esfuerzo axil como los momentos flectores y los esfuerzos cortantes en las dos direcciones consideradas (análisis tridimensional), calculados previamente a partir del estudio del pórtico en cuestión con la hipótesis de pilares perfectamente empotrados en la cimentación.

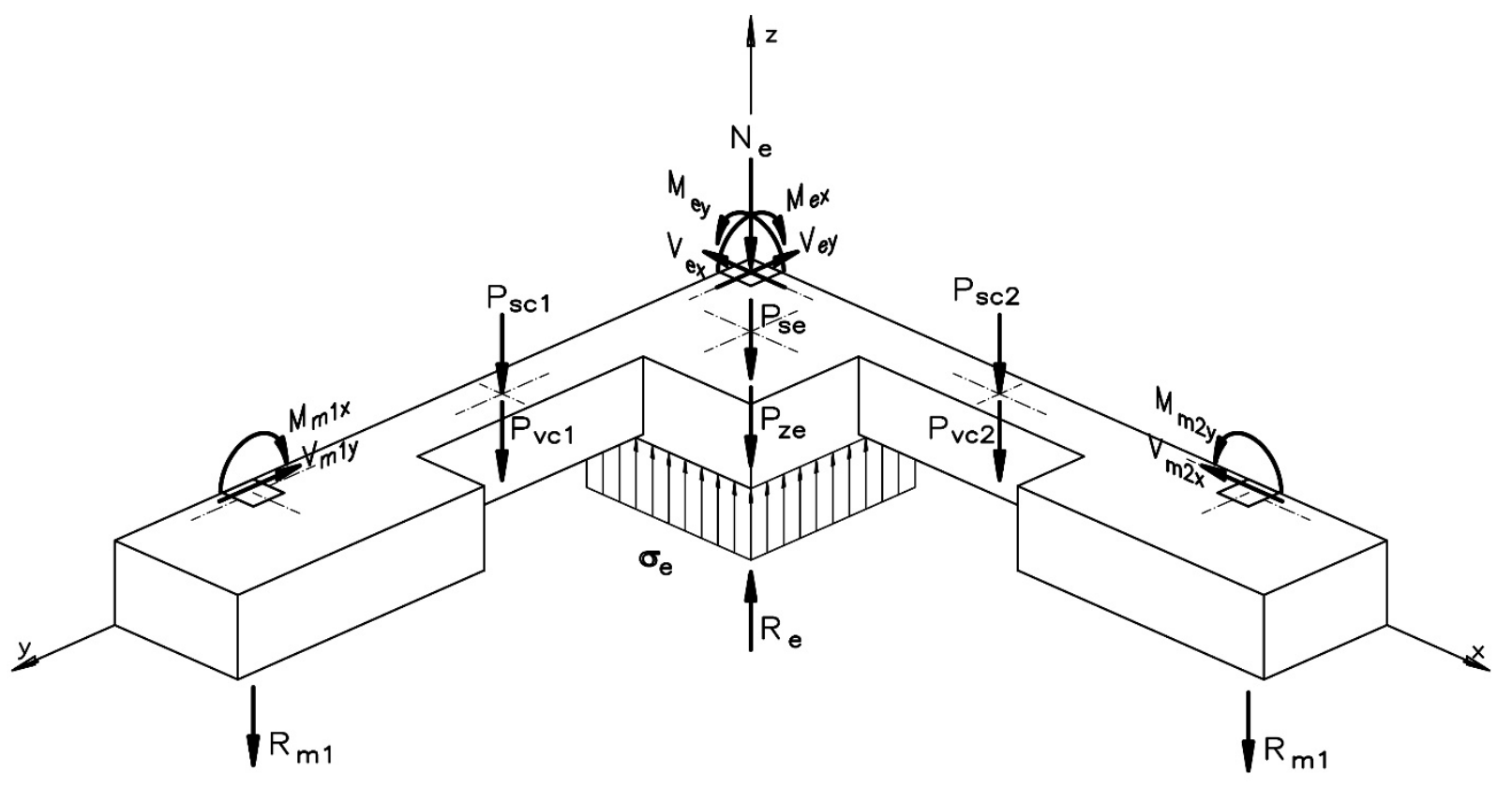

Fig.12. Zapata de esquina con vigas centradoras. Acciones y reacciones

Para independizar el problema del propio equilibrio de las zapatas de medianería auxiliares, no se ha considerado, ni el peso de las mismas, ni la resultante de sus tensiones de contacto con el terreno, ya que dichas fuerzas quedarían excéntricas respecto de su pilar y obligarían a la zapata de esquina y a la otra zapata de medianería a hacerse responsables de contrarrestar el desequilibrio que generan, mediante el trabajo a torsión de la viga centradora de esquina más próxima. Solamente se consideran en los pilares de medianería los momentos y cortantes orientados según los planos que contienen a las dos vigas centradoras de esquina, junto con las fuerzas $R_{\mathrm{m} 1}$ y $R_{\mathrm{m} 2}$, aplicadas en el eje de los pilares de medianería, que permiten evaluar el efecto estabilizador que las zapatas de medianería auxiliares ejercen sobre la zapata de esquina. Dichas fuerzas $R_{m 1}$ y $R_{m 2}$ suponen un efecto de levantamiento sobre las zapatas de medianería que deberá tenerse en cuenta al estudiar el equilibrio de dichas zapatas de medianería junto con la cuarta zapata interior. 
Las cargas descritas se equilibran gracias a las tensiones que se generan en el contacto entre la zapata de esquina y el terreno. En el modelo convencional se plantea una distribución de tensiones uniformemente repartida, considerando nula la tensión de contacto bajo las dos vigas centradoras. Como consecuencia de ello, el modelo clásico presente solamente tres incógnitas a resolver (Fig. 12), la resultante $R_{e}$ del diagrama uniforme de tensiones de contacto de la zapata de esquina aplicada en el centro de la misma y las fuerzas $R_{m 1}$ y $R_{m 2}$, que evalúan el efecto estabilizador de las zapatas de medianería auxiliares sobre la zapata de esquina

Para la resolución de la tres incógnitas que presenta el modelo $\left(R_{e}, R_{m 1}\right.$ y $\left.R_{m 2}\right)$ es preciso plantear tres ecuaciones, que se obtienen de aplicar, al sólido representado en la Fig. 12, las condiciones de equilibrio estático de fuerzas en el eje vertical y equilibrio estático de momentos respecto de dos ejes. Como ejes de referencia para el equilibrio de momentos se han adoptado dos ejes, paralelos respectivamente a les ejes x e y, que pasan por los centros de gravedad de las correspondientes zapatas de medianería, a los que se ha denominado ejes $\mathrm{m} 1 \mathrm{x}$ y m2y.

Las ecuaciones de equilibrio estático indicadas responden a las siguientes expresiones:

$$
\begin{aligned}
& \Sigma F_{\mathrm{z}}=0 \quad \mathrm{R}_{\mathrm{e}}-\mathrm{R}_{\mathrm{m} 1}-\mathrm{R}_{\mathrm{m} 2}-\mathrm{N}_{\mathrm{e}}-\mathrm{P}_{\mathrm{ze}}-\mathrm{P}_{\mathrm{se}}-\mathrm{P}_{\mathrm{vc} 1}-\mathrm{P}_{\mathrm{sc} 1}-\mathrm{P}_{\mathrm{vc} 2}-\mathrm{P}_{\mathrm{sc} 2}=0 \\
& \Sigma M_{m 1 x}=0 \quad N_{e} \cdot L_{\text {ey }}+\left(P_{z e}+P_{s e}-R_{e}\right) \cdot L_{z e y}+R_{m 2} \cdot L_{z m 2 y}+\left(P_{v c 1}+P_{s c 1}\right) \cdot L_{c 1 y}+ \\
& +\left(P_{\mathrm{vc} 2}+P_{\mathrm{sc} 2}\right) \cdot L_{\mathrm{c} 2 \mathrm{y}}+\left(\mathrm{V}_{\mathrm{ey}}+\mathrm{V}_{\mathrm{m} 1 \mathrm{y}}\right) \cdot \mathrm{h}+\mathrm{M}_{\mathrm{ex}}+\mathrm{M}_{\mathrm{m} 1 \mathrm{x}}=0 \\
& \Sigma M_{m 2 y}=0 \quad N_{e} \cdot L_{e x}+\left(P_{z e}+P_{s e}-R_{e}\right) \cdot L_{z e x}+R_{m 1} \cdot L_{z m 1 x}+\left(P_{v c 1}+P_{s c 1}\right) \cdot L_{c 1 x}+ \\
& +\left(P_{\mathrm{vc} 2}+P_{\mathrm{sc} 2}\right) \cdot L_{c 2 x}+\left(V_{e x}+V_{m 2 x}\right) \cdot h+M_{e y}+M_{m 2 y}=0
\end{aligned}
$$

Resuelto el sistema de ecuaciones y obtenidas las tres reacciones incógnita $R_{e}, R_{m 1}$ y $R_{m 2}$, la tensión de contacto transmitida al terreno por la zapatas de esquina será:

$$
\sigma_{e}=\frac{R_{e}}{a_{e} \cdot b_{e}}
$$

La verificación de tensiones de contacto se cumplirá siempre y cuando:

$$
\sigma_{\mathrm{e}} \leq \sigma_{\mathrm{adm}}
$$

En caso contrario será preciso incrementar la superficie de contacto entre la cimentación y el terreno, con el fin de reducir las tensiones transmitidas al suelo hasta que cumplan. 


\subsubsection{CÁLCULO DE ESFUERZOS EN LAS VIGAS CENTRADORAS}

Determinado el tamaño de la cimentación, se procede al cálculo de esfuerzos internos en las dos vigas centradoras, de cara al dimensionamiento del armado de las mismas. En las Fig. 13 y 14 se representan los esquemas de cálculo de las vigas centradoras 1 y 2 respectivamente. Es preciso indicar, que los esquemas de sólido libre de las vigas centradoras representados en las Fig.13 y 14, son esquemas bidimensionales obtenidos a partir del esquema tridimensional completo del conjunto de la cimentación de esquina junto con las dos zapatas de medianería auxiliares (Fig. 12). La superposición de los dos esquemas bidimensionales indicados debe dar lugar al esquema tridimensional original sin duplicidad de acciones ni reacciones en el pilar y zapata de esquina. Por ello, en cada uno de los esquemas dibujados en las Fig. 13 y 14 debe representarse solamente la fracción de las acciones y reacciones de la zapata de esquina correspondiente al esquema en cuestión.

\section{VIGA CENTRADORA 1}

Comienza el cálculo por la viga centradora 1 que conecta la zapata de esquina con la zapata de medianería 1 (Fig. 13). Por ser el cálculo del armado una comprobación estructural, las solicitaciones a emplear en dicho cálculo deben estar mayoradas, con los correspondientes coeficientes de seguridad establecidos por la EHE 08.

Las acciones y reacciones, tanto de la zapata de medianería 1 como de la viga centradora 1 , son las acciones y reacciones íntegras correspondientes a dichos elementos (Fig.13.(a)). En cambio al pilar y la zapata de esquina se le asigna únicamente la fracción de las acciones y reacciones correspondiente al plano bidimensional de la viga centradora 1 . Los vectores que forman parte de dicha fracción de acciones y reacciones se identifican con la notación (e -1).

El valor de la fracción de acciones y reacciones a asignar al pilar y la zapata de esquina es, a priori, desconocido. Ahora bien, dicho valor ha de ser compatible con los resultados obtenidos para la zapata de medianería 1 a partir del esquema tridimensional conjunto (Fig.12). Por ello, dicho valor debe ser aquel que permita el cumplimiento de las ecuaciones de equilibrio estático del esquema bidimensional de la Fig.13:

$$
\begin{array}{ll}
\Sigma F_{z}=0 & \left(R_{(e-1) d}-P_{z(e-1) d}-P_{s(e-1) d}\right)-\left(P_{v c 1 d}+P_{s c 1 d}\right)-R_{m 1 d}-N_{(e-1) d}=0 \\
\Sigma M_{m 1}=0 & N_{(e-1) d} \cdot L_{e y}+\left(P_{v c 1 d}+P_{s c 1 d}\right) \cdot L_{c 1 y}-\left(R_{(e-1) d}-P_{z(e-1) d}-P_{s(e-1) d}\right) \cdot L_{z e y}+ \\
& +\left(V_{e y d}+V_{m 1 y d}\right) \cdot h+M_{e x d}+M_{m 1 x d}=0
\end{array}
$$



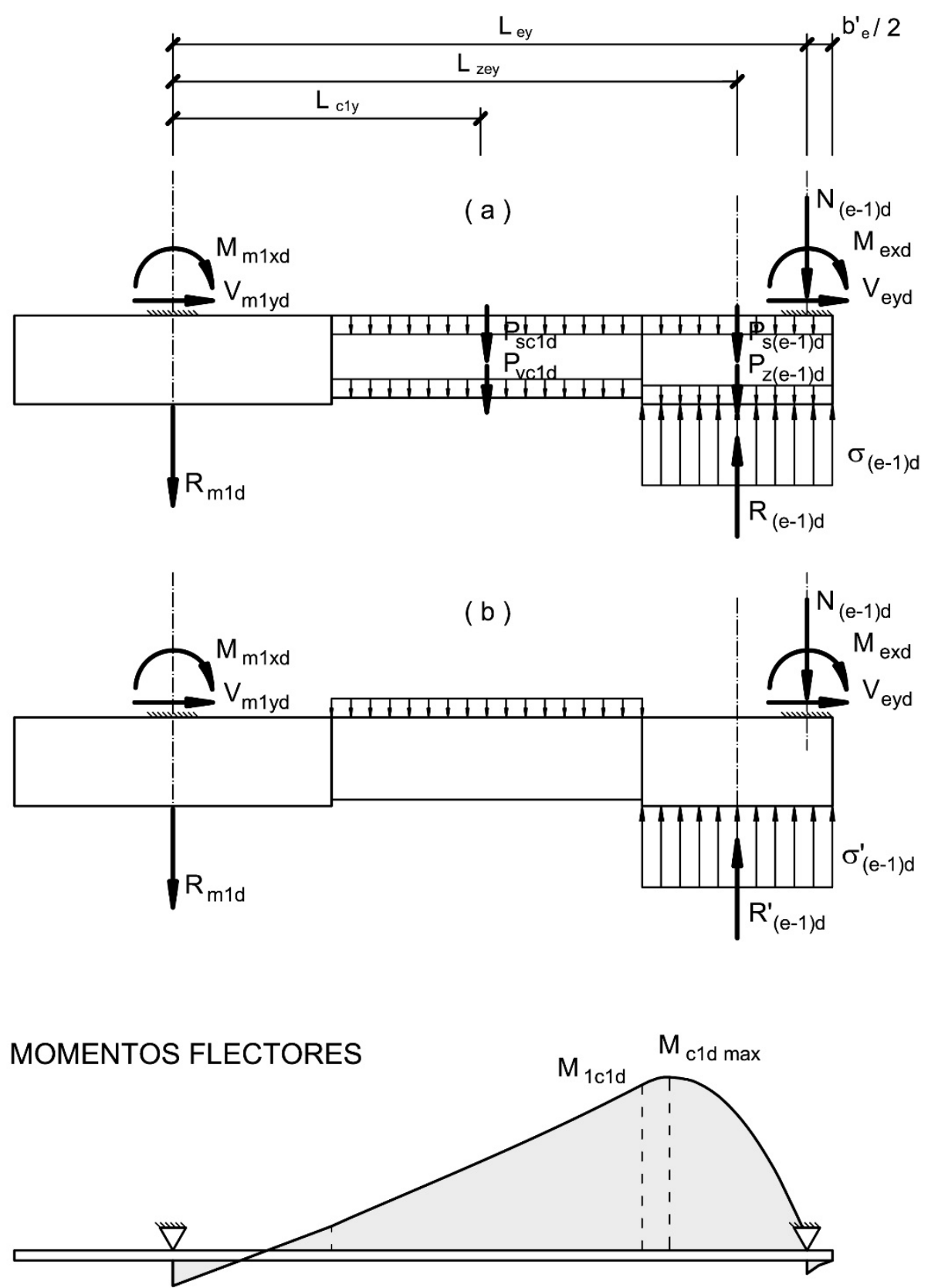

(c)

\section{ESFUERZOS CORTANTES}

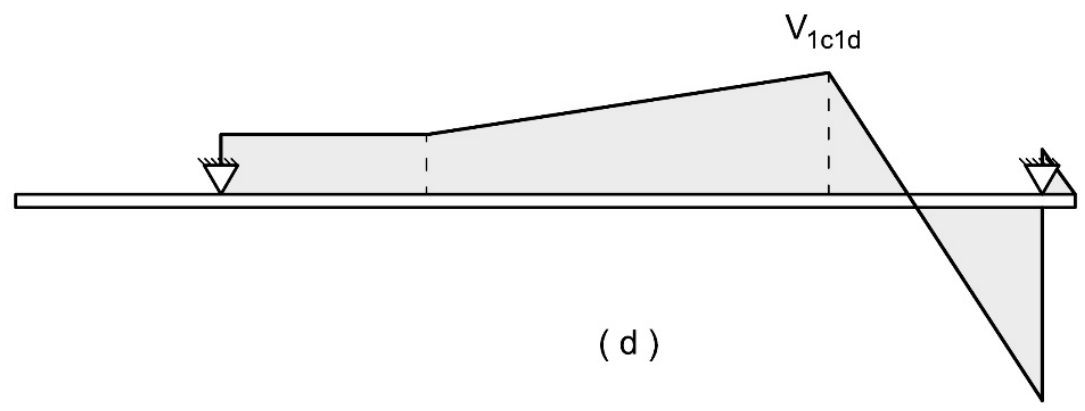

Fig.13. Cálculo de esfuerzos en la viga centradora 1 
Denominando reacción reducida de la zapata de esquina $\mathrm{R}_{(\mathrm{e}-1) \mathrm{d}}$ al valor obtenido al descontar a la reacción del terreno los pesos, tanto de la zapata como de la solera (Fig.13.(b), dicha reacción reducida vendrá dada por la expresión:

$$
R_{(e-1) d}^{\prime}=R_{(e-1) d}-P_{z(e-1) d}-P_{s(e-1) d}
$$

Finalmente, sustituyendo la expresión de la reacción efectiva en las ec. 25 y 26 , se obtiene la expresión simplificada de las mismas, que queda del siguiente modo:

$$
\begin{array}{ll}
\Sigma F_{z}=0 & R_{(e-1) d}^{\prime}-\left(P_{v c 1 d}+P_{s c 1 d}\right)-R_{m 1 d}-N_{(e-1) d}=0 \\
\Sigma M_{m 1}=0 & N_{(e-1) d} \cdot L_{e y}+\left(P_{v c 1 d}+P_{s c 1 d}\right) \cdot L_{c 1 y}-R_{(e-1) d}^{\prime} \cdot L_{z e y}+ \\
& +\left(V_{e y d}+V_{m 1 y d}\right) \cdot h+M_{e x d}+M_{m 1 x d}=0
\end{array}
$$

Sistema de dos ecuaciones que permite resolver las dos incógnitas, $R_{(e-1) d}^{\prime} \mathrm{N} \mathrm{N}_{(\mathrm{e}-1) \mathrm{d}}$ del modelo bidimensional de la viga centradora 1.

Conocida la reacción reducida $R_{(\mathrm{e}-1) d}$ la tensión reducida $\sigma_{(\mathrm{e}-1) \mathrm{d}}^{\prime}$ que debe ser tenida en cuenta para el cálculo estructural de la cimentación vendrá dada por la expresión:

$$
\sigma_{(e-1) d}^{\prime}=\frac{R_{(e-1) d}^{\prime}}{a_{e} \cdot b_{e}}
$$

Al igual que se indicó en el apartado 2.2.2. para la zapata de medianería, también en el caso de la zapata de esquina, la modelización convencional aborda cada uno de los esquemas bidimensionales de la misma asimilándolos a un único elemento lineal conjunto, solicitado fundamentalmente a flexión simple, con axiles despreciables. En la Fig.13.(c) y (d) se ofrecen los diagramas de momentos y cortantes correspondientes al elemento lineal conjunto equivalente.

Dichos diagramas muestran que los esfuerzos máximos se producen en el interior de la zapata de esquina. Ahora bien, dado que la sección transversal de la zapata es muy superior a la de la viga centradora, debe considerarse como sección más desfavorable para el dimensionamiento de la viga centradora, la sección de contacto de la viga con la zapata. De acuerdo con los esquemas de la Fig.13, los esfuerzos (momento y cortante) en la citada sección vendrán dados por:

$$
\begin{aligned}
& M_{1 c 1 d}=\sigma_{(e-1) d}^{\prime} \cdot a_{e} \cdot \frac{b_{e}^{2}}{2}-N_{(e-1) d} \cdot\left(b_{e}-\frac{b_{e}^{\prime}}{2}\right)-V_{e y d} \cdot h-M_{e x d} \\
& V_{1 c 1 d}=\sigma_{(e-1) d}^{\prime} \cdot a_{e} \cdot b_{e}-N_{(e-1) d}
\end{aligned}
$$




\section{VIGA CENTRADORA 2}

Por lo que respecta a la viga centradora 2, se muestra en la Fig.14 el esquema de cálculo de la misma junto con la zapata de esquina y la zapata de medianería 2. Las acciones y reacciones, tanto de la zapata de medianería 2 como de la viga centradora 2 , son las acciones y reacciones íntegras correspondientes a dichos elementos (Fig.14.(a)). En cambio al pilar y la zapata de esquina se le asigna únicamente la fracción de las acciones y reacciones correspondiente al plano bidimensional de la viga centradora 2 . Los vectores que forman parte de dicha fracción de acciones y reacciones se identifican con la notación (e - 2).

El valor de la fracción de acciones y reacciones a asignar al pilar y la zapata de esquina es, a priori, desconocido. Ahora bien, dicho valor ha de ser compatible con los resultados obtenidos para la zapata de medianería 2 a partir del esquema tridimensional conjunto (Fig.12). Por ello, dicho valor debe ser aquel que permita el cumplimiento de las ecuaciones de equilibrio estático del esquema bidimensional de la Fig.14:

$$
\begin{array}{ll}
\Sigma F_{z}=0 & \left(R_{(e-2) d}-P_{z(e-1) d}-P_{s(e-2) d}\right)-\left(P_{v c 2 d}+P_{s c 2 d}\right)-R_{m 2 d}-N_{(e-2) d}=0 \\
\Sigma M_{m 2}=0 & N_{(e-2) d} \cdot L_{e x}+\left(P_{v c 2 d}+P_{s c 2 d}\right) \cdot L_{c 2 x}+\left(V_{e x d}+V_{m 2 x d}\right) \cdot h+M_{e y d}+M_{m 2 y d}- \\
& -\left(R_{(e-2) d}-P_{z(e-2) d}-P_{s(e-2) d}\right) \cdot L_{z e x}=0
\end{array}
$$

Denominando reacción reducida de la zapata de esquina $\mathrm{R}_{(\mathrm{e}-2) \mathrm{d}}$ al valor obtenido al descontar a la reacción del terreno los pesos, tanto de la zapata como de la solera (Fig.13.(b), dicha reacción reducida vendrá dada por la expresión:

$$
R_{(e-2) d}^{\prime}=R_{(e-2) d}-P_{z(e-2) d}-P_{s(e-2) d}
$$

Finalmente, sustituyendo la expresión de la reacción efectiva en las ec. 25 y 26 , se obtiene la expresión simplificada de las mismas, que queda del siguiente modo:

$$
\begin{array}{ll}
\Sigma \mathrm{F}_{\mathrm{z}}=0 & \mathrm{R}_{(\mathrm{e}-2) \mathrm{d}}^{\prime}-\left(\mathrm{P}_{\mathrm{vc} 2 \mathrm{~d}}+\mathrm{P}_{\mathrm{sc} 2 \mathrm{~d}}\right)+\mathrm{R}_{\mathrm{m} 2 \mathrm{~d}}-\mathrm{N}_{(\mathrm{e}-2) \mathrm{d}}=0 \\
\Sigma \mathrm{M}_{\mathrm{m} 1}=0 & \mathrm{~N}_{(\mathrm{e}-2) \mathrm{d}} \cdot \mathrm{L}_{\mathrm{ex}}+\left(\mathrm{P}_{\mathrm{vc} 2 \mathrm{~d}}+\mathrm{P}_{\mathrm{sc} 2 \mathrm{~d}}\right) \cdot \mathrm{L}_{\mathrm{c} 2 \mathrm{x}}-\mathrm{R}_{(\mathrm{e}-2) \mathrm{d}}^{\prime} \cdot \mathrm{L}_{\mathrm{zex}}+ \\
& +\left(\mathrm{V}_{\mathrm{exd}}+\mathrm{V}_{\mathrm{m} 2 \mathrm{xd}}\right) \cdot \mathrm{h}+\mathrm{M}_{\mathrm{eyd}}+\mathrm{M}_{\mathrm{m} 2 \mathrm{yd}}=0
\end{array}
$$

Sistema de dos ecuaciones que permite resolver las dos incógnitas, $R_{(e-2) d}$ y $N_{(e-2) d}$ del modelo bidimensional de la viga centradora 2. 

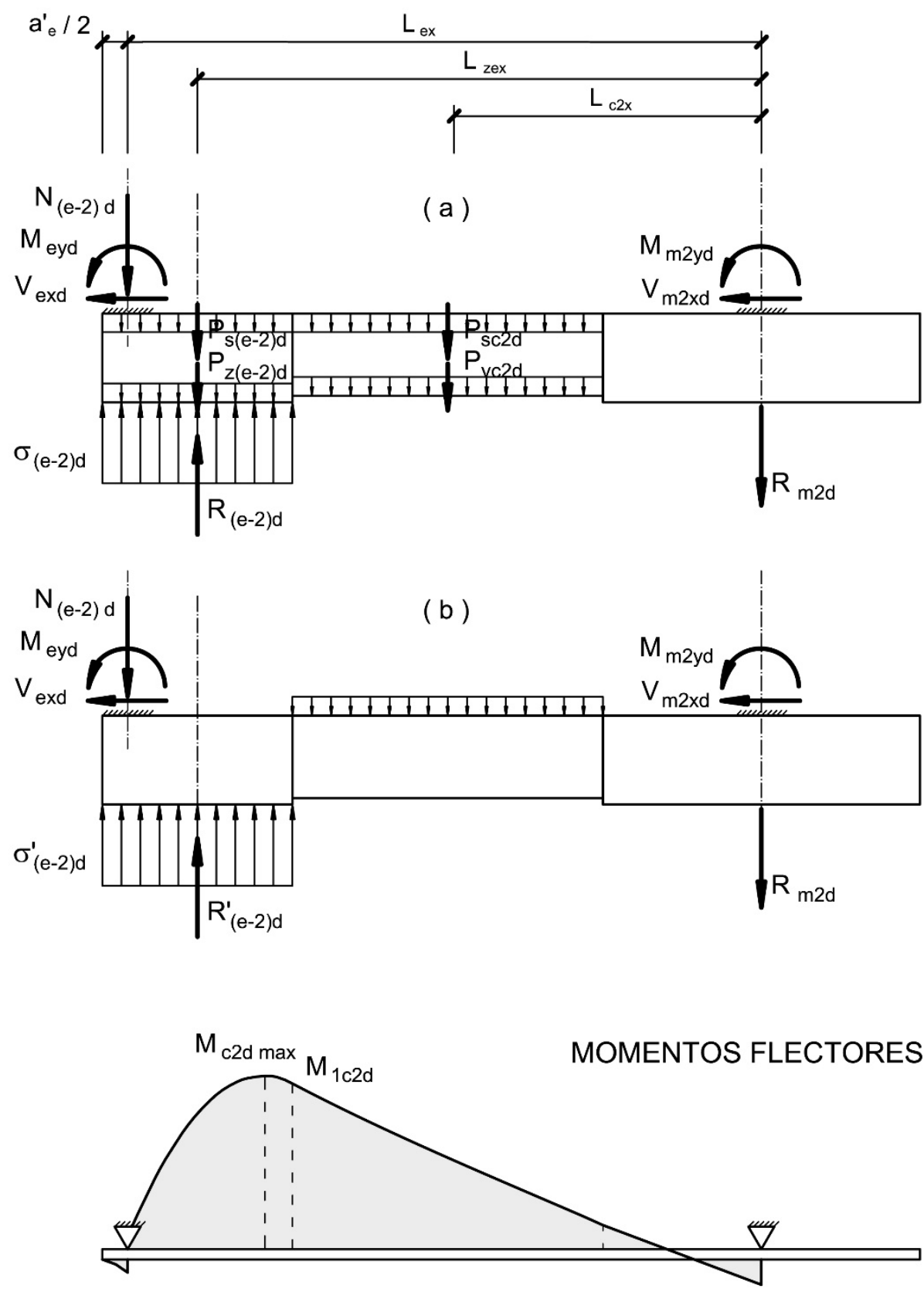

(c)

ESFUERZOS CORTANTES

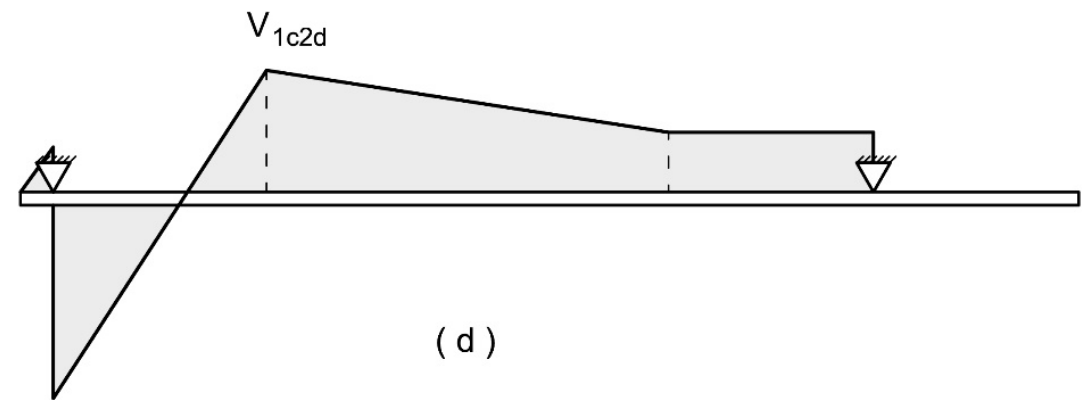

Fig.14. Cálculo de esfuerzos en la viga centradora 2 
Conocida la reacción reducida $\mathrm{R}_{(\mathrm{e}-2) \mathrm{d}}$ la tensión reducida $\sigma_{(\mathrm{e}-2) \mathrm{d}}^{\prime}$ que debe ser tenida en cuenta para el cálculo estructural de la cimentación vendrá dada por la expresión:

$$
\sigma_{(e-2) d}^{\prime}=\frac{R_{(e-2) d}^{\prime}}{a_{e} \cdot b_{e}}
$$

Tal y como se hizo para la viga centradora 1, en la Fig.14.(c) y (d) se ofrecen los diagramas de momentos y cortantes correspondientes al elemento lineal conjunto equivalente a la viga centradora 2. De igual manera, dichos diagramas muestran que los esfuerzos máximos se producen en el interior de la zapata de esquina, si bien, debido a que la sección transversal de la zapata es muy superior a la de la viga centradora, debe considerarse como sección más desfavorable para el dimensionamiento de la viga centradora, la sección de contacto de la viga con la zapata. De acuerdo con los esquemas de la Fig.14, los esfuerzos (momento y cortante) en la citada sección vendrán dados por:

$$
\begin{aligned}
& M_{1 c 2 d}=\sigma_{(e-2) d}^{\prime} \cdot b_{e} \cdot \frac{a_{e}{ }^{2}}{2}-N_{(e-2) d} \cdot\left(a_{e}-\frac{a_{e}^{\prime}}{2}\right)-V_{e x d} \cdot h-M_{e y d} \\
& V_{1 c 2 d}=\sigma_{(e-2) d}^{\prime} \cdot b_{e} \cdot a_{e}-N_{(e-2) d}
\end{aligned}
$$




\subsection{VALORACIÓN CRÍTICA DE LOS MODELOS CONVENCIONALES}

Los modelos convencionales descritos para el cálculo de cimentaciones directas de medianería y esquina, plantean una serie de simplificaciones respecto de los modelos reales ideales. Dichas simplificaciones tienen la ventaja de permitir el cálculo de las citadas cimentaciones, por medios manuales, en un tiempo razonable pero, como toda simplificación, presentan el inconveniente de alejarse del comportamiento real de la cimentación, conduciendo a decisiones de dimensionamiento no ajustadas a la realidad. En esta línea, es preciso incidir sobre la idea de que no tiene sentido luchar por un incremento en la precisión del cálculo si realmente dicho aumento de precisión no conduce a decisiones de dimensionamiento diferentes, por lo cual, es necesario analizar sólo aquellas cuestiones que conduzcan a cambios significativos.
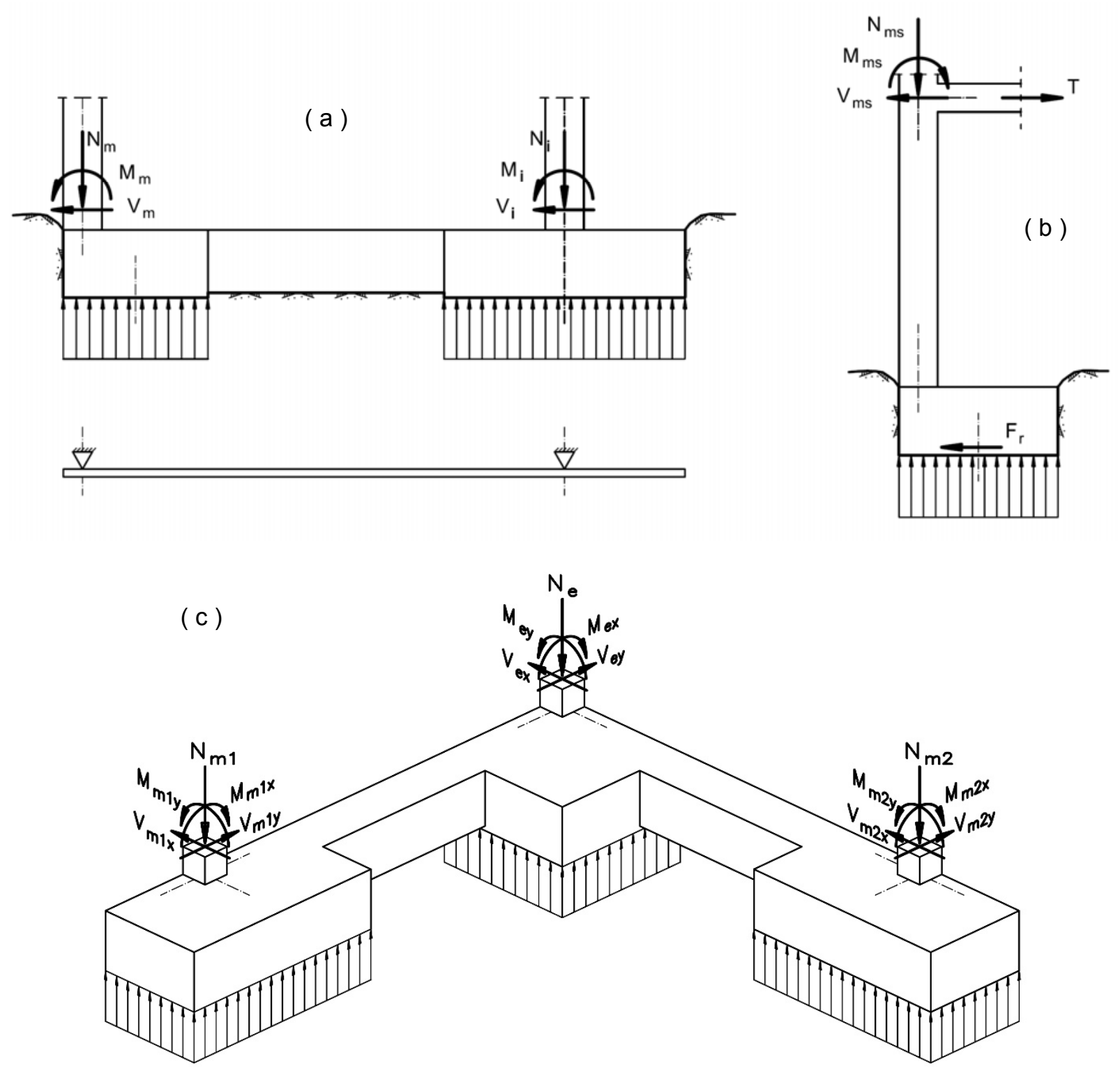

Fig.15. Valoración crítica de los modelos convencionales 
Las principales simplificaciones de los modelos convencionales que podrían ponerse en tela de juicio, por las posibles consecuencias que suponen para el dimensionamiento de la cimentación, son las siguientes:

- No integración en un modelo único de la interacción suelo - cimiento - estructura

- Independencia de los modelos de viga centradora y tirante

- Simplificación de las cargas transmitidas por los pilares

- Modelización del conjunto zapata de medianería - viga centradora - zapata interior como un único elemento lineal global

- Consideración de diagramas de distribución de tensiones de contacto uniformemente repartidos bajo las zapatas

- Ausencia de interacción con el terreno bajo las vigas centradoras

- No consideración del pilar interior ni de las vigas centradoras de las zapatas de medianería auxiliares de la zapata de esquina

\section{NO INTEGRACIÓN EN UN MODELO ÚNICO DE LA INTERACCIÓN SUELO - CIMIENTO - ESTRUCTURA}

Los modelos convencionales abordan el cálculo de los diferentes elementos estructurales de un edificio separándolos en tres partes claramente diferenciadas:

- Por un lado, se considera la parte aérea de la estructura (el pórtico) realizando un cálculo del mismo (por método matricial o método de Cross) para obtener las reacciones en la base de los pilares como dato de carga para la cimentación.

- Por otro lado, se considera la cimentación como elemento estructural aislado que recibe la carga del pórtico por medio de sus pilares y la respuesta del terreno para equilibrarla.

- Por último aparece el suelo que, por medio de las tensiones de contacto, recibe finalmente la carga como último eslabón de esta cadena de transmisión.

La consideración de estos tres elementos en modelos separados, obliga a introducir las correspondientes condiciones de contorno en las fronteras entre ellos. Así, en la base de los pilares se presupone empotramiento perfecto, con ausencia de giro, que conduce también a la hipótesis de distribución de tensiones de contacto uniformemente repartida. Estas condiciones de contorno son unas hipótesis simplificadoras, que facilitan el cálculo pero desvirtúan la realidad. 
La creación de un modelo de cálculo único, que considerase simultáneamente la interacción pórtico - cimentación - suelo, permitiría un estudio más real del comportamiento de estos tres elementos estructurales en las fronteras entre unos y otros, pero hay que comprender que un modelo de tal calibre resultaría inviable en un cálculo manual.

\section{INDEPENDENCIA DE LOS DOS MODELOS DE VIGA CENTRADORA Y TIRANTE}

Continuando con la línea introducida en el punto anterior, cabe preguntarse, si es posible el funcionamiento independiente de los modelos de viga centradora y tirantes o, por el contrario, se dan simultáneamente. Ciertamente es posible construir cimentaciones de medianería sin viga centradora y con equilibrio gracias a la colaboración de la viga superior, sin embargo, no es posible plantear en la práctica el modelo de viga centradora en estado puro (equilibrio con viga centradora pero sin colaboración de la viga superior). Se quiera o no se quiera, la viga superior existe y, cuando se emplea viga centradora también trabaja simultáneamente la viga de la primera planta. Ello trae como consecuencia un posible dimensionamiento por exceso de la viga centradora y un dimensionamiento por defecto de la viga superior. Esto es debido a que cuando se trabaja con el modelo de tirante se tiene muy presente que hay que incrementar la armadura de la viga superior debido a su trabajo a flexotracción, pero cuando se trabaja con el modelo de viga centradora se suele ignorar que la viga superior sigue funcionando como tirante aunque no figure en el modelo y, por ello, se infradimensiona su armadura.

La crítica es por tanto evidente: el modelo de viga centradora no existe en estado puro. Cuando se emplea viga centradora siempre se produce una combinación de ambos modelos. El motivo por el que los modelos convencionales no contemplan esta cuestión parece bastante claro. Los modelos convencionales buscan, sobre todo, soluciones isostáticas, que puedan ser resueltas manualmente en un tiempo reducido. Si además de la viga centradora, se considera la intervención de la viga superior trabajando como tirante, se plantearía un esquema hiperestático de más compleja solución.

\section{SIMPLIFICACIÓN DE LAS CARGAS TRANSMITIDAS POR LOS PILARES}

Es frecuente en muchos autores, la consideración únicamente de los axiles transmitidos por los pilares, ignorando los posibles momentos y cortantes que se producen en la base de éstos. El argumento planteado, totalmente válido, es que la magnitud de dichos esfuerzos suele ser muy reducida y, por tanto, despreciable frente al efecto producido por los axiles. 
Puede intuirse un segundo motivo, normalmente no explicitado. Cuando se crearon estos modelos, la potencia de las herramientas de cálculo disponibles era reducida y calcular la distribución de momentos en un pórtico de tamaño medio resultaba muy complejo, frente a la sencillez de la evaluación de los axiles transmitidos por los pilares. Ello, evidentemente unido al reducido valor de dichos esfuerzos, invitaba aún más a despreciarlos. Hoy por hoy, si se dispone de herramientas para calcular cómodamente los esfuerzos en el pórtico, no tiene mucho sentido ignorar los citados esfuerzos, teniendo en cuenta además, que su inclusión en el modelo convencional no supone un incremento considerable en el tiempo de cálculo.

\section{MODELIZACIÓN DEL CONJUNTO DE LA CIMENTACIÓN COMO ELEMENTO LINEAL}

Cuando se utiliza viga centradora se plantea que el conjunto de la cimentación (zapata de medianería - viga centradora - zapata interior) constituye un único elemento lineal tipo viga, que recibe como cargas las de contacto con el terreno y que se apoya en los dos pilares que arrancan en las citadas zapatas (Fig.15.(a)). El planteamiento es sumamente sencillo y simplifica considerablemente el cálculo de esfuerzos en el conjunto, pero resulta evidente su alejamiento de la realidad, ya que se ignoran por completo las zonas de discontinuidad que se producen entre la viga centradora y las dos zapatas y se obvia el hecho de que las zapatas en cuestión no tienen nada de elemento lineal.

\section{DIAGRAMAS DE TENSIONES UNIFORMEMENTE REPARTIDOS}

Posiblemente, una de las cuestiones más discutibles de los modelos convencionales sea la utilización de diagramas de tensiones uniformemente repartidos en el contacto entre las zapatas y el terreno (Fig.15). Dicho planteamiento supone la total ausencia de giro en las zapatas de cimentación y la condición de empotramiento perfecto en la base de los pilares y en el arranque de la viga centradora. Cualquier análisis que se haga al respecto conduce rápidamente a la sospecha de lo alejado que se encuentra dicha hipótesis de la realidad. El motivo de la utilización de tal simplificación es obvio. Al hacerlo, cada zapata aporta una única incógnita, el valor de la resultante centrada del diagrama de tensiones, con lo cual, todos los modelos convencionales se convierten en modelos isostáticos de fácil aplicación.

Algunos autores (Calavera, J. 2000), desarrollan una variante del modelo de tirante con distribución de tensiones variable trapecial en la cara de contacto entre la cimentación y el terreno (Fig.16). Dicho planteamiento se ajusta más a la realidad pero convierte el esquema 
de cálculo en hiperestático, debiendo recurrir para su solución, al estudio de la compatibilidad de deformaciones entre el terreno, la zapata de medianería y el arranque del pilar.

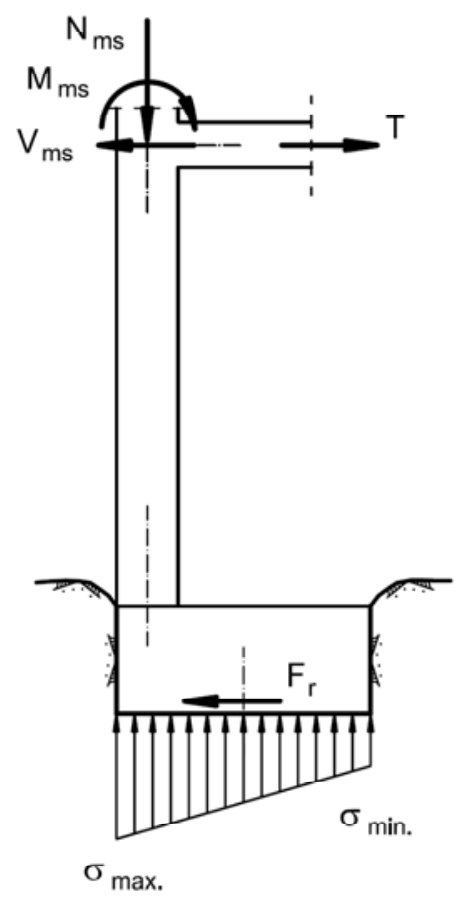

Fig.16. Zapata de medianería con colaboración de la viga superior y diagrama trapecial

Ninguno de los autores consultados hace un planteamiento similar en el caso de la zapata de medianería con viga centradora, ya que ello implicaría un mayor grado de hiperestaticidad, al contar con dos zapatas con distribución trapecial conectadas por una viga centradora. La solución de dicho modelo requeriría contemplar una múltiple compatibilidad de deformaciones entre varios elementos: el terreno, dos zapatas, una viga centradora y dos pilares, lo cual complicaría considerablemente el proceso de cálculo.

\section{AUSENCIA DE INTERACCIÓN CON EL TERRENO BAJO LA VIGA CENTRADORA}

Ninguno de los autores consultados plantea distribución de tensiones de contacto entre la viga centradora y el terreno bajo la misma. Dicha hipótesis simplificadora se apoya, por un lado, en la idea de que la magnitud de la viga centradora es despreciable en planta frente al tamaño de las zapatas y, por otro, en el hecho de que la flexión negativa en la viga centradora tiende, con su curvatura, a despegarla del terreno, eliminando el contacto con éste. Siendo lógicos los dos argumentos citados, vuelve a intuirse la idea de que la consideración de la tensión de contacto entre la viga centradora y el terreno convertiría el esquema de cálculo en hiperestático y complicaría, de nuevo, la resolución del mismo. 


\section{NO CONSIDERACIÓN DEL PILAR INTERIOR NI DE LAS VIGAS CENTRADORAS DE LAS ZAPATAS DE MEDIANERÍA AUXILIARES DE LA ZAPATA DE ESQUINA}

El modelo convencional para la zapata de esquina plantea el centrado de la respuesta del terreno bajo la zapata de esquina mediante el empleo de dos vigas centradoras que la conectan con las dos zapatas más próximas que se encuentran a su alrededor (Fig.5). Debido a la confluencia de una doble medianería o doble alineación de fachada en la zapata de esquina, las dos zapatas auxiliares deben ser, por lógica, zapatas de medianería, que requerirían ser estabilizadas mediante otras dos vigas centradoras conectadas a un cuarto pilar con su cimentación, esta vez interior (Fig.10).

El modelo convencional para la zapata de esquina (Fig.5, 10, 11 y 12) no contempla para nada la interacción ni del cuarto pilar ni de las dos últimas vigas centradoras que estabilizan a las zapatas de medianería planteando, por superposición, la total independencia de la zapata de esquina del problema de excentricidad de las zapatas de medianería, que no le transmiten ningún esfuerzo por este motivo. Nuevamente el asunto remite a la complejidad del proceso de cálculo. La puesta en escena del cuarto pilar interior con su cimentación introduciría una cuarta reacción incógnita en el cálculo, que convertiría el sistema en esquema hiperestático difícil de abordar. 
CAPÍTULO 3

PLAN EXPERIMENTAL 



\section{PLAN EXPERIMENTAL}

\subsection{PLANTEAMIENTO GENERAL. DISEÑO EXPERIMENTAL}

La presente tesis doctoral plantea una etapa experimental inicial (de carácter virtual), seguida por un proceso de análisis e interpretación de resultados.

La etapa experimental supone la ejecución de las siguientes fases:

- Definición de los pórticos tipo objeto de estudio, así como de las cargas o acciones a considerar sobre los mismos.

- Selección de variables y definición de los casos objeto de estudio.

- Cálculo del catálogo de casos resultantes, tanto por métodos convencionales como por elementos finitos.

Posteriormente, finalizado el cálculo de todos los casos de la fase experimental, se procederá al contraste, análisis e interpretación de los resultados obtenidos por ambos métodos, así como a la propuesta de un método alternativo de carácter convencional más ajustado al comportamiento real de este tipo de cimentación.

\subsubsection{PÓRTICOS TIPO}

El estudio de las zapatas de medianería se lleva a cabo tomando como referencia un pórtico tipo, ortogonal, de dos y número variable de plantas (Fig.17). Los vanos son de igual luz, siendo ésta variable según los casos de estudio. La altura de las plantas es de $4 \mathrm{~m}$ para la planta baja y $3 \mathrm{~m}$ para cada una de las plantas superiores. La crujía entre pórticos sucesivos es de $5 \mathrm{~m}$.

Se considera, como hipótesis, que el pilar izquierdo se encuentra en el límite de la propiedad y, por tanto, en medianería (Fig.17). La cimentación de dicho pilar es una zapata de medianería, la del pilar central hace las funciones, en su caso, de zapata interior que sirve de apoyo para el centrado de la zapata de medianería y, por último, la zapata del pilar derecho es una zapata aislada normal.

El pórtico es de hormigón armado y las uniones del mismo se consideran rígidas. Las bases de los pilares (unión de los pilares con la cimentación) están perfectamente empotradas en la cimentación en los modelos convencionales, mientras que en los modelos de elementos finitos, el propio funcionamiento del M.E.F. permite evaluar el grado de empotramiento de las mismas. 


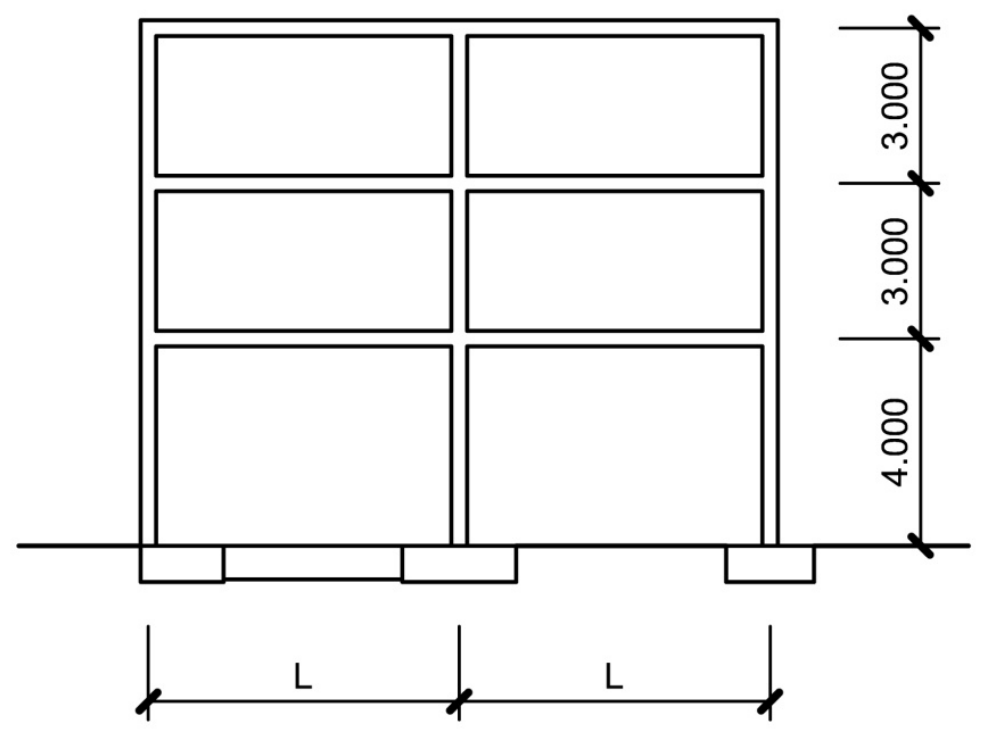

Fig.17. Pórtico tipo para el estudio de las zapatas de medianería

Por su parte, el estudio de las zapatas de esquina se lleva a cabo tomando como referencia dos pórticos consecutivos similares a los anteriores, también con dos vanos y número variable de plantas (Fig.18). Al igual que en el caso anterior, los vanos son de igual luz, siendo ésta variable según los casos de estudio, la altura de las plantas es de $4 \mathrm{~m}$ para la planta baja y de $3 \mathrm{~m}$ para cada una de las plantas superiores y la separación entre pórticos igual a la luz considerada en los vanos. Dicho entramado presenta un pilar, con su correspondiente zapata, en posición de esquina y dos alineaciones perpendiculares en medianería.

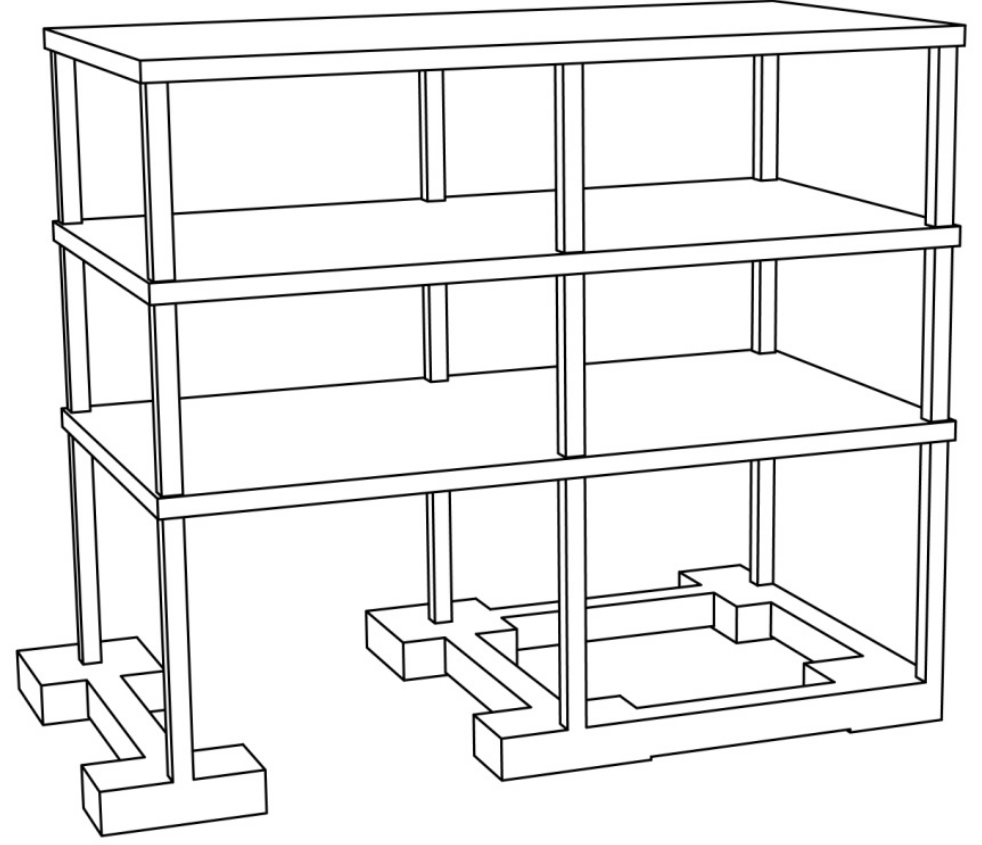

Fig.18. Pórticos tipo para el estudio de las zapatas de esquina 


\subsubsection{ACCIONES}

Las acciones sobre los pórticos objeto de estudio se han determinado de acuerdo con el C.T.E. Documento Básico Seguridad Estructural, Acciones en la Edificación (DB SE - AE). Se han considerado las siguientes hipótesis de carga:

- Peso propio y carga permanente

- Sobrecarga de uso

\section{PESO PROPIO Y CARGA PERMANENTE}

En la hipótesis de peso propio y carga permanente se tiene en cuenta: el peso propio de los elementos estructurales del pórtico (vigas y pilares), las cargas gravitatorias asociadas a los forjados de las plantas intermedias (peso propio del forjado y carga permanente de pavimentos, enlucidos y tabiquerías), las cargas gravitatorias asociadas al forjado de cubierta (peso propio del forjado y carga permanente del enlucido y de la cubierta plana) y la carga permanente debida al peso del cerramiento exterior $y$ al antepecho de cubierta. Los elementos constructivos de referencia empleados, tanto en los casos de zapata de medianería como en los casos de zapata de esquina, son los mismos, por los cual, se adoptan las mismas cargas unitarias en ambos casos.

El peso propio de los elementos de los pórticos (vigas y pilares) se obtiene a partir de las dimensiones de los mismos y del peso específico del material. Al ser los pórticos de hormigón armado se ha adoptado para el mismo un peso específico de $\gamma_{\text {ho }}=25 \mathrm{kN} / \mathrm{m}^{3}$. Las diferentes herramientas informáticas utilizadas para el cálculo de esfuerzos (CYPE 3D y ANSYS) contemplan de forma automática el peso propio de los elementos estructurales definidos en el fichero de cálculo.

La carga unitaria correspondiente a los forjados de las plantas intermedias responde al siguiente desglose:

- Peso propio forjado

$3,00 \mathrm{kN} / \mathrm{m}^{2}$

- Enlucido yeso (e=15 mm)

$$
12,00\left(\mathrm{kN} / \mathrm{m}^{3}\right) \cdot 0,015(\mathrm{~m})
$$

$0,18 \mathrm{kN} / \mathrm{m}^{2}$

- Pavimento (Terrazo sobre mortero) $0,80 \mathrm{kN} / \mathrm{m}^{2}$

- Tabiquería $1,00 \mathrm{kN} / \mathrm{m}^{2}$

TOTAL $\quad \mathbf{4 , 9 8} \mathbf{k N} / \mathbf{m}^{2}$ 
Asimismo, la carga unitaria correspondiente al forjado de cubierta viene dada por la siguiente descomposición:

- Peso propio forjado

$3,00 \mathrm{kN} / \mathrm{m}^{2}$

- Enlucido yeso $(\mathrm{e}=15 \mathrm{~mm})$

$12,00\left(\mathrm{kN} / \mathrm{m}^{3}\right) \cdot 0,015(\mathrm{~m})$

$0,18 \mathrm{kN} / \mathrm{m}^{2}$

- Cubierta plana invertida

$2,50 \mathrm{kN} / \mathrm{m}^{2}$

TOTAL $\quad \mathbf{5 , 6 8} \mathbf{~ k N / m ^ { 2 }}$

Por su parte, la carga unitaria del cerramiento exterior se obtiene a partir de la definición de capas del mismo:

- Fábrica lad. perforado $\mathrm{C} / \mathrm{V}(\mathrm{e}=120 \mathrm{~mm})$

$$
15,00\left(\mathrm{kN} / \mathrm{m}^{3}\right) \cdot 0,120(\mathrm{~m}) \quad \ldots \ldots . \quad 1,80 \mathrm{kN} / \mathrm{m}^{2}
$$

- Enfoscado mortero cemento $(\mathrm{e}=15 \mathrm{~mm})$

$$
20,00\left(\mathrm{kN} / \mathrm{m}^{3}\right) \cdot 0,015(\mathrm{~m}) \quad \ldots \ldots . \quad 0,30 \mathrm{kN} / \mathrm{m}^{2}
$$

- Aislamiento térmico (e=40 mm)

$$
0,02\left(\mathrm{kN} / \mathrm{m}^{2}\right) \cdot 4 \quad \ldots \ldots . \quad 0,08 \mathrm{kN} / \mathrm{m}^{2}
$$

- Fábrica ladrillo hueco $\quad(\mathrm{e}=70 \mathrm{~mm})$

$$
12,00\left(\mathrm{kN} / \mathrm{m}^{3}\right) \cdot 0,070(\mathrm{~m}) \quad \ldots \ldots . \quad 0,84 \mathrm{kN} / \mathrm{m}^{2}
$$

- Enlucido de yeso (e=15 mm)

$$
12,00\left(\mathrm{kN} / \mathrm{m}^{3}\right) \cdot 0,015(\mathrm{~m}) \quad \ldots \ldots . \quad 0,18 \mathrm{kN} / \mathrm{m}^{2}
$$

TOTAL $\quad 3,20 \mathrm{kN} / \mathrm{m}^{2}$

Finalmente, la carga unitaria correspondiente al antepecho de cubierta, en función de su composición es:

- Fábrica lad. perforado $\mathrm{C} / \mathrm{V}(\mathrm{e}=120 \mathrm{~mm})$

$$
15,00\left(\mathrm{kN} / \mathrm{m}^{3}\right) \cdot 0,120(\mathrm{~m}) \quad \ldots \ldots . \quad 1,80 \mathrm{kN} / \mathrm{m}^{2}
$$

- Fábrica lad. perforado $\quad(\mathrm{e}=120 \mathrm{~mm})$

$$
15,00\left(\mathrm{kN} / \mathrm{m}^{3}\right) \cdot 0,120(\mathrm{~m}) \quad \ldots \ldots . \quad 1,80 \mathrm{kN} / \mathrm{m}^{2}
$$

- Enfoscado mortero cemento $(\mathrm{e}=15 \mathrm{~mm})$

$$
20\left(\mathrm{kN} / \mathrm{m}^{3}\right) \cdot 0,015(\mathrm{~m}) \quad \ldots \ldots . \quad 0,30 \mathrm{kN} / \mathrm{m}^{2}
$$

TOTAL $\quad 3,90 \mathrm{kN} / \mathrm{m}^{2}$

Conocidas las cargas unitarias correspondientes a los distintos elementos constructivos empleados, se procede al cálculo de los vectores de carga a aplicar sobre los pórticos. La carga correspondiente a cada forjado se transmite a los pórticos en cuestión como un vector uniformemente repartido. Para el cálculo del mismo, en los casos de medianería, es preciso 
tener en cuenta que el pórtico elegido es uno de los pórticos interiores del edificio, que la crujía o separación entre pórticos sucesivos es de $5 \mathrm{~m}$ y que se va a considerar el efecto de la continuidad del forjado sobre la distribución de cargas a los distintos pórticos, adoptando un coeficiente de incremento de carga por continuidad para los pórticos interiores de valor 1,15. Con estos datos, la carga uniformemente repartida a aplicar en las vigas del pórtico es:

$$
\begin{array}{lll}
\text { Forjado Plantas Interm. } & \mathrm{q}_{\mathrm{p}}=4,98 \cdot 5 \cdot 1,15=\mathbf{2 8 , 6 4} \mathrm{kN} / \mathrm{m} \\
\text { Forjado Cubierta } & \mathrm{q}_{\mathrm{p}}=5,68 \cdot 5 \cdot 1,15=\mathbf{3 2 , 6 6 \mathrm { kN } / \mathrm { m }}
\end{array}
$$

Por su parte, la carga correspondiente, tanto al cerramiento exterior como al antepecho de cubierta, llega al pórtico en forma de vectores puntuales aplicados en los nudos correspondientes. Para el cálculo de los citados vectores puntuales, además de los comentarios realizados en el párrafo anterior para el cálculo de los vectores repartidos, hay que considerar que la altura de las plantas es de $3 \mathrm{~m}$ y que el antepecho de la cubierta tiene una altura de $1,1 \mathrm{~m}$.

$$
\begin{array}{ll}
\text { Cerramiento Exterior } & q_{p}=3,20 \cdot 5 \cdot 3 \cdot 1,15=\mathbf{5 5 , 2 0} \mathbf{~ k N} \\
\text { Antepecho Cubierta } & q_{p}=3,90 \cdot 5 \cdot 1,1 \cdot 1,15=\mathbf{2 4 , 6 7} \mathbf{~ k N}
\end{array}
$$

En la Fig.19 se representa el esquema del pórtico con los vectores de carga correspondientes a la hipótesis de Peso Propio y Carga Permanente

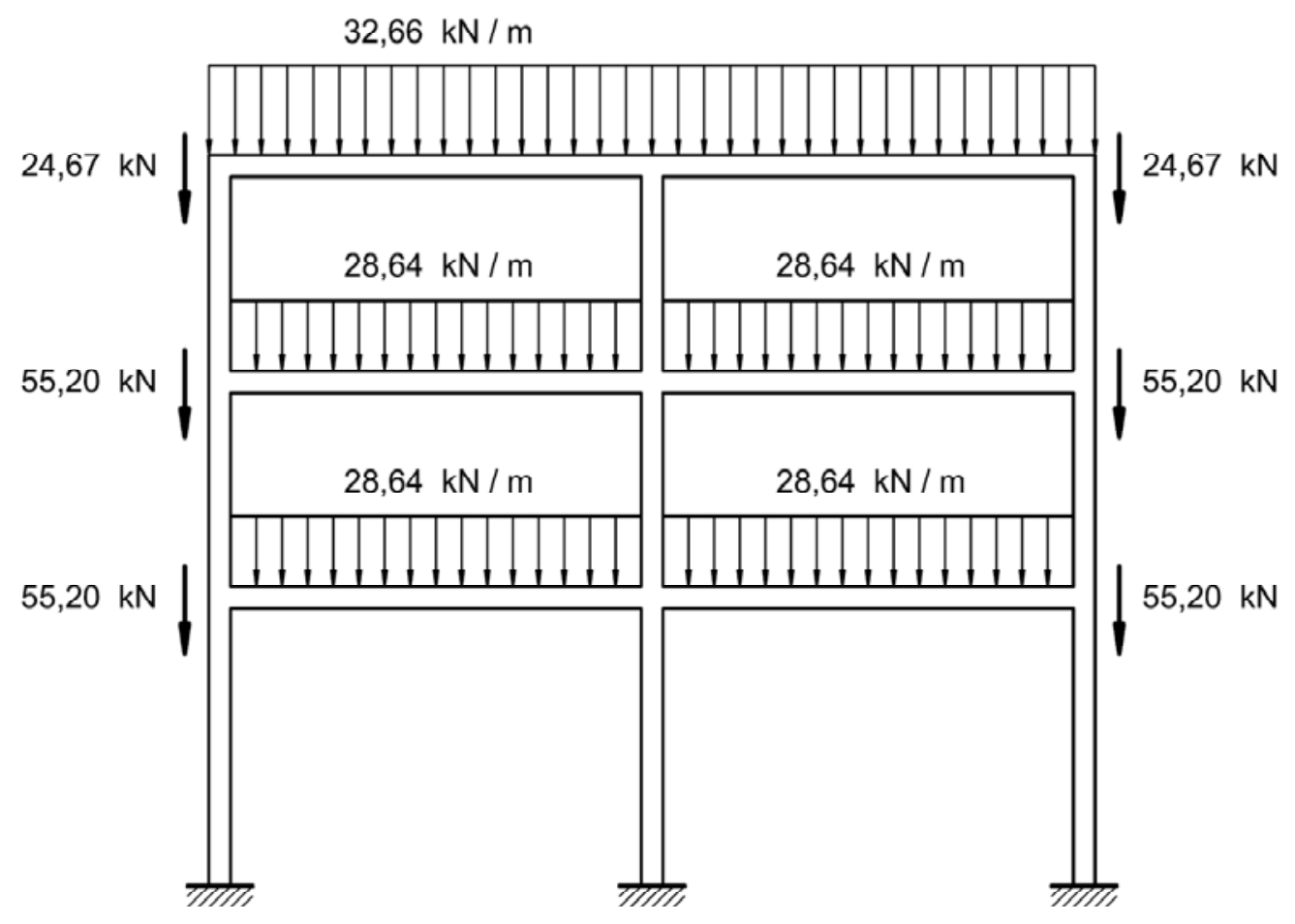

Fig.19. Acciones. Peso Propio y Carga Permanente 


\section{SOBRECARGA DE USO}

Se plantea como hipótesis un edificio de viviendas. Por ello, de acuerdo con la vigente normativa C.T.E. DB SE - AE, para los forjados de las plantas intermedias se considera una sobrecarga de uso de valor:

$$
q_{s}=2,00 \mathrm{kN} / \mathrm{m}^{2}
$$

Por lo que respecta a la cubierta, es preciso tener en cuenta una sobrecarga de mantenimiento de cubierta de valor:

$$
q_{s}=1,00 \mathrm{kN} / \mathrm{m}^{2}
$$

Las cargas en cuestión gravitan sobre los forjados, los cuales transmiten dicha carga a las vigas del pórtico en forma de vectores uniformemente repartidos. Para el cálculo de dichos vectores es preciso tener en cuenta, como ya se hizo con la hipótesis de peso propio, que el pórtico elegido es uno de los pórticos interiores del edificio, que la crujía o separación entre pórticos sucesivos es de $5 \mathrm{~m}$ y que se considera el efecto de la continuidad del forjado sobre la distribución de cargas a los distintos pórticos. Con estos datos, la carga uniformemente repartida a aplicar en las vigas del pórtico será:

$$
\begin{array}{lll}
\text { Forjado Plantas Interm. } & \mathrm{q}_{\mathrm{s}}=2,00 \cdot 5 \cdot 1,15=\mathbf{1 1 , 5 0} \mathbf{k N} / \mathbf{m} \\
\text { Forjado Cubierta } & \mathrm{q}_{\mathrm{s}}=1,00 \cdot 5 \cdot 1,15=\mathbf{5 , 7 5} \mathbf{k N} / \mathbf{m}
\end{array}
$$

En la Fig.20 se representa el esquema del pórtico con los vectores de carga correspondientes a la hipótesis de Sobrecarga de Uso.

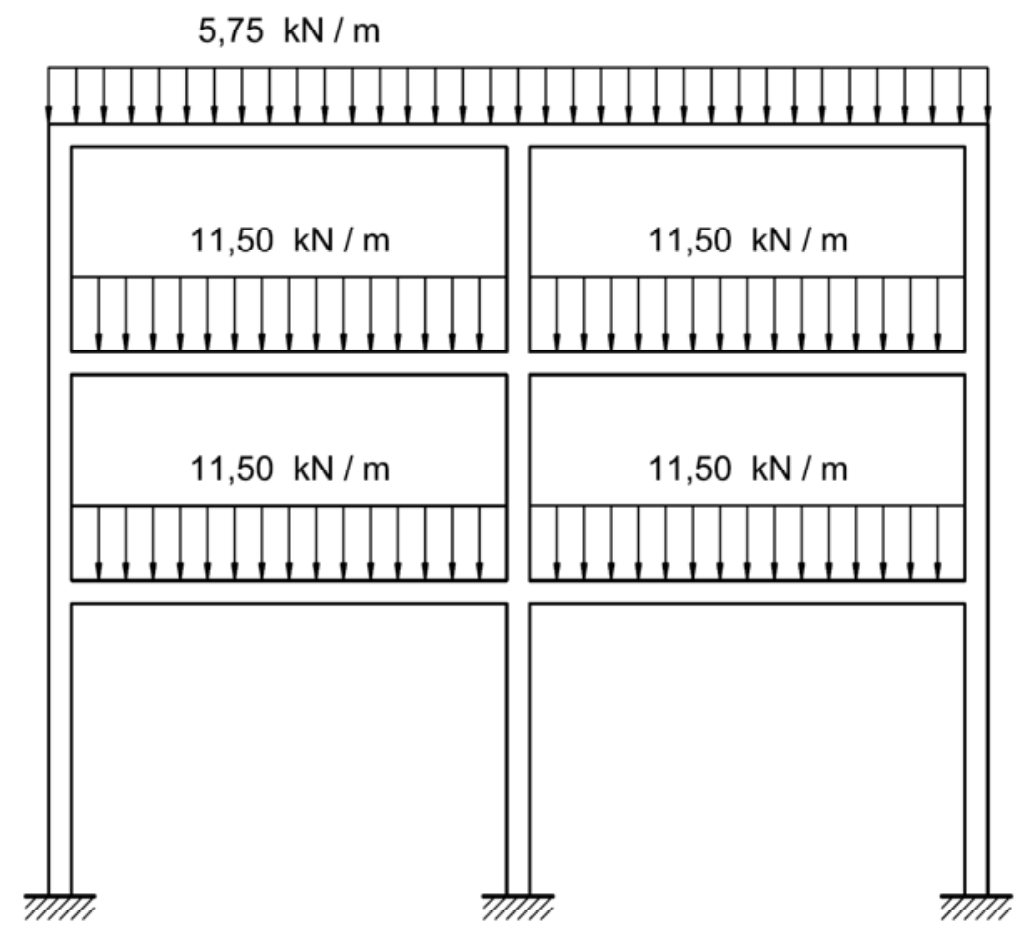

Fig.20. Acciones. Sobrecarga de Uso 
El cálculo de los vectores que actúan sobre los pórticos, en los casos de zapata de esquina, se realiza del mismo modo planteado para los casos de zapata de medianería. En esta ocasión se considera que, de los dos pórticos consecutivos empleados, el pórtico medianero ocupa una posición extrema mientras que el segundo pórtico es un pórtico interior del edificio. Por ello, el pórtico medianero cuenta con una superficie tributaria igual a la mitad del pórtico interior y los coeficientes de continuidad a emplear son 1,15 para el pórtico interior y 0,80 para el pórtico extremo.

\subsubsection{VARIABLES Y CASOS PLANTEADOS}

El núcleo central del trabajo de investigación de la tesis doctoral ha sido el estudio de las zapatas de medianería, entendiendo las zapatas de esquina como un caso particular de las anteriores. El plan experimental diseñado para el caso de las zapatas de medianería ha constituido un proceso de búsqueda cuyo objetivo ha sido identificar cuáles son las variables que controlan el auténtico comportamiento de este tipo de cimentación. Una vez localizadas las citadas variables se procede a su aplicación concreta al caso de las zapatas de esquina, pero el verdadero terreno de estudio es el campo de las zapatas de medianería.

A la hora de decidir las variables con las que se va a trabajar en la fase experimental, es preciso volver a reflexionar sobre la valoración crítica de los modelos convencionales realizada en el apartado 2.5. Los modelos convencionales plantean una serie de simplificaciones que, evidentemente, agilizan el proceso de cálculo, pero conducen a resultados alejados de la realidad y a decisiones de dimensionamiento posiblemente incorrectas. La relación de las citadas simplificaciones, puesta de manifiesto en el apartado 2.5 , es la siguiente:

- No integración en un modelo único de la interacción suelo - cimiento - estructura

- Independencia de los modelos de viga centradora y tirante

- Simplificación de las cargas transmitidas por los pilares

- Modelización del conjunto zapata de medianería - viga centradora - zapata interior como un único elemento lineal global

- Consideración de diagramas de distribución de tensiones de contacto uniformemente repartidos bajo las zapatas

- Ausencia de interacción con el terreno bajo las vigas centradoras

- No consideración del pilar interior ni de las vigas centradoras de las zapatas de medianería auxiliares de la zapata de esquina 
De todas estas cuestiones, es preciso seleccionar cuáles son las que pueden tener un mayor protagonismo a la hora de alejar el modelo de la realidad, desvirtuando el dimensionamiento de la cimentación.

La tercera cuestión planteada (simplificación de las cargas transmitidas por los pilares) no supone en la práctica ningún problema. Cierto es que muchos autores desprecian el momento y el cortante transmitido por el pilar a la cimentación, pero también es cierto, que los propios métodos convencionales permiten contemplarlos (si así se desea) y alcanzar un resultado adecuado en un tiempo razonable, incluso en un cálculo manual con calculadora.

La primera, la segunda, la cuarta y la sexta cuestión planteadas son evidentemente ciertas. Cuando se utiliza viga centradora, se quiera o no se quiera, la viga superior existe y, por ello, el efecto de la viga de la primera planta, trabajando como tirante, siempre es simultáneo con el efecto estabilizador de la viga centradora trabajando a flexión. Por su parte, resulta claro que la zapata de medianería y la zapata interior no son elementos lineales, por lo cual, hay discontinuidades volumétricas a lo largo del conjunto de la cimentación. Y, finalmente, es un hecho que entre la viga centradora y el terreno debe producirse algún tipo de contacto. Los modelos convencionales no contemplan ninguna de estas cuestiones y, por contraste, se toma la decisión de generar modelos de elementos finitos que contemplen todos estos aspectos para conocer, a la vista de la comparación de resultados, la incidencia que puede tener el hecho de ponerlos en escena o no.

Ahora bien, la decisión de generar modelos de elementos finitos que integren simultáneamente pórtico cimentación y suelo, que contemplen la función de la viga superior simultáneamente con la viga centradora, que consideren las discontinuidades volumétricas a lo largo de la cimentación y que tengan en cuenta el contacto de la viga centradora con el terreno, supone solamente una declaración de intenciones que no conduce ni a un conjunto de variables ni a un abanico de casos de estudio.

La simplificación más susceptible de no ser cierta y que probablemente tenga mayor influencia sobre el dimensionamiento final de la cimentación es la quinta. Plantear diagramas de tensiones uniformemente repartidos con resultante totalmente centrada, supone aceptar la idea de que las zapatas no experimentan el más mínimo giro y que, por tanto, las bases de los pilares y los arranques de la viga centradora están perfectamente empotrados. Esta afirmación es poco creíble, como puede observarse en la Fig.21, que presenta la deformada de una zapata de medianería con viga centradora, en la que quedan de manifiesto los giros de ambas zapatas. 


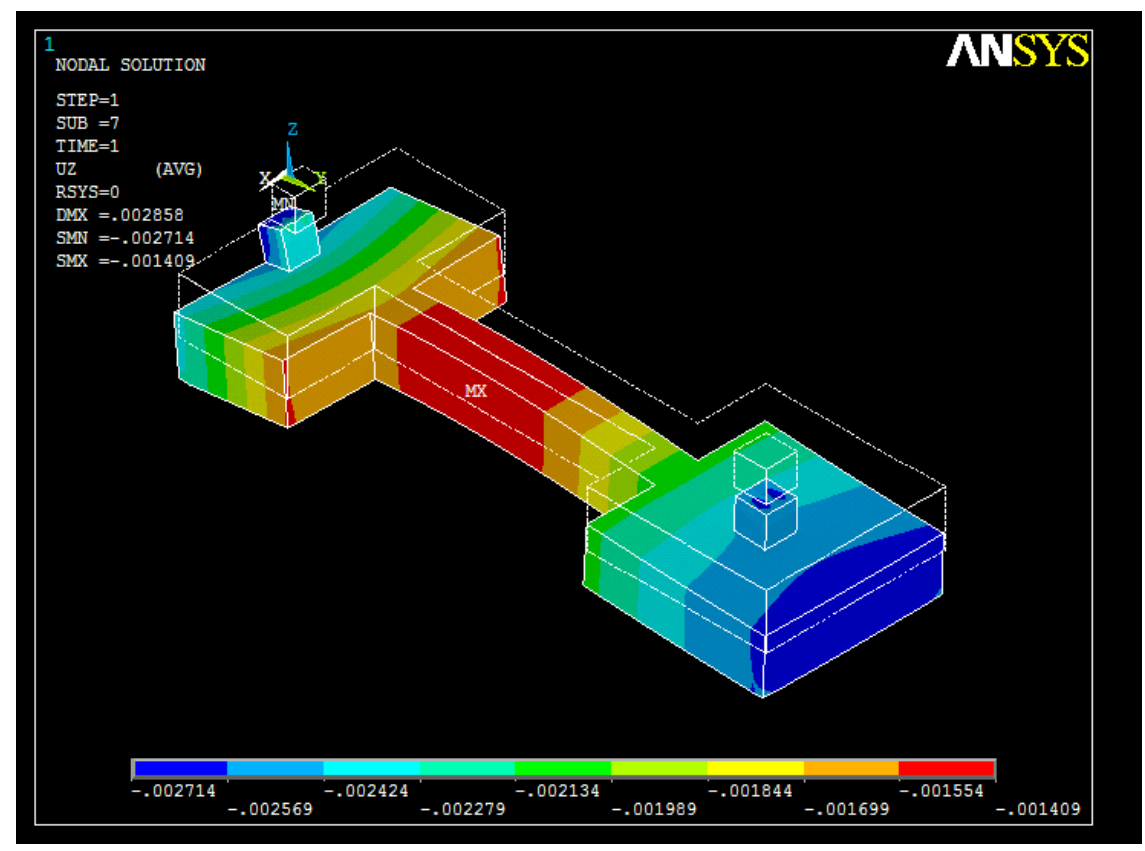

Fig.21. Deformada de una zapata de medianería con viga centradora

Intuida la importancia clave del giro de las zapatas como origen del problema objeto de estudio el trabajo de investigación desarrollado en la tesis doctoral se convierte en un proceso de búsqueda que persigue identificar cuáles son las variables que controlan el mecanismo del giro de la zapata.

La expresión proceso de búsqueda transmite perfectamente la idea de la evolución del trabajo de investigación. No se trata de un estudio estanco, con unas variables fijas y definitivas desde el primer momento, que conducen a un conjunto cerrado de casos a estudiar, como si se conociese a priori el resultado que se va a obtener. Al contrario, se trata de un proceso vivo, en evolución, en el que se van ensayando variables de forma sucesiva, de modo que las ideas e intuiciones conducen a proponer variables que, una vez ensayadas generan certezas, por un lado, e incertidumbres, por otro, que conducen a una nueva etapa de reflexión sobre el problema y propuesta de nuevas variables, en un proceso cíclico de propuesta - ensayo - reflexión en busca de la respuesta al problema planteado.

Planteado el trabajo de investigación como proceso, pueden identificarse en él cuatro etapas. Las tres primeras constituyen el auténtico proceso de búsqueda llevada a cabo sobre las zapatas de medianería, la cuarta consiste en la aplicación a las zapatas de esquina de los resultados obtenidos para las zapatas de medianería. 


\subsubsection{ETAPA I}

La primera etapa de la presente tesis doctoral está constituida por el trabajo de investigación desarrollado por el doctorando para la obtención del Diploma de Estudios Avanzados (D.E.A.) (Galletero, P., 2009). Los pórticos empleados en esta Etapa I son de dos vanos y tres plantas (baja más dos) (Fig.22). Se plantea una luz de $6 \mathrm{~m}$ para cada uno de los vanos, altura de la planta baja de $4 \mathrm{~m}$ y altura de $3 \mathrm{~m}$ para cada una de las plantas superiores. Se considera, como hipótesis, que el pilar izquierdo se encuentra en el límite de la propiedad, por lo cual, dicho pilar cuenta con una zapata de medianería equilibrada mediante una viga centradora conectada al pilar interior.

Analizado el papel clave del giro de las zapatas, la primera reflexión acerca de los factores que pueden incidir sobre dicho giro conduce a dos posibles frentes: por un lado, la rigidez del pórtico que arranca de la cimentación y, por otro, la flexión en la viga centradora como consecuencia de la excentricidad de la zapata de medianería.

El primer frente procede de la intuición de que cuanto mayor sea la rigidez del pórtico más oposición ejercerá éste al giro de la zapata. El segundo frente nace de la idea de que cuanto mayor sea la flexión en la viga centradora mayor será el giro en las zapatas que se unen a la citada viga. Dicha flexión en la viga centradora depende directamente de la excentricidad de la zapata de medianería y ésta, a su vez, depende de la relación entre la dimensión de la zapata en el plano del pórtico y la luz de éste. Cuanto mayor sea el tamaño de la zapata de medianería en la dirección del pórtico mayor será su excentricidad, mayor la flexión de la viga $y$, como consecuencia, mayor el giro de la propia zapata. Son dos los factores que conducen a incrementar el tamaño de la cimentación en el plano del pórtico: la tensión admisible del terreno y la relación de forma que se adopta en el diseño de la zapata de medianería. Cuanto menos resistente sea el terreno mayor será la zapata de medianería y su excentricidad y, cuanto más cuadrada sea dicha zapata también será mayor su excentricidad.

Por todo ello, a modo de resumen, se plantean como variables a estudiar en la Etapa I las siguientes:

- Rigidez del pórtico

- Tensión admisible del terreno

- Relación de forma de la zapata de medianería

\section{RIGIDEZ DEL PÓRTICO}

Esta variable pretende evaluar la oposición del propio pórtico al giro de sus zapatas de cimentación. Se consideran tres niveles de rigidez para el pórtico (Fig.22): 

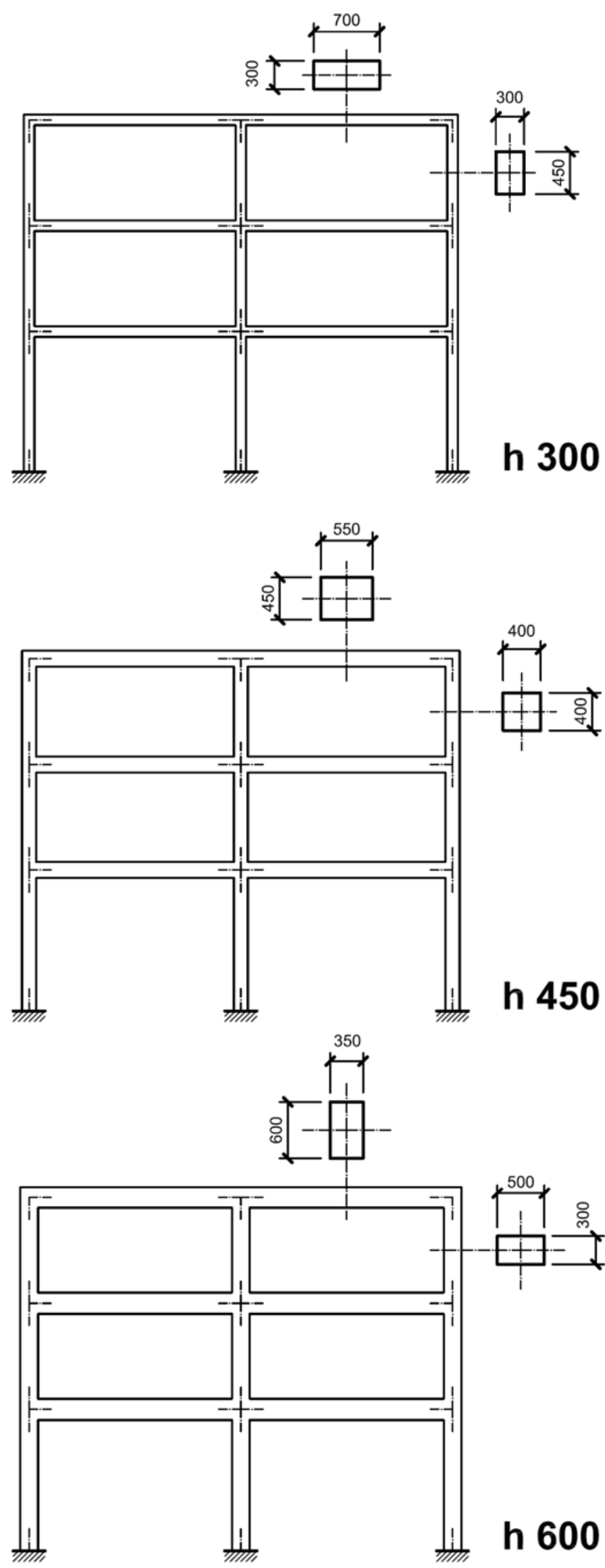

Fig.22. Pórtico tipo y niveles de rigidez planteados en la Etapa I 
- El primer nivel de rigidez, identificado como $\mathbf{h} 300$, corresponde a un pórtico flexible, con pilares y vigas planos, cuya sección es de 700 × 300 (mm) para las vigas y $450 \times 300(\mathrm{~mm})$ para los pilares.

- El segundo nivel de rigidez, identificado como $h \mathbf{4 5 0}$, corresponde a un pórtico intermedio, con pilares y vigas prácticamente cuadrados, de 550 × $450(\mathrm{~mm})$ de sección para las vigas y 400 x $400(\mathrm{~mm})$ para los pilares.

- El tercer nivel de rigidez, identificado como h 600 , corresponde a un pórtico rígido, con pilares y vigas de canto, cuya sección es de 350 x $600(\mathrm{~mm})$ para las vigas y $300 \times 500(\mathrm{~mm})$ para los pilares.

Dentro de la idea general de plantear pórticos con secciones de barras planas, cuadradas o de canto, las dimensiones de las secciones no se han elegido de forma arbitraria. Al contrario, se ha procedido al cálculo y dimensionamiento del pórtico en cada una de las tres versiones, con el fin de trabajar con secciones reales que permitan alojar los correspondientes armados que sean constructivamente correctos y que verifiquen los diferentes Estados Límites Últimos y de Servicio a cumplir.

\section{TENSIÓN ADMISIBLE DEL TERRENO}

Una reducción en la tensión admisible del terreno supone un incremento del tamaño de la zapata de medianería y, por tanto, de su excentricidad, con la consiguiente influencia sobre la flexión de la viga centradora y el posible giro de la cimentación. Para valorar el grado de incidencia de este parámetro sobre el giro de la cimentación se proponen tres niveles de tensión admisible del terreno, que son:

- $\sigma_{\mathrm{adm}}=100 \mathrm{kN} / \mathrm{m}^{2}$

- $\sigma_{\text {adm }}=200 \mathrm{kN} / \mathrm{m}^{2}$

- $\sigma_{\mathrm{adm}}=300 \mathrm{kN} / \mathrm{m}^{2}$

\section{RELACIÓN DE FORMA DE LA ZAPATA DE MEDIANERÍA}

La relación de forma de la zapata de medianería, entendida como proporción que guardan las dos dimensiones en planta de la misma, tiene una evidente influencia sobre la excentricidad de la zapata, de tal modo que cuanto más cuadrada sea dicha zapata mayor será su excentricidad. Cierto es que, a la vista de los propios modelos convencionales, resulta siempre recomendable disponer las zapatas con su menor dimensión en planta paralela al 
plano del pórtico, pero cabe preguntarse cómo valorar la influencia de la relación de forma sobre la flexión de la viga centradora y el intuido giro de la zapata y, si dicha influencia es siempre constante o no. Por ello, se van a estudiar tres relaciones de forma diferentes (Fig.23) 2:1, 1,5:1 y $1: 1$ :
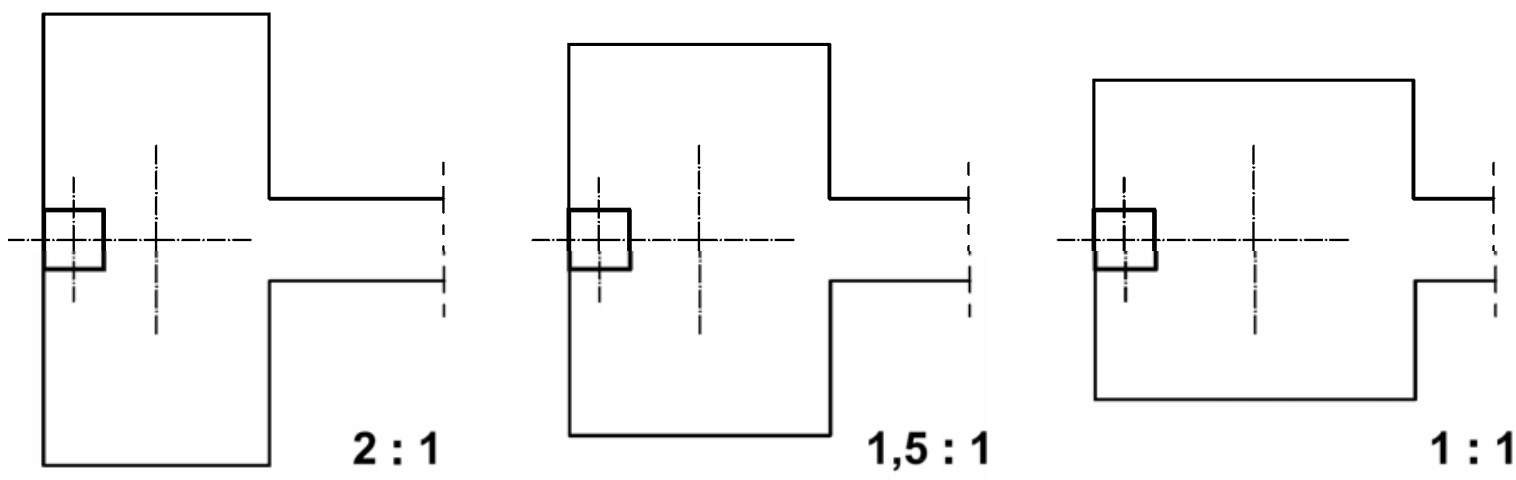

Fig.23. Relaciones de forma consideradas en la zapata de medianería

\section{ETAPA I. CASOS PLANTEADOS}

Se muestra en la Tabla 1 el abanico de variables planteadas en la Etapa I. Se proponen tres variables distintas con tres valores diferentes para cada una de ellas. La combinación de todas las variables planteadas conduce, por tanto, a un total de 27 CASOS.

\begin{tabular}{|c|c|c|}
\hline $\begin{array}{l}\text { RIGIDEZ } \\
\text { PÓRTICO }\end{array}$ & $\begin{array}{l}\text { TENSIÓN ADMISIBLE } \\
\left(\mathbf{k N} / \mathrm{m}^{2}\right)\end{array}$ & $\begin{array}{l}\text { RELACIÓN } \\
\text { FORMA }\end{array}$ \\
\hline h 300 & 100 & $2: 1$ \\
\hline h 450 & 200 & $1,5: 1$ \\
\hline h 600 & 300 & $1: 1$ \\
\hline
\end{tabular}

Tabla 1. Variables planteadas en la Etapa I

Definidos los 27 casos que se obtienen de las posibles permutaciones con las variables de la Tabla 1, se procede al cálculo de cada uno de ellos, tanto con los modelos convencionales como con el correspondiente modelo de elementos finitos, con el fin de poder contrastar los resultados obtenidos con los diferentes métodos.

Para que los resultados puedan ser comparables, el tamaño de la cimentación considerado en el modelo de elementos finitos ha de ser el mismo que el considerado en el respectivo 
modelo convencional. Por ello, se calculará en primer lugar el caso en cuestión con los modelos convencionales (siendo el modelo de viga centradora el que suele condicionar el dimensionamiento) y, una vez conocidas las dimensiones de las zapatas, se le impondrán como dato al modelo de elementos finitos, ya que el contraste de resultados entre los distintos modelos ha de realizarse en igualdad de condiciones y, por ello, el punto de partida ha de ser el mismo para todos.

Asimismo, hay que indicar que, tal y como se expone más ampliamente en el apartado 3.3.1, los modelos de elementos finitos de la Etapa I se calculan bajo la hipótesis de comportamiento elástico lineal de todos los materiales implicados (hormigón y suelo).

\subsubsection{ETAPA II}

Los resultados de la fase experimental de la Etapa I (apartado 4.1), ponen de manifiesto la clara influencia, tanto de la tensión admisible del terreno como de la relación de forma de la zapata de medianería, sobre los giros de la cimentación (apartado 5.1). Por el contrario, la rigidez del pórtico resulta tener prácticamente nula incidencia sobre dichos giros.

La primera parte del análisis de los resultados de la Etapa I (apartado 5.1) resulta lógica y esperable. Tensiones admisibles del terreno bajas, ciertamente conducen a zapatas de mayor tamaño, más excéntricas y, por tanto, con resultantes de reacción más hacia el centro de la viga centradora, incrementando así la flexión de ésta y el correspondiente giro de las zapatas. Por su parte, la relación de forma incide de forma similar. Cuanto más cuadrada sea la zapata de medianería más excéntrica resulta, generando la misma secuencia de incremento de la flexión de la viga centradora y del correspondiente giro de las zapatas.

En cambio, la prácticamente nula influencia de la variable rigidez (apartado 5.1), en un estudio relacionado con una cuestión de giros, resulta sorprendente $\mathrm{y}$, hasta cierto punto, desconcertante, pues es sobradamente conocida la relación entre ambos parámetros.

La reflexión sobre este asunto conduce a dos posibles vías de actuación. La primera sería continuar insistiendo en la rigidez del pórtico. Ciertamente, en la Etapa I, se ha jugado con diferentes anchos y cantos de sección, tanto en pilares como en vigas, pero todos ellos de un rango similar. Probablemente, para observar una clara coacción del giro de la cimentación por parte del pórtico, sería necesario poner en escena pilares mucho más apantallados, que 
generasen un salto cualitativo en la rigidez del pórtico, convirtiéndolo en un elemento autoportante que impidiese los giros de las zapatas.

La segunda vía conduce a estudiar la rigidez de la propia viga centradora, es decir, el elemento directamente implicado en el proceso, cuya flexión condiciona, en primera instancia, el giro de las zapatas que de ella dependen. Dado el papel protagonista de la viga centradora en el problema objeto de estudio, se opta por seguir este segundo camino.

Entendida la rigidez a flexión de un elemento estructural como la oposición que ejerce el mismo a ser curvado ante la aplicación de cargas exteriores, son dos los parámetros fundamentales que definen dicha rigidez: la longitud del elemento en cuestión y la inercia del mismo, que depende especialmente del canto de la sección transversal. La forma más sencilla de contemplar ambos parámetros (luz y canto) es jugar con la geometría del pórtico, estudiando luces variables para los vanos del mismo, a diferencia de la Etapa I en la que los vanos eran de luz constante de $6 \mathrm{~m}$. Luces variables de vano, automáticamente generan luces variables de viga centradora, no siendo necesario introducir la variable canto de forma explícita ya que el propio dimensionamiento del pórtico y su cimentación, en función de la geometría y las cargas de cada caso, conduce a un abanico variado de cantos.

Por otra parte, una vez abierta la vía geométrica de la variación de las luces del pórtico, parece indicado también plantear casos con número de plantas variable. Tal y como se ha comentado, las variables con influencia confirmada sobre el problema (tensión admisible del terreno y relación de forma) tienen dicha influencia no por sí mismas sino por los tamaños de cimentación y excentricidades a que dan lugar. Por ello, la consideración de un número variable de plantas enriquece el abanico de resultados, ya que al aumentar el número de plantas se incrementan las cargas transmitidas a la cimentación y, por ello, el tamaño de las zapatas obtenidas, que es uno de los factores clave.

Estas son las dos nuevas variables introducidas, en sustitución de la rigidez del pórtico, junto con las dos variables que se confirman, tensión admisible del terreno y relación de forma de la zapata de medianería. Por todo ello, la relación de variables a estudiar en la Etapa II es la siguiente:

- Luz de vano

- Número de plantas

- Tensión admisible del terreno

- Relación de forma de la zapata de medianería 


\section{LUZ DE VANO}

Se consideran tres luces para los vanos del pórtico tipo (Fig. 24), $\mathrm{L}=3 \mathrm{~m}, \mathrm{~L}=5 \mathrm{~m}$ y $\mathrm{L}=7 \mathrm{~m}$.
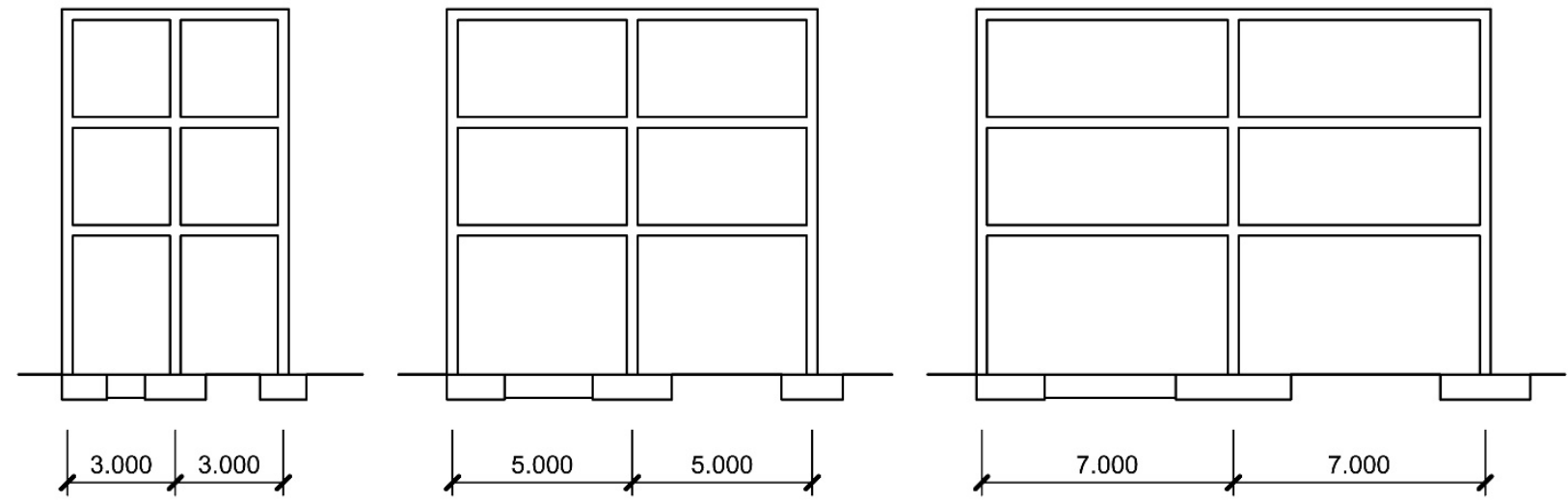

Fig.24. Luces de vano consideradas en el pórtico tipo

\section{NÚMERO DE PLANTAS}

Se consideran cuatro valores distintos para el número de plantas del pórtico tipo (Fig. 25), desde Baja +1 hasta Baja +4 .

$\mathrm{B}+1$

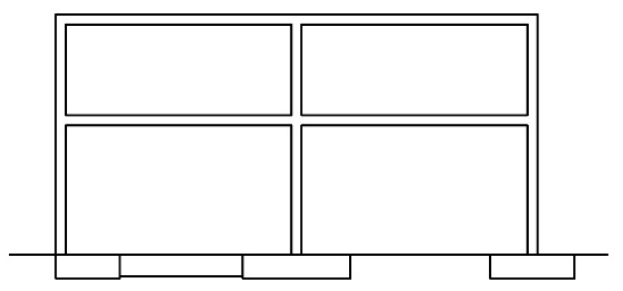

$\mathrm{B}+3$

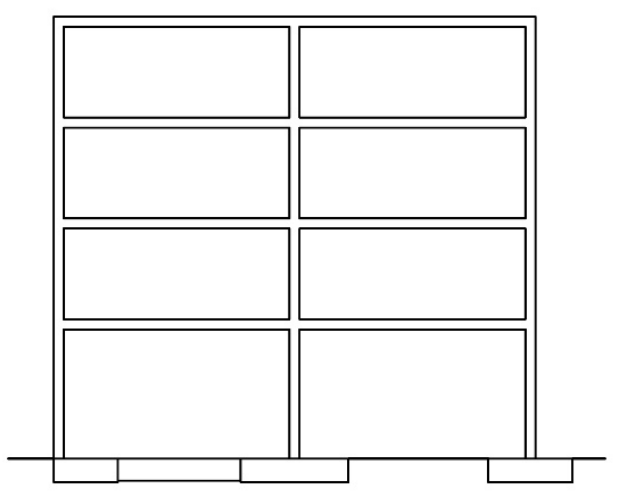

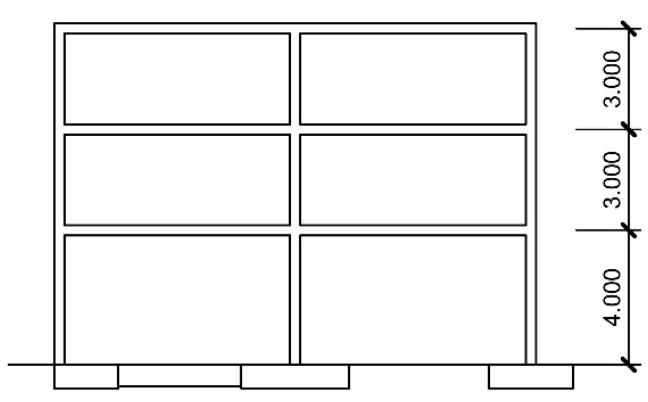

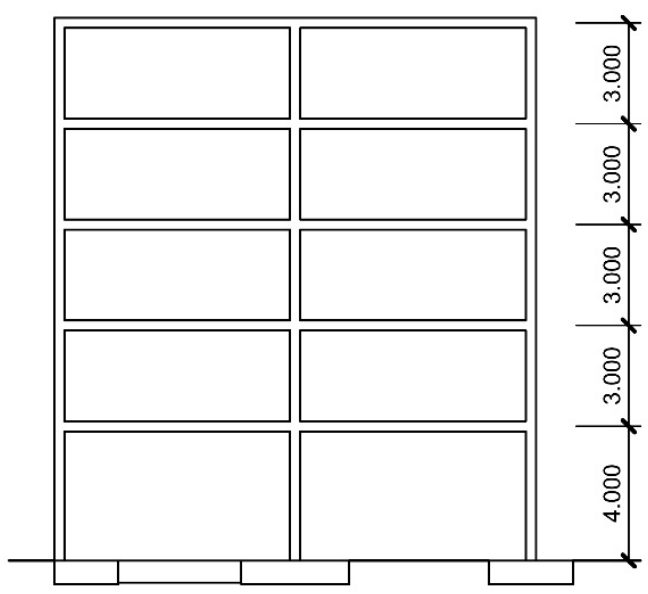

Fig.25. Número de plantas consideradas en el pórtico tipo 


\section{TENSIÓN ADMISIBLE DEL TERRENO}

Se mantienen en la Etapa II los mismos tres niveles de tensión admisible del terreno planteados en la Etapa I, es decir:

- $\sigma_{\text {adm }}=100 \mathrm{kN} / \mathrm{m}^{2}$

- $\sigma_{\text {adm }}=200 \mathrm{kN} / \mathrm{m}^{2}$

- $\sigma_{\text {adm }}=300 \mathrm{kN} / \mathrm{m}^{2}$

\section{RELACIÓN DE FORMA DE LA ZAPATA DE MEDIANERÍA}

Se mantiene la relación de forma de la zapata de medianería como variable de estudio, si bien se reduce el número de casos respecto de la Etapa I, eliminando la zapata de medianería cuadrada (evidentemente desfavorable y nada recomendable) y manteniendo las relaciones de forma $2: 1$ y $1,5: 1$ (Fig.26)

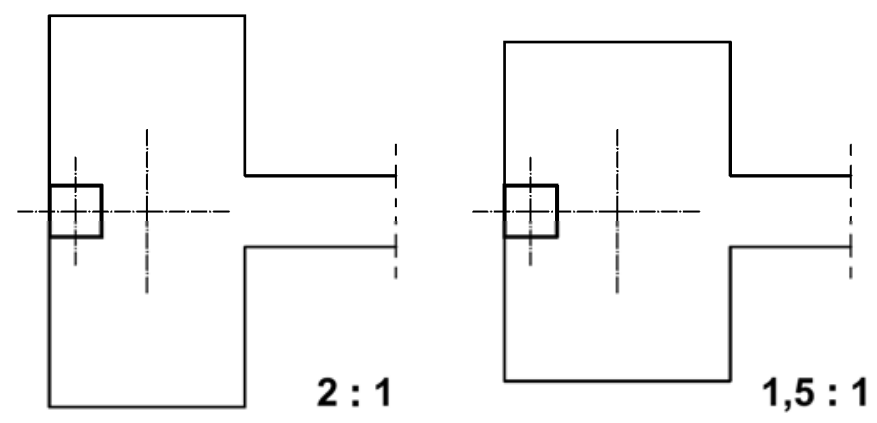

Fig.26. Relaciones de forma consideradas en la Etapa II

\section{ETAPA II. CASOS PLANTEADOS}

Se muestra en la Tabla 2 el abanico de variables planteadas en la Etapa II. Se proponen cuatro variables con cuatro valores diferentes para la primera, tres para la segunda y la tercera y dos para la cuarta.

\begin{tabular}{|c|c|c|c|}
\hline $\begin{array}{c}\text { NÚMERO } \\
\text { PLANTAS }\end{array}$ & $\begin{array}{c}\text { LUZ VANO } \\
\mathbf{( m )}\end{array}$ & $\begin{array}{c}\text { TENSIÓN ADM. } \\
\left(\mathbf{k N} / \mathbf{~ m}^{\mathbf{2}}\right)\end{array}$ & $\begin{array}{c}\text { RELACIÓN } \\
\text { FORMA }\end{array}$ \\
\hline Baja +1 & 3 & 100 & $2: 1$ \\
\hline Baja +2 & 5 & 200 & $1,5: 1$ \\
\hline Baja +3 & 7 & 300 & \\
\hline Baja +4 & & \\
\hline
\end{tabular}

Tabla 2. Variables planteadas en la Etapa II 
La combinación de las variables indicadas con sus correspondientes valores conduce en algunas ocasiones a casos, o bien imposibles, o bien dudosos. Se trata, en general de casos de poca luz, reducida tensión admisible en el terreno y elevado número de plantas, que generan zapatas de gran tamaño que, o bien se solapan físicamente, o bien quedan tan próximas que seguramente produzcan efectos adicionales por solape de bulbos de tensiones.

Teniendo en cuenta este hecho, descontando del conjunto de permutaciones de variables y valores los casos imposibles o dudosos, se obtienen para la Etapa II un total de 65 CASOS.

Al igual que en la Etapa I, una vez definidos los 65 casos a estudiar, se procede al cálculo de cada uno de ellos, tanto con los modelos convencionales como con el correspondiente modelo de elementos finitos, imponiéndole a los modelos de elementos finitos los dimensionamientos obtenidos con métodos convencionales, con el fin de poder contrastar los resultados obtenidos por los diferentes métodos en igualdad de condiciones.

Se utilizan para los pórticos pilares cuadrados, con escuadrías que oscilan según los casos entre $300 \times 300(\mathrm{~mm} \times \mathrm{mm})$ y $400 \times 400(\mathrm{~mm} \times \mathrm{mm})$. Para las vigas se emplean secciones tipo plano (mayor ancho que canto) con suficiente canto para cumplir las distintas comprobaciones establecidas por la normativa vigente. La escuadría de dichas vigas varía, según los casos, desde 450 × $300(\mathrm{~mm} \times \mathrm{mm})$ hasta 650 × $400(\mathrm{~mm} \times \mathrm{mm})$.

Por su parte, para las cimentaciones se proponen zapatas con el mínimo canto compatible con la condición de anclaje de las armaduras de los pilares que de ellas arrancas, oscilando dicho canto desde $\mathrm{h}=500 \mathrm{~mm}$ hasta $\mathrm{h}=700 \mathrm{~mm}$. Las vigas centradoras aprovechan al máximo el canto de la cimentación presentando ancho variable con valores comprendidos entre $b=450 \mathrm{~mm}$ y $b=800 \mathrm{~mm}$.

No obstante, es preciso señalar que, por encima de los cambios introducidos en las variables a estudiar y en las dimensiones de los pórticos, la diferencia fundamental entre la Etapa I y la Etapa II radica en la manera de abordar las propiedades de los materiales en los modelos de elementos finitos. En la Etapa I se realiza un cálculo con comportamiento elástico lineal por parte de todos los materiales. En el caso concreto del hormigón armado, dicha consideración queda muy alejada de la realidad. El hormigón no tiene comportamiento elástico (salvo en situaciones iniciales de aplicación de carga con pequeñas solicitaciones), su diagrama tensión - deformación no responde a un diagrama rectilíneo lineal (al contrario, es parabólico rectangular) y, además, es un material anisótropo con distinto comportamiento a tracción y a compresión, que fisura cuando se encuentra solicitado a tracción, siendo esa fisuración 
variable en función de la cuantía de armado del elemento. En la Etapa II se realiza, en los modelos de elementos finitos, un cálculo plástico con fisuración a tracción en los elementos de hormigón armado. Ello requiere, para cada pórtico, no solo el dimensionamiento de las escuadrías de pilares, vigas y zapatas, sino también la detallada definición de los armados de cada elemento, con el fin de introducir dichos armados en los correspondientes modelos de elementos finitos, para poder considerar correctamente la fisuración del hormigón y su influencia sobre la distribución de esfuerzos.

En el apartado 3.3.2. se describe detalladamente el proceso de configuración de los modelos de elementos finitos para contemplar un comportamiento del hormigón más ajustado a la realidad. Por su parte, en el Capítulo 4, se exponen los resultados del dimensionamiento previo de cada uno de los pórticos obtenido por métodos convencionales mostrando, para cada caso, las escuadrías resultantes para pilares, vigas y zapatas, así como la definición detallada de los armados necesarios en cada elemento.

\subsubsection{ETAPA III}

El análisis de los resultados de la Etapa I (apartados 4.3 y 5.3) confirma el giro de las zapatas de cimentación, que conduce a un desplazamiento de la resultante de las tensiones de contacto de la zapata de medianería hacia la medianera, alejando dicha resultante del centro de la viga centradora. Ello conduce, por un lado, a una importante reducción en el momento flector que solicita la viga centradora y, por otro, a una distribución de tensiones de contacto bajo la zapata de medianería de tipo trapecial, con tendencia al incremento de tensiones en el borde medianero.

Ahora bien, dicho análisis de resultados de la Etapa I también confirma la colaboración portante de la viga centradora, que da lugar a una descarga de la zapata de medianería, como consecuencia de la cual, no supone especial problema la distribución de tensiones de tipo trapecial que se genera bajo la zapata de medianería.

Frente al planteamiento elástico lineal de la Etapa I, en la Etapa II se desarrolla un cálculo plástico con fisuración del hormigón, fruto de la cual, se produce una pérdida rigidez de la viga centradora, al verse mermada su inercia por la fisuración de la sección (apartado 5.3). La pérdida de rigidez de la viga centradora genera un incremento en la flexión de la misma que produce un aumento en el giro de las zapatas, un mayor desplazamiento de la resultante de las tensiones de contacto de la zapata de medianería hacia el borde medianero y un aumento 
en la curvatura de la viga que reduce la colaboración portante de la misma. Ciertamente este escenario resulta muy favorable para la viga centradora, que se ve solicitada por momentos flectores todavía inferiores a los de la Etapa I pero, por el contrario, se ven incrementadas las tensiones en el borde medianero de la zapata de medianería, pasando a ser un problema el comportamiento geotécnico de la misma.

Nuevamente el análisis de los resultados conduce a dos posibles caminos, en principio contradictorios. Por un lado, la reducción en el momento flector de la viga centradora invita a disminuir el armado de la misma. Ahora bien, una reducción de armadura podría conducir a una mayor fisuración de la viga con la consecuente pérdida de rigidez y aumento en su flexión y el correspondiente incremento en el giro de las zapatas que empeoraría el problema. Surge la interesante pregunta de si la reducción de armadura a medida que la viga centradora se va viendo menos solicitada conduciría a un bucle infinito cuyo final sería la eliminación práctica de la viga centradora y ¿qué ocurriría en ese supuesto?

Por otro lado, los problemas geotécnicos surgidos en la zapata de medianería se deben a una pérdida de rigidez de la viga centradora que invita, o bien a aumentar la armadura de la viga centradora con el fin de disminuir su fisuración evitando así la perdida de rigidez de la misma, o bien a aumentar el canto de la cimentación, que es el mecanismo más eficaz para lograr vigas centradoras de gran inercia.

Por lo que respecta a la tensión admisible del terreno y a la relación de forma de la zapata de medianería, nuevamente se confirma con los resultados de la Etapa II (apartado 4.2) su influencia sobre el giro de las zapatas. Ahora bien, sigue percibiéndose que dicha influencia no es intrínseca a la propia tensión admisible del terreno o a la relación de forma, sino indirecta a través de los tamaños de cimentación a los que dan lugar. Por ello, lo realmente importante es el tamaño de las zapatas y el porcentaje de luz de vano que invaden, independientemente de la causa que dio lugar a ese tamaño. Esta reflexión, unida a la necesidad de optimizar el número de casos a estudiar, lleva a eliminar la tensión admisible del terreno y la relación de forma de la zapata de medianería como parámetros variables seleccionando para ellos los siguientes valores fijos:

- Tensión Admisible del Terreno

- Relación de Forma $\sigma_{\mathrm{adm}}=200 \mathrm{kN} / \mathrm{m}^{2}$

2:1

Por su parte, se sigue manteniendo el mismo juego de luces de vano y número de plantas de pórtico contemplado en la Etapa II 
Por todo ello, la relación de variables a estudiar en la Etapa III es la siguiente:

- Luz de vano

- Número de plantas

- Reducción de armadura

- Eliminación de la viga centradora

- Aumento de armadura

- Aumento del canto de la viga centradora

\section{LUZ DE VANO}

Se consideran tres luces para los vanos del pórtico tipo, tal y como se realizó en la Etapa II (Fig. 24), $L=3 \mathrm{~m}, \mathrm{~L}=5 \mathrm{~m}$ y $\mathrm{L}=7 \mathrm{~m}$.

\section{NÚMERO DE PLANTAS}

Se consideran los mismos cuatro valores para el número de plantas del pórtico tipo contemplados en la Etapa II (Fig. 25), Baja +1, Baja +2, Baja +3 y Baja +4.

\section{REDUCCIÓN DE ARMADURA}

Además del armado de referencia de la viga centradora obtenido al dimensionar la armadura con los esfuerzos (momentos flectores) resultantes de los modelos convencionales, se realiza un juego de casos con la armadura necesaria para los esfuerzos (momentos flectores) obtenidos de los modelos de elementos finitos de la Etapa II, considerablemente inferiores a los convencionales. En el apartado 4.3 se ofrece una relación con la definición detallada del armado de la viga centradora para los diferentes casos a estudiar.

\section{ELIMINACIÓN DE LA VIGA CENTRADORA}
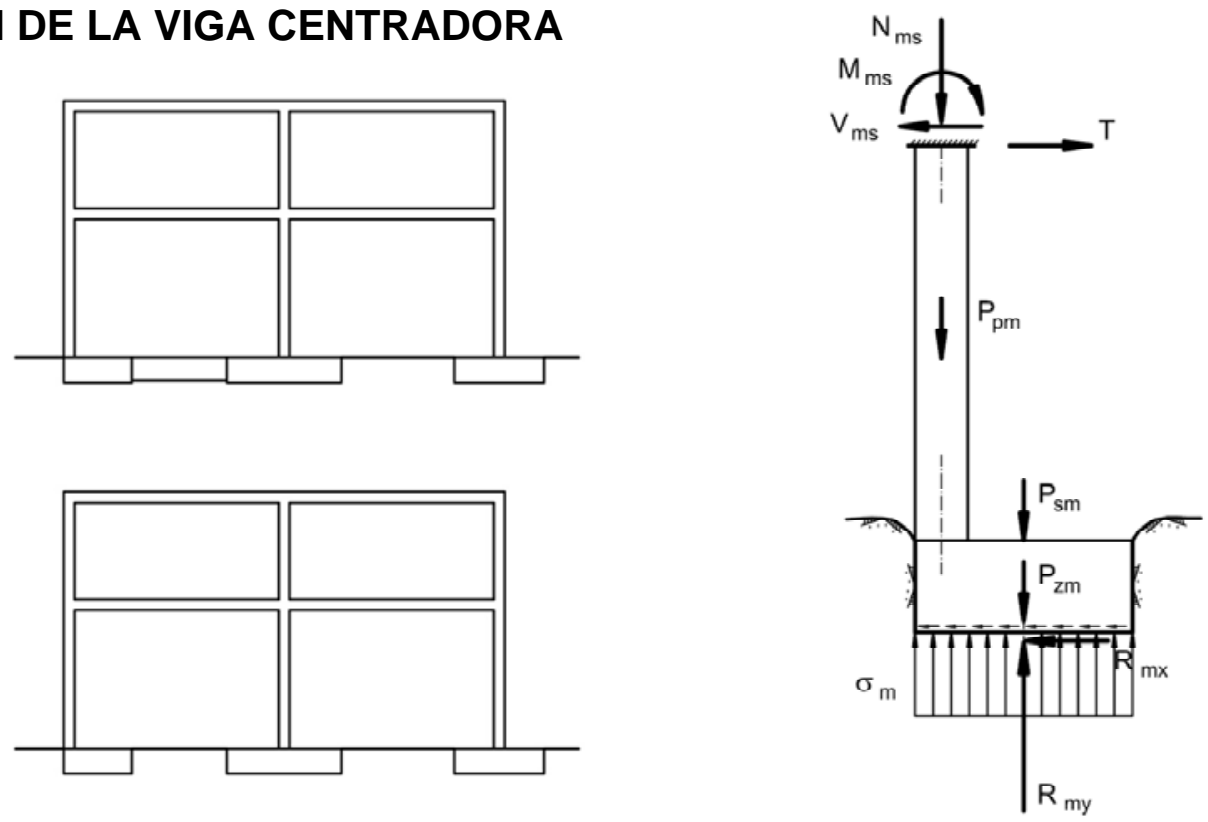

Fig.27. Eliminación de la viga centradora 
Se realiza un juego de casos en el que se elimina la viga centradora (Fig.27). Ello permite valorar la verdadera eficacia de la viga centradora y contrastar el modelo convencional de zapata de medianería con colaboración de viga superior sin viga centradora.

\section{AUMENTO DE ARMADURA}

Los problemas detectados en la Etapa II tienen su origen en la pérdida de rigidez debida a la fisuración de la viga centradora siendo, por ello, una primera vía de actuación el aumento de armadura para intentar controlar la fisuración de la viga. Resulta ilustrativa en este sentido la fórmula (Branson, D.E., 1977) (ec.47), habitualmente empleada para determinar la inercia equivalente en el cálculo de deformaciones en elementos flectados de hormigón armado.

$$
I_{e}=\left(\frac{M_{f}}{M_{a}}\right)^{3} \cdot I_{b}+\left[1-\left(\frac{M_{f}}{M_{a}}\right)^{3}\right] \cdot I_{f}
$$

siendo:

- $\mathrm{I}_{\mathrm{e}}$ : Inercia equivalente

- $\mathrm{I}_{\mathrm{b}}$ : Inercia bruta

- If : Inercia fisurada

- $\mathrm{M}_{\mathrm{a}}$ : Momento aplicado

- $\mathrm{M}_{\mathrm{f}}$ : Momento de fisuración

La inercia eficaz realmente disponible por parte de una sección, o inercia equivalente, depende de la magnitud de los elementos no fisurados de una sección de hormigón armado. El hormigón de la zona traccionada y fisurada de la sección (Fig.28) es incapaz de aportar inercia y, por tanto, rigidez a la viga. Si la armadura de la sección es reducida, la profundidad de la fibra neutra será pequeña, la magnitud de la zona traccionada y fisurada muy grande y, como consecuencia de ello, la inercia fisurada $\left(\mathrm{I}_{\mathrm{f}}\right)$ y el momento de fisuración $\left(\mathrm{M}_{\mathrm{f}}\right)$ muy pequeños, obteniéndose una inercia equivalente limitada, con la correspondiente pérdida de rigidez.
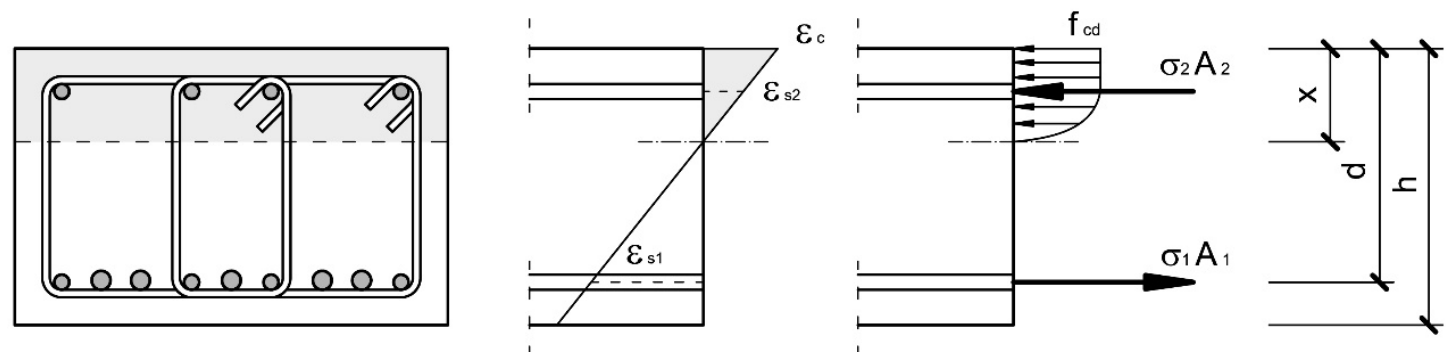

Fig.28. Sección fisurada de hormigón armado 
La primera respuesta inmediata ante la pérdida de rigidez debida a la fisuración de la sección parece evidente, auméntese la armadura en la cuantía necesaria para incrementar la profundidad de la fibra neutra, reduciendo así la zona fisurada y obtener, de este modo, mayores inercias equivalentes en la sección. La cuestión es si sería razonable aumentar indiscriminadamente la cuantía del armado.

La respuesta es no. Si se produce un aumento excesivo de la cuantía de la armadura de tracción, la fibra neutra bajaría mucho y la sección llegaría un momento en que entraría en dominio 4 (Fig.29), con una enorme cantidad de acero desperdiciado por estar trabajando a una tensión muy reducida.

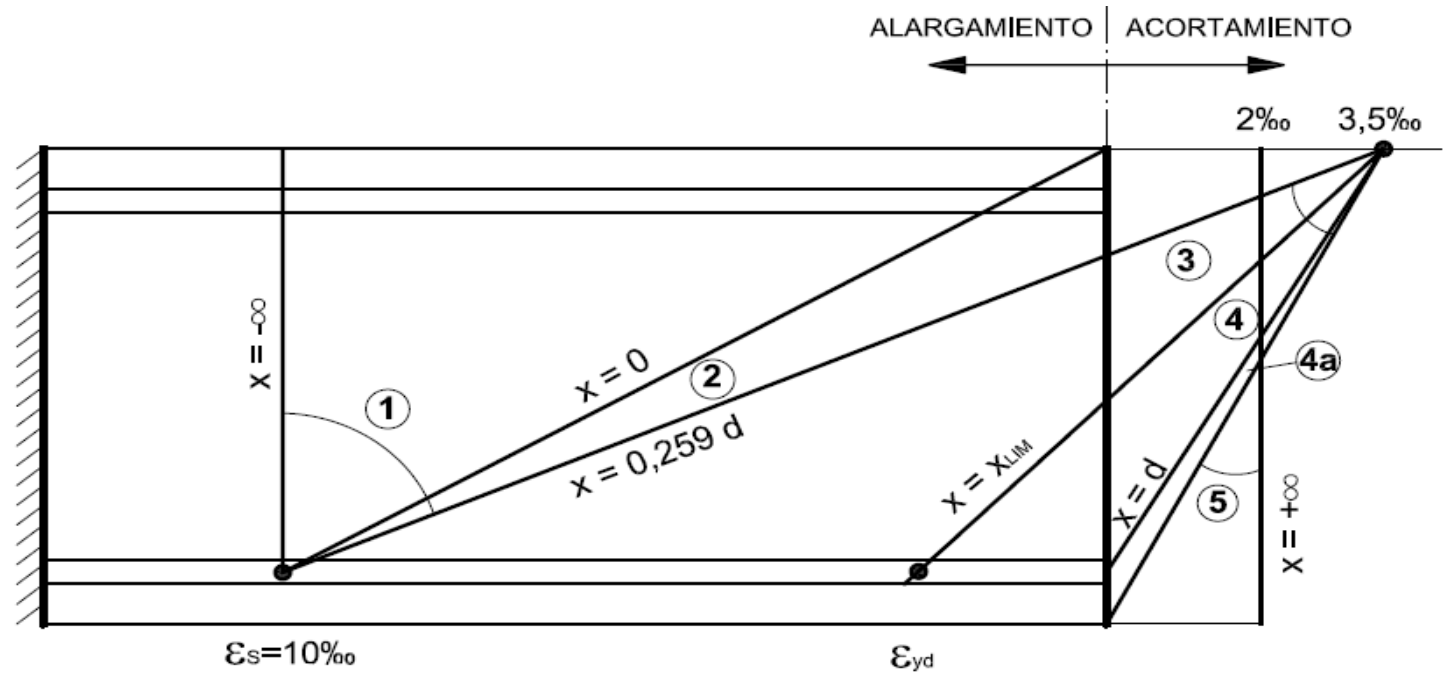

Fig.29. Dominios de deformación

Por tanto, es preciso fijar un tope al incremento de armadura, asociado a la profundidad de la fibra neutra en relación con el canto útil de la sección. Una primera posibilidad es utilizar como referencia la profundidad límite $\left(\mathrm{x}_{\mathrm{lim}}\right)$, frontera entre los dominios 3 y 4 , cuyo valor para acero B 500 es:

$$
x_{\lim } \approx 0,60 \cdot d
$$

Otras recomendaciones relativas a requisitos mínimos de ductilidad en elementos estructurales (CEB Task Group 2.2 (1998)) establecen, en función del tipo de acero, los siguientes límites:

$$
\begin{array}{ll}
\text { Acero B } 500 S & x \leq 0,30 \cdot d \\
\text { Acero B 500 SD } & x \leq 0,50 \cdot d
\end{array}
$$

Por su parte, la antigua instrucción EHE, independientemente del tipo de acero, fijaba como condición en este sentido, la siguiente:

$$
x \leq 0,45 \cdot d
$$


Esta última limitación se encuentra en la posición central dentro del rango de limitaciones planteadas y es la que se adopta como referencia. Por ello, además del armado de referencia de la viga centradora obtenido al dimensionar la armadura con los esfuerzos (momentos flectores) resultantes de los modelos convencionales, se realiza un juego de casos incrementando la armadura hasta un punto tal que se alcance una profundidad de fibra neutra próxima a:

$$
x=0,45 \cdot d
$$

Ello supone incrementos de armadura considerables, superiores al doble de la armadura obtenida por métodos convencionales. En el apartado 4.3 se ofrece una relación con la definición detallada del armado de la viga centradora para los diferentes casos a estudiar al aplicar este criterio.

\section{AUMENTO DEL CANTO DE LA VIGA CENTRADORA}

La segunda vía para aumentar la rigidez de la viga centradora consiste en el aumento del canto de la viga centradora, optándose por incrementar en la misma medida el canto del conjunto de la cimentación con el fin de tener modelos homogéneos.

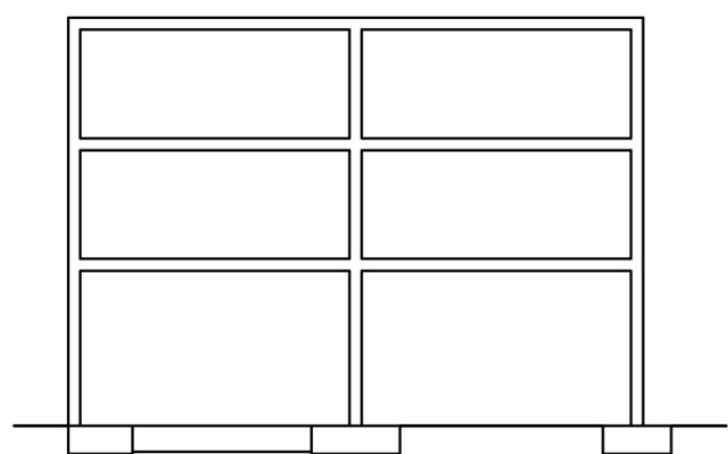

$\mathrm{H}_{\Perp}$

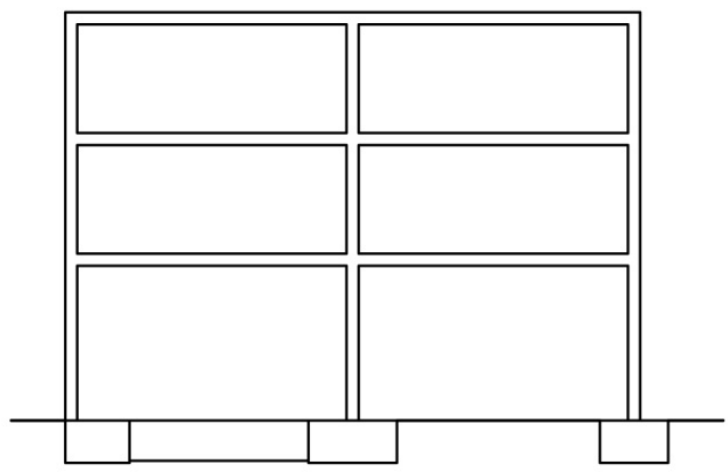

$1,50 \cdot \mathrm{H}_{\|}$

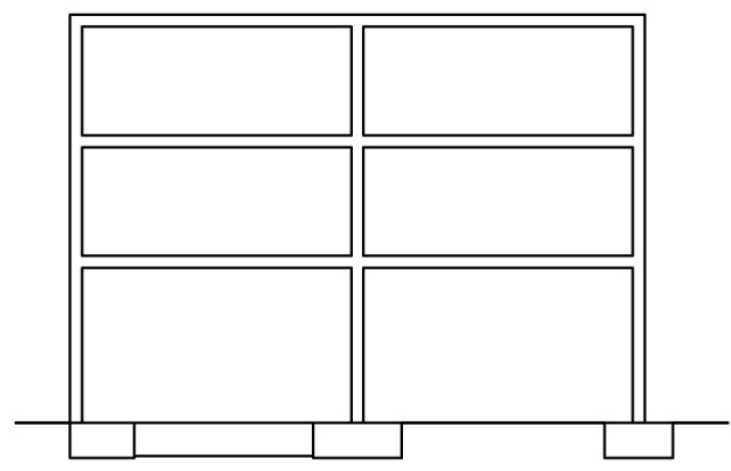

$1,25 \cdot \mathrm{H}_{\Perp}$

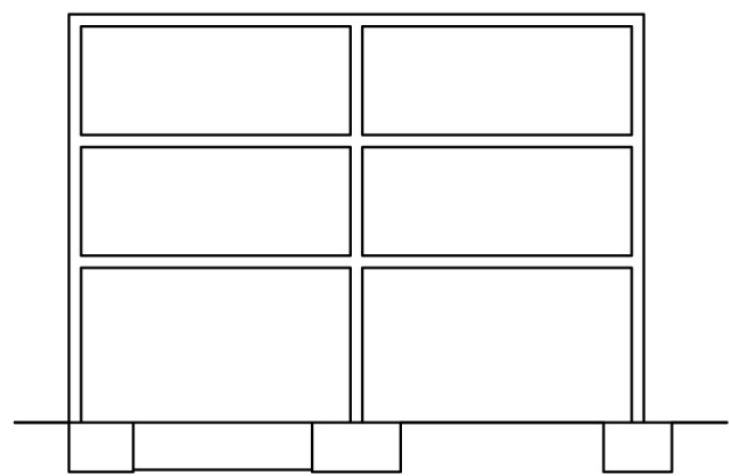

$1,75 \cdot \mathrm{H}_{\|}$

Fig.30. Incremento del canto de la cimentación 
Tanto en la Etapa I como en la Etapa II se plantean cimentaciones con el mínimo canto compatible con el anclaje de las armaduras de los correspondientes pilares obteniéndose, en general, zapatas flexibles.

Se plantean en la Etapa III tres niveles de canto adicionales al contemplado en la Etapa II, que se obtienen al incrementar los cantos de referencia planteados en la Etapa II en un 25\%, $50 \%$ y $75 \%$ respectivamente (Fig. 30 ):

\section{ETAPA III. CASOS PLANTEADOS}

Se muestra en la Tabla 3 el abanico de variables planteadas en la Etapa III.

\begin{tabular}{|c|c|c|c|c|c||}
\hline $\begin{array}{c}\text { NÚMERO } \\
\text { PLANTAS }\end{array}$ & $\begin{array}{c}\text { LUZ VANO } \\
\mathbf{( m )}\end{array}$ & $\begin{array}{c}\text { REDUCCIÓN } \\
\text { ARMADURA }\end{array}$ & $\begin{array}{c}\text { ELIMINACIÓN } \\
\text { VIGA CENT. }\end{array}$ & $\begin{array}{c}\text { AUMENTO } \\
\text { ARMADURA }\end{array}$ & $\begin{array}{c}\text { AUMENTO } \\
\text { CANTO }\end{array}$ \\
\hline Baja +1 & 3 & $M_{E t \|}$ & Sin V. Cent. & $x \leq 0,45 \cdot \mathrm{d}$ & $1,25 \cdot \mathrm{H}_{\|}$ \\
\hline Baja +2 & 5 & & & & $1,50 \cdot \mathrm{H}_{\|}$ \\
\hline Baja +3 & 7 & & & & $1,75 \cdot \mathrm{H}_{\|}$ \\
\hline Baja +4 & & & & \\
\hline
\end{tabular}

Tabla 3. Variables planteadas en la Etapa III

Teniendo en cuenta las variables planteadas y descontando del conjunto de permutaciones de variables los casos de $3 \mathrm{~m}$ de luz y baja +4 plantas, por solapamiento de zapatas y bulbos de tensiones de contacto, se obtienen para la Etapa III un total de 66 CASOS.

Al igual que en las etapas anteriores, una vez definidos los 66 casos a estudiar, se procede al cálculo de cada uno de ellos, con los correspondiente modelos de elementos finitos, imponiéndole a dichos modelos de elementos finitos las dimensiones obtenidas con métodos convencionales, con el fin de poder contrastar los resultados obtenidos por los diferentes métodos en igualdad de condiciones. Es preciso indicar que, al no contemplar los modelos convencionales al armado de los elementos de hormigón de la cimentación, los modelos convencionales de referencia para el contraste de resultados son los mismos que los de la Etapa II.

Continuando con la línea abierta en la Etapa II, los modelos de elementos finitos elaborados en la Etapa III presentan un cálculo plástico con fisuración del hormigón en tracción, ajustándose así al comportamiento real del hormigón. 


\subsubsection{ETAPA IV}

Los resultados de la tercera etapa experimental (apartado 4.4) ponen de manifiesto (apartado 5.4) la limitada influencia que sobre el giro de las zapatas tienen las variaciones en la cuantía de armado, ya sea por aumento o reducción de la misma, resultando ser el canto de la viga centradora el principal parámetro que controla el giro de la cimentación (elemento clave en el comportamiento de la misma).

El estudio realizado en las tres primeras etapas experimentales, utilizando casos de zapata de medianería, ha servido para estudiar en profundidad el problema, identificando los parámetros y variables que lo regulan. Una vez finalizado dicho proceso con la zapata de medianería, la Etapa IV constituye una aplicación de todo lo estudiado al caso de las zapatas de esquina, entendidas como un caso particular de las zapatas de medianería.

Lógicamente, el trabajo experimental de la Etapa IV se beneficia de la reflexión previa generada a partir de las tres primeras etapas, jugando por ello, solamente con las variables de influencia contrastada sobre el problema y descartando las que han demostrado tener poco o nulo efecto sobre el mismo. Al igual que en la Etapa III, para la tensión admisible del terreno se adopta el valor fijo $\sigma_{\text {adm }}=200 \mathrm{kN} / \mathrm{m}^{2}$. En cuanto a la relación de forma de las zapatas, la zapata de esquina se plantea cuadrada, mientras que las dos zapatas de medianería auxiliares que estabilizan a la zapata de esquina se proponen con relación 2:1.

Por todo ello, la relación de variables a estudiar en la Etapa IV es la siguiente:

- Luz de vano y crujía

- Número de plantas

- Canto de las vigas centradoras

\section{LUZ DE VANO Y CRUJÍA}

Se consideran tres luces para los vanos del pórtico tipo, tal y como se realizó en la Etapa II y en la Etapa III (Fig. 31) L = 3 m, L = 5 m y L = 7 m. Para la separación entre los dos pórticos contemplados en el modelo tridimensional de la zapata de esquina, se utilizan crujías iguales a las luces asignadas al vano del pórtico en el caso correspondiente.

\section{NÚMERO DE PLANTAS}

Se consideran los mismos cuatro valores para el número de plantas del pórtico tipo contemplados en las Etapa II y III (Fig. 31), Baja +1, Baja +2, Baja +3 y Baja +4. 


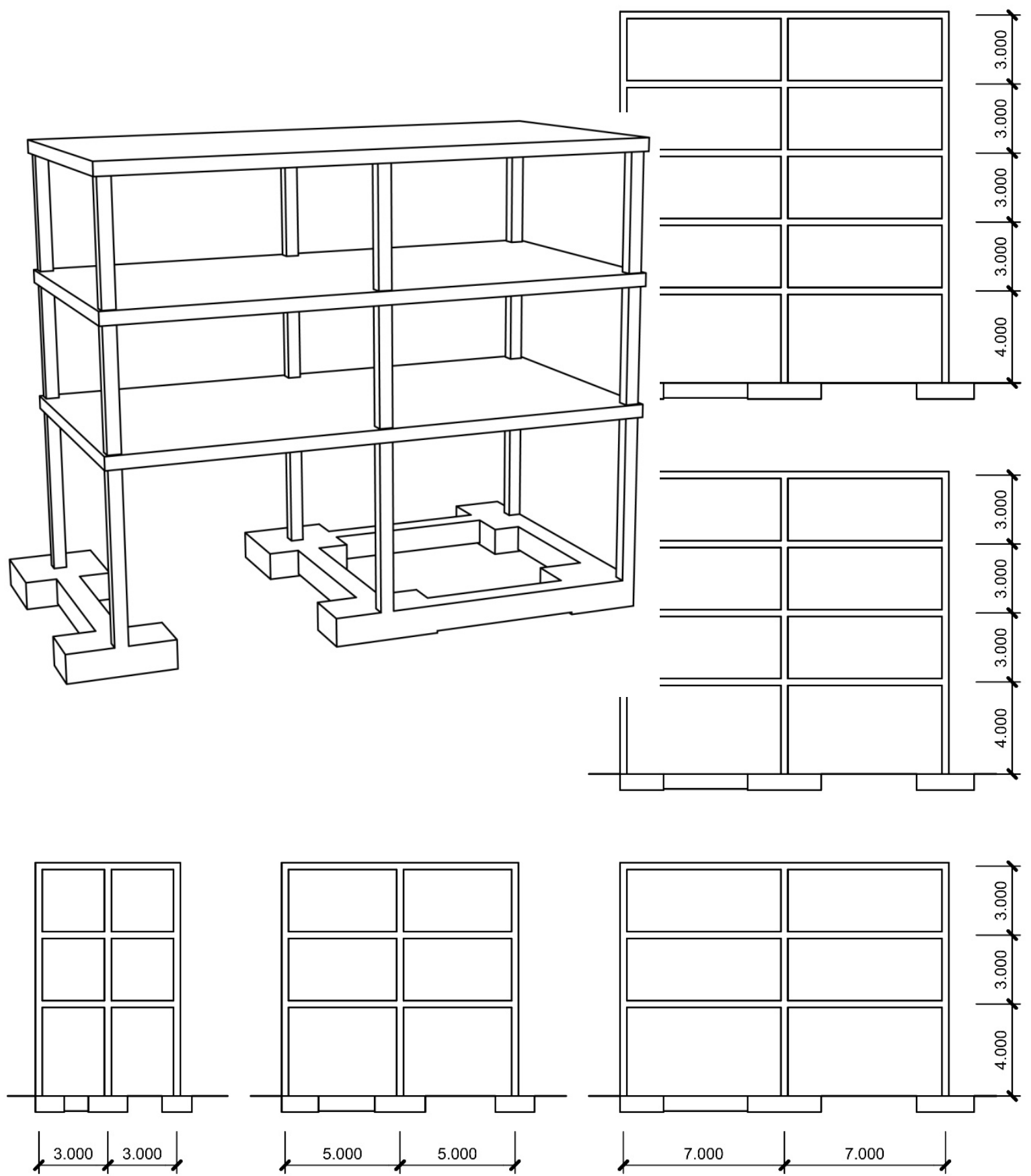

Fig.31. Luces y número de plantas consideradas en el pórtico tipo

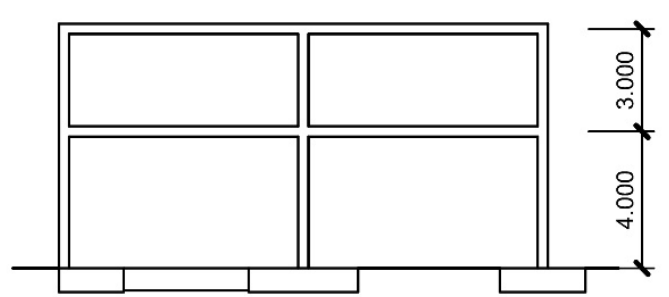

\section{CANTO DE LAS VIGAS CENTRADORAS}

Se plantean dos niveles de rigidez en las vigas centradoras en función del canto de las mismas, de forma similar a como se hizo en las Etapas II y III. El primero de ellos, identificado como $\mathrm{H}_{\text {min }}$, corresponde a vigas centradoras proyectadas, junto con la cimentación, con el 
mínimo canto compatible con la condición de anclaje de las armaduras de los pilares del pórtico. Dicho nivel de rigidez conduce, en muchos casos, a cimentaciones flexibles. Por lo que respecta al otro nivel de rigidez, se obtiene incrementando el canto mínimo antes citado en un $75 \%$, identificándolo con la notación $1,75 \cdot \mathrm{H}_{\text {min }}$.

\section{ETAPA IV. CASOS PLANTEADOS}

Se muestra en la Tabla 4 el abanico de variables planteadas en la Etapa IV.

\begin{tabular}{|c|c|c|}
\hline $\begin{array}{c}\text { NÚMERO } \\
\text { PLANTAS }\end{array}$ & $\begin{array}{c}\text { LUZ VANO - CRUJíA } \\
(\mathbf{m})\end{array}$ & $\begin{array}{c}\text { AUMENTO } \\
\text { CANTO }\end{array}$ \\
\hline Baja +1 & 3 & $\mathrm{H}_{\text {min }}$ \\
\hline Baja +2 & 5 & $1,75 \cdot \mathrm{H}_{\text {min }}$ \\
\hline Baja +3 & 7 & \\
\hline Baja +4 & & \\
\hline
\end{tabular}

Tabla 4. Variables planteadas en la Etapa IV

Teniendo en cuenta las variables planteadas y descontando del conjunto de permutaciones de variables los casos de $3 \mathrm{~m}$ de luz y baja +4 plantas, por solapamiento de zapatas y bulbos de tensiones de contacto, se obtienen para la Etapa IV un total de 22 CASOS.

Al igual que en etapas anteriores, una vez definidos los 22 casos a estudiar, se procede al cálculo de cada uno de ellos, tanto con el modelo convencional como con el correspondiente modelo de elementos finitos, imponiéndole a los modelos de elementos finitos los dimensionamientos obtenidos con métodos convencionales, con el fin de poder contrastar los resultados obtenidos por los diferentes métodos en igualdad de condiciones. 


\subsection{MODELIZACIÓN CONVENCIONAL}

\subsubsection{CÁLCULO DE ESFUERZOS EN LOS PÓRTICOS}

Los modelos convencionales incluyen, cómo sólidos objeto de estudio, solamente los de la cimentación o, como mucho, la cimentación más el pilar de la planta baja y la viga de la primera planta. Por ello se parte, como dato inicial, de los esfuerzos transmitidos a la cimentación y su entorno por los pilares del pórtico.

El cálculo de los esfuerzos en los pórticos, para cada uno de los casos definidos en el apartado 3.1.3. en las Etapas I, II y IV, se ha realizado con ayuda del programa CYPE 3D (Fig.32). Dicho programa trabaja con cálculo matricial, llevando a cabo un cálculo elástico lineal a partir de las secciones brutas de hormigón, definidas en 3.1.3. bajo la hipótesis de bases de pilares perfectamente empotradas en la cimentación y, por tanto, sin ningún tipo de giro por parte de las zapatas.

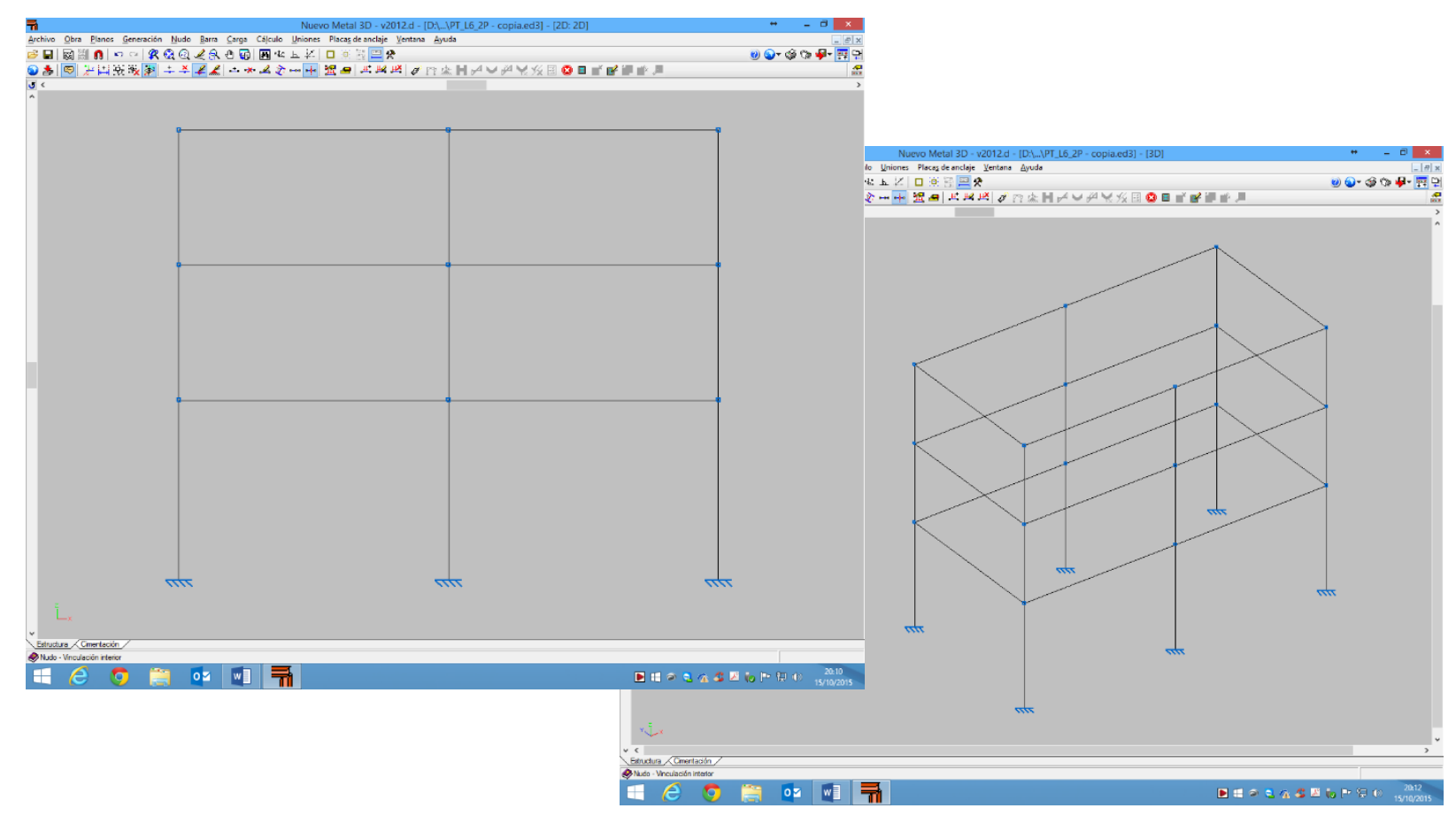

Fig.32. Programa de cálculo matricial CYPE 3D

\subsubsection{CÁLCULO DE MODELOS CONVENCIONALES}

Conocidos los esfuerzos transmitidos por los pilares a la cimentación en cada uno de los casos planteados para el pórtico, en las distintas etapas de la fase experimental, se procede al cálculo de la cimentación por métodos convencionales, de acuerdo con lo descrito en los Capítulo 2, en los apartados $2.2,2.3$ y 2.4 . 


\subsubsection{ZAPATA DE MEDIANERÍA CON VIGA CENTRADORA}

El cálculo por métodos convencionales de una zapata de medianería equilibrada mediante viga centradora se describe en el apartado 2.2. del Capítulo 2. En la Fig.33 se reproduce el esquema de cálculo de dicho modelo.

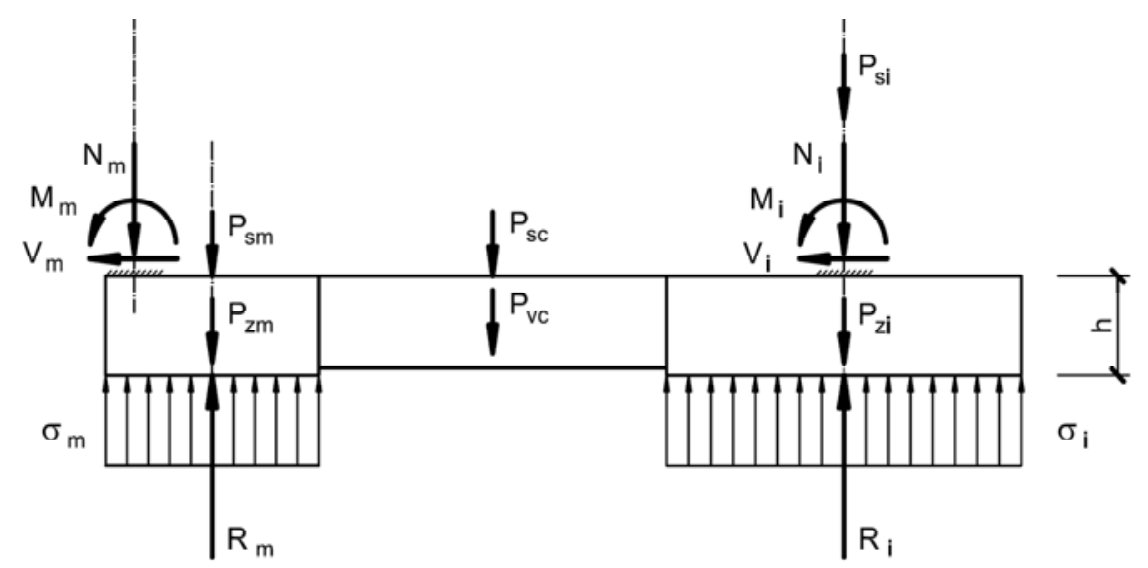

Fig.33. Esquema de cálculo de una zapata de medianería con viga centradora

Para agilizar la aplicación del proceso de cálculo del modelo convencional a los casos objeto de estudio, se han programado las ecuaciones de dicho modelo (ec. 3, 4, 5, 6 y 7) mediante una hoja de cálculo Excel que se muestra en la Tabla 5. Hay que indicar que el momento de la viga centradora que figura en dicha tabla es de servicio (sin mayorar).

\section{ZAPATA DE MEDIANERÍA CON VIGA CENTRADORA}

\begin{tabular}{|c|c|c|c|c|c|c|c|}
\hline \multicolumn{8}{|c|}{ DIMENSIONES } \\
\hline \multicolumn{3}{|c|}{ ZAPATA MEDIANERIA } & \multicolumn{3}{|c|}{ ZAPATA INTERIOR } & \multicolumn{2}{|c|}{ VIGA CENTRADORA } \\
\hline LARGO (a) & (m) & 1,350 & LARGO (a) & & 2,250 & $\mathrm{ANCHO}(\mathrm{b}) \quad(\mathrm{m})$ & 0,550 \\
\hline ANCHO (b) & $(m)$ & 2,700 & $\mathrm{ANCHO}(\mathrm{b})$ & (m) & 2,250 & \multicolumn{2}{|c|}{ ESPESOR SOLERA (m) } \\
\hline ALTO (h) & (m) & 0,700 & ALTO (h) & (m) & 0,700 & \multirow{2}{*}{\multicolumn{2}{|c|}{ 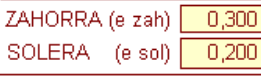 }} \\
\hline RESULTANT & ) (m) & 0,675 & RESULTANT & (m) & 1,125 & & \\
\hline \multicolumn{3}{|c|}{ PILAR MEDIANERIAA } & \multicolumn{3}{|c|}{ PILAR INTERIOR } & \multicolumn{2}{|c|}{ LUZ (m) } \\
\hline LARGO (a) & (m) & 0,300 & LARGO (a) & (m) & 0,300 & PÓRTICO & 6,000 \\
\hline $\mathrm{ANCHO}(\mathrm{b})$ & (m) & 0,450 & $\mathrm{ANCHO}(\mathrm{b})$ & (m) & 0,450 & CENTRADORA & 3,675 \\
\hline
\end{tabular}

\begin{tabular}{|c|c|c|c|c|}
\hline \multicolumn{4}{|c|}{ ESFUERZOS } & MATERIALES \\
\hline \multicolumn{2}{|c|}{ PILAR MEDIANERIAA } & \multicolumn{2}{|c|}{ PILAR INTERIOR } & TERRENO $\sigma_{\text {adm }}\left(\mathrm{kN} / \mathrm{m}^{2}\right)$ \\
\hline \multirow{3}{*}{$\begin{array}{l}N \quad(k N) \\
V \quad(k N) \\
M(k N \cdot m)\end{array}$} & 517,96 & \multirow{3}{*}{$\begin{array}{l}N(k N) \\
V(k N) \\
M(k N \cdot m)\end{array}$} & 853,87 & 200,00 \\
\hline & 13,86 & & 0,00 & ZAHORRA \\
\hline & 18,41 & & 0,00 & 18,00 \\
\hline
\end{tabular}

\begin{tabular}{|c|c|c|c|c|}
\hline \multirow{2}{*}{\multicolumn{2}{|c|}{ REACCION RESULTANTE (kN) }} & TENSIÓN UNIFORME & $\left(\mathrm{kN} / \mathrm{m}^{2}\right)$ & VIGA CENTRADORA \\
\hline & & \multirow{2}{*}{$\begin{array}{l}\text { ZAPATA MEDIANERÍA } \\
\text { ZAPATA INTERIOR }\end{array}$} & 193,41 & MOM. FLECTOR $(\mathrm{kN} \cdot \mathrm{m})$ \\
\hline ZAPATA INTERIOR & 966,19 & & 190,85 & 242,45 \\
\hline
\end{tabular}

Tabla 5. Hoja de cálculo para resolución de zapata de medianería con viga centradora 


\subsubsection{ZAPATA DE MEDIANERÍA CON COLABORACIÓN DE LA VIGA SUPERIOR}

El cálculo por métodos convencionales de una zapata de medianería equilibrada mediante la colaboración de la viga superior se describe en el apartado 2.3. del Capítulo 2. En la Fig.34 se reproduce el esquema de cálculo de dicho modelo.

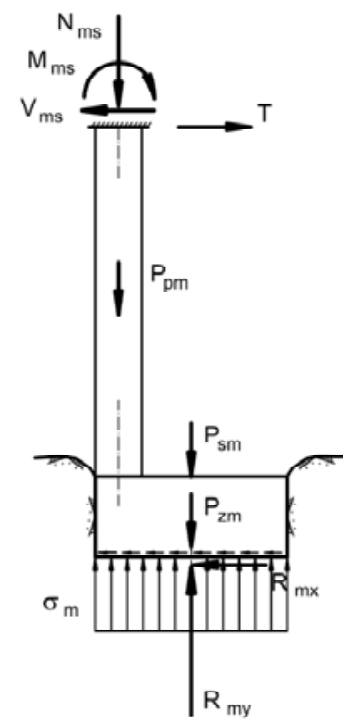

Fig.34. Esquema de cálculo de zapata de medianería con colaboración de la viga superior

Para agilizar la aplicación del proceso de cálculo del modelo convencional a los casos objeto de estudio, se han programado las ecuaciones de dicho modelo (ec. 11, 12, 14, 15, 16 y 18) mediante una hoja de cálculo Excel que se muestra en la Tabla 6. Hay que indicar que la tracción de la viga superior que figura en dicha tabla es de servicio (sin mayorar).

\section{ZAPATA DE MEDIANERÍA CON TIRANTE SUPERIOR}

\begin{tabular}{|c|c|c|c|c|c|c|}
\hline \multicolumn{7}{|l|}{ DIMENSIONES } \\
\hline \multicolumn{2}{|l|}{ ZAPATA MEDIANERIÁA } & \multicolumn{3}{|c|}{ PILAR MEDIANERÍA } & \multicolumn{2}{|c|}{\begin{tabular}{|l|l|} 
ESPESOR SOLERA & $(\mathrm{m})$ \\
\end{tabular}} \\
\hline LARGO $\left(\mathrm{a}_{\mathrm{m}}\right)$ & 1,350 & LARGO $\left(\mathrm{a}_{\mathrm{m}}^{\prime}\right)$ & (m) & 0,300 & ZAHORRA (e zah) & 0,300 \\
\hline ANCHO $\left(b_{m}\right)$ & 2,700 & ANCHO $\left(b_{m}^{\prime}\right)$ & (m) & 0,450 & SOLERA (e sol) & 0,200 \\
\hline ALTO (h) & 0,700 & ALTO $\quad(H)$ & (m) & 4,000 & & \\
\hline RESULTANTE $\left(\mathrm{d}_{\mathrm{m}}\right)(\mathrm{m})$ & 0,675 & & & & & \\
\hline
\end{tabular}

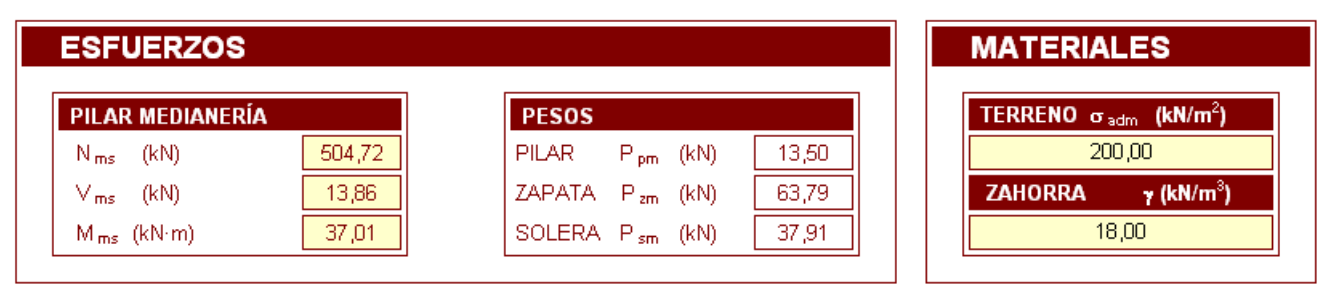

\begin{tabular}{|c|c|c|c|c|c|}
\hline \multicolumn{6}{|c|}{ RESULTADOS } \\
\hline FUERZAS & (kN) & \multicolumn{2}{|c|}{\begin{tabular}{|l|} 
HUNDIMIENTO \\
\end{tabular}} & \multicolumn{2}{|c|}{ DESLIZAMIENTO } \\
\hline $\mathrm{R}_{\mathrm{mx}} \quad(\mathrm{kN})$ & 50,01 & $\sigma\left(\mathrm{kN} / \mathrm{m}^{2}\right)$ & 170,07 & $\gamma_{\text {seg }}$ & 4,51 \\
\hline$R_{\operatorname{my}}(\mathrm{kN})$ & (619,92 & VALIDEZ & \begin{tabular}{|l|} 
CUMPLE \\
\end{tabular} & VALIDEZ & CUMPLE \\
\hline $\begin{array}{ll}\mathrm{T} & (\mathrm{kN})\end{array}$ & $\begin{array}{ll}63,87 \\
\end{array}$ & & & & \\
\hline
\end{tabular}

Tabla 6. Hoja de cálculo para resolución de zapata de medianería con colaboración de la viga superior 


\subsubsection{ZAPATA DE ESQUINA CON VIGAS CENTRADORAS}

El cálculo por métodos convencionales de una zapata de esquina equilibrada mediante dos vigas centradoras se describe en el apartado 2.4. del Capítulo 2. En la Fig.35 se reproduce el esquema de cálculo de dicho modelo.

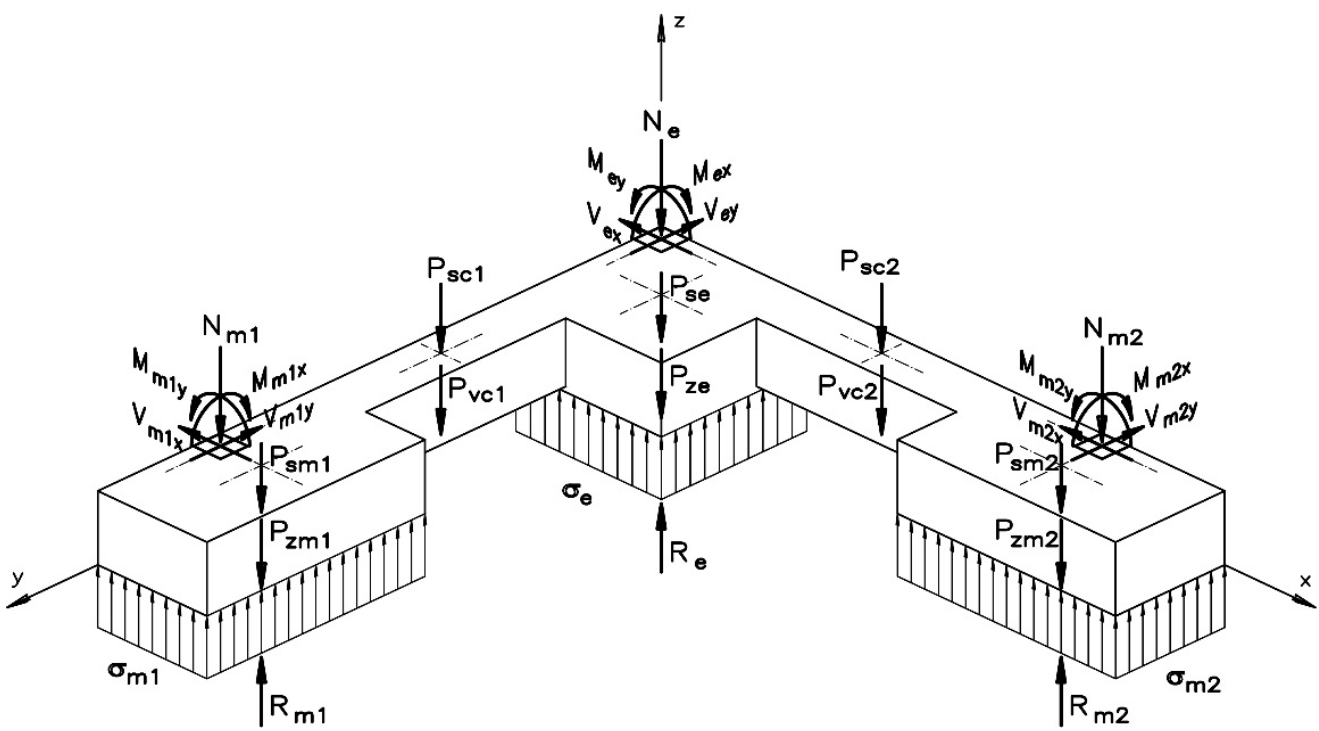

Fig.35. Esquema de cálculo de una zapata de esquina con dos vigas centradoras

Al igual que en los dos modelos anteriores, se muestra en la Tabla 7 la hoja de cálculo utilizada para agilizar el proceso de cálculo de los diferentes casos planteados.

\section{ZAPATA DE ESQUINA CON DOS VIGAS CENTRADORAS}

\begin{tabular}{|c|c|c|c|c|c|c|c|}
\hline \multicolumn{2}{|c|}{ ZAPATA ESQUINA } & \multicolumn{2}{|c|}{ ZAPATA MEDIANERÍA 1} & \multicolumn{2}{|c|}{ ZAPATA MEDIANERÍA 2} & \multicolumn{2}{|c|}{ VIGAS CENTRADORAS } \\
\hline LARGO (a) & $(\mathrm{m}) \quad 1,350$ & LARGO (a) & (m) 2,300 & LARGO (a) & (m) 1,800 & $\mathrm{ANCHO}(\mathrm{b})(\mathrm{m})$ & 0,550 \\
\hline $\mathrm{ANCHO}$ (b) & $(\mathrm{m} 2,700$ & $\mathrm{ANCHO}(\mathrm{b})$ & (m) 2,300 & $\mathrm{ANCHO}(\mathrm{b})$ & (m) 1,800 & \multicolumn{2}{|c|}{ ESPESOR SOLERA (m) } \\
\hline \multirow{2}{*}{\multicolumn{2}{|c|}{ ALTO (h) }} & ALTO (h) & (m) 0,600 & ALTO (h) & (m) 0,600 & \multirow{2}{*}{$\begin{array}{l}\text { ZAHORRA (e zah) } \\
\text { SOLERA (e sol) }\end{array}$} & 0,300 \\
\hline & & \multicolumn{2}{|l|}{ 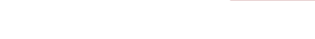 } & & & & 0,200 \\
\hline \multicolumn{2}{|c|}{ PILAR ESQUINA } & \multicolumn{2}{|c|}{ PILAR MEDIANERÍA 1} & \multicolumn{2}{|c|}{ PILAR MEDIANERÍA 2} & LUZ & (m) \\
\hline LARGO (a) & $(\mathrm{m}) \quad 0,300$ & LARGO (a) & $(\mathrm{m}) \quad 0,300$ & LARGO (a) & $(\mathrm{m}) \quad 0,300$ & PÓRT. - CRUJÍA & 6,000 \\
\hline $\mathrm{ANCHO}$ (b) & $(\mathrm{m} 0,300$ & $\mathrm{ANCHO}(\mathrm{b})$ & $(\mathrm{m} \quad 0,300$ & $\mathrm{ANCHO}(\mathrm{b})$ & $(\mathrm{m} \quad 0,300$ & CENTRADORAS & 3,650 \\
\hline
\end{tabular}

\begin{tabular}{|c|c|c|c|c|c|c|c|c|c|}
\hline \multicolumn{9}{|c|}{ ESFUERZOS } & MATERIALES \\
\hline \multicolumn{3}{|c|}{ PILAR ESQUINA (kN y kN·m) } & \multicolumn{3}{|c|}{ PILAR MEDIANER. 1 (kN y kN/m } & \multicolumn{3}{|c|}{ PILAR MEDIANER. 2 (kN y kN·m } & TERRENO $\sigma_{\text {adm }}\left(\mathrm{kN} / \mathrm{m}^{2}\right)$ \\
\hline \multicolumn{3}{|c|}{ TILAK LJQUINA (KIT Y kITIII) } & \multirow{2}{*}{$\begin{array}{l}\mathrm{N} \\
\mathrm{M}_{\mathrm{y}}\end{array}$} & \multirow{3}{*}{$\begin{array}{l}\mathrm{M}_{\mathrm{x}} \\
\mathrm{v}_{\mathrm{y}}\end{array}$} & & \multirow{3}{*}{$\begin{array}{l}\mathrm{N} \\
\mathrm{M}_{\mathrm{y}} \\
\mathrm{V}_{\mathrm{x}}\end{array}$} & \multirow{3}{*}{$\begin{array}{l}\mathrm{M}_{\mathrm{x}} \\
\mathrm{V}_{\mathrm{y}}\end{array}$} & & 200,00 \\
\hline $\mathrm{M}_{\mathrm{y}}$ & $M_{x}$ & 9,51 & & & 9,51 & & & 9,51 & ZAHORRA $\quad \gamma\left(\mathrm{kN} / \mathrm{m}^{3}\right)$ \\
\hline$v_{x}$ & $v_{y}$ & 12,62 & $v_{x}$ & & 12,62 & & & 12,62 & 18,00 \\
\hline
\end{tabular}

\begin{tabular}{|c|c|c|c|c|c|}
\hline \multicolumn{2}{|l|}{ ZAPATA ESQUINA } & \multicolumn{3}{|c|}{ ZAPATA MEDIANERIAA 1} & VIGAS CENTRADORAS \\
\hline RESULTANTE (kN) & 139,02 & RESULTANTE (kN) & RESULTANTE (kN) & 0,223 & MOM. FLECTOR $(\mathrm{kN} \cdot \mathrm{m})$ \\
\hline TENSIÓN $\sigma \quad\left(\mathrm{kN} / \mathrm{m}^{2}\right)$ & 138,92 & TENSIÓN $\sigma \quad\left(\mathrm{kN} / \mathrm{m}^{2}\right)$ & TENSIÓN $\sigma \quad\left(\mathrm{kN} / \mathrm{m}^{2}\right)$ & 33,75 & $-106,86$ \\
\hline
\end{tabular}

Tabla 7. Hoja de cálculo para resolución de zapata de esquina con dos vigas centradoras 


\subsection{MODELIZACIÓN POR ELEMENTOS FINITOS}

Calculados los casos planteados en las distintas etapas por métodos convencionales, se realiza un cálculo alternativo de los mismos generando modelos de elementos finitos. El desarrollo de los citados modelos se ha llevado a cabo con ayuda del programa ANSYS, tanto en su versión ANSYS Clásico, como en su versión ANSYS Workbench.

Para poder contrastar los dos tipos de modelos en igualdad de condiciones, los modelos de elementos finitos se construyen con las mismas dimensiones obtenidas para la cimentación en el cálculo por métodos convencionales. Según se expuso en el apartado 2.2.1, cuando se utiliza viga centradora la reacción resultante para la zapata de medianería es superior a la que tendría si trabajase como zapata aislada (ec.3), por ello, suele ser los modelos convencionales de zapata de medianería con viga centradora (o en su caso de esquina) los que condicionan normalmente el tamaño de la cimentación.

El cálculo de una estructura por elementos finitos se divide habitualmente en tres fases o etapas, que son:

- Preproceso

- Cálculo

- Postproceso

El preproceso corresponde a la fase inicial de definición de datos geométricos, mecánicos y de cargas de la estructura. El cálculo es la fase en la cual el ordenador, internamente, procede a averiguar la solución del problema estructural (cálculo de desplazamientos, esfuerzos y tensiones en distintos puntos de la estructura). Finalmente el postproceso implica la fase de comunicación con el ordenador para obtener físicamente los resultados que él previamente ha calculado.

Ciertamente estas mismas tres fases están presentes en el cálculo de cualquier estructura por métodos matriciales (los más frecuentes en software de cálculo de estructuras), sin embargo, en el caso del cálculo de estructuras por elementos finitos, las fases de cálculo y postproceso, debido a su mayor complejidad respecto del cálculo matricial, acaban adquiriendo entidad propia y diferenciada.

Se describen a continuación, en los siguientes apartados, los detalles de la ejecución de los modelos de elementos finitos para las distintas etapas de la fase experimental de la tesis doctoral. Asimismo, en los Anejos I y II, se ofrecen los listados de comandos, en lenguaje APDL de ANSYS, que permiten desarrollar los modelos de elementos finitos empleados. 


\subsubsection{MODELOS DE ELEMENTOS FINITOS. ETAPA I}

\subsubsection{PREPROCESO}

El preproceso hace referencia al conjunto de operaciones que se realizan con el fin definir los datos de partida para el cálculo de la estructura. Esquemáticamente, el preproceso está integrado por los siguientes pasos:

- Modelado

- Definición de materiales

- Mallado

- Definición de coacciones

- Definición de contactos

- Aplicación de cargas

Algunos de estos pasos deben realizarse forzosamente en el orden descrito, otros en cambio no. Así por ejemplo, es imposible llevar a cabo el mallado de los elementos finitos si previamente no se ha modelado la estructura ni se han definido las propiedades de los materiales. Asimismo, la definición de coacciones, contactos y cargas debe realizarse posteriormente al mallado del modelo, pero el orden de estas tres últimas operaciones entre sí puede alterarse.

\section{MODELADO}

La primera operación consiste en construir físicamente (más bien virtualmente) la estructura a calcular y su entorno, utilizando para ello volúmenes sólidos que reproduzcan lo más fielmente posible la forma y dimensiones de la estructura real que se quiere modelizar. Se trata, en la práctica, de construir una maqueta virtual con volúmenes sólidos.

En concreto, para los casos definidos en el Etapa I (apartado 3.1.3.1), se han modelado los siguientes elementos (Fig.36):

- Un volumen de suelo de $10 \mathrm{~m}$ de profundidad y $5 \mathrm{~m}$ de anchura a cada lado del pórtico por cada uno de sus cuatro caras

- La cimentación del pórtico con zapata de medianería y viga centradora, con su volumetría real y las mismas dimensiones obtenidas por métodos convencionales

- El pórtico analizado completo, con todas sus vigas y pilares

- Una solera, compuesta por una capa de zahorra compactada de $300 \mathrm{~mm}$ de espesor y la solera propiamente dicha, de hormigón armado de $200 \mathrm{~mm}$ de espesor 


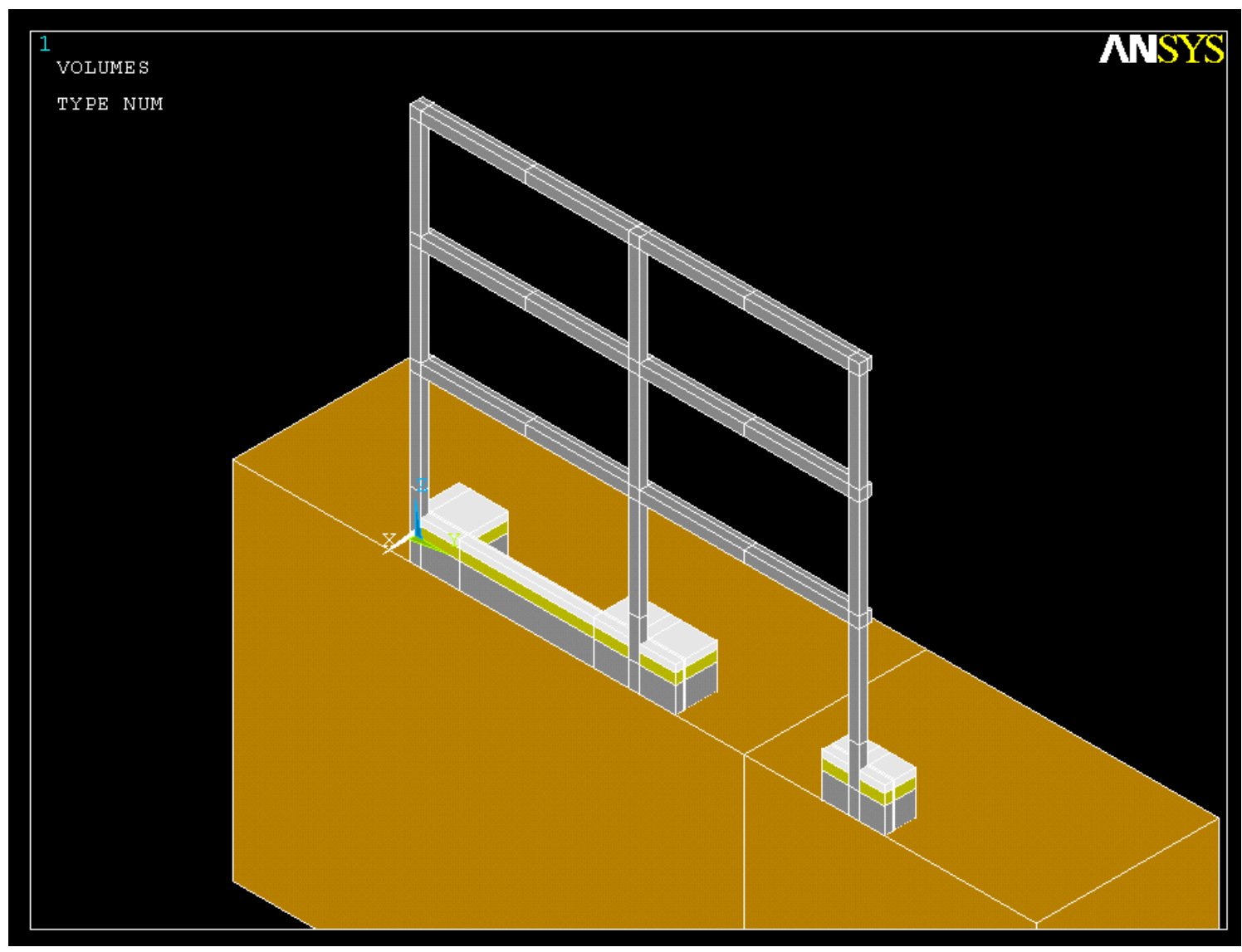

Fig.36. Modelado de un caso tipo de la Etapa I

En los modelos convencionales el pórtico, la cimentación y el suelo se contemplan por separado. Por un lado, se calcula el pórtico por métodos matriciales considerando las bases de los pilares como empotramientos perfectos. Por otro, se calcula la cimentación de forma independiente, recibiendo las reacciones de los pilares (obtenidas del pórtico) y una hipotética distribución de tensiones de contacto del terreno. Y, finalmente se estudia el comportamiento del suelo frente a las tensiones de contacto que le transmite la cimentación.

Frente a ello, la maqueta virtual descrita en la Fig.36 integra en un único modelo tanto el pórtico, como su cimentación, como el suelo que los recibe. De este modo se pueden analizar de forma simultánea las interacciones que se producen entre los distintos elementos, de una forma mucho más ajustada a la realidad, sin recurrir a condiciones de contorno simplificadas en las fronteras entre los distintos elementos.

Con el modelado adoptado en la Fig.36, además, se da respuesta a otras críticas planteadas a los métodos convencionales. En este modelo de elementos finitos se contempla el trabajo conjunto y simultáneo de la viga centradora y de la viga de la primera planta y, por su parte, 
se considera la volumetría real de la cimentación, sin considerar que el conjunto de las zapatas y la viga centradora es un elemento lineal único.

A pesar de las posibilidades del método, es preciso analizar la magnitud del modelo creado con el fin de encontrar el punto óptimo entre tiempo de cálculo y precisión en el resultado. En este caso, el volumen de suelo es de tal magnitud, que el número de elementos que genera es enorme y el tiempo de cálculo disparatado. Aprovechando la simetría del modelo, es posible generar solamente una de las mitades del mismo, lo cual reduce considerablemente el tiempo de cálculo, sin renunciar lo más mínimo a la precisión en el resultado, si se establecen las adecuadas condiciones de contorno en el plano de simetría.

\section{DEFINICIÓN DE MATERIALES}

Tal y como ya se indicó en el apartado 3.1.3.1, la Etapa I de la presente tesis doctoral está constituida por el trabajo de investigación desarrollado por el doctorando para la obtención del Diploma de Estudios Avanzados (D.E.A.) (Galletero, P., 2009). Dicho trabajo, considerado como punto inicial de la línea de investigación, se realiza bajo la hipótesis de comportamiento elástico lineal de todos los materiales implicados en el modelo (hormigón armado y suelo).

Con dicho comportamiento, los parámetros que es preciso definir en cada uno de los materiales son los siguientes:

- Módulo de elasticidad longitudinal (E)

- Coeficiente de Poisson $(\mu)$

- Peso específico $(\gamma)$

\section{HORMIGÓN ARMADO}

El pórtico y su cimentación se construirán con hormigón armado HA - 25, con una resistencia característica a compresión a los 28 días de edad de $\mathrm{f}_{\mathrm{ck}}=25 \mathrm{~N} / \mathrm{mm}^{2}$

Para el módulo de elasticidad longitudinal se utilizará (según el art.39.6 de la EHE 08) el módulo de deformación longitudinal secante a 28 días $\left(\mathrm{E}_{\mathrm{cm}}\right)$ dado por la ec.53 en función de la resistencia media a compresión del hormigón a los 28 días $\left(\mathrm{f}_{\mathrm{cm}}\right)$ :

$$
E_{c m}=8500 \cdot \sqrt[3]{f_{c m}}=8500 \cdot \sqrt[3]{f_{c k}+8}
$$


Cuyo valor para el caso concreto del hormigón HA - 25 es:

$$
\mathrm{E}_{\mathrm{cm}}=8500 \cdot \sqrt[3]{25+8}=26986 \mathrm{~N} / \mathrm{mm}^{2}
$$

Por su parte, de acuerdo con el art.39.9 de la EHE 08, se adopta para el coeficiente de Poisson del hormigón armado el valor:

$$
v_{c}=0,2
$$

Y, finalmente, se utiliza como valor del peso específico del hormigón armado:

$$
\gamma_{\text {ho }}=25 \mathrm{kN} / \mathrm{m}^{3}
$$

\section{SUELO}

Tal y como se refleja en el apartado 3.1.3.1. se contemplan en la Etapa I tres tipos de suelo, con tensiones admisibles de valor:

$$
\begin{aligned}
& \text { - } \sigma_{\text {adm }}=100 \mathrm{kN} / \mathrm{m}^{2} \\
& \text { - } \sigma_{\text {adm }}=200 \mathrm{kN} / \mathrm{m}^{2} \\
& \text { - } \sigma_{\text {adm }}=300 \mathrm{kN} / \mathrm{m}^{2}
\end{aligned}
$$

Para la determinación del módulo de elasticidad longitudinal del suelo bajo la hipótesis de comportamiento elástico lineal, se ha utilizado como referencia el Anejo D del DB SE - C del C.T.E. Dicho código presenta, por un lado, la Tabla D.23 (Tabla 8) que relaciona el tipo de suelo con el módulo de elasticidad longitudinal (E) y, por otro lado, la Tabla D.25 (Tabla 9) que relaciona el tipo de suelo con la tensión admisible del mismo.

Tabla D.23. Valores orientativos de $\mathrm{N}_{\mathrm{SPT}}$, resistencia a compresión simple y módulo de elasticidad de suelos

\begin{tabular}{lccc}
\hline Tipo de suelo & $\mathbf{N}_{\text {SPT }}$ & $\mathbf{q}_{\mathbf{u}}\left(\mathbf{k N} / \mathbf{m}^{2}\right)$ & $\mathbf{E}\left(\mathbf{M N} / \mathbf{m}^{2}\right)$ \\
\hline Suelos muy flojos o & $<10$ & $0-80$ & $<8$ \\
muy blandos & $10-25$ & $80-150$ & $8-40$ \\
Suelos flojos o blandos & $25-50$ & $150-300$ & $40-100$ \\
Suelos medios & $50-$ Rechazo & $300-500$ & $100-500$ \\
Suelos compactos o & Rechazo & $500-5.000$ & $500-8.000$ \\
duros & Rechazo & $5.000-40.000$ & $8.000-15.000$ \\
Rocas blandas & Rechazo & $>40.000$ & $>15.000$ \\
Rocas duras & & & \\
Rocas muy duras &
\end{tabular}

Tabla 8. Módulo de elasticidad longitudinal de suelos 
Tabla D.25. Presiones admisibles a efectos orientativos

\begin{tabular}{|c|c|c|c|}
\hline Terreno & Tipos y condiciones & $\begin{array}{l}\text { Presión } \\
\text { admisisible } \\
\text { [Mpa] }\end{array}$ & Observaciones \\
\hline \multirow[t]{7}{*}{ Rocas } & $\begin{array}{l}\text { Rocas ígneas y metamórficas } \\
\text { sanas (1) (Granito, diorita, basal- } \\
\text { to, gneis) }\end{array}$ & 10 & \multirow[t]{7}{*}{$\begin{array}{l}\text { Para los valores apuntados se supone } \\
\text { que la cimentación se sitúa sobre roca no } \\
\text { meteorizada }\end{array}$} \\
\hline & $\begin{array}{l}\text { Rocas metamórficas foliadas } \\
\text { sanas }^{(1) .(2)} \text { (Esquistos, piza- } \\
\text { rras) }\end{array}$ & 3 & \\
\hline & $\begin{array}{l}\text { Rocas sedimentarias sanas } \\
(1) \text {, } \\
\text { Pizarras cementadas, limoli- } \\
\text { tas, areniscas, calizas sin kars- } \\
\text { tificar, conglomerados cemen- } \\
\text { tados }\end{array}$ & 1 a 4 & \\
\hline & Rocas arcillosas sanas ${ }^{(2),(4)}$ & 0,5 a 1 & \\
\hline & $\begin{array}{l}\text { Rocas diaclasadas de cualquier } \\
\text { tipo con espaciamiento de } \\
\text { discontinuidades superior a } \\
0,30 \mathrm{~m} \text {, excepto rocas arcillosas }\end{array}$ & 1 & \\
\hline & $\begin{array}{l}\text { Calizas, areniscas y rocas } \\
\text { pizarrosas con pequeño espa- } \\
\text { ciamiento de los planos de } \\
\text { estratificación } \\
(3)\end{array}$ & - & \\
\hline & $\begin{array}{l}\text { Rocas muy diaclasadas o me- } \\
\text { teorizadas }^{(3)}\end{array}$ & - & \\
\hline \multirow{6}{*}{$\begin{array}{l}\text { Suelos granulares } \\
\text { (\% finos inferior al } \\
35 \% \text { en peso) }\end{array}$} & $\begin{array}{l}\text { Gravas y mezclas de arena y } \\
\text { grava, muy densas }\end{array}$ & $>0,6$ & \multirow{6}{*}{$\begin{array}{l}\text { Para anchos de cimentación (B) mayor o } \\
\text { igual a } 1 \mathrm{~m} \text { y nivel freático situado a una } \\
\text { profundidad mayor al ancho de la cimen- } \\
\text { tación (B) por debajo de ésta }\end{array}$} \\
\hline & $\begin{array}{l}\text { Gravas y mezclas de grava y } \\
\text { arena, medianamente densas a } \\
\text { densas }\end{array}$ & 0,2 a 0,6 & \\
\hline & $\begin{array}{l}\text { Gravas y mezclas de arena y } \\
\text { grava, sueltas }\end{array}$ & $<0,2$ & \\
\hline & Arena muy densa & $>0,3$ & \\
\hline & Arena medianamente densa & 0,1 a 0,3 & \\
\hline & Arena suelta & $<0,1$ & \\
\hline \multirow{5}{*}{$\begin{array}{l}\text { Suelos finos } \\
\text { (\% de finos supe- } \\
\text { rior al } 35 \% \text { en } \\
\text { peso) }\end{array}$} & Arcillas duras & 0,3 a 0,6 & \multirow{5}{*}{$\begin{array}{l}\text { Los suelos finos normalmente consolida- } \\
\text { dos y ligeramente sobreconsolidados en } \\
\text { los que sean de esperar asientos de } \\
\text { consolidación serán objeto de un estudio } \\
\text { especial. Los suelos arcillosos poten- } \\
\text { cialmente expansivos serán objeto de un } \\
\text { estudio especial }\end{array}$} \\
\hline & Arcillas muy firmes & 0,15 a 0,3 & \\
\hline & Arcillas firmes & 0,075 a 0,15 & \\
\hline & Arcillas y limos blandos & $<0,075$ & \\
\hline & Arcillas y limos muy blandos & & \\
\hline
\end{tabular}

Tabla 9. Tensiones admisibles de suelos

Enlazando ambas tablas, mediante el factor común del tipo de suelo, se obtiene la siguiente asociación de módulos de elasticidad longitudinal con tensiones admisibles:

$$
\begin{array}{lll}
\sigma_{\text {adm }}=100 \mathrm{kN} / \mathrm{m}^{2} & \Rightarrow & E_{\mathrm{s}}=28 \mathrm{~N} / \mathrm{mm}^{2} \\
\sigma_{\mathrm{adm}}=200 \mathrm{kN} / \mathrm{m}^{2} & \Rightarrow & E_{\mathrm{s}}=59 \mathrm{~N} / \mathrm{mm}^{2} \\
\sigma_{\mathrm{adm}}=300 \mathrm{kN} / \mathrm{m}^{2} & \Rightarrow & E_{\mathrm{s}}=88 \mathrm{~N} / \mathrm{mm}^{2}
\end{array}
$$


Para el coeficiente de Poisson del suelo se adopta el valor:

$$
v_{\text {su }}=0,3
$$

$\mathrm{Y}$, finalmente, se ha considerado como valor del peso específico del suelo:

$$
\gamma_{\mathrm{su}}=18 \mathrm{kN} / \mathrm{m}^{3}
$$

\section{MALLADO}

El mallado es el proceso por el cual se divide la materia de los diferentes volúmenes sólidos que componen un modelo, en una serie de porciones discretas de determinado tamaño, denominadas elementos finitos (Fig.37). Existe una enorme similitud entre el concepto de elemento finito y el de elemento diferencial empleado en el cálculo diferencial e integral. El proceso de mallado debe cubrir por completo la materia de los sólidos en cuestión, sin solapes, de tal forma que no puede quedar ninguna porción de materia sin asociar a un elemento finito, ni puede darse el caso de una porción de materia vinculada a varios elementos finitos al mismo tiempo.
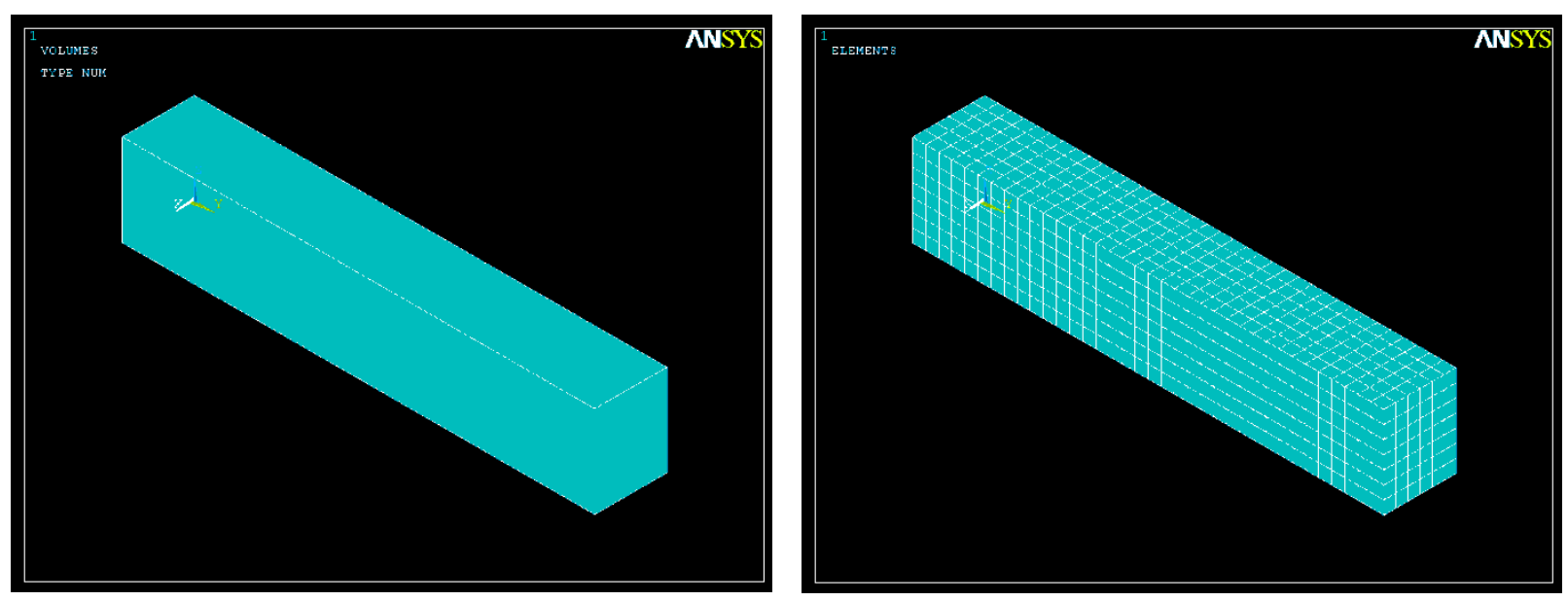

Fig.37. Concepto de mallado

Cada elemento finito va asociado a una serie de puntos singulares llamados nodos, que se constituyen en puntos de integración del proceso de cálculo, es decir, puntos en los que se obtienen resultados de desplazamientos, fuerzas y tensiones. Los sucesivos elementos finitos se consideran vinculados por medio de los nodos. 
Existen muchos posibles tipos de elementos finitos, tanto por las posibles formas de los mismos, como por la cantidad de nodos de referencia que emplean. En este caso, se han empleado elementos hexaédricos rectos con 8 nodos y 3 grados de libertad por nodo (paralelepípedos con un nodo en cada uno de los vértices) (Fig.38) (Oñate, E. 1995). Dicho elemento presenta la denominación de SOLID 45 en el programa ANSYS empleado para el desarrollo de los modelos de elementos finitos.
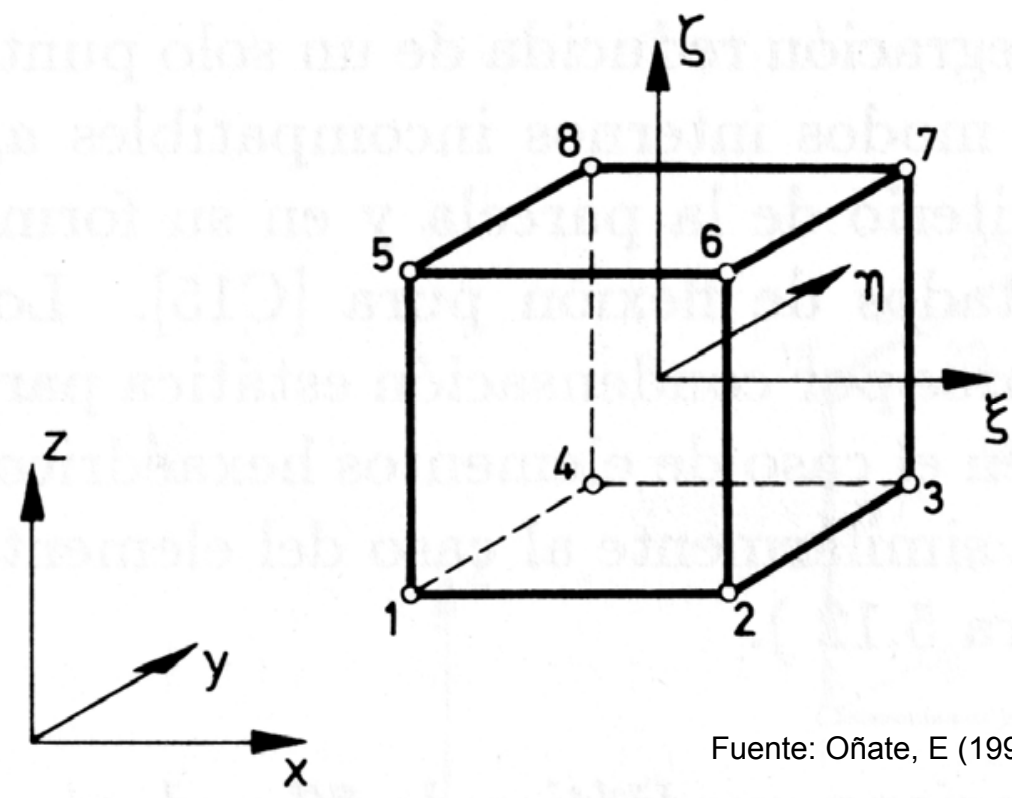

Fuente: Oñate, E (1995)

Fig.38. Elemento hexaédrico recto de 8 nodos

Además del tipo de elemento elegido, una cuestión fundamental para el proceso de cálculo es la decisión del tamaño del mismo. Dicha decisión tiene una repercusión directa sobre dos parámetros muy importantes, que son, la precisión en los resultados y el tiempo necesario para el cálculo. Si el tamaño de los elementos es excesivamente grande, habrá muy pocos elementos, el tiempo de cálculo será muy reducido, pero los resultados serán muy groseros. Por el contrario, si se emplean elementos extremadamente pequeños (casi diferenciales), los resultados serán muy precisos, pero la cantidad de elementos será enorme y el tiempo de cálculo posiblemente inadmisible. Es por ello preciso encontrar el punto óptimo entre los parámetros tamaño de elemento - precisión - tiempo.

En el caso del presente trabajo de investigación se han planteado elementos de 0,100 m de tamaño en los sólidos de hormigón armado y 0,250 m en los sólidos de suelo, mallando solamente la mitad del modelo en función de la simetría del mismo. Con dichos valores (y gracias a la simetría) se obtienen modelos de tan solo 80000 elementos que, incluso con un ordenador de última generación en este momento, supone un tiempo de cálculo de varias horas para cada uno de los casos. 
En la Fig.39 se ofrece una imagen del modelo mallado, una vez asignadas las propiedades de los materiales y los tamaños de elemento.

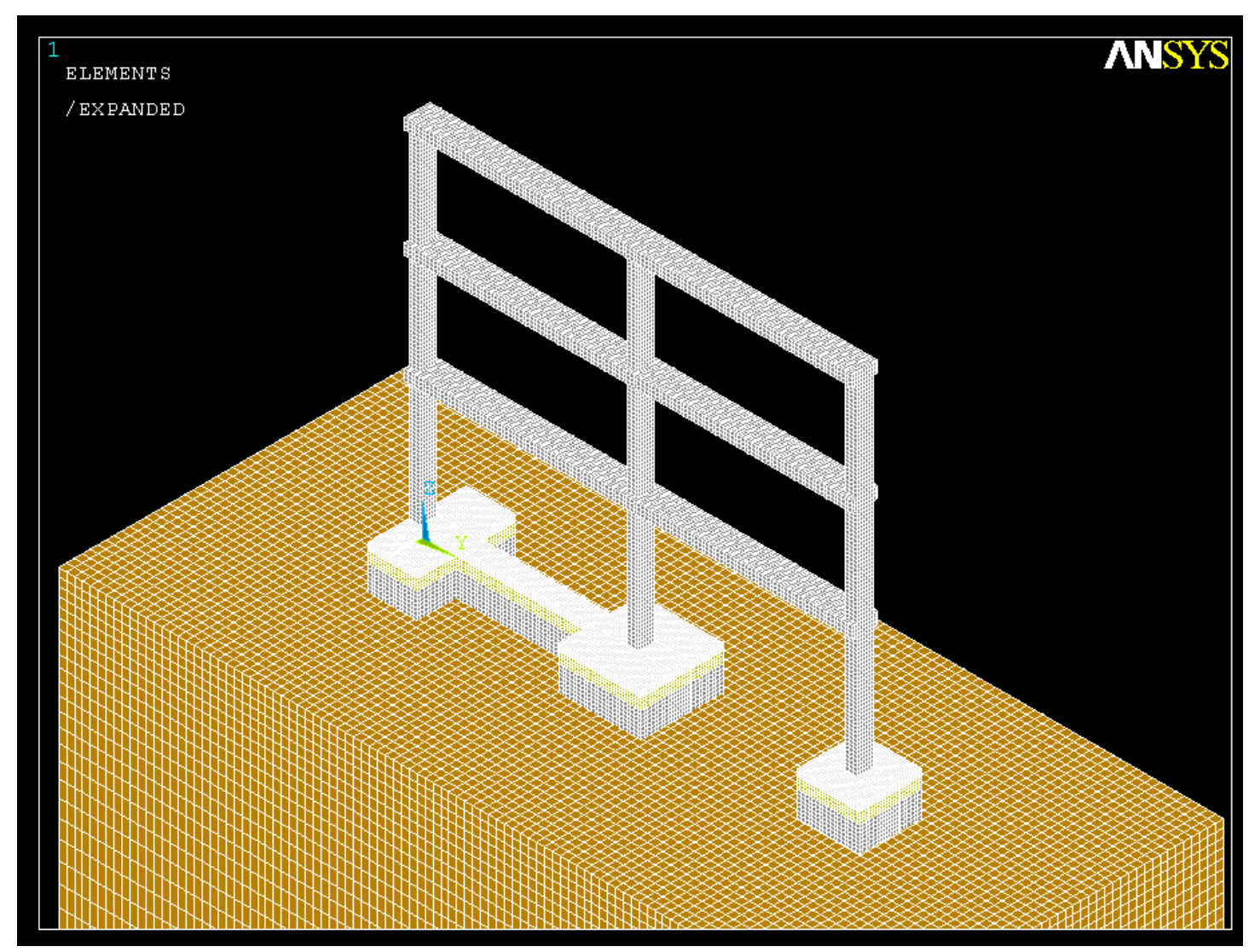

Fig.39. Modelo tipo mallado

\section{DEFINICIÓN DE COACCIONES}

Las coacciones definen las vinculaciones del modelo con el exterior y están constituidas por grados de libertad absolutamente impedidos. El tipo de elemento elegido (hexaedro o paralelepípedo recto de 8 nodos) presenta en cada nodo tres posibles grados de libertad de tipo desplazamiento, uno por cada una de las tres direcciones del espacio ( $x, y, z)$. Por ello, la definición de coacciones supone la decisión de cuáles son los nodos que tienen impedido el desplazamiento en alguna de las direcciones indicadas.

Es importante señalar que en esta tesis doctoral se persigue conocer el comportamiento real de la estructura en el contacto cimiento terreno, por ello, en contra de lo que suele hacerse en el cálculo de pórticos por método matricial, no se va a imponer ninguna coacción al pórtico ni a su cimentación, para que sea el propio M.E.F. el que describa la interacción sueloestructura. 
Por el motivo indicado, salvo las necesarias condiciones de contorno imprescindibles para modelizar la simetría, solo se impondrán coacciones a los nodos extremos del volumen de suelo. Todos los nodos incluidos en la cara inferior del volumen de suelo tendrán coartados los tres grados de libertad, con desplazamiento impedido en todas las direcciones del espacio. Por su parte, todos los nodos incluidos en las cuatro caras perimetrales verticales del volumen de suelo, tendrán impedido el desplazamiento en la dirección perpendicular a la cara en cuestión. Finalmente, todos los nodos de la cara superior del volumen de suelo tendrán desplazamiento libre.

\section{DEFINICIÓN DE CONTACTOS}

Cuando se produce una discontinuidad entre dos materiales es preciso definir el tipo de contacto que se produce entre ellos, con el fin de poder realizar el cálculo. En caso contrario se genera un mecanismo incapaz de encontrar equilibrio estático.

En los modelos de elementos finitos utilizados en la presente tesis doctoral se han tenido en cuenta los contactos, tanto entre las zapatas y el terreno, como entre la viga centradora y el terreno. Asimismo, se ha considerado el contacto entre la solera y la zahorra compactada, así como entre ésta y la cimentación.

Todos los contactos indicados se han definido como contactos por compresión y fricción. Respecto de la compresión hay que señalar que el contacto se opone a la penetración de un sólido en el otro mediante la correspondiente tensión de contacto pero, sin embargo, no se opone al posible despegue de un sólido respecto del otro. Por su parte, los contactos definidos también implican una oposición al deslizamiento mediante la correspondiente fuerza de rozamiento. Para el cálculo de la fuerza de rozamiento se utiliza como coeficiente de rozamiento $(\mu)$ el dado por la ec.55 en función del ángulo de rozamiento interno $(\phi)$.

$$
\mu=\operatorname{tg}\left(\frac{2}{3} \cdot \phi\right)
$$

Para el valor del ángulo de rozamiento interno del suelo se ha utilizado como referencia la Tabla D.27 (Tabla 10) del DB SE - C del C.T.E. 
Tabla D.27. Propiedades básicas de los suelos

\begin{tabular}{llcc}
\hline Clase de suelo & $\begin{array}{c}\text { Peso específico } \\
\text { aparente }\left(\mathbf{k N} / \mathbf{m}^{3}\right)\end{array}$ & $\begin{array}{c}\text { Ángulo de rozamiento } \\
\text { interno }\end{array}$ \\
\hline Terreno natural & Grava & $19-22$ & $34^{\circ}-45^{\circ}$ \\
& Arena & $17-20$ & $30^{\circ}-36^{\circ}$ \\
& Limo & $17-20$ & $25-32^{\circ}$ \\
& Arcilla & $15-22$ & $16^{\circ}-28^{\circ}$ \\
\hline Rellenos & Tierra vegetal & 17 & $25^{\circ}$ \\
& Terraplén & 17 & $30^{\circ}$ \\
& Pedraplén & 18 & $40^{\circ}$ \\
\hline
\end{tabular}

Tabla 10. Ángulo de rozamiento interno de suelos

Dada la evidente dificultad de vinculación de esta tabla con la Tabla 8 que asocia tensiones admisibles con tipos de suelo, se ha adoptado un ángulo de rozamiento medio de valor $\phi=30^{\circ}$ vinculado a la tensión admisible $\sigma_{\text {adm }}=200 \mathrm{kN} / \mathrm{m}^{2}$ y una oscilación de $5^{\circ}$ por encima y por debajo de dicho valor para las otras dos tensiones admisibles, quedando el siguiente resultado:

$$
\begin{aligned}
& \sigma_{\text {adm }}=100 \mathrm{kN} / \mathrm{m}^{2} \Rightarrow \phi=25^{\circ} \\
& \sigma_{\mathrm{adm}}=200 \mathrm{kN} / \mathrm{m}^{2} \Rightarrow \phi=30^{\circ} \\
& \sigma_{\text {adm }}=300 \mathrm{kN} / \mathrm{m}^{2} \Rightarrow \phi=35^{\circ}
\end{aligned}
$$

El cálculo de los contactos por compresión se desarrolla en el programa ANSYS por aplicación del algoritmo de Lagrange ampliado.

\section{APLICACIÓN DE CARGAS}

Los modelos de elementos finitos se calculan con las mismas cargas que los modelos convencionales, obtenidas previamente en el apartado 3.1.2 y reflejadas en las Fig.19 y 20.

La única particularidad que puede comentarse es que las cargas se han aplicado en los nodos de los elementos y se ha tenido que proceder al cálculo de la magnitud de la carga por nodo en función de los datos de las Fig.19 y 20 y del tamaño de los correspondientes elementos finitos. 


\subsubsection{CÁLCULO}

El cálculo de los modelos de elementos finitos de la Etapa I se realiza a partir de la hipótesis de comportamiento elástico lineal de cada uno de los materiales, considerados de forma individual. Ahora bien, si se analiza el conjunto del modelo, aparece una no linealidad, constituida por la discontinuidad del material en los correspondientes contactos. Por ello, aunque de forma individual el cálculo es lineal, el modelo completo es no lineal.

Un cálculo lineal con un programa de elementos finitos es tan sencillo como con un programa de cálculo matricial, simplemente hay que ordenar el cálculo y esperar el resultado. En cambio, cuando el cálculo es no lineal por algún motivo, el proceso se complica, ya que la solución se obtiene por métodos numéricos de aproximaciones sucesivas. En el caso concreto del programa ANSYS se utiliza el método de Newton - Raphson, cuya aplicación se representa esquemáticamente en la Fig.40:

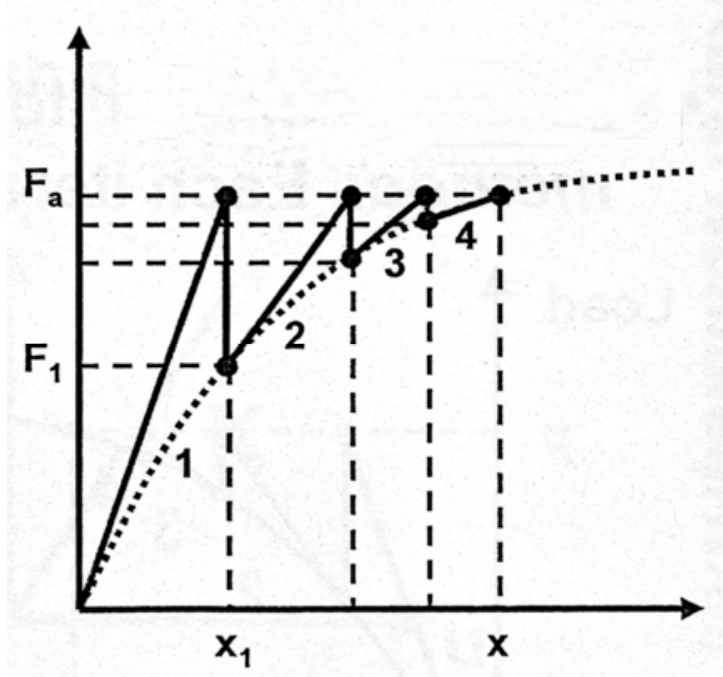

Fig.40. Método de cálculo numérico de Newton - Raphson

Con los citados métodos de cálculo numérico, la solución se obtiene por aplicación de sucesivos pasos de carga, siendo necesaria la definición de la amplitud de los pasos de carga a utilizar por parte de la persona que controla el proceso de cálculo. Si se programan pocos pasos de carga con una amplitud muy grande, es posible que el cálculo numérico no converja y no se obtenga solución. Por el contrario, si se plantean muchos pasos de carga de muy poca amplitud, es posible que el proceso de cálculo se alargue innecesariamente. Por ello, es preciso encontrar la magnitud óptima de los pasos de carga empleados, de modo que se consiga la convergencia del problema de cálculo numérico en el menor tiempo posible.

En el caso de los modelos de elementos finitos empleados en este estudio se encuentra convergencia tras 10 pasos de carga o ciclos de cálculo. 
El hecho de la indeterminación en el número de ciclos de cálculo a emplear cuando el cálculo es no lineal, le concede a la fase de cálculo del M.E.F. un protagonismo propio que no tiene en modo alguno el cálculo matricial lineal y que puede conducir, si no se controla bien el proceso, a la ausencia de convergencia y a la imposibilidad de obtener la solución del modelo.

\subsubsection{POSTPROCESO}

Es la última fase del proceso del cálculo de una estructura por elementos finitos y tiene por objeto la obtención de resultados de forma cómoda e inteligible.

Al hablar de resultados del cálculo de una estructura por elementos finitos, hay que tener que el método discretiza la materia en una serie de elementos finitos asociados a nodos y que lo que se hace realmente es calcular determinados parámetros en dichos nodos. En concreto, los resultados que se obtienen son los desplazamientos y las tensiones (tanto normales como tangenciales) para todos los nodos y las fuerzas o reacciones que se generan en los nodos coaccionados.

Dichos resultados se obtienen físicamente en dos formatos, o bien gráficos de la estructura con escalas cromáticas para indicar las intensidades de los desplazamientos y/o tensiones (Fig.41), o bien listados con indicación del número del nodo y el valor numérico del desplazamiento y/o la tensión en dicho nodo (Fig.42).

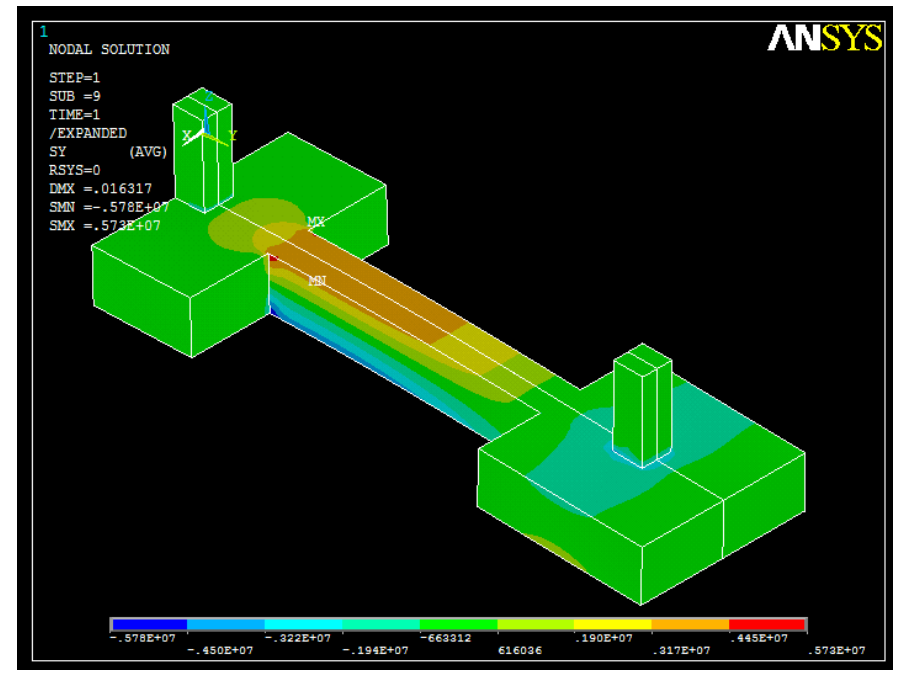

Fig.41. Salida gráfica de resultados con indicación de valor por escala cromática 
PRINT S NODAL SOLUTION PER NODE

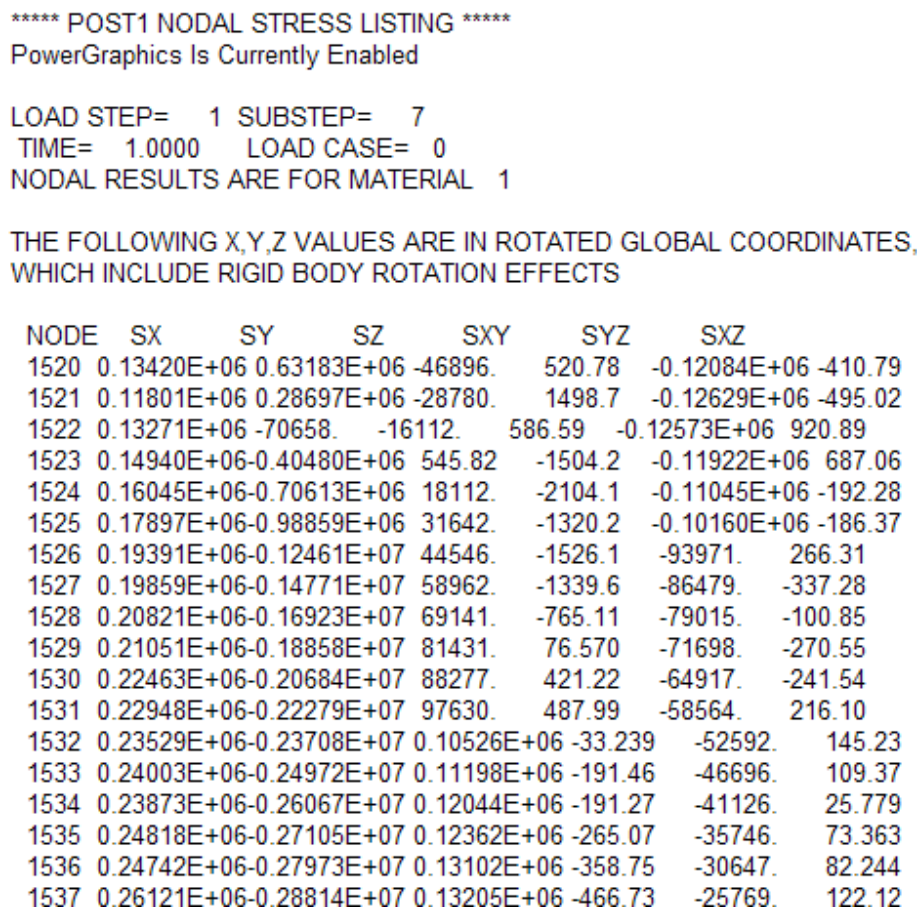

Fig.42. Listado con relación de tensiones correspondientes a diferentes nodos

El manejo de los resultados de un cálculo estructural por elementos finitos es una tarea laboriosa y compleja. Tras una brillante toma de contacto inicial con los gráficos cromáticos (que sorprenden por su vistosidad) es preciso pasar a los listados, ya que los gráficos permiten una rápida visión cualitativa de la solución pero, si se quieren resultados concretos de carácter cuantitativo, no queda más remedio que trabajar con los listados numéricos. Dichos listados numéricos pueden llegar a ser un auténtico problema, ya que, tan malo como no tener información, es tenerla en exceso si no se puede gestionar. De nada sirve un listado con las tensiones y desplazamientos de los nodos de 80000 elementos si, para empezar, no se sabe quién es quién.

Así pues, la primera función importante que implica el postproceso es el desarrollo de herramientas de identificación y selección de nodos y elementos que permitan, por un lado, identificar cómodamente a quién corresponde un determinado número de nodo, dónde se encuentra, a qué sección pertenece... y, por otro, ser capaces de seleccionar un determinado conjunto de nodos o elementos para obtener resultados (desplazamientos y/o tensiones) solamente de dichos nodos o elementos. De este modo se obtienen listados manejables e interpretables de componentes conocidos. 
Superada esta primera cuestión, surge un segundo problema. Los modelos convencionales y los de elementos finitos no hablan el mismo idioma y sus resultados no son, en principio, comparables. Efectivamente, los modelos convencionales hacen referencia, por ejemplo, a la resultante del bloque completo de tensiones de contacto bajo una zapata o al momento flector que afecta a una sección completa de la viga centradora, en cambio, para el modelo de elementos finitos no existe la sección de la viga centradora, lo que existen son los múltiples elementos y nodos que integran dicha sección. Por ello, los modelos de elementos finitos no proporcionan directamente el momento flector que afecta a la sección, sino más bien, las tensiones en los diferentes nodos que componen dicha sección (Fig.43) que son, en principio, resultados distintos aunque puedan estar relacionados.

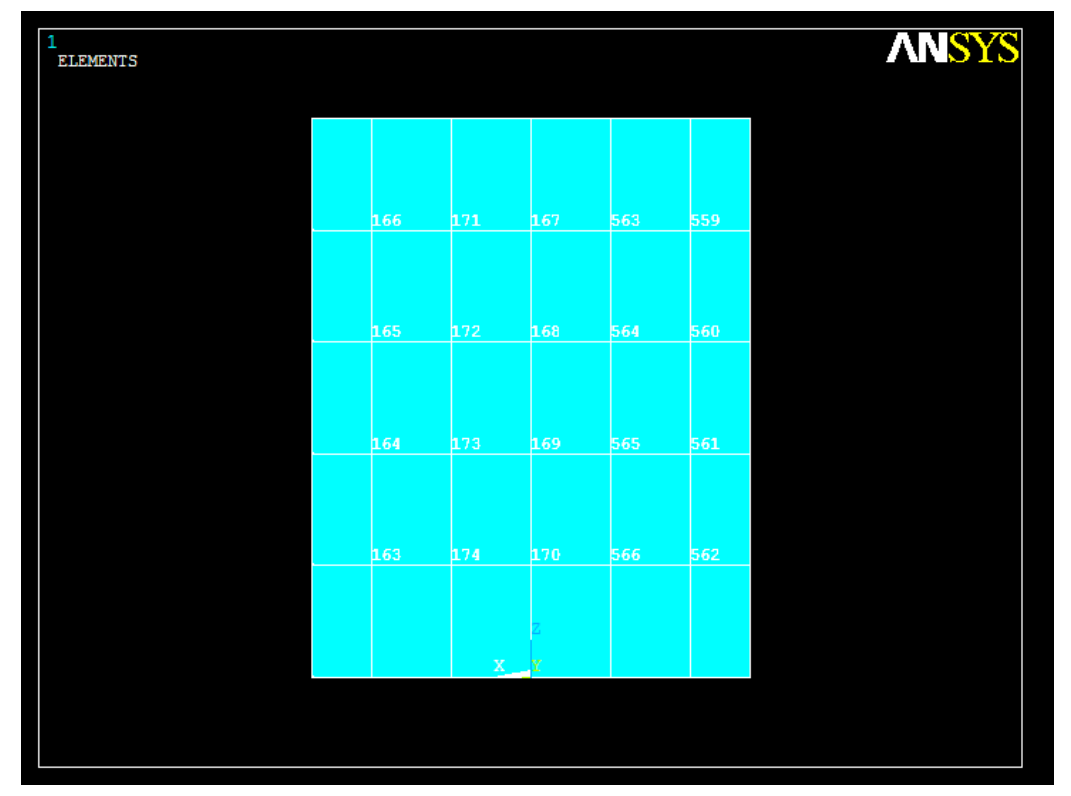

Fig.43. Sección transversal y relación de elementos y nodos que la componen

Para hacer equiparables los resultados y poder contrastarlos, utilizando el símil de los elementos finitos como "elementos diferenciales", es preciso "integrar" el valor de las tensiones a lo largo de todos los "elementos diferenciales" que componen la sección.

Conocido el tamaño de los elementos, es posible determinar la superficie tributaria asignada a cada nodo. A partir de este dato, el "diferencial de fuerza" que aporta un nodo se obtendrá mediante el producto de la tensión en el mismo por su superficie tributaria y, el "diferencial de momento" que aporta el citado nodo respecto de un eje, se obtendrá multiplicando su diferencial de fuerza por la distancia al eje considerado. Finalmente, la fuerza y el momento total correspondientes al conjunto de la sección considerada se calculan sumando (integrando) el conjunto de diferenciales de fuerza y diferenciales de momento de la totalidad de la sección. 
El planteamiento descrito puede realizarse, exportando los datos de tensión a una hoja de cálculo en la que se programa el citado proceso de integración o, en el caso de ANSYS, utilizando determinados comandos que ejecutan la integración en cuestión (Fig.44).

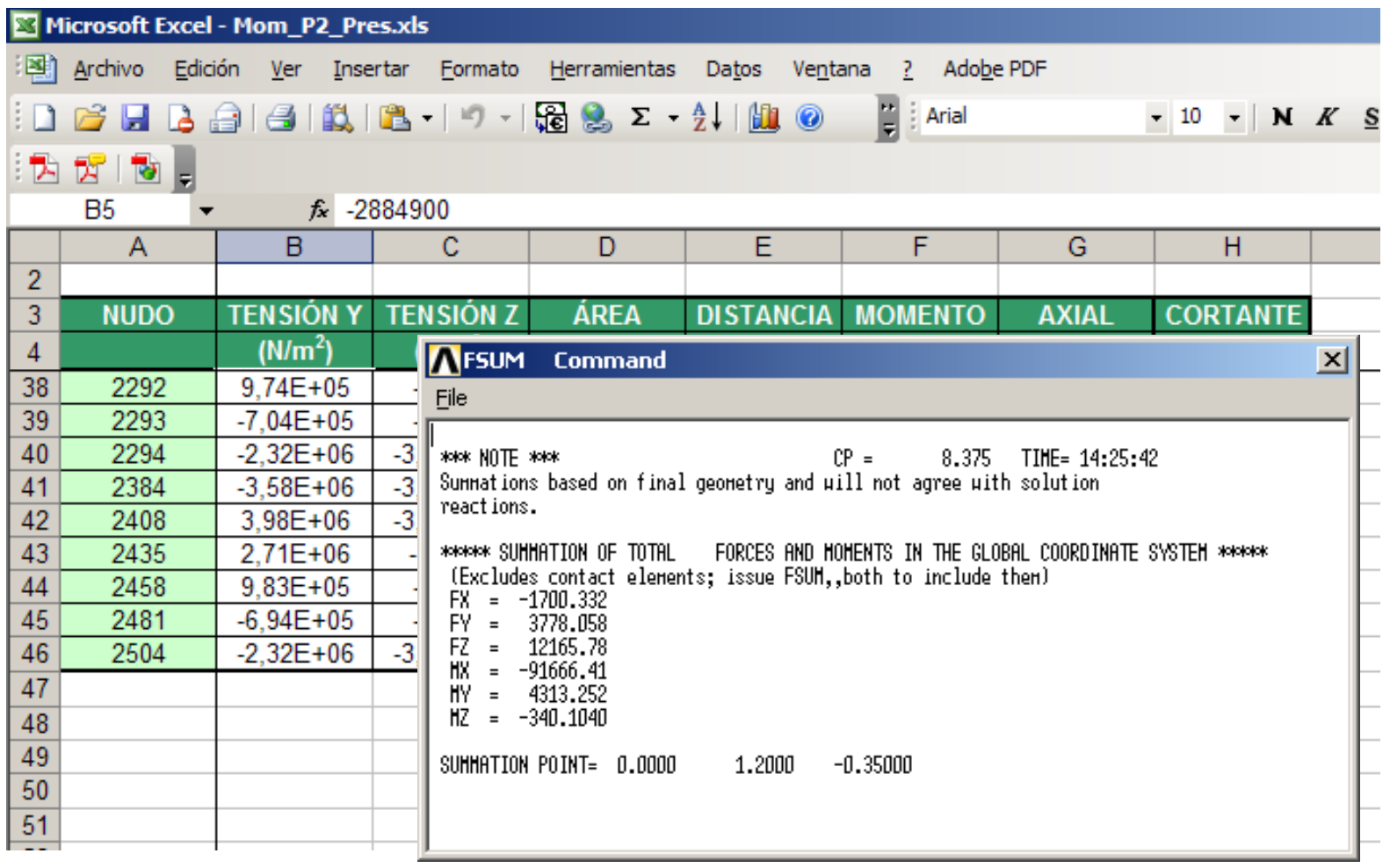

Fig.44. Proceso de integración de tensiones para una sección

Finalizado el proceso de integración, los resultados serán equiparables y se puede proceder al contraste de resultados y a su análisis e interpretación. 


\subsubsection{MODELOS DE ELEMENTOS FINITOS. ETAPAS II Y III}

\subsubsection{PREPROCESO. DEFINICIÓN DE MATERIALES}

Los modelos de elementos finitos desarrollados en la Etapa I se llevan a cabo con un planteamiento elástico lineal para todos los materiales implicados en los mismos. Dicho planteamiento supone tres hipótesis básicas de partida:

- Comportamiento elástico del material

- Diagrama tensión - deformación lineal

- Capacidad resistente isótropa

El comportamiento elástico de un material supone la deformación del mismo ante la aplicación de cargas externas y la recuperación íntegra de la forma y dimensiones originales al retirarse la carga aplicada. Un diagrama tensión - deformación lineal, por su parte, plantea una relación proporcional entre tensiones y deformaciones a lo largo de todo el recorrido resistente del material (Fig.45), desde su entrada en carga hasta alcanzar su máxima tensión admisible, siendo el módulo de elasticidad del material $(E)$ la constante de proporcionalidad o pendiente de la recta. Por último, en un cálculo elástico lineal se presupone un comportamiento isótropo del material, con igual capacidad resistente en cualquier punto con independencia de la dirección y el sentido considerado.
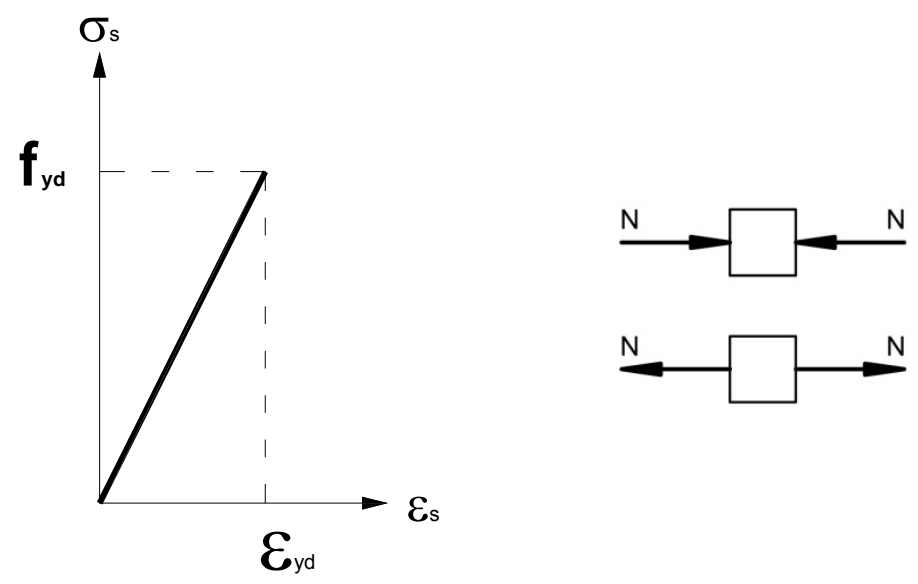

Fig.45. Comportamiento elástico lineal isótropo

La propuesta elástico lineal no se ajusta al comportamiento real del hormigón. Frente a lo planteado en la Etapa I, el hormigón presenta una respuesta fundamentalmente plástica (solo podría considerarse un comportamiento elástico en estados iniciales de aplicación de carga). El diagrama tensión deformación del hormigón no es en absoluto lineal rectilíneo, respondiendo más bien a un diagrama parabólico rectangular (Fig.46). Y, por último, el 
hormigón es el claro ejemplo de material anisótropo, resistente a compresión pero con una muy reducida (prácticamente nula ) resistencia a tracción. Este último dato conduce, además, a un fenómeno muy característico de los elementos resistentes de hormigón, como es la fisuración de las zonas traccionadas del mismo con la consecuente necesidad de armado o cosido de las zonas traccionadas y la pérdida de inercia y rigidez de dichos elementos.
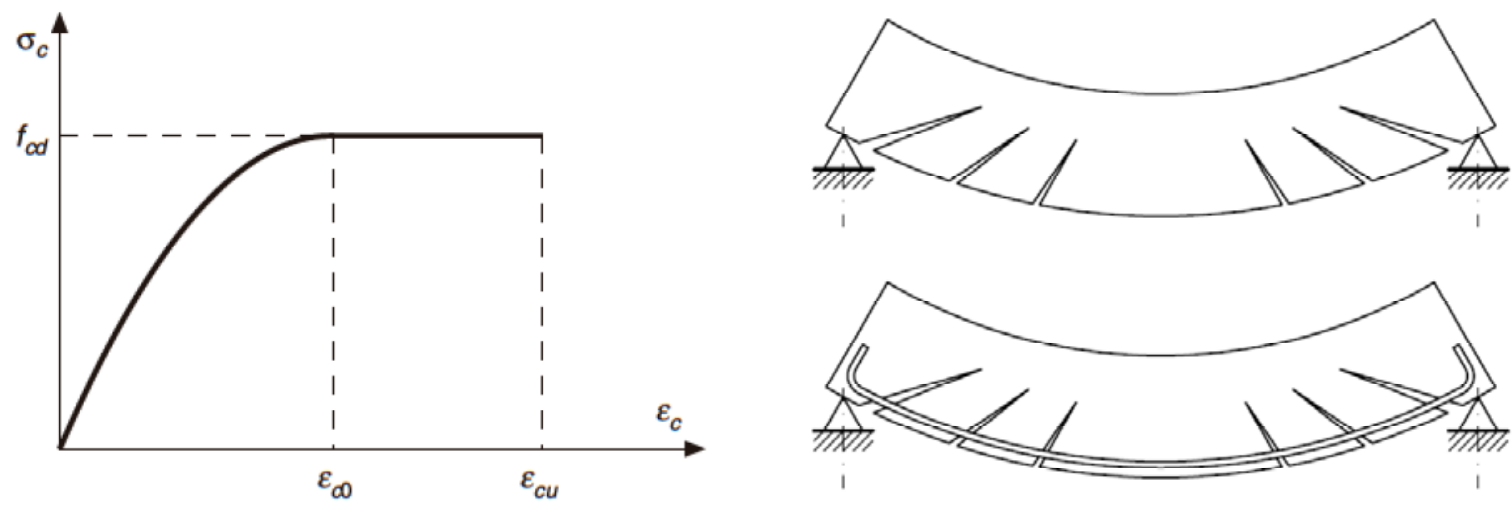

Fig.46. Diagrama parabólico rectangular del hormigón y fisuración de zonas traccionadas

Con independencia de los cambios introducidos en las variables a estudiar en las Etapas II y III, ya comentados en los apartados 3.1.3.2. y 3.1.3.3, la principal diferencia y aportación de estas Etapas II y III es el desarrollo de un planteamiento más ajustado al comportamiento real del hormigón armado como material estructural. La elaboración de los modelos de elementos finitos se lleva a cabo con ayuda del programa de cálculo por elementos finitos ANSYS Clásico en la Etapa I y ANSYS Workbench en las Etapas II, III y IV. En este sentido, ANSYS dispone de un tipo de elemento, el SOLID 65, capaz de utilizar el material CONCRETE que contempla, tanto la diferente resistencia del hormigón a tracción y compresión, como el hecho de la fisuración y fractura de los elementos de hormigón en aquellas zonas que superan la limitada resistencia a tracción del mismo. Las Etapas II y III utilizan estas herramientas en la confección de los modelos de elementos finitos, de acuerdo con los datos y propiedades que a continuación se detallan.

- Los pórtico y su cimentación, al igual que en la Etapa I, se construirán con hormigón HA - 25, con una resistencia característica a compresión a los 28 días de edad de:

$$
f_{c k}=25 \mathrm{~N} / \mathrm{mm}^{2}
$$

- Para el módulo de elasticidad longitudinal se utiliza (según el art.39.6 de la EHE 08) el módulo de deformación longitudinal secante a 28 días $\left(E_{\mathrm{cm}}\right)$ dado por la ec.53 en función de la resistencia media a compresión del hormigón a los 28 días $\left(\mathrm{f}_{\mathrm{cm}}\right)$ : 


$$
E_{c m}=8500 \cdot \sqrt[3]{f_{c m}}=8500 \cdot \sqrt[3]{f_{c k}+8}
$$

Cuyo valor para el caso concreto del hormigón HA - 25 es:

$$
E_{c m}=8500 \cdot \sqrt[3]{25+8}=26986 \mathrm{~N} / \mathrm{mm}^{2}
$$

- Por su parte, de acuerdo con el art.39.9 de la EHE 08, se adopta para el coeficiente de Poisson del hormigón el valor:

$$
v_{c}=0,2
$$

- Se utiliza como valor del peso específico del hormigón armado:

$$
\gamma_{\text {ho }}=25 \mathrm{kN} / \mathrm{m}^{3}
$$

- El diagrama tensión deformación del hormigón definido para el cálculo es parabólico rectangular, como el representado en la Fig.46, que responde a la ecuación dada por la norma EHE-08:

$$
\begin{aligned}
& \sigma_{c}=f_{c d}\left[1-\left(1-\frac{\varepsilon_{c}}{\varepsilon_{c 0}}\right)^{n}\right] \text { si } 0 \leq \varepsilon_{c} \leq \varepsilon_{c 0} \\
& \sigma_{c}=f_{c d} \quad \text { si } 0 \leq \varepsilon_{c} \leq \varepsilon_{c 0}
\end{aligned}
$$

con $n=2$ y $\quad \varepsilon_{\mathrm{c} 0}=0,002$ por tratarse de hormigón HA-25

- Y, por último, para la resistencia característica a tracción del hormigón se adopta la expresión de la EHE-08:

$$
\sigma_{\mathrm{ct}, \mathrm{k}}=0,21 \sqrt[3]{\mathrm{f}_{\mathrm{ck}}^{2}}
$$

Cuyo valor para el caso concreto del hormigón HA - 25 es:

$$
\sigma_{\mathrm{ct}, \mathrm{k}}=0,21 \sqrt[3]{\mathrm{f}_{\mathrm{ck}}^{2}}=0,21 \sqrt[3]{25^{2}}=1,80 \mathrm{~N} / \mathrm{mm}^{2}
$$

En el Anejo II se ofrecen los listados detallados de programación en lenguaje APDL de ANSYS con los parámetros empleados en la configuración, tanto de SOLID 65 como del material CONCRETE.

Es preciso indicar que el empleo del tipo de elemento SOLID 65 y del material CONCRETE conduce a importantes cambios en la manera de abordar el preproceso, especialmente en su fase de modelado y en su fase de mallado. 


\subsubsection{PREPROCESO. MODELADO}

En la Etapa I, con cálculo elástico lineal, solamente se procede al modelado de los volúmenes sólidos de la estructura de hormigón, no existiendo la necesidad de definir ningún tipo de armadura, por lo que las estructuras de hormigón armado sencillamente se modelan, en cálculo elástico lineal, como si fuesen estructuras de hormigón en masa.

Ahora bien, del mismo modo que una estructura real de hormigón ejecutada con hormigón en masa colapsaría simplemente con la aplicación de unas reducidas cargas, siendo necesaria la disposición de las correspondientes armaduras, un modelo de elementos finitos elaborado con SOLID 65 y material CONCRETE colapsa (no converge) si se modela solo con volúmenes sólidos de hormigón (hormigón en masa), siendo preciso entrar en un laborioso proceso de armado del modelo de elementos finitos, modelando todas y cada una de las armaduras, exactamente las mismas armaduras que necesitaría la estructura real para su correcto funcionamiento.

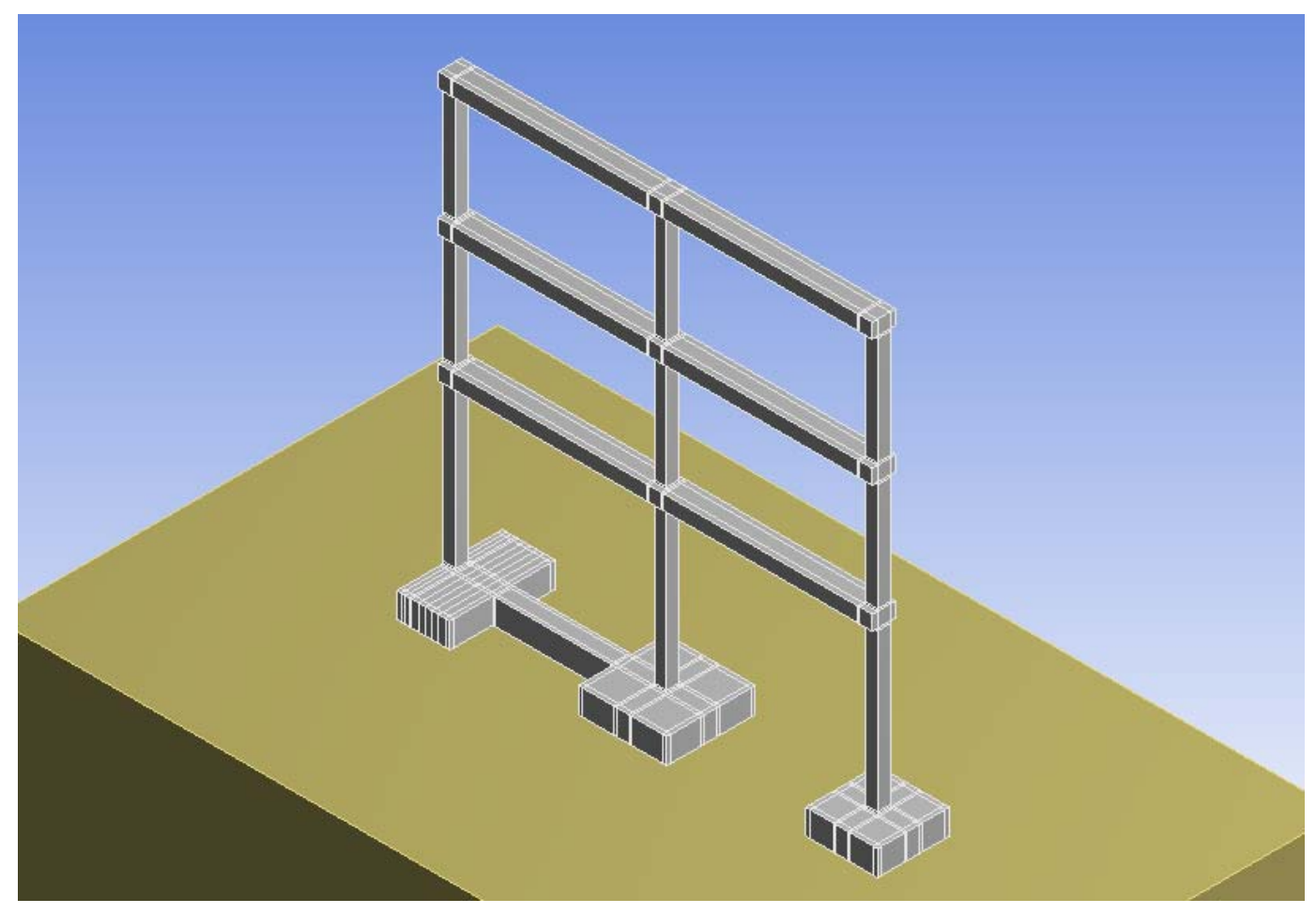

Fig.47. Modelado de pórtico tipo. Vista general exterior

En la Fig.47 se muestra el modelado de un pórtico tipo con su vista exterior, en la que puede observarse el volumen de suelo considerado, las zapatas de cimentación con la viga centradora y el entramado de vigas y pilares del pórtico. Por su parte, en la Fig.48 se muestra, gracias a la aplicación de una transparencia, el armado general del pórtico. 


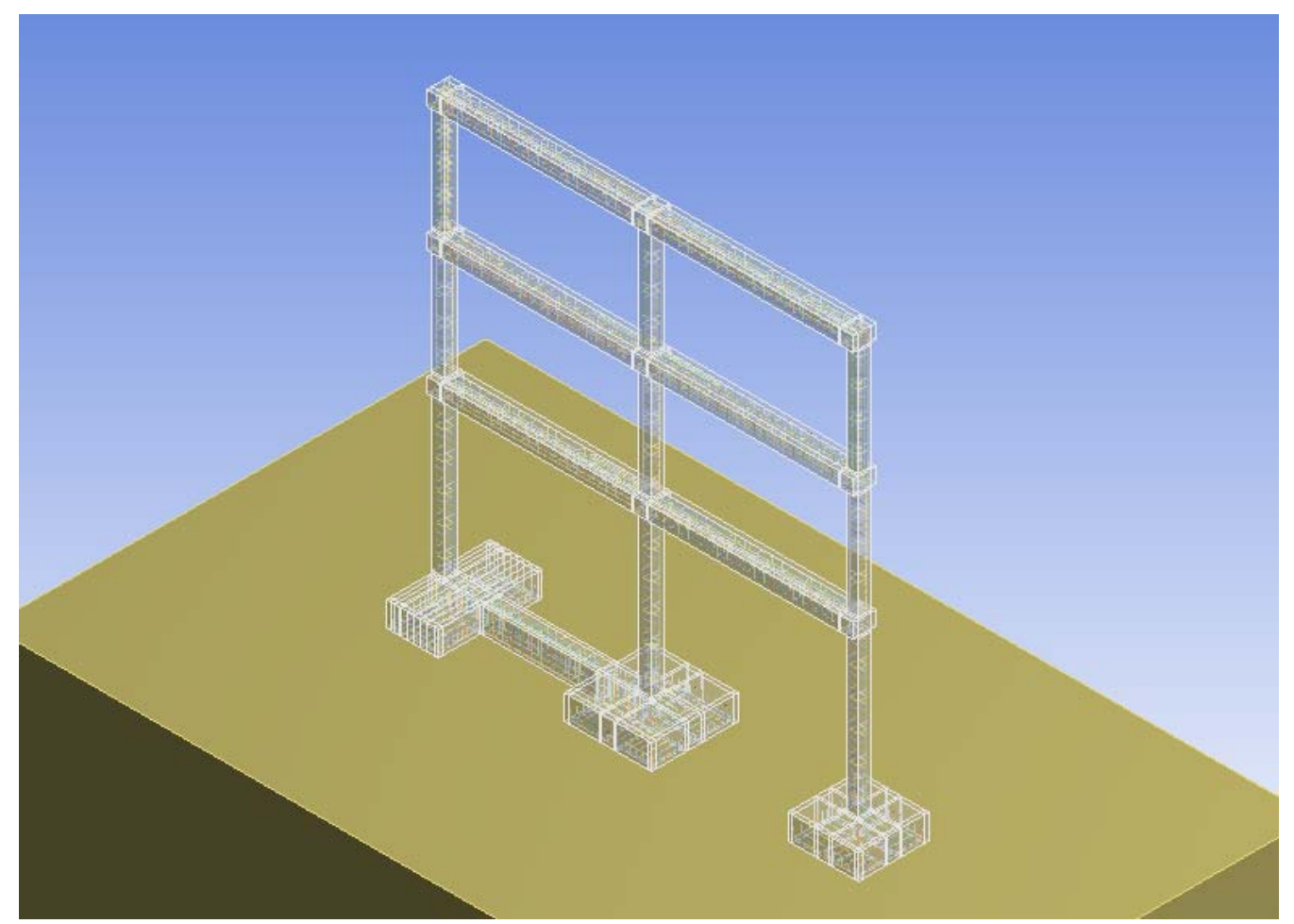

Fig.48. Modelado de las armaduras del pórtico tipo

Así, las vigas van provistas de sus armaduras de montaje, con sus correspondientes armaduras de refuerzo, tanto en positivos como en negativos, sin faltar su armadura transversal. Los pilares presentan también sus armaduras longitudinales y transversales

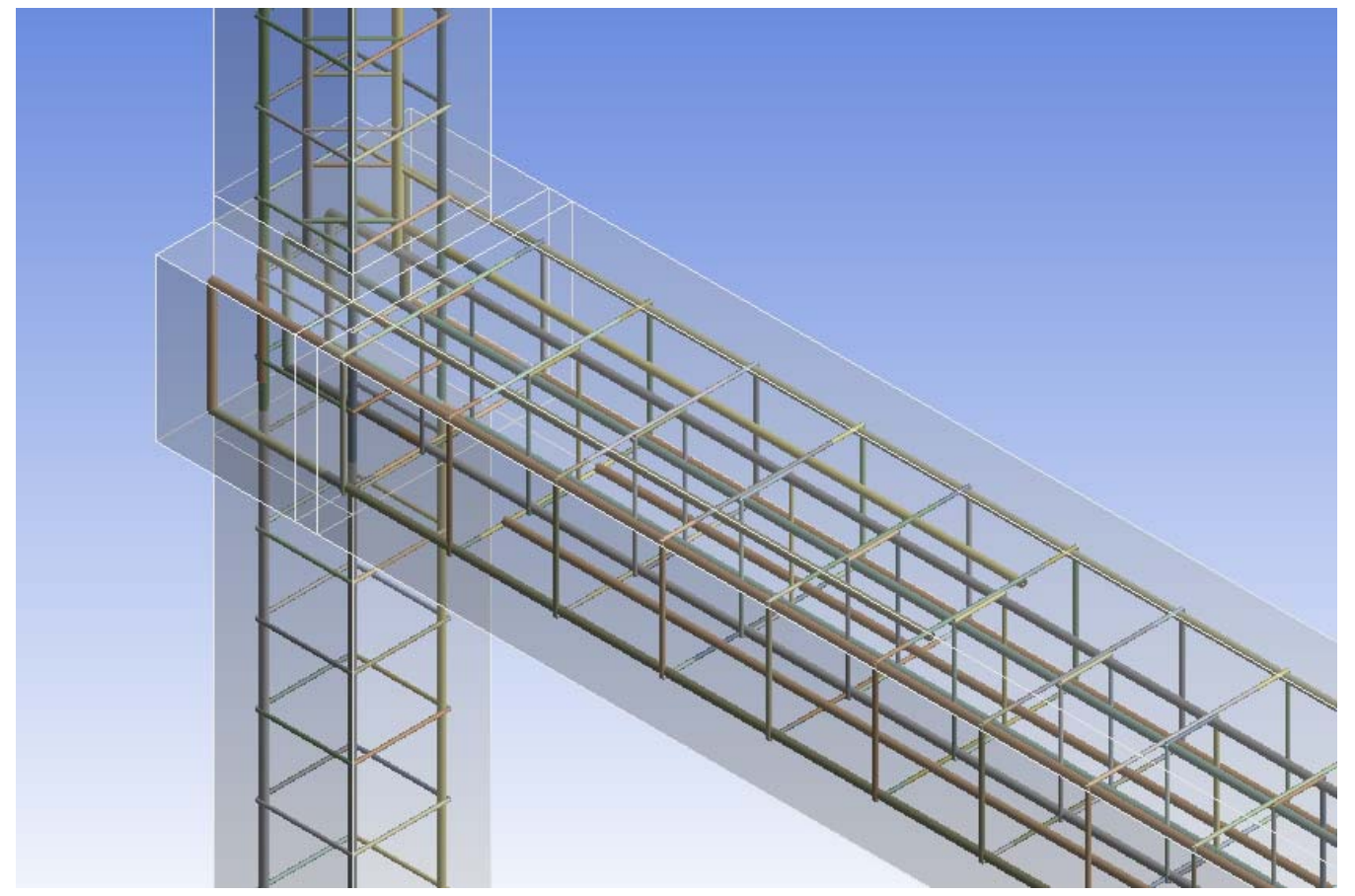

Fig.49. Detalle del modelado de las armaduras de vigas y pilares 


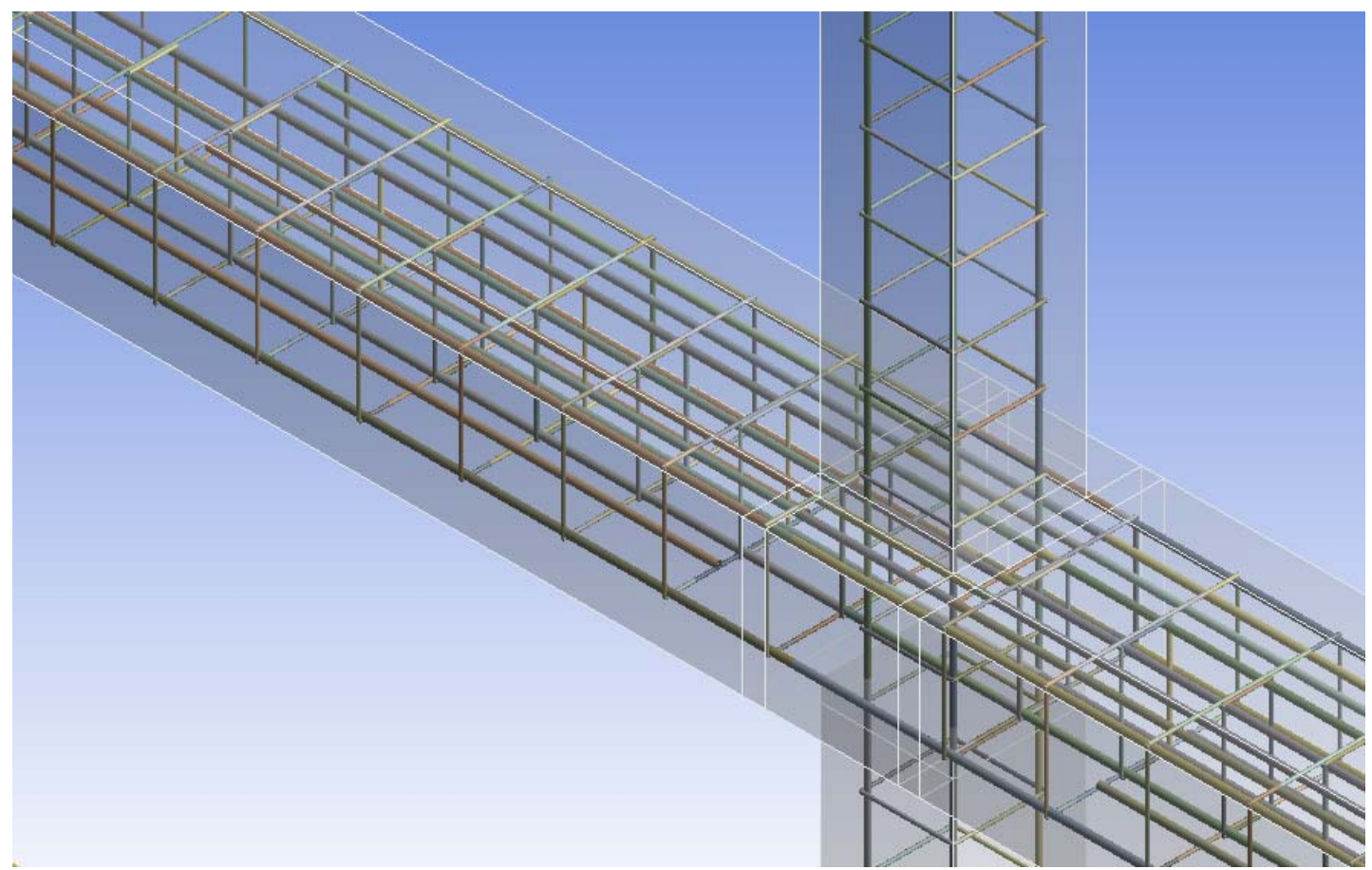

Fig.50. Detalle del modelado de las armaduras de vigas y pilares

Por su parte, en la cimentación (Fig.51) se modela la malla de armaduras de la cara traccionada de las zapatas, la armadura de espera de los pilares y las armaduras de montaje refuerzo y cercos de la viga centradora, todo ello con sus correspondientes anclajes.

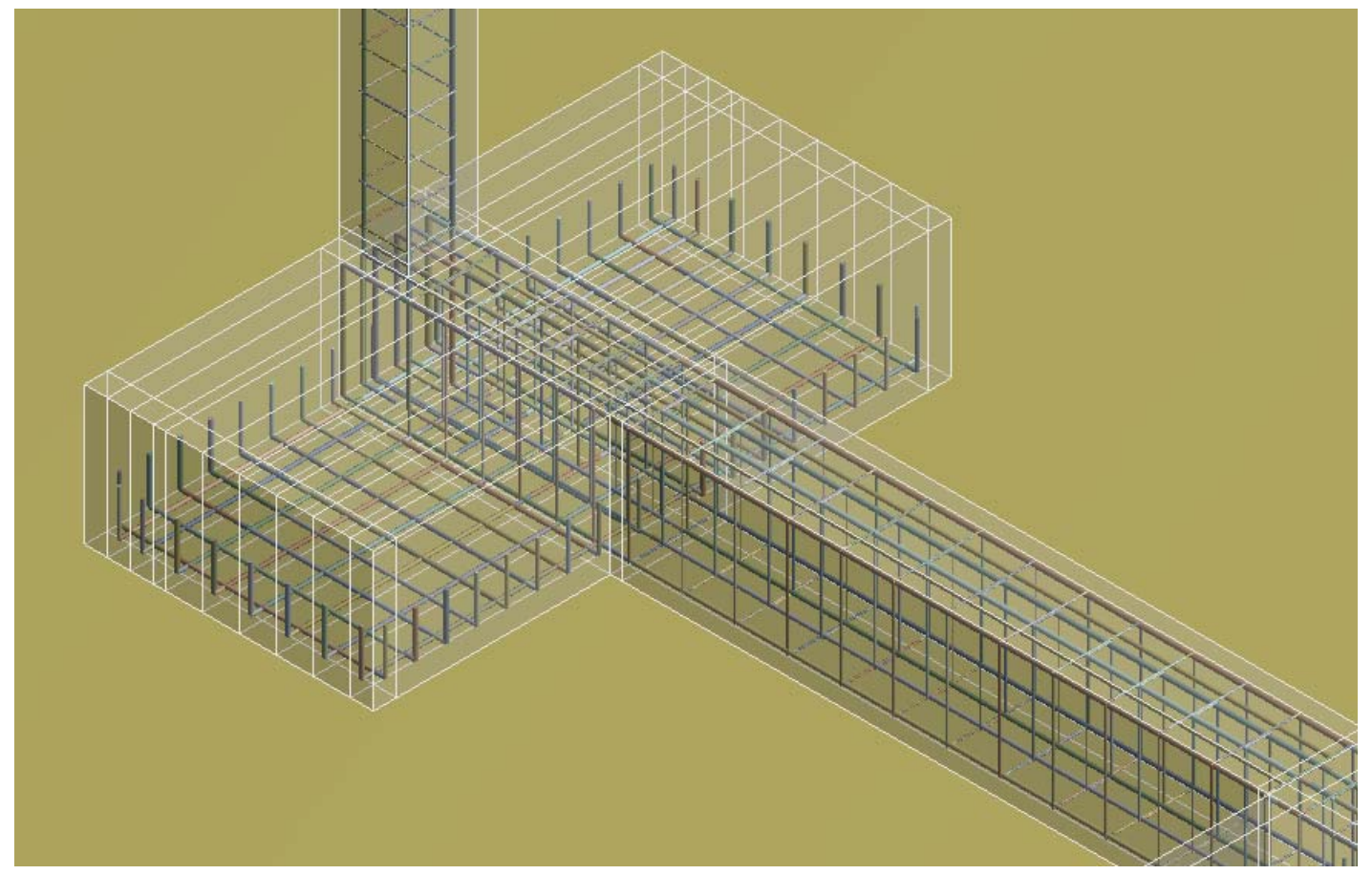

Fig.51. Detalle del modelado de las armaduras de la cimentación 


\subsubsection{PREPROCESO. MALLADO}

El hormigón armado, como material compuesto, constituye un ingenioso invento en el que la casi nula resistencia a tracción del hormigón en masa se resuelve gracias a la colaboración de la armadura de tracción. Las armaduras de acero dispuestas en las zonas traccionadas (Fig.52), desempeñan una función de "cosido", al conectar las dos orillas de las fisuras del hormigón, impidiendo que se abran de forma irreversible.

Para que el cosido de las fisuras por parte de la armadura pueda llevarse a cabo de forma efectiva, es preciso que en todo momento la armadura se encuentre firmemente vinculada al hormigón. Si la armadura deslizase o resbalase respecto del hormigón, la armadura sería incapaz de vincularse al hormigón para conectar las respectivas orillas de las sucesivas fisuras y estas progresarían indefinidamente hasta alcanzarse la rotura de la pieza de hormigón.
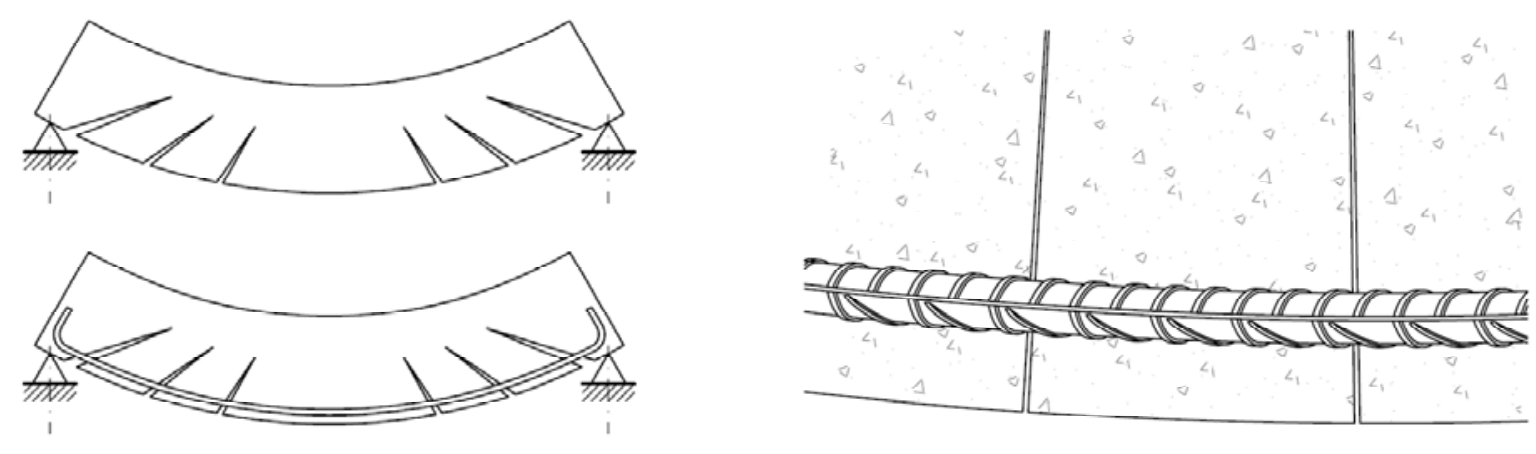

Fig.52. Concepto de adherencia

El correcto funcionamiento del hormigón armado depende, por tanto, de que quede garantizada en todo momento la adherencia entre la armadura y el hormigón. El término adherencia describe un complejo fenómeno que incluye aspectos como la adhesión o pegado entre el hormigón y el acero, la fuerza de rozamiento entre ambos y la compresión del hormigón contra los resaltos de las corrugas del acero, debido al efecto de engarce que producen las mismas (Fig.52).

Siendo fundamental la adherencia entre la armadura y el hormigón en una estructura real de hormigón armado, no lo es menos en un modelo virtual de elementos finitos que pretende reproducir el comportamiento real del hormigón de tal forma que, si no se resuelve bien la cuestión, el modelo de elementos finitos colapsa y deja de converger (como le ocurriría a una estructura real). 
El método empleado, en los modelos de elementos finitos, para simular la adherencia entre el hormigón y el acero consiste en un emparejamiento o coacción nodo a nodo entre los nodos de los elementos hexaédricos del material hormigón con los nodos de los elementos del material acero. Este método presenta un requisito importante y es que para poder vincular dos nodos de distintos materiales ambos nodos deben encontrarse, lógicamente, en la misma posición espacial con un pequeño margen de tolerancia.

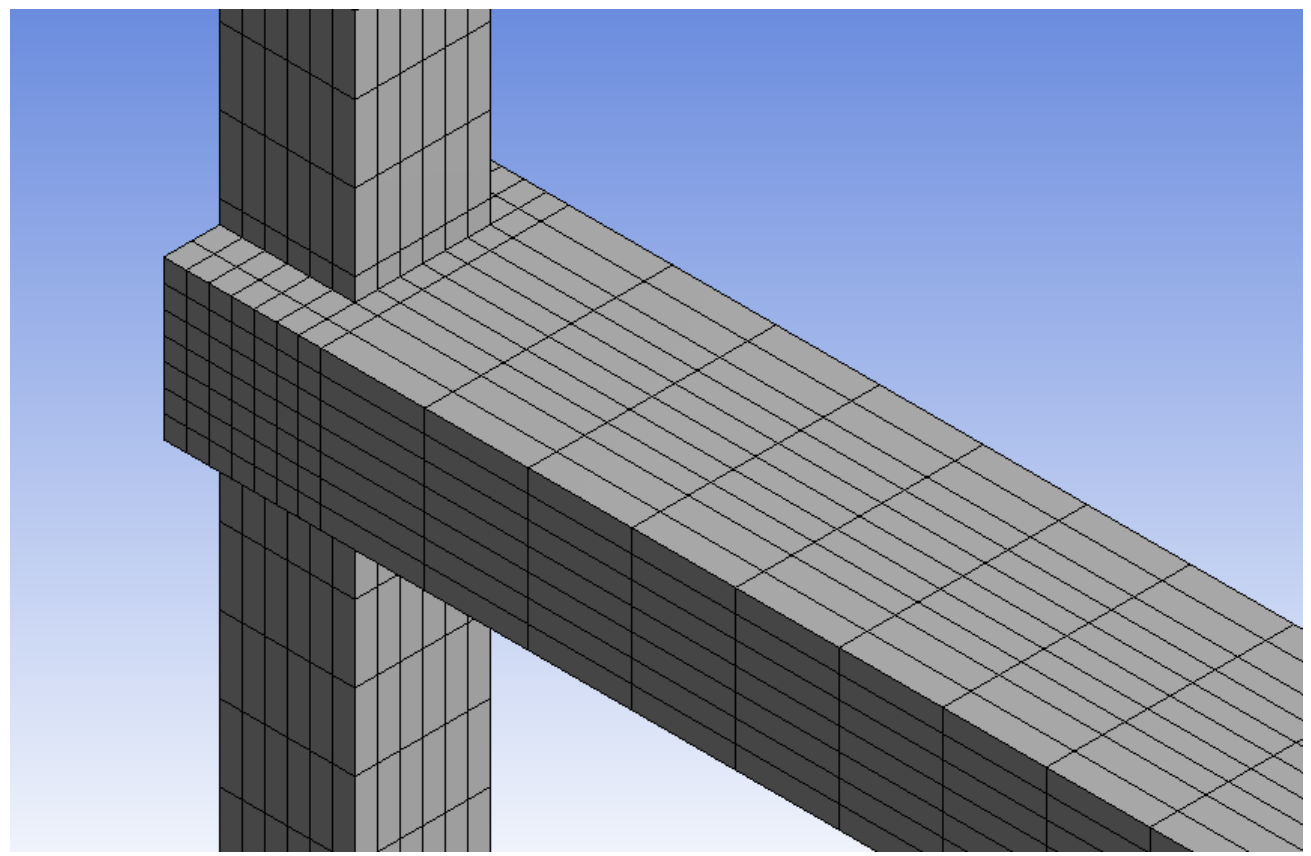

Fig.53. Mallado del material hormigón

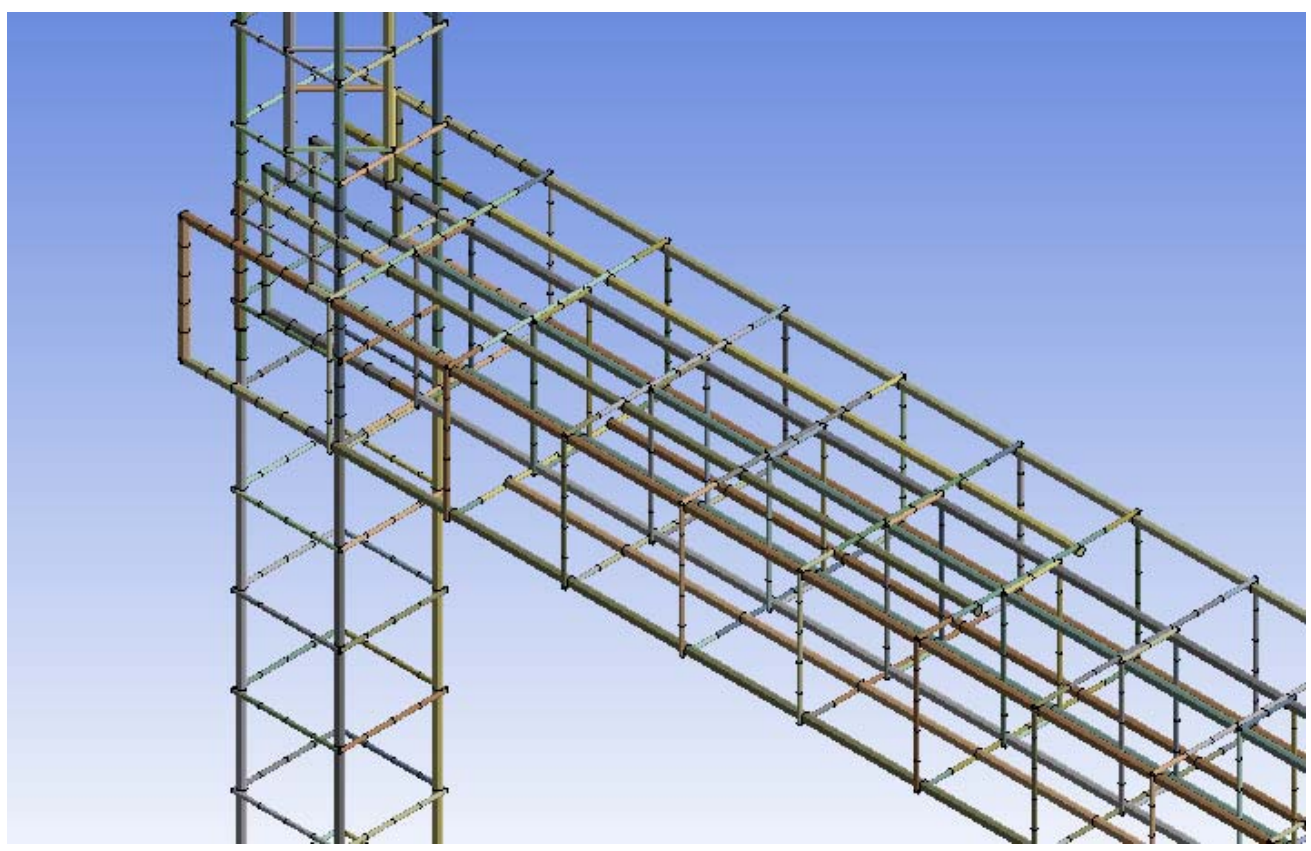

Fig.54. Mallado del material acero 
Este requisito convierte la fase de mallado del preproceso de un modelo de elementos finitos de hormigón armado en un delicadísima operación, que consiga mallar los elementos de hormigón por un lado y los de las armaduras de acero por otro, logrando la total coincidencia de los nodos de uno y otro material (Fig.53 y 54). Un error en el mallado de un elemento da lugar a la no coincidencia entre nodos y, por ello, a la "pérdida de adherencia" con el correspondiente colapso de la estructura, que se materializa en un error por imposible convergencia del modelo.

Es preciso indicar que un modelo del calibre de los empleados en esta tesis doctoral está integrado por cientos de miles de nodos, lo cual pone de manifiesto la dificultad de la operación de mallado en los mismos.

\subsubsection{CÁLCULO Y POSTPROCESO}

Tal y como se indicó en el apartado 3.3.1.2, el cálculo de un modelo de elementos finitos se lleva a cabo mediante métodos numéricos de aproximaciones sucesivas, donde la solución se obtiene por aplicación de sucesivos pasos de carga, siendo fundamental encontrar la amplitud adecuada del paso de carga acorde al problema a resolver.

Frente al planteamiento elástico lineal de la Etapa I, en las Etapas II y III se analiza el comportamiento del hormigón con un diagrama tensión - deformación parabólico rectangular más ajustado a la realidad (Fig.46) pero, al mismo, tiempo más difícil de abordar en el cálculo, tanto por el tramo parabólico como, especialmente, por el tramo horizontal de la parte rectangular.

Ello ha obligado a dos medidas para lograr la convergencia de los modelos, la primera aumentar considerablemente los pasos de carga dada la mayor complejidad del problema, llegando en algunos casos hasta 150 pasos de carga y , la segunda, darle una sutil pendiente al tramo horizontal del diagrama parábola rectángulo, que sin desvirtuar la esencia del diagrama facilita considerablemente la convergencia del mismo.

Finalmente queda la lectura e interpretación de resultados en la fase de postproceso. Pocos aspectos nuevos que comentar diferentes a los ya citados para la Etapa I. Indicar simplemente que, al contar en las Etapas II y III con dos materiales diferentes 
interactuando en la estructura de hormigón armado el hormigón y la armadura de acero) a la hora de realizar los procesos de integración de tensiones para obtener esfuerzos internos para el conjunto de las distintas secciones (Fig.55 y 56) es preciso integrar por separado la aportación de cada uno de los materiales, combinando al final el efecto conjunto y simultáneo de ambos.

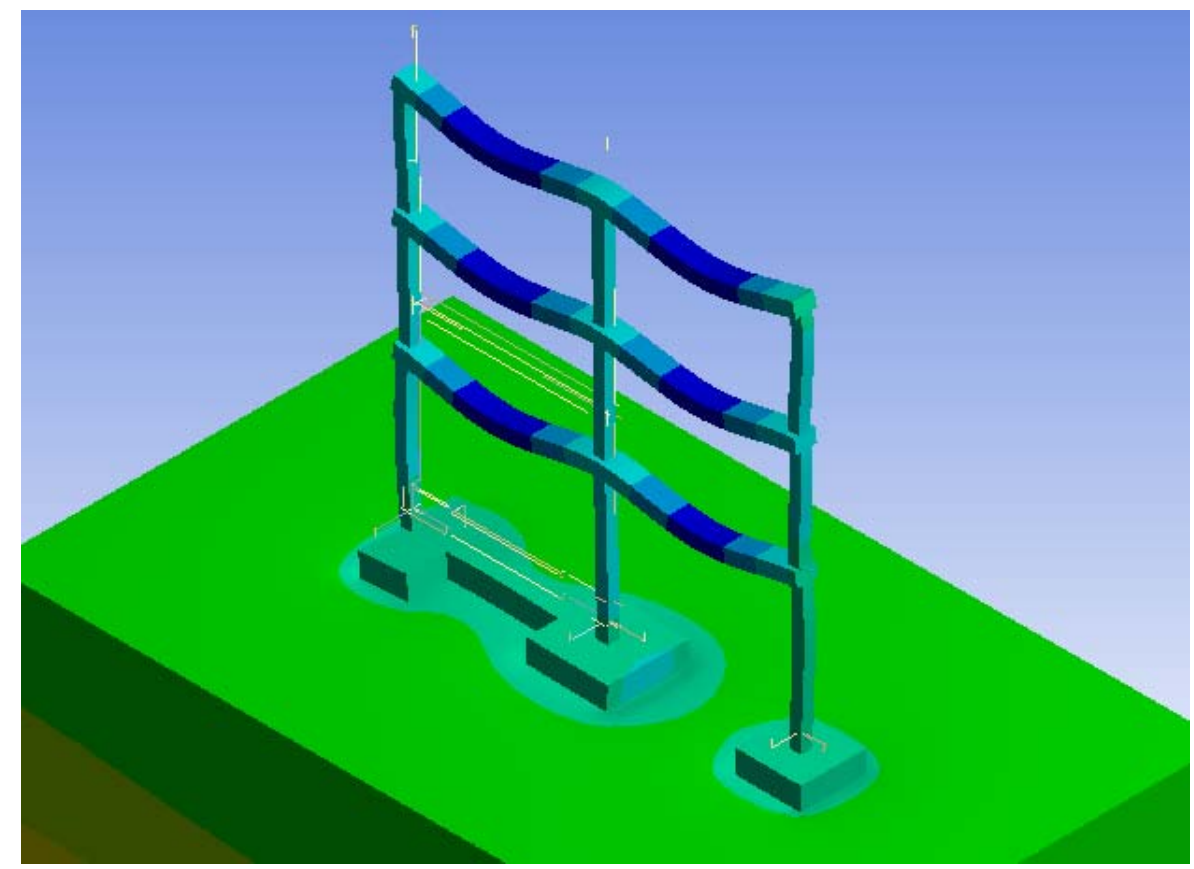

Fig.55. Integración de resultados en el hormigón

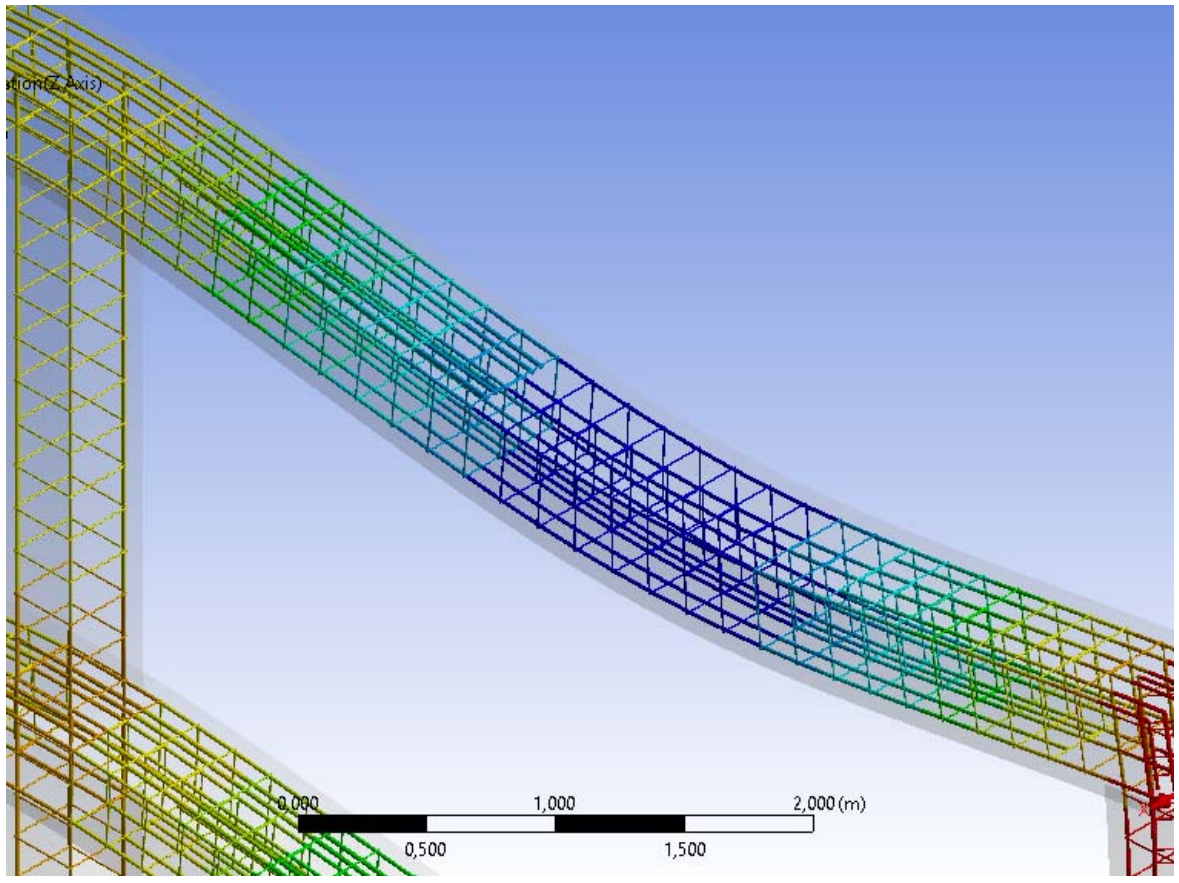

Fig.56. Integración de resultados en la armadura de acero 


\subsubsection{MODELOS DE ELEMENTOS FINITOS. ETAPA IV}

Los modelos de elementos finitos empleados en la Etapa IV para estudiar el caso de las zapatas de esquina presentan un considerable tamaño frente a los modelos empleados para los casos de zapata de medianería en las etapas anteriores. Ello se debe al hecho de emplear dos pórticos consecutivos con sus correspondientes elementos de atado, frente al único pórtico de los modelos de medianería, junto con un volumen de suelo mucho mayor, con el fin de poder abarcar el conjunto de los dos pórticos, sin olvidar el completo armado de todos los elementos de hormigón indicados.

El escenario descrito genera modelos de elementos finitos enormes, que pueden llegar a alcanzar cifras próximas al millón de elementos. Ello obliga a un ejercicio de racionalidad, con el fin de optimizar los modelos, de forma que sean técnicamente abordables desde un punto de vista informático.

Los resultados de la Etapa I ponen de manifiesto la prácticamente nula influencia de la rigidez de los pórticos en el comportamiento de la cimentación. Siendo esto así, la detallada definición de los armados de los pórticos para estudiar con precisión la deformabilidad de los mismos, puede suponer un considerable empleo de recursos que probablemente no conduzca a una variación de los resultados relativos al comportamiento de la cimentación.

Esta idea señala a los pórticos como los elementos estructurales más propicios para ser simplificados sin perder precisión en los resultados de la cimentación. Dicha simplificación puede llevarse a cabo realizando un cálculo elástico lineal de esta parte del modelo, bien con secciones brutas o bien con secciones reducidas para simular el efecto de la fisuración del hormigón. En este sentido el código ACI 318 - 14 plantea que pueden obtenerse de forma aproximada los esfuerzos en un pórtico, simulando el efecto de la fisuración del hormigón, si se realiza un cálculo elástico lineal con reducción del $70 \%$ en la rigidez de los pilares y del $35 \%$ en la rigidez de las vigas.

Por todo ello, se opta finalmente por un esquema mixto, abordando los modelos de elementos finitos para la zapata de esquina con un planteamiento elástico lineal con secciones reducidas en la parte aérea de la estructura, reservando el estudio detallado del hormigón, con sus armados y su fisuración, para los elementos de cimentación del entorno de la zapata de esquina, que son los que realmente influyen en el resultado del problema. De esta forma, puede prescindirse de la definición detallada de los armados de los pórticos y 
pueden emplearse tamaños de elemento más grandes, que conducen en conjunto, a modelos más manejables, informáticamente hablando, si bien se siguen alcanzando modelos de hasta 400.000 elementos en los casos de mayor luz y mayor número de plantas. 
CAPÍTULO 4

RESULTADOS EXPERIMENTALES 



\section{RESULTADOS EXPERIMENTALES}

\subsection{RESULTADOS EXPERIMENTALES. ETAPA I}

\subsubsection{RESULTADOS DE LOS MODELOS CONVENCIONALES}

\subsubsection{ZAPATA DE MEDIANERÍA CON VIGA CENTRADORA}

Se ofrecen en las Tablas 11, 12 y 13, los resultados del cálculo del modelo convencional de zapata de medianería con viga centradora, correspondientes a la Etapa I, para cada uno de los tres niveles de rigidez planteados en el pórtico tipo. Los parámetros a los que hacen referencia dichos resultados son los representados en las Fig. 6 y 7.

En cada tabla se exponen, en primer lugar, las reacciones en la base de los pilares utilizadas como dato de partida en el cálculo. Dichas reacciones se han obtenido del cálculo del pórtico tipo por método matricial bajo la hipótesis de bases de pilares perfectamente empotrados en la cimentación. El cálculo en cuestión se ha realizado con ayuda del programa de cálculo matricial CYPE 3D.

Asimismo, en el primer bloque (relacionado con los esfuerzos), se ofrecen los esfuerzos en el nudo de medianería de la viga de la primera planta. El objetivo de esta información es conocer el axil en dicha viga de acuerdo con el cálculo del pórtico por método matricial. Una de las cuestiones planteadas en esta tesis es el estudio del trabajo conjunto de la pareja viga centradora - viga primera planta. El modelo convencional con viga centradora no considera en absoluto la intervención de la viga de la primera planta, pero como utiliza como dato de partida las reacciones de los pilares obtenidas del método matricial, se ha considerado que el axil de dicha viga proporcionado por el método matricial puede ser un término de referencia adecuado (tal vez el único) para contrastar posteriormente con los resultados del M.E.F.

Los axiles en cuestión dependen solamente de la rigidez del pórtico y no varían ni con la resistencia del terreno ni con la relación de forma de la cimentación. Los valores obtenidos para dicho axil han sido siempre de tracción y muy reducidos, motivo por el cual, suelen despreciarse en la práctica, calculando la viga a flexión simple.

Seguidamente se ofrecen, para cada nivel de tensión admisible del terreno y relación de forma de la zapata de medianería, los siguientes resultados: 
- Dimensionamiento necesario para las zapatas de medianería e interior de acuerdo con el modelo convencional.

- Resultante de las presiones de contacto en la zapata de medianería $R_{m}(k N)$.

- Tensión transmitida al terreno en la zapata de medianería $\sigma_{m}\left(\mathrm{kN} / \mathrm{m}^{2}\right)$, calculada bajo la hipótesis de distribución de tensiones uniformemente repartida.

- Resultante de las tensiones de contacto en la zapata interior $R_{i}(k N)$.

- Tensión transmitida al terreno por la zapata interior $\sigma_{i}\left(\mathrm{kN} / \mathrm{m}^{2}\right)$, calculada bajo la hipótesis de distribución de presiones uniformemente repartida.

- Momento flector de servicio $M_{1 v}$ en la sección más desfavorable de la viga centradora (unión de la viga centradora con la zapata de medianería)

Es preciso indicar que, de los dos modelos convencionales expuestos para la zapata de medianería, es el de zapata con viga centradora el que condiciona el dimensionamiento de la zapata de medianería, debido al incremento de reacción que experimenta dicha zapata respecto del modelo con colaboración de la viga superior. Como consecuencia de ello, para poder contrastar resultados, los otros dos modelos (convencional con viga superior y M.E.F) se calculan con las mismas dimensiones de zapata obtenidas con el modelo convencional de viga centradora. Puede comprobarse que la variación del nivel de rigidez del pórtico ha tenido nula incidencia sobre los resultados de las dimensiones de las diversas zapatas.

Al considerar el modelo convencional de zapata con viga centradora, distribuciones de tensiones sobre el terreno uniformemente repartidas, las resultantes en cuestión se encuentran aplicadas en el centro de las respectivas zapatas. Por ese motivo, no se hace aquí referencia a ninguna excentricidad respecto del centro de las zapatas, ya que sería en todos los casos nula.

Finalmente señalar, que a la vista del esquema del modelo convencional (Fig. 6 y 7), la viga centradora se encuentra solicitada a flexión simple, con axil nulo. 


\begin{tabular}{|c|c|c|c|}
\hline$h=300$ & \multicolumn{3}{|c|}{ REACCIONES } \\
\hline PILAR MEDIANERIA & 517,96 & 13,91 & 18,41 \\
\hline PILAR INTERIOR & 853,87 & - & - \\
\hline VIGA $1^{\mathrm{a}}$ PLANTA & 25,12 & 127,50 & 100,42 \\
\hline
\end{tabular}

\begin{tabular}{|c|c|c|c|c|c|}
\hline & \multirow{2}{*}{\multicolumn{2}{|c|}{$h=300$}} & \multicolumn{3}{|c|}{ TENSIÓN ADMISIBLE } \\
\hline & & & $100 \mathrm{kN} / \mathrm{m}^{2}$ & $200 \mathrm{kN} / \mathrm{m}^{2}$ & $300 \mathrm{kN} / \mathrm{m}^{2}$ \\
\hline \multirow{18}{*}{$\begin{array}{l}\text { 뜰 } \\
\text { о } \\
\text { 안 }\end{array}$} & \multirow{6}{*}{$2: 1$} & $\begin{array}{l}\text { ZAPATA MED. } \\
\text { ZAPATA INT. }\end{array}$ & $\begin{array}{l}4.400 \times 2.200 \times 700 \\
3.400 \times 3.400 \times 700\end{array}$ & $\begin{array}{l}2.700 \times 1.350 \times 700 \\
2.250 \times 2.250 \times 700\end{array}$ & $\begin{array}{l}2.200 \times 1.100 \times 700 \\
1.800 \times 1.800 \times 700\end{array}$ \\
\hline & & $\mathrm{R}_{\mathrm{m}}(\mathrm{kN})$ & 910,35 & 704,97 & 661,33 \\
\hline & & $\sigma_{\mathrm{m}}\left(\mathrm{kN} / \mathrm{m}^{2}\right)$ & 94,04 & 193,41 & 273,28 \\
\hline & & $\mathrm{R}_{\mathrm{i}}(\mathrm{kN})$ & 1088,60 & 966,19 & 932,10 \\
\hline & & $\sigma_{\mathrm{i}} \quad\left(\mathrm{kN} / \mathrm{m}^{2}\right)$ & 94,17 & 190,85 & 287,69 \\
\hline & & $\mathrm{M}_{1 \mathrm{v}}(\mathrm{kN} \cdot \mathrm{m})$ & 385,62 & 242,45 & 193,58 \\
\hline & \multirow{6}{*}{$1,5: 1$} & $\begin{array}{l}\text { ZAPATA MED. } \\
\text { ZAPATA INT. }\end{array}$ & $\begin{array}{l}3.900 \times 2.600 \times 700 \\
3.300 \times 3.300 \times 700\end{array}$ & $\begin{array}{l}2.400 \times 1.600 \times 700 \\
2.200 \times 2.200 \times 700\end{array}$ & $\begin{array}{l}1.900 \times 1.266 \times 700 \\
1.800 \times 1.800 \times 700\end{array}$ \\
\hline & & $\mathrm{R}_{\mathrm{m}}(\mathrm{kN})$ & 945,11 & 721,23 & 667,56 \\
\hline & & $\sigma_{\mathrm{m}}\left(\mathrm{kN} / \mathrm{m}^{2}\right)$ & 93,21 & 187,82 & 277,53 \\
\hline & & $\mathrm{R}_{\mathrm{i}} \quad(\mathrm{kN})$ & 1042,62 & 945,71 & 922,91 \\
\hline & & $\sigma_{\mathrm{i}} \quad\left(\mathrm{kN} / \mathrm{m}^{2}\right)$ & 95,74 & 195,39 & 284,85 \\
\hline & & $\mathrm{M}_{1 \mathrm{v}}(\mathrm{kN} \cdot \mathrm{m})$ & 436,25 & 287,88 & 226,07 \\
\hline & \multirow{6}{*}{$1: 1$} & $\begin{array}{l}\text { ZAPATA MED. } \\
\text { ZAPATA INT. }\end{array}$ & $\begin{array}{l}3.250 \times 3.250 \times 700 \\
3.250 \times 3.250 \times 700\end{array}$ & $\begin{array}{l}2.000 \times 2.000 \times 700 \\
2.200 \times 2.200 \times 700\end{array}$ & $\begin{array}{l}1.550 \times 1.550 \times 700 \\
1.800 \times 1.800 \times 700\end{array}$ \\
\hline & & $\mathrm{R}_{\mathrm{m}}(\mathrm{kN})$ & 997,49 & 744,36 & 679,56 \\
\hline & & $\sigma_{\mathrm{m}}\left(\mathrm{kN} / \mathrm{m}^{2}\right)$ & 94,44 & 186,09 & 282,86 \\
\hline & & $\mathrm{R}_{\mathrm{i}} \quad(\mathrm{kN})$ & 983,30 & 920,91 & 901,90 \\
\hline & & $\sigma_{\mathrm{i}} \quad\left(\mathrm{kN} / \mathrm{m}^{2}\right)$ & 93,09 & 190,27 & 294,50 \\
\hline & & $\mathrm{M}_{1 \mathrm{v}}(\mathrm{kN} \cdot \mathrm{m})$ & 491,75 & 353,58 & 278,55 \\
\hline
\end{tabular}

Tabla 11. Zapata de medianería con viga centradora. Modelo convencional. Etapa I Resultados para nivel de rigidez de pórtico tipo $h=300$ 


\begin{tabular}{|c|c|c|c|}
\hline \multirow{2}{*}{$h=450$} & \multicolumn{3}{|c|}{ REACCIONES } \\
\hline & $N(k N)$ & $V(k N)$ & $M(k N \cdot m)$ \\
\hline PILAR MEDIANERIA & 520,10 & 21,18 & 20,82 \\
\hline PILAR INTERIOR & 865,53 & - & - \\
\hline VIGA $1^{\mathrm{a}}$ PLANTA & 15,54 & 129,91 & 100,99 \\
\hline
\end{tabular}

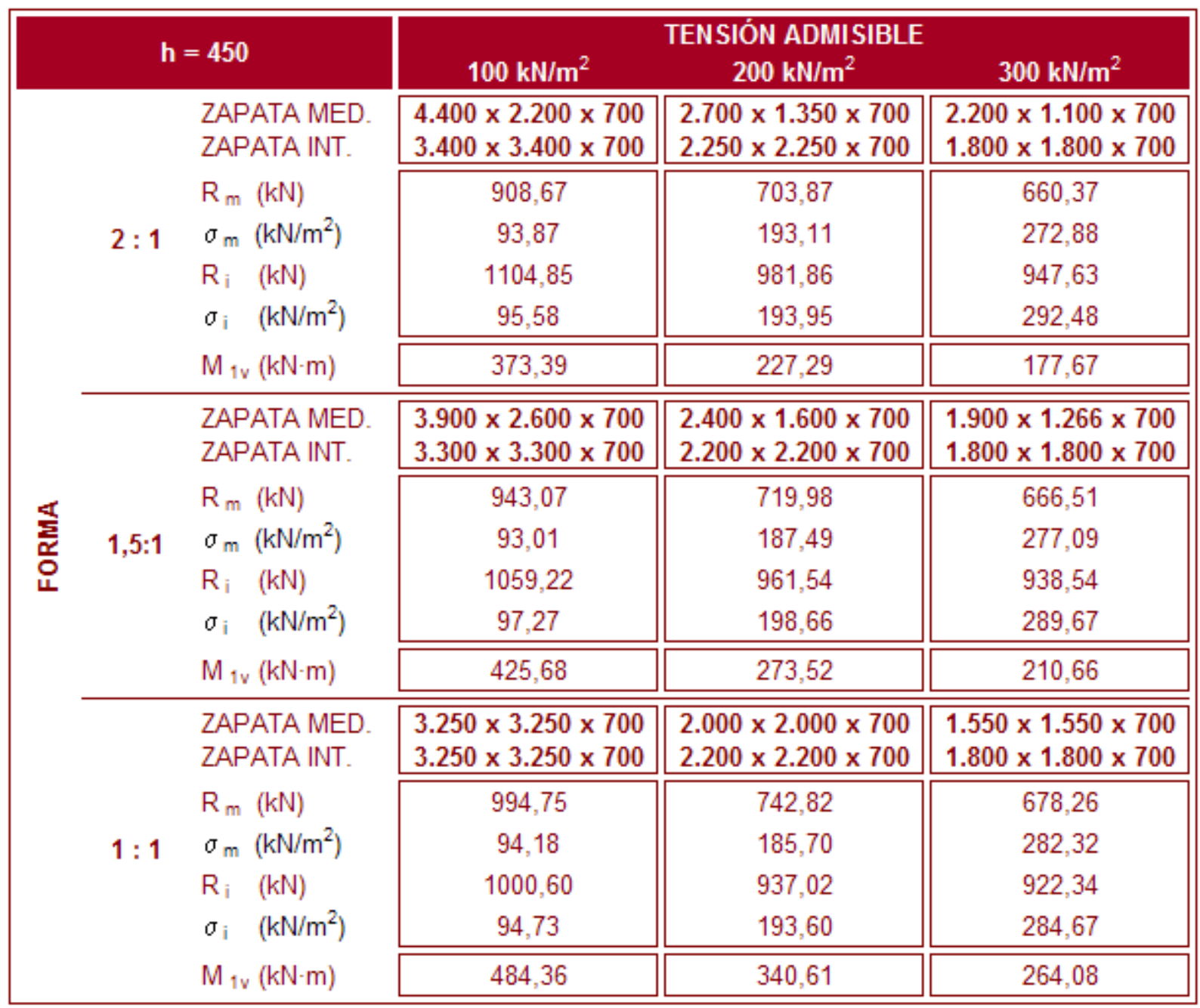

Tabla 12. Zapata de medianería con viga centradora. Modelo convencional. Etapa I Resultados para nivel de rigidez de pórtico tipo $\mathrm{h}=450$ 


\begin{tabular}{|l|c|c|c|}
\hline \multicolumn{1}{|c|}{$\mathbf{h}=\mathbf{6 0 0}$} & \multicolumn{3}{|c|}{ REACCIONES } \\
$\mathbf{V}(\mathbf{k N})$ & $\mathbf{M}(\mathbf{k N} \cdot \mathbf{m})$ \\
\hline PILAR MEDIANERIA & $\mathbf{N}(\mathbf{k N})$ & 13,22 & 17,49 \\
PILAR INTERIOR & 512,58 & - & - \\
VIGA 1 ${ }^{\mathbf{s}}$ PLANTA & 841,35 & 128,07 & 96,52 \\
\hline
\end{tabular}

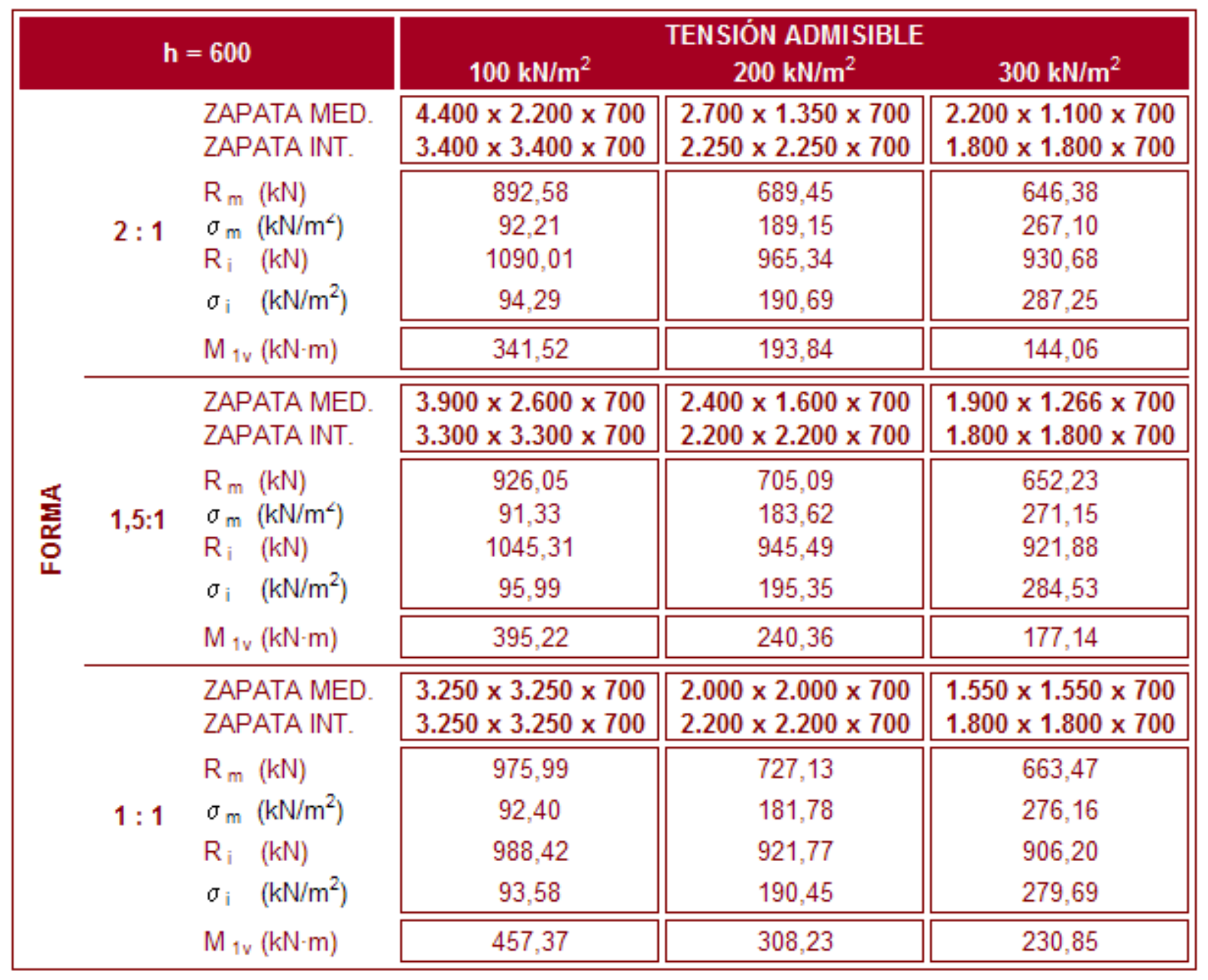

Tabla 13. Zapata de medianería con viga centradora. Modelo convencional. Etapa I Resultados para nivel de rigidez de pórtico tipo $\mathrm{h}=600$ 


\subsubsection{ZAPATA DE MEDIANERÍA CON COLABORACIÓN DE VIGA SUPERIOR}

Se ofrecen en las Tablas 14, 15 y 16, los resultados del cálculo del modelo convencional de zapata de medianería con colaboración de viga superior, para cada uno de los tres niveles de rigidez planteados en el pórtico tipo, en la Etapa I. Los parámetros a los que hacen referencia dichos resultados son los representados en las Fig. 8 y 9.

En cada tabla se exponen, en primer lugar, las reacciones en cabeza del pilar de medianería, como dato de partida para el cálculo. Dichas reacciones se han obtenido del mismo cálculo del pórtico tipo por método matricial, bajo la hipótesis de bases de pilares perfectamente empotrados en la cimentación, realizado a propósito del cálculo del modelo convencional con viga centradora.

Seguidamente se ofrecen, para cada nivel de tensión admisible del terreno y relación de forma de la zapata de medianería, los siguientes resultados:

- Dimensionamiento utilizado para la zapata de medianería.

- Resultante de la fuerza de rozamiento entre zapata y terreno $R_{m x}(k N)$.

- Resultante de las tensiones de contacto en la zapata de medianería $\mathrm{R}_{\text {my }}(\mathrm{kN})$.

- Tensión transmitida al terreno por la zapata de medianería $\sigma_{m}\left(\mathrm{kN} / \mathrm{m}^{2}\right)$, calculada bajo la hipótesis de distribución de presiones uniformemente repartida.

- Fuerza de tracción T (kN) generada en la viga de la primera planta para equilibrar y centrar el comportamiento de la zapata de medianería.

Tal y como se ha indicado en el apartado anterior, el modelo de zapata de medianería con viga centradora es más restrictivo respecto del tamaño necesario para la zapata de medianería, por lo cual, se han utilizado las mismas dimensiones de zapata obtenidas en el caso anterior con el fin de poder contrastar resultados. 


\begin{tabular}{|c|c|c|c|}
\hline $\mathbf{h}=\mathbf{3 0 0}$ & \multicolumn{3}{|c|}{ REACCIONES } \\
$\mathbf{V}(\mathbf{k N})$ & $\mathbf{M}(\mathbf{k N} \cdot \mathbf{m})$ \\
\hline PILAR MED. NUDO SUP. & $\mathbf{N}(\mathbf{k N})$ & 13,86 & 37,01 \\
\hline
\end{tabular}

\begin{tabular}{|c|c|c|c|c|c|}
\hline \multirow{2}{*}{\multicolumn{3}{|c|}{$h=300$}} & \multicolumn{3}{|c|}{ TENSIÓN ADMISIBLE } \\
\hline & & & $100 \mathrm{kN} / \mathrm{m}^{2}$ & $200 \mathrm{kN} / \mathrm{m}^{2}$ & $300 \mathrm{kN} / \mathrm{m}^{2}$ \\
\hline \multirow{15}{*}{$\begin{array}{l}\frac{1}{5} \\
\text { 몽 } \\
\text { 난 }\end{array}$} & & $4.400 \times 2.200 \times 700$ & $2.700 \times 1.350 \times 700$ & $2.200 \times 1.100 \times 700$ \\
\hline & \multirow{4}{*}{$2: 1$} & \multirow{4}{*}{$\begin{array}{ll}\mathrm{R}_{\mathrm{mx}} & (\mathrm{kN}) \\
\mathrm{R}_{\mathrm{my}} & (\mathrm{kN}) \\
\sigma_{\mathrm{m}} & \left(\mathrm{kN} / \mathrm{m}^{2}\right) \\
\mathrm{T} & (\mathrm{kN})\end{array}$} & 96,87 & 50,01 & 36,23 \\
\hline & & & 788,29 & 619,92 & 585,74 \\
\hline & & & 81,44 & 170,07 & 242,04 \\
\hline & & & 110,73 & 63,87 & 50,09 \\
\hline & \multirow{5}{*}{$1,5: 1$} & \multirow{5}{*}{$\begin{array}{l}\text { ZAPATA MED. } \\
\mathrm{R}_{\mathrm{mx}}(\mathrm{kN}) \\
\mathrm{R}_{\mathrm{my}}(\mathrm{kN}) \\
\sigma_{\mathrm{m}}\left(\mathrm{kN} / \mathrm{m}^{2}\right) \\
\mathrm{T} \quad(\mathrm{kN})\end{array}$} & $3.900 \times 2.600 \times 700$ & $2.400 \times 1.600 \times 700$ & $1.900 \times 1.266 \times 700$ \\
\hline & & & 118,92 & 63,79 & 45,38 \\
\hline & & & 801,13 & 625,36 & 585,33 \\
\hline & & & 79,01 & 162,85 & 243,34 \\
\hline & & & 132,78 & 77,65 & 59,24 \\
\hline & \multirow{5}{*}{$1: 1$} & ZAPATA MED. & $3.250 \times 3.250 \times 700$ & $2.000 \times 2.000 \times 700$ & $1.550 \times 1.550 \times 700$ \\
\hline & & $\mathrm{R}_{\mathrm{mx}}(\mathrm{kN})$ & 154,76 & 85,85 & 61,04 \\
\hline & & $\mathrm{R}_{\mathrm{my}}(\mathrm{kN})$ & 812,91 & 629,82 & 585,25 \\
\hline & & $\sigma_{\mathrm{m}}\left(\mathrm{kN} / \mathrm{m}^{2}\right)$ & 76,96 & 157,46 & 243,60 \\
\hline & & $\mathrm{T} \quad(\mathrm{kN})$ & 168,62 & 99,71 & 74,90 \\
\hline
\end{tabular}

Tabla 14. Zapata de medianería con colaboración de viga superior. M. convencional. Etapa I Resultados para nivel de rigidez de pórtico tipo $h=300$ 


\begin{tabular}{|c|c|c|c|}
\hline \multicolumn{1}{|c|}{$\mathbf{h}=\mathbf{4 5 0}$} & \multicolumn{3}{|c|}{ REACCIONES } \\
$\mathbf{V}(\mathbf{k N})$ & $\mathbf{M}(\mathbf{k N} \cdot \mathbf{m})$ \\
\hline PILAR MED. NUDO SUP. & $\mathbf{N}(\mathbf{k N})$ & 21,18 & 42,73 \\
\hline
\end{tabular}

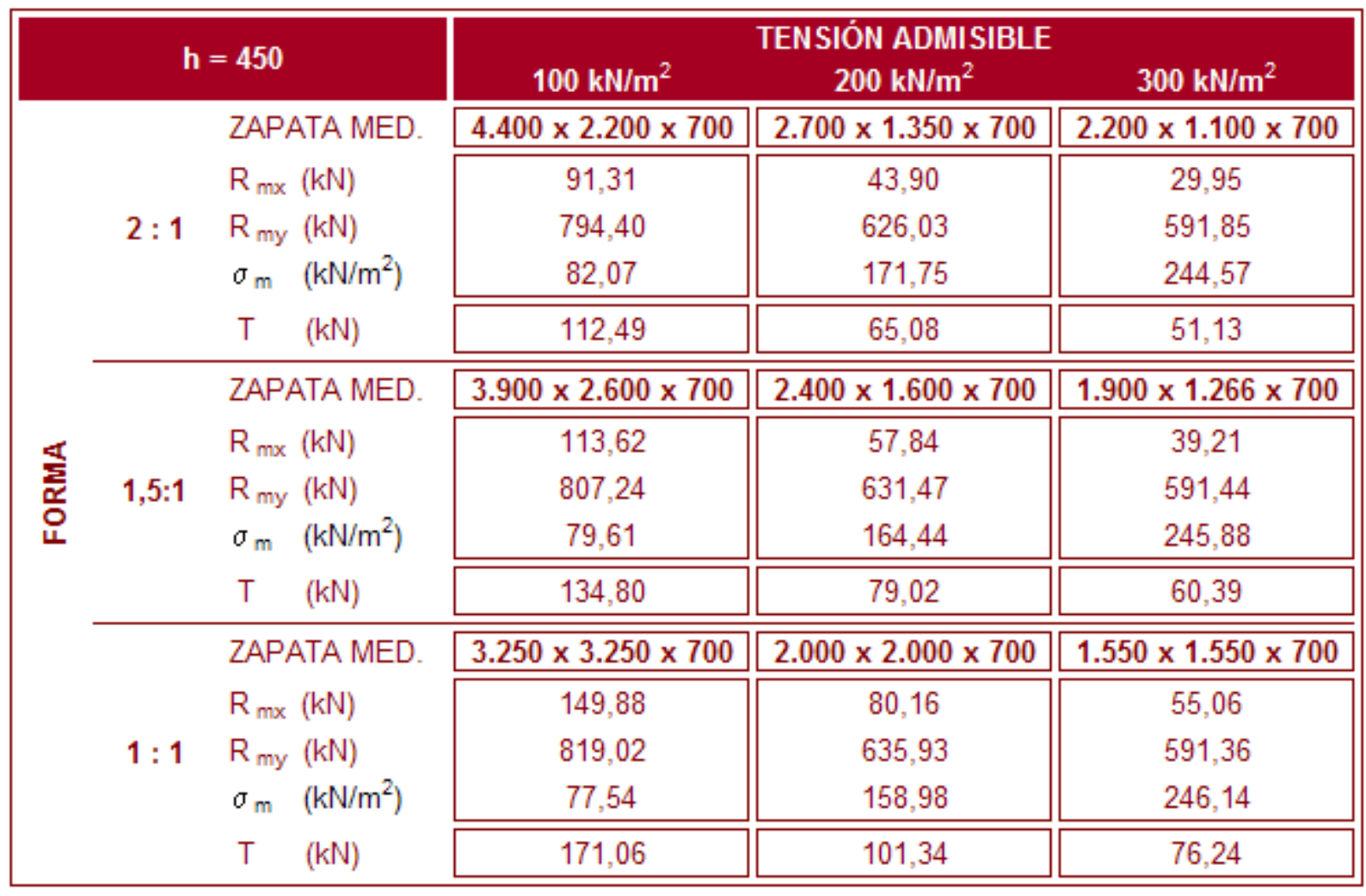

Tabla 15. Zapata de medianería con colaboración de viga superior. M. convencional. Etapa I Resultados para nivel de rigidez de pórtico tipo $h=450$ 


\begin{tabular}{|c|c|c|c|}
\hline \multicolumn{1}{|c|}{$\mathbf{h}=\mathbf{6 0 0}$} & \multicolumn{3}{|c|}{$\begin{array}{c}\text { REACCIONES } \\
\mathbf{V}(\mathbf{k N})\end{array}$} \\
\hline PILAR MED. NUDO SUP. & $\mathbf{N}$ (kN) & $\mathbf{M}$ (kN·m) \\
\cline { 2 - 4 } & 497,86 & 13,22 & 35,40 \\
\hline
\end{tabular}

\begin{tabular}{|c|c|c|c|c|c|}
\hline \multirow{2}{*}{\multicolumn{3}{|c|}{$h=600$}} & \multicolumn{3}{|c|}{ TENSIÓN ADMISIBLE } \\
\hline & & & $100 \mathrm{kN} / \mathrm{m}^{2}$ & $200 \mathrm{kN} / \mathrm{m}^{2}$ & $300 \mathrm{kN} / \mathrm{m}^{2}$ \\
\hline \multirow{15}{*}{$\begin{array}{l}\frac{\pi}{5} \\
\text { 잉 } \\
\text { 인 }\end{array}$} & \multirow{5}{*}{$2: 1$} & ZAPATA MED. & $4.400 \times 2.200 \times 700$ & $2.700 \times 1.350 \times 700$ & $2.200 \times 1.100 \times 700$ \\
\hline & & \multirow{2}{*}{$\begin{array}{l}R_{m x}(k N) \\
R_{m y}(k N)\end{array}$} & 85,22 & 38,84 & 25,20 \\
\hline & & & 782,93 & 614,56 & 580,38 \\
\hline & & $\sigma_{\mathrm{m}} \quad\left(\mathrm{kN} / \mathrm{m}^{2}\right)$ & 80,88 & 168,60 & 239,83 \\
\hline & & $\mathrm{T} \quad(\mathrm{kN})$ & 98,44 & 52,06 & 38,42 \\
\hline & \multirow{5}{*}{$1,5: 1$} & \multirow{3}{*}{$\begin{array}{l}\text { ZAPATA MED. } \\
\mathrm{R}_{\operatorname{mx}}(\mathrm{kN}) \\
\mathrm{R}_{\mathrm{my}}(\mathrm{kN})\end{array}$} & $3.900 \times 2.600 \times 700$ & $2.400 \times 1.600 \times 700$ & $1.900 \times 1.266 \times 700$ \\
\hline & & & 107,04 & 52,48 & 34,26 \\
\hline & & & 795,77 & 620,00 & 579,97 \\
\hline & & \multirow{2}{*}{$\begin{array}{ll}\sigma_{\mathrm{m}} & \left(\mathrm{kN} / \mathrm{m}^{2}\right) \\
\mathrm{T} & (\mathrm{kN})\end{array}$} & 78,48 & 161,46 & 241,11 \\
\hline & & & 120,26 & 65,70 & 47,48 \\
\hline & \multirow{5}{*}{$1: 1$} & \multirow{2}{*}{$\begin{array}{l}\text { ZAPATA MED. } \\
\mathrm{R}_{\mathrm{mx}}(\mathrm{kN})\end{array}$} & $3.250 \times 3.250 \times 700$ & $2.000 \times 2.000 \times 700$ & $1.550 \times 1.550 \times 700$ \\
\hline & & & 142,51 & 74,31 & 49,76 \\
\hline & & $\mathrm{R}_{\mathrm{my}}(\mathrm{kN})$ & 807,55 & 624,46 & 579,89 \\
\hline & & $\sigma_{\mathrm{m}} \quad\left(\mathrm{kN} / \mathrm{m}^{2}\right)$ & 76,45 & 156,12 & 241,37 \\
\hline & & $\mathrm{T} \quad(\mathrm{kN})$ & 155,73 & 87,53 & 62,98 \\
\hline
\end{tabular}

Tabla 16. Zapata de medianería con colaboración de viga superior. M. convencional. Etapa I Resultados para nivel de rigidez de pórtico tipo $\mathrm{h}=600$ 


\subsubsection{RESULTADOS DE LOS MODELOS DE ELEMENTOS FINITOS}

Los resultados de los modelos de elementos finitos de la Etapa I se exponen en dos grupos de tablas, de acuerdo con los siguientes criterios:

- Resultantes y excentricidades absolutas de tensiones de contacto con el terreno y esfuerzos en la viga centradora y en la viga superior (Tablas 17, 18 y 19)

- Excentricidades relativas de tensiones de contacto con el terreno, tipo de diagrama de distribución de tensiones y tensiones máximas (Tablas 20, 21 y 22)

Los parámetros expuestos en las citadas tablas se representan en la Fig. 57:

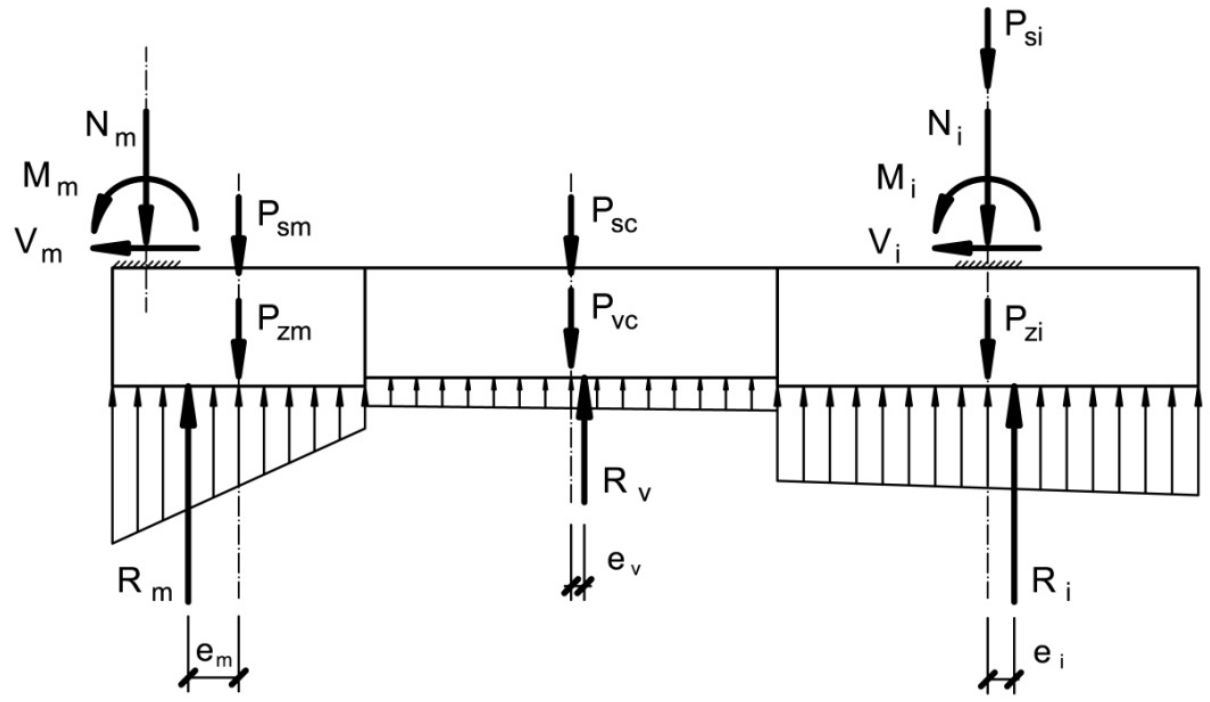

Fig.57. Resultados de los modelos de elementos finitos

El primer grupo de tablas (Tablas 17, 18 y 19) muestra las dimensiones de las zapatas utilizadas en el modelo (tanto la de medianería como la interior), las resultantes de las tensiones de contacto con el terreno y los esfuerzos más relevantes de la viga centradora y de la viga de la primera planta.

Como ya se ha indicado anteriormente, por cuestiones de validación de posteriores contrastes, se han empleado las mismas dimensiones utilizadas en los modelos convencionales.

Por lo que respecta a las resultantes de las tensiones de contacto con el terreno, se ha considerado simultáneamente en el mismo modelo, tanto el pórtico, como su cimentación, 
como el suelo que la sustenta, contemplando todos los contactos activos que se producen con el terreno, no solo bajo las zapatas, sino también bajo la viga centradora. Además de mostrar los valores de las resultantes de dichos contactos (resultante de la zapata de medianería $\left(R_{m}\right)$, resultante de la zapata interior $\left(R_{i}\right)$ y resultante de la viga centradora $\left(R_{v}\right)$ ), se aporta la localización de dichas resultantes mediante la excentricidad absoluta de su punto de aplicación respecto del punto medio de la zapata o la viga en cuestión (excentricidad de la resultante de medianería $\left(e_{m}\right)$, excentricidad de la resultante interior $\left(e_{i}\right)$ y excentricidad de la resultante de la viga centradora $\left.\left(e_{v}\right)\right)$ (Fig. 57).

Se ha considerado como positiva, toda aquella excentricidad que suponga un desplazamiento de la resultante hacia la derecha del punto medio del elemento correspondiente (alejamiento respecto de la medianería) y negativa, toda aquella excentricidad que suponga un desplazamiento de la resultante hacia la izquierda del punto medio en cuestión (acercamiento a la medianería).

Ninguno de los valores obtenidos para la excentricidad de las resultantes es nulo, lo cual pone de manifiesto que las distribuciones de tensiones de contacto no son uniformemente repartidas, tal y como presuponen los modelos convencionales.

Por último, en este primer grupo de tablas de modelos de elementos finitos, se muestran los esfuerzos resultantes, tanto en la viga centradora como en la viga de la primera planta. De la viga centradora se proporciona el momento flector $\left(M_{1 v}\right)$ y el esfuerzo axil $\left(N_{1 v}\right)$ en la sección más desfavorable de la misma (unión de la viga centradora con la zapata de medianería). Por su parte, de la viga de la primera planta se proporciona el esfuerzo axil de tracción $(T)$ que se produce en la misma trabajando como supuesto tirante. Dichos esfuerzos figuran en las citadas tablas con sus valores de servicio.

Todos los esfuerzos axiles en la viga de la primera planta han resultado de tracción (signo positivo), lo cual confirma el mayor o menor efecto tirante de la misma. En cambio, los esfuerzos axiles en la viga centradora son de valor bastante reducido y sin una tendencia clara, ya que aparecen valores tanto de tracción (signo positivo) como de compresión (signo negativo).

Es importante resaltar que el modelo de elementos finitos que se ha utilizado en la fase experimental contempla la interacción del pórtico, de la cimentación y del terreno que los sustenta, por lo cual, los resultados obtenidos valoran el trabajo conjunto y simultáneo de la viga centradora y la viga de la primera planta. 


\begin{tabular}{|c|c|c|c|c|c|}
\hline \multirow{2}{*}{\multicolumn{3}{|c|}{$h=300$}} & \multicolumn{3}{|c|}{ TENSIÓN ADMISIBLE } \\
\hline & & & $100 \mathrm{kN} / \mathrm{m}^{2}$ & $200 \mathrm{kN} / \mathrm{m}^{2}$ & $300 \mathrm{kN} / \mathrm{m}^{2}$ \\
\hline \multirow{31}{*}{$\begin{array}{l}\text { 뜰 } \\
\text { 운 } \\
\text { L }\end{array}$} & & $\begin{array}{l}\text { ZAPATA MED. } \\
\text { ZAPATA INT. }\end{array}$ & $\begin{array}{l}4.400 \times 2.200 \times 700 \\
3.400 \times 3.400 \times 700 \\
\end{array}$ & $\begin{array}{l}2.700 \times 1.350 \times 700 \\
2.250 \times 2.250 \times 700 \\
\end{array}$ & $\begin{array}{l}2.200 \times 1.100 \times 700 \\
1.800 \times 1.800 \times 700 \\
\end{array}$ \\
\hline & & $\mathrm{R} m \quad(\mathrm{kN})$ & 864,58 & 601,54 & 540,96 \\
\hline & & e $m(m)$ & $-0,227$ & $-0,165$ & $-0,147$ \\
\hline & & $\mathrm{Ri} \quad(\mathrm{kN})$ & 1032,92 & 833,60 & 778,86 \\
\hline & $2: 1$ & e i $\quad(m)$ & 0,190 & 0,183 & 0,162 \\
\hline & & $\mathrm{R} v \quad(\mathrm{kN})$ & 93,58 & 227,34 & 266,74 \\
\hline & & ev (m) & $-0,021$ & 0,081 & 0,152 \\
\hline & & $\mathrm{M} 1 \mathrm{v}(\mathrm{kN} \cdot \mathrm{m})$ & 236,96 & 183,54 & 146,96 \\
\hline & & $\mathrm{N} 1 \mathrm{v}(\mathrm{kN})$ & $-1,74$ & 7,56 & 13,5 \\
\hline & & $\mathrm{T} \quad(\mathrm{kN})$ & 35,68 & 37,84 & 38,62 \\
\hline & \multirow{10}{*}{$1,5: 1$} & $\begin{array}{l}\text { ZAPATA MED. } \\
\text { ZAPATA INT }\end{array}$ & $\begin{array}{l}3.900 \times 2.600 \times 700 \\
3.300 \times 3.300 \times 700\end{array}$ & $\begin{array}{l}2.400 \times 1.600 \times 700 \\
2.200 \times 2.200 \times 700\end{array}$ & $\begin{array}{l}1.900 \times 1.266 \times 700 \\
1.800 \times 1.800 \times 700\end{array}$ \\
\hline & & $R m \quad(k N)$ & 902,32 & 625,08 & 551,56 \\
\hline & & e $m \quad(m)$ & $-0,270$ & $-0,199$ & $-0,172$ \\
\hline & & $\mathrm{Ri} \quad(\mathrm{kN})$ & 993,58 & 824,30 & 777,18 \\
\hline & & e i $(m)$ & 0,214 & 0,175 & 0,163 \\
\hline & & $\mathrm{R} v \quad(\mathrm{kN})$ & 79,50 & 208,94 & 255,48 \\
\hline & & e v (m) & 0,019 & 0,093 & 0,149 \\
\hline & & $\mathrm{M} 1 \mathrm{v}(\mathrm{kN} \cdot \mathrm{m})$ & 246,10 & 210,52 & 170,06 \\
\hline & & $\mathrm{N} 1 \mathrm{v}(\mathrm{kN})$ & $-2,62$ & 7,54 & 13,96 \\
\hline & & $\mathrm{T} \quad(\mathrm{kN})$ & 35,24 & 38,22 & 38,86 \\
\hline & \multirow{11}{*}{$1: 1$} & ZAPATA MED. & $3.250 \times 3.250 \times 700$ & $2.000 \times 2.000 \times 700$ & $1.550 \times 1.550 \times 700$ \\
\hline & & ZAPATA INT. & $3.250 \times 3.250 \times 700$ & $2.200 \times 2.200 \times 700$ & $1.800 \times 1.800 \times 700$ \\
\hline & & $\mathrm{R} m \quad(\mathrm{kN})$ & 958,22 & 653,92 & 568,70 \\
\hline & & e $m(m)$ & $-0,333$ & $-0,264$ & $-0,225$ \\
\hline & & $\mathrm{Ri} \quad(\mathrm{kN})$ & 966,28 & 819,74 & 774,58 \\
\hline & & e i $\quad(m)$ & 0,229 & 0,176 & 0,164 \\
\hline & & $R v \quad(k N)$ & 47,42 & 183,90 & 237,30 \\
\hline & & e v (m) & 0,010 & 0,073 & 0,138 \\
\hline & & M 1v $(\mathrm{kN}-\mathrm{m})$ & 239,64 & 241,06 & 200,66 \\
\hline & & $\mathrm{N} 1 \mathrm{v}(\mathrm{kN})$ & $-7,24$ & 7,34 & 14,36 \\
\hline & & $\mathrm{T} \quad(\mathrm{kN})$ & 34,62 & 38,14 & 39,06 \\
\hline
\end{tabular}

Tabla 17. Modelo de elementos finitos. Etapa I. Resultantes tensiones terreno.

Esfuerzos en vigas centradora y superior. Pórtico tipo $h=300$ 


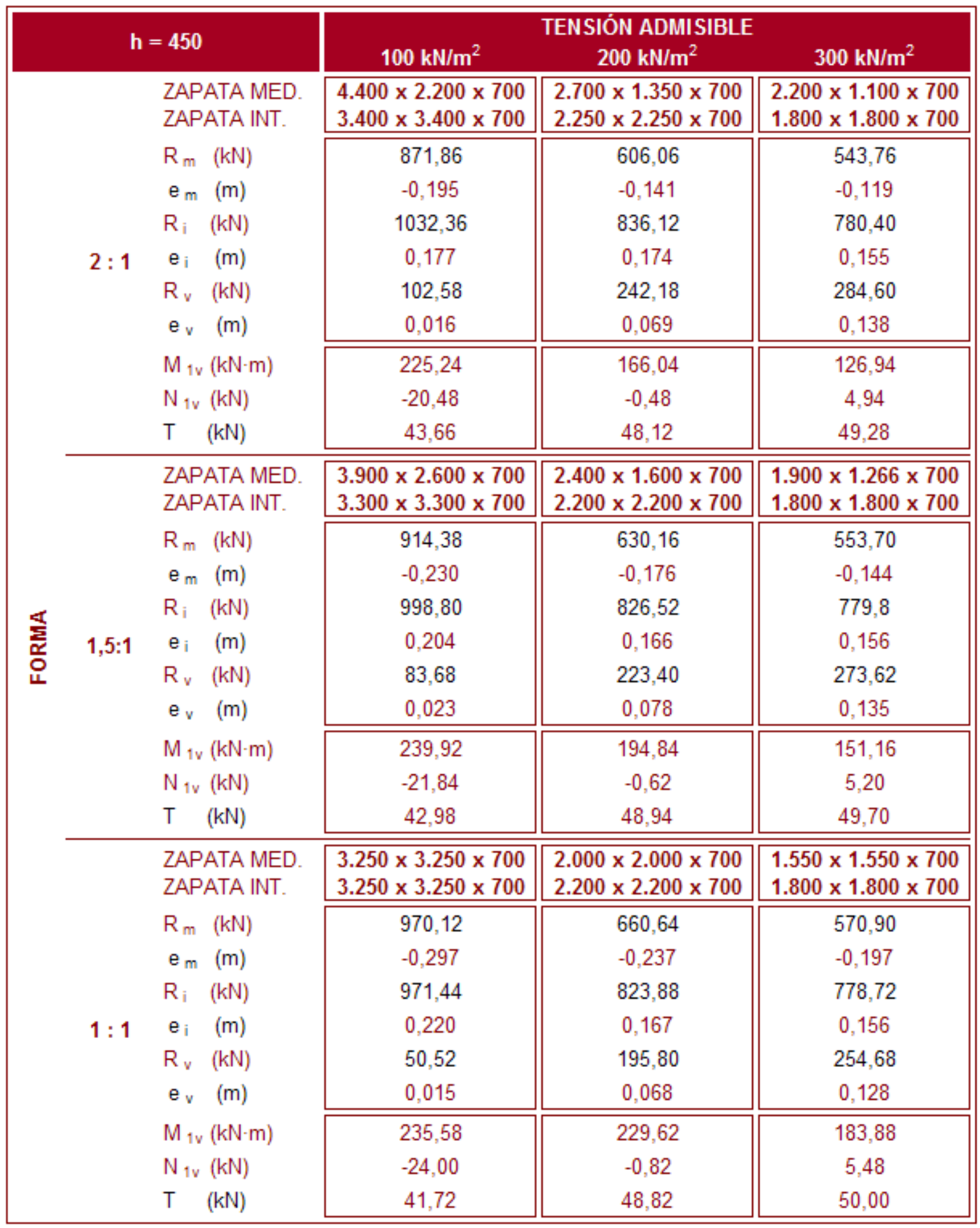

Tabla 18. Modelo de elementos finitos. Etapa I. Resultantes tensiones terreno.

Esfuerzos en vigas centradora y superior. Pórtico tipo $\mathrm{h}=450$ 


\begin{tabular}{|c|c|c|c|c|c|}
\hline \multirow{2}{*}{\multicolumn{3}{|c|}{$h=600$}} & \multicolumn{3}{|c|}{ TENSIÓN ADMISIBLE } \\
\hline & & & $100 \mathrm{kN} / \mathrm{m}^{2}$ & $200 \mathrm{kN} / \mathrm{m}^{2}$ & $300 \mathrm{kN} / \mathrm{m}^{2}$ \\
\hline \multirow{31}{*}{$\begin{array}{l}\frac{1}{\sum_{0}^{\circ}} \\
\text { ơ }\end{array}$} & \multirow{10}{*}{$2: 1$} & $\begin{array}{l}\text { ZAPATA MED. } \\
\text { ZAPATA INT. }\end{array}$ & $\begin{array}{l}4.400 \times 2.200 \times 700 \\
3.400 \times 3.400 \times 700\end{array}$ & $\begin{array}{l}2.700 \times 1.350 \times 700 \\
2.250 \times 2.250 \times 700\end{array}$ & $\begin{array}{l}2.200 \times 1.100 \times 700 \\
1.800 \times 1.800 \times 700\end{array}$ \\
\hline & & $\mathrm{R}_{\mathrm{m}}(\mathrm{kN})$ & 862,74 & 598,02 & 533,70 \\
\hline & & $\mathrm{e}_{\mathrm{m}}(\mathrm{m})$ & $-0,189$ & $-0,130$ & $-0,109$ \\
\hline & & $\mathrm{R}_{\mathrm{i}} \quad(\mathrm{kN})$ & 1006,56 & 807,02 & 750,10 \\
\hline & & $e_{i} \quad(m)$ & 0,168 & 0,168 & 0,152 \\
\hline & & $R_{v} \quad(k N)$ & 104,06 & 245,42 & 291,24 \\
\hline & & $e_{v}(m)$ & 0,021 & 0,068 & 0,123 \\
\hline & & $\mathrm{M}_{1 \mathrm{v}}(\mathrm{kN}-\mathrm{m})$ & 205,08 & 140,42 & 99,74 \\
\hline & & $\mathrm{N}_{1 \mathrm{v}}(\mathrm{kN})$ & $-23,38$ & $-6,20$ & $-0,94$ \\
\hline & & $\mathrm{T} \quad(\mathrm{kN})$ & 48,88 & 54,42 & 55,76 \\
\hline & \multirow{10}{*}{$1,5: 1$} & $\begin{array}{l}\text { ZAPATA MED. } \\
\text { ZAPATA INT. }\end{array}$ & $\begin{array}{l}3.900 \times 2.600 \times 700 \\
3.300 \times 3.300 \times 700\end{array}$ & $\begin{array}{l}2.400 \times 1.600 \times 700 \\
2.200 \times 2.200 \times 700\end{array}$ & $\begin{array}{l}1.900 \times 1.266 \times 700 \\
1.800 \times 1.800 \times 700\end{array}$ \\
\hline & & $R_{m}(k N)$ & 903,14 & 620.50 & 541.54 \\
\hline & & $e_{m}(m)$ & $-0,228$ & $-0,171$ & $-0,140$ \\
\hline & & $\mathrm{R}_{\mathrm{i}} \quad(\mathrm{kN})$ & 975,04 & 797,62 & 750,62 \\
\hline & & $e_{i}(m)$ & 0,195 & 0,160 & 0,152 \\
\hline & & $R_{v} \quad(k N)$ & 85,68 & 228,12 & 281,74 \\
\hline & & $e_{\mathrm{v}}(\mathrm{m})$ & 0,028 & 0,073 & 0,114 \\
\hline & & $\mathrm{M}_{1 \mathrm{v}}(\mathrm{kN} \cdot \mathrm{m})$ & 220,36 & 168,28 & 123,06 \\
\hline & & $\mathrm{N}_{1 \mathrm{v}}(\mathrm{kN})$ & $-24,24$ & $-6,10$ & $-0,54$ \\
\hline & & $\mathrm{T} \quad(\mathrm{kN})$ & 47,94 & 55,54 & 56,32 \\
\hline & \multirow{11}{*}{$1: 1$} & ZAPATA MED. & $3.250 \times 3.250 \times 700$ & $2.000 \times 2.000 \times 700$ & $1.550 \times 1.550 \times 700$ \\
\hline & & & & $c r a$ & \\
\hline & & & & & 560,50 \\
\hline & & $e_{m}(m)$ & $-0,296$ & $-0,226$ & $-0,186$ \\
\hline & & $\mathrm{R}_{\mathrm{i}} \quad(\mathrm{kN})$ & 949,18 & 796,44 & 750,66 \\
\hline & & $\mathrm{e}_{\mathrm{i}} \quad(\mathrm{m})$ & 0,212 & 0,161 & 0,152 \\
\hline & & $R_{v} \quad(k N)$ & 52,60 & 198,94 & 260,46 \\
\hline & & $e_{v}(m)$ & 0,015 & 0,068 & 0,118 \\
\hline & & $\mathrm{M}_{1 \mathrm{v}}(\mathrm{kN} \cdot \mathrm{m})$ & 219,920 & 206,440 & 158,440 \\
\hline & & $\mathrm{N}_{1 \mathrm{v}}(\mathrm{kN})$ & $-26,100$ & $-6,400$ & $-0,480$ \\
\hline & & $\mathrm{T} \quad(\mathrm{kN})$ & 46,320 & 55,520 & 56,800 \\
\hline
\end{tabular}

Tabla 19. Modelo de elementos finitos. Etapa I. Resultantes tensiones terreno. Esfuerzos en vigas centradora y superior. Pórtico tipo $h=600$ 
Los diagramas de distribución de tensiones de contacto bajo las zapatas de medianería de los modelos de elementos finitos responden, en general, al esquema tipo representado en la Fig.58. Los resultados confirman la no uniformidad del diagrama de tensiones con un incremento de las mismas hacia el pilar de medianería, como ya anticipaba la excentricidad de la resultante de la zapata de medianería. Si dicho diagrama de distribución de tensiones (evidentemente irregular) tuviese que asemejarse a un esquema linealmente variable equivalente, el modelo adecuado sería una distribución trapecial con tensión máxima bajo el pilar de medianería.
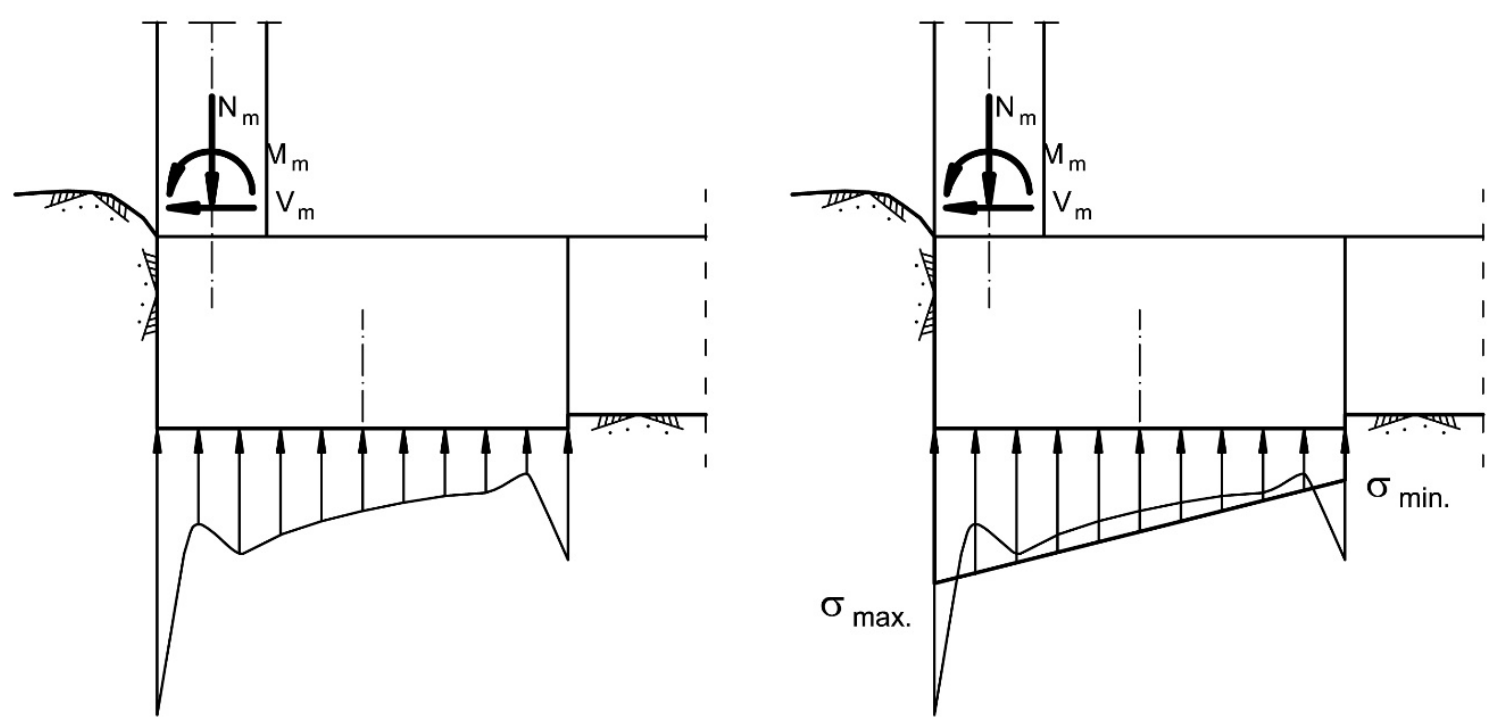

Fig.58. Distribución de tensiones de contacto en modelos de elementos finitos

A la hora de valorar la excentricidad de la resultante de tensiones de contacto bajo la zapata de medianería, de cara a relacionarla con el diagrama de tensiones a que da lugar, el empleo del valor absoluto de dicha excentricidad respecto del centro de la zapata (Fig.57) resulta confuso y falto de orden de magnitud. Es más significativo el valor relativo de la citada excentricidad, o más bien la posición relativa de la resultante, expresada a partir del extremo de la zapata y respecto del tamaño total de la misma (Fig.59). La posición de la resultante $R_{m}$ respecto del extremo de la zapata de medianería, que coincide con la posición del centro de gravedad del gráfico del diagrama trapecial de tensiones (c.d.g. $R_{m}$ ), vendrá dada por:

$$
\text { c.d.g. } R_{m}=\frac{a_{m}}{2}+e_{m}
$$

Y la expresión relativa de dicha posición respecto del tamaño total de la zapata, denotada como c.d.g. $R_{m}(\%)$, será:

$$
\text { c.d.g. } R_{m}(\%)=\frac{\frac{a_{m}}{2}+e_{m}}{a_{m}} \cdot 100
$$




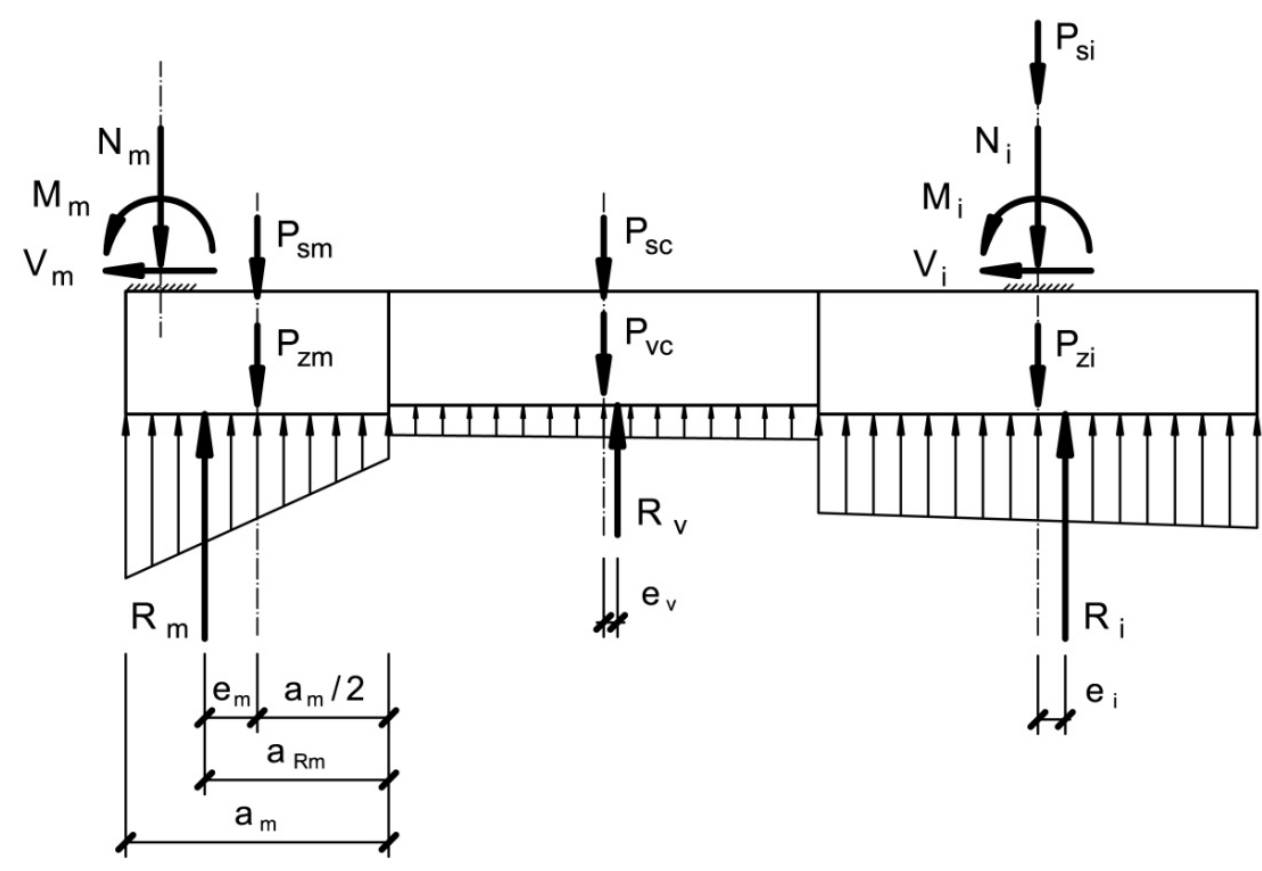

Fig.59. Posición absoluta y relativa de la resultante de la zapata de medianería

Así, si toman como referencia los diagramas lineales de distribución de tensiones clásicos, representados en al Fig.60, se comprueba que un diagrama de distribución de tensiones uniforme (Fig.60.a) presenta su resultante en la mitad del diagrama, es decir, en la posición que ocupa el $50 \%$ del tamaño de la zapata en cuestión (centro de gravedad de un gráfico rectangular).

Por su parte, si se pasa a la Fig.60.c, se observa un diagrama triangular estricto, que ocupa la totalidad de la cara de contacto de la zapata, cuya resultante se encuentra a dos tercios de la longitud de la zapata medidos desde el extremo, es decir, en la posición que ocupa el $66 \%$ del tamaño de la zapata (centro de gravedad de un gráfico triangular). A partir de este, los diagramas trapeciales puros (Fig.60.b) presentan una posición relativa de la resultante comprendida entre el $50 \%$ y el $66 \%$ del tamaño de la zapata y los diagramas triangulares puros (Fig.60.d) entre el $66 \%$ y el $100 \%$ del citado tamaño de la zapata.

Las Tablas 20, 21 y 22 muestran las posiciones relativas de las resultantes de tensiones de contacto de las zapatas de medianería $R_{m}$ para los distintos casos estudiados, ordenados según el nivel de rigidez de los pórticos. Todos los casos analizados en la Etapa I se corresponden con diagramas de tipo trapecial. 

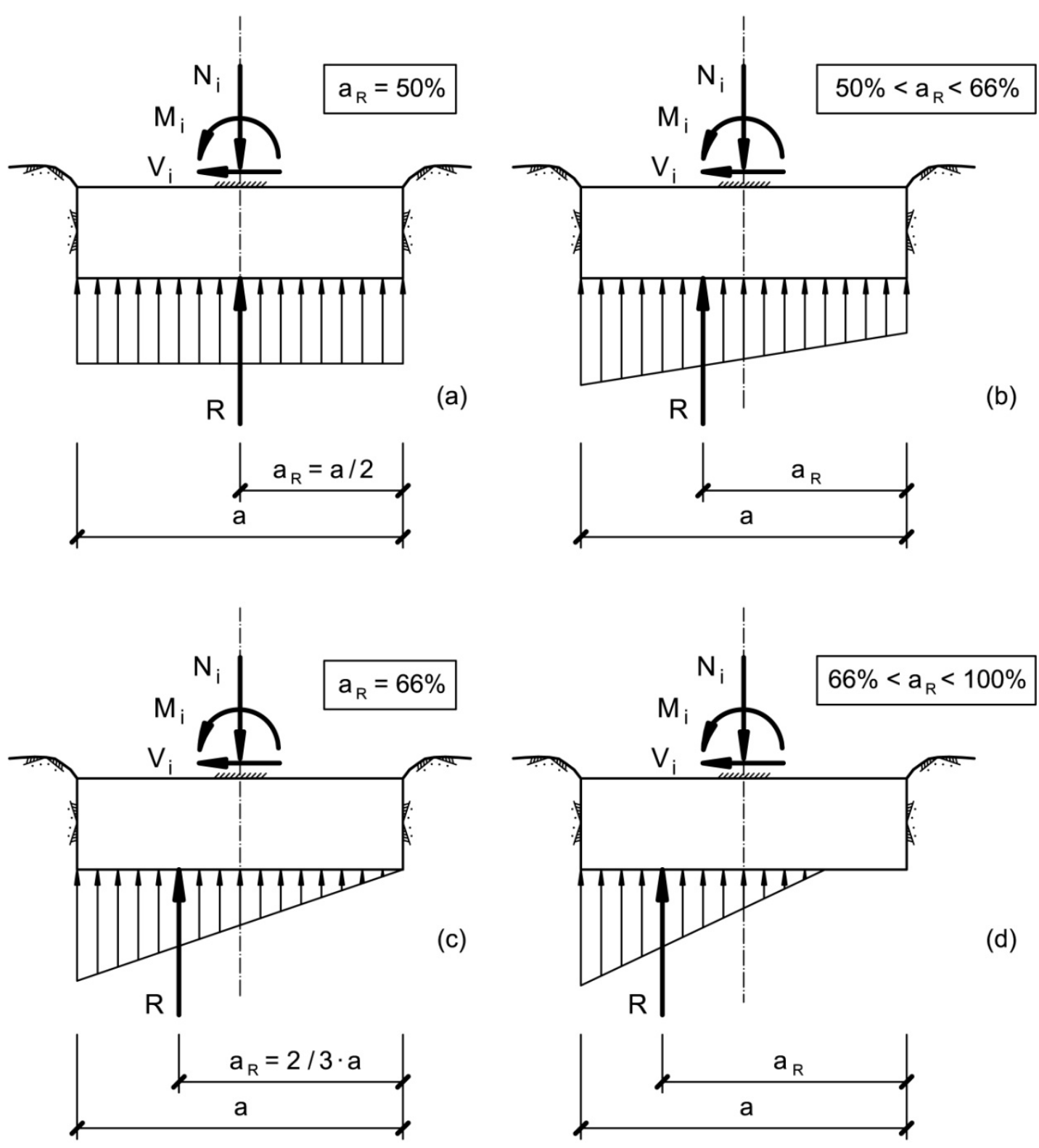

Fig.60. Diagramas lineales de distribución de tensiones de contacto

Dichas tablas incluyen también la tensión máxima generada en el diagrama de tensiones trapecial equivalente, $\sigma$ max. (Fig.58), acompañada del resultado de la comprobación de tensiones de contacto o verificación del E.L.U. de hundimiento. Se ha adoptado como tensión última de referencia para dicha comprobación 1,25 $\sigma_{\text {adm. }}$ por tratarse de una distribución lineal variable. La verificación se expresa con forma de proporción relativa o nivel de agotamiento de la comprobación:

$$
\sigma_{\text {max. }} \leq 1,25 \cdot \sigma_{\text {adm }} \quad \Rightarrow \quad \frac{\sigma_{\text {max. }}}{1,25 \cdot \sigma_{\text {adm }}} \leq 1
$$

por lo que cumplirán la comprobación del E.L.U. de hundimiento todos aquellos casos que presenten un nivel de agotamiento inferior o igual a 1. 


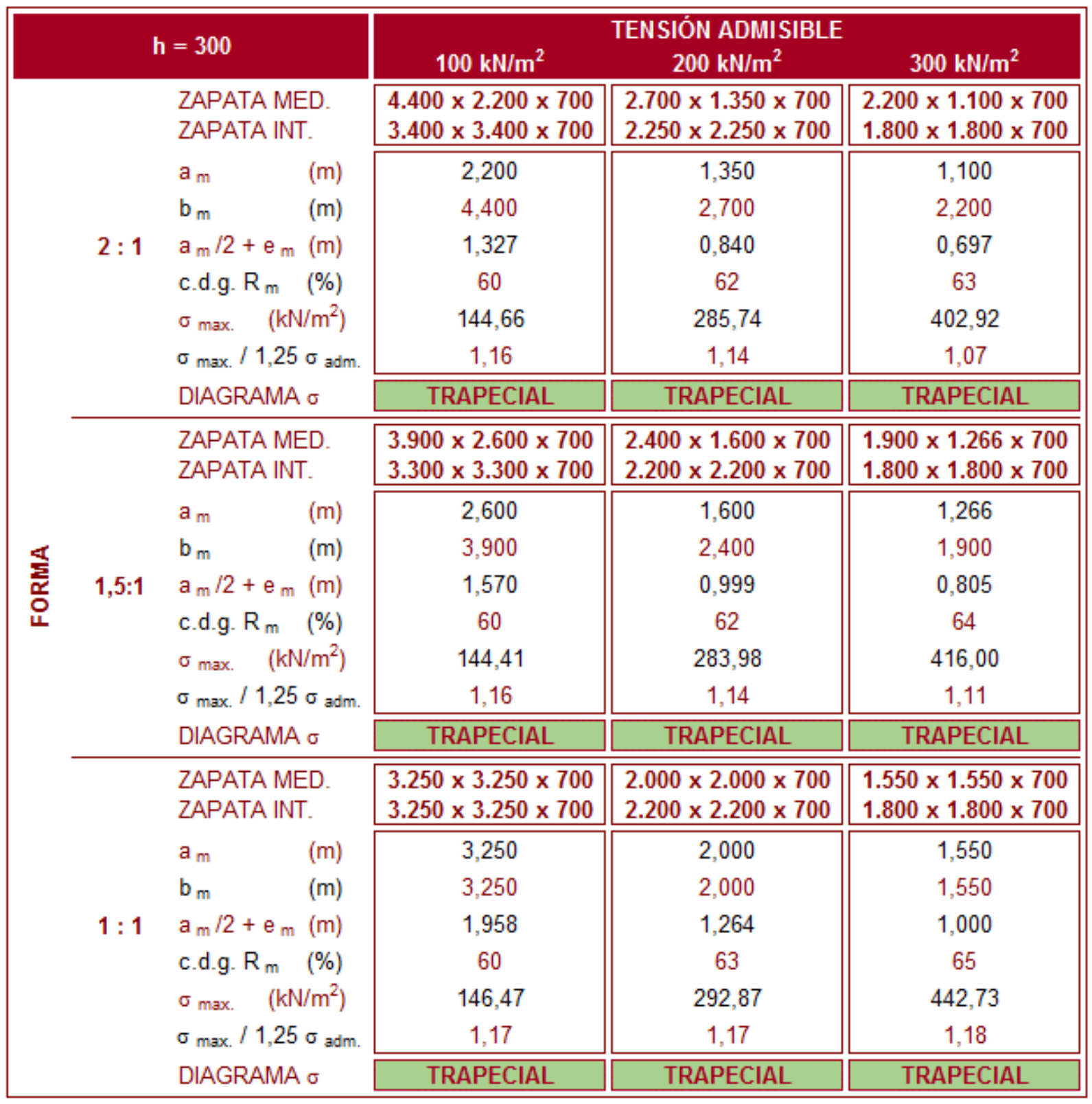

Tabla 20. Distribución de tensiones de contacto en modelo de elementos finitos. Etapa I. Pórtico tipo $\mathrm{h}=300$ 


\begin{tabular}{|c|c|c|c|c|c|}
\hline \multirow{2}{*}{\multicolumn{3}{|c|}{$h=450$}} & \multicolumn{3}{|c|}{ TENSIÓN ADMISIBLE } \\
\hline & & & $100 \mathrm{kN} / \mathrm{m}^{2}$ & $200 \mathrm{kN} / \mathrm{m}^{2}$ & $300 \mathrm{kN} / \mathrm{m}^{2}$ \\
\hline \multirow{24}{*}{ 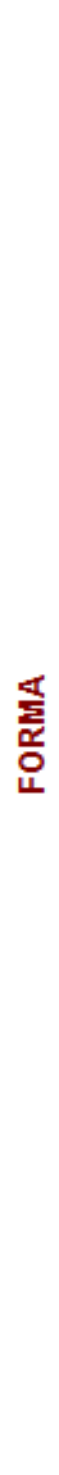 } & \multirow{8}{*}{$2: 1$} & $\begin{array}{l}\text { ZAPATA MED. } \\
\text { ZAPATA INT. }\end{array}$ & $\begin{array}{l}4.400 \times 2.200 \times 700 \\
3.400 \times 3.400 \times 700\end{array}$ & $\begin{array}{l}2.700 \times 1.350 \times 700 \\
2.250 \times 2.250 \times 700\end{array}$ & $\begin{array}{l}2.200 \times 1.100 \times 700 \\
1.800 \times 1.800 \times 700\end{array}$ \\
\hline & & $(\mathrm{m})$ & 2,200 & 1,350 & 1,100 \\
\hline & & $(\mathrm{m})$ & 4,400 & 2,700 & 2,200 \\
\hline & & $a_{m} / 2+e_{m}(m)$ & 1,295 & 0,816 & 0,669 \\
\hline & & c.d.g. $R_{m} \quad(\%)$ & 59 & 60 & 61 \\
\hline & & $\sigma_{\max .}\left(\mathrm{kN} / \mathrm{m}^{2}\right)$ & 137,86 & 270,32 & 370,50 \\
\hline & & $\sigma_{\max } / 1,25 \sigma \sigma_{\mathrm{adm}}$ & 1,10 & 1,08 & 0,99 \\
\hline & & DIAGRAMA $\sigma$ & TRAPECIAL & TRAPECIAL & TRAPECIAL \\
\hline & \multirow{8}{*}{$1,5: 1$} & $\begin{array}{l}\text { ZAPATA MED. } \\
\text { ZAPATA INT. }\end{array}$ & $\begin{array}{l}3.900 \times 2.600 \times 700 \\
3.300 \times 3.300 \times 700 \\
\end{array}$ & $\begin{array}{l}2.400 \times 1.600 \times 700 \\
2.200 \times 2.200 \times 700 \\
\end{array}$ & \begin{tabular}{|l}
$1.900 \times 1.266 \times 700$ \\
$1.800 \times 1.800 \times 700$ \\
\end{tabular} \\
\hline & & $a_{m}$ & 2,600 & 1,600 & 1,266 \\
\hline & & $\mathrm{b}_{\mathrm{m}}$ & 3,900 & 2,400 & 1,900 \\
\hline & & $a_{m} / 2+e_{m}(m)$ & 1,530 & 0,976 & 0,777 \\
\hline & & 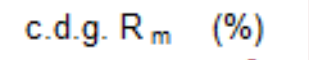 & 59 & 61 & 61 \\
\hline & & $\sigma_{\max .} \quad\left(\mathrm{kN} / \mathrm{m}^{2}\right)$ & 137,94 & 272,55 & 387,36 \\
\hline & & $\sigma_{\max } / 1,25 \sigma \mathrm{adm}$ & 1,10 & 1,09 & 1,03 \\
\hline & & DIAGRAMA $\sigma$ & TRAPECIAL & TRAPECIAL & TRAPECIAL \\
\hline & \multirow{8}{*}{$1: 1$} & $\begin{array}{l}\text { ZAPATA MED. } \\
\text { ZAPATA INT. }\end{array}$ & $\begin{array}{l}3.250 \times 3.250 \times 700 \\
3.250 \times 3.250 \times 700 \\
\end{array}$ & $\begin{array}{l}2.000 \times 2.000 \times 700 \\
2.200 \times 2.200 \times 700\end{array}$ & $\begin{array}{l}1.550 \times 1.550 \times 700 \\
1.800 \times 1.800 \times 700 \\
\end{array}$ \\
\hline & & $(\mathrm{m})$ & 3,250 & 2,000 & 1,550 \\
\hline & & $(\mathrm{m})$ & 3,250 & 2,000 & 1,550 \\
\hline & & $a_{m} / 2+e_{m}(m)$ & 1,922 & 1,237 & 0,972 \\
\hline & & c.d.g. $R_{m} \quad(\%)$ & 59 & 62 & 63 \\
\hline & & $\sigma_{\max .} \quad\left(\mathrm{kN} / \mathrm{m}^{2}\right)$ & 142,21 & 282,55 & 418,90 \\
\hline & & $\sigma_{\max .} / 1,25 \sigma \sigma_{\mathrm{adm}}$ & 1,14 & 1,13 & 1,12 \\
\hline & & DIAGRAMA $\sigma$ & TRAPECIAL & TRAPECIAL & TRAPECIAL \\
\hline
\end{tabular}

Tabla 21. Distribución de tensiones de contacto en modelo de elementos finitos. Etapa I.

Pórtico tipo $\mathrm{h}=450$ 


\begin{tabular}{|c|c|c|c|c|c|}
\hline \multirow{2}{*}{\multicolumn{3}{|c|}{$h=600$}} & \multicolumn{3}{|c|}{ TENSIÓN ADMISIBLE } \\
\hline & & & $100 \mathrm{kN} / \mathrm{m}^{2}$ & $200 \mathrm{kN} / \mathrm{m}^{2}$ & $300 \mathrm{kN} / \mathrm{m}^{2}$ \\
\hline \multirow{24}{*}{$\begin{array}{l}\frac{\mathbb{s}}{\bar{y}} \\
\text { 운 }\end{array}$} & \multirow{8}{*}{$2: 1$} & $\begin{array}{l}\text { ZAPATA MED. } \\
\text { ZAPATA INT. }\end{array}$ & $\begin{array}{l}4.400 \times 2.200 \times 700 \\
3.400 \times 3.400 \times 700\end{array}$ & \begin{tabular}{|l|}
$2.700 \times 1.350 \times 700$ \\
$2.250 \times 2.250 \times 700$ \\
\end{tabular} & $\begin{array}{l}2.200 \times 1.100 \times 700 \\
1.800 \times 1.800 \times 700\end{array}$ \\
\hline & & $(\mathrm{m})$ & 2,200 & 1,350 & 1,100 \\
\hline & & $b_{m}$ & 4,400 & 2,700 & 2,200 \\
\hline & & $a_{m} / 2+e_{m}(m)$ & 1,289 & 0,805 & 0,659 \\
\hline & & c.d.g. $R_{m} \quad(\%)$ & 59 & 60 & 60 \\
\hline & & $\sigma_{\max } \quad\left(\mathrm{kN} / \mathrm{m}^{2}\right)$ & 135,04 & 259,18 & 351,80 \\
\hline & & $\sigma_{\max .} / 1,25 \sigma_{\text {adm. }}$. & 1,08 & 1,04 & 0,94 \\
\hline & & DIAGRAMA $\sigma$ & TRAPECIAL & TRAPECIAL & TRAPECIAL \\
\hline & \multirow{8}{*}{$1,5: 1$} & $\begin{array}{l}\text { ZAPATA MED. } \\
\text { ZAPATA INT. }\end{array}$ & $\begin{array}{l}3.900 \times 2.600 \times 700 \\
3.300 \times 3.300 \times 700\end{array}$ & $\begin{array}{l}2.400 \times 1.600 \times 700 \\
2.200 \times 2.200 \times 700 \\
\end{array}$ & $\begin{array}{l}1.900 \times 1.266 \times 700 \\
1.800 \times 1.800 \times 700\end{array}$ \\
\hline & & $a_{m}$ & 2,600 & 1,600 & 1,266 \\
\hline & & $\mathrm{b}_{\mathrm{m}}$ & 3,900 & 2,400 & 1,900 \\
\hline & & $a_{m} / 2+e_{m}(m)$ & 1,528 & 0,971 & 0,773 \\
\hline & & c.d.g. $R_{m} \quad(\%)$ & 59 & 61 & 61 \\
\hline & & $\sigma_{\max .}\left(\mathrm{kN} / \mathrm{m}^{2}\right)$ & 135,93 & 265,38 & 374,04 \\
\hline & & $\sigma_{\max .} / 1,25 \sigma_{\text {adm. }}$. & 1,09 & 1,06 & 1,00 \\
\hline & & DIAGRAMA $\sigma$ & TRAPECIAL & TRAPECIAL & TRAPECIAL \\
\hline & \multirow{8}{*}{$1: 1$} & $\begin{array}{l}\text { ZAPATA MED. } \\
\text { ZAPATA INT. }\end{array}$ & $\begin{array}{l}3.250 \times 3.250 \times 700 \\
3.250 \times 3.250 \times 700 \\
\end{array}$ & \begin{tabular}{|l|}
$2.000 \times 2.000 \times 700$ \\
$2.200 \times 2.200 \times 700$ \\
\end{tabular} & $\begin{array}{l}1.550 \times 1.550 \times 700 \\
1.800 \times 1.800 \times 700\end{array}$ \\
\hline & & $(\mathrm{m})$ & 3,250 & 2,000 & 1,550 \\
\hline & & $\mathrm{b}_{\mathrm{m}}$ & 3,250 & 2,000 & 1,550 \\
\hline & & $a_{m} / 2+e_{m}(m)$ & 1,921 & 1,226 & 0,961 \\
\hline & & c.d.g. $R_{m} \quad(\%)$ & 59 & 61 & 62 \\
\hline & & $\sigma_{\max .} \quad\left(\mathrm{kN} / \mathrm{m}^{2}\right)$ & 140,17 & 273,51 & 401,36 \\
\hline & & $\sigma_{\text {max. }} / 1,25 \sigma$ adm. & 1,12 & 1,09 & 1,07 \\
\hline & & DIAGRAMA $\sigma$ & TRAPECIAL & TRAPECIAL & TRAPECIAL \\
\hline
\end{tabular}

Tabla 22. Distribución de tensiones de contacto en modelo de elementos finitos. Etapa I. Pórtico tipo $\mathrm{h}=600$ 


\subsection{RESULTADOS EXPERIMENTALES. ETAPA II}

\subsubsection{RESULTADOS DE LOS MODELOS CONVENCIONALES}

\subsubsection{ZAPATA DE MEDIANERÍA CON VIGA CENTRADORA}

Se ofrecen en las Tablas 23, 24, 25, 26, 27 y 28 los resultados del cálculo del modelo convencional de zapata de medianería con viga centradora, para cada uno de los casos planteados en la Etapa II. Los parámetros a los que hacen referencia dichos resultados son los representados en las Fig. 6 y 7.

Las tablas, ordenadas por tensiones admisibles del terreno y relaciones de forma, ofrecen para los distintos casos en función de la luz y el número de plantas, los siguientes resultados:

- Dimensionamiento necesario para las zapatas de medianería, zapata interior, tercera zapata y viga centradora de acuerdo con el modelo convencional.

- Resultante de las presiones de contacto en la zapata de medianería $R_{m}(k N)$.

- Tensión transmitida al terreno por la zapata de medianería $\sigma_{m}\left(\mathrm{kN} / \mathrm{m}^{2}\right)$, calculada bajo la hipótesis de distribución de tensiones uniformemente repartida.

- Resultante de las tensiones de contacto en la zapata interior $R_{i}(k N)$.

- Tensión transmitida al terreno por la zapata interior $\sigma_{i}\left(\mathrm{kN} / \mathrm{m}^{2}\right)$, calculada bajo la hipótesis de distribución de presiones uniformemente repartida.

- Resultante de las tensiones de contacto en la tercera zapata interior $R_{t z}(k N)$.

- Tensión transmitida al terreno por la tercera zapata $\sigma_{\mathrm{tz}}\left(\mathrm{kN} / \mathrm{m}^{2}\right)$, calculada bajo la hipótesis de distribución de presiones uniformemente repartida.

- Momento flector de servicio $M_{1 v}$ en la sección más desfavorable de la viga centradora (unión de la viga centradora con la zapata de medianería)

Al considerar el modelo convencional de zapata con viga centradora, distribuciones de tensiones sobre el terreno uniformemente repartidas, las resultantes en cuestión se encuentran aplicadas en el centro de las respectivas zapatas. Por ese motivo, no se hace aquí referencia a ninguna excentricidad respecto del centro de las zapatas, ya que sería en todos los casos nula. 


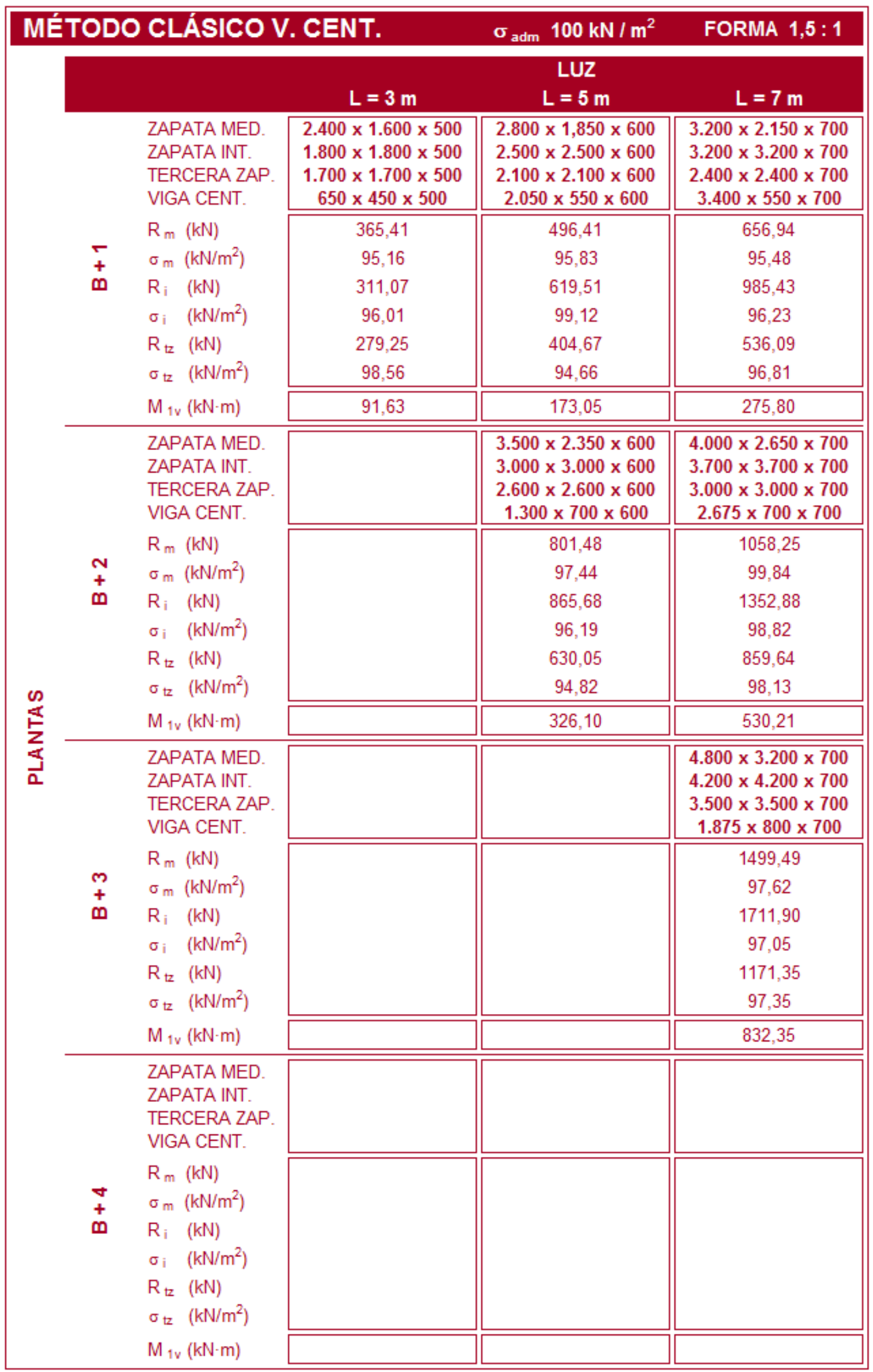

Tabla 23. Zapata de medianería con viga centradora. Modelo convencional. Etapa II Resultados para $\sigma_{\text {adm. }}=100 \mathrm{kN} / \mathrm{m}^{2}$ y relación de forma $1,5: 1$ 


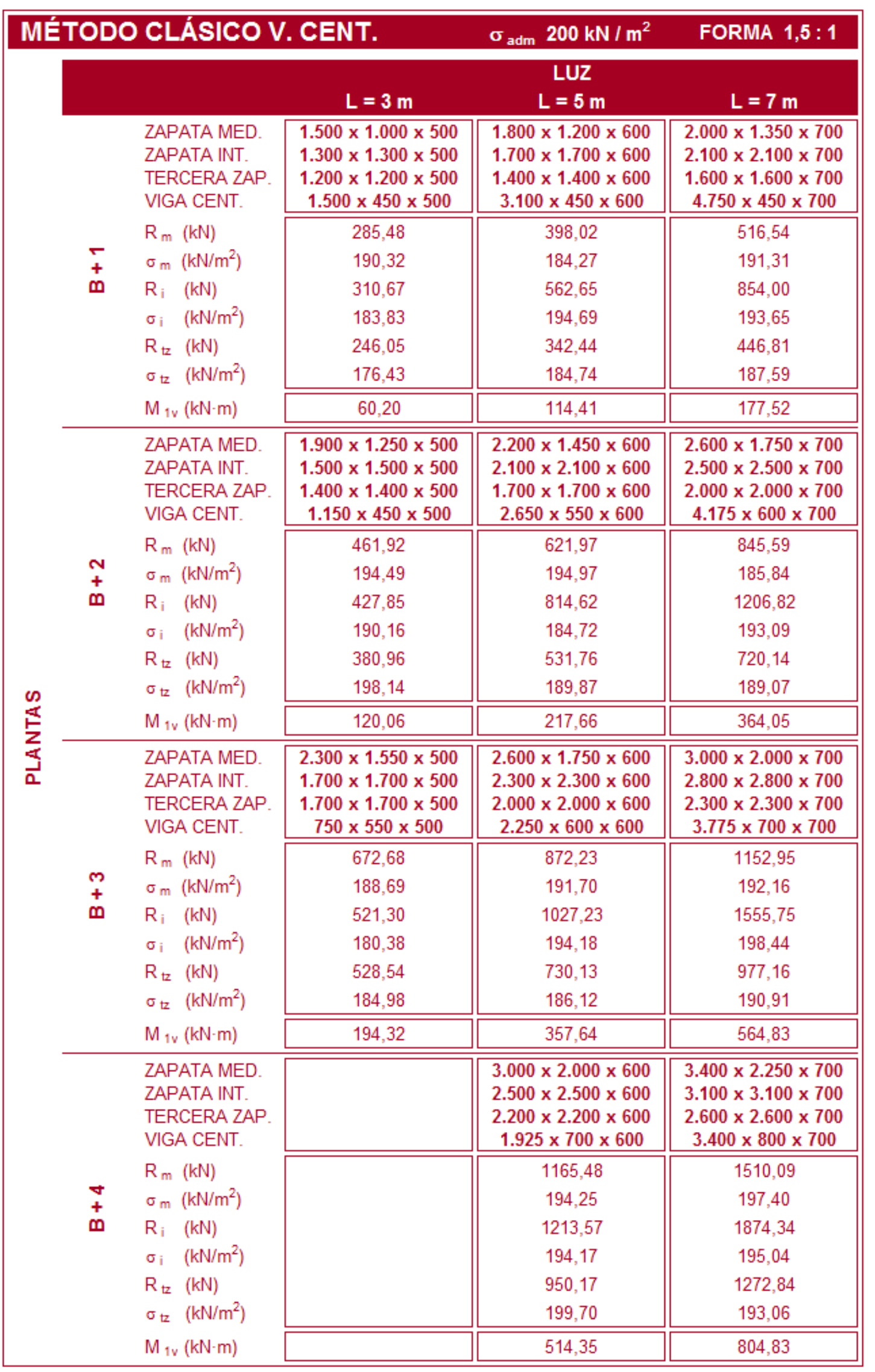

Tabla 24. Zapata de medianería con viga centradora. Modelo convencional. Etapa II. Resultados para $\sigma_{\text {adm. }}=200 \mathrm{kN} / \mathrm{m}^{2}$ y relación de forma $1,5: 1$ 


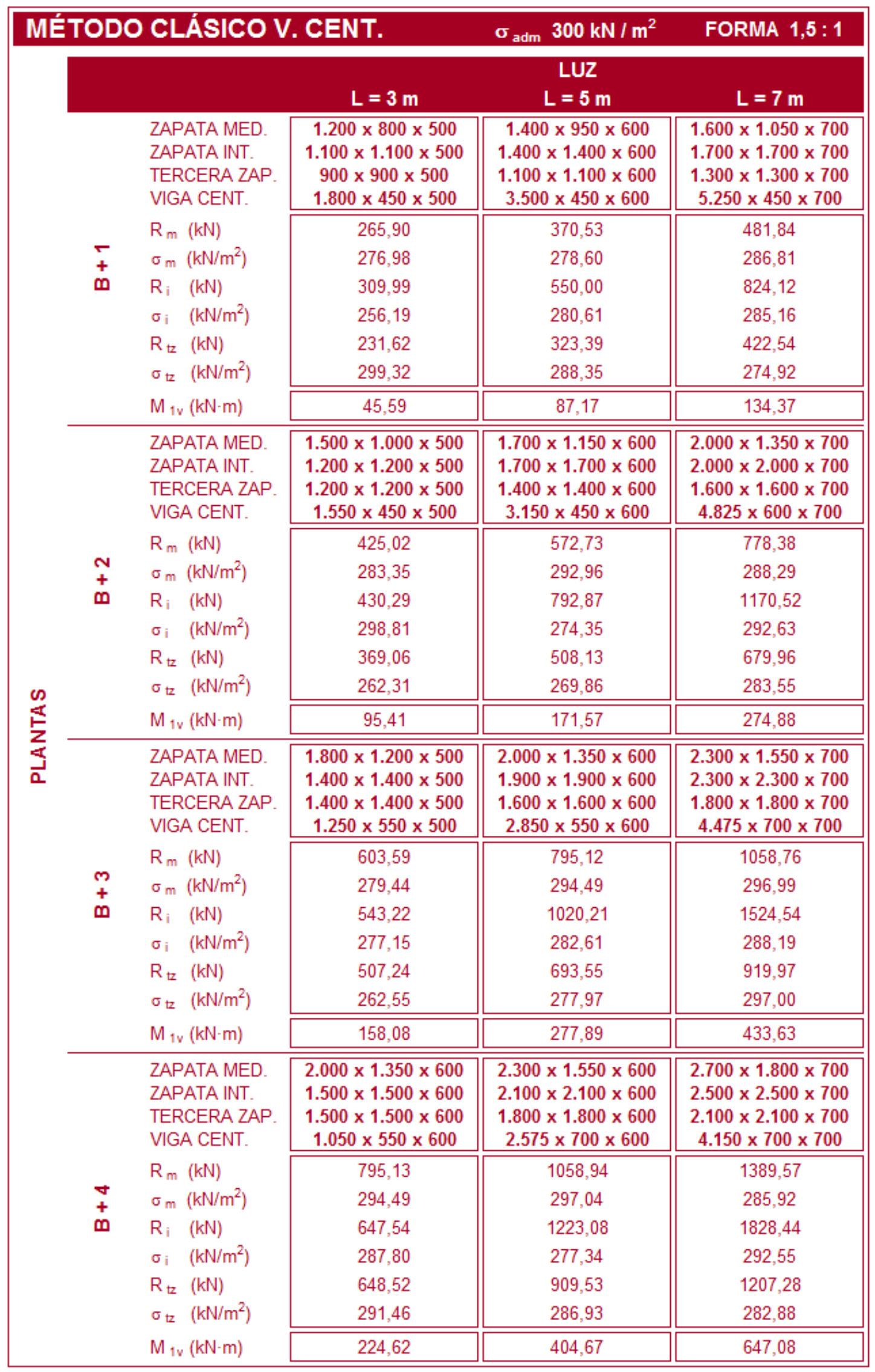

Tabla 25. Zapata de medianería con viga centradora. Modelo convencional. Etapa II. Resultados para $\sigma_{\text {adm. }}=300 \mathrm{kN} / \mathrm{m}^{2}$ y relación de forma $1,5: 1$ 


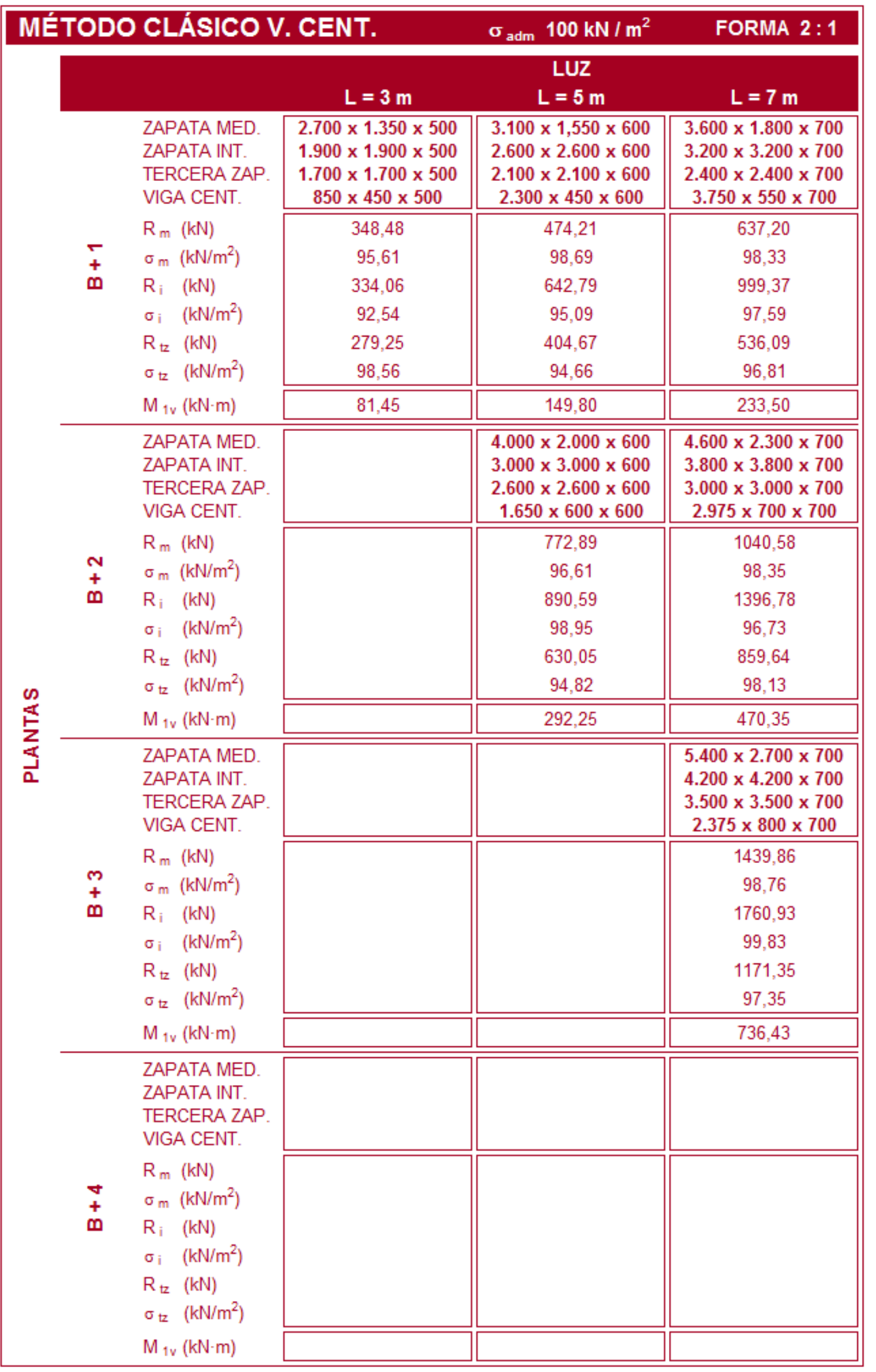

Tabla 26. Zapata de medianería con viga centradora. Modelo convencional. Etapa II. Resultados para $\sigma_{\text {adm. }}=100 \mathrm{kN} / \mathrm{m}^{2}$ y relación de forma $2: 1$ 


\begin{tabular}{|c|c|c|c|c|c|}
\hline \multicolumn{4}{|c|}{ MÉTODO CLÁSICO V. CENT. } & $\sigma_{\text {adm }} 200 \mathrm{kN} / \mathrm{m}^{2}$ & FORMA $2: 1$ \\
\hline \multirow{10}{*}{\multicolumn{2}{|c|}{$\stackrel{+}{\dot{m}}$}} & & \multicolumn{3}{|c|}{ LUZ } \\
\hline & & & $\mathrm{L}=\mathbf{3} \mathrm{m}$ & $\mathrm{L}=5 \mathrm{~m}$ & $\mathrm{~L}=7 \mathrm{~m}$ \\
\hline & & $\begin{array}{l}\text { ZAPATA MED. } \\
\text { ZAPATA INT. } \\
\text { TERCERA ZAP. } \\
\text { VIGA CENT. }\end{array}$ & $\begin{array}{c}1.700 \times 850 \times 500 \\
1.300 \times 1.300 \times 500 \\
1.200 \times 1.200 \times 500 \\
1.650 \times 450 \times 500\end{array}$ & $\begin{array}{c}2.000 \times 1.000 \times 600 \\
1.700 \times 1.700 \times 600 \\
1.400 \times 1.400 \times 600 \\
3.300 \times 450 \times 600\end{array}$ & $\begin{array}{c}2.300 \times 1.150 \times 700 \\
2.100 \times 2.100 \times 700 \\
1.600 \times 1.600 \times 700 \\
4.950 \times 450 \times 700 \\
\end{array}$ \\
\hline & & $\mathrm{R}_{\mathrm{m}}(\mathrm{kN})$ & 278,57 & 388,56 & 510,55 \\
\hline & & $\sigma_{m}\left(k N / m^{2}\right)$ & 192,79 & 194,28 & 193,03 \\
\hline & & $\mathrm{R}_{\mathrm{i}} \quad(\mathrm{kN})$ & 317,87 & 570,32 & 860,97 \\
\hline & & $\sigma_{\mathrm{i}} \quad\left(\mathrm{kN} / \mathrm{m}^{2}\right)$ & 188,09 & 197,34 & 195,23 \\
\hline & & $\mathrm{R}_{\mathrm{tz}}(\mathrm{kN})$ & 246,05 & 342,44 & 446,81 \\
\hline & & $\sigma_{t z}\left(k N / m^{2}\right)$ & 176,43 & 184,74 & 187,59 \\
\hline & & $\mathrm{M}_{1 \mathrm{v}}(\mathrm{kN}-\mathrm{m})$ & 49,47 & 92,88 & 149,13 \\
\hline \multirow{24}{*}{$\begin{array}{l}\infty \\
\mathbb{1} \\
\mathbf{L}\end{array}$} & & $\begin{array}{l}\text { ZAPATA MED. } \\
\text { ZAPATA INT. } \\
\text { TERCERA ZAP. } \\
\text { VIGA CENT. }\end{array}$ & $\begin{array}{c}2.200 \times 1.100 \times 500 \\
1.500 \times 1.500 \times 500 \\
1.400 \times 1.400 \times 500 \\
1.300 \times 450 \times 500\end{array}$ & $\begin{array}{c}2.500 \times 1.250 \times 600 \\
2.100 \times 2.100 \times 600 \\
1.700 \times 1.700 \times 600 \\
2.850 \times 450 \times 600\end{array}$ & $\begin{array}{c}2.900 \times 1.450 \times 700 \\
2.500 \times 2.500 \times 700 \\
2.000 \times 2.000 \times 700 \\
4.475 \times 600 \times 700\end{array}$ \\
\hline & & $\mathrm{R}_{\mathrm{m}}(\mathrm{kN})$ & 452,37 & 606,75 & 823,59 \\
\hline & $\stackrel{n}{+}$ & $\sigma_{m}\left(k N / m^{2}\right)$ & 186,93 & 194,16 & 195,86 \\
\hline & $\boldsymbol{m}$ & $\mathrm{R}_{\mathrm{i}} \quad(\mathrm{kN})$ & 439,98 & 823,75 & 1224,22 \\
\hline & & $\sigma_{i} \quad\left(k N / m^{2}\right)$ & 195,55 & 186,79 & 195,87 \\
\hline & & $\mathrm{R}_{\mathrm{tz}}(\mathrm{kN})$ & 380,96 & 531,76 & 720,14 \\
\hline & & $\sigma_{\mathrm{tz}}\left(\mathrm{kN} / \mathrm{m}^{2}\right)$ & 198,14 & 189,87 & 189,07 \\
\hline & & $M_{1 v}(k N \cdot m)$ & 106,03 & 188,56 & 298,25 \\
\hline & \multirow{8}{*}{$\begin{array}{l}m \\
+ \\
m\end{array}$} & $\begin{array}{l}\text { ZAPATA MED. } \\
\text { ZAPATA INT. } \\
\text { TERCERA ZAP. } \\
\text { VIGA CENT. }\end{array}$ & $\begin{array}{c}2.600 \times 1.300 \times 500 \\
1.700 \times 1.700 \times 500 \\
1.700 \times 1.700 \times 500 \\
1.000 \times 450 \times 500\end{array}$ & $\begin{array}{c}3.000 \times 1.500 \times 600 \\
2.300 \times 2.300 \times 600 \\
2.000 \times 2.000 \times 600 \\
2.500 \times 600 \times 600\end{array}$ & $\begin{array}{c}3.400 \times 1.700 \times 700 \\
2.900 \times 2.900 \times 700 \\
2.300 \times 2.300 \times 700 \\
4.025 \times 700 \times 700\end{array}$ \\
\hline & & $\mathrm{R}_{\mathrm{m}}(\mathrm{kN})$ & 639,83 & 852,52 & 1128,15 \\
\hline & & $\sigma_{m}\left(\mathrm{kN} / \mathrm{m}^{2}\right)$ & 189,30 & 189,45 & 195,18 \\
\hline & & $\mathrm{R}_{\mathrm{i}} \quad(\mathrm{kN})$ & 550,78 & 1049,49 & 1595,20 \\
\hline & & $\sigma_{i} \quad\left(k N / m^{2}\right)$ & 190,58 & 198,39 & 189,68 \\
\hline & & $R_{t z}(k N)$ & 528,54 & 730,13 & 977,16 \\
\hline & & $\sigma_{\mathrm{tz}}\left(\mathrm{kN} / \mathrm{m}^{2}\right)$ & 184,98 & 186,12 & 190,91 \\
\hline & & $\mathrm{M}_{1 \mathrm{v}}(\mathrm{kN} \cdot \mathrm{m})$ & 171,22 & 308,92 & 479,66 \\
\hline & \multirow{8}{*}{$\begin{array}{l}+ \\
+ \\
m\end{array}$} & $\begin{array}{l}\text { ZAPATA MED. } \\
\text { ZAPATA INT. } \\
\text { TERCERA ZAP. } \\
\text { VIGA CENT. }\end{array}$ & & $\begin{array}{r}3.400 \times 1.700 \times 600 \\
2.500 \times 2.500 \times 600 \\
2.200 \times 2.200 \times 600 \\
2.225 \times 700 \times 600 \\
\end{array}$ & $\begin{array}{r}3.900 \times 1.950 \times 700 \\
3.100 \times 3.100 \times 700 \\
2.600 \times 2.600 \times 700 \\
3.700 \times 700 \times 700 \\
\end{array}$ \\
\hline & & $\mathrm{R}_{\mathrm{m}}(\mathrm{kN})$ & & 1128,86 & 1477,44 \\
\hline & & $\sigma_{\mathrm{m}}\left(\mathrm{kN} / \mathrm{m}^{2}\right)$ & & 195,30 & 194,27 \\
\hline & & $\mathrm{R}_{\mathrm{i}} \quad(\mathrm{kN})$ & & 1249,94 & 1902,11 \\
\hline & & $\sigma_{i} \quad\left(k N / m^{2}\right)$ & & 199,99 & 197,93 \\
\hline & & $\mathrm{R}_{\mathrm{tz}}(\mathrm{kN})$ & & 950,17 & 1272,84 \\
\hline & & $\sigma_{\mathrm{tz}}\left(\mathrm{kN} / \mathrm{m}^{2}\right)$ & & 199,70 & 193,06 \\
\hline & & $\mathrm{M}_{1 \mathrm{v}}(\mathrm{kN} \cdot \mathrm{m})$ & & 444,52 & 704,66 \\
\hline
\end{tabular}

Tabla 27. Zapata de medianería con viga centradora. Modelo convencional. Etapa II Resultados para $\sigma_{\text {adm. }}=200 \mathrm{kN} / \mathrm{m}^{2}$ y relación de forma $2: 1$ 


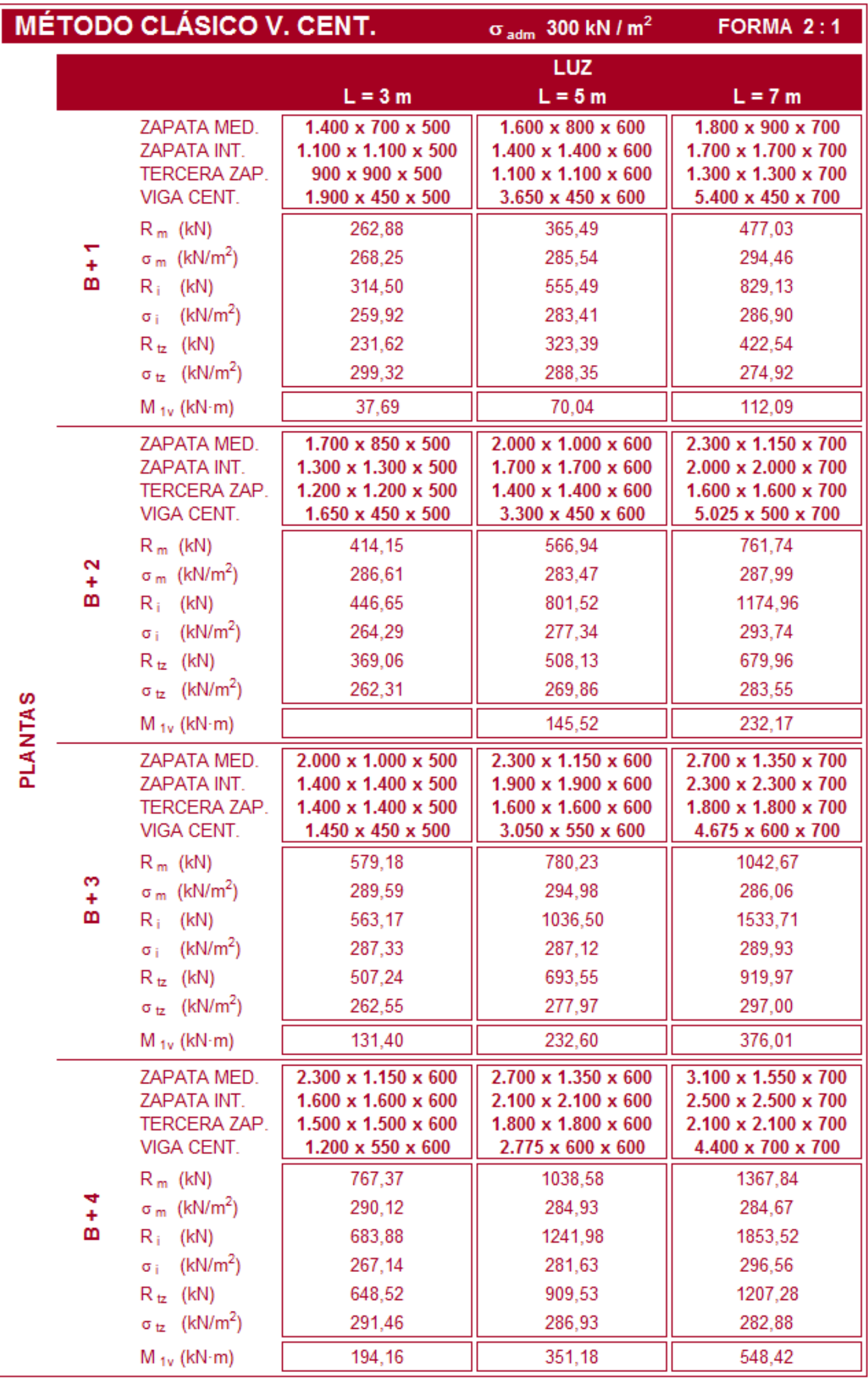

Tabla 28. Zapata de medianería con viga centradora. Modelo convencional. Etapa II Resultados para $\sigma_{\text {adm. }}=300 \mathrm{kN} / \mathrm{m}^{2}$ y relación de forma $2: 1$ 


\subsubsection{ZAPATA DE MEDIANERÍA CON COLABORACIÓN DE VIGA SUPERIOR}

Se ofrecen en las Tablas 29, 30, 31, 32, 33 y 34, los resultados del cálculo del modelo convencional de zapata de medianería con colaboración de viga superior, para cada uno de los casos planteados en la Etapa II. Los parámetros a los que hacen referencia dichos resultados son los representados en las Fig. 8 y 9.

Las tablas, ordenadas por tensiones admisibles del terreno y relaciones de forma, ofrecen para los distintos casos en función de la luz y el número de plantas, los siguientes resultados:

- Dimensionamiento utilizado para la zapata de medianería.

- Resultante de la fuerza de rozamiento entre zapata y terreno $R_{m x}(k N)$.

- Resultante de las tensiones de contacto en la zapata de medianería $\mathrm{R}_{\text {my }}(\mathrm{kN})$.

- Tensión transmitida al terreno por la zapata de medianería $\sigma_{\mathrm{m}}\left(\mathrm{kN} / \mathrm{m}^{2}\right)$, calculada bajo la hipótesis de distribución de presiones uniformemente repartida.

- Fuerza de tracción $\mathrm{T}(\mathrm{kN})$ generada en la viga de la primera planta para equilibrar y centrar el comportamiento de la zapata de medianería.

Tal y como se ha indicado en apartados anteriores, el modelo convencional de zapata de medianería con viga centradora es más restrictivo respecto del tamaño necesario para la zapata de medianería, por lo cual, se han utilizado las mismas dimensiones de zapata obtenidas en dicho modelo con el fin de poder contrastar resultados. 


\begin{tabular}{|c|c|c|c|c|c|}
\hline \multicolumn{4}{|c|}{ MÉTODO CLÁSICO V.SUP. } & $\sigma_{\text {adm }} 100 \mathrm{kN} / \mathrm{m}^{2}$ & FORMA 1,5:1 \\
\hline \multirow{22}{*}{ 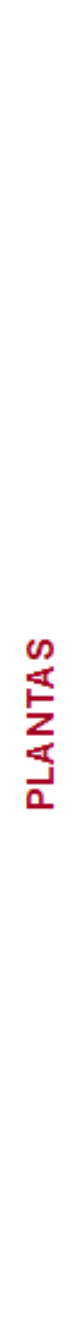 } & & & & LUZ & \\
\hline & & & $L=3 \mathrm{~m}$ & $\mathrm{~L}=5 \mathrm{~m}$ & $\mathrm{~L}=7 \mathrm{~m}$ \\
\hline & \multirow{5}{*}{$\begin{array}{c}\dot{+} \\
\dot{m}\end{array}$} & \multirow{5}{*}{$\begin{array}{ll}\text { ZAPATA MED. } \\
\mathrm{R}_{\mathrm{mx}}(\mathrm{kN}) \\
\mathrm{R}_{\mathrm{my}}(\mathrm{kN}) \\
\sigma_{\mathrm{m}} & \left(\mathrm{kN} / \mathrm{m}^{2}\right) \\
\mathrm{T} & (\mathrm{kN})\end{array}$} & $2.400 \times 1.600 \times 500$ & $2.800 \times 1,850 \times 600$ & $3.200 \times 2.150 \times 700$ \\
\hline & & & 29,29 & 45,42 & 66,95 \\
\hline & & & 301,18 & 424,40 & 567,51 \\
\hline & & & 78,43 & 81,93 & 82,49 \\
\hline & & & 31,84 & 52,16 & 79,21 \\
\hline & \multirow{5}{*}{$\begin{array}{l}n \\
+ \\
m\end{array}$} & \multirow{5}{*}{$\begin{array}{ll}\text { ZAPATA MED. } & \\
\mathrm{R}_{\mathrm{mx}} & (\mathrm{kN}) \\
\mathrm{R}_{\mathrm{my}} & (\mathrm{kN}) \\
\sigma_{\mathrm{m}} & \left(\mathrm{kN} / \mathrm{m}^{2}\right) \\
\mathrm{T} & (\mathrm{kN})\end{array}$} & & $3.500 \times 2.350 \times 600$ & $4.000 \times 2.650 \times 700$ \\
\hline & & & & 97,95 & 139,30 \\
\hline & & & & 667,44 & 904,51 \\
\hline & & & & 81,15 & 85,33 \\
\hline & & & & 105,21 & 156,28 \\
\hline & \multirow{5}{*}{$\stackrel{m}{+}$} & \multirow{5}{*}{$\begin{array}{ll}\text { ZAPATA MED. } & \\
R_{\mathrm{mx}} & (\mathrm{kN}) \\
\mathrm{R}_{\mathrm{my}} & (\mathrm{kN}) \\
\sigma_{\mathrm{m}} & \left(\mathrm{kN} / \mathrm{m}^{2}\right) \\
\mathrm{T} & (\mathrm{kN})\end{array}$} & & & $4.800 \times 3.200 \times 700$ \\
\hline & & & & & 241,96 \\
\hline & & & & & 1258,34 \\
\hline & & & & & 81,92 \\
\hline & & & & & 258,89 \\
\hline & \multirow{5}{*}{$\stackrel{+}{+}+$} & ZAPATA MED. & & & \\
\hline & & $\mathrm{R}_{\mathrm{mx}}(\mathrm{kN})$ & & & \\
\hline & & $\mathrm{R}_{\mathrm{my}}(\mathrm{kN})$ & & & \\
\hline & & $\sigma_{\mathrm{m}} \quad\left(\mathrm{kN} / \mathrm{m}^{2}\right)$ & & & \\
\hline & & $\mathrm{T} \quad(\mathrm{kN})$ & & & \\
\hline
\end{tabular}

Tabla 29. Zapata de medianería con colaboración de viga superior. M. convencional. Etapa II Resultados para $\sigma_{\text {adm. }}=100 \mathrm{kN} / \mathrm{m}^{2}$ y relación de forma $1,5: 1$ 


\begin{tabular}{|c|c|c|c|c|c|}
\hline \multicolumn{4}{|c|}{ MÉTODO CLÁSICO V.SUP. } & $\sigma_{\mathrm{adm}} 200 \mathrm{kN} / \mathrm{m}^{2}$ & FORMA $1,5: 1$ \\
\hline \multirow{22}{*}{$\begin{array}{l}\infty \\
\mathbb{1} \\
\mathbf{5} \\
\mathbf{a}\end{array}$} & & & & LUZ & \\
\hline & & & $L=3 \mathrm{~m}$ & $\mathrm{~L}=5 \mathrm{~m}$ & $\mathrm{~L}=7 \mathrm{~m}$ \\
\hline & \multirow{5}{*}{$\stackrel{\vec{m}}{\dot{m}}$} & ZAPATA MED. & $1.500 \times 1.000 \times 500$ & $1.800 \times 1.200 \times 600$ & $2.000 \times 1.350 \times 700$ \\
\hline & & $\mathrm{R}_{\operatorname{mx}}(\mathrm{kN})$ & 15,07 & 24,73 & 34,98 \\
\hline & & $\mathrm{R}_{\mathrm{my}}(\mathrm{kN})$ & 247,59 & 347,69 & 450,89 \\
\hline & & $\sigma_{\mathrm{m}} \quad\left(\mathrm{kN} / \mathrm{m}^{2}\right)$ & 165,06 & 160,97 & 167,00 \\
\hline & & $\mathrm{T} \quad(\mathrm{kN})$ & 17,62 & 31,47 & 47,24 \\
\hline & \multirow{5}{*}{$\begin{array}{l}\mathbf{+} \\
\dot{m}\end{array}$} & ZAPATA MED. & $1.900 \times 1.250 \times 500$ & $2.200 \times 1.450 \times 600$ & $2.600 \times 1.750 \times 700$ \\
\hline & & $R_{\mathrm{mx}}(\mathrm{kN})$ & 33,84 & 53,10 & 81,01 \\
\hline & & $\mathrm{R}_{\text {my }}(\mathrm{kN})$ & 390,64 & 539,55 & 735,72 \\
\hline & & $\sigma_{\mathrm{m}} \quad\left(\mathrm{kN} / \mathrm{m}^{2}\right)$ & 164,48 & 169,14 & 161,70 \\
\hline & & $\mathrm{T} \quad(\mathrm{kN})$ & 36,62 & 60,36 & 97,99 \\
\hline & \multirow{5}{*}{$\begin{array}{c}m \\
+ \\
m\end{array}$} & ZAPATA MED. & $2.300 \times 1.550 \times 500$ & $2.600 \times 1.750 \times 600$ & $3.000 \times 2.000 \times 700$ \\
\hline & & $\mathrm{R}_{\mathrm{mx}}(\mathrm{kN})$ & 62,59 & 94,85 & 136,03 \\
\hline & & $R_{\text {my }}(k N)$ & 544,17 & 744,27 & 997,20 \\
\hline & & $\sigma_{\mathrm{m}} \quad\left(\mathrm{kN} / \mathrm{m}^{2}\right)$ & 152,64 & 163,58 & 166,20 \\
\hline & & $\mathrm{T} \quad(\mathrm{kN})$ & 65,37 & 102,15 & 152,96 \\
\hline & \multirow{5}{*}{$\begin{array}{l}+ \\
\dot{m}\end{array}$} & ZAPATA MED. & & $3.000 \times 2.000 \times 600$ & $3.400 \times 2.250 \times 700$ \\
\hline & & $\mathrm{R}_{\mathrm{mx}}(\mathrm{kN})$ & & 143,06 & 201,99 \\
\hline & & $\mathrm{R}_{\mathrm{my}}(\mathrm{kN})$ & & 979,86 & 1297,98 \\
\hline & & $\sigma_{\mathrm{m}} \quad\left(\mathrm{kN} / \mathrm{m}^{2}\right)$ & & 163,31 & 169,67 \\
\hline & & $\mathrm{T} \quad(\mathrm{kN})$ & & 152,26 & 222,14 \\
\hline
\end{tabular}

Tabla 30. Zapata de medianería con colaboración de viga superior. M. convencional. Etapa II Resultados para $\sigma_{\text {adm. }}=200 \mathrm{kN} / \mathrm{m}^{2}$ y relación de forma $1,5: 1$ 


\begin{tabular}{|c|c|c|c|c|c|}
\hline \multicolumn{4}{|c|}{ MÉTODO CLÁSICO V.SUP. } & $\sigma_{\text {adm }} 300 \mathrm{kN} / \mathrm{m}^{2}$ & FORMA $1,5: 1$ \\
\hline \multirow{13}{*}{ 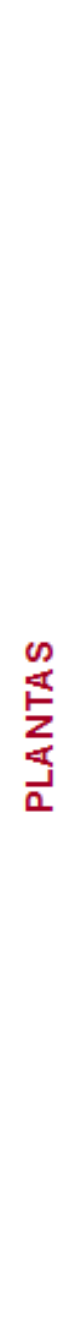 } & & & $L=3 \mathrm{~m}$ & $\begin{array}{c}\text { LUZ } \\
L=5 \mathrm{~m}\end{array}$ & $L=7 \mathrm{~m}$ \\
\hline & \multirow{3}{*}{$\stackrel{+}{+}$} & ZAPATA MED. & $1.200 \times 800 \times 500$ & $1.400 \times 950 \times 600$ & $1.600 \times 1.050 \times 700$ \\
\hline & & $\begin{array}{l}\mathrm{R}_{\mathrm{mx}}(\mathrm{kN}) \\
\mathrm{R}_{\mathrm{my}}(\mathrm{kN}) \\
\sigma_{\mathrm{m}}\left(\mathrm{kN} / \mathrm{m}^{2}\right)\end{array}$ & $\begin{array}{c}10,34 \\
235,22 \\
245,03 \\
\end{array}$ & $\begin{array}{c}16,78 \\
326,61 \\
245,57 \\
\end{array}$ & $\begin{array}{r}23,00 \\
422,43 \\
251,45 \\
\end{array}$ \\
\hline & & $\mathrm{T} \quad(\mathrm{kN})$ & 12,89 & 23,52 & 35,26 \\
\hline & \multirow{3}{*}{$\begin{array}{l}N \\
+ \\
m\end{array}$} & ZAPATA MED. & $1.500 \times 1.000 \times 500$ & $1.700 \times 1.150 \times 600$ & $2.000 \times 1.350 \times 700$ \\
\hline & & $\begin{array}{l}R_{m x}(k N) \\
R_{m y}(k N) \\
\sigma_{m}\left(k N / m^{2}\right)\end{array}$ & $\begin{array}{c}24,50 \\
370,60 \\
247,07 \\
\end{array}$ & $\begin{array}{c}38,15 \\
508,18 \\
259,94 \\
\end{array}$ & $\begin{array}{c}55,11 \\
684,10 \\
253,37 \\
\end{array}$ \\
\hline & & $\mathrm{T} \quad(\mathrm{kN})$ & 27,28 & 45,41 & 72,09 \\
\hline & \multirow{3}{*}{$\stackrel{m}{+}$} & ZAPATA MED. & $1.800 \times 1.200 \times 500$ & $2.000 \times 1.350 \times 600$ & $2.300 \times 1.550 \times 700$ \\
\hline & & $\begin{array}{l}\mathrm{R}_{\mathrm{mx}}(\mathrm{kN}) \\
\mathrm{R}_{\mathrm{my}}(\mathrm{kN}) \\
\sigma_{\mathrm{m}}\left(\mathrm{kN} / \mathrm{m}^{2}\right)\end{array}$ & $\begin{array}{l}44,60 \\
511,99 \\
237,03\end{array}$ & $\begin{array}{c}67,51 \\
697,28 \\
258,25\end{array}$ & $\begin{array}{c}96,31 \\
929,26 \\
260,66\end{array}$ \\
\hline & & $\mathrm{T} \quad(\mathrm{kN})$ & 47,38 & 74,81 & 113,24 \\
\hline & \multirow{3}{*}{$\begin{array}{l}+ \\
\dot{m}\end{array}$} & ZAPATA MED. & $2.000 \times 1.350 \times 600$ & $2.300 \times 1.550 \times 600$ & $2.700 \times 1.800 \times 700$ \\
\hline & & $\begin{array}{l}\mathrm{R}_{\mathrm{mx}}(\mathrm{kN}) \\
\mathrm{R}_{\mathrm{my}}(\mathrm{kN}) \\
\sigma_{\mathrm{m}}\left(\mathrm{kN} / \mathrm{m}^{2}\right)\end{array}$ & $\begin{array}{c}65,89 \\
660,12 \\
244,49 \\
\end{array}$ & $\begin{array}{l}102,58 \\
918,01 \\
257,51\end{array}$ & $\begin{array}{c}150,07 \\
1220,13 \\
251,06\end{array}$ \\
\hline & & $\mathrm{T} \quad(\mathrm{kN})$ & 68,69 & 111,78 & 170,22 \\
\hline
\end{tabular}

Tabla 31. Zapata de medianería con colaboración de viga superior. M. convencional. Etapa II Resultados para $\sigma_{\text {adm. }}=300 \mathrm{kN} / \mathrm{m}^{2}$ y relación de forma $1,5: 1$ 


\begin{tabular}{|c|c|c|c|c|c|}
\hline \multicolumn{4}{|c|}{ MÉTODO CLÁSICO V.SUP. } & $\sigma_{\text {adm }} 100 \mathrm{kN} / \mathrm{m}^{2}$ & FORMA $2: 1$ \\
\hline \multirow{22}{*}{$\begin{array}{l}\infty \\
\frac{1}{2} \\
\frac{1}{2}\end{array}$} & & & & LUZ & \\
\hline & & & $L=3 \mathrm{~m}$ & $\mathrm{~L}=5 \mathrm{~m}$ & $\mathrm{~L}=7 \mathrm{~m}$ \\
\hline & \multirow{5}{*}{$\begin{array}{c}\overrightarrow{+} \\
\mathbf{m}\end{array}$} & \multirow{5}{*}{$\begin{array}{ll}\text { ZAPATA MED. } & \\
\mathrm{R}_{\mathrm{mx}} & (\mathrm{kN}) \\
\mathrm{R}_{\mathrm{my}} & (\mathrm{kN}) \\
\sigma_{\mathrm{m}} & \left(\mathrm{kN} / \mathrm{m}^{2}\right) \\
\mathrm{T} & (\mathrm{kN})\end{array}$} & $2.700 \times 1.350 \times 500$ & $3.100 \times 1,550 \times 600$ & $3.600 \times 1.800 \times 700$ \\
\hline & & & 23,37 & 35,87 & 52,96 \\
\hline & & & 296,71 & 414,88 & 556,35 \\
\hline & & & 81,40 & 86,34 & 85,86 \\
\hline & & & 25,92 & 42,61 & 65,22 \\
\hline & \multirow{5}{*}{$\begin{array}{l}\mathbf{N} \\
\dot{m}\end{array}$} & \multirow{5}{*}{$\begin{array}{ll}\text { ZAPATA MED. } & \\
\mathrm{R}_{\mathrm{mx}} & (\mathrm{kN}) \\
\mathrm{R}_{\mathrm{my}} & (\mathrm{kN}) \\
\sigma_{\mathrm{m}} & \left(\mathrm{kN} / \mathrm{m}^{2}\right) \\
\mathrm{T} & (\mathrm{kN})\end{array}$} & & $4.000 \times 2.000 \times 600$ & $4.600 \times 2.300 \times 700$ \\
\hline & & & & 80,51 & 116,63 \\
\hline & & & & 661,72 & 903,95 \\
\hline & & & & 82,72 & 85,44 \\
\hline & & & & 87,77 & 133,61 \\
\hline & \multirow{5}{*}{$\begin{array}{l}m \\
\mathbf{m}\end{array}$} & \multirow{5}{*}{$\begin{array}{l}\text { ZAPATA MED. } \\
\mathrm{R}_{\mathrm{mx}}(\mathrm{kN}) \\
\mathrm{R}_{\mathrm{my}}(\mathrm{kN}) \\
\sigma_{\mathrm{m}}\left(\mathrm{kN} / \mathrm{m}^{2}\right) \\
\mathrm{T} \quad(\mathrm{kN})\end{array}$} & & & $5.400 \times 2.700 \times 700$ \\
\hline & & & & & 197,82 \\
\hline & & & & & 1236,58 \\
\hline & & & & & 84,81 \\
\hline & & & & & 214,75 \\
\hline & \multirow{5}{*}{$\begin{array}{l}+ \\
\dot{m}\end{array}$} & ZAPATA MED. & & & \\
\hline & & $\mathrm{R}_{\mathrm{mx}}(\mathrm{kN})$ & & & \\
\hline & & $\mathrm{R}_{\text {my }}(\mathrm{kN})$ & & & \\
\hline & & $\sigma_{\mathrm{m}} \quad\left(\mathrm{kN} / \mathrm{m}^{2}\right)$ & & & \\
\hline & & $(\mathrm{kN})$ & & & \\
\hline
\end{tabular}

Tabla 32. Zapata de medianería con colaboración de viga superior. M. convencional. Etapa II Resultados para $\sigma_{\text {adm. }}=100 \mathrm{kN} / \mathrm{m}^{2}$ y relación de forma $2: 1$ 


\begin{tabular}{|c|c|c|c|c|c|}
\hline \multicolumn{4}{|c|}{ MÉTODO CLÁSICO V.SUP. } & $\sigma_{\text {adm }} 200 \mathrm{kN} / \mathrm{m}^{2}$ & FORMA $2: 1$ \\
\hline \multirow{22}{*}{$\begin{array}{l}\infty \\
\frac{1}{z} \\
\frac{1}{2}\end{array}$} & & & & LUZ & \\
\hline & & & $L=3 \mathrm{~m}$ & $L=5 \mathrm{~m}$ & $L=7 \mathrm{~m}$ \\
\hline & \multirow{5}{*}{$\stackrel{\check{+}}{\mathbf{m}}$} & ZAPATA MED. & $1.700 \times 850 \times 500$ & $2.000 \times 1.000 \times 600$ & $2.300 \times 1.150 \times 700$ \\
\hline & & $\mathrm{R}_{\mathrm{mx}}(\mathrm{kN})$ & 11,52 & 18,37 & 26,99 \\
\hline & & $R_{\text {my }}(k N)$ & 246,33 & 343,63 & 449,36 \\
\hline & & $\sigma_{\mathrm{m}} \quad\left(\mathrm{kN} / \mathrm{m}^{2}\right)$ & 170,47 & 171,82 & 169,89 \\
\hline & & $\mathrm{T} \quad(\mathrm{kN})$ & 14,07 & 25,11 & 39,25 \\
\hline & \multirow{5}{*}{$\begin{array}{l}\mathbf{N} \\
+ \\
\mathbf{m}\end{array}$} & ZAPATA MED. & $2.200 \times 1.100 \times 500$ & $2.500 \times 1.250 \times 600$ & $2.900 \times 1.450 \times 700$ \\
\hline & & $\mathrm{R}_{\mathrm{mx}}(\mathrm{kN})$ & 28,24 & 43,13 & 61,58 \\
\hline & & $\mathrm{R}_{\mathrm{my}}(\mathrm{kN})$ & 391,67 & 537,90 & 726,09 \\
\hline & & $\sigma_{\mathrm{m}} \quad\left(\mathrm{kN} / \mathrm{m}^{2}\right)$ & 161,85 & 172,13 & 172,67 \\
\hline & & $\mathrm{T} \quad(\mathrm{kN})$ & 31,02 & 50,39 & 78,56 \\
\hline & \multirow{5}{*}{$\begin{array}{l}m \\
+ \\
m\end{array}$} & ZAPATA MED. & $2.600 \times 1.300 \times 500$ & $3.000 \times 1.500 \times 600$ & $3.400 \times 1.700 \times 700$ \\
\hline & & $\mathrm{R}_{\mathrm{mx}}(\mathrm{kN})$ & 49,74 & 77,76 & 109,55 \\
\hline & & $R_{\text {my }}(k N)$ & 539,93 & 743,00 & 991,06 \\
\hline & & $\sigma_{\mathrm{m}} \quad\left(\mathrm{kN} / \mathrm{m}^{2}\right)$ & 159,74 & 165,11 & 171,46 \\
\hline & & $(\mathrm{kN})$ & 52,52 & 85,06 & 126,48 \\
\hline & \multirow{5}{*}{$\begin{array}{l}+ \\
+ \\
m\end{array}$} & ZAPATA MED. & & $3.400 \times 1.700 \times 600$ & $3.900 \times 1.950 \times 700$ \\
\hline & & $\mathrm{R}_{\mathrm{mx}}(\mathrm{kN})$ & & 116,08 & 167,38 \\
\hline & & $\mathrm{R}_{\mathrm{my}}(\mathrm{kN})$ & & 974,27 & 1296,72 \\
\hline & & $\sigma_{\mathrm{m}} \quad\left(\mathrm{kN} / \mathrm{m}^{2}\right)$ & & 168,56 & 170,51 \\
\hline & & $\mathrm{T} \quad(\mathrm{kN})$ & & 125,28 & 187,53 \\
\hline
\end{tabular}

Tabla 33. Zapata de medianería con colaboración de viga superior. M. convencional. Etapa II Resultados para $\sigma_{\text {adm. }}=200 \mathrm{kN} / \mathrm{m}^{2}$ y relación de forma $2: 1$ 


\begin{tabular}{|c|c|c|c|c|c|}
\hline \multicolumn{4}{|c|}{ MÉTODO CLÁSICO V.SUP. } & $\sigma_{\text {adm }} 300 \mathrm{kN} / \mathrm{m}^{2}$ & FORMA $2: 1$ \\
\hline \multirow{22}{*}{ 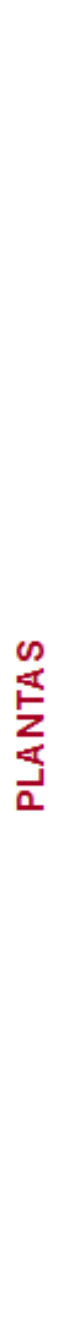 } & & & & LUZ & \\
\hline & & & $L=3 \mathrm{~m}$ & $\mathrm{~L}=5 \mathrm{~m}$ & $\mathrm{~L}=7 \mathrm{~m}$ \\
\hline & \multirow{5}{*}{$\stackrel{+}{+}$} & ZAPATA MED. & $1.400 \times 700 \times 500$ & $1.600 \times 800 \times 600$ & $1.800 \times 900 \times 700$ \\
\hline & & $\mathrm{R}_{\mathrm{mx}}(\mathrm{kN})$ & 7,97 & 12,00 & 17,01 \\
\hline & & $\mathrm{R}_{\text {my }}(\mathrm{kN})$ & 235,68 & 325,34 & 420,76 \\
\hline & & $\sigma_{\mathrm{m}} \quad\left(\mathrm{kN} / \mathrm{m}^{2}\right)$ & 240,49 & 254,17 & 259,73 \\
\hline & & $\mathrm{T} \quad(\mathrm{kN})$ & 10,52 & 18,74 & 29,27 \\
\hline & \multirow{5}{*}{$\begin{array}{l}\sim \\
+ \\
m\end{array}$} & ZAPATA MED. & $1.700 \times 850 \times 500$ & $2.000 \times 1.000 \times 600$ & $2.300 \times 1.150 \times 700$ \\
\hline & & $\mathrm{R}_{\mathrm{mx}}(\mathrm{kN})$ & 18,90 & 30,67 & 42,15 \\
\hline & & $\mathrm{R}_{\mathrm{my}}(\mathrm{kN})$ & 369,34 & 509,32 & 682,57 \\
\hline & & $\sigma_{\mathrm{m}} \quad\left(\mathrm{kN} / \mathrm{m}^{2}\right)$ & 255,60 & 254,66 & 258,06 \\
\hline & & $\mathrm{T} \quad(\mathrm{kN})$ & 21,68 & 37,93 & 59,13 \\
\hline & \multirow{5}{*}{$\begin{array}{l}m \\
+ \\
m\end{array}$} & ZAPATA MED. & $2.000 \times 1.000 \times 500$ & $2.300 \times 1.150 \times 600$ & $2.700 \times 1.350 \times 700$ \\
\hline & & $\mathrm{R}_{\mathrm{mx}}(\mathrm{kN})$ & 34,32 & 53,85 & 78,65 \\
\hline & & $\mathrm{R}_{\mathrm{my}}(\mathrm{kN})$ & 508,33 & 695,88 & 931,50 \\
\hline & & $\sigma_{\mathrm{m}} \quad\left(\mathrm{kN} / \mathrm{m}^{2}\right)$ & 254,17 & 263,09 & 255,55 \\
\hline & & $(\mathrm{kN})$ & 37,10 & 61,15 & 95,58 \\
\hline & \multirow{5}{*}{$\begin{array}{l}+ \\
+ \\
m\end{array}$} & ZAPATA MED. & $2.300 \times 1.150 \times 600$ & $2.700 \times 1.350 \times 600$ & $3.100 \times 1.550 \times 700$ \\
\hline & & $\mathrm{R}_{\mathrm{mx}}(\mathrm{kN})$ & 53,03 & 84,60 & 121,23 \\
\hline & & $\mathrm{R}_{\mathrm{my}}(\mathrm{kN})$ & 658,72 & 920,04 & 1218,60 \\
\hline & & $\sigma_{\mathrm{m}} \quad\left(\mathrm{kN} / \mathrm{m}^{2}\right)$ & 249,04 & 252,41 & 253,61 \\
\hline & & $\mathrm{T} \quad(\mathrm{kN})$ & 55,83 & 93,80 & 141,38 \\
\hline
\end{tabular}

Tabla 34. Zapata de medianería con colaboración de viga superior. M. convencional. Etapa II Resultados para $\sigma_{\text {adm. }}=300 \mathrm{kN} / \mathrm{m}^{2}$ y relación de forma $2: 1$ 


\subsubsection{RESULTADOS DE LOS MODELOS DE ELEMENTOS FINITOS}

Con independencia de los cambios introducidos en las variables a estudiar en la Etapa II, ya descritos en el apartado 3.1.3.2, el planteamiento fundamental que caracteriza y diferencia la Etapa II de la anterior, en los modelos de elementos finitos, es la consideración del comportamiento del hormigón de una forma más ajustada a la realidad, con un diagrama tensión deformación parabólico rectangular, distinta resistencia a tracción y a compresión y fisuración y fractura de los elementos de hormigón que superen la reducida resistencia a tracción del mismo (apartado 3.3.2.).

Este planteamiento, al igual que si se tratase de una estructura real, obliga a introducir en los modelos de elementos finitos el correcto armado de los diferentes pilares, vigas y zapatas que lo integran para evitar su colapso. Se ofrece a continuación el resultado del armado obtenido para los distintos casos del pórtico tipo, calculado de acuerdo con las verificaciones establecidas por la vigente normativa, EHE-08 y C.T.E.

En primer lugar, en las Tablas 35, 36, 37 y 38 se muestran los resultados correspondientes al dimensionamiento de los pilares y vigas del pórtico tipo, ordenados por número de plantas del pórtico, para las distintas luces del mismo.

Para cada caso se ofrece la escuadría obtenida tanto para pilares como para vigas. Los pilares son todos de sección cuadrada, con escuadrías que oscilan entre $300 \times 300\left(\mathrm{~mm}^{2}\right)$ y $400 \times 400\left(\mathrm{~mm}^{2}\right)$. El tamaño de la sección de los pilares de cada caso es común para los pilares interiores y exteriores, manteniéndose constante a lo largo de las distintas plantas del pórtico. Por su parte, las vigas son de sección rectangular, de tipo plano con suficiente canto para cumplir todas las comprobaciones exigibles. Su tamaño oscila entre $450 \times 300\left(\mathrm{~mm}^{2}\right)$ y 650 x $400\left(\mathrm{~mm}^{2}\right)$. Las vigas de las distintas plantas constituyen un único grupo con sección y armado común.

El armado de los pilares responde al esquema representado en la Fig.61. Se han empleado dos armados tipo. El primero define un armado base empleado a lo largo de todo el pilar en sus distintas plantas y está formado por cuatro redondos, de diámetro variable según el caso, con cerco sencillo. El segundo, constituye una versión reforzada del anterior, con ocho redondos y doble cerco, uno de ellos girado a $45^{\circ}$. 

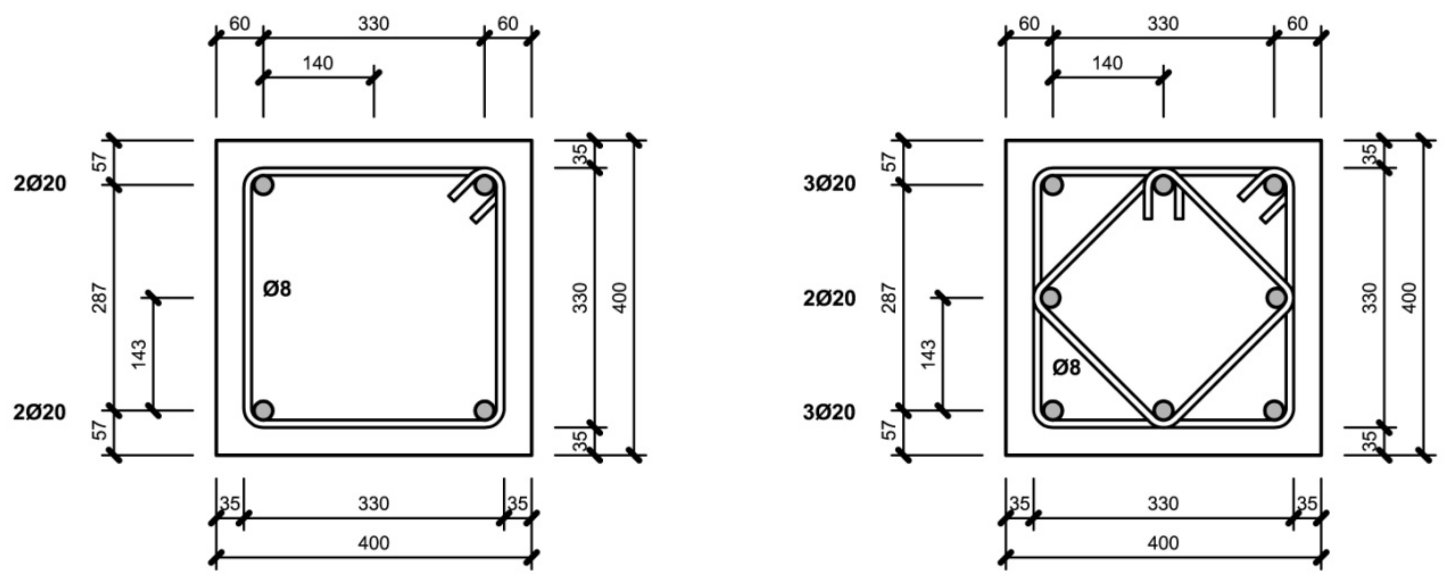

Fig.61. Armado tipo en pilares

Por su parte (Fig.62), para las vigas se dispone un armado constituido por una armadura longitudinal de montaje con cuatro redondos en cada cara, con las correspondientes armaduras de refuerzo, tanto de positivos en centro de vano, como de negativos en las uniones de la viga con los pilares. El número de redondos de las armaduras de refuerzo varía según los casos, indicándose en las tablas, además del diámetro y número de redondos, la longitud del refuerzo en cuestión. Como armadura transversal se dispone doble cerco con cuatro ramas resistentes. En cada pórtico tipo, se plantea el mismo armado para las vigas de las distintas plantas del pórtico, constituyendo todas ellas un mismo grupo de barras.

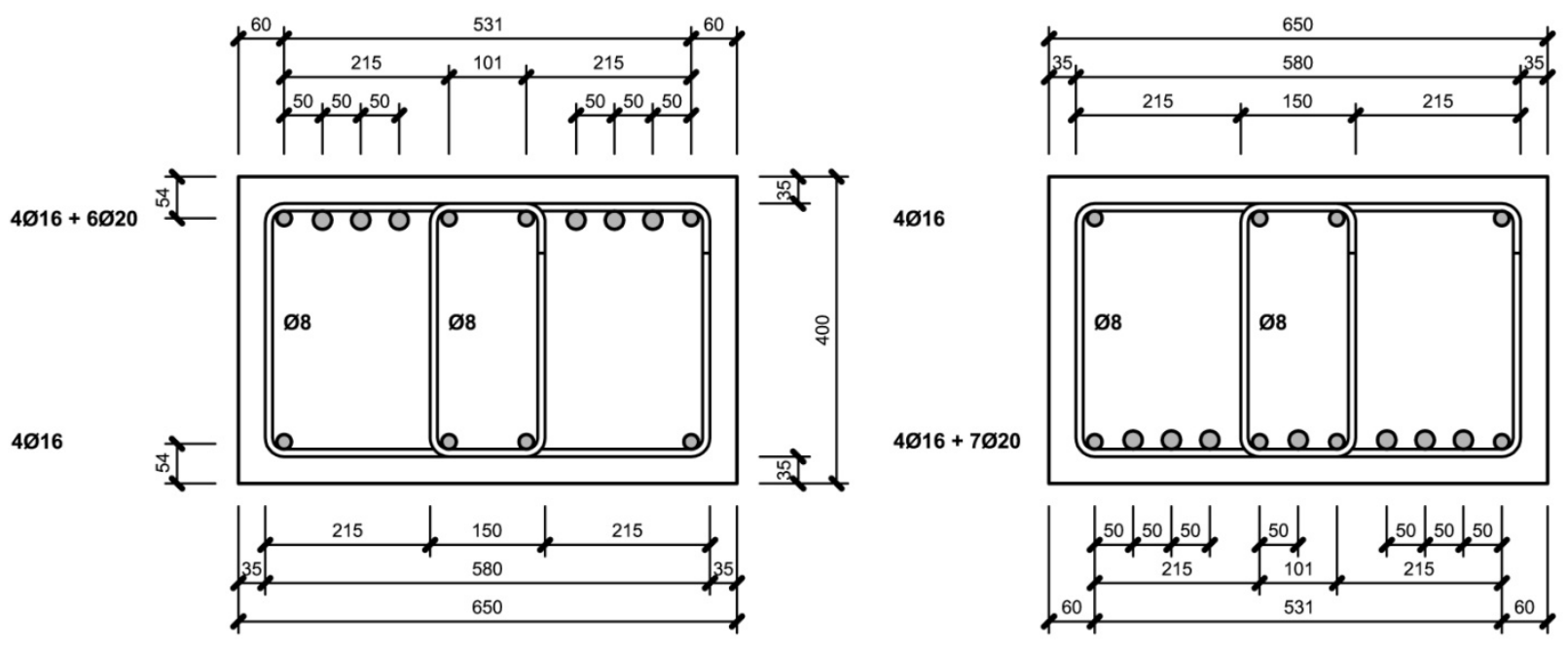

Fig.62. Armado tipo en vigas 


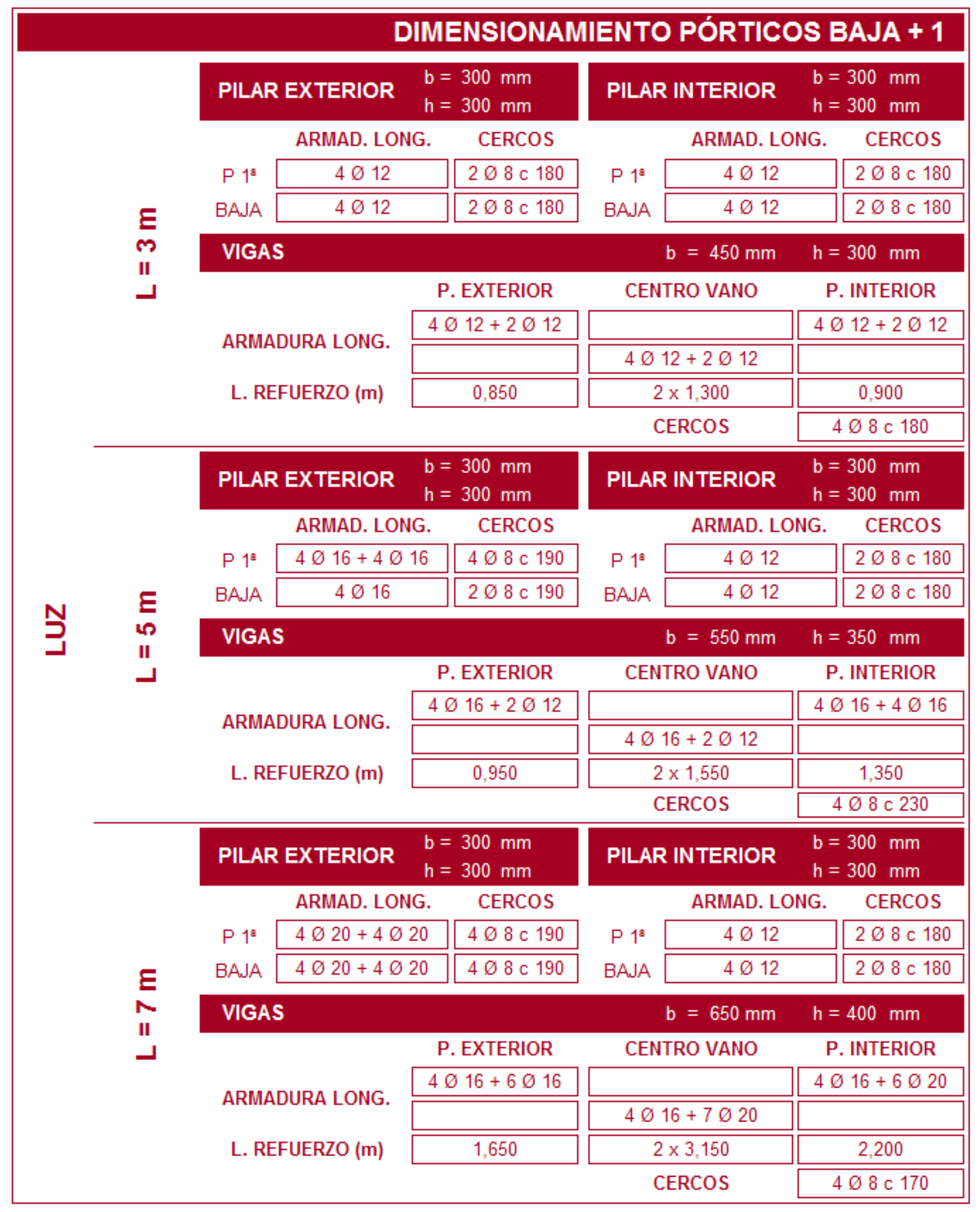

Tabla 35. Dimensionamiento y armado de pórticos con Baja +1 plantas.

Modelos de elementos finitos. Etapa II 


\begin{tabular}{|c|c|c|c|c|c|c|c|c|c|}
\hline & & \multicolumn{8}{|c|}{ DIMENSIONAMIENTO PÓRTICOS BAJA + 2} \\
\hline & \multirow{11}{*}{$\begin{array}{l}\text { E } \\
\text { m } \\
\text { II } \\
\end{array}$} & \multicolumn{2}{|c|}{ PILAR EXTERIOR } & \multicolumn{2}{|c|}{$\mathrm{b}=300 \mathrm{~mm}$} & \multicolumn{2}{|c|}{ PILAR INTERIOR } & \multicolumn{2}{|c|}{$\begin{array}{l}\mathrm{b}=300 \mathrm{~mm} \\
\mathrm{~h}=300 \mathrm{~mm}\end{array}$} \\
\hline & & \multicolumn{4}{|c|}{ ARMAD. LONG. CERCOS } & \multicolumn{3}{|c|}{ ARMAD. LONG. } & CERCOS \\
\hline & & \multirow{3}{*}{$\begin{array}{c}P 2^{\mathrm{a}} \\
P 1^{\mathrm{a}} \\
\text { BAJA }\end{array}$} & \multicolumn{2}{|l|}{$4 \varnothing 12$} & $2 \varnothing 8 \mathrm{c} 180$ & \multirow{3}{*}{$\begin{array}{l}P 2^{\mathrm{a}} \\
\mathrm{P} 1^{\mathrm{a}} \\
\text { BAJA }\end{array}$} & \multicolumn{2}{|l|}{$4 \varnothing 12$} & $2 \varnothing 8 \mathrm{c} 180$ \\
\hline & & & \multicolumn{2}{|l|}{$4 \varnothing 12$} & $2 \varnothing 8 \mathrm{c} 180$ & & \multicolumn{2}{|l|}{$4 \varnothing 12$} & $2 \varnothing 8 \mathrm{c} 180$ \\
\hline & & & $4 \varnothing 12$ & & $2 \varnothing 8 \mathrm{c} 180$ & & \multicolumn{2}{|l|}{$4 \varnothing 12$} & $2 \varnothing 8$ с 180 \\
\hline & & \multicolumn{4}{|c|}{ VIGAS } & \multicolumn{4}{|c|}{$\mathrm{b}=450 \mathrm{~mm} \quad \mathrm{~h}=300 \mathrm{~mm}$} \\
\hline & & \multicolumn{4}{|c|}{ P. EXTERIOR } & \multicolumn{2}{|c|}{ CENTRO VANO } & \multicolumn{2}{|c|}{ P. INTERIOR } \\
\hline & & \multirow{2}{*}{\multicolumn{2}{|c|}{ ARMADURA LONG. }} & \multicolumn{2}{|c|}{$4 \varnothing 12+2 \varnothing 12$} & & & \multicolumn{2}{|c|}{$4 \varnothing 12+2 \varnothing 12$} \\
\hline & & & & & & $4 \varnothing$ & $2+2 \varnothing 12$ & & \\
\hline & & \multicolumn{2}{|c|}{ L. REFUERZO (m) } & & 0,850 & \multicolumn{2}{|c|}{$2 \times 1,300$} & \multicolumn{2}{|r|}{0,900} \\
\hline & & & & & & \multicolumn{2}{|c|}{ CERCOS } & & $\varnothing 8 \mathrm{c} 180$ \\
\hline & & PILA & XTERIOR & & $\begin{array}{l}300 \mathrm{~mm} \\
300 \mathrm{~mm}\end{array}$ & PILA & INTERIOR & $\begin{array}{l}b= \\
h=\end{array}$ & $\begin{array}{l}300 \mathrm{~mm} \\
300 \mathrm{~mm}\end{array}$ \\
\hline & & & ARMAD. L & JG. & CERCOS & & ARMAD. L & IG. & CERCOS \\
\hline & & $\mathrm{P} 2^{\mathrm{s}}$ & $4 \varnothing 16+4 \varnothing$ & & $4 \varnothing 8$ c 190 & $P 2^{\mathrm{s}}$ & $4 \varnothing 12$ & & $2 \varnothing 8$ c 180 \\
\hline & & $P 1^{a}$ & $4 \varnothing 16$ & & $2 \varnothing 8 \mathrm{c} 190$ & $P 1^{\mathrm{s}}$ & $4 \varnothing 12$ & & $2 \varnothing 8 \mathrm{c} 180$ \\
\hline & E & BAJA & $4 \varnothing 16$ & & $208 \mathrm{c} 190$ & BAJA & $4 \varnothing 12$ & & $2 \varnothing 8 c 180$ \\
\hline 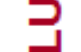 & II & VIGAS & & & & & $\mathrm{b}=550 \mathrm{~mm}$ & $h=$ & $350 \mathrm{~mm}$ \\
\hline & - & & & & EXTERIOR & CEN & RO VANO & & INTERIOR \\
\hline & & & & & $16+2 \varnothing 16$ & & & $4 \varnothing$ & $16+4 \varnothing 16$ \\
\hline & & ARTivit & OTA LUIVO. & & & $4 \varnothing$ & $6+2 \varnothing 16$ & & \\
\hline & & L. $R$ & UERZO $(\mathrm{m})$ & & 1,100 & & $\times 1,850$ & & 1,350 \\
\hline & & & & & & & RCOS & & $\varnothing 8 c 230$ \\
\hline & & PILA & EXTERIOR & & $\begin{array}{l}350 \mathrm{~mm} \\
350 \mathrm{~mm}\end{array}$ & PILA & INTERIOR & $\begin{array}{l}b= \\
h=\end{array}$ & $\begin{array}{l}350 \mathrm{~mm} \\
350 \mathrm{~mm}\end{array}$ \\
\hline & & & ARMAD. L & JG. & CERCOS & & ARMAD. L & IG. & CERCOS \\
\hline & & $P 2^{\mathrm{a}}$ & $4 \varnothing 20+4 \varnothing$ & & $4 \varnothing 8 c 230$ & $P 2^{\mathrm{a}}$ & $4 \varnothing 16$ & & $2 \varnothing 8 c 230$ \\
\hline & & $P 1^{\mathrm{a}}$ & $4 \varnothing 20+4 \varnothing$ & & $4 \varnothing 8 c 230$ & $P 1^{\mathrm{s}}$ & $4 \varnothing 16$ & & $2 \varnothing 8 c 230$ \\
\hline & E & BAJA & $4 \varnothing 20$ & & $2 \varnothing 8 \mathrm{c} 230$ & BAJA & $4 \varnothing 16$ & & $4 \varnothing 8 c 230$ \\
\hline & II & VIGAS & & & & & $\mathrm{b}=650 \mathrm{~mm}$ & $h=$ & $400 \mathrm{~mm}$ \\
\hline & - & & & & EXTERIOR & CEI & RO VANO & & INTERIOR \\
\hline & & & & & $16+6 \varnothing 16$ & & & $4 \varnothing$ & $16+6 \varnothing 20$ \\
\hline & & & & & & $4 \varnothing$ & $6+7 \varnothing 20$ & & \\
\hline & & L. $\mathrm{R}$ & UERZO (m) & & 1,650 & & $\times 3,150$ & & 2,200 \\
\hline & & & & & & & RCOS & & $\varnothing 8 \mathrm{c} 170$ \\
\hline
\end{tabular}

Tabla 36. Dimensionamiento y armado de pórticos con Baja +2 plantas.

Modelos de elementos finitos. Etapa II 


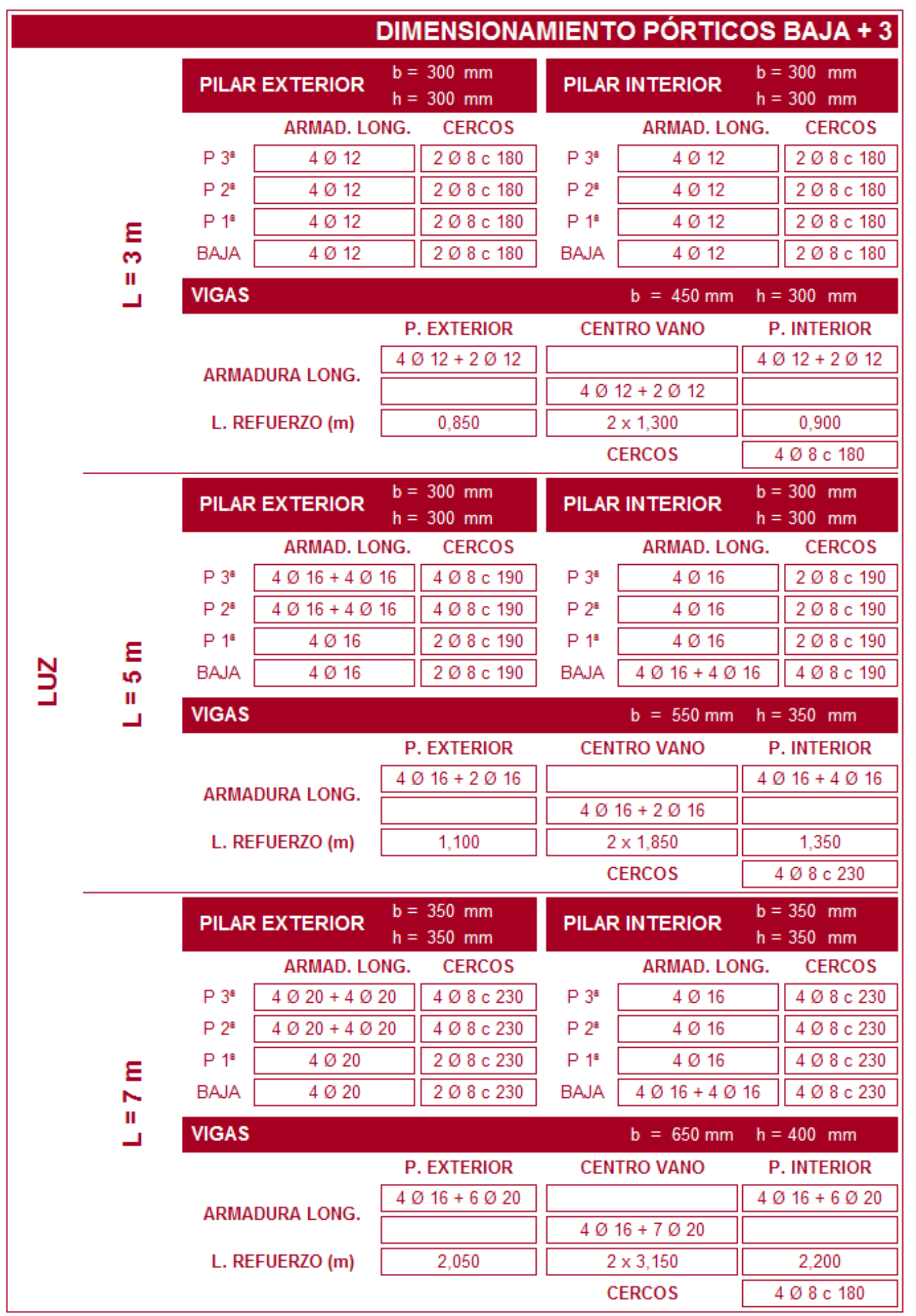

Tabla 37. Dimensionamiento y armado de pórticos con Baja +3 plantas.

Modelos de elementos finitos. Etapa II 


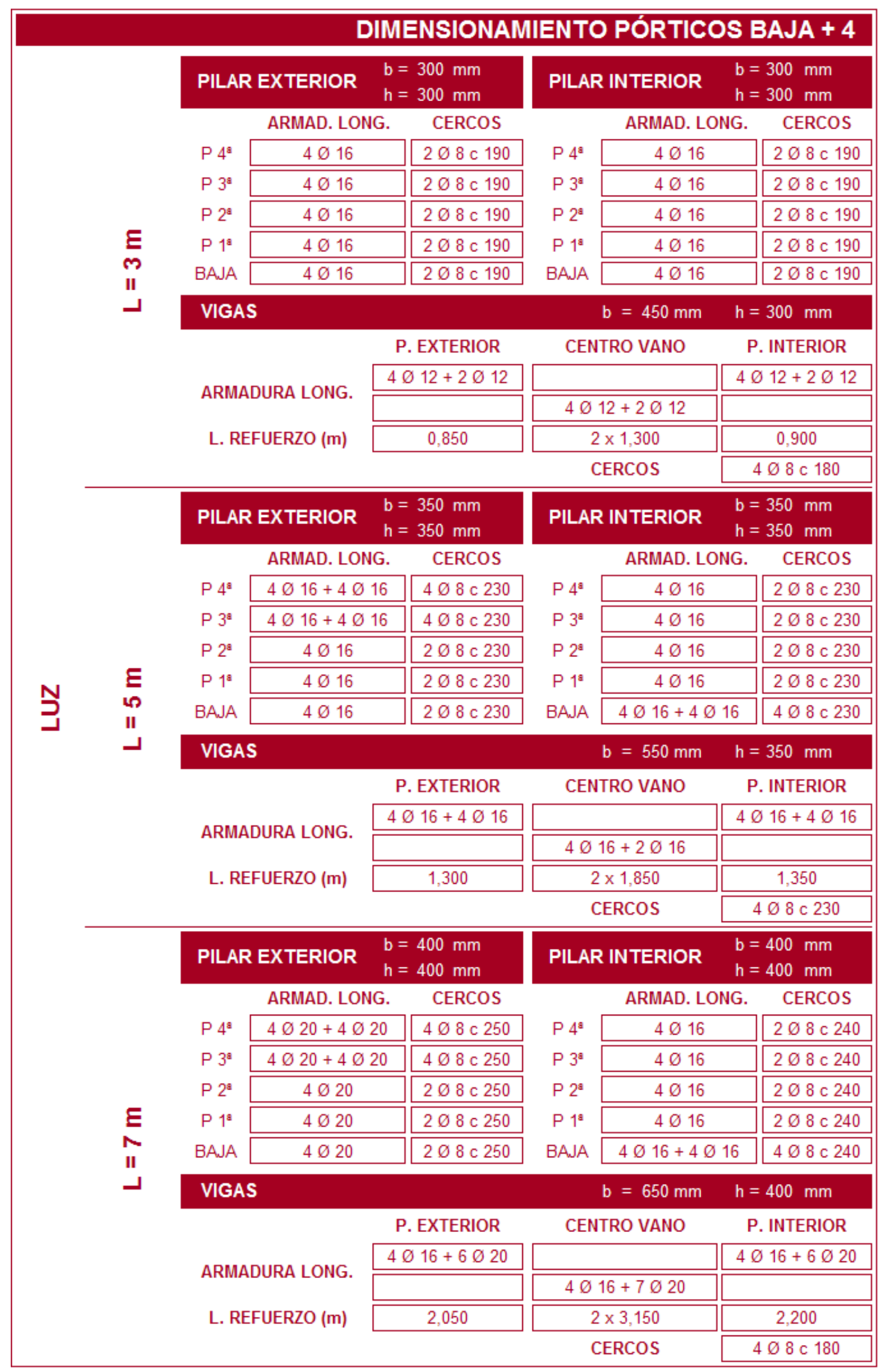

Tabla 38. Dimensionamiento y armado de pórticos con Baja +4 plantas. Modelos de elementos finitos. Etapa II 
En segundo lugar, en las Tablas 39, 40, 41, 42, 43 y 44, ordenadas por tensiones admisibles del terreno y relaciones de forma se muestran, para los distintos casos, en función de la luz y el número de plantas, los resultados correspondientes al dimensionamiento de los elementos de cimentación, indicando el armado necesario para la zapata de medianería, la zapata interior, la tercera zapata y la viga centradora. Tal y como ya se ha indicado anteriormente en varias ocasiones, las dimensiones exteriores adoptadas para los citados elementos son las mismas que las planteadas en los modelos convencionales para poder realizar el contraste entre los diferentes métodos en igualdad de condiciones.

Las citadas zapatas cuentan con una armadura en su cara inferior constituida por una malla ortogonal de redondos de acero corrugado (Fig.63). En dichas tablas se indica el diámetro y número de redondos de la malla en cuestión tanto en la dirección paralela al pórtico como en la perpendicular.

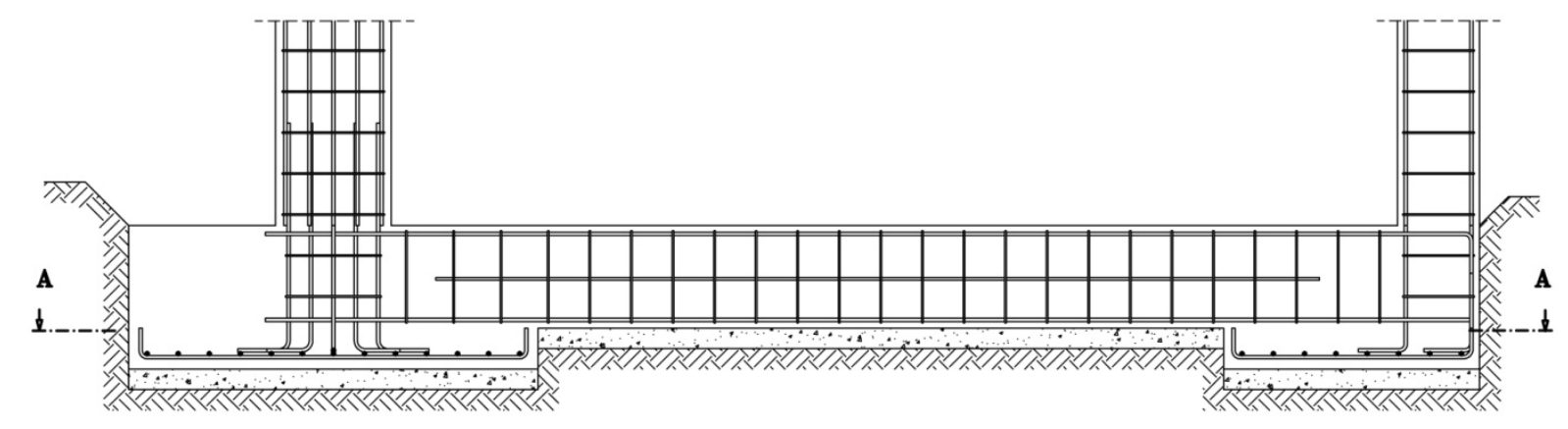

ALZADO

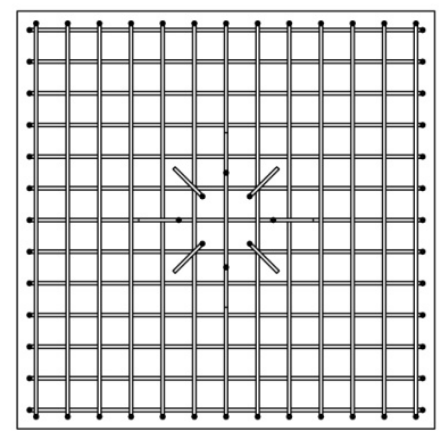

SECCION AA

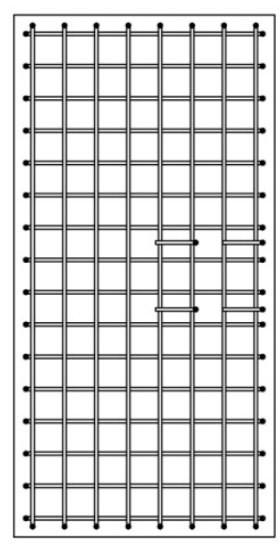

Fig.63. Armado tipo en zapatas

Por su parte (Fig.64), para las vigas centradoras se dispone una armadura longitudinal de montaje con cuatro redondos en cada cara, con la correspondientes armadura de refuerzo, de negativos en la cara superior. El número de redondos de la armadura de refuerzo varía según los casos, presentándose también una doble situación de vigas que requieren refuerzo 
solamente en la zona de la viga frente a otras vigas, generalmente de pequeña longitud, que necesitan anclar la armadura de refuerzo en el pilar interior. Como armadura transversal se dispone doble cerco con cuatro ramas resistentes.
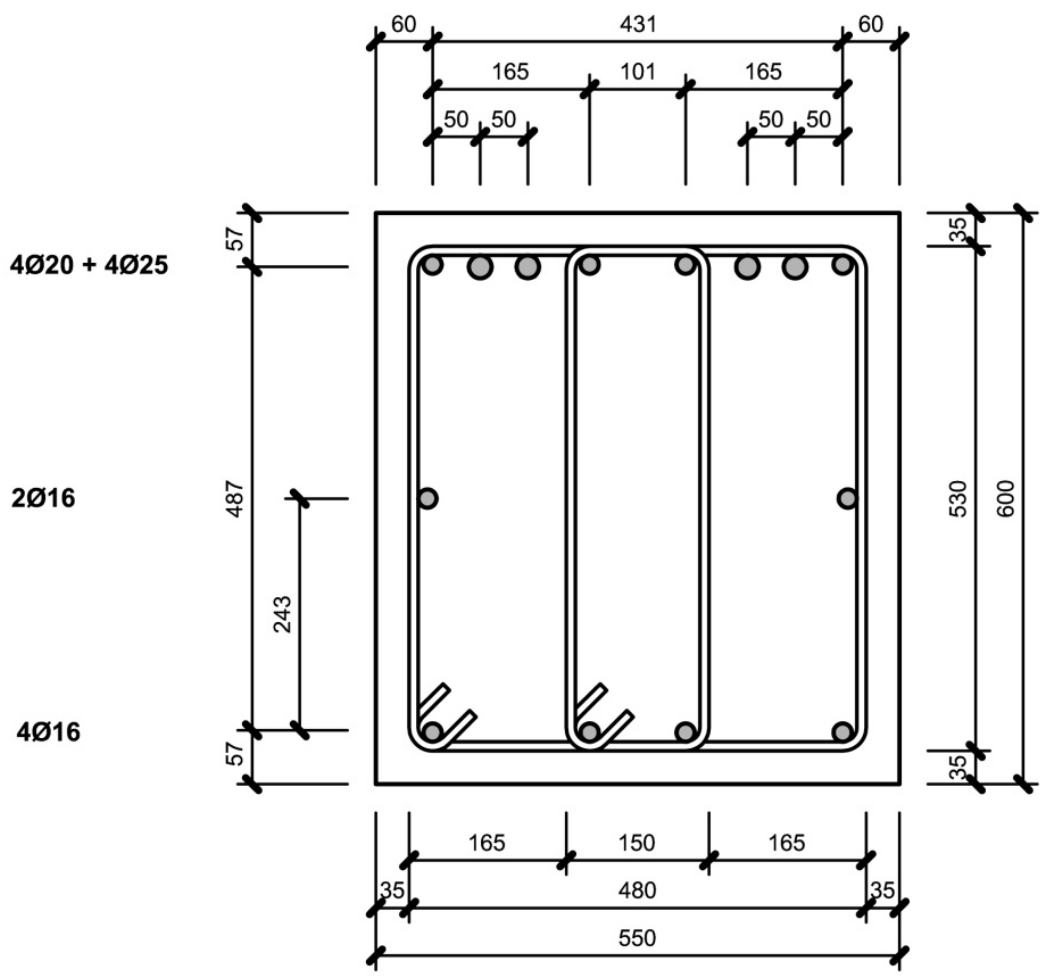

Fig.64. Armado tipo en vigas centradoras 


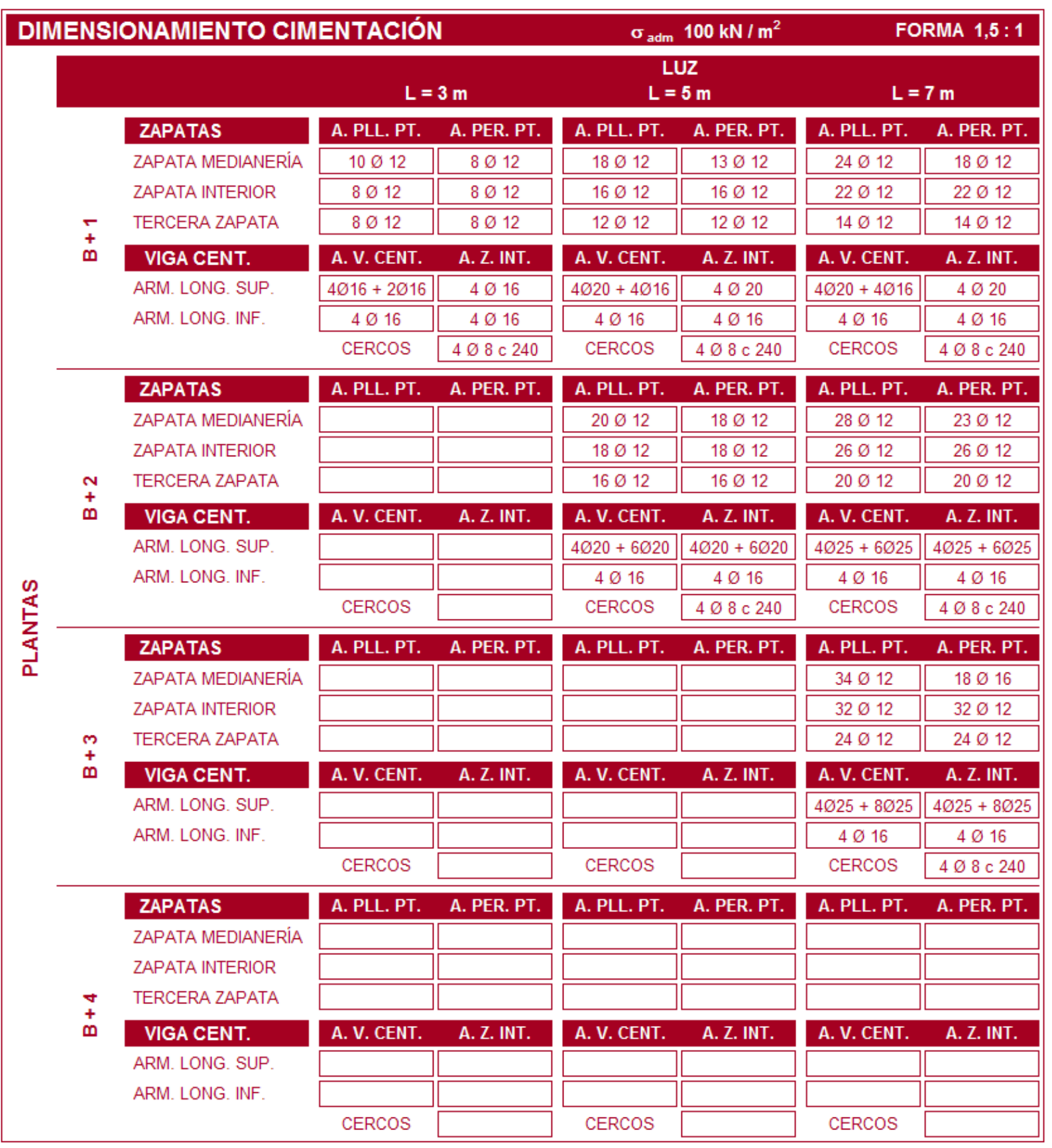

Tabla 39. Dimensionamiento cimentación para $\sigma_{\text {adm. }}=100 \mathrm{kN} / \mathrm{m}^{2}$ y relación de forma 1,5:1 Modelos de elementos finitos. Etapa II 


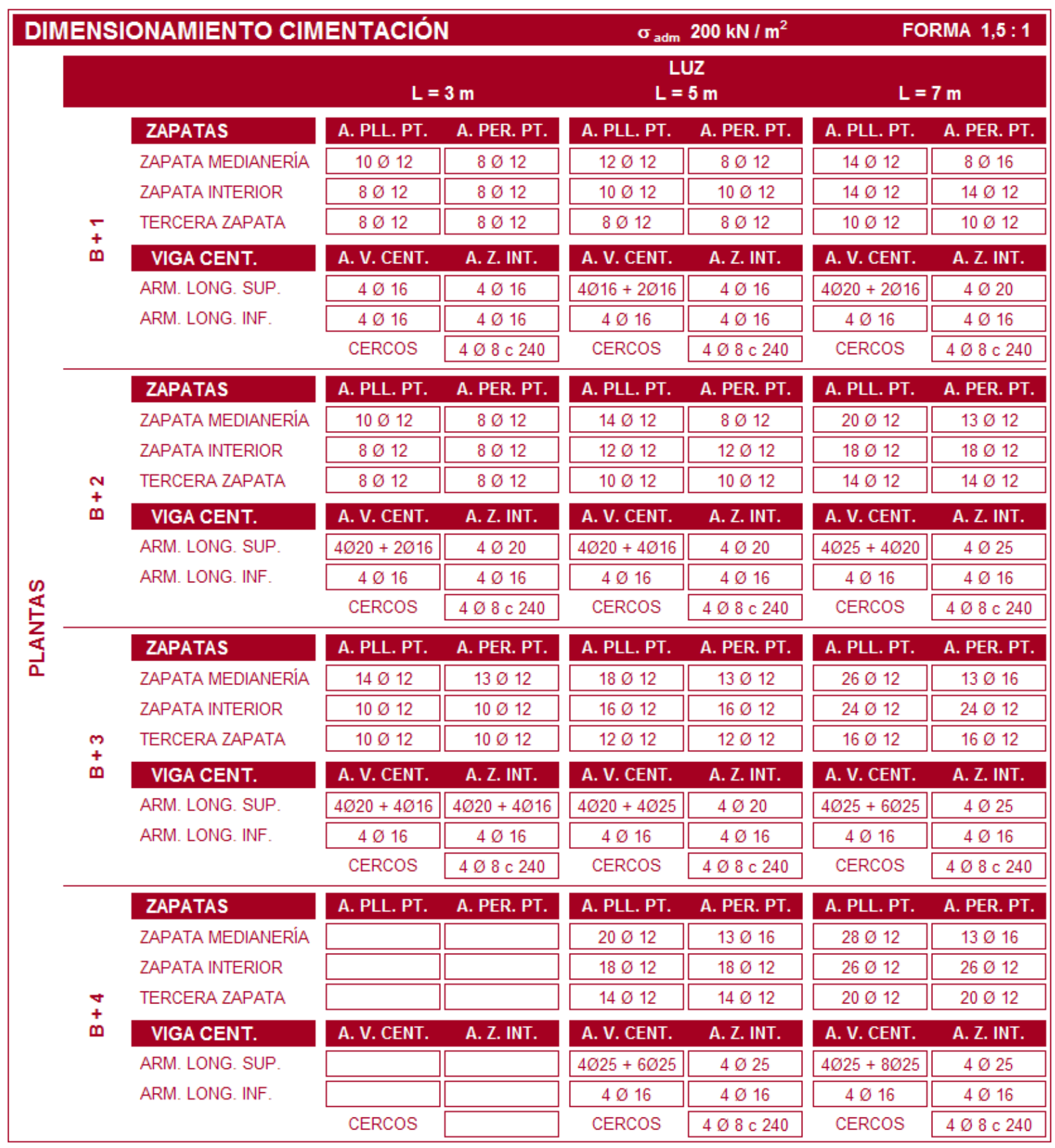

Tabla 40. Dimensionamiento cimentación para $\sigma_{\mathrm{adm} .}=200 \mathrm{kN} / \mathrm{m}^{2}$ y relación de forma 1,5:1 Modelos de elementos finitos. Etapa II 


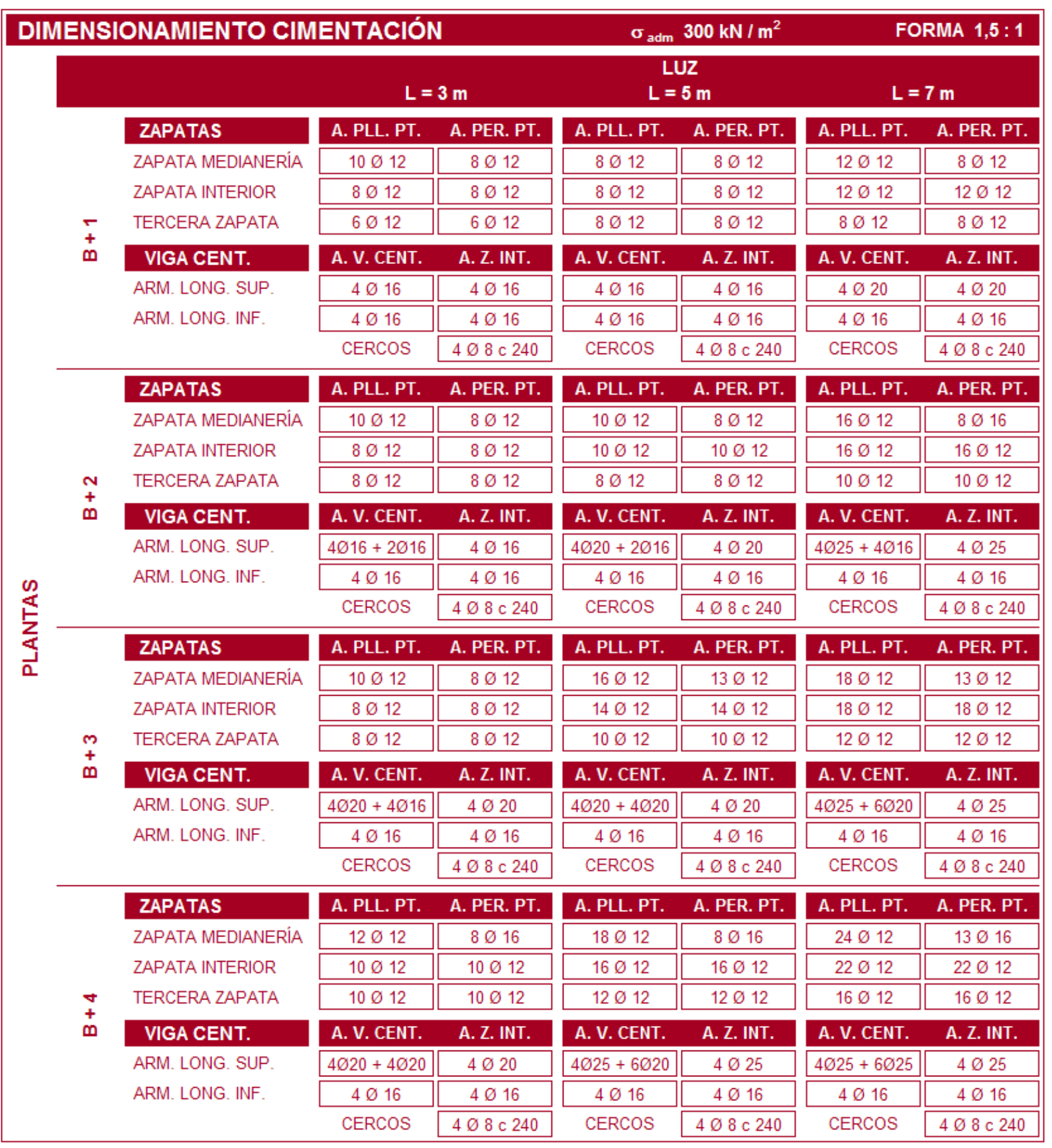

Tabla 41. Dimensionamiento cimentación para $\sigma_{\text {adm. }}=300 \mathrm{kN} / \mathrm{m}^{2}$ y relación de forma 1,5:1 Modelos de elementos finitos. Etapa II 


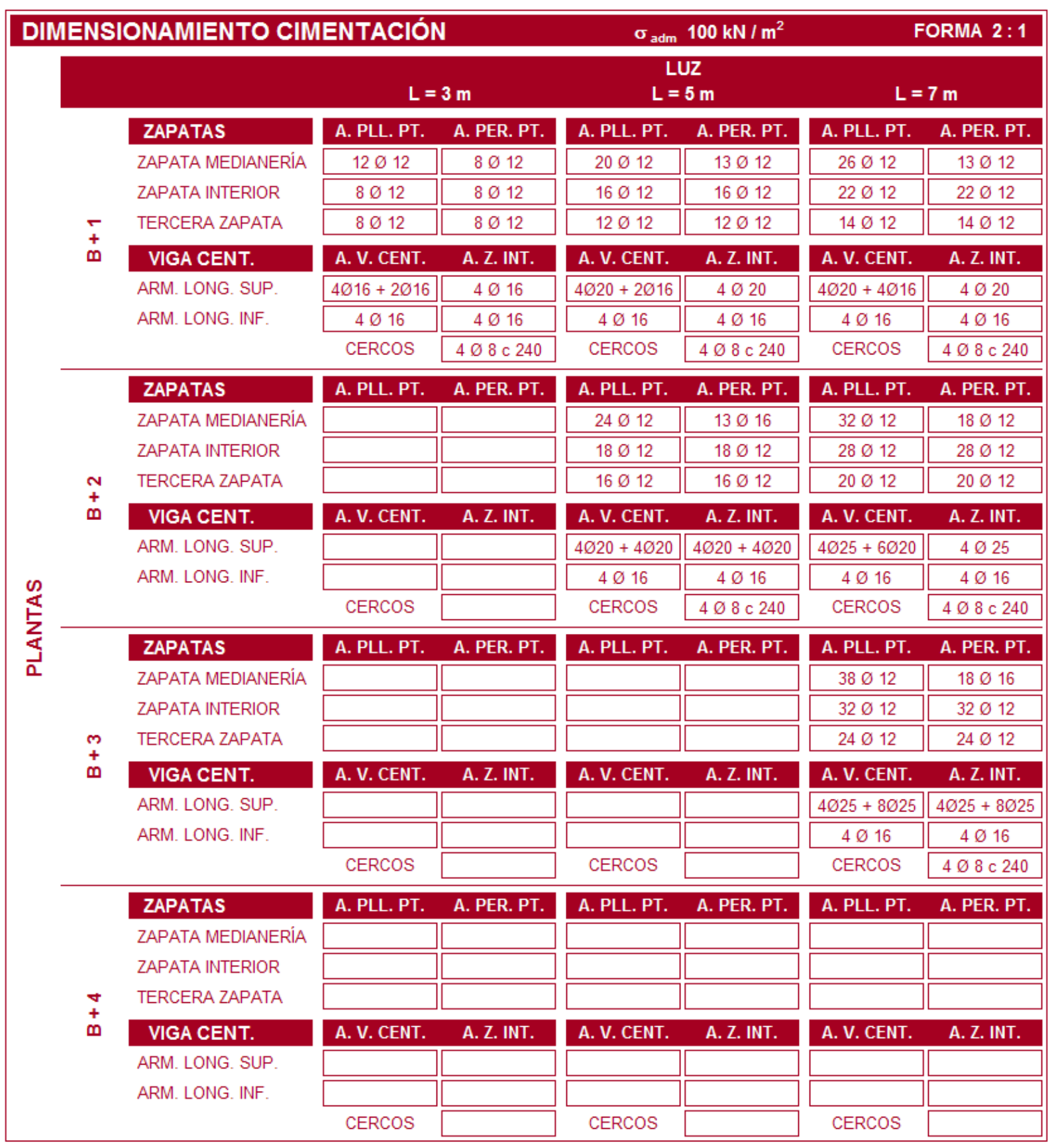

Tabla 42. Dimensionamiento cimentación para $\sigma_{\text {adm. }}=100 \mathrm{kN} / \mathrm{m}^{2}$ y relación de forma $2: 1$ Modelos de elementos finitos. Etapa II 


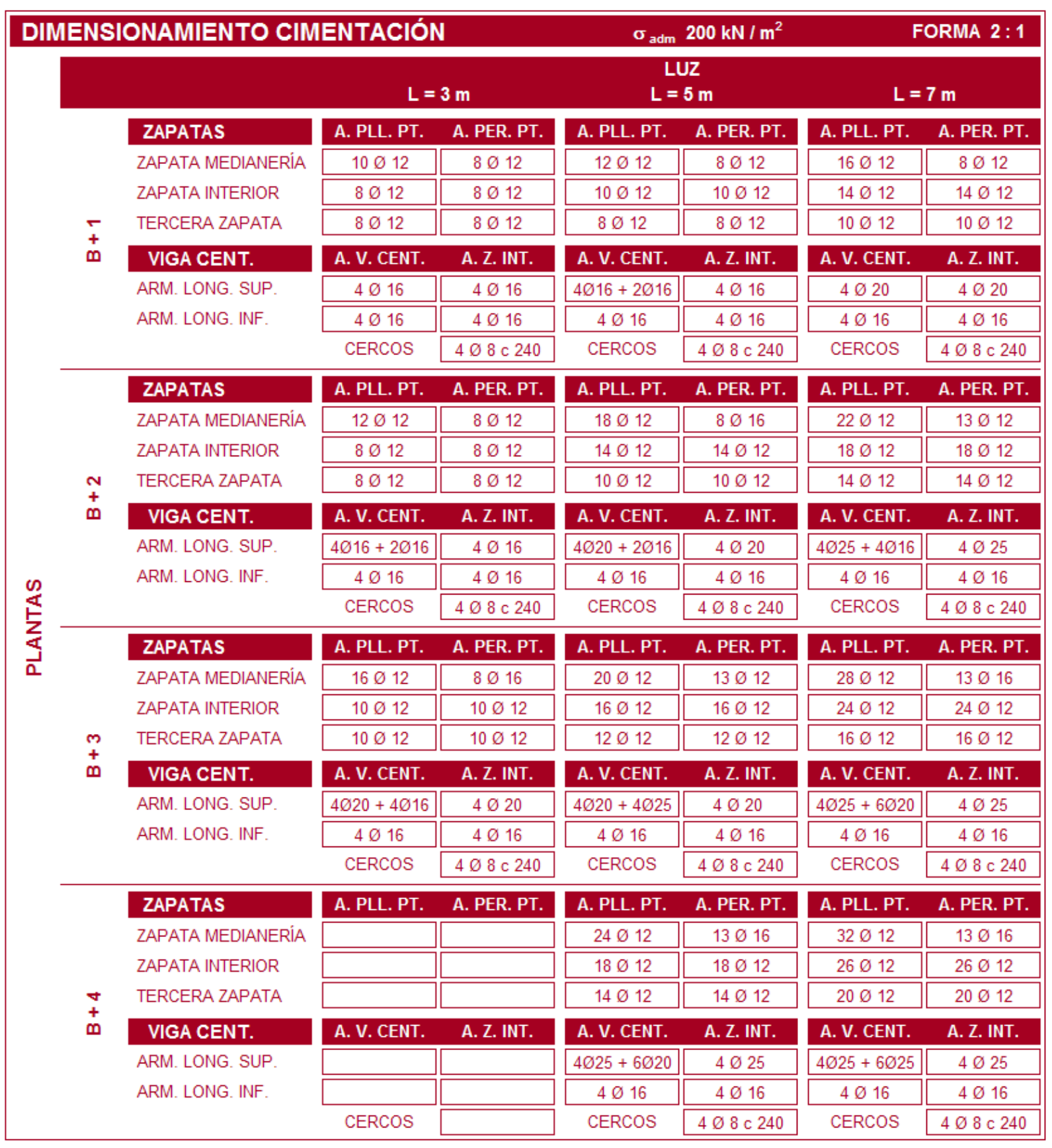

Tabla 43. Dimensionamiento cimentación para $\sigma_{\text {adm. }}=200 \mathrm{kN} / \mathrm{m}^{2}$ y relación de forma $2: 1$ Modelos de elementos finitos. Etapa II 


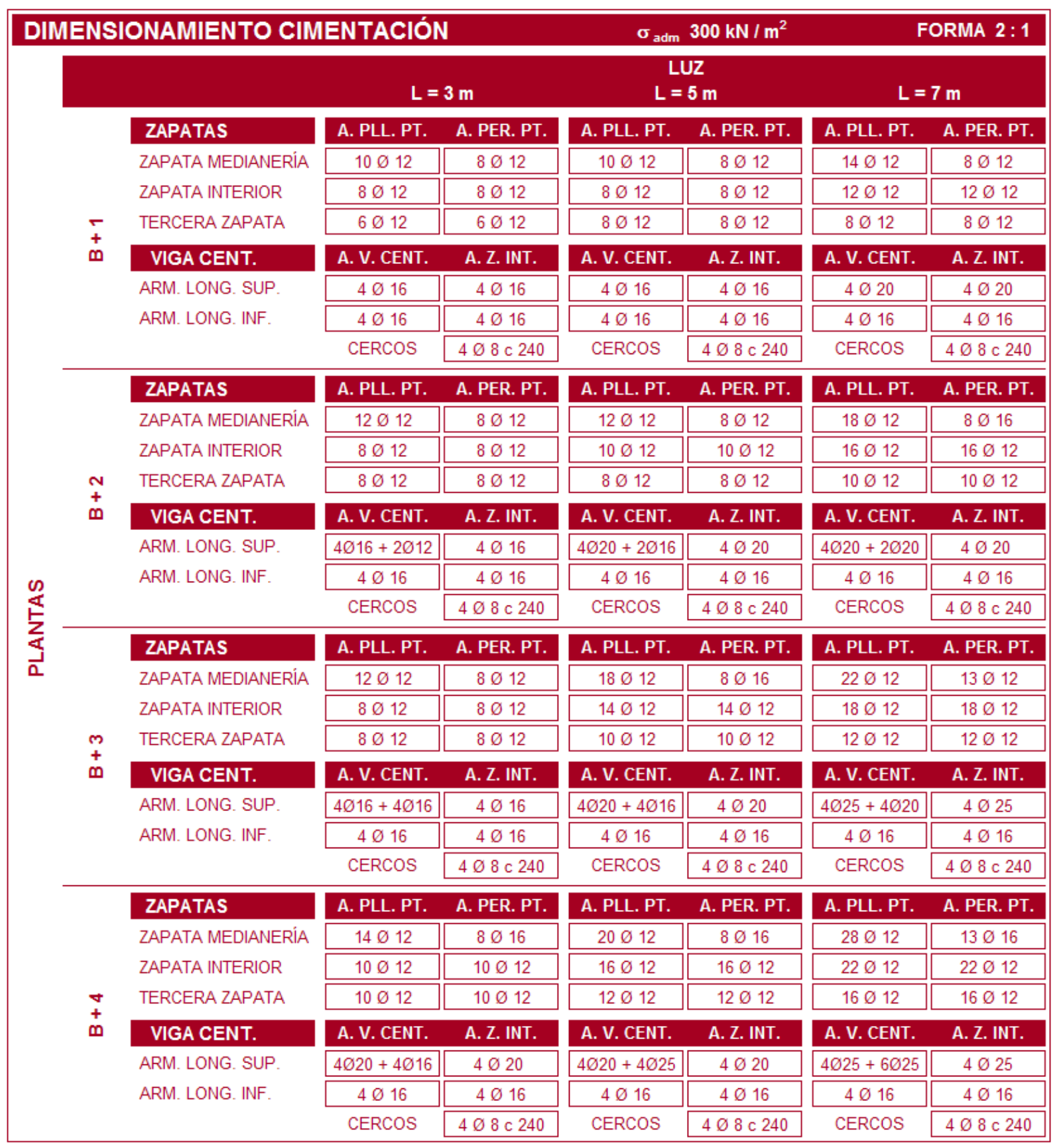

Tabla 44. Dimensionamiento cimentación para $\sigma_{\text {adm. }}=300 \mathrm{kN} / \mathrm{m}^{2}$ y relación de forma $2: 1$ Modelos de elementos finitos. Etapa II 
Una vez definidos los armados necesarios en los distintos casos planteados para el pórtico tipo y su cimentación, se procede al cálculo de los modelos de elementos finitos de los mismos.

Las tablas comprendidas entre la Tabla 45 y 56 muestran los resultados de dichos modelos de elementos finitos. Los parámetros recogidos en las citadas tablas y su significado son los mismos que los mostrados en las tablas de resultados de la Etapa I (apartado 4.1.2), por tanto, para cualquier aclaración sobre los parámetros indicados, son válidas las explicaciones del citado apartado 4.1.2.

Las tablas, ordenadas por tensiones admisibles del terreno y relaciones de forma, ofrecen los resultados para los distintos casos, en función de la luz y el número de plantas. Para cada pareja Tensión Admisible - Relación de Forma se ofrecen, de forma consecutiva, dos tablas.

La primera con las resultantes de tensiones de contacto con el terreno en las distintas zapatas, con sus excentricidades absolutas y con los esfuerzos en la vigas centradora y superior.

La segunda con las excentricidades o posiciones relativas de las resultantes de tensiones de contacto bajo la zapata de medianería, junto con el tipo de distribución de tensiones de contacto, sus valores significativos y el nivel de cumplimiento de la verificación del E.L.U.de hundimiento. 


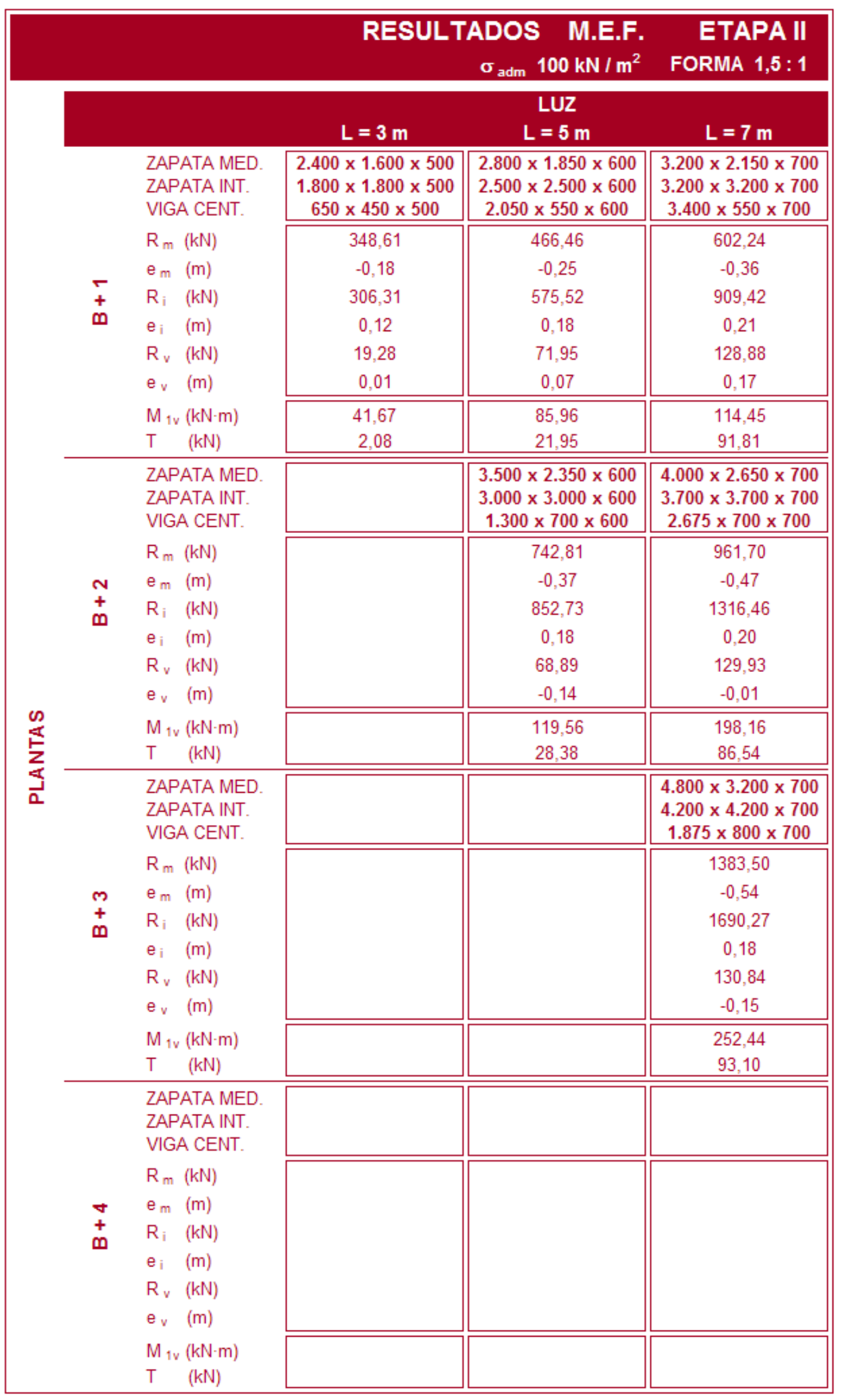

Tabla 45. Resultantes tensiones terreno y esfuerzos en vigas centradora y superior. M.E.F. Etapa II. $\sigma_{\text {adm. }}=100 \mathrm{kN} / \mathrm{m}^{2}$ y relación de forma $1,5: 1$ 


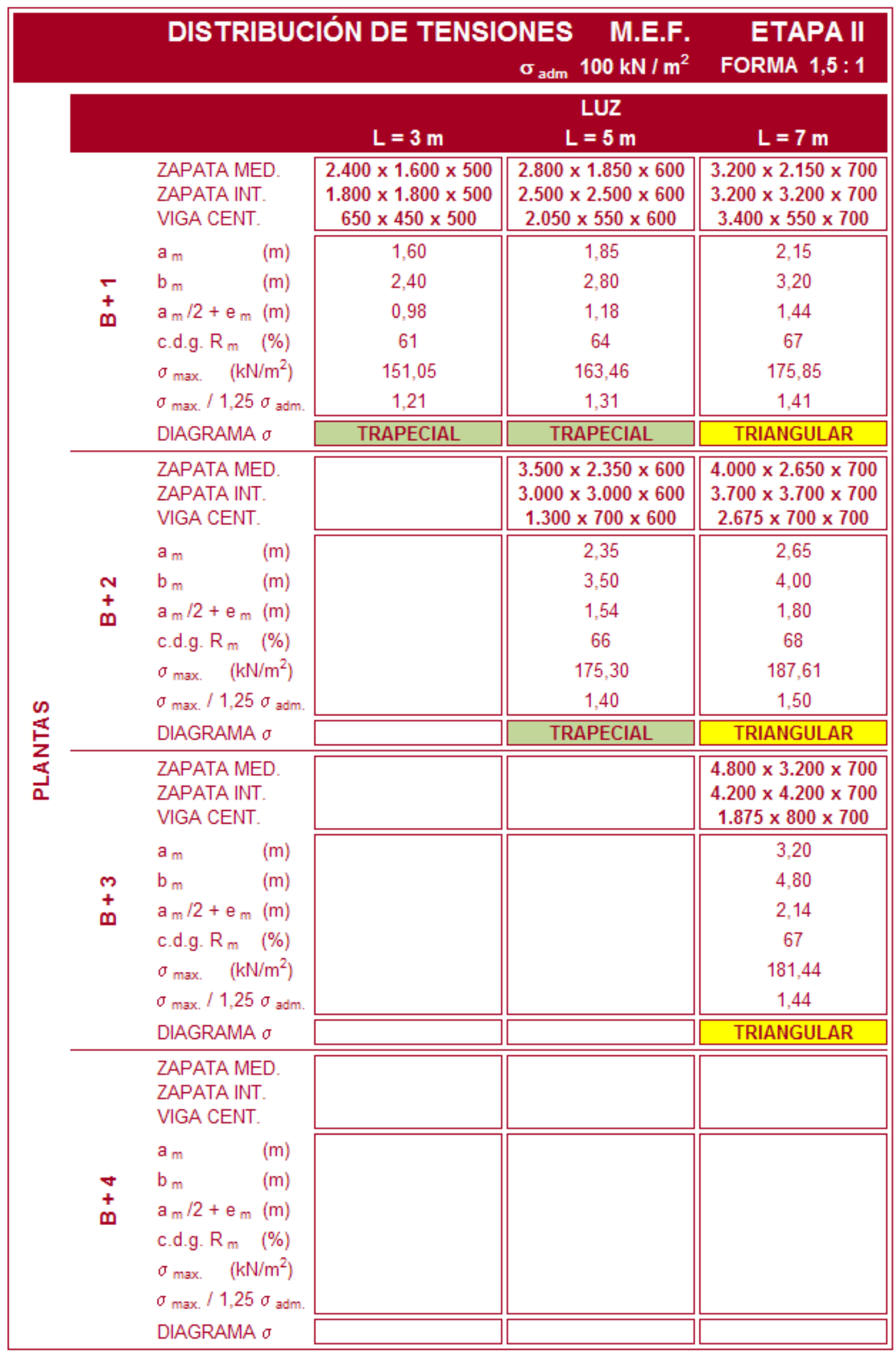

Tabla 46. Distribución de tensiones de contacto. Modelo de elementos finitos. Etapa II.

$\sigma_{\text {adm. }}=100 \mathrm{kN} / \mathrm{m}^{2}$ y relación de forma 1,5:1 


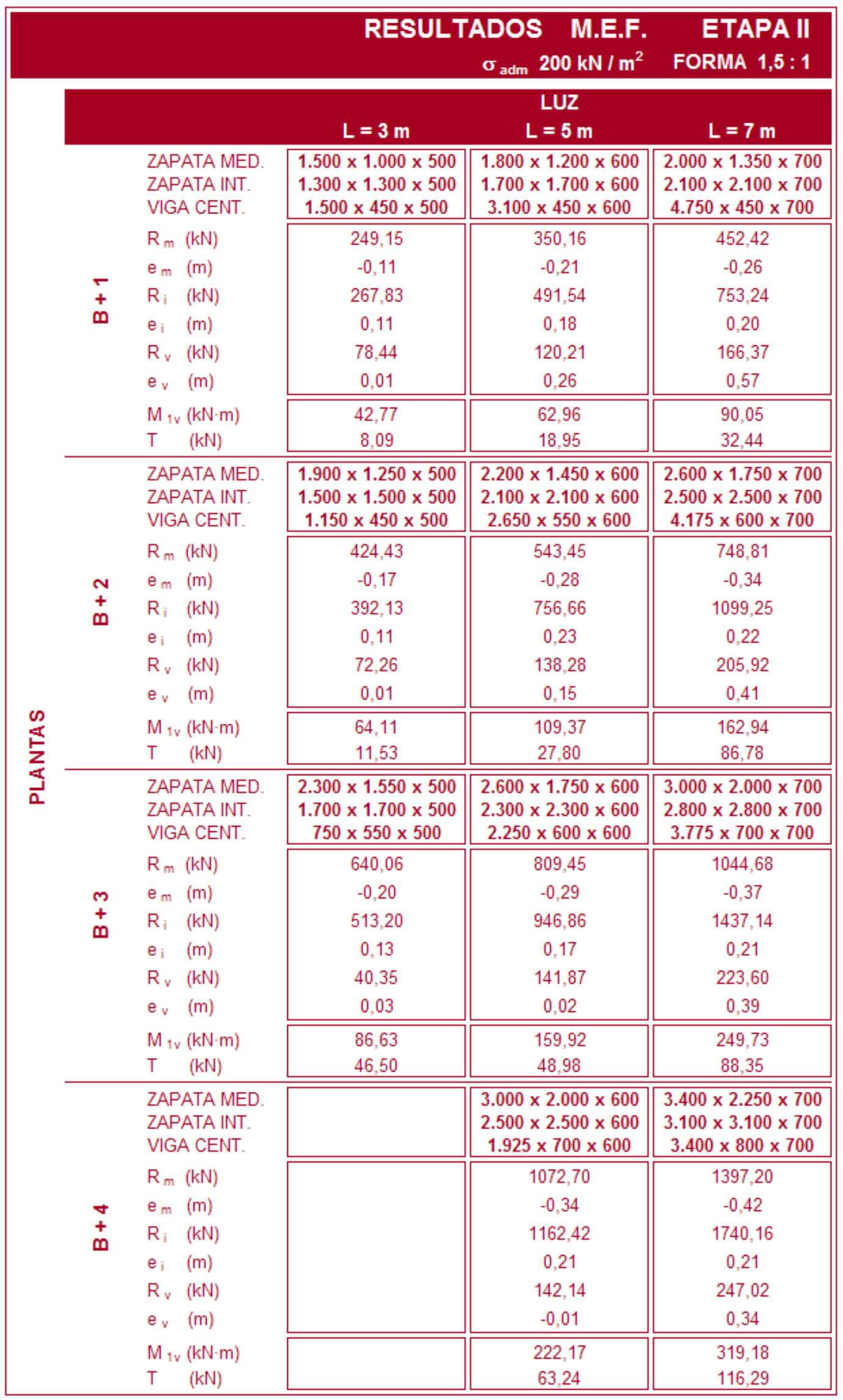

Tabla 47. Resultantes tensiones terreno y esfuerzos en vigas centradora y superior. M.E.F. Etapa II. $\sigma_{\text {adm. }}=200 \mathrm{kN} / \mathrm{m}^{2}$ y relación de forma $1,5: 1$ 


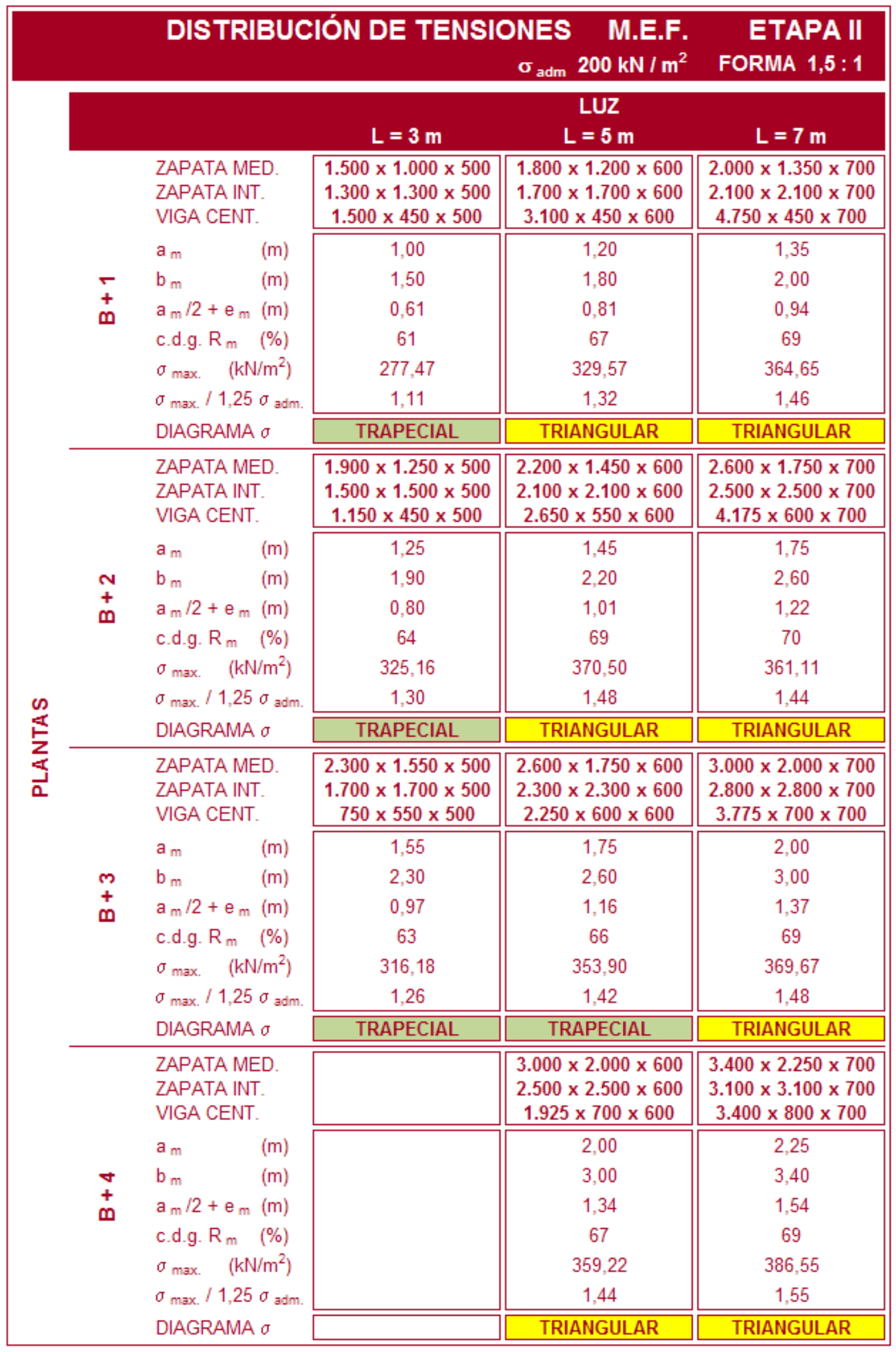

Tabla 48. Distribución de tensiones de contacto. Modelo de elementos finitos. Etapa II.

$\sigma_{\mathrm{adm} .}=200 \mathrm{kN} / \mathrm{m}^{2}$ y relación de forma $1,5: 1$ 


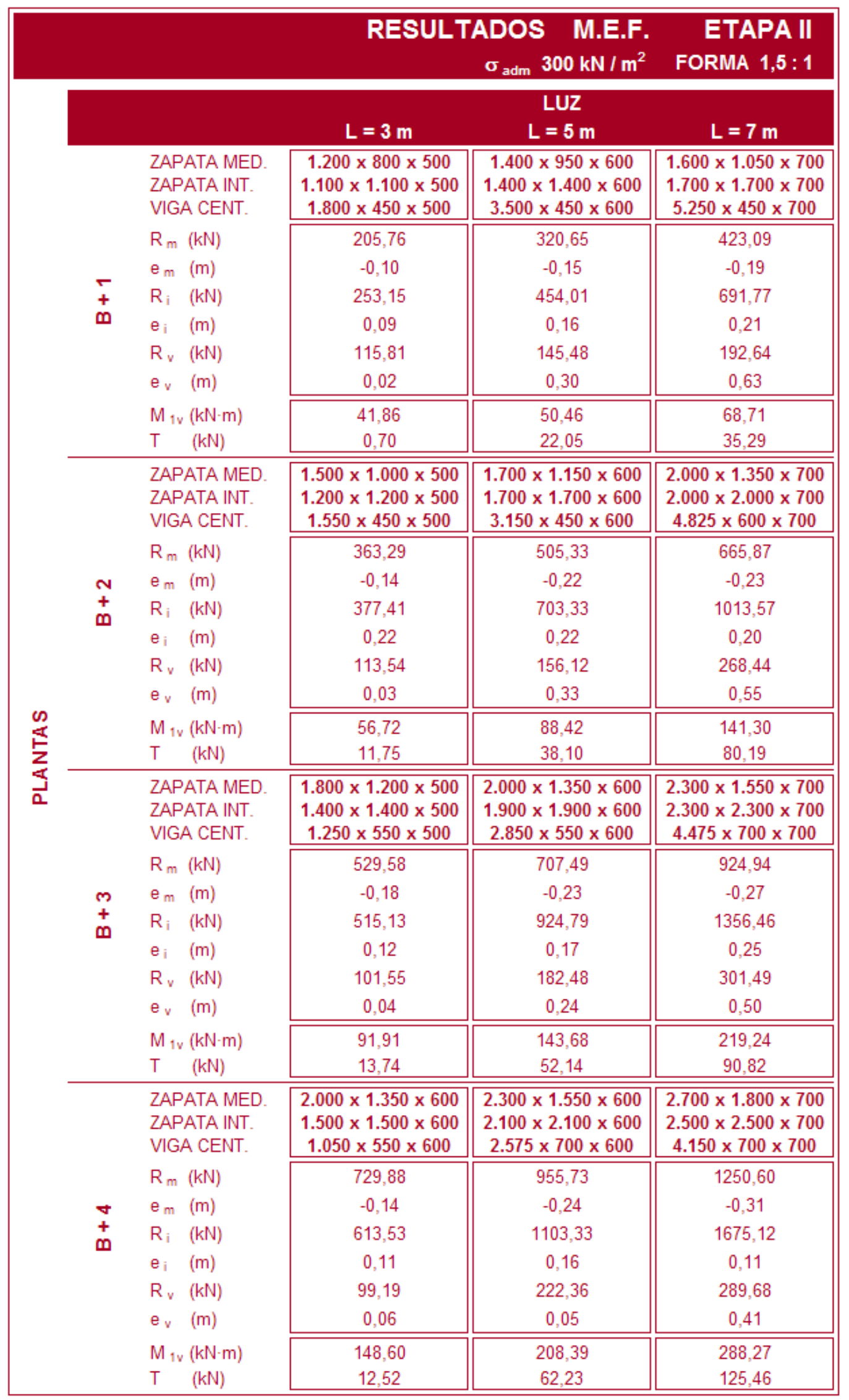

Tabla 49. Resultantes tensiones terreno y esfuerzos en vigas centradora y superior. M.E.F. Etapa II. $\sigma_{\text {adm. }}=300 \mathrm{kN} / \mathrm{m}^{2}$ y relación de forma $1,5: 1$ 


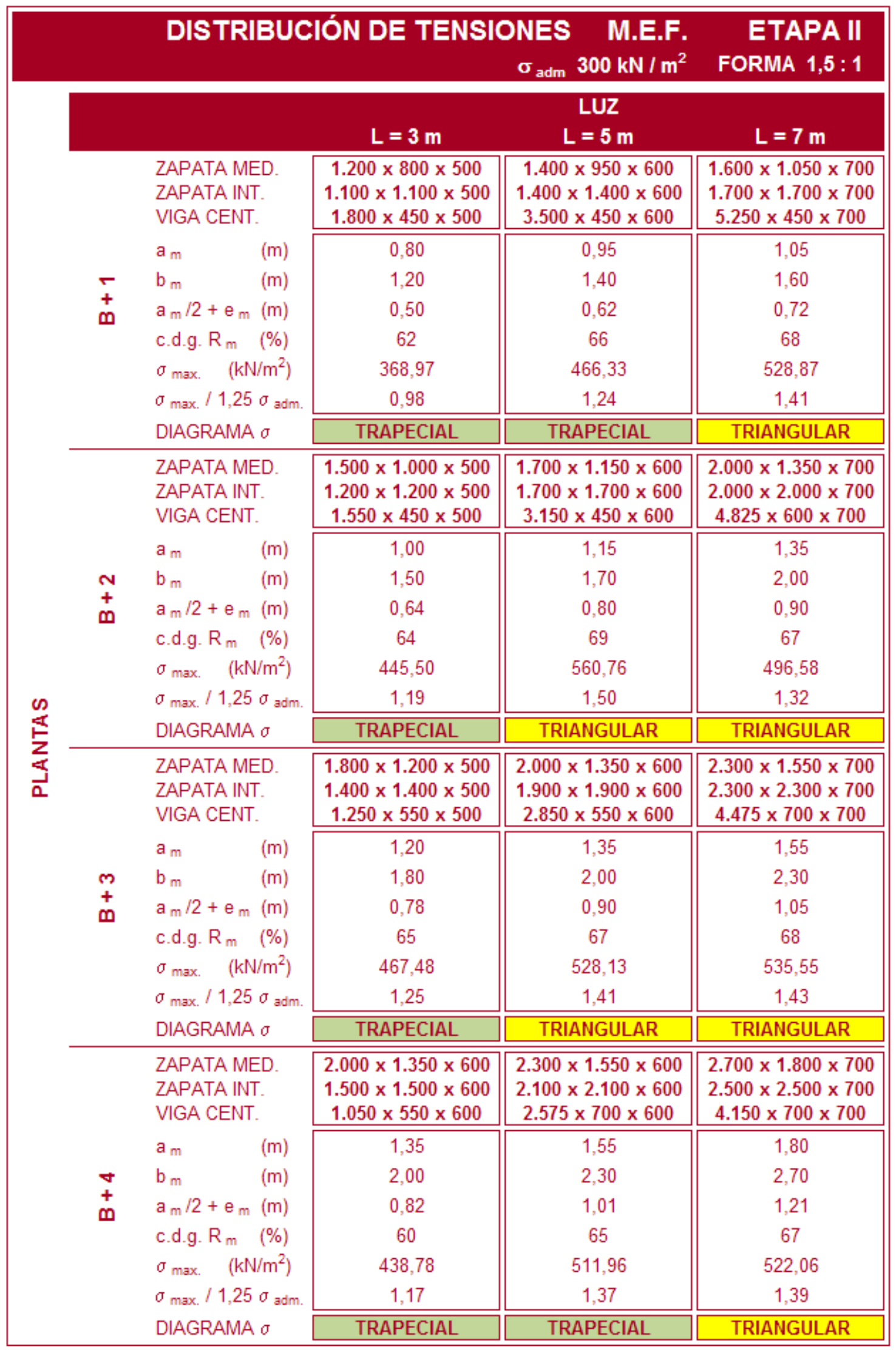

Tabla 50. Distribución de tensiones de contacto. Modelo de elementos finitos. Etapa II.

$\sigma_{\text {adm. }}=300 \mathrm{kN} / \mathrm{m}^{2}$ y relación de forma 1,5:1 


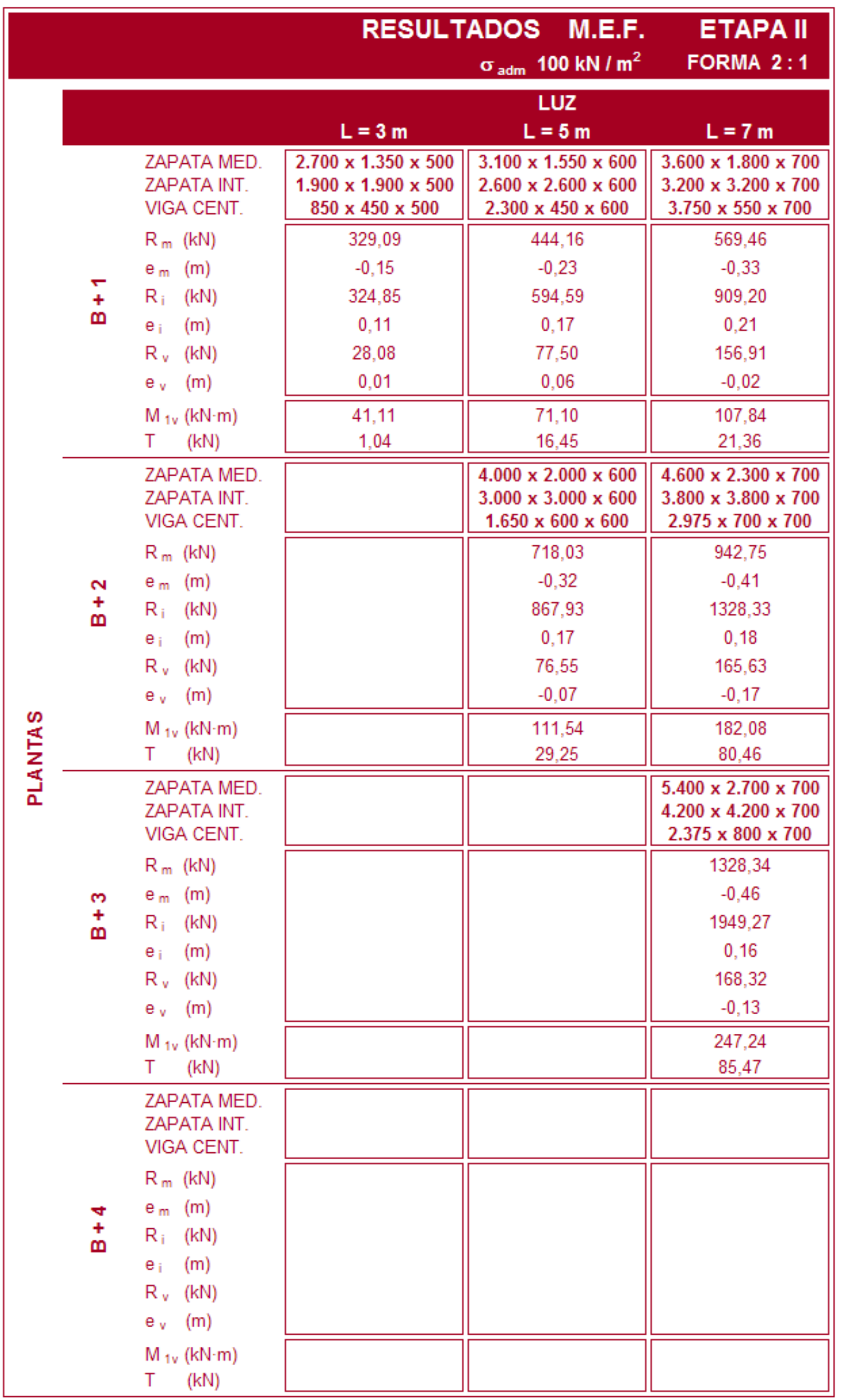

Tabla 51. Resultantes tensiones terreno y esfuerzos en vigas centradora y superior. M.E.F. Etapa II. $\sigma_{\text {adm. }}=100 \mathrm{kN} / \mathrm{m}^{2}$ y relación de forma $2: 1$ 


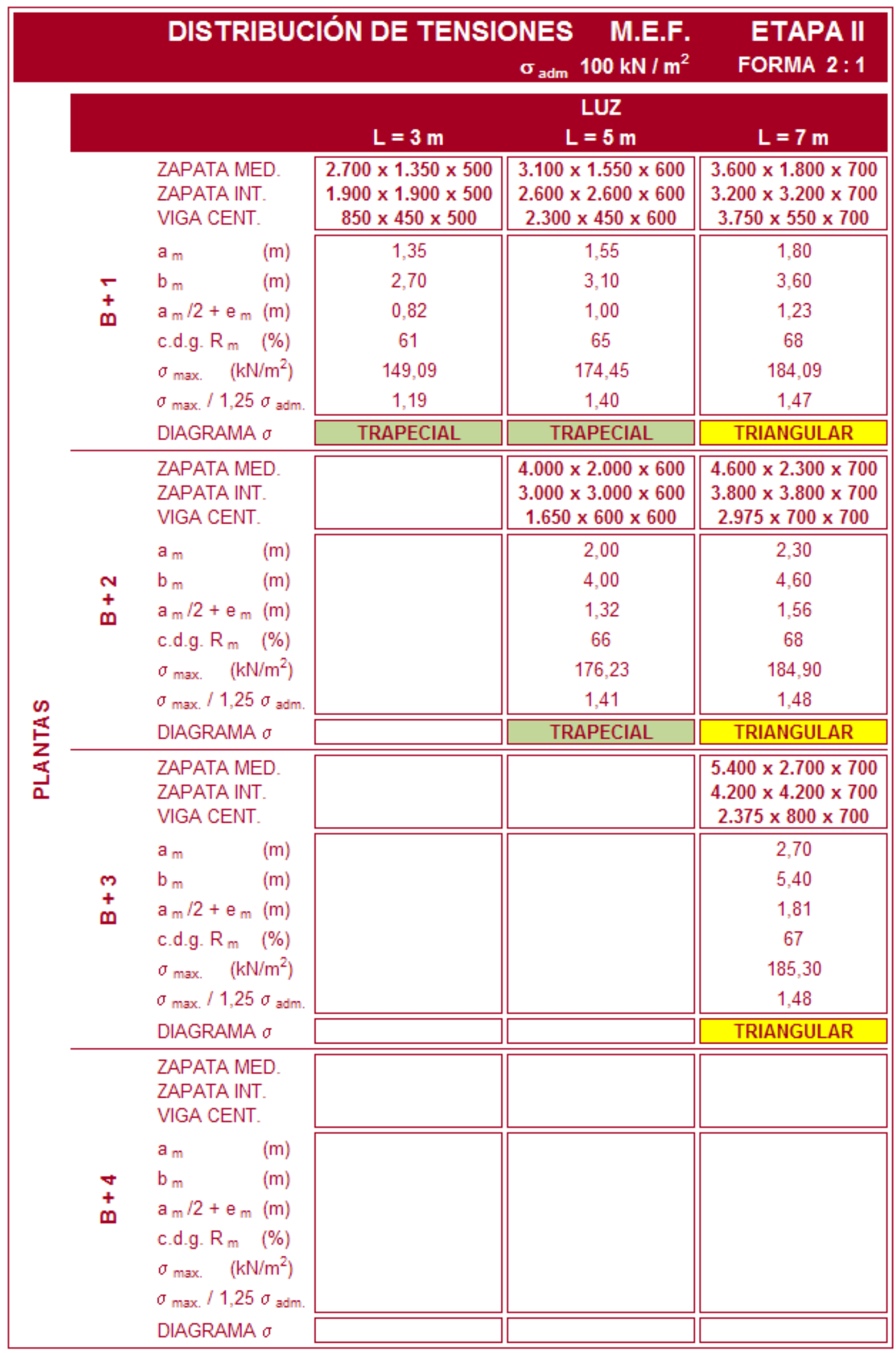

Tabla 52. Distribución de tensiones de contacto. Modelo de elementos finitos. Etapa II. $\sigma_{\text {adm. }}=100 \mathrm{kN} / \mathrm{m}^{2}$ y relación de forma $2: 1$ 


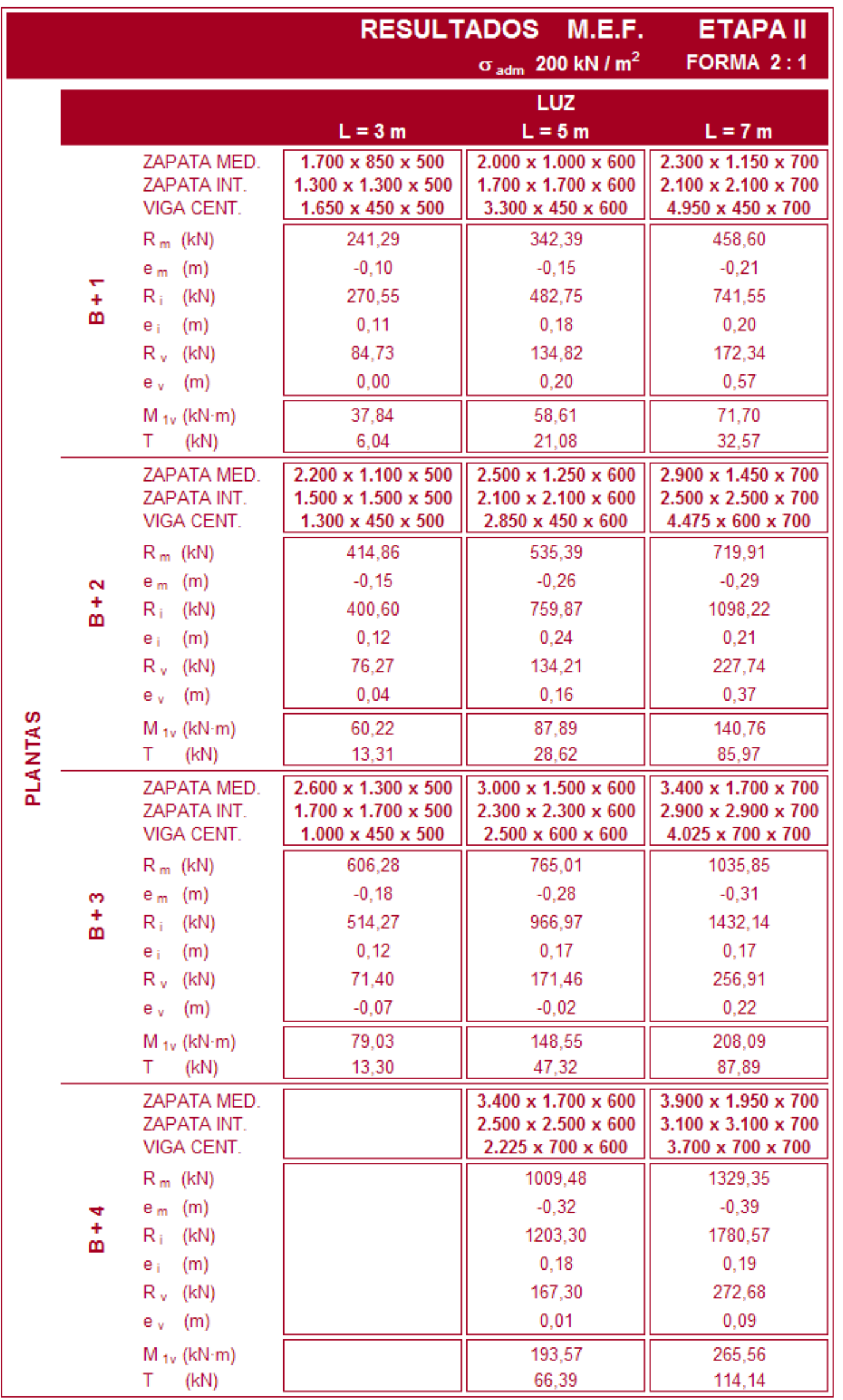

Tabla 53. Resultantes tensiones terreno y esfuerzos en vigas centradora y superior. M.E.F. Etapa II. $\sigma_{\text {adm. }}=200 \mathrm{kN} / \mathrm{m}^{2}$ y relación de forma $2: 1$ 


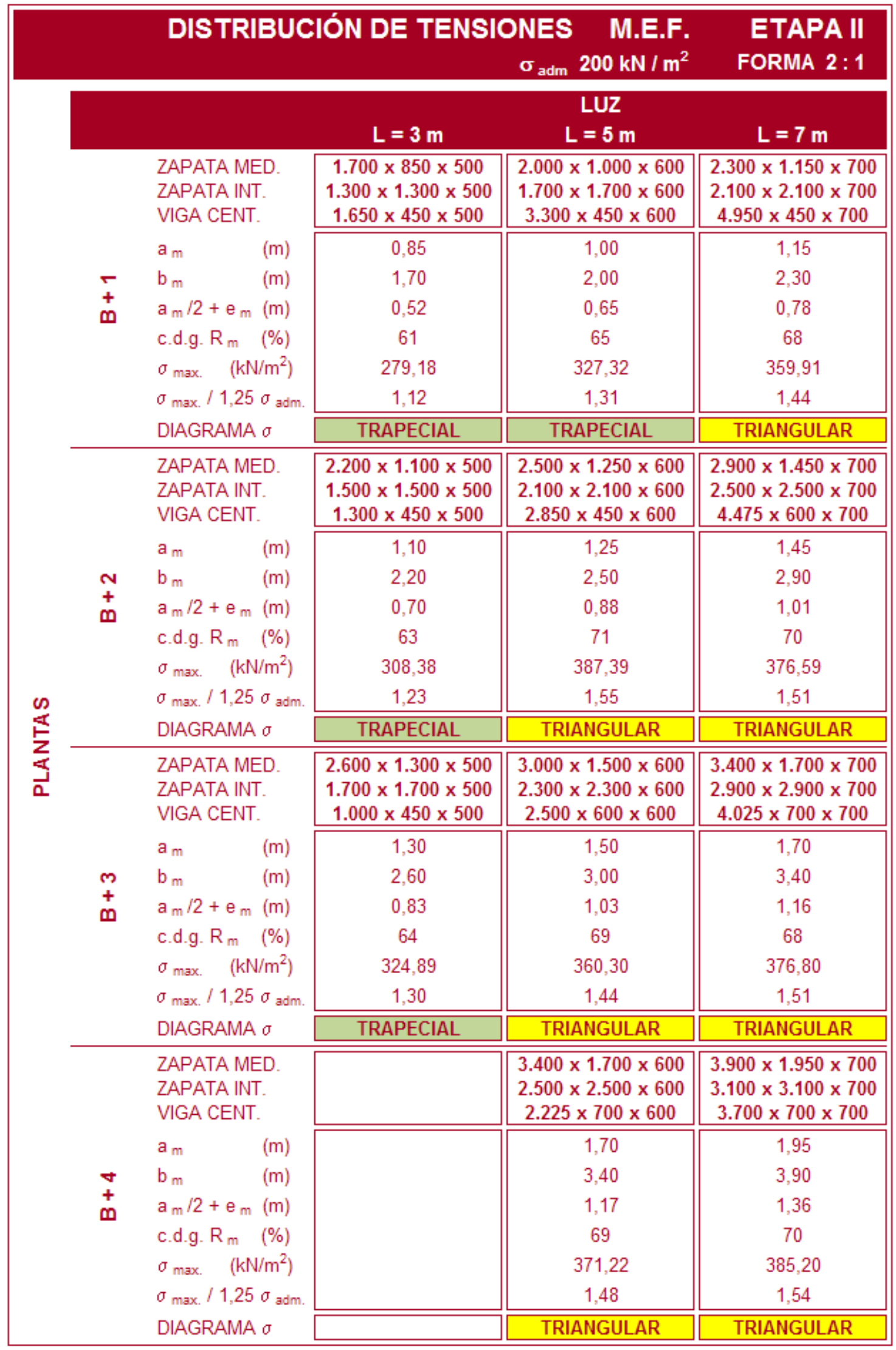

Tabla 54. Distribución de tensiones de contacto. Modelo de elementos finitos. Etapa II. $\sigma_{\text {adm. }}=200 \mathrm{kN} / \mathrm{m}^{2}$ y relación de forma $2: 1$ 


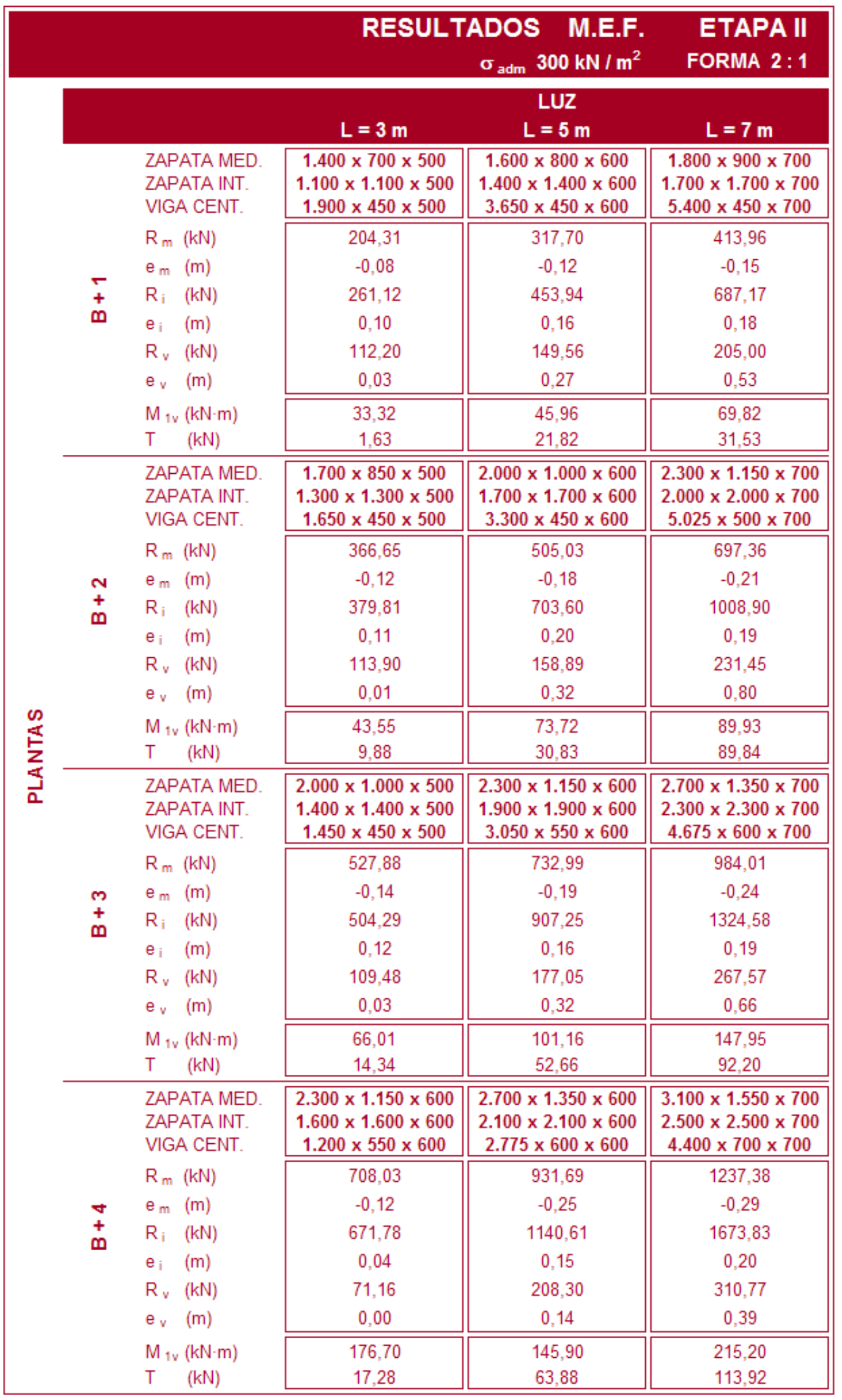

Tabla 55. Resultantes tensiones terreno y esfuerzos en vigas centradora y superior. M.E.F. Etapa II. $\sigma_{\text {adm. }}=300 \mathrm{kN} / \mathrm{m}^{2}$ y relación de forma $2: 1$ 


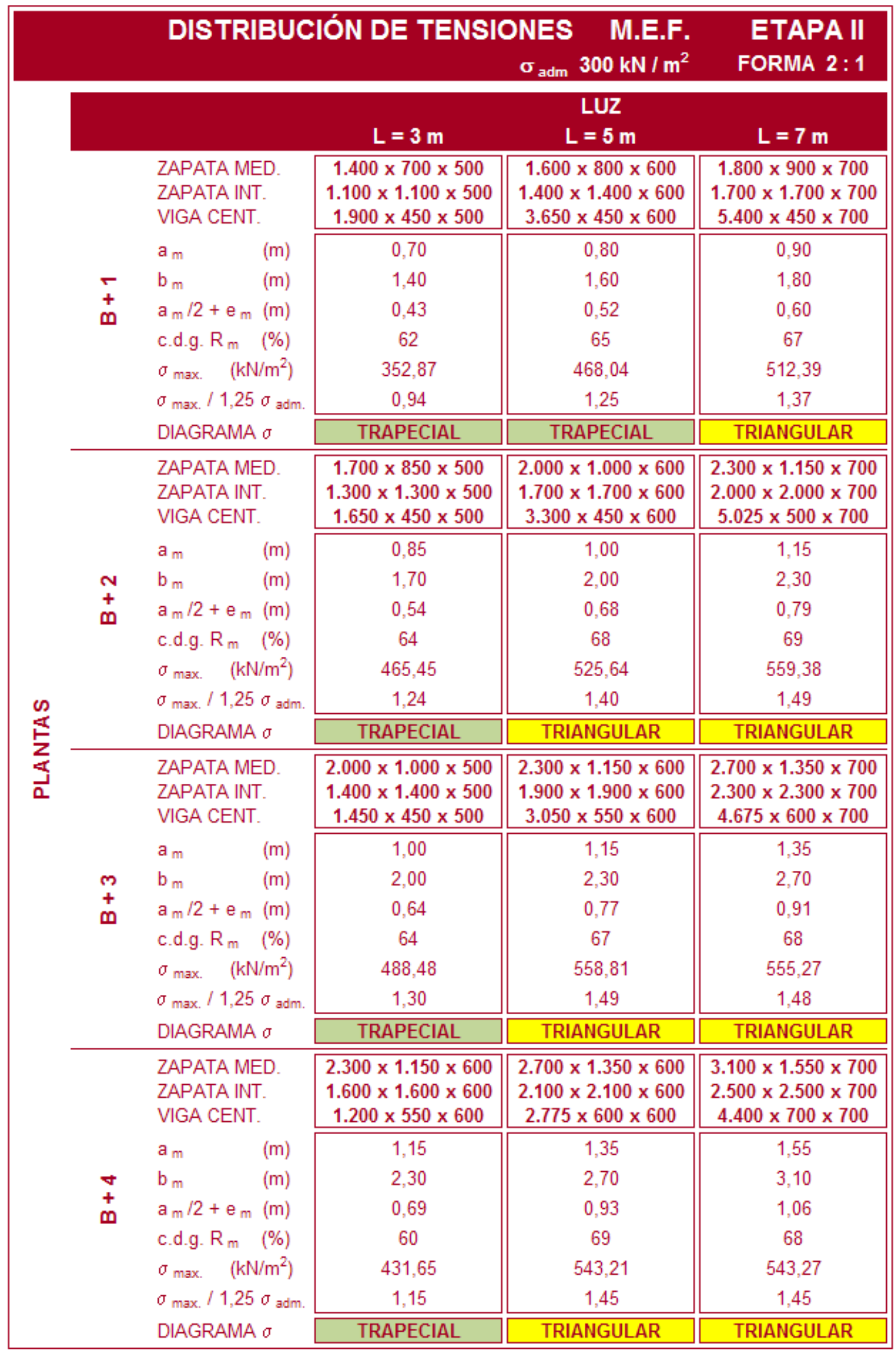

Tabla 56. Distribución de tensiones de contacto. Modelo de elementos finitos. Etapa II. $\sigma_{\text {adm. }}=300 \mathrm{kN} / \mathrm{m}^{2}$ y relación de forma $2: 1$ 



\subsection{RESULTADOS EXPERIMENTALES. ETAPA III}

\subsubsection{REDUCCIÓN DE ARMADURA}

El análisis de los resultados de las Etapas I y II (apartados 5.1 y 5.2) pone de manifiesto la considerable reducción que experimenta el momento flector que solicita a la viga centradora, debido al giro de la cimentación inducido por la flexión de la misma, que desplaza la resultante de tensiones de contacto de la zapata de medianería hacia el pilar medianero, alejándola así de la zona central de la viga centradora. Dicha reducción del momento flector que solicita a la viga centradora, ya de por sí notable en los resultados de la Etapa I y todavía más acentuada si cabe en los resultados de la Etapa II (apartado 5.2.1.2), conduce a la idea de estudiar el efecto que produciría en el modelo la reducción de la armadura de la viga centradora, acomodándola a las demandas reales que presenta.

Para ello, se vuelve a dimensionar la armadura necesaria en la viga centradora, pero en lugar de hacerlo con los momentos flectores generados por los modelos convencionales se dimensiona con los momentos flectores generados por los modelos de elementos finitos de la Etapa II, considerablemente inferiores a los obtenidos por el método convencional.

En la Tabla 57 se muestran los resultados del dimensionamiento obtenido para la armadura de la viga centradora en función de los momentos generados en la misma por los modelos de elementos finitos de la Etapa II, indicándose en cada caso el porcentaje que representa el área de armadura con el nuevo criterio, respecto del área de armadura inicial a partir de los métodos convencionales.

Una vez definidos los armados necesarios en los distintos casos planteados, se procede al cálculo de los modelos de elementos finitos de los mismos, mostrándose sus resultados en las Tablas 58 y 59. Los parámetros recogidos en las citadas tablas y su significado son los mismos que los mostrados en las tablas de resultados de las Etapas I y II (apartados 4.1.2 y 4.2.2.), por tanto, para cualquier aclaración sobre los parámetros indicados, son válidas las explicaciones dadas en el apartado 4.1.2.

Por último indicar que, tal y como se argumentó en el apartado 3.1.3.3, en la Etapa III se juega como variable con las luces y el número de plantas del pórtico, adoptándose para la tensión admisible del terreno y la relación de forma de la zapata de medianería los siguientes valores fijos:

- Tensión Admisible del Terreno

$$
\sigma_{\mathrm{adm}}=200 \mathrm{kN} / \mathrm{m}^{2}
$$

- Relación de Forma 


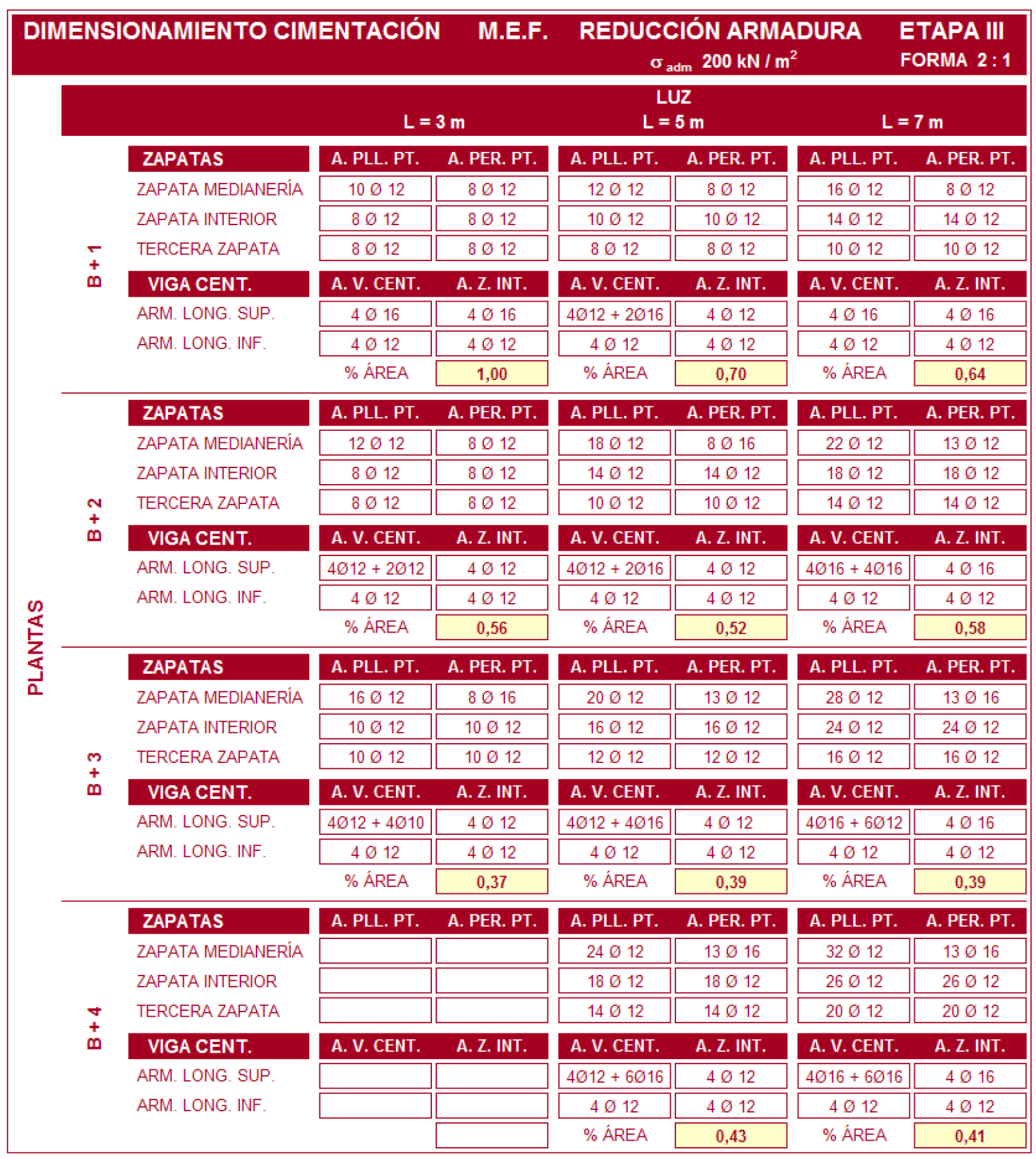

Tabla 57. Dimensionamiento cimentación. Reducción de armadura. M.E.F. Etapa III $\sigma_{\text {adm. }}=200 \mathrm{kN} / \mathrm{m}^{2}$ y relación de forma $2: 1$ 


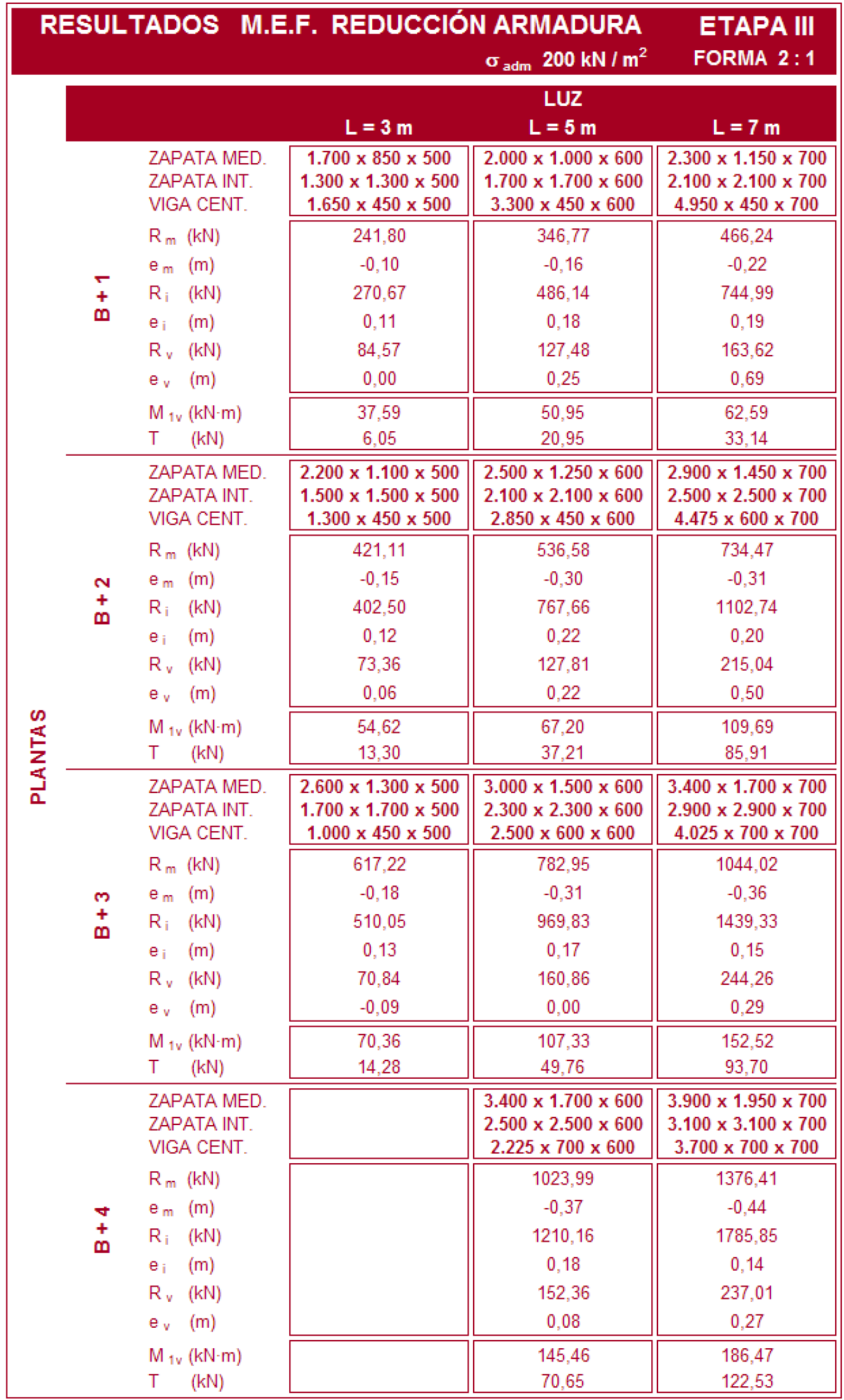

Tabla 58. Resultantes tensiones terreno y esfuerzos en vigas centradora y superior. M.E.F. Red. Arm. Etapa III. $\sigma_{\text {adm. }}=200 \mathrm{kN} / \mathrm{m}^{2}$ y relación de forma $2: 1$ 


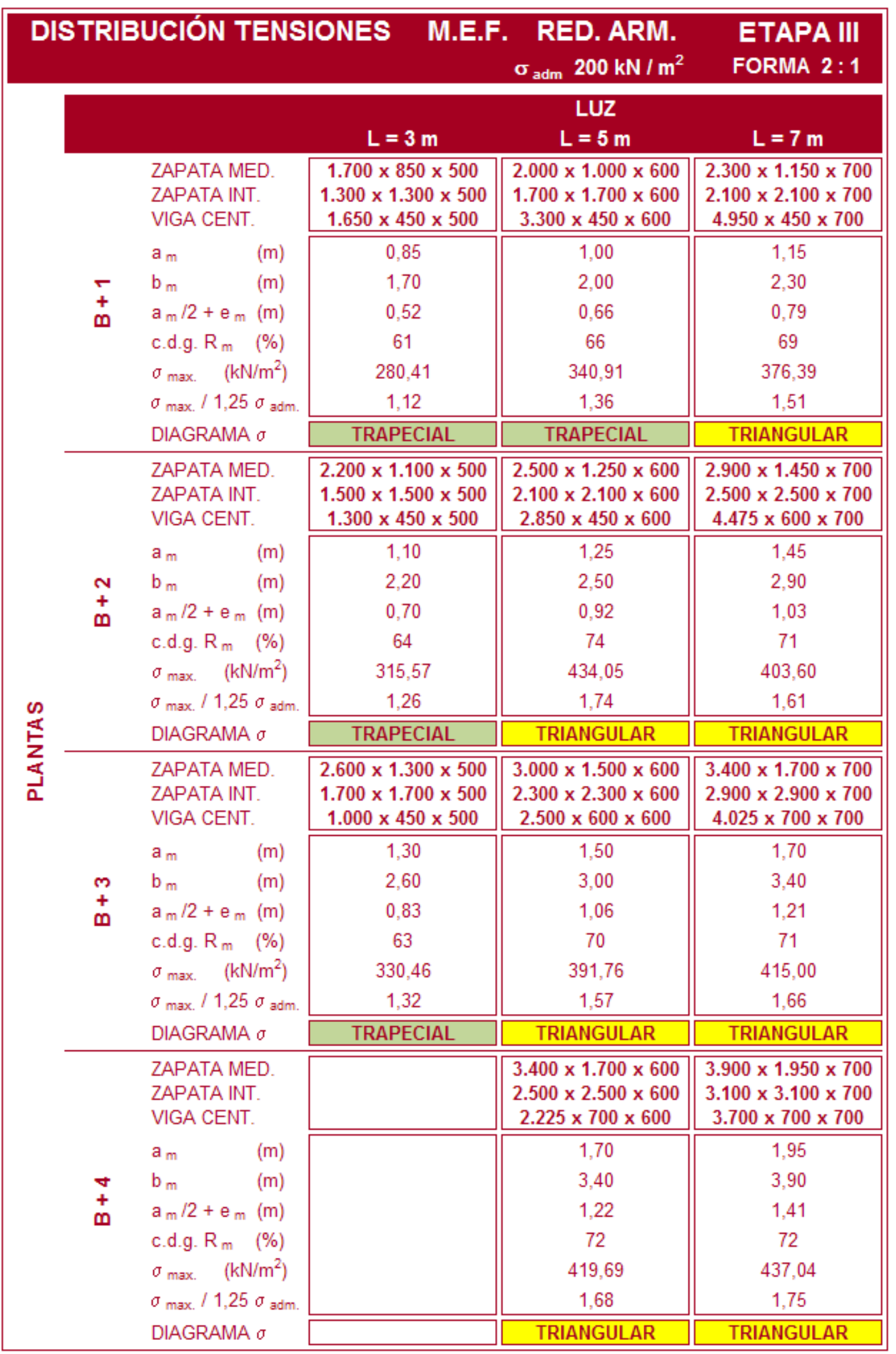

Tabla 59. Distribución de tensiones de contacto. M.E.F. Red. Armadura. Etapa III. $\sigma_{\text {adm. }}=200 \mathrm{kN} / \mathrm{m}^{2}$ y relación de forma $2: 1$ 


\subsubsection{ELIMINACIÓN DE LA VIGA CENTRADORA}

El estudio de modelos de elementos finitos sin viga centradora en la Etapa III permite, por un lado, valorar la verdadera eficacia de la viga centradora y, por otro, contrastar el modelo convencional puro de zapata de medianería con colaboración de viga superior.

Las Tablas 60 y 61 muestran los resultados de dichos modelos. Los parámetros recogidos en las citadas tablas y su significado son los mismos que los mostrados en las tablas de resultados de las Etapas I y II (apartados 4.1 .2 y 4.2.2.), por tanto, para cualquier aclaración sobre los parámetros indicados, son válidas las explicaciones dadas en el apartado 4.1.2.

Al igual que ya se comentó en el apartado anterior, en la Etapa III se juega como variable con las luces y el número de plantas del pórtico, adoptándose para la tensión admisible del terreno y la relación de forma de la zapata de medianería los siguientes valores fijos:

- Tensión Admisible del Terreno

$\sigma_{\text {adm }}=200 \mathrm{kN} / \mathrm{m}^{2}$

- Relación de Forma

$2: 1$ 


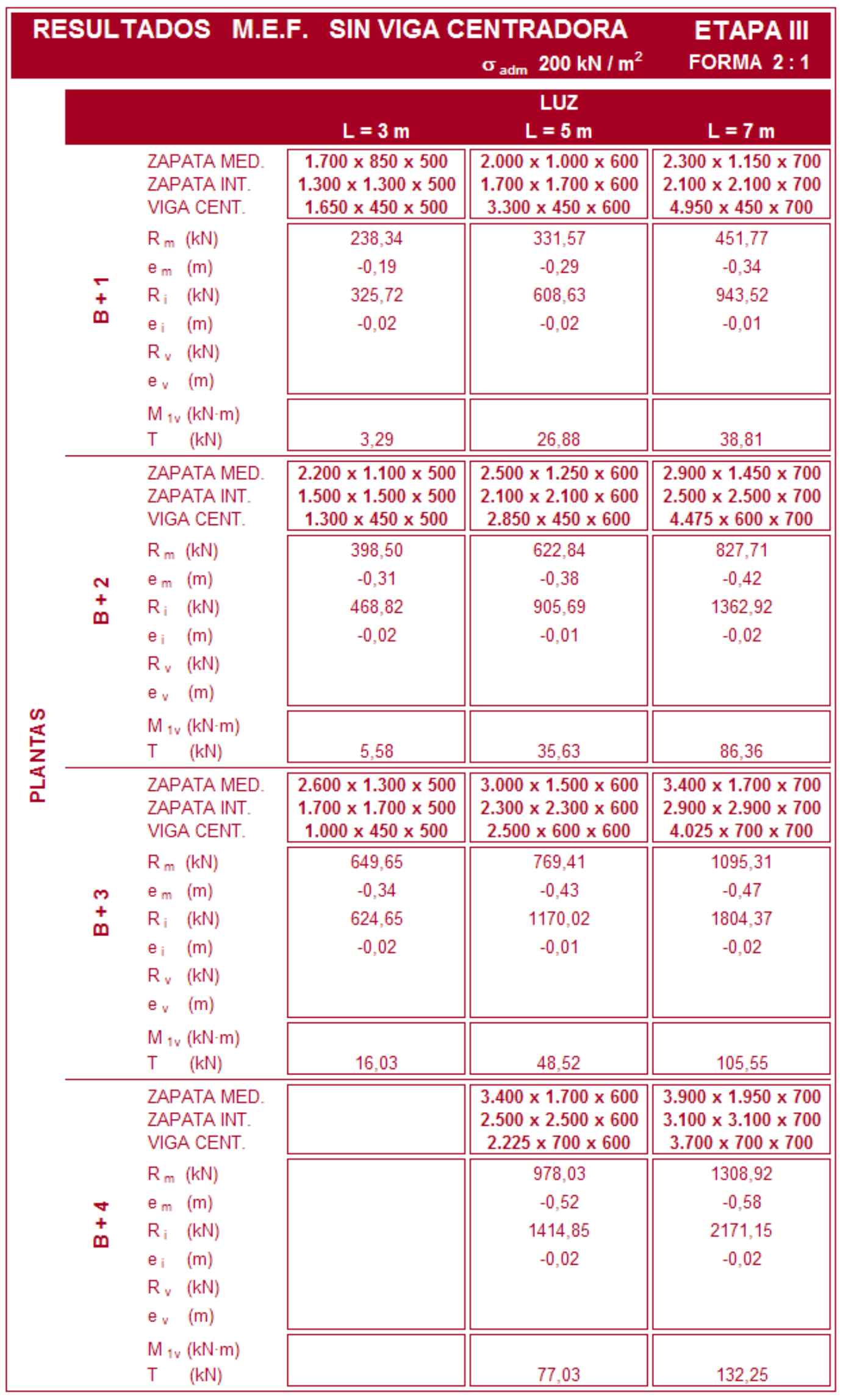

Tabla 60. Resultantes tensiones terreno y esfuerzos en viga superior. M.E.F. Sin V.CEN.. Etapa III. $\sigma_{\text {adm. }}=200 \mathrm{kN} / \mathrm{m}^{2}$ y relación de forma $2: 1$ 


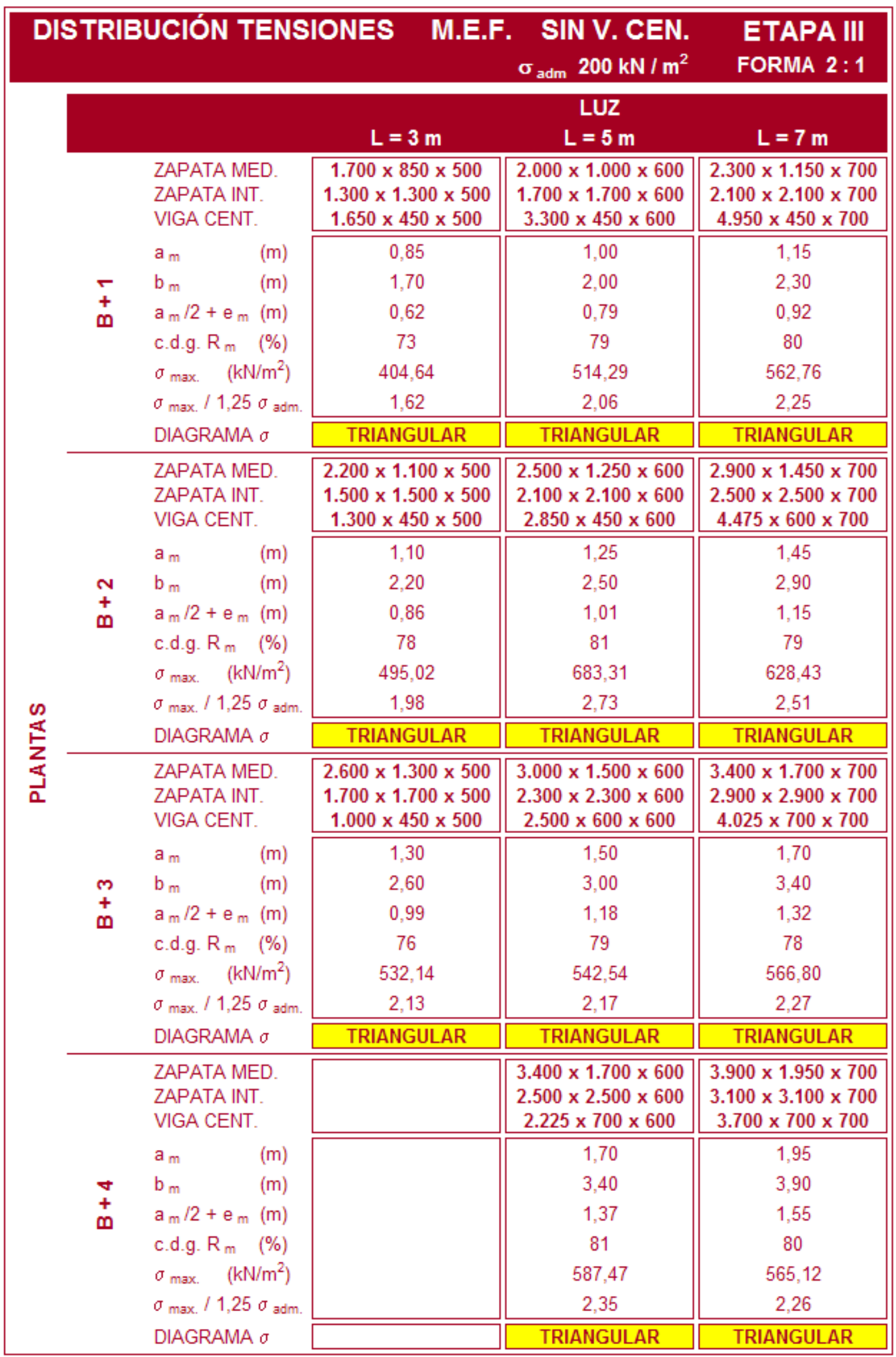

Tabla 61. Distribución de tensiones de contacto. M.E.F. Sin V. Centradora. Etapa III. $\sigma_{\text {adm. }}=200 \mathrm{kN} / \mathrm{m}^{2}$ y relación de forma $2: 1$ 


\subsubsection{INCREMENTO DE ARMADURA}

El análisis de los resultados de la Etapas II (apartado 5.2.) pone de manifiesto el incremento en la excentricidad o posición relativa de la resultante de la zapata de medianería, debido a la pérdida de rigidez de la viga centradora, como consecuencia de la fisuración de la misma. Dicha incremento en la excentricidad trae como consecuencia un deficiente comportamiento geotécnico de la zapata de medianería, con tensiones de contacto inadmisibles en su borde medianero.

La cuestión planteada requeriría un aumento en la rigidez de la viga centradora, que puede abordarse por dos vías. La primera, mediante el incremento de la armadura de la viga con el fin de reducir el proceso de fisuración que la debilita. La segunda, mediante el incremento del canto de la viga con el fin de aumentar su inercia y, con ello, su rigidez.

Se procede pues, en primer lugar, a experimentar con el aumento de la armadura de la viga centradora hasta una cuantía de armado (apartado 3.1.3.3) tal que se alcance una profundidad de fibra neutra próxima a $x=0,45 \cdot d$, cuantía esta considerablemente superior a la obtenida en función de los momentos generados por los métodos convencionales

En la Tabla 62 se muestran los resultados del dimensionamiento obtenido para la armadura de la viga centradora en función del criterio descrito, indicándose en cada caso el porcentaje que representa el área de armadura obtenida con el nuevo criterio, respecto del área de armadura inicial a partir de los métodos convencionales.

Una vez definidos los armados necesarios en los distintos casos planteados, se procede al cálculo de los modelos de elementos finitos de los mismos, mostrándose sus resultados en las Tablas 63 y 64. Los parámetros recogidos en las citadas tablas y su significado son los mismos que los mostrados en las tablas de resultados de las Etapas I y II (apartados 4.1 .2 y 4.2.2.), por tanto, para cualquier aclaración sobre los parámetros indicados, son válidas las explicaciones dadas en el apartado 4.1.2.

Por último indicar que, tal y como se argumentó en el apartado 3.1.3.3, en la Etapa III se juega como variable con las luces y el número de plantas del pórtico, adoptándose para la tensión admisible del terreno y la relación de forma de la zapata de medianería los siguientes valores fijos:

- Tensión Admisible del Terreno

- Relación de Forma $\sigma_{\mathrm{adm}}=200 \mathrm{kN} / \mathrm{m}^{2}$

2:1 


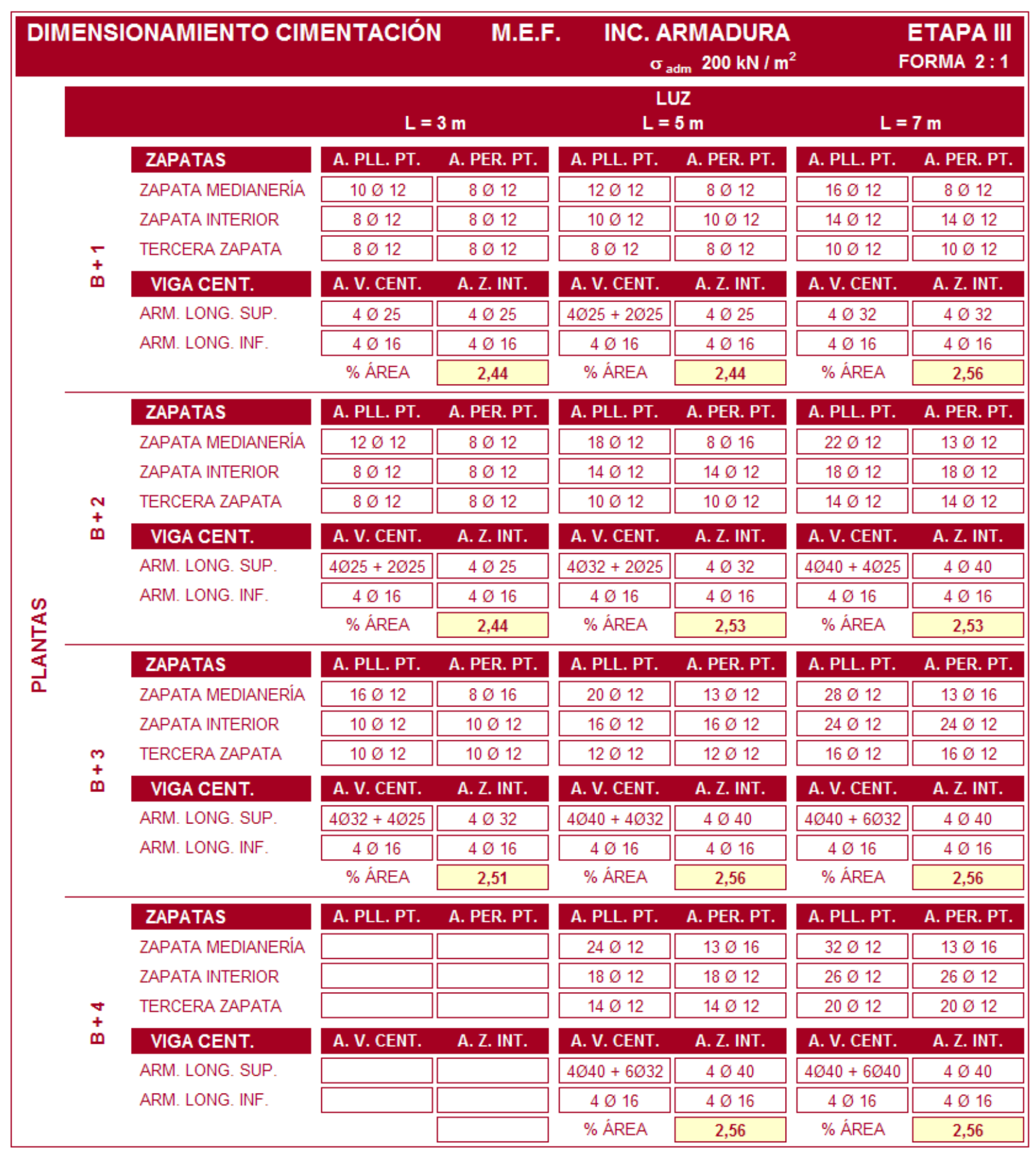

Tabla 62. Dimensionamiento cimentación. Incremento de armadura. M.E.F. Etapa II $\sigma_{\text {adm. }}=200 \mathrm{kN} / \mathrm{m}^{2}$ y relación de forma $2: 1$ 


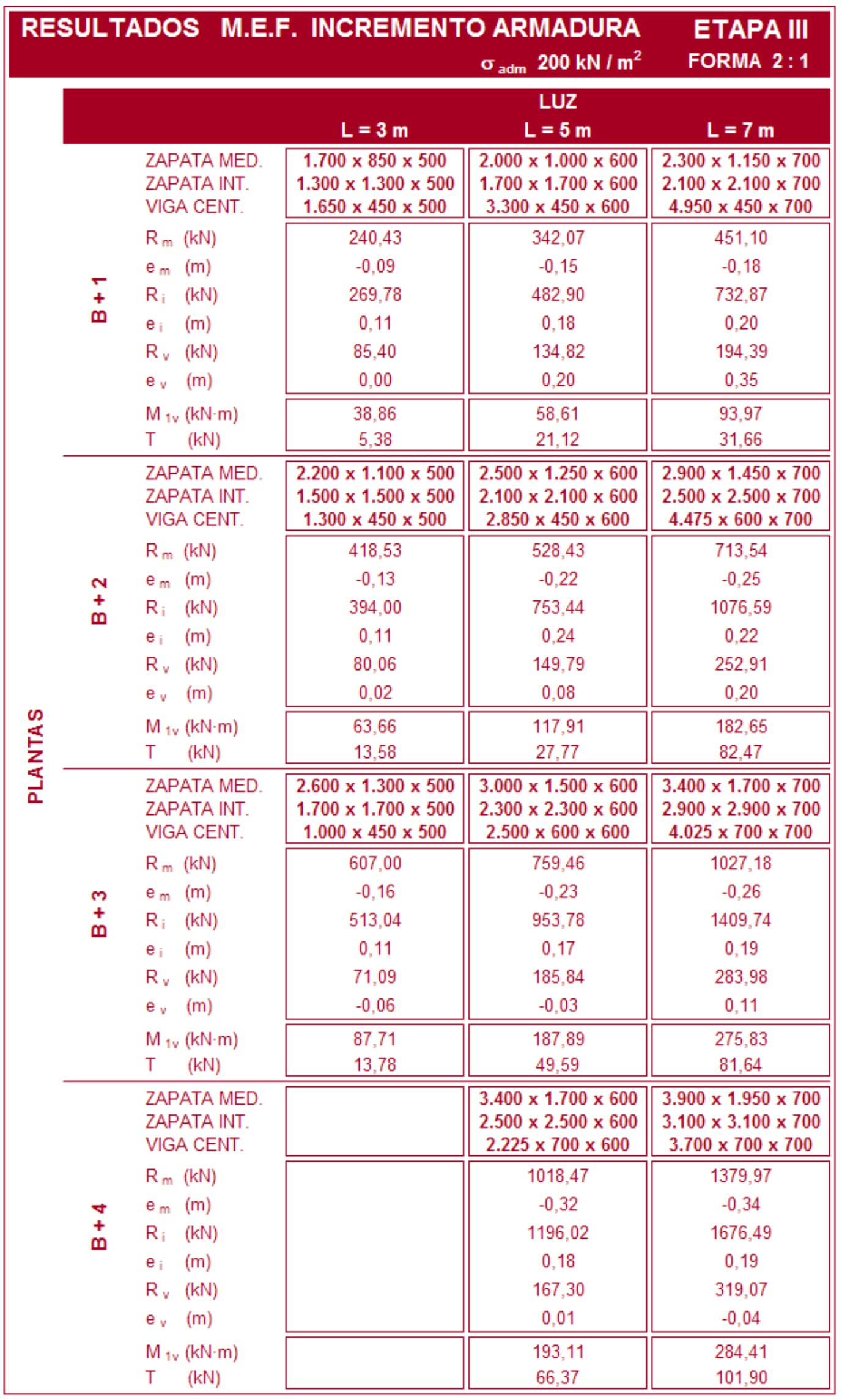

Tabla 63. Resultantes tensiones terreno y esfuerzos en vigas centradora y superior. M.E.F. Inc. Arm. Etapa III. $\sigma_{\text {adm. }}=200 \mathrm{kN} / \mathrm{m}^{2}$ y relación de forma $2: 1$ 


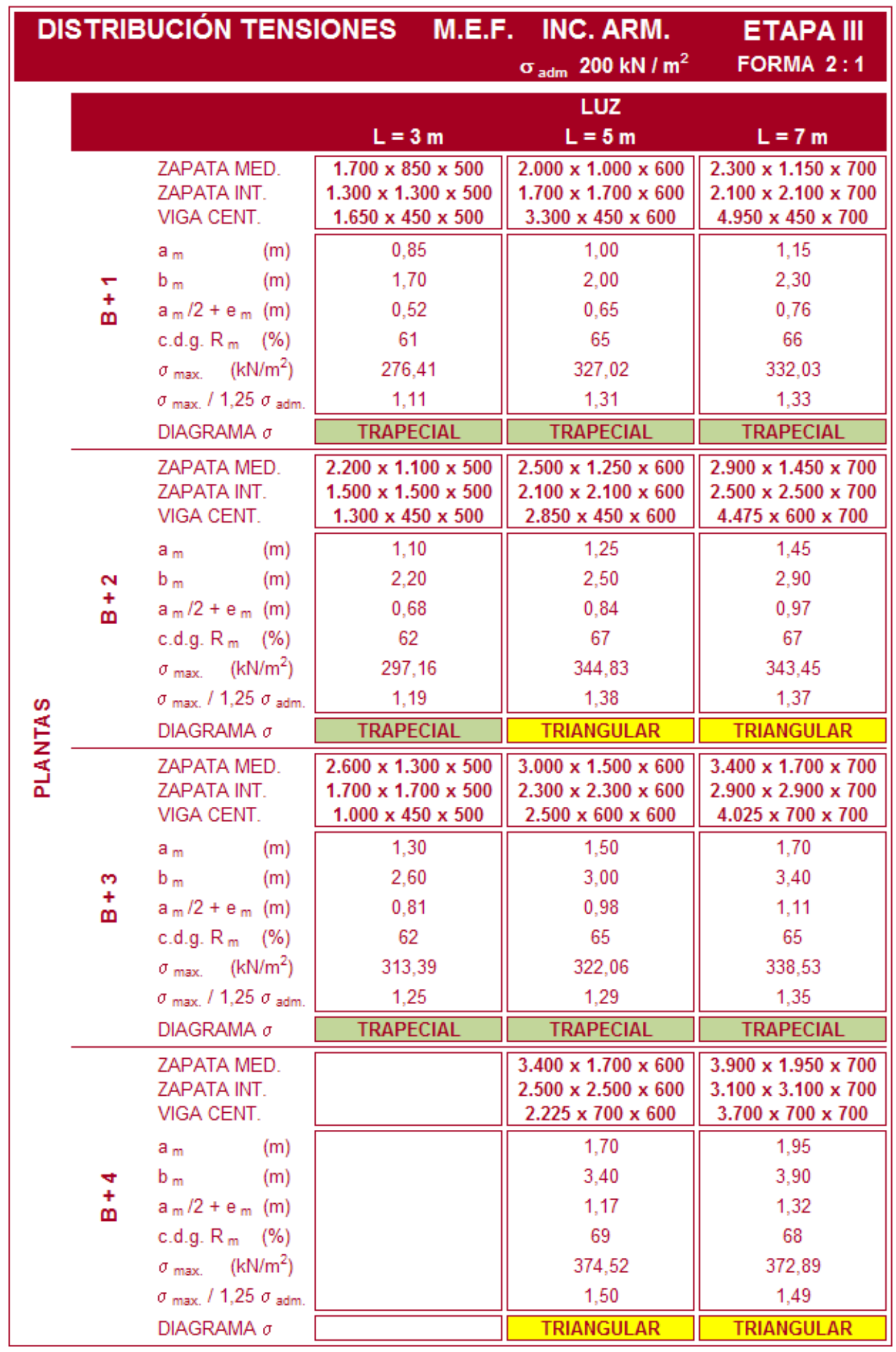

Tabla 64. Distribución de tensiones de contacto. M.E.F. Inc. Armadura. Etapa III. $\sigma_{\text {adm. }}=200 \mathrm{kN} / \mathrm{m}^{2}$ y relación de forma $2: 1$ 


\subsubsection{INCREMENTO DEL CANTO DE LA VIGA CENTRADORA}

La segunda vía planteada para lograr un aumento de la rigidez de la viga centradora consiste en el incremento del canto de la misma, con el fin de aumentar su inercia. Tanto en la Etapa I como en la Etapa II se plantean cimentaciones con el mínimo canto compatible con el anclaje de las armaduras de los correspondientes pilares obteniéndose, en general, zapatas flexibles.

Se plantean en la Etapa III, tres niveles de canto adicionales al contemplado en la Etapa II, que se obtienen incrementando los cantos de referencia, planteados en la Etapa II, en un $25 \%, 50 \%$ y $75 \%$ respectivamente (apartado 3.1 .3 .3 ). Por su parte, los armados utilizados, tanto en los pórticos como en la cimentación, son los mismos que los definidos en la Etapa II, es decir, se incrementa canto manteniendo armadura.

Una vez definidos los cantos a estudiar, se procede al cálculo de los modelos de elementos finitos de los distintos casos planteados, mostrándose sus resultados en las Tablas 65,66 , 67, 68, 69 y 70. Los parámetros recogidos en las citadas tablas y su significado son los mismos que los mostrados en las tablas de resultados de las Etapas I y II (apartados 4.1 .2 y 4.2.2.), por tanto, para cualquier aclaración sobre los parámetros indicados, son válidas las explicaciones dadas en el apartado 4.1.2.

Recordar, al igual que en casos anteriores, que en la Etapa III se juega como variable con las luces y el número de plantas del pórtico, adoptándose para la tensión admisible del terreno y la relación de forma de la zapata de medianería los siguientes valores fijos:

- Tensión Admisible del Terreno

- Relación de Forma

$$
\sigma_{\mathrm{adm}}=200 \mathrm{kN} / \mathrm{m}^{2}
$$

2:1 


\begin{tabular}{|c|c|c|c|c|c|}
\hline RE & \multicolumn{2}{|c|}{ ULTADOS } & M.E.F. & $\begin{array}{l}\mathrm{H}=1,25 \cdot \mathrm{H}_{\text {II }} \\
\sigma_{\text {adm }} 200 \mathrm{kN} / \mathrm{m}^{2}\end{array}$ & $\begin{array}{l}\text { ETAPA III } \\
\text { FORMA } 2: 1\end{array}$ \\
\hline \multirow{11}{*}{\multicolumn{2}{|c|}{$\begin{array}{r}+ \\
\dot{m}\end{array}$}} & & \multicolumn{3}{|c|}{ LUZ } \\
\hline & & & $\mathrm{L}=\mathbf{3} \mathrm{m}$ & $L=5 \mathrm{~m}$ & $\mathrm{~L}=7 \mathrm{~m}$ \\
\hline & & $\begin{array}{l}\text { ZAPATA MED. } \\
\text { ZAPATA INT. } \\
\text { VIGA CENT. }\end{array}$ & \begin{tabular}{|c|}
$1.700 \times 850 \times 500$ \\
$1.300 \times 1.300 \times 500$ \\
$1.650 \times 450 \times 500$ \\
\end{tabular} & $\begin{array}{c}2.000 \times 1.000 \times 600 \\
1.700 \times 1.700 \times 600 \\
3.300 \times 450 \times 600 \\
\end{array}$ & $\begin{array}{c}2.300 \times 1.150 \times 700 \\
2.100 \times 2.100 \times 700 \\
4.950 \times 450 \times 700\end{array}$ \\
\hline & & $\mathrm{R}_{\mathrm{m}}(\mathrm{kN})$ & 229,01 & 329,30 & 462,54 \\
\hline & & $e_{m}(m)$ & $-0,08$ & $-0,10$ & $-0,16$ \\
\hline & & $\mathrm{R}_{\mathrm{i}} \quad(\mathrm{kN})$ & 247,83 & 450,45 & 659,17 \\
\hline & & $e_{i} \quad(m)$ & 0,10 & 0,17 & 0,20 \\
\hline & & $R_{v} \quad(k N)$ & 90,71 & 176,97 & 220,74 \\
\hline & & $e_{v}(m)$ & 0,00 & 0,05 & 0,27 \\
\hline & & $\mathrm{M}_{1 \mathrm{v}}(\mathrm{kN} \cdot \mathrm{m})$ & 45,49 & 90,59 & 105,11 \\
\hline & & $\mathrm{T} \quad(\mathrm{kN})$ & 2,80 & 20,94 & 28,30 \\
\hline \multirow{8}{*}{\multicolumn{2}{|c|}{$\begin{array}{l}n \\
\mathbb{E} \\
\mathbf{E}\end{array}$}} & $\begin{array}{l}\text { ZAPATA MED. } \\
\text { ZAPATA INT. } \\
\text { VIGA CENT. }\end{array}$ & \begin{tabular}{|c|}
$2.200 \times 1.100 \times 500$ \\
$1.500 \times 1.500 \times 500$ \\
$1.300 \times 450 \times 500$ \\
\end{tabular} & $\begin{array}{c}2.500 \times 1.250 \times 600 \\
2.100 \times 2.100 \times 600 \\
2.850 \times 450 \times 600 \\
\end{array}$ & $\begin{array}{c}2.900 \times 1.450 \times 700 \\
2.500 \times 2.500 \times 700 \\
4.475 \times 600 \times 700\end{array}$ \\
\hline & & $R_{m}(k N)$ & 435,71 & 549,02 & 744,69 \\
\hline & & $e_{m}(m)$ & $-0,10$ & $-0,20$ & $-0,23$ \\
\hline & & $\mathrm{R}_{\mathrm{i}} \quad(\mathrm{kN})$ & 367,52 & 740,07 & 1026,77 \\
\hline & & $e_{i} \quad(m)$ & 0,11 & 0,24 & 0,23 \\
\hline & & $R_{v} \quad(k N)$ & 86,12 & 158,67 & 274,45 \\
\hline & & $e_{v}(m)$ & 0,02 & 0,09 & 0,21 \\
\hline & & $\begin{array}{l}\mathrm{M}_{1 \mathrm{v}}(\mathrm{kN} \cdot \mathrm{m}) \\
\mathrm{T} \quad(\mathrm{kN})\end{array}$ & $\begin{array}{l}69,20 \\
14,10\end{array}$ & $\begin{array}{c}120,77 \\
30,69\end{array}$ & $\begin{array}{c}190,63 \\
86,97\end{array}$ \\
\hline$\frac{1}{0}$ & \multirow{8}{*}{$\begin{array}{l}m \\
+ \\
m\end{array}$} & $\begin{array}{l}\text { ZAPATA MED. } \\
\text { ZAPATA INT. } \\
\text { VIGA CENT. }\end{array}$ & \begin{tabular}{|c|}
$2.600 \times 1.300 \times 500$ \\
$1.700 \times 1.700 \times 500$ \\
$1.000 \times 450 \times 500$
\end{tabular} & $\begin{array}{c}3.000 \times 1.500 \times 600 \\
2.300 \times 2.300 \times 600 \\
2.500 \times 600 \times 600\end{array}$ & $\begin{array}{c}3.400 \times 1.700 \times 700 \\
2.900 \times 2.900 \times 700 \\
4.025 \times 700 \times 700\end{array}$ \\
\hline & & $\mathrm{R}_{\mathrm{m}}(\mathrm{kN})$ & 613,96 & 775,83 & 1025,60 \\
\hline & & $e_{m}(m)$ & $-0,15$ & $-0,22$ & $-0,28$ \\
\hline & & $\mathrm{R}_{\mathrm{i}} \quad(\mathrm{kN})$ & 511,16 & 945,75 & 1405,90 \\
\hline & & $e_{i} \quad(m)$ & 0,11 & 0,19 & 0,26 \\
\hline & & $R_{v} \quad(k N)$ & 65,27 & 184,28 & 298,16 \\
\hline & & $e_{v}(m)$ & $-0,01$ & 0,01 & 0,15 \\
\hline & & $\begin{array}{l}\mathrm{M}_{1 \mathrm{v}}(\mathrm{kN}-\mathrm{m}) \\
\mathrm{T} \quad(\mathrm{kN})\end{array}$ & $\begin{array}{l}91,22 \\
10,88 \\
\end{array}$ & $\begin{array}{c}200,78 \\
53,42 \\
\end{array}$ & $\begin{array}{c}284,81 \\
88,58 \\
\end{array}$ \\
\hline & \multirow{8}{*}{$\begin{array}{l}+ \\
\dot{m}\end{array}$} & $\begin{array}{l}\text { ZAPATA MED. } \\
\text { ZAPATA INT. } \\
\text { VIGA CENT. }\end{array}$ & & $\begin{array}{c}3.400 \times 1.700 \times 600 \\
2.500 \times 2.500 \times 600 \\
2.225 \times 700 \times 600 \\
\end{array}$ & $\begin{array}{c}3.900 \times 1.950 \times 700 \\
3.100 \times 3.100 \times 700 \\
3.700 \times 700 \times 700\end{array}$ \\
\hline & & $\mathrm{R}_{\mathrm{m}}(\mathrm{kN})$ & & 1046,36 & 1425,86 \\
\hline & & $e_{m}(m)$ & & $-0,25$ & $-0,28$ \\
\hline & & $\mathrm{R}_{\mathrm{i}} \quad(\mathrm{kN})$ & & 1161,13 & 1629,48 \\
\hline & & $e_{i} \quad(m)$ & & 0,24 & 0,22 \\
\hline & & $R_{v} \quad(k N)$ & & 174,51 & 324,66 \\
\hline & & $e_{v}(m)$ & & 0,04 & 0,00 \\
\hline & & $\begin{array}{l}\mathrm{M}_{1 \mathrm{v}}(\mathrm{kN}-\mathrm{m}) \\
\mathrm{T} \quad(\mathrm{kN})\end{array}$ & & $\begin{array}{c}261,87 \\
58,32\end{array}$ & $\begin{array}{l}364,81 \\
108,80\end{array}$ \\
\hline
\end{tabular}

Tabla 65. Resultantes tensiones terreno y esfuerzos en vigas centradora y superior. M.E.F. $\mathrm{H}=1,25 \cdot \mathrm{H}_{\|}$. Etapa III. $\sigma_{\text {adm. }}=200 \mathrm{kN} / \mathrm{m}^{2}$ y relación de forma $2: 1$ 


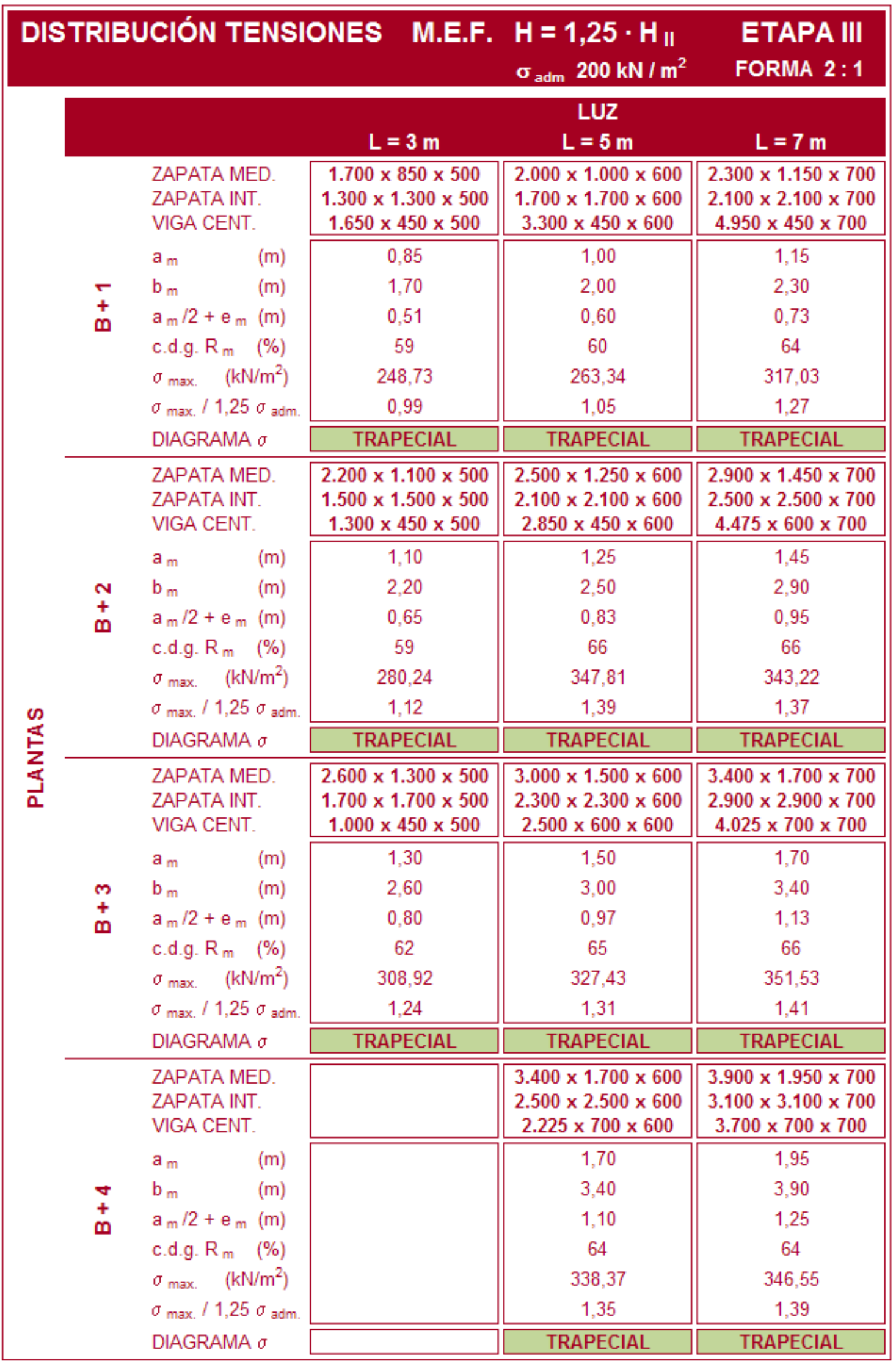

Tabla 66. Distribución de tensiones de contacto. M.E.F. $\mathrm{H}=1,25 \cdot \mathrm{H}_{\|}$. Etapa III. $\sigma_{\text {adm. }}=200 \mathrm{kN} / \mathrm{m}^{2}$ y relación de forma $2: 1$ 


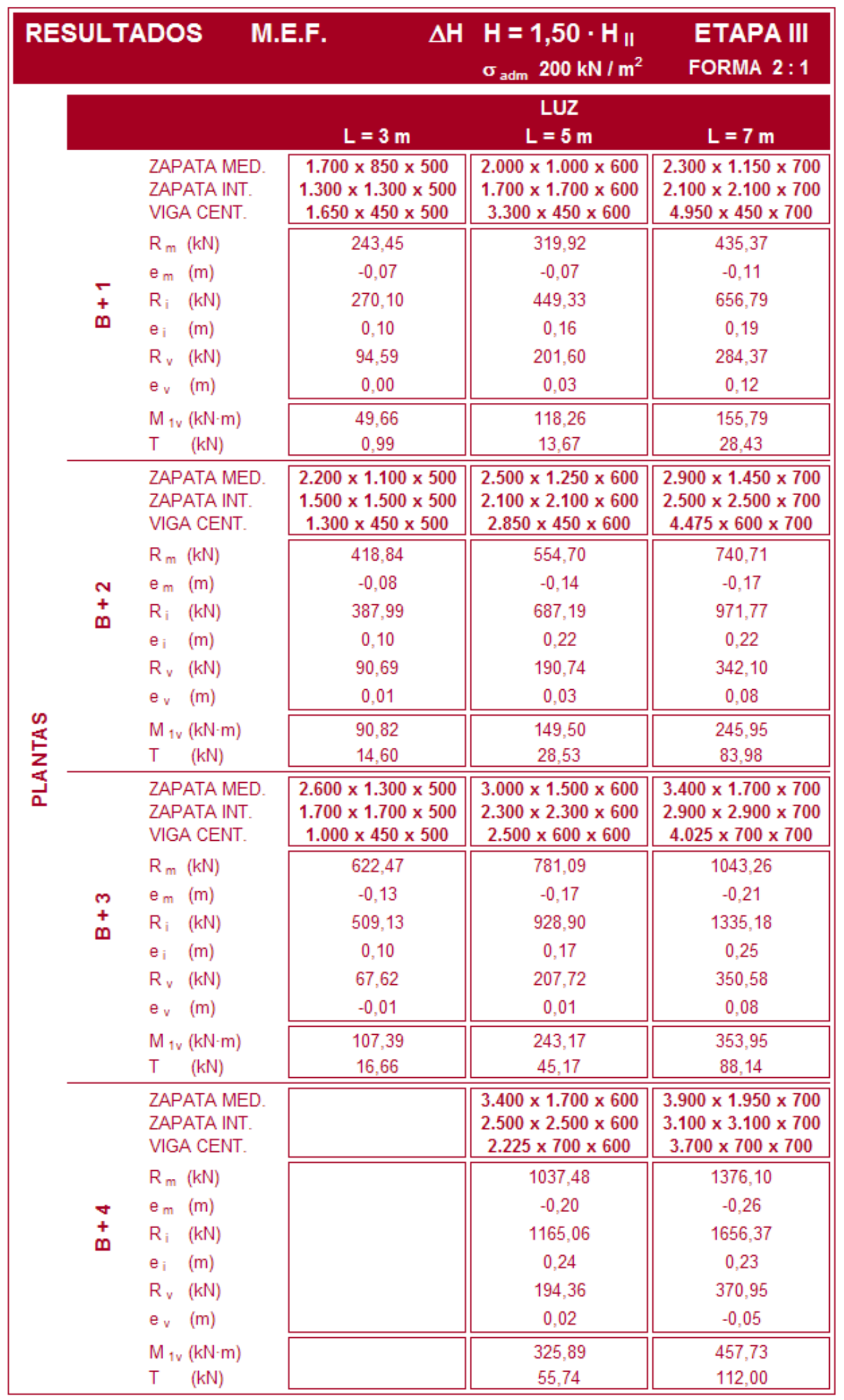

Tabla 67. Resultantes tensiones terreno y esfuerzos en vigas centradora y superior. M.E.F. $\mathrm{H}=1,50 \cdot \mathrm{H}_{\|}$. Etapa III. $\sigma_{\mathrm{adm}}=200 \mathrm{kN} / \mathrm{m}^{2}$ y relación de forma $2: 1$ 


\begin{tabular}{|c|c|c|c|c|c|}
\hline \multicolumn{4}{|c|}{ DISTRIBUCIÓN TENSIONES } & $\begin{array}{l}\mathrm{H}=1,50 \cdot \mathrm{H}_{\|} \\
\sigma_{\text {adm }} 200 \mathrm{kN} / \mathrm{m}^{2}\end{array}$ & $\begin{array}{l}\text { ETAPA III } \\
\text { FORMA } 2: 1\end{array}$ \\
\hline \multirow{9}{*}{\multicolumn{2}{|c|}{$\stackrel{\tau}{+}$}} & & \multicolumn{3}{|c|}{ LUZ } \\
\hline & & $\begin{array}{l}\text { ZAPATA MED. } \\
\text { ZAPATA INT. } \\
\text { VIGA CENT. }\end{array}$ & $\begin{array}{c}1.700 \times 850 \times 500 \\
1.300 \times 1.300 \times 500 \\
1.650 \times 450 \times 500\end{array}$ & $\begin{array}{c}2.000 \times 1.000 \times 600 \\
1.700 \times 1.700 \times 600 \\
3.300 \times 450 \times 600\end{array}$ & $\begin{array}{c}2.300 \times 1.150 \times 700 \\
2.100 \times 2.100 \times 700 \\
4.950 \times 450 \times 700\end{array}$ \\
\hline & & (m) & 0,85 & 1,00 & 1,15 \\
\hline & & $(\mathrm{m})$ & 1,70 & 2,00 & 2,30 \\
\hline & & $a_{m} / 2+e_{m}(m)$ & 0,50 & 0,57 & 0,69 \\
\hline & & c.d.g. $R_{m} \quad(\%)$ & 59 & 57 & 60 \\
\hline & & $\sigma_{\max } \quad\left(\mathrm{kN} / \mathrm{m}^{2}\right)$ & 254,47 & 230,98 & 262,40 \\
\hline & & $\sigma_{\mathrm{max}} / 1,25 \sigma_{\mathrm{adm}}$ & 1,02 & 0,92 & 1,05 \\
\hline & & DIAGRAMA $\sigma$ & TRAPECIAL & TRAPECIAL & TRAPECIAL \\
\hline \multirow{8}{*}{\multicolumn{2}{|c|}{$\underset{\mathbb{Z}}{\infty}$}} & $\begin{array}{l}\text { ZAPATA MED. } \\
\text { ZAPATA INT. } \\
\text { VIGA CENT. }\end{array}$ & $\begin{array}{c}2.200 \times 1.100 \times 500 \\
1.500 \times 1.500 \times 500 \\
1.300 \times 450 \times 500\end{array}$ & $\begin{array}{c}2.500 \times 1.250 \times 600 \\
2.100 \times 2.100 \times 600 \\
2.850 \times 450 \times 600\end{array}$ & $\begin{array}{c}2.900 \times 1.450 \times 700 \\
2.500 \times 2.500 \times 700 \\
4.475 \times 600 \times 700\end{array}$ \\
\hline & & $(\mathrm{m})$ & 1,10 & 1,25 & 1,45 \\
\hline & & $b_{m}$ & 2,20 & 2,50 & 2,90 \\
\hline & & $a_{m} / 2+e_{m}(m)$ & 0,63 & 0,76 & 0,89 \\
\hline & & c.d.g. $R_{m} \quad(\%)$ & 58 & 61 & 62 \\
\hline & & $\sigma_{\max .} \quad\left(\mathrm{kN} / \mathrm{m}^{2}\right)$ & 253,30 & 292,83 & 299,79 \\
\hline & & $\sigma_{\max } / 1,25 \sigma_{\mathrm{adm}}$ & 1,01 & 1,17 & 1,20 \\
\hline & & DIAGRAMA $\sigma$ & TRAPECIAL & TRAPECIAL & TRAPECIAL \\
\hline$\frac{1}{2}$ & & $\begin{array}{l}\text { ZAPATA MED. } \\
\text { ZAPATA INT. } \\
\text { VIGA CENT. }\end{array}$ & $\begin{array}{c}2.600 \times 1.300 \times 500 \\
1.700 \times 1.700 \times 500 \\
1.000 \times 450 \times 500\end{array}$ & $\begin{array}{c}.000 \times 1.500 \times 600 \\
2.300 \times 2.300 \times 600 \\
2.500 \times 600 \times 600\end{array}$ & $\begin{array}{c}3.400 \times 1.700 \times 700 \\
2.900 \times 2.900 \times 700 \\
4.025 \times 700 \times 700\end{array}$ \\
\hline & & $a_{m}$ & 1,30 & 1,50 & 1,70 \\
\hline & & $b_{m}$ & 2,60 & 3,00 & 3,40 \\
\hline & & $a_{m} / 2+e_{m}(m)$ & 0,78 & 0,92 & 1,06 \\
\hline & & c.d.g. $R_{m} \quad(\%)$ & 60 & 61 & 62 \\
\hline & & $\sigma_{\max } \quad\left(\mathrm{kN} / \mathrm{m}^{2}\right)$ & 291,63 & 291,58 & 314,22 \\
\hline & & $\sigma_{\mathrm{max}} / 1,25 \sigma_{\mathrm{adm}}$. & 1,17 & 1,17 & 1,26 \\
\hline & & DIAGRAMA $\sigma$ & TRAPECIAL & TRAPECIAL & TRAPECIAL \\
\hline & & $\begin{array}{l}\text { ZAPATA MED. } \\
\text { ZAPATA INT. } \\
\text { VIGA CENT. }\end{array}$ & & $\begin{array}{c}3.400 \times 1.700 \times 600 \\
2.500 \times 2.500 \times 600 \\
2.225 \times 700 \times 600\end{array}$ & $\begin{array}{c}3.900 \times 1.950 \times 700 \\
3.100 \times 3.100 \times 700 \\
3.700 \times 700 \times 700\end{array}$ \\
\hline & & $a_{m}$ & & 1,70 & 1,95 \\
\hline & & $(\mathrm{m})$ & & 3,40 & 3,90 \\
\hline & & $a_{m} / 2+e_{m}(m)$ & & 1,05 & 1,24 \\
\hline & & c.d.g. $R_{m} \quad(\%)$ & & 62 & 63 \\
\hline & & $\sigma_{\max } \quad\left(\mathrm{kN} / \mathrm{m}^{2}\right)$ & & 306,06 & 326,42 \\
\hline & & $\sigma_{\text {max. }} / 1,25 \sigma_{\text {adm. }}$. & & 1,22 & 1,31 \\
\hline & & DIAGRAMA $\sigma$ & & TRAPECIAL & TRAPECIAL \\
\hline
\end{tabular}

Tabla 68. Distribución de tensiones de contacto. M.E.F. $\mathrm{H}=1,50 \cdot \mathrm{H}_{\|}$. Etapa III. $\sigma_{\text {adm. }}=200 \mathrm{kN} / \mathrm{m}^{2}$ y relación de forma $2: 1$ 


\begin{tabular}{|c|c|c|c|c|c|}
\hline RE & \multicolumn{2}{|c|}{ JLTADOS } & M.E.F. & $\begin{array}{l}H=1,75 \cdot H_{\|} \\
\sigma_{\text {adm }} 200 \mathrm{kN} / \mathrm{m}^{2}\end{array}$ & $\begin{array}{l}\text { ETAPA III } \\
\text { FORMA } 2: 1\end{array}$ \\
\hline \multirow{10}{*}{\multicolumn{2}{|c|}{$\stackrel{+}{+}$}} & & \multicolumn{3}{|c|}{ LUZ } \\
\hline & & & $L=3 \mathrm{~m}$ & $L=5 \mathrm{~m}$ & $L=7 \mathrm{~m}$ \\
\hline & & $\begin{array}{l}\text { ZAPATA MED. } \\
\text { ZAPATA INT. } \\
\text { VIGA CENT. }\end{array}$ & $\begin{array}{c}1.700 \times 850 \times 500 \\
1.300 \times 1.300 \times 500 \\
1.650 \times 450 \times 500 \\
\end{array}$ & $\begin{array}{c}2.000 \times 1.000 \times 600 \\
1.700 \times 1.700 \times 600 \\
3.300 \times 450 \times 600 \\
\end{array}$ & $\begin{array}{c}2.300 \times 1.150 \times 700 \\
2.100 \times 2.100 \times 700 \\
4.950 \times 450 \times 700 \\
\end{array}$ \\
\hline & & $\mathrm{R}_{\mathrm{m}}(\mathrm{kN})$ & 238,48 & 324,44 & 420,18 \\
\hline & & $e_{m}(m)$ & $-0,07$ & $-0,06$ & $-0,09$ \\
\hline & & $\mathrm{R}_{\mathrm{i}} \quad(\mathrm{kN})$ & 263,68 & 433,81 & 646,33 \\
\hline & & $e_{i} \quad(m)$ & 0,09 & 0,15 & 0,18 \\
\hline & & $\mathrm{R}_{\mathrm{v}} \quad(\mathrm{kN})$ & 97,36 & 217,48 & 324,48 \\
\hline & & $e_{v}(\mathrm{~m})$ & 0,01 & 0,02 & 0,09 \\
\hline & & $\begin{array}{l}\mathrm{M}_{1 \mathrm{v}}(\mathrm{kN} \cdot \mathrm{m}) \\
\mathrm{T} \quad(\mathrm{kN})\end{array}$ & $\begin{array}{c}52,58 \\
0,79\end{array}$ & $\begin{array}{l}126,55 \\
22,03\end{array}$ & $\begin{array}{c}185,38 \\
28,75\end{array}$ \\
\hline \multirow{8}{*}{\multicolumn{2}{|c|}{$\begin{array}{l}\infty \\
\mathbf{E}\end{array}$}} & $\begin{array}{l}\text { ZAPATA MED. } \\
\text { ZAPATA INT. } \\
\text { VIGA CENT. }\end{array}$ & $\begin{array}{c}2.200 \times 1.100 \times 500 \\
1.500 \times 1.500 \times 500 \\
1.300 \times 450 \times 500 \\
\end{array}$ & $\begin{array}{c}2.500 \times 1.250 \times 600 \\
2.100 \times 2.100 \times 600 \\
2.850 \times 450 \times 600 \\
\end{array}$ & $\begin{array}{c}2.900 \times 1.450 \times 700 \\
2.500 \times 2.500 \times 700 \\
4.475 \times 600 \times 700\end{array}$ \\
\hline & & $\mathrm{R}_{\mathrm{m}}(\mathrm{kN})$ & 421,92 & 572,27 & 728,63 \\
\hline & & $e_{m}(m)$ & $-0,07$ & $-0,10$ & $-0,13$ \\
\hline & & $\mathrm{R}_{\mathrm{i}} \quad(\mathrm{kN})$ & 385,59 & 648,64 & 954,49 \\
\hline & & $e_{i} \quad(m)$ & 0,09 & 0,21 & 0,20 \\
\hline & & $R_{v} \quad(k N)$ & 93,83 & 211,42 & 388,88 \\
\hline & & $e_{v}(m)$ & 0,01 & 0,02 & 0,05 \\
\hline & & $\begin{array}{l}\mathrm{M}_{1 \mathrm{v}}(\mathrm{kN}-\mathrm{m}) \\
T \quad(\mathrm{kN})\end{array}$ & $\begin{array}{l}98,55 \\
14,91\end{array}$ & $\begin{array}{l}174,85 \\
29,66\end{array}$ & $\begin{array}{c}313,56 \\
81,25\end{array}$ \\
\hline$\frac{1}{2}$ & \multirow{8}{*}{$\begin{array}{l}m \\
+ \\
m\end{array}$} & $\begin{array}{l}\text { ZAPATA MED. } \\
\text { ZAPATA INT. } \\
\text { VIGA CENT. }\end{array}$ & $\begin{array}{c}2.600 \times 1.300 \times 500 \\
1.700 \times 1.700 \times 500 \\
1.000 \times 450 \times 500 \\
\end{array}$ & $\begin{array}{c}3.000 \times 1.500 \times 600 \\
2.300 \times 2.300 \times 600 \\
2.500 \times 600 \times 600 \\
\end{array}$ & $\begin{array}{c}3.400 \times 1.700 \times 700 \\
2.900 \times 2.900 \times 700 \\
4.025 \times 700 \times 700 \\
\end{array}$ \\
\hline & & $\mathrm{R}_{\mathrm{m}}(\mathrm{kN})$ & 621,71 & 821,46 & 1079,16 \\
\hline & & $e_{m}(m)$ & $-0,11$ & $-0,12$ & $-0,16$ \\
\hline & & $\mathrm{R}_{\mathrm{i}} \quad(\mathrm{kN})$ & 505,32 & 868,16 & 1305,87 \\
\hline & & $e_{i} \quad(m)$ & 0,10 & 0,16 & 0,24 \\
\hline & & $R_{v} \quad(k N)$ & 69,21 & 224,21 & 402,64 \\
\hline & & $e_{v}(m)$ & 0,00 & 0,01 & 0,03 \\
\hline & & $\begin{array}{l}M_{1 \mathrm{v}}(\mathrm{kN}-\mathrm{m}) \\
T \quad(\mathrm{kN})\end{array}$ & $\begin{array}{c}124,42 \\
15,90 \\
\end{array}$ & $\begin{array}{c}262,15 \\
45,02 \\
\end{array}$ & $\begin{array}{c}399,99 \\
83,66 \\
\end{array}$ \\
\hline & \multirow{8}{*}{$\begin{array}{l}+ \\
+ \\
m\end{array}$} & $\begin{array}{l}\text { ZAPATA MED. } \\
\text { ZAPATA INT. } \\
\text { VIGA CENT. }\end{array}$ & & $\begin{array}{c}3.400 \times 1.700 \times 600 \\
2.500 \times 2.500 \times 600 \\
2.225 \times 700 \times 600 \\
\end{array}$ & $\begin{array}{c}3.900 \times 1.950 \times 700 \\
3.100 \times 3.100 \times 700 \\
3.700 \times 700 \times 700\end{array}$ \\
\hline & & $\mathrm{R}_{\mathrm{m}}(\mathrm{kN})$ & & 1082,76 & 1389,21 \\
\hline & & $\mathrm{e}_{\mathrm{m}}(\mathrm{m})$ & & $-0,15$ & $-0,22$ \\
\hline & & $\mathrm{R}_{\mathrm{i}} \quad(\mathrm{kN})$ & & 1126,56 & 1642,51 \\
\hline & & $e_{i} \quad(m)$ & & 0,19 & 0,21 \\
\hline & & $R_{v} \quad(k N)$ & & 212,19 & 428,25 \\
\hline & & $e_{v} \quad(m)$ & & 0,02 & $-0,11$ \\
\hline & & $\begin{array}{l}\mathrm{M}_{1 \mathrm{v}}(\mathrm{kN} \cdot \mathrm{m}) \\
\mathrm{T} \quad(\mathrm{kN})\end{array}$ & & $\begin{array}{c}357,12 \\
54,55\end{array}$ & $\begin{array}{l}542,29 \\
108,25\end{array}$ \\
\hline
\end{tabular}

Tabla 69. Resultantes tensiones terreno y esfuerzos en vigas centradora y superior. M.E.F. $\mathrm{H}=1,75 \cdot \mathrm{H}_{\|}$. Etapa III. $\sigma_{\text {adm. }}=200 \mathrm{kN} / \mathrm{m}^{2}$ y relación de forma $2: 1$ 


\section{DISTRIBUCIÓN TENSIONES M.E.F. $\mathrm{H}=1,75 \cdot \mathrm{H}_{\|}$ETAPA III $\sigma_{\text {adm }} 200 \mathrm{kN} / \mathrm{m}^{2} \quad$ FORMA $2: 1$}

\begin{tabular}{|c|c|c|c|c|}
\hline & & \multicolumn{3}{|c|}{ LUZ } \\
\hline & & $L=3 \mathrm{~m}$ & $\mathrm{~L}=5 \mathrm{~m}$ & $L=7 \mathrm{~m}$ \\
\hline \multirow{8}{*}{$\begin{array}{r}\dot{+} \\
\dot{m}\end{array}$} & $\begin{array}{l}\text { ZAPATA MED. } \\
\text { ZAPATA INT. } \\
\text { VIGA CENT. }\end{array}$ & $\begin{array}{c}1.700 \times 850 \times 500 \\
1.300 \times 1.300 \times 500 \\
1.650 \times 450 \times 500\end{array}$ & $\begin{array}{c}2.000 \times 1.000 \times 600 \\
1.700 \times 1.700 \times 600 \\
3.300 \times 450 \times 600\end{array}$ & $\begin{array}{c}2.300 \times 1.150 \times 700 \\
2.100 \times 2.100 \times 700 \\
4.950 \times 450 \times 700 \\
\end{array}$ \\
\hline & $a_{m}$ & 0,85 & 1,00 & 1,15 \\
\hline & $\mathrm{b}_{\mathrm{m}}$ & 1,70 & 2,00 & 2,30 \\
\hline & $a_{m} / 2+e_{m}(m)$ & 0,49 & 0,56 & 0,67 \\
\hline & c.d.g. $R_{m} \quad(\%)$ & 58 & 56 & 58 \\
\hline & $\sigma_{\max .} \quad\left(\mathrm{kN} / \mathrm{m}^{2}\right)$ & 243,21 & 220,41 & 233,53 \\
\hline & $\sigma_{\max .} / 1,25 \sigma_{\text {adm }}$. & 0,97 & 0,88 & 0,93 \\
\hline & DIAGRAMA $\sigma$ & TRAPECIAL & TRAPECIAL & TRAPECIAL \\
\hline \multirow{8}{*}{$\begin{array}{l}\mathbf{N} \\
+ \\
m\end{array}$} & $\begin{array}{l}\text { ZAPATA MED. } \\
\text { ZAPATA INT. } \\
\text { VIGA CENT. }\end{array}$ & $\begin{array}{c}2.200 \times 1.100 \times 500 \\
1.500 \times 1.500 \times 500 \\
1.300 \times 450 \times 500 \\
\end{array}$ & $\begin{array}{c}2.500 \times 1.250 \times 600 \\
2.100 \times 2.100 \times 600 \\
2.850 \times 450 \times 600 \\
\end{array}$ & $\begin{array}{c}2.900 \times 1.450 \times 700 \\
2.500 \times 2.500 \times 700 \\
4.475 \times 600 \times 700 \\
\end{array}$ \\
\hline & $a_{m}$ & 1,10 & 1,25 & 1,45 \\
\hline & $b_{m}$ & 2,20 & 2,50 & 2,90 \\
\hline & $a_{m} / 2+e_{m}(m)$ & 0,62 & 0,72 & 0,85 \\
\hline & c.d.g. $R_{m} \quad(\%)$ & 57 & 58 & 59 \\
\hline & $\sigma_{\max .} \quad\left(\mathrm{kN} / \mathrm{m}^{2}\right)$ & 245,62 & 268,57 & 263,74 \\
\hline & $\sigma_{\max .} / 1,25 \sigma_{\text {adm. }}$. & 0,98 & 1,07 & 1,05 \\
\hline & DIAGRAMA $\sigma$ & TRAPECIAL & TRAPECIAL & TRAPECIAL \\
\hline \multirow{8}{*}{$\begin{array}{l}m \\
+ \\
m\end{array}$} & $\begin{array}{l}\text { ZAPATA MED. } \\
\text { ZAPATA INT. } \\
\text { VIGA CENT. }\end{array}$ & $\begin{array}{c}2.600 \times 1.300 \times 500 \\
1.700 \times 1.700 \times 500 \\
1.000 \times 450 \times 500 \\
\end{array}$ & $\begin{array}{c}3.000 \times 1.500 \times 600 \\
2.300 \times 2.300 \times 600 \\
2.500 \times 600 \times 600 \\
\end{array}$ & $\begin{array}{c}3.400 \times 1.700 \times 700 \\
2.900 \times 2.900 \times 700 \\
4.025 \times 700 \times 700 \\
\end{array}$ \\
\hline & $a_{m}$ & 1,30 & 1,50 & 1,70 \\
\hline & $b_{m}$ & 2,60 & 3,00 & 3,40 \\
\hline & $a_{m} / 2+e_{m}(m)$ & 0,76 & 0,87 & 1,01 \\
\hline & c.d.g. $R_{m} \quad(\%)$ & 59 & 58 & 59 \\
\hline & $\sigma_{\max .} \quad\left(\mathrm{kN} / \mathrm{m}^{2}\right)$ & 280,30 & 271,02 & 291,63 \\
\hline & $\sigma_{\max .} / 1,25 \sigma_{\text {adm }}$. & 1,12 & 1,08 & 1,17 \\
\hline & DIAGRAMA $\sigma$ & TRAPECIAL & TRAPECIAL & TRAPECIAL \\
\hline \multirow{8}{*}{$\begin{array}{l}+ \\
\dot{m}\end{array}$} & $\begin{array}{l}\text { ZAPATA MED. } \\
\text { ZAPATA INT. } \\
\text { VIGA CENT. }\end{array}$ & & $\begin{array}{c}3.400 \times 1.700 \times 600 \\
2.500 \times 2.500 \times 600 \\
2.225 \times 700 \times 600 \\
\end{array}$ & $\begin{array}{c}3.900 \times 1.950 \times 700 \\
3.100 \times 3.100 \times 700 \\
3.700 \times 700 \times 700 \\
\end{array}$ \\
\hline & $(\mathrm{m})$ & & 1,70 & 1,95 \\
\hline & $\mathrm{b}_{\mathrm{m}}$ & & 3,40 & 3,90 \\
\hline & $\mathrm{a}_{\mathrm{m}} / 2+\mathrm{e}_{\mathrm{m}}(\mathrm{m})$ & & 1,00 & 1,19 \\
\hline & c.d.g. $R_{m} \quad(\%)$ & & 59 & 61 \\
\hline & $\sigma_{\max .} \quad\left(\mathrm{kN} / \mathrm{m}^{2}\right)$ & & 287,99 & 304,06 \\
\hline & $\sigma_{\max .} / 1,25 \sigma$ adm. & & 1,15 & 1,22 \\
\hline & DIAGRAMA $\sigma$ & & TRAPECIAL & TRAPECIAL \\
\hline
\end{tabular}

Tabla 70. Distribución de tensiones de contacto. M.E.F. $\mathrm{H}=1,75 \cdot \mathrm{H}_{\|}$. Etapa III. $\sigma_{\text {adm. }}=200 \mathrm{kN} / \mathrm{m}^{2}$ y relación de forma $2: 1$ 


\subsection{RESULTADOS EXPERIMENTALES. ETAPA IV}

\subsubsection{RESULTADOS DE LOS MODELOS CONVENCIONALES}

Se ofrecen en la Tabla 71 los resultados del cálculo del modelo convencional de zapata de esquina con dos vigas centradoras, para cada uno de los casos planteados en la Etapa IV. Los parámetros a los que hacen referencia dichos resultados son los representados en las Fig. 10, 11, 12 y 13.

Las tabla, correspondiente a una tensión admisible del terreno $\sigma_{\mathrm{adm}}=200 \mathrm{kN} / \mathrm{m}^{2}$ y una relación de forma $2: 1$ en las zapatas de medianería auxiliares, ofrece para los distintos casos, en función de la luz y el número de plantas, los siguientes resultados:

- Dimensionamiento necesario para la zapata de esquina, zapatas de medianería auxiliares y vigas centradoras, de acuerdo con el modelo convencional.

- Resultante de las presiones de contacto en la zapata de esquina $R_{e}(k N)$.

- Tensión transmitida al terreno por la zapata de esquina $\sigma_{\mathrm{e}}\left(\mathrm{kN} / \mathrm{m}^{2}\right)$, calculada bajo la hipótesis de distribución de tensiones uniformemente repartida.

- Resultante de las tensiones de contacto bajo las zapatas de mediantería auxiliares $R_{m 1} y_{m 2}(k N)$.

- Tensión transmitida al terreno por las zapatas de medianería $\sigma_{\mathrm{m} 1}$ y $\sigma_{\mathrm{m} 2}\left(\mathrm{kN} / \mathrm{m}^{2}\right)$, calculada bajo la hipótesis de distribución de presiones uniformemente repartida.

- Momentos flectores de servicio $\mathrm{M}_{1 \mathrm{c} 1}$ y $\mathrm{M}_{1 \mathrm{c} 2}$ en la sección más desfavorable de las dos vigas centradoras (unión de la viga centradora con la zapata de esquina).

Al considerar el modelo convencional de zapata con viga centradora, distribuciones de tensiones sobre el terreno uniformemente repartidas, las resultantes en cuestión se encuentran aplicadas en el centro de las respectivas zapatas. Por ese motivo, no se hace aquí referencia a ninguna excentricidad respecto del centro de las zapatas, ya que sería en todos los casos nula. 


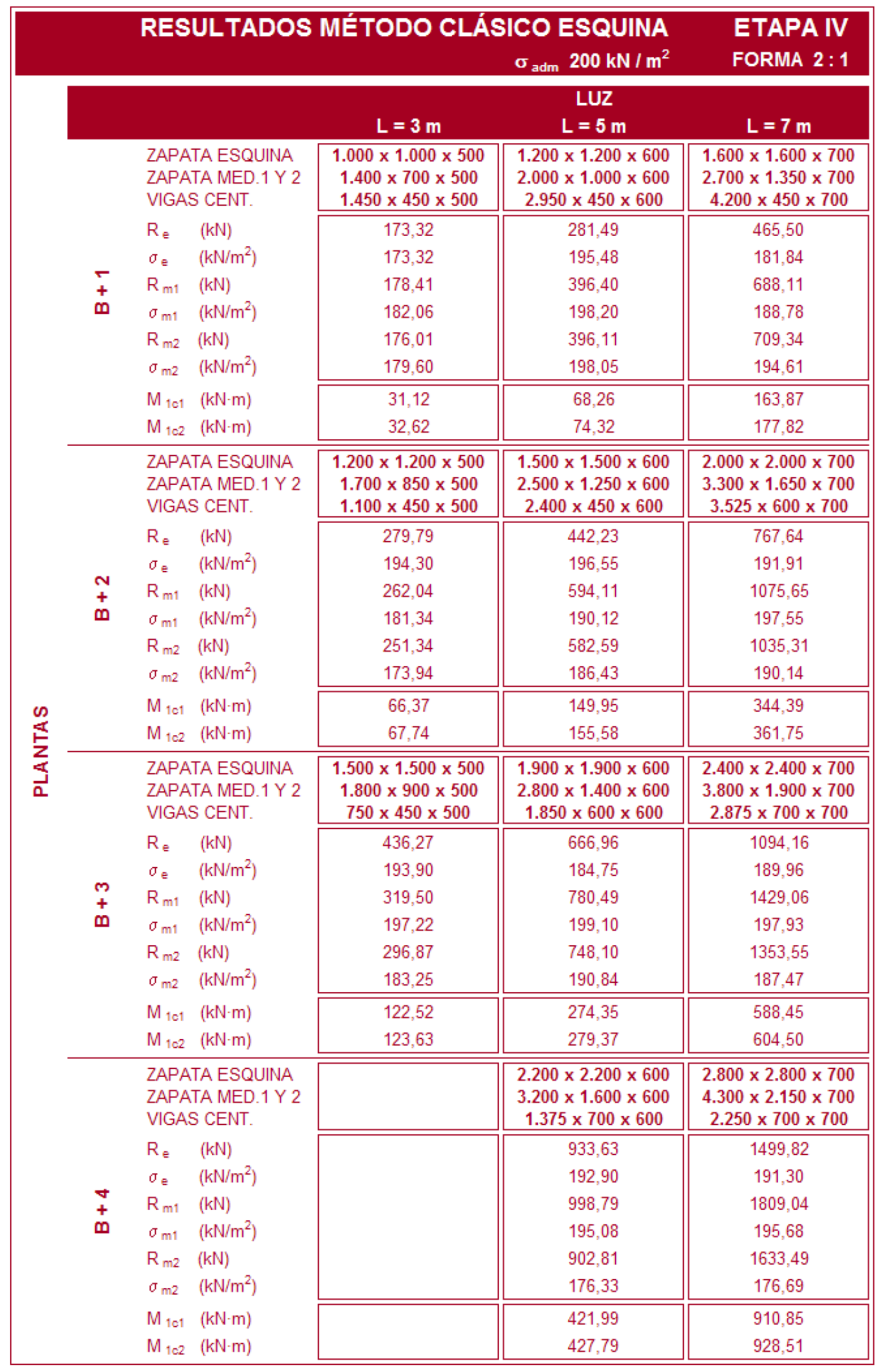

Tabla 71. Zapata de esquina con vigas centradoras. Modelo convencional. Etapa IV Resultados para $\sigma_{\text {adm. }}=200 \mathrm{kN} / \mathrm{m}^{2}$ y relación de forma $2: 1$ 


\subsubsection{RESULTADOS DE LOS MODELOS DE ELEMENTOS FINITOS}

Los resultados de los modelos de elementos finitos de la Etapa IV se exponen en dos grupos de tablas, de acuerdo con los siguientes criterios:

- Resultantes y excentricidades absolutas de tensiones de contacto con el terreno y esfuerzos en las vigas centradoras (Tablas $72,73,75$ y 76 )

- Excentricidades relativas de tensiones de contacto con el terreno, tipo de diagrama de distribución de tensiones y tensiones máximas (Tablas 74 y 77)

El primer grupo de tablas (Tablas $72,73,75$ y 76) muestra las dimensiones de las zapatas utilizadas en el modelo (tanto la de esquina como las auxiliares de medianería), las resultantes de las tensiones de contacto con el terreno (resultante de tensiones de la zapata de esquina $\left(R_{e}\right)$, resultante de las zapata de medianería auxiliares $\left(R_{m 1}\right.$ y $\left.R_{m 1}\right)$ y resultante de la vigas centradoras $\left(R_{c 1}\right.$ y $\left.R_{c 2}\right)$ ), así como las localizaciones de dichas resultantes mediante la excentricidad absoluta de su punto de aplicación respecto del punto medio de la zapata o la viga en cuestión (excentricidades de la resultante de esquina ( $e_{\text {ex }}$ y e ey), excentricidades de las resultantes de las zapatas de medianería (e m1y y e m2x) y excentricidades de la resultante de las vigas centradoras $\left(e_{c 1 y} y e_{c 2 x}\right)$ ). Por último, en este primer grupo de tablas de modelos de elementos finitos, se muestran los momentos flectores de servicio de las vigas centradoras $\left(M_{1 \mathrm{c} 1}\right.$ y $\left.M_{1 \mathrm{c} 2}\right)$.

Por su parte, las Tablas 74 y 77 muestran las posiciones relativas de las resultantes de tensiones de contacto de las zapatas de esquine $R_{e}$ para los distintos casos estudiados, junto con la tensión máxima $(\sigma \max )$ generada en el diagrama de tensiones equivalente, acompañada del resultado de la comprobación de tensiones de contacto o verificación del E.L.U. de hundimiento.

Las tablas están ordenadas según el nivel de rigidez de la viga centradora en función del canto de la misma, variando en función de las luces y número de plantas del pórtico, para unos valores fijos $\sigma_{\text {adm. }}=200 \mathrm{kN} / \mathrm{m}^{2}$ y relación de forma $2: 1$ en las zapatas de medianería auxiliares. 


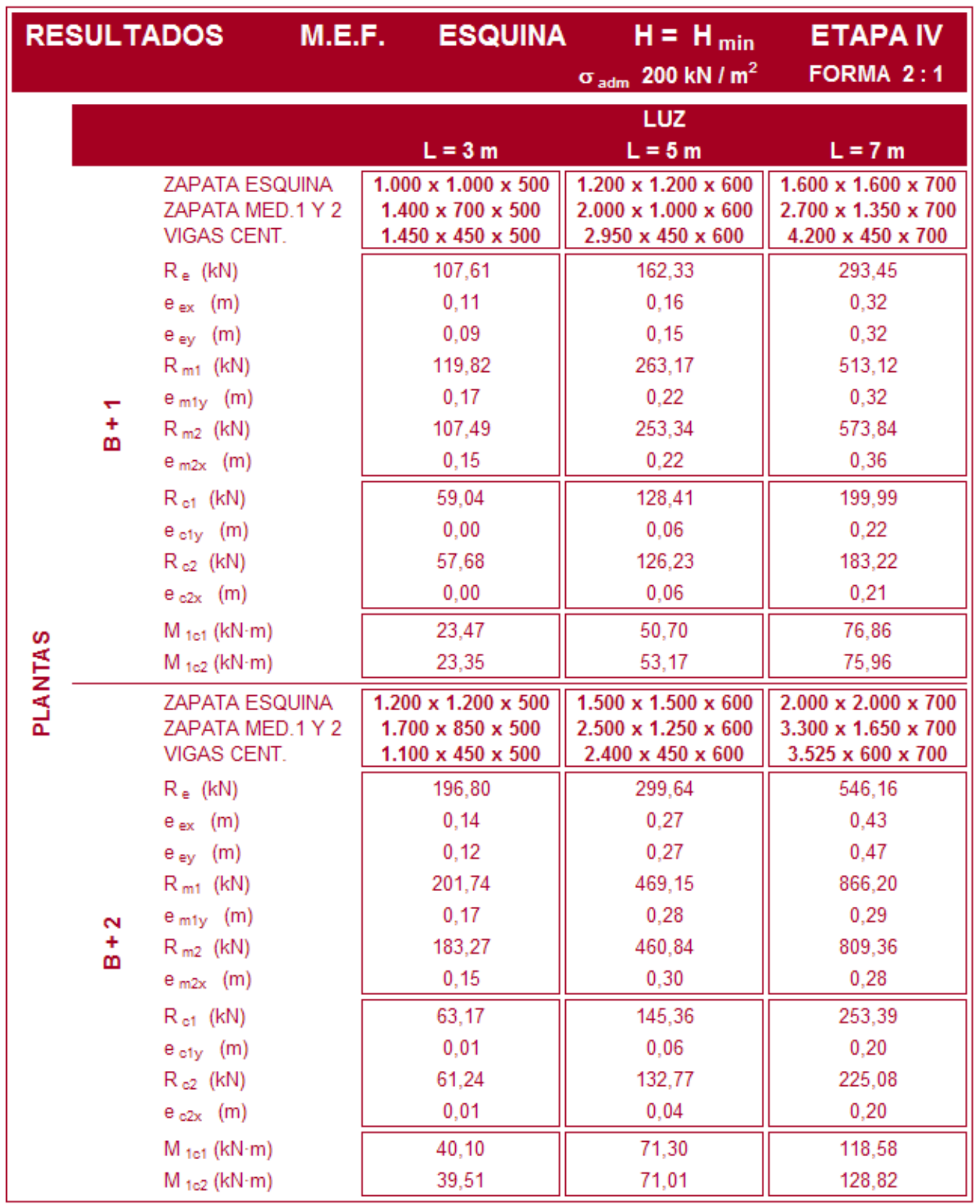

Tabla 72. Resultantes tensiones terreno y esfuerzos en vigas centradoras. Zapata de esquina M.E.F. $\quad H=H_{\min }(\mathrm{I})$. Etapa IV. $\sigma_{\text {adm. }}=200 \mathrm{kN} / \mathrm{m}^{2}$ y relación de forma $2: 1$ 


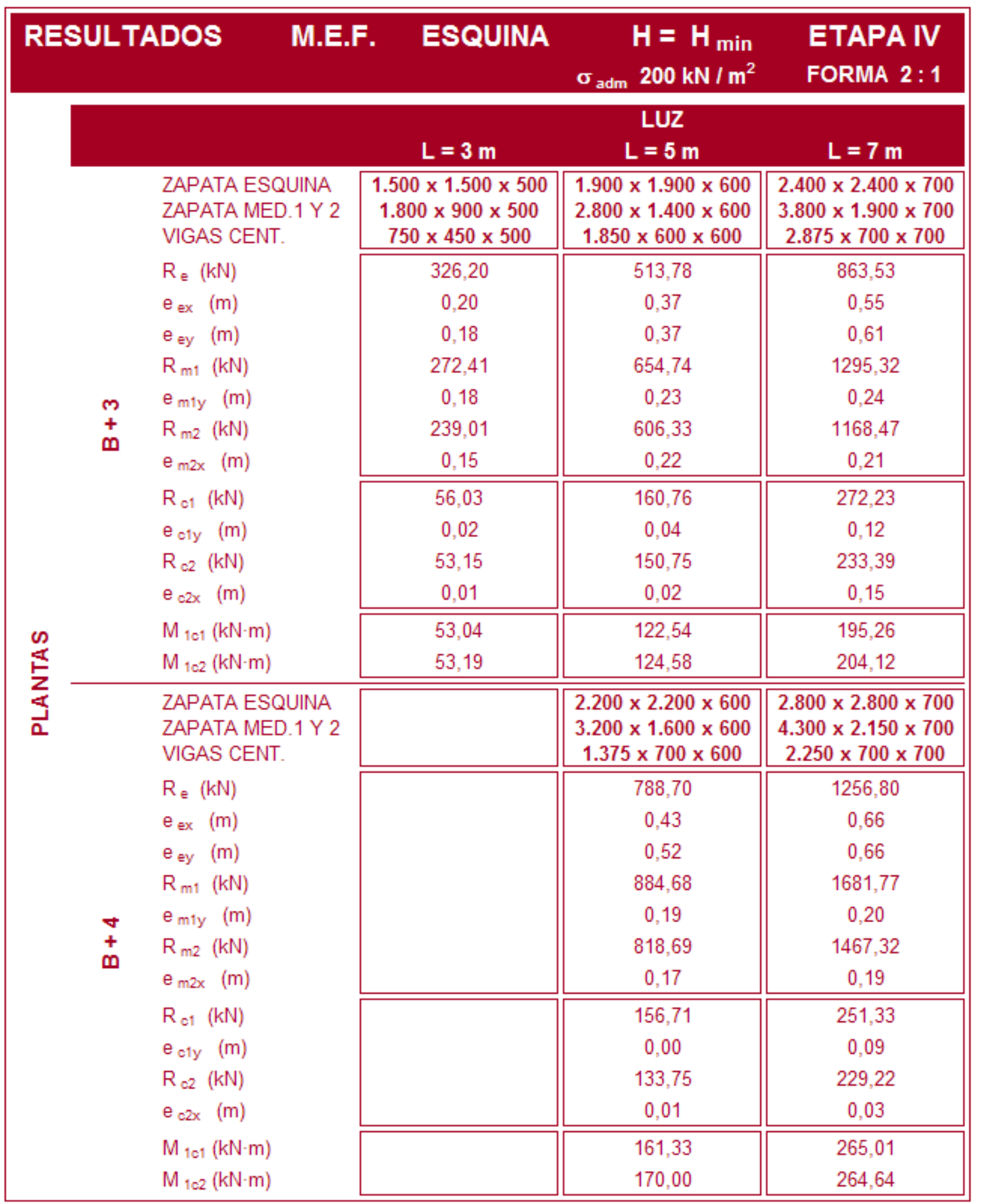

Tabla 73. Resultantes tensiones terreno y esfuerzos en vigas centradoras. Zapata de esquina M.E.F. $\quad H=H_{\min }$ (II). Etapa IV. $\sigma_{\text {adm. }}=200 \mathrm{kN} / \mathrm{m}^{2}$ y relación de forma $2: 1$ 


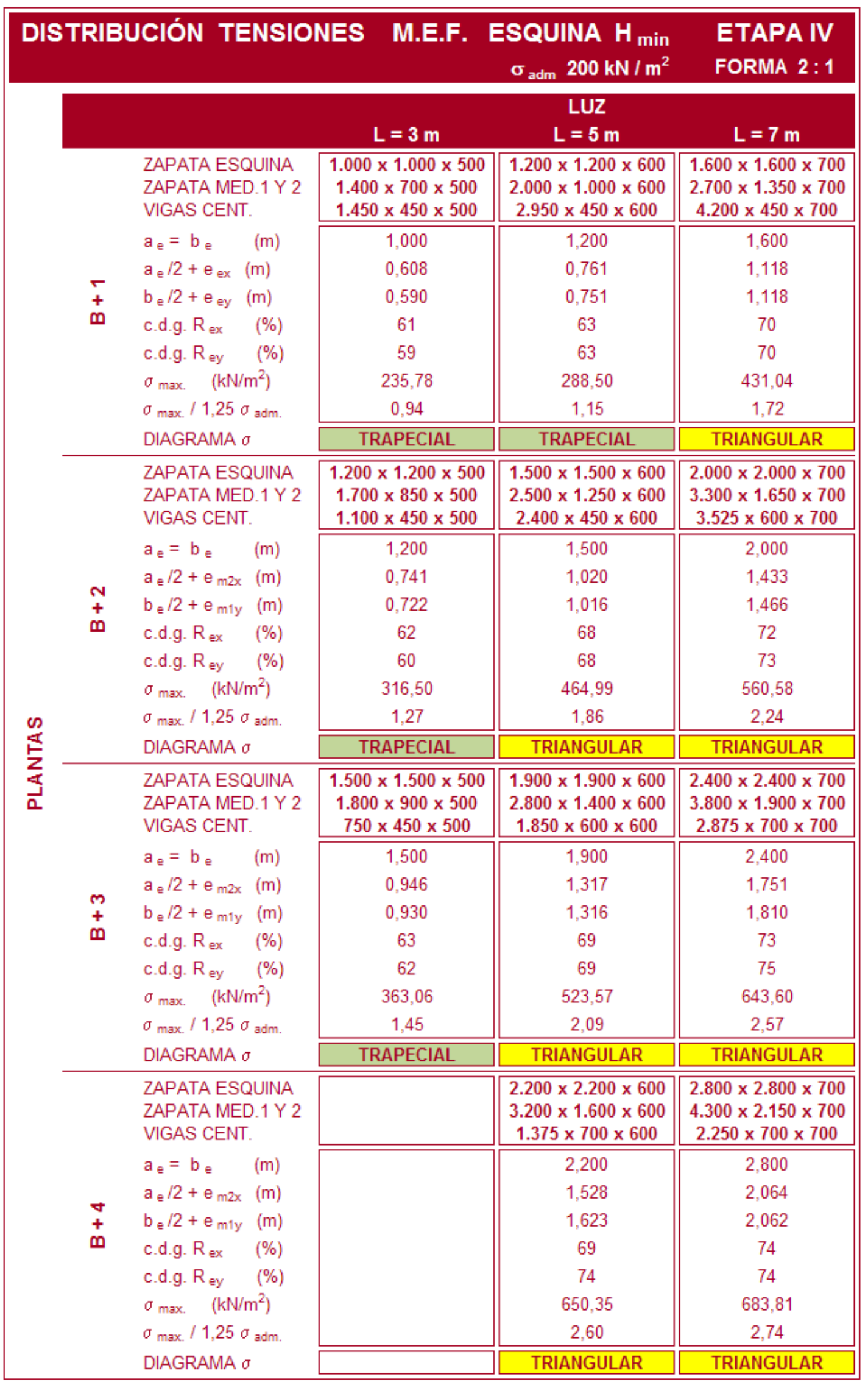

Tabla 74. Distribución de tensiones de contacto. Zapata de esquina. M.E.F.

$$
\mathrm{H}=\mathrm{H}_{\text {min }} \text {. Etapa IV. } \sigma_{\text {adm. }}=200 \mathrm{kN} / \mathrm{m}^{2} \text { y relación de forma } 2: 1
$$




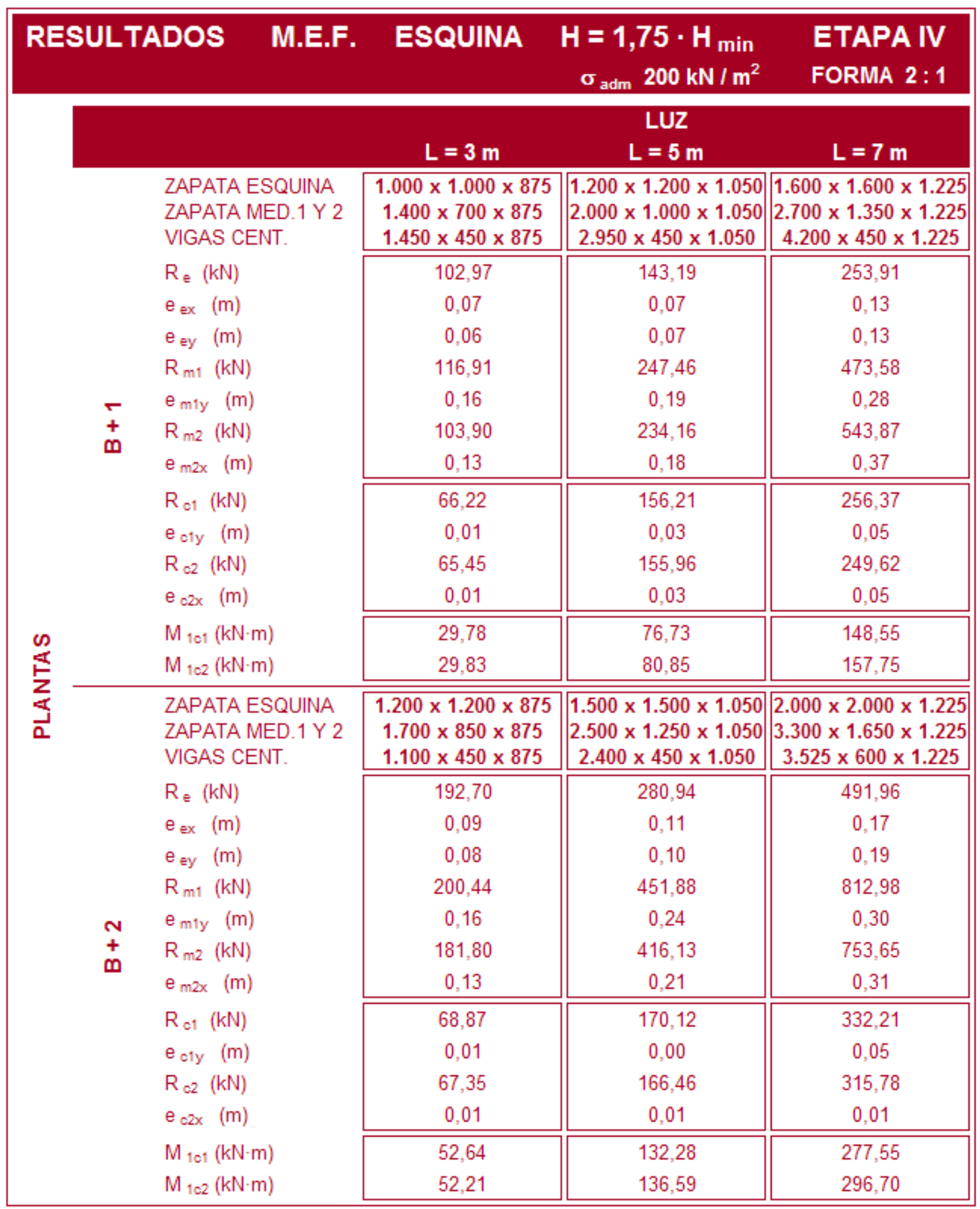

Tabla 75. Resultantes tensiones terreno y esfuerzos en vigas centradoras. Zapata de esquina M.E.F. $H=1,75 \cdot H_{\min }(\mathrm{I})$. Etapa IV. $\sigma_{\text {adm. }}=200 \mathrm{kN} / \mathrm{m}^{2}$ y relación de forma $2: 1$ 


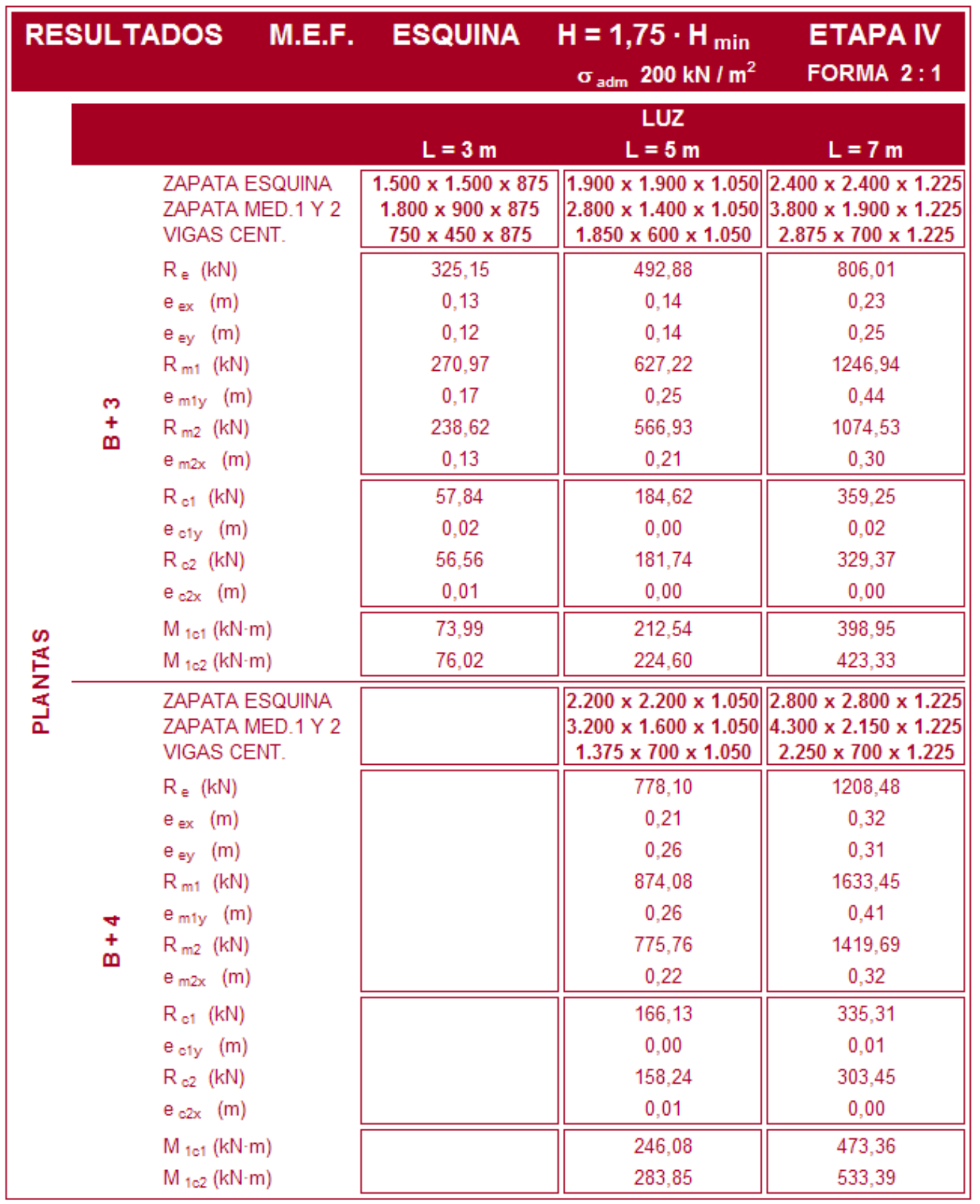

Tabla 76. Resultantes tensiones terreno y esfuerzos en vigas centradoras. Zapata de esquina M.E.F. $\mathrm{H}=1,75 \cdot \mathrm{H}_{\min }$. (II). Etapa IV. $\sigma_{\text {adm. }}=200 \mathrm{kN} / \mathrm{m}^{2}$ y relación de forma $2: 1$ 


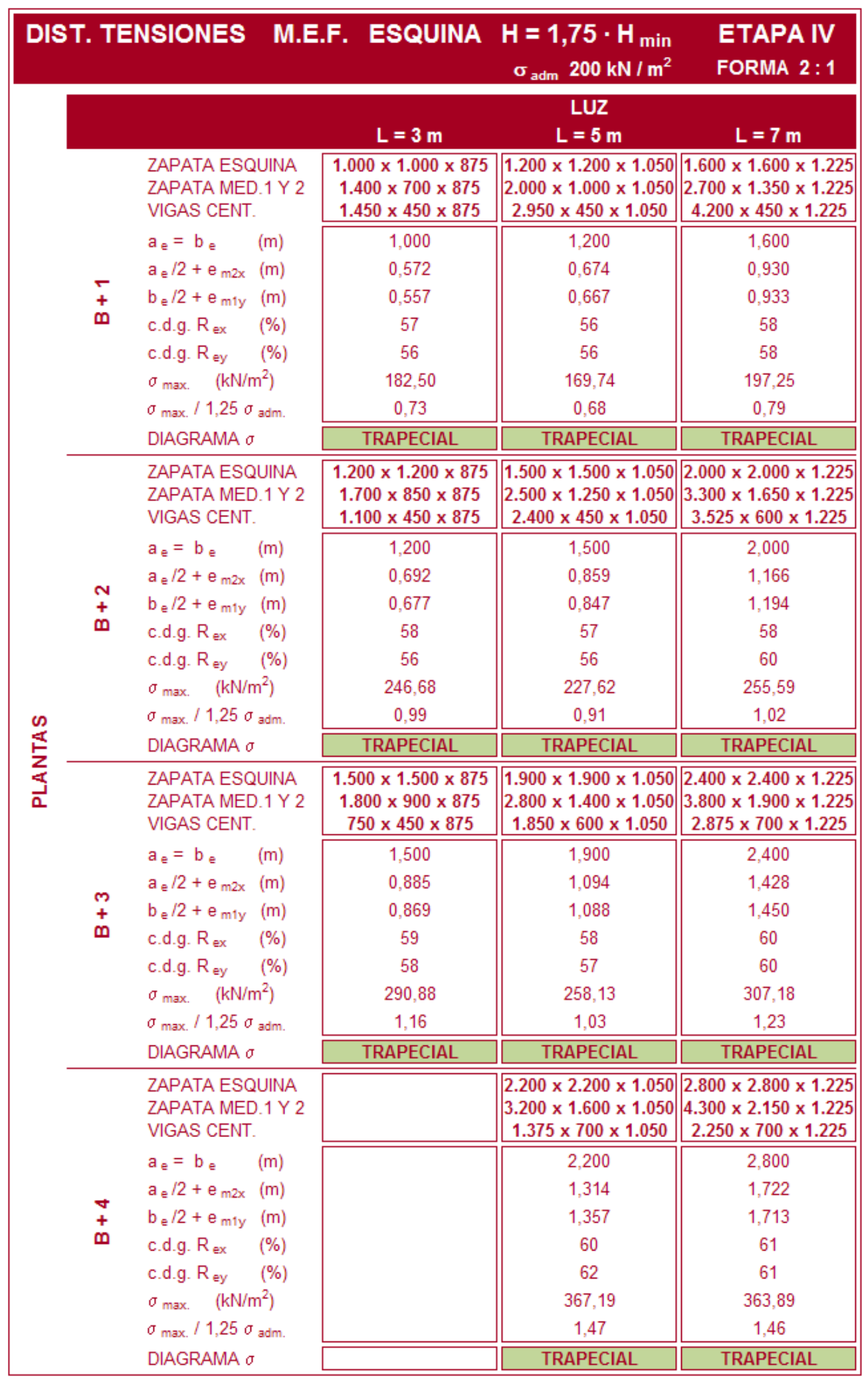

Tabla 77. Distribución de tensiones de contacto. Zapata de esquina. M.E.F.

$\mathrm{H}=1,75 \cdot \mathrm{H}_{\min }$. Etapa IV. $\sigma_{\mathrm{adm}}=200 \mathrm{kN} / \mathrm{m}^{2}$ y relación de forma $2: 1$ 

CAPÍTULO 5

ANÁLISIS Y DISCUSIÓN DE RESULTADOS 



\section{ANÁLISIS Y DISCUSIÓN DE RESULTADOS}

\subsection{ANÁLISIS Y DISCUSIÓN DE RESULTADOS. ETAPA I}

\subsubsection{ESFUERZOS EN LA VIGA CENTRADORA}

\section{MOMENTO FLECTOR}

Uno de los aspectos más llamativo de las cimentaciones de medianería con viga centradora es la considerable escuadría de la viga centradora y la importante cuantía de armado que resulta en su cara traccionada, como consecuencia del importante trabajo a flexión que realiza la misma, con un elevado momento flector en la sección de contacto de la viga con la zapata de medianería.

No obstante, si bien es cierto que el trabajo a flexión de la viga centradora es innegable, resulta sorprendente el contraste entre los valores del momento flector de la viga centradora obtenidos según el modelo convencional y según el modelo de elementos finitos.

En las Fig. 65, 66 y 67 se ofrece la comparación entre el valor del momento flector obtenido por métodos convencionales (CLÁSICO) y por el método de elementos finitos (M.E.F.). La Fig. 65 muestra la influencia del nivel de rigidez del pórtico para una relación de forma 1:1 y una tensión admisible del terreno de $100 \mathrm{kN} / \mathrm{m}^{2}$. Dicha figura pone claramente de manifiesto que los momentos obtenidos por el método convencional son del orden del doble de los obtenidos por elementos finitos, no pareciendo tener mucha influencia el nivel de rigidez del pórtico en la magnitud de la comparación

\section{$1: 1 \quad 100$}

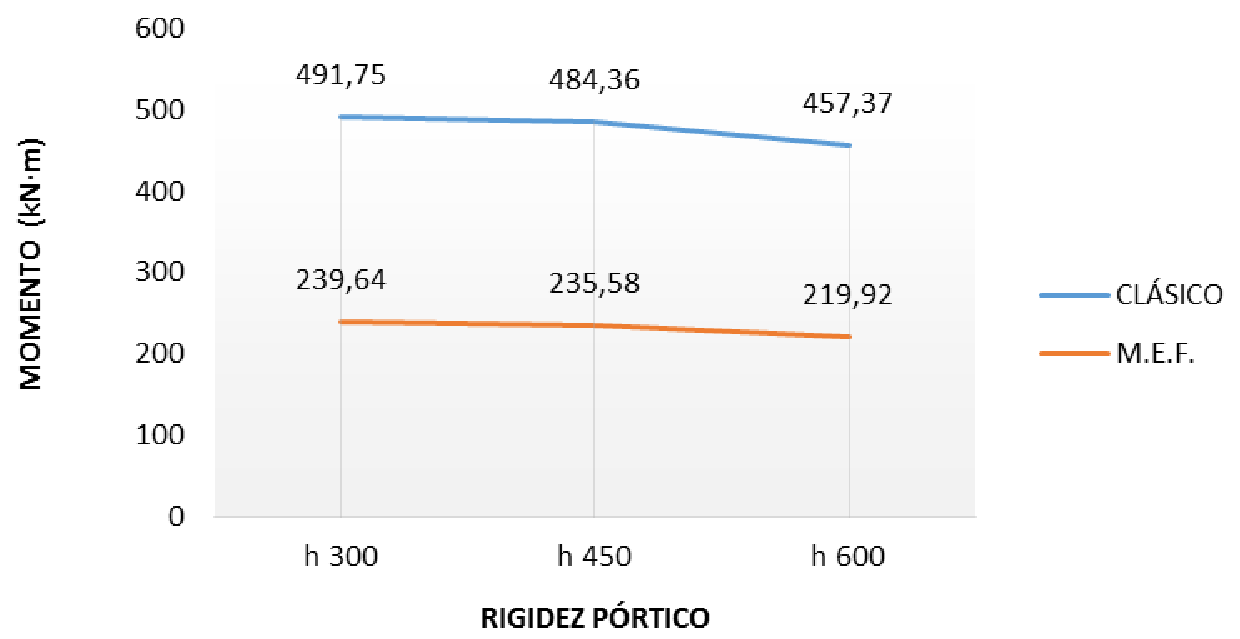

Fig.65. Contraste del valor del momento flector en la viga centradora en función de la rigidez del pórtico 
Por su parte, en la Fig. 66, se comparan los momentos flectores en función de la tensión admisible del terreno, para las distintas relaciones de forma consideradas. Dado que ha quedado vista la poca influencia de la rigidez del pórtico, se muestran solamente los del tipo de rigidez $\mathrm{h}$ 300. Los tres gráficos de la Fig.66, muestran que cuanto menor es la tensión admisible del terreno mayor es la diferencia entre los dos métodos, llegando como tope a ser el doble en el caso de suelos con una tensión admisible de $100 \mathrm{kN} / \mathrm{m}^{2}$.

h $300 \quad 2: 1$

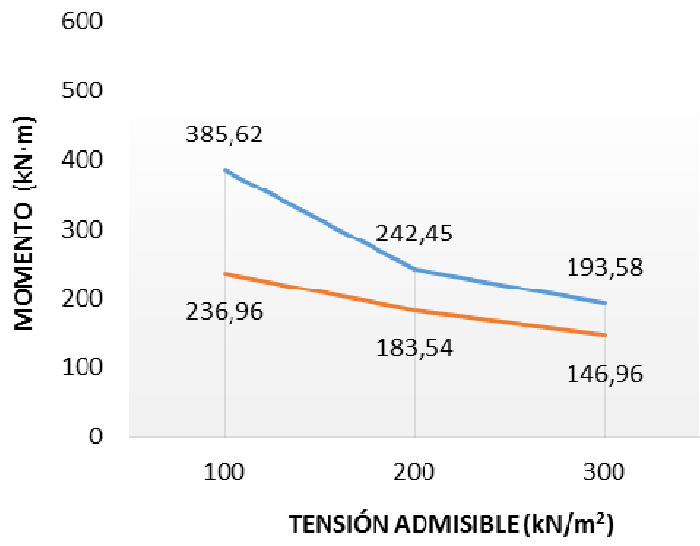

h 300

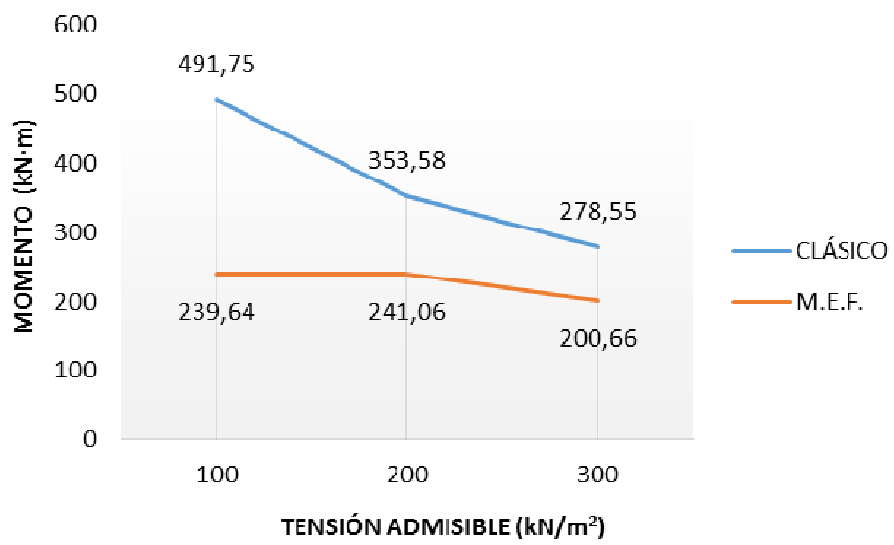

h $300 \quad 1,5: 1$

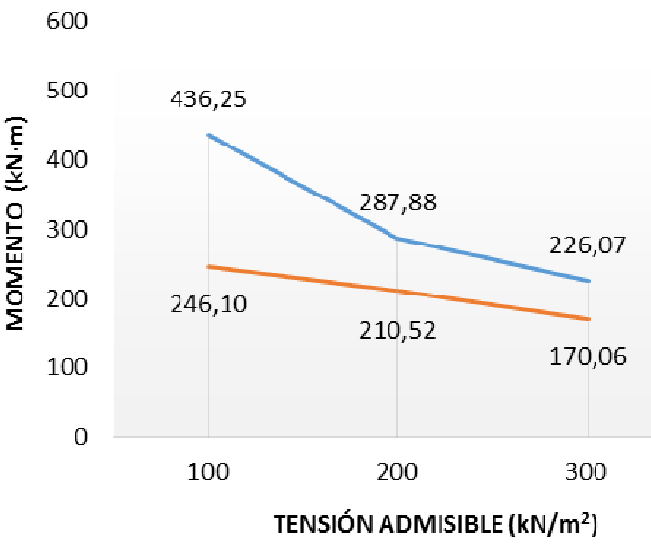

Fig.66. Contraste del valor del momento flector en la viga centradora en función de la tensión admisible del terreno

Finalmente, la Fig.67 presenta la evolución de la diferencia en el momento flector a medida que varía la relación de forma de la zapata de medianería, para las distintas tensiones admisibles del terreno consideradas, siendo mayor dicha diferencia a medida que se utilizan zapatas de medianería cada vez más cuadradas. 
h 300100

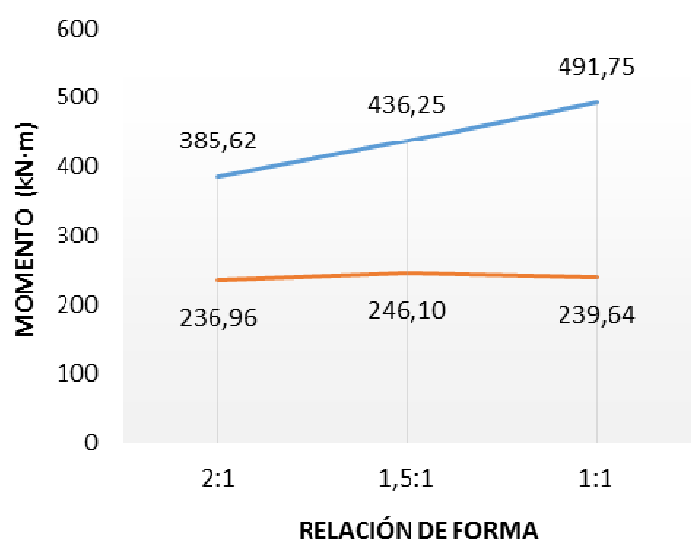

h $300 \quad 300$

400

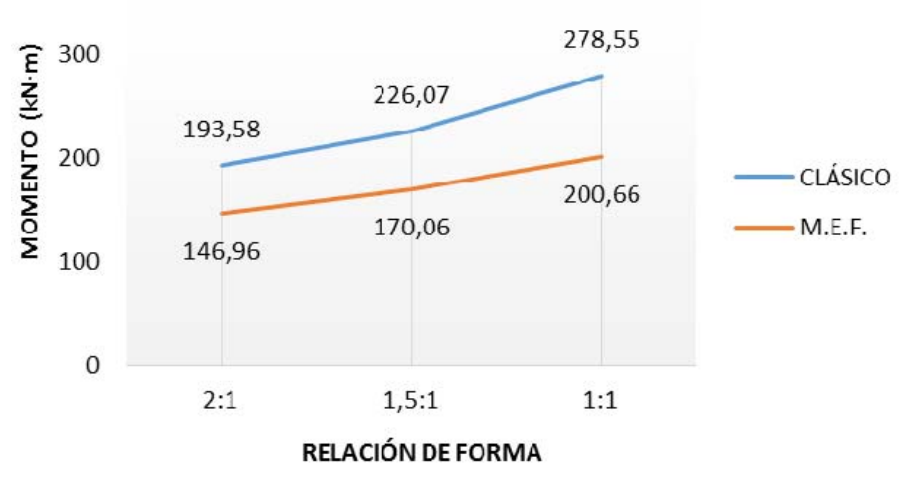

h 300200

500

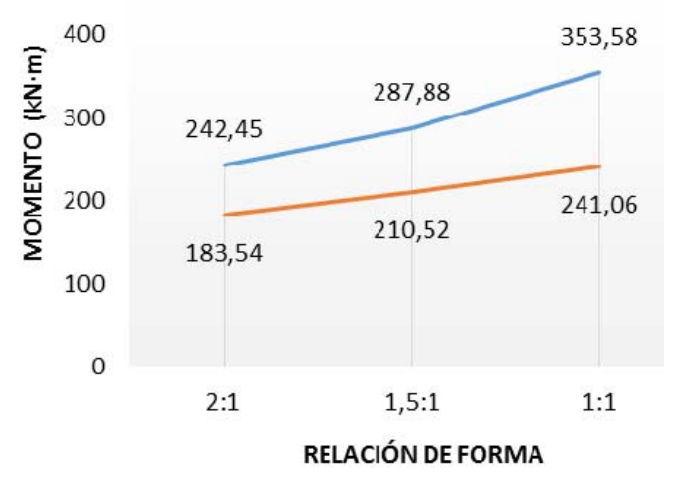

Fig.67. Contraste del valor del momento flector en la viga centradora en función de la relación de forma

Resulta interesante señalar que en las Fig. 66 y 67 se aprecia otra cuestión y es que, mientras en el modelo convencional el momento flector crece continuamente a medida que disminuye la tensión admisible o se hace más cuadrada la zapata de medianería, en el modelo de elementos finitos el momento crece ligeramente al inicio de dicha tendencia pero finalmente tiende a estabilizarse o incluso experimenta un pequeño descenso.

De las tres variables analizadas, son las dos últimas las que tienen una clara incidencia en la diferencia en el resultado del momento flector, mientras que la primera (la variación de la rigidez del pórtico) no parece influir.

La escasa influencia de la rigidez del pórtico resulta sorprendente respecto de las intuiciones iniciales, que puede encontrar su explicación en el siguiente razonamiento (Fig.68). La 
hipótesis del modelo convencional de distribución de tensiones uniformemente repartida, con resultante centrada, no es cierta. Ambas zapatas, debido al trabajo a flexión de la viga centradora, experimentan giros que invalidan la hipótesis de pilares perfectamente empotrados y suponen empotramientos flexibles de las bases de los pilares.

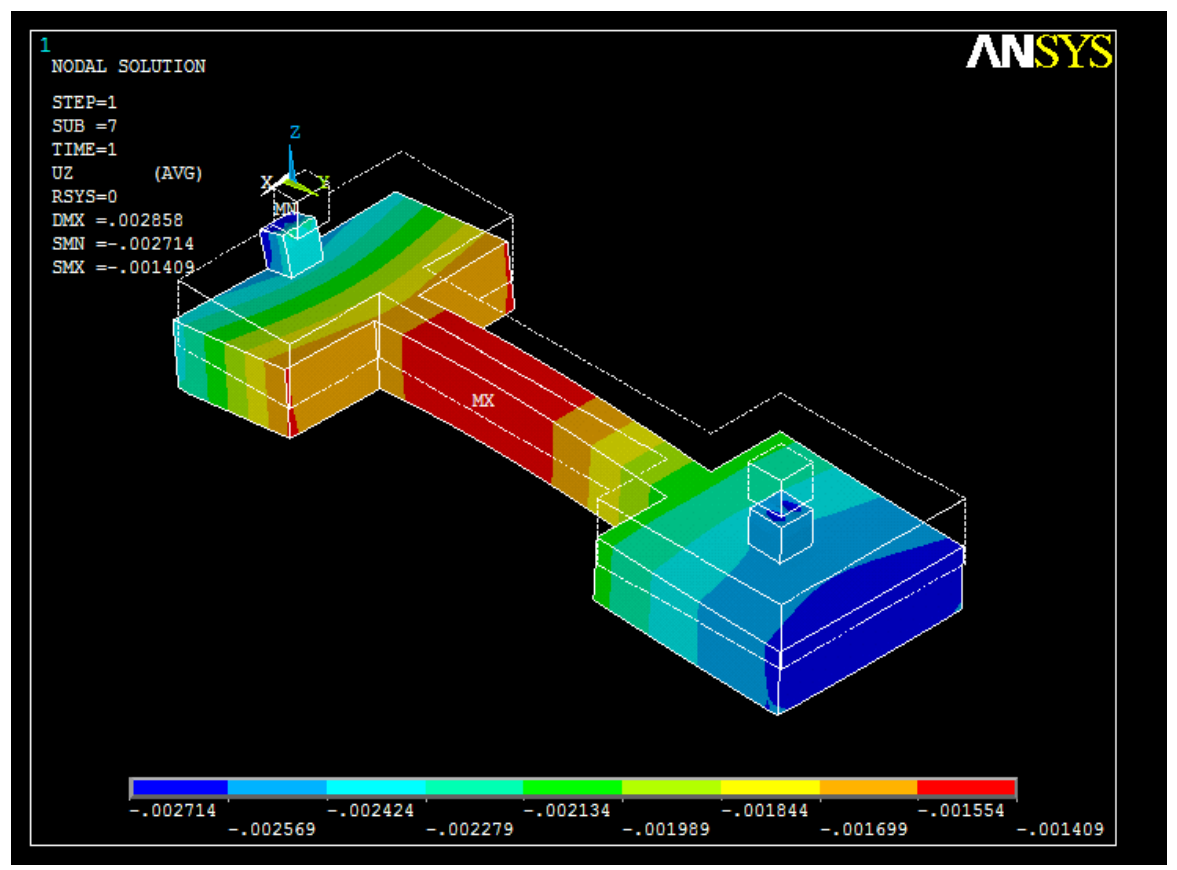

Fig.68. Giro de la cimentación según el modelo de elementos finitos

Caben a partir de aquí tres posibles lecturas. La primera es que por muy rígido que sea el pórtico, poca influencia puede tener al respecto, si su vinculación con la cimentación se "flexibiliza". La segunda es que, aunque se hayan considerado tres niveles de rigidez, la eficacia de cualquiera de ellos ha sido muy limitada por ser todos del mismo orden de magnitud y, habría que hablar de pilares mucho más apantallados o incluso pantallas (propias de estructuras sometidas a importantes esfuerzos horizontales) para lograr un resultado realmente eficaz en el control de la deformación de la viga centradora. Y la tercera es que, en el estudio se ha contemplado únicamente la rigidez del pórtico, manteniendo constante el canto de la cimentación. Dado que la flexión de la viga centradora y los giros que induce en las zapatas están en el centro del debate, a la vista de los resultados surge un nuevo camino de búsqueda, que es el estudio de la influencia de la rigidez de la propia cimentación, analizando el comportamiento de ésta con diferentes cantos. 


\section{EXCENTRICIDAD DE LAS RESULTANTES DE TENSIONES DE CONTACTO}

La explicación de la gran diferencia entre el valor del momento flector de la viga centradora obtenido por métodos convencionales o por elementos finitos (diferencia que puede llegar a tener valor doble), se encuentra en el mecanismo que regula la flexión de la propia viga centradora. Dicho mecanismo queda claramente reflejado en el esquema del modelo convencional representado en la Fig. 69.
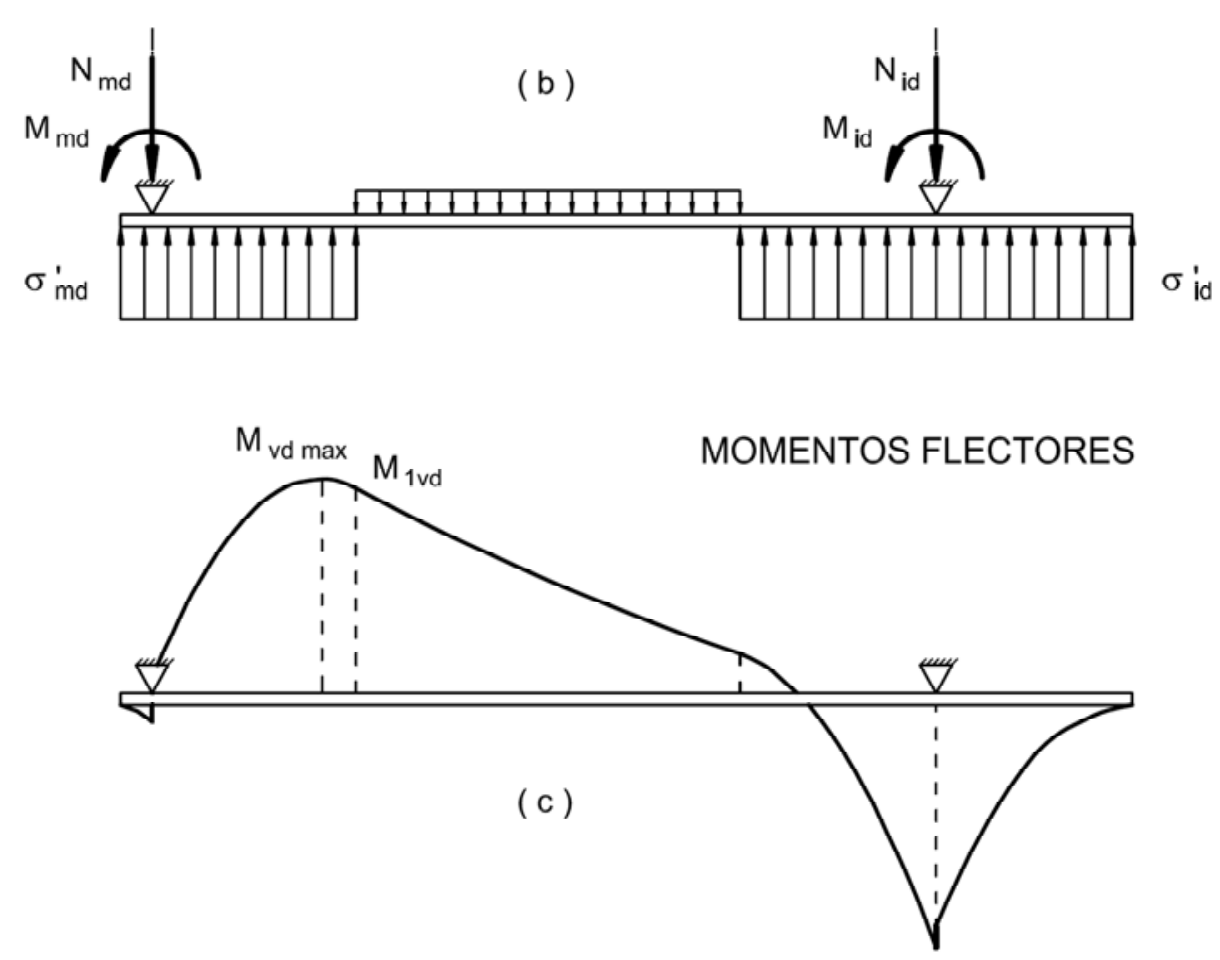

Fig.69. Modelo convencional de zapata de medianería con viga centradora

El modelo convencional considera el conjunto de la cimentación (zapatas más viga centradora) como un único elemento lineal, apoyado en los pilares, que recibe como carga las tensiones de contacto entre las zapatas y el terreno. Debido al desplazamiento del centro de la zapata de medianería respecto del eje del pilar, la resultante de dichas tensiones de contacto en la zapata de medianería se sitúa entre ambos apoyos, generando un momento flector cuyo valor aumenta cuanto mayor sea la magnitud de la resultante y más hacia el centro del vano se sitúe la citada resultante.

El modelo convencional plantea un diagrama de distribución de tensiones de contacto uniformemente repartido, con resultante aplicada en el centro de la cara inferior de la zapata de medianería. Dicho diagrama presupone la ausencia de giros en las zapatas y la hipótesis 
de pilares perfectamente empotrados. Los resultados del modelo de elementos finitos, en la Etapa I, reflejados en las Tablas 17, 18 y 19, confirman la idea del giro de las zapatas inducido por la flexión de la viga centradora. Dicho giro hace que las resultantes de tensiones de contacto en el modelo de elementos finitos no se apliquen en el centro de la cara inferior de la zapata de medianería, sino que presenten una excentricidad respecto de dicho centro de la zapata que las aleja del centro del vano y las aproxima al eje del pilar (apoyo del elemento lineal virtual del modelo convencional).

En los gráficos de las Fig. 70, 71 y 72 se representa la evolución de la excentricidad de las resultantes de tensiones en la zapata de medianería respecto del centro de la cara inferior de la zapata, así como la variación del valor de las citadas resultantes.

$1: 1 \quad 100$

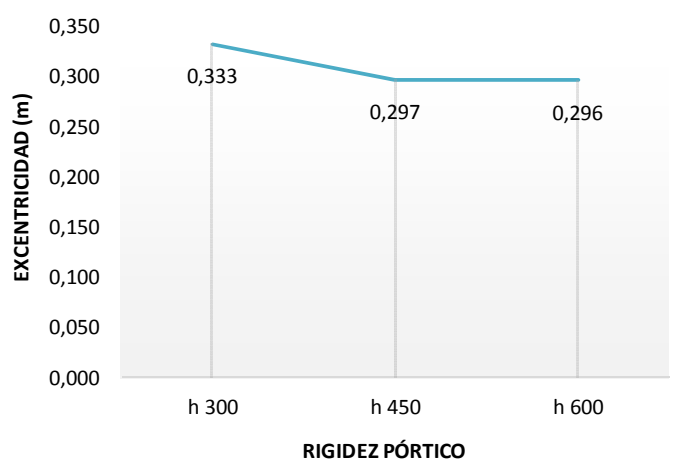

$1: 1 \quad 100$

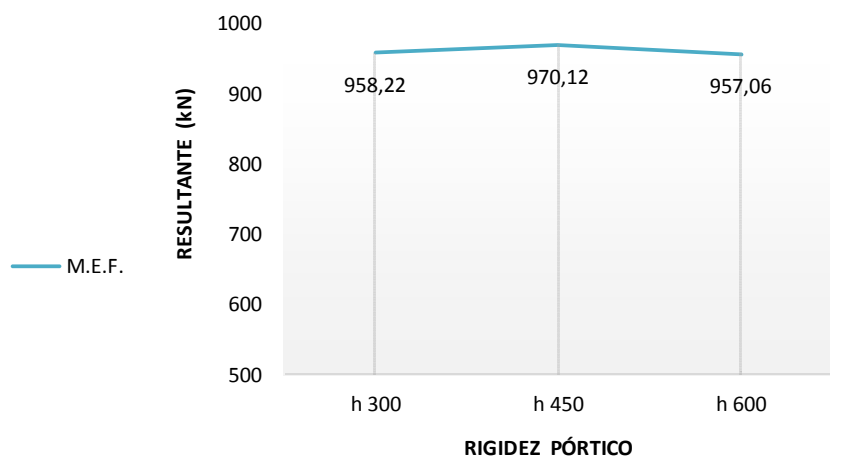

Fig.70. Variación de la excentricidad y valor de la resultante de la zapata de medianería en función del nivel de rigidez del pórtico

Los gráficos de la Fig.70 confirman, de nuevo, la no influencia de la rigidez del pórtico en el comportamiento de la cimentación al no apreciarse variaciones en el valor de la resultante y ser muy reducida la variación en la excentricidad al cambiar el nivel de rigidez del pórtico.

En cambio, los gráficos de las Fig.71 y 72 evidencian la influencia de las otras dos variables, ya que, a medida que disminuye la tensión admisible del terreno o la zapata de medianería se hace más cuadrada, aumentan el valor de la resultante y la excentricidad de la misma respecto del centro de la zapata de medianería. 
h $300 \quad 2: 1$

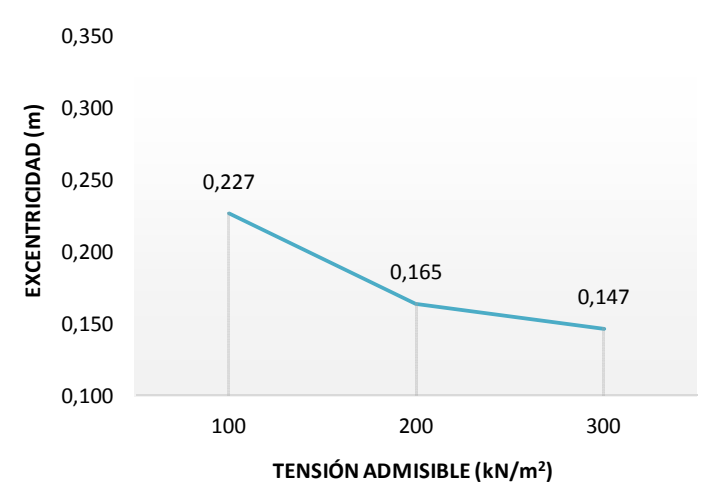

h $300 \quad 1,5: 1$

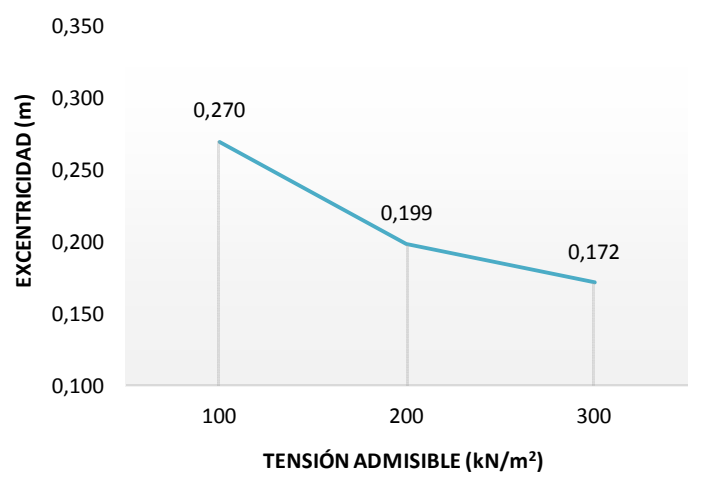

h $300 \quad 1: 1$

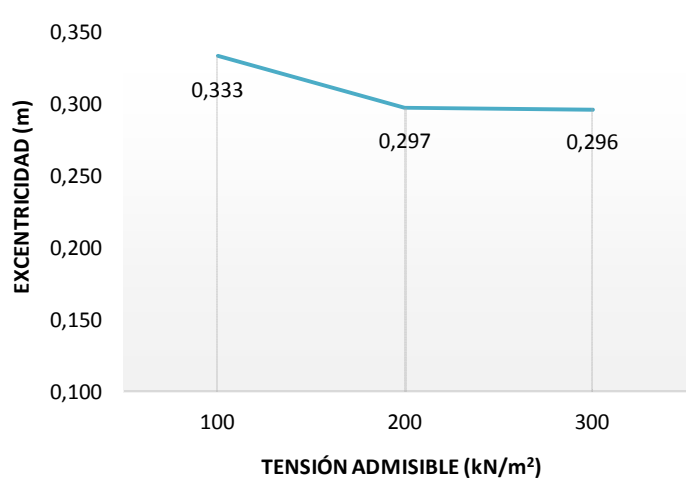

h $300 \quad 2: 1$

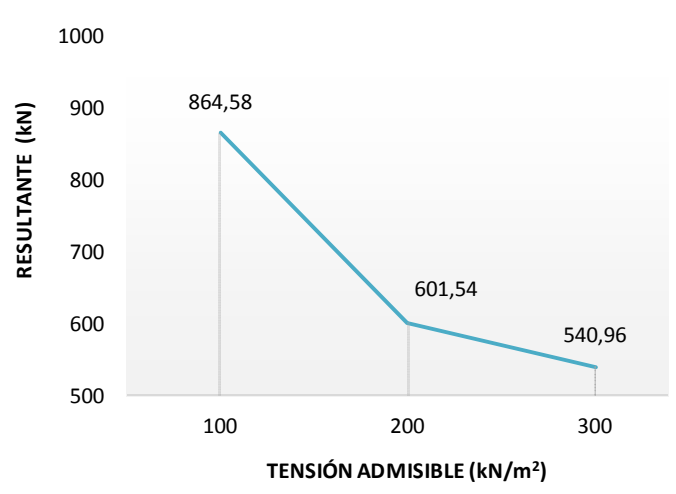

h $300 \quad 1,5: 1$

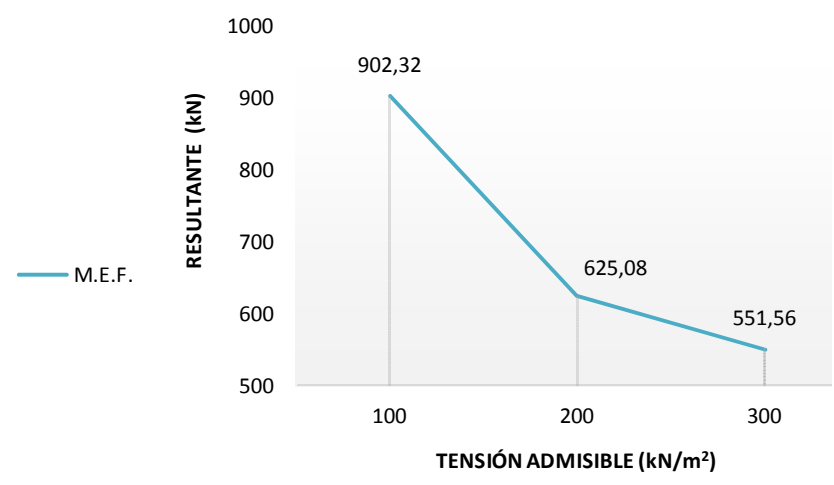

h $300 \quad 1: 1$

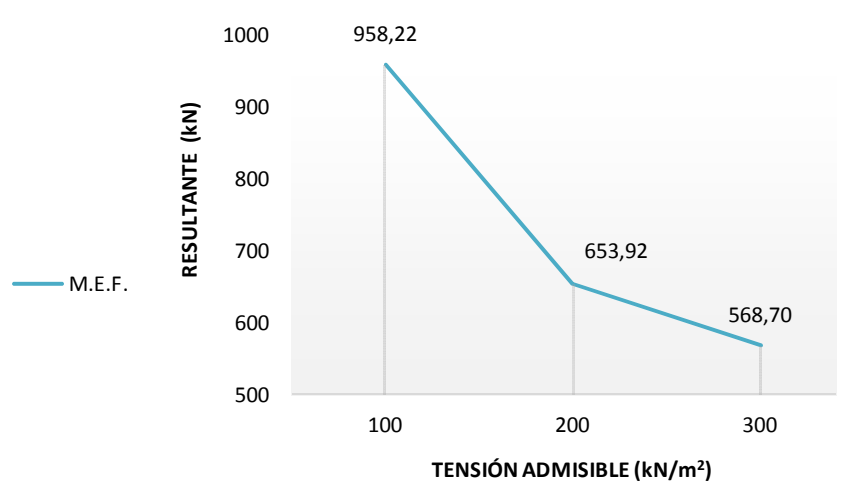

Fig.71. Variación de la excentricidad y valor de la resultante de la zapata de medianería en función de la tensión admisible del terreno 

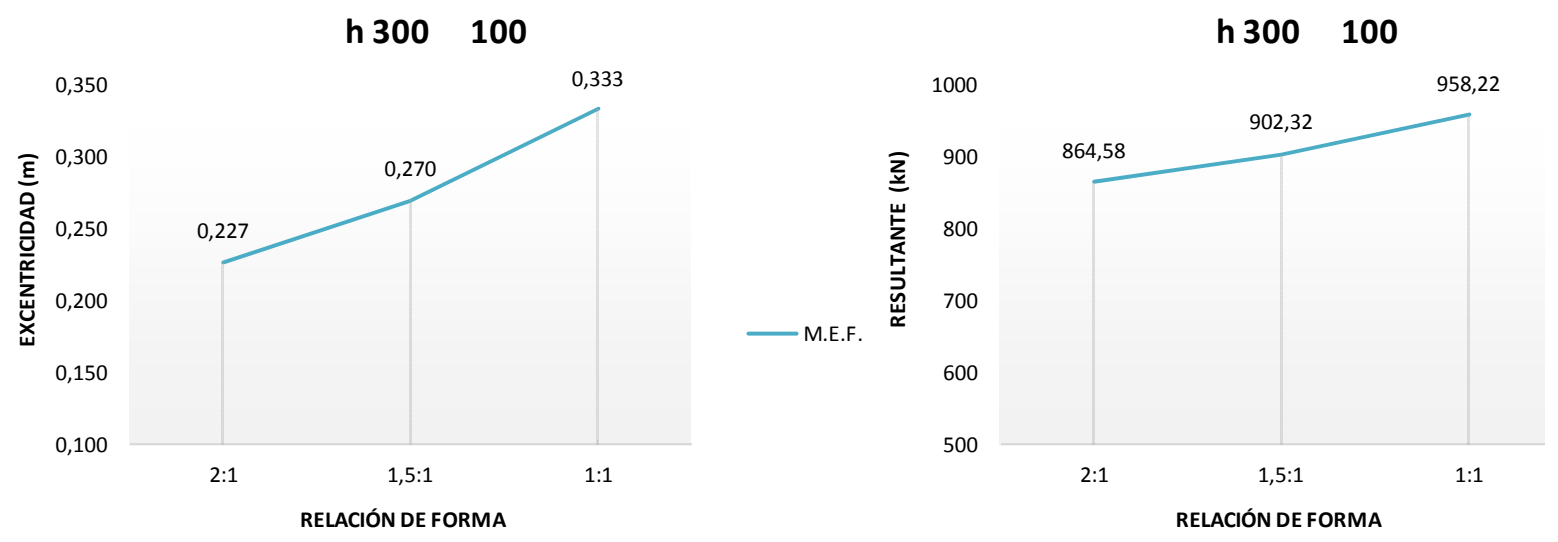

h 300200

h 300200
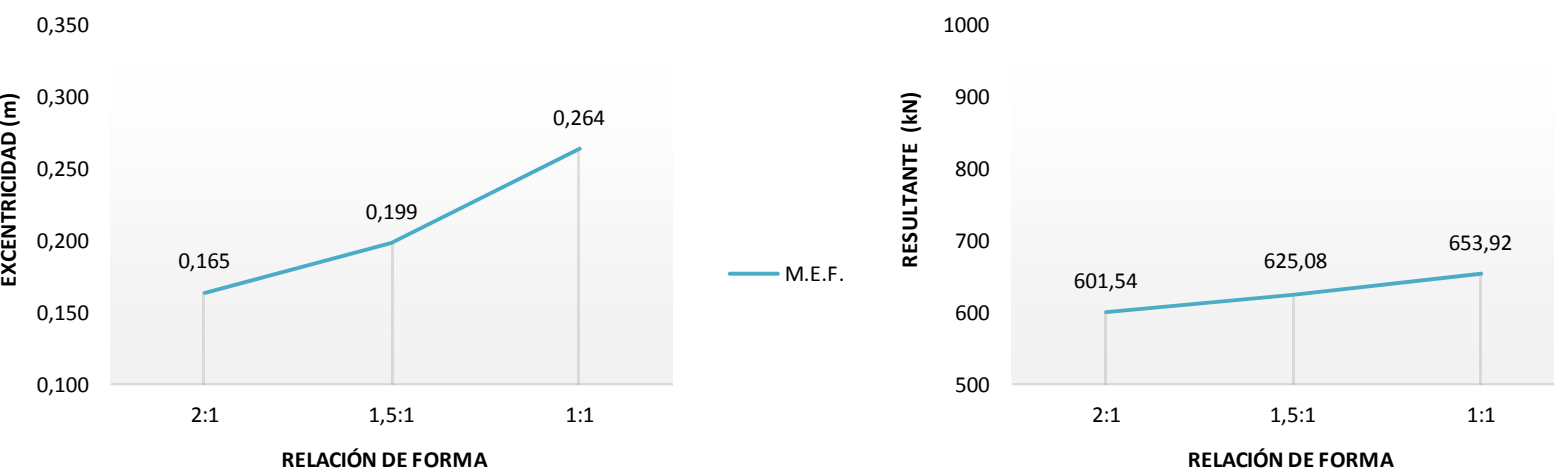

h 300300

h 300300
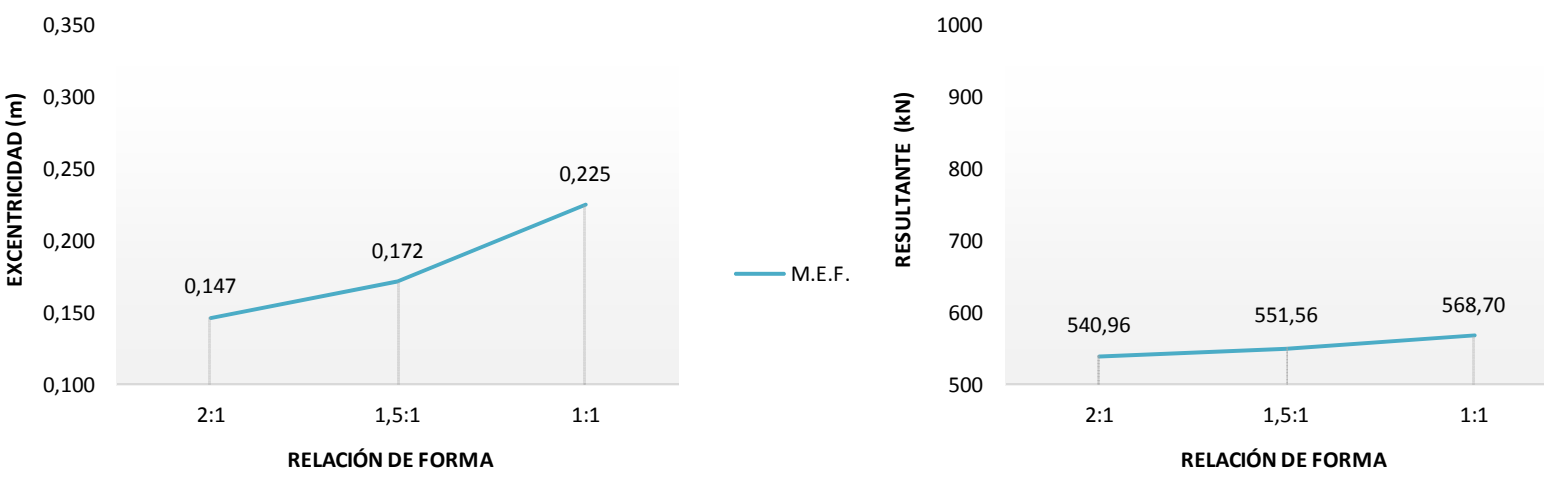

Fig.72. Variación de la excentricidad y valor de la resultante de la zapata de medianería en función de la relación de forma de la zapata 
Este hecho explica el aumento de la diferencia en el momento flector de la viga centradora entre ambos modelos al disminuir la tensión admisible del terreno o hacer la zapata de medianería más cuadrada, ya que es obvio que mayores resultantes desplazadas a una mayor distancia producen una mayor variación del momento flector. El desplazamiento de resultante que manifiesta el modelo de elementos finitos se produce hacia el pilar de medianería, es decir, alejándose del centro del vano de la viga centradora y aproximándose al apoyo, por lo cual, la creciente variación del momento flector se traduce en una creciente reducción del mismo (Fig.73).

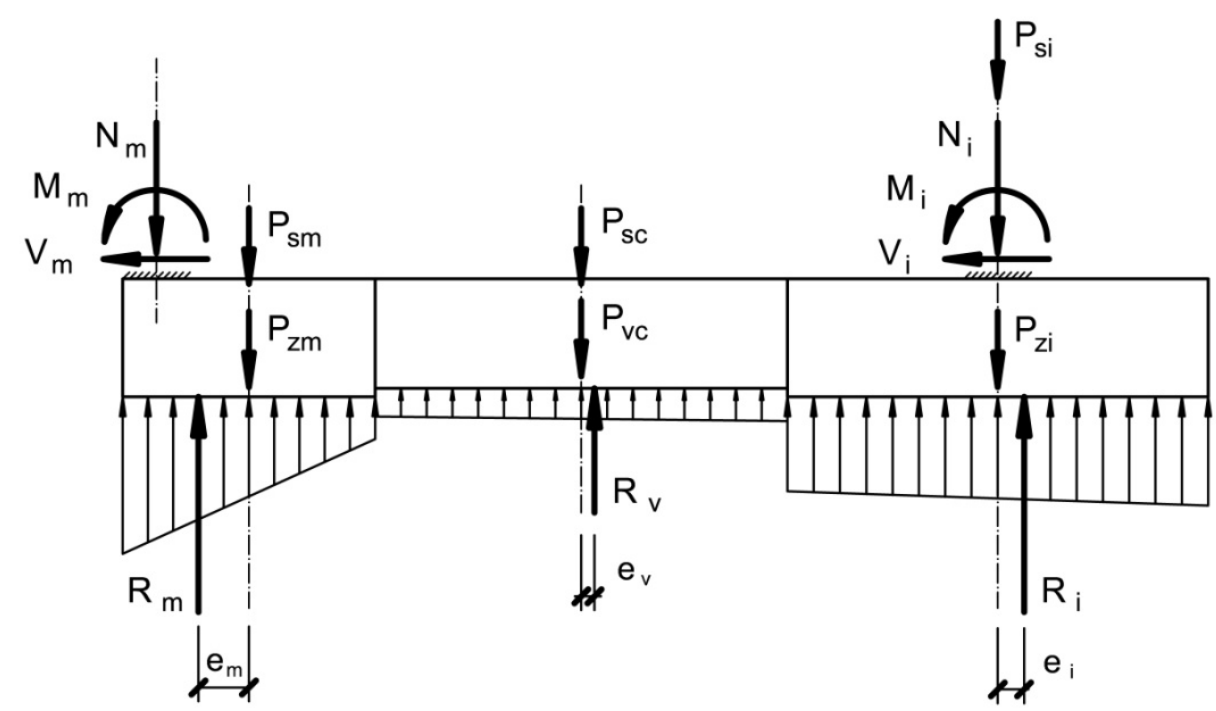

Fig.73. Desplazamiento de la resultante de tensiones de la zapata de medianería

Analizado el mecanismo que regula la flexión en la viga centradora, cabe plantearse que las dos variables que sí influyen sobre el momento flector de la misma podrían tener un mecanismo de funcionamiento común. Realmente, tanto las tensiones admisibles bajas, como las zapatas de medianería de forma cuadrada, lo que hacen es conducir a zapatas de mayor tamaño, que invaden cada vez más el espacio correspondiente a la viga centradora. Cuanto mayor es el porcentaje de luz del vano de medianería invadido por la zapata de medianería, mayor es el momento resultante en el modelo convencional y mayor la diferencia de momento respecto del modelo de elementos finitos. Podría afirmarse, entonces, que la tensión admisible y la relación de forma no intervienen directamente en el problema, sino más bien de forma indirecta, a través del porcentaje de luz de vano de medianería que invaden las zapatas que generan.

Asimismo, el mecanismo de la flexión en la viga centradora, a partir de la posición de la resultante de medianería, puede explicar la estabilización observada en el momento en el modelo de elementos finitos (Fig.66 y 67) y puede conducir al concepto de eficacia de la zapata de medianería (Fig.74). 


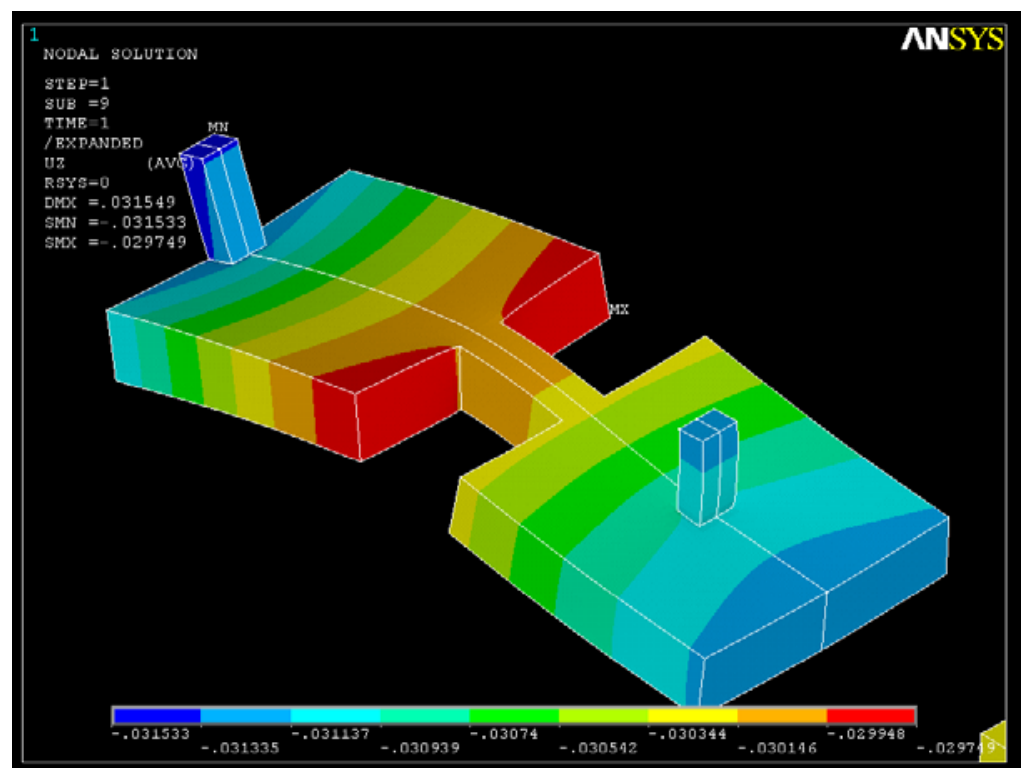

Fig.74. Reducción de eficacia de las zonas de la zapata de medianería próximas al centro del vano

En el modelo convencional, que siempre plantea la resultante en el centro de la cara inferior de la zapata de medianería, la resultante acompaña al crecimiento de la zapata en la dirección del pórtico, de tal modo que cuanto más porcentaje de luz invade la zapata de medianería más hacia el centro del vano se sitúa la resultante y más momento flector produce.

En el modelo de elementos finitos, en cambio, cuanto mayor es el porcentaje de luz invadido por la zapata, mayor es la excentricidad en contra que experimenta la resultante. Es como si al crecer la zapata la resultante se frenase, "negándose" a acompañar a la zapata en su crecimiento y generando un momento flector que tiende a estabilizarse en un tope límite (en el sentido de límite matemático de una función). Esta idea encuentra su apoyo en la deformada de casos extremos que invaden un porcentaje muy elevado de luz de vano (Fig.74). En tales casos, debido al giro y a la deformación que sufre la zapata de medianería, las zonas de la misma situadas hacia el interior del vano no son tan eficaces en su función de transmitir carga al terreno. Por ello, llegará un momento en que, por mucho que crezca la zapata en ese sentido, la distribución de tensiones seguirá produciéndose en un determinado sector en torno al pilar, es como si la resultante se "negará" a acompañar al crecimiento de la zapata más allá de un determinado punto, a partir del cual cualquier crecimiento de la zapata se convierte en ineficaz. 


\subsubsection{ESFUERZOS EN LA VIGA SUPERIOR}

Cuando se utiliza zapata de medianería con viga centradora, la viga de la primera planta que se encuentra sobre la viga centradora cumple una doble misión. Por un lado, el habitual trabajo a flexión de la viga recibiendo las cargas propias del correspondiente forjado y, por otro, la función adicional de tirante para colaborar junto con la viga centradora en la estabilización de la zapata de medianería. Se produce, por tanto, una combinación simultánea de los dos modelos convencionales (viga centradora y tirante). Este hecho puede suponer, en la práctica, el infradimensionado de la armadura de la viga de la primera planta, ya que se encuentra realmente solicitada a flexotracción y es muy usual su dimensionamiento a flexión simple, despreciando el esfuerzo axil de tracción inducido por el efecto tirante.

Las Fig.75, 76 y 77 muestran la evolución del axil de tracción en la viga de la primera planta al variar la rigidez del pórtico, la tensión admisible y la relación de forma respectivamente. Dicha variación en la tracción de la viga superior se expone para los tres modelos estudiados (M.E.F., modelo convencional con tirante y modelo convencional con viga centradora). Los dos primeros modelos sí contemplan directamente la viga de la primera planta. En cambio, el modelo convencional con viga centradora no considera dicha viga, por lo cual, el esfuerzo axil de tracción ofrecido para el citado modelo corresponde al obtenido en el cálculo matricial del pórtico tipo en la hipótesis de pilares perfectamente empotrados en su base.

\section{$1: 1 \quad 100$}

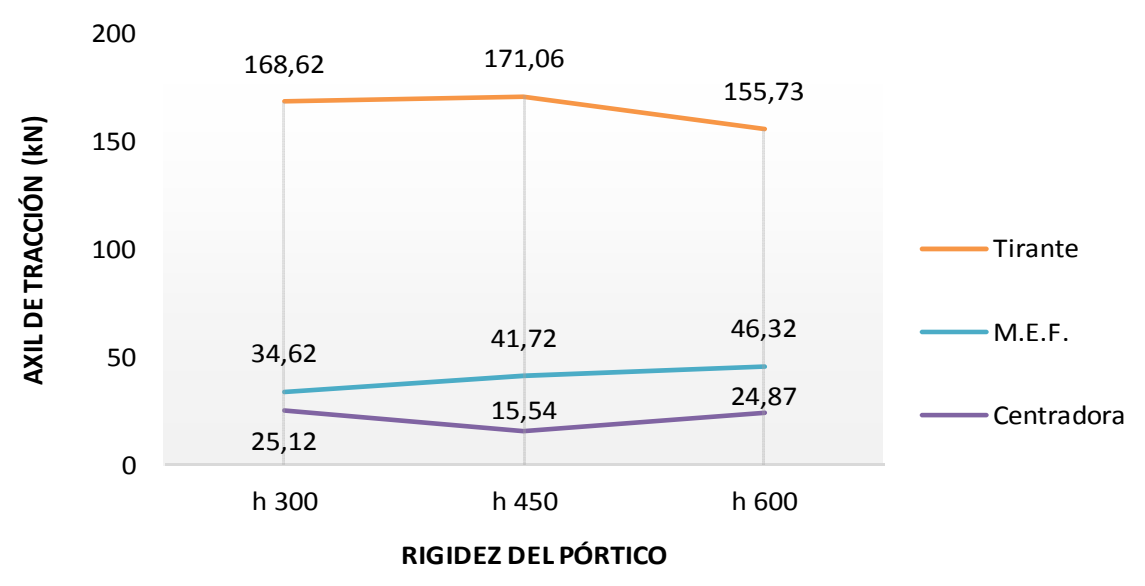

Fig.75. Variación del esfuerzo axil en la viga de la primera planta en función de la rigidez del pórtico

Tal y como ya se ha comprobado en análisis anteriores, la rigidez del pórtico (Fig.75) tiene poca influencia sobre esta cuestión, siendo de nuevo la tensión admisible del terreno y la relación de forma, las variables que más inciden en el problema (Fig.76 y 77). 


\section{h $300 \quad 2: 1$}

200

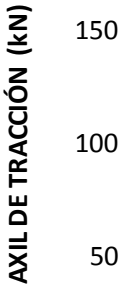

0

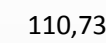

-

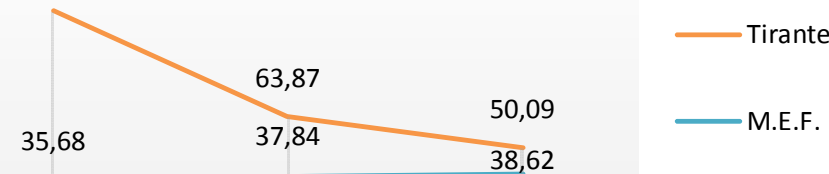

25,12

38,62

Centradora

100

200

25,12

200

300

TENSIÓN ADMISIBLE $\left(\mathrm{kN} / \mathrm{m}^{2}\right)$

\section{h $300 \quad 1,5: 1$}

200

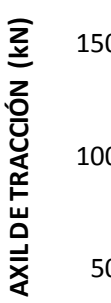

132,78

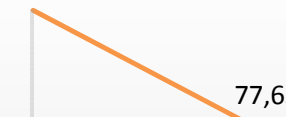

77,65

Tirante

50

35,24

38,22

59,24

25,12

25,12

38,86

-M.E.F.

100

25,12

25,12

Centradora

\section{h $300 \quad 1: 1$}

200

168,62

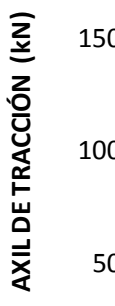

0

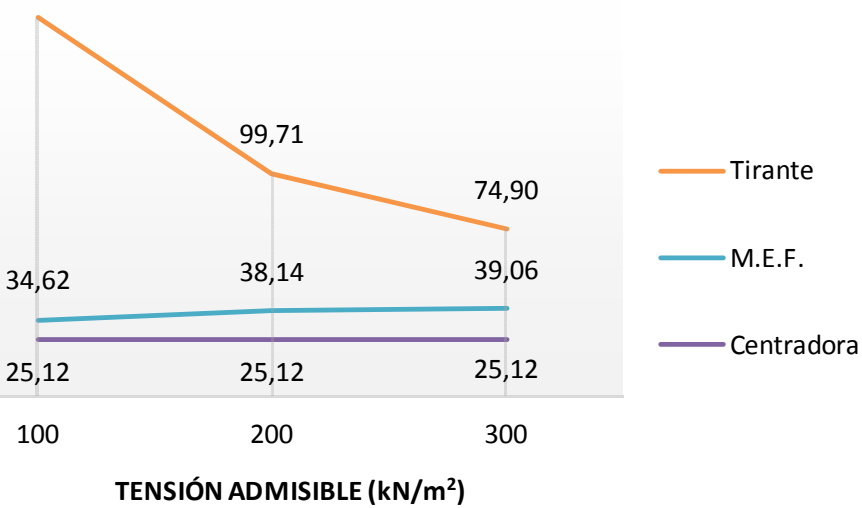

Fig.76. Variación del esfuerzo axil en la viga de la primera planta en función de la tensión admisible del terreno 


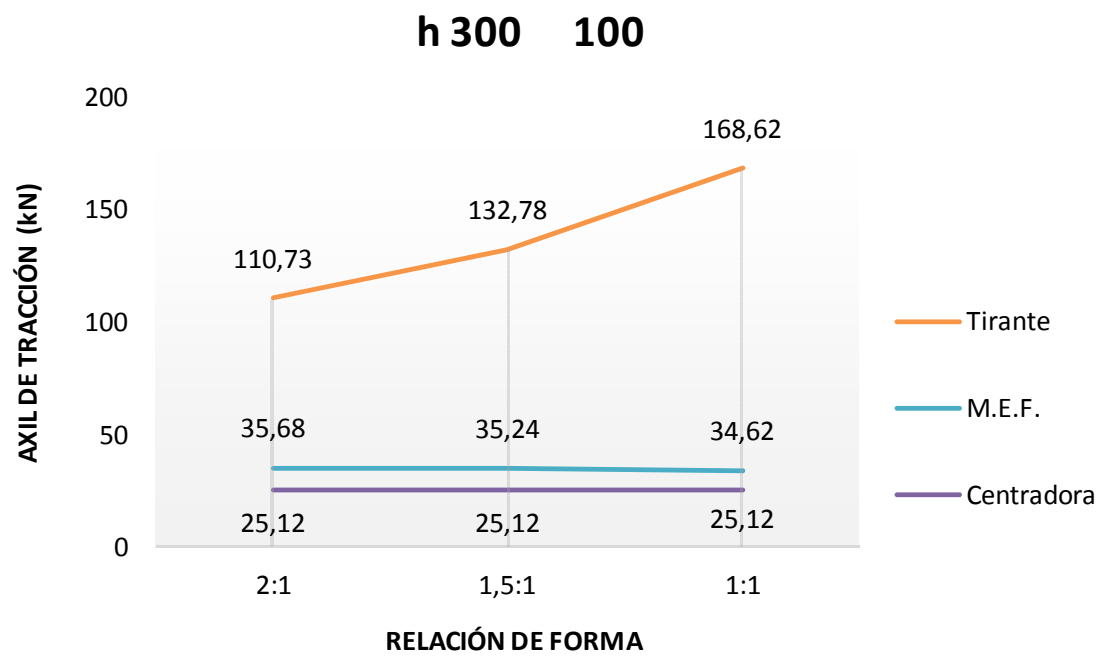

\section{h 300200}

200

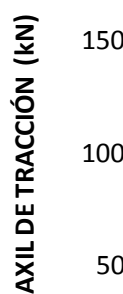

0

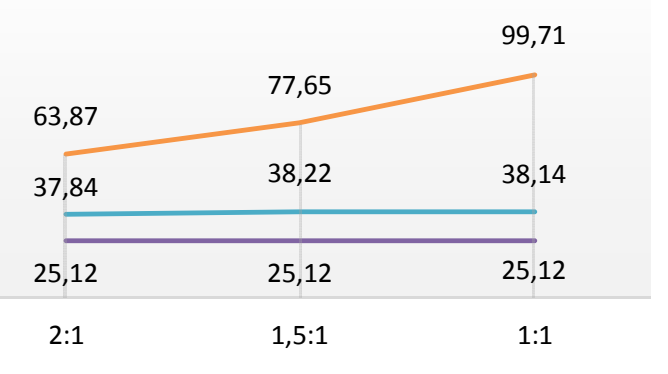

Tirante

M.E.F.

Centradora

\section{h $300 \quad 300$}

200

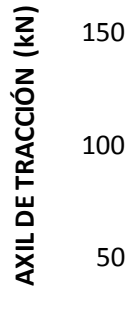

RELACIÓN DE FORMA

0

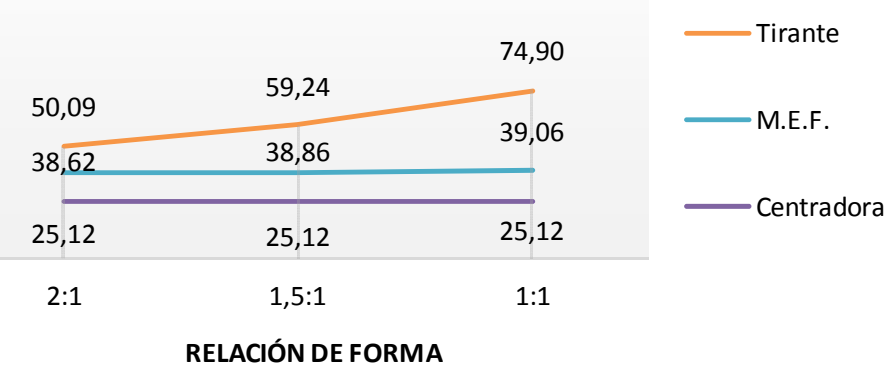

Fig.77. Variación del esfuerzo axil en la viga de la primera planta en función de la relación de forma 
A la vista de los gráficos de las Fig. 76 y 77 , resulta especialmente llamativa la magnitud de los esfuerzos axiles de tracción que genera el modelo convencional con tirante, que se incrementan considerablemente a medida que disminuye la tensión admisible del terreno o se utilizan zapatas de medianería cada vez más cuadradas.

Por su parte, los resultados proporcionados por el modelo de elementos finitos confirman el trabajo a flexotracción de la viga de la primera planta pero, en contra del temor inicial, las tracciones que se producen en la viga superior en dicho modelo son considerablemente inferiores a las obtenidas por el modelo convencional con tirante y, por supuesto, superiores a las del modelo convencional con viga centradora. Las tracciones obtenidas con el modelo de elementos finitos presentan valores constantes (del orden de $40-50 \mathrm{kN}$ ) que no dependen de ninguna de las variables analizadas y cuya magnitud viene a ser el doble de las obtenidas en el cálculo matricial del pórtico (del orden de 25 kN).

Resulta difícil dar una regla general cualitativa acerca de cuándo un esfuerzo axil es despreciable frente al cálculo a flexión. Habitualmente los axiles en las vigas de los pórticos (del orden de $25 \mathrm{kN}$ ) se desprecian, calculando las vigas a flexión simple. En este caso, si bien el resultado no es tan alarmante como indica el método convencional con tirante, parece recomendable no despreciar el esfuerzo axil y considerar la tracción generada por el efecto tirante, evaluándola y calculando la viga a flexotracción. 


\subsubsection{DISTRIBUCIÓN DE TENSIONES DE CONTACTO}

La Fig.78, obtenida a partir de los resultados de los modelos de elementos finitos generados en la Etapa I, muestra claramente la no uniformidad de la distribución de tensiones bajo la zapata de medianería, con una tendencia al incremento de tensiones hacia el pilar de medianería.
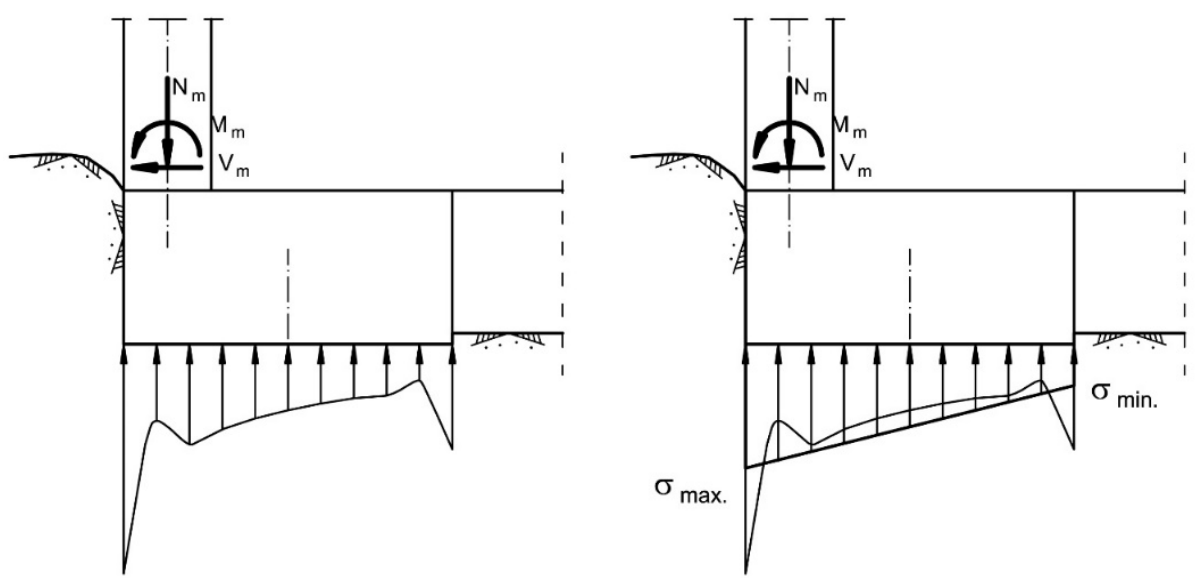

Fig.78. Distribución de tensiones de contacto en modelos de elementos finitos
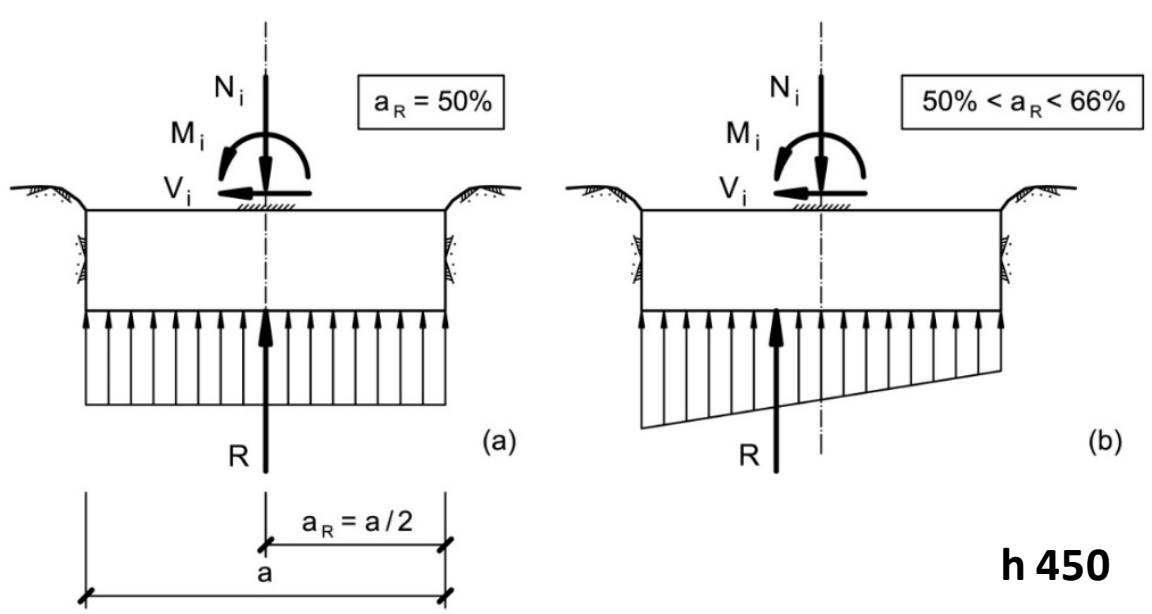

h $450 \quad 2: 1$
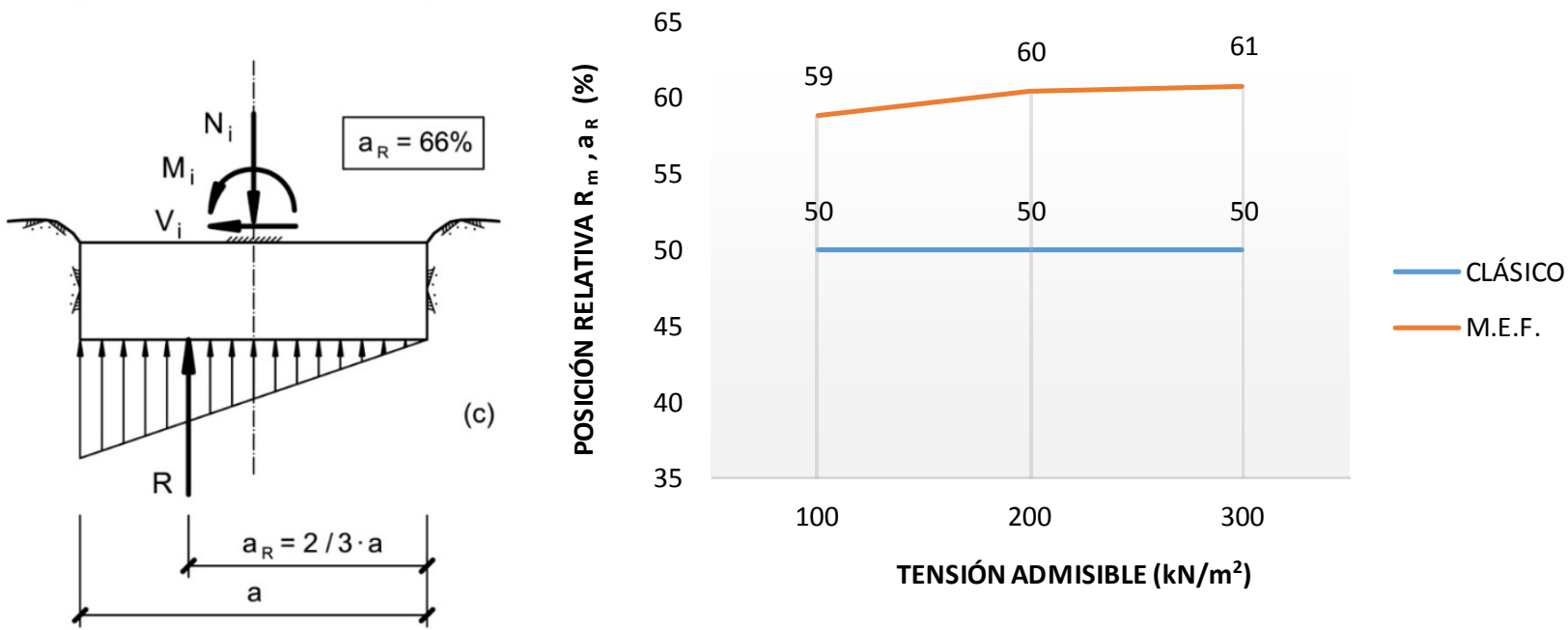

Fig.79. Diagrama de distribución de tensiones lineal equivalente 
Asimismo, los resultados de las Tablas 20, 21 y 22, muestran que los casos planteados en la Etapa I presentan posiciones relativas de la resultante de tensiones de contacto de la zapata de medianería comprendidas entre el $59 \%$ y el $63 \%$ de la dimensión de la zapata paralela al plano del pórtico (Fig.79), de tal forma que, en caso de asimilar el diagrama de distribución de tensiones a un esquema lineal equivalente, habría que utilizar un modelo trapecial con tensión máxima bajo el pilar de medianería.

La punta de tensión máxima que se produce en los diagramas trapeciales, supone un incremento de tensión respecto de los diagramas iniciales uniformemente repartidos de los modelos convencionales. Dicho incremento de tensión coloca, a priori, a los diagramas trapeciales en una posición cualitativamente desfavorable respecto de los diagramas uniformemente distribuidos ya que, a igualdad de resultante transmitida, generan tensiones máximas superiores, susceptibles de no cumplir la comprobación de tensiones de contacto o verificación del E.L.U. de hundimiento, incluso admitiendo un incremento de la tensión en punta del $25 \%$ respecto de la tensión admisible.
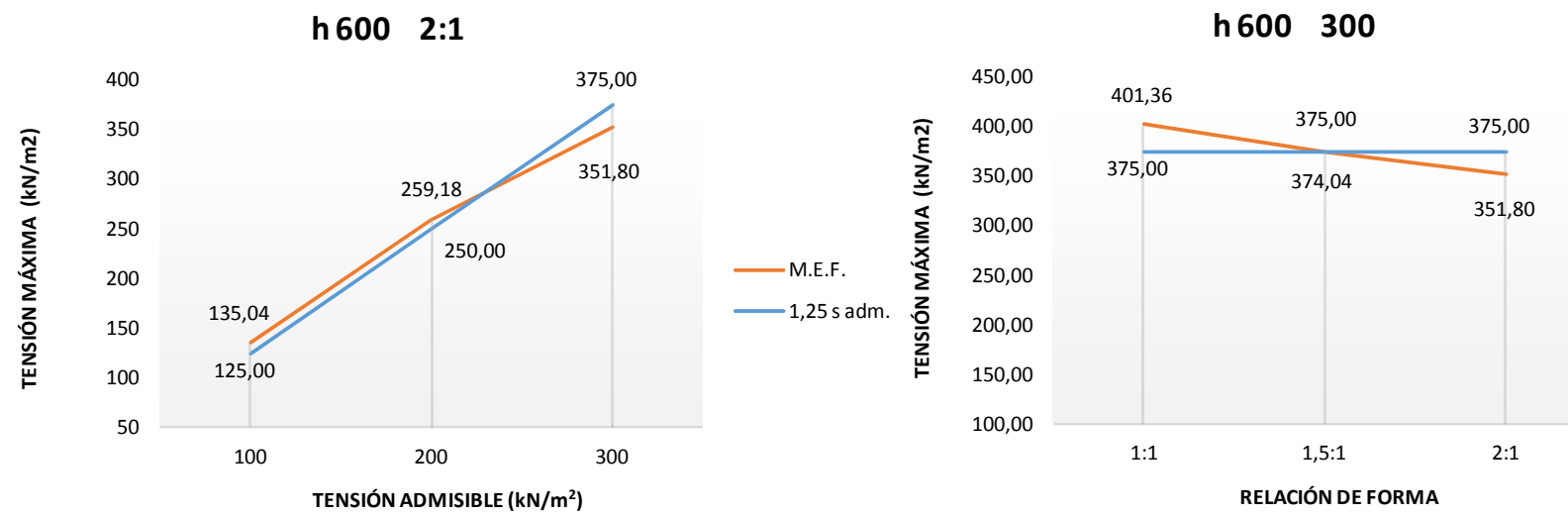

Fig.80. Verificación de tensiones de contacto con modelos de elementos finitos. Etapa I

Ahora bien, en contra del temor cualitativo inicial, los resultados de las Tablas 20, 21 y 22 muestran que, si bien hay casos que presentan un nivel de agotamiento de la comprobación de tensiones de contacto ligeramente superior a 1 (incumplimiento de la comprobación) hay otros que, a pesar de la punta de tensión máxima siguen cumpliendo la verificación del E.L.U. de hundimiento (nivel de agotamiento inferior a 1), como puede verse en los gráficos de la Fig. 80 que representan la relación entre la tensión máxima bajo la zapata de medianería y el límite marcado por un incremento del $25 \%$ sobre la tensión admisible, para el nivel de rigidez del pórtico $h=600$. Puede comprobarse en los gráficos de la Fig.80 que el grado de cumplimiento de la comprobación de tensiones de contacto mejora cuanto mayor sea la 
tensión admisible del terreno y cuanto más rectangular sea la zapata de medianería, llegando a cumplir en algunos casos a pesar incluso del pico de tensiones que le introduce el esquema trapecial de distribución de tensiones.

h $300 \quad 2: 1$

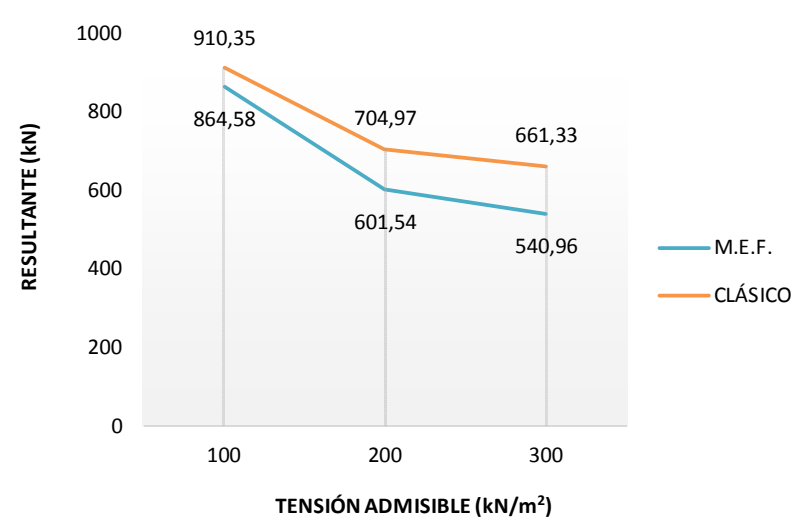

(a) h $300 \quad 2: 1$

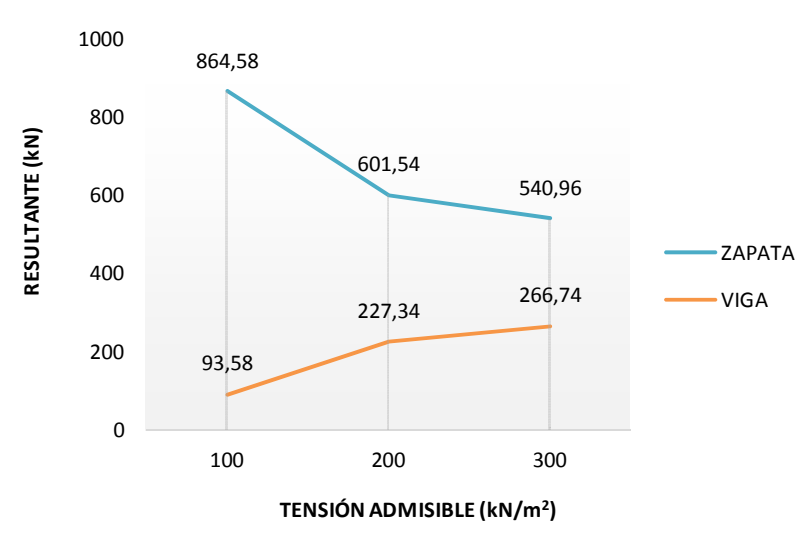

(b)

Fig.81. Contraste de resultantes de tensiones de contacto en zapata de medianería y viga centradora

La explicación de este hecho puede encontrarse en el análisis del valor de las resultantes de tensiones de contacto tanto bajo la zapata de medianería como bajo la viga centradora (Fig.81). En efecto, si se comparan las resultantes bajo la zapata de medianería entre ambos modelos (Fig.81.a) se comprueba que la resultante con el modelo de elementos finitos siempre es menor que con el modelo convencional, siendo similar para tensiones admisibles bajas y progresivamente menor a medida que aumenta la tensión admisible del terreno. Este descenso en el valor de la resultante bajo la zapata de medianería con el modelo de elementos finitos se debe al protagonismo de la viga centradora puesto de manifiesto en la Fig.81.b. El modelo convencional desprecia por completo la colaboración de la viga centradora como elemento de cimentación para transmitir carga al terreno, sin embargo el modelo de elementos finitos muestra que la resultante de tensiones de contacto correspondiente a la viga centradora aumenta a medida que se incrementa el valor de la tensión admisible del terreno.

Es más, el gráfico de la Fig.82, que analiza la relación entre la resultante de tensiones bajo la viga centradora y la resultante de tensiones bajo la zapata de medianería, muestra claramente que el protagonismo de la viga centradora como elemento de cimentación aumenta con la tensión admisible del terreno, llegando adquirir su resultante un valor próximo 
al $50 \%$ de la resultante de la zapata. Difícilmente puede ser despreciable una variable que alcanza el $50 \%$ del valor de otra que sí se tiene en cuenta.

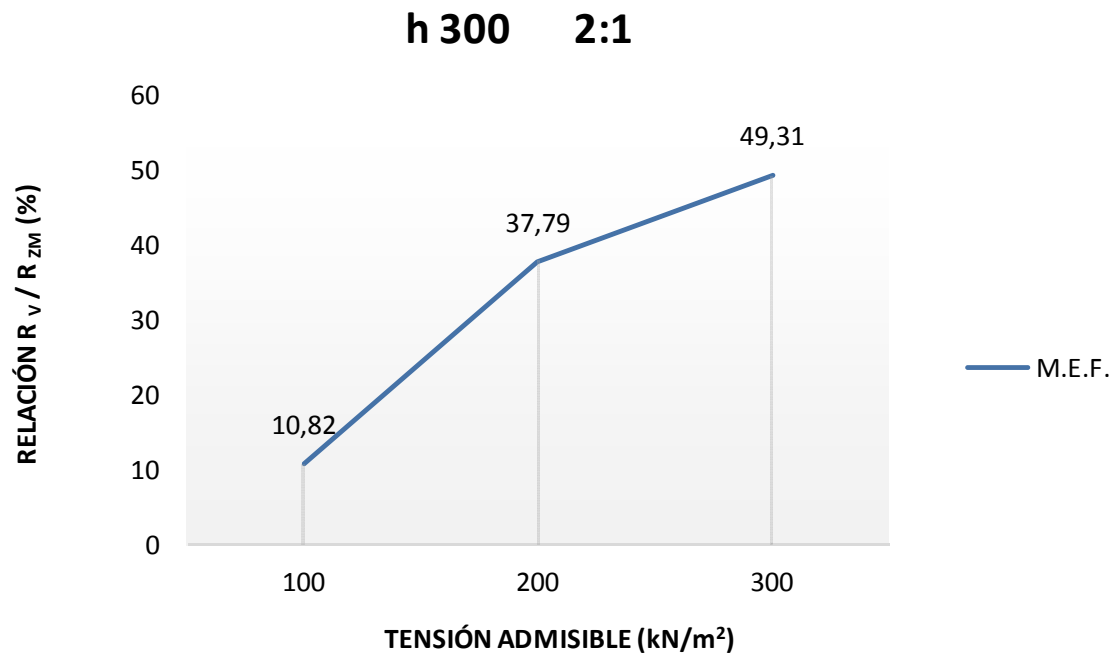

Fig.82. Relación resultante viga centradora - resultante zapata

Estos datos conducen a la conclusión de que es erróneo el planteamiento de despreciar la resultante de las tensiones de contacto que realmente se producen bajo la viga centradora. Dicha viga centradora, además de estabilizar e intentar centrar el comportamiento de la zapata de medianería, lleva a cabo la misión de viga de cimentación o viga flotante, que colabora junto con las zapatas de medianería e interior, en la tarea de transmitir la carga al terreno.

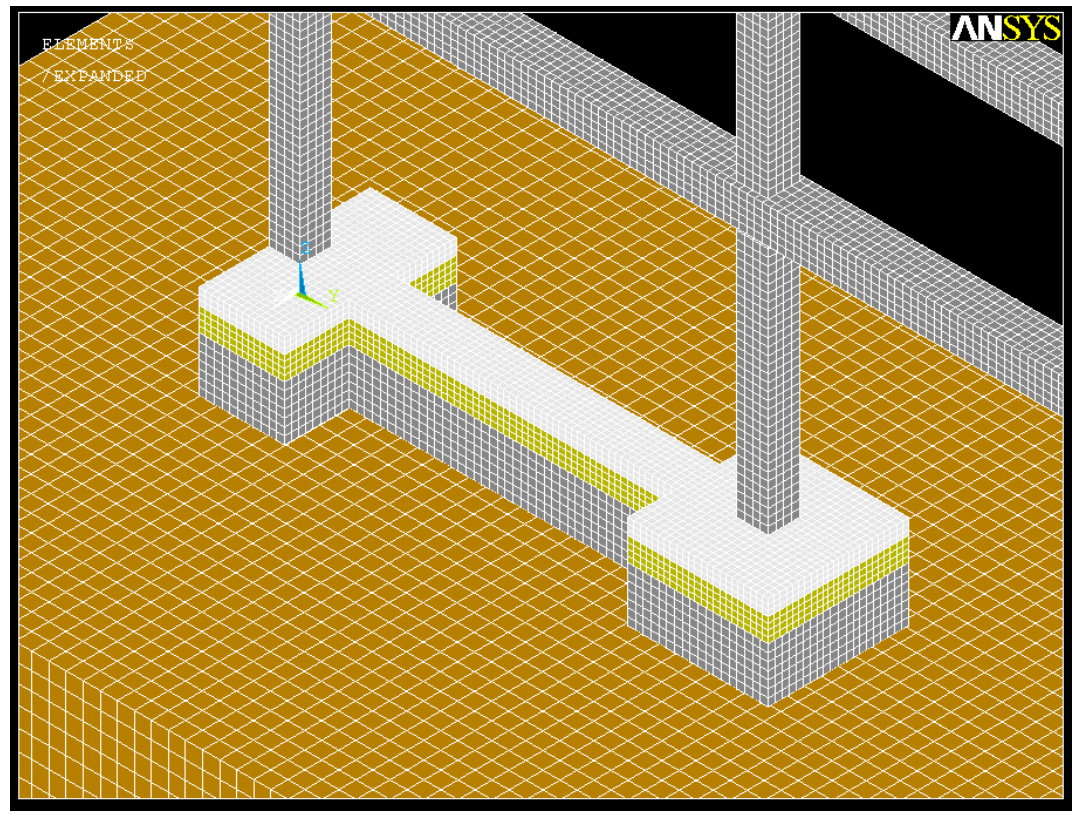

Figura 83. Viga centradora como viga de cimentación 
El mecanismo por el cual aumenta el protagonismo de la viga centradora al incrementarse la tensión admisible parece claro (Fig.83). Cuanto mayor es la tensión admisible, más pequeñas resultan las zapatas y mayor es, en proporción, el tamaño de la viga centradora. Cuanto mayor superficie relativa de contacto presenta la viga centradora respecto de la zapata de medianería mayor es el porcentaje de reacción que asume la viga. 


\subsection{ANÁLISIS Y DISCUSIÓN DE RESULTADOS. ETAPA II}

\subsubsection{ESFUERZOS EN LA VIGA CENTRADORA}

Los resultados de los modelos de elementos finitos elaborados en la Etapa II (apartado 4.2, Tablas 45 a 56) vuelven a poner de manifiesto la considerable diferencia en el momento flector que solicita la viga centradora, según se realice el cálculo con modelos convencionales o con modelos de elementos finitos (Fig.84 y 85)

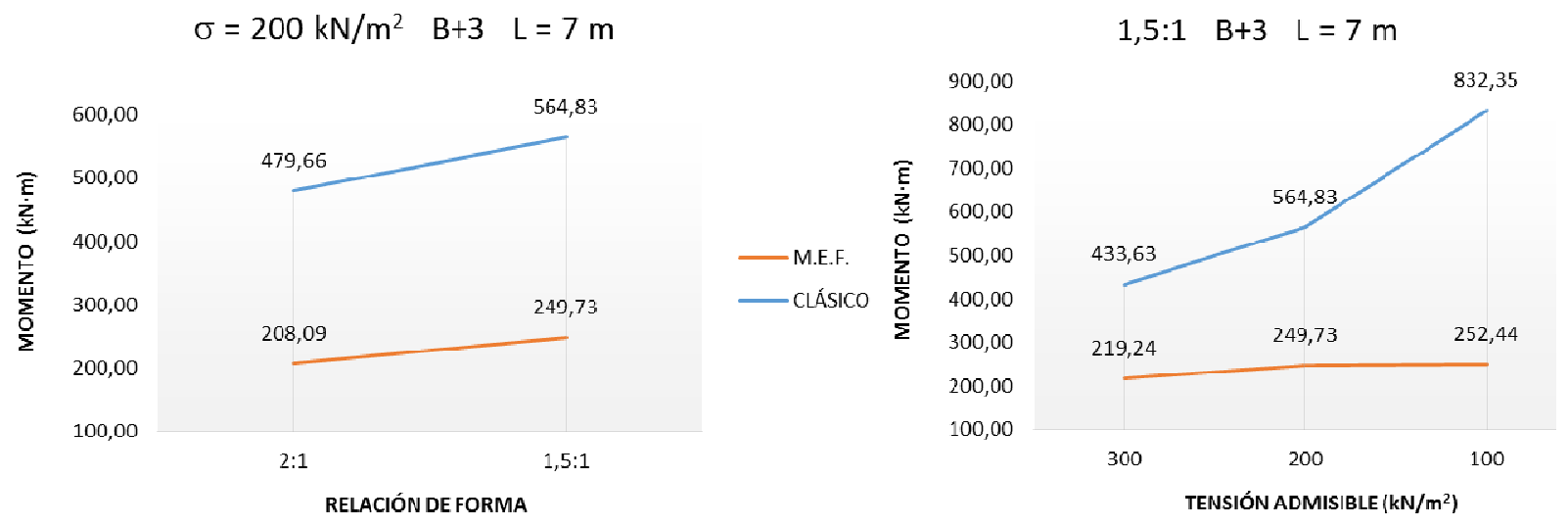

Fig.84. Contraste del valor del momento flector en la viga centradora en función de la relación de forma y de la tensión admisible del terreno

$2: 1 \quad \sigma=200 \mathrm{kN} / \mathrm{m}^{2} \quad \mathrm{~B}+3$

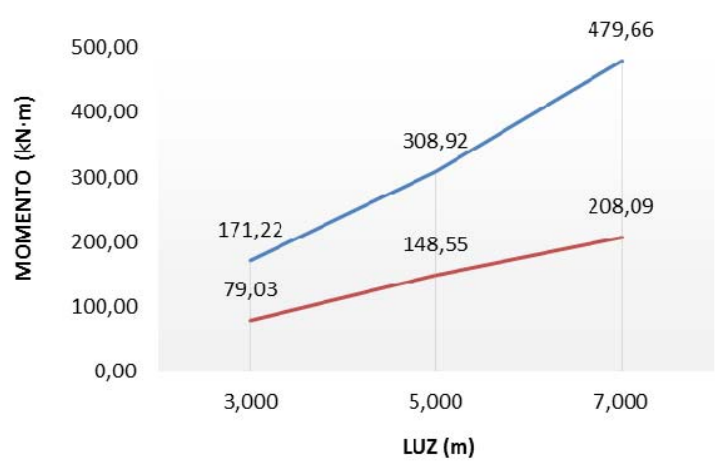

$2: 1 \quad \sigma=200 \mathrm{kN} / \mathrm{m}^{2} \quad \mathrm{~L}=5 \mathrm{~m}$

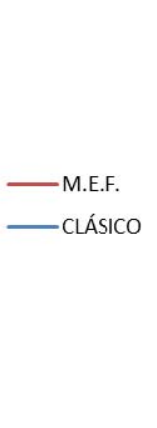

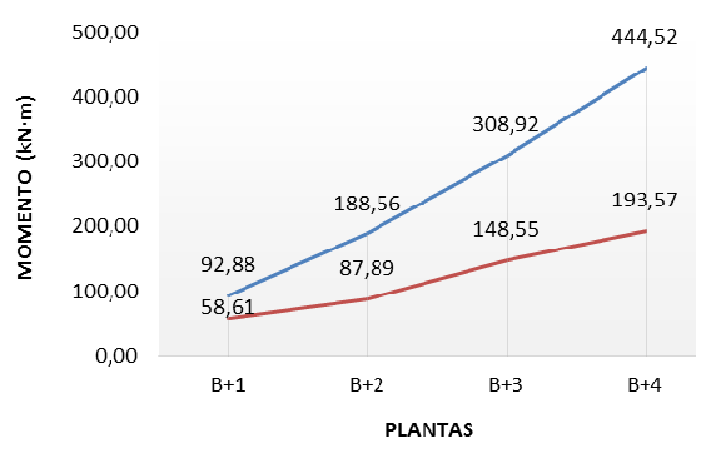

Fig.85. Contraste del valor del momento flector en la viga centradora en función de la luz y el número de plantas del pórtico

Al igual que en los resultados de la Etapa I, se comprueba que la diferencia en el valor de los momentos aumenta cuanto menor es la tensión admisible del terreno y más cuadrada se hace la zapata de medianería y, respecto de las nuevas variables introducidas en la Etapa II, dicha diferencia en el valor de los momentos aumenta con la luz del pórtico y con el número de plantas del mismo. 
Ahora bien, lo que resulta especialmente llamativo es el incremento en la reducción del momento experimentado en la Etapa II frente a los resultados de la Etapa I. Ciertamente en la Etapa I se llegaban a encontrar casos de modelos de elementos finitos cuyo momento flector en la viga centradora era del orden del $50 \%$ del momento del correspondiente modelo convencional. Pero es que en la Etapa II esa cifra, ya de por sí llamativa, desciende por término medio al $40 \%$ y llega a bajar al $30 \%$ en casos extremos de reducida tensión admisible $\sigma_{\text {adm. }}=100 \mathrm{kN} / \mathrm{m}^{2}$, relación de forma $1,5: 1$, elevada luz $L=7 \mathrm{~m}$ y alto número de plantas $($ Baja +3$)$.
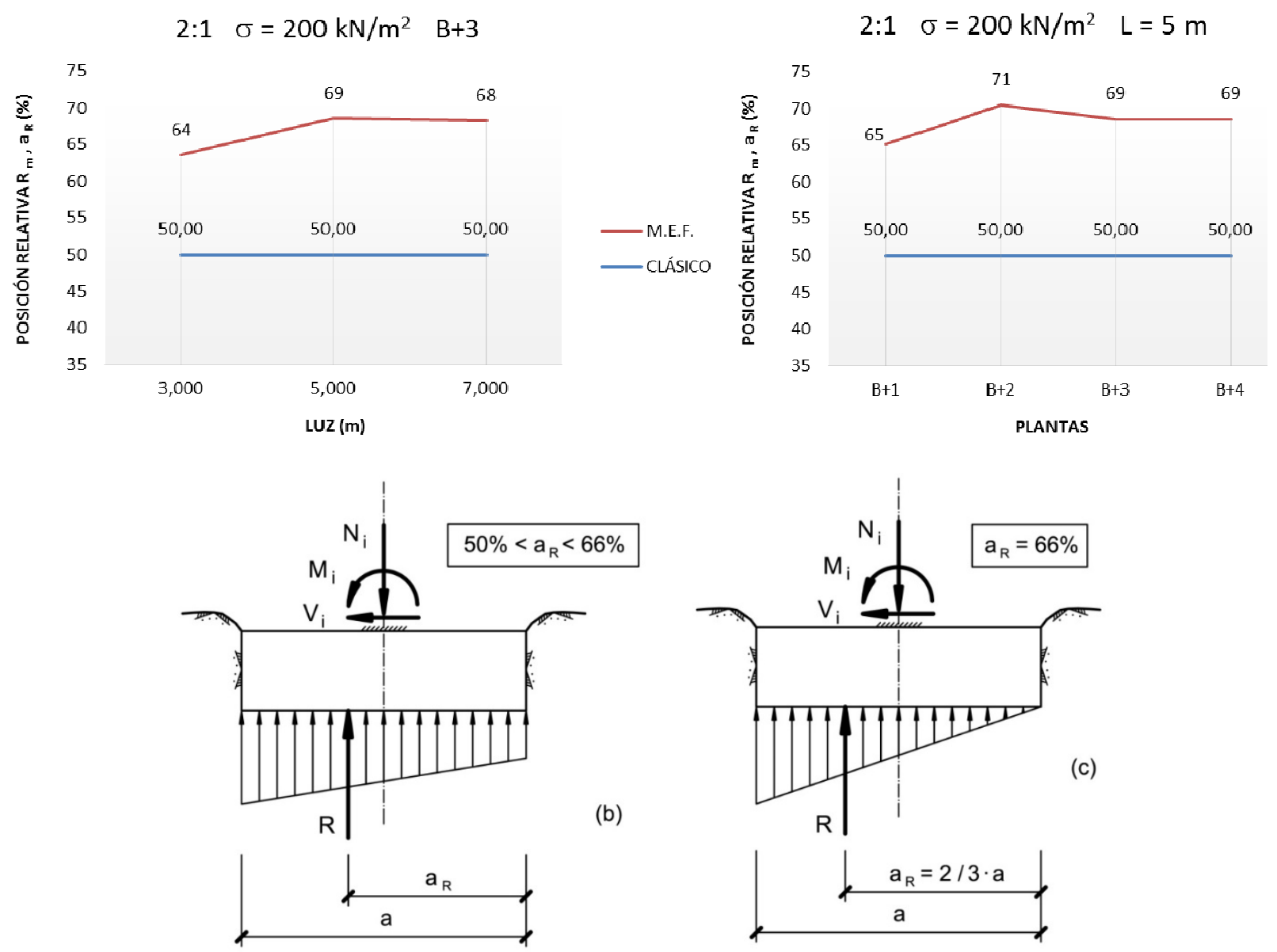

Fig.86. Excentricidades relativas de la resultante de la zapata de medianería. Etapa II

El mecanismo que conduce a esta mayor reducción en el momento de la viga centradora se encuentra en la excentricidad de la resultante de la zapata de medianería. Frente a los resultados de la Etapa I, que ofrecían posiciones relativas de la resultante de tensiones de contacto de la zapata de medianería entre el $59 \%$ y el $63 \%$ del tamaño de la zapata (distribución trapecial), los resultados de la Etapa II (Fig.86) presentan excentricidades o posiciones relativas de la resultante de la zapata de medianería entre el $64 \%$ y el $71 \%$ del tamaño de la zapata de medianería, colocándose de este modo dicha zapata en torno al límite de la distribución triangular de tensiones. 
El aumento experimentado en la excentricidad de la resultante de la zapata de medianería, aproxima dicha resultante al pilar medianero y la aleja del centro de la viga centradora, reduciendo así el momento flector que genera (Fig.87).

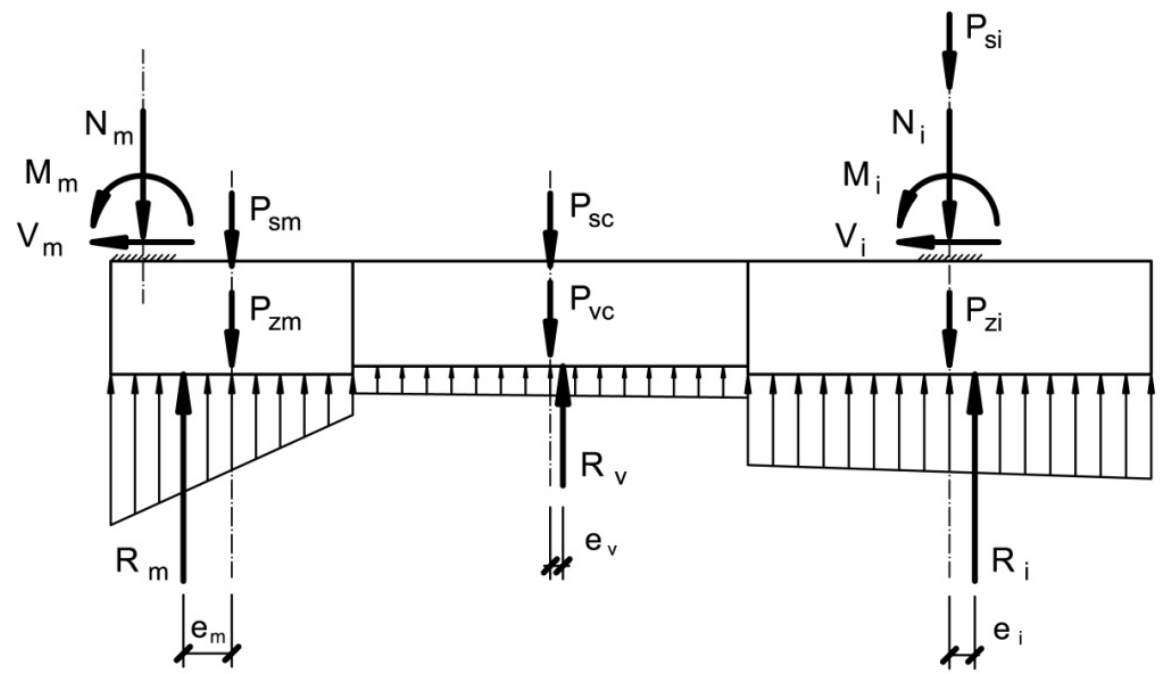

Fig.87. Aumento de la excentricidad de la resultante de la zapata de medianería.

La causa primera del citado aumento en la excentricidad de la resultante está en el planteamiento fundamental que caracteriza a la Etapa II, la consideración del hormigón como un material con comportamiento parabólico rectangular y con una muy reducida resistencia a tracción que trae consigo la fisuración y fractura del hormigón en la zona traccionada de la viga centradora. Dicho proceso de fisuración debilita la viga centradora, perdiendo inercia y, por ello, rigidez. Al ser la viga centradora menos rígida, experimenta una mayor deformación al entrar en carga, permitiendo un mayor giro de la zapata de medianería, que desplaza la resultante hacia el pilar medianero.

El impulso inmediato ante la drástica reducción del momento en la viga centradora sería la correspondiente reducción en el armado de la misma, acorde con el momento que realmente la solicita. Ahora bien, esa reducción plantea dos cuestiones, por un lado, la reducción de armadura empeoraría el problema de la fisuración en la viga, que se vería más debilitada, aún menos rígida y permitiría un mayor giro de la zapata, generando de nuevo un menor momento flector que sugiere un probable bucle indefinido que conduciría prácticamente a la eliminación de la viga centradora y, por otro lado, llegado a ese punto, podría cuestionarse cuál sería el comportamiento real de la cimentación sin viga centradora, dependiendo solamente de la colaboración de la viga superior como en el segundo modelo convencional.

Estas dos cuestiones, junto con otras que surgen a continuación, plantean la necesidad de una nueva etapa experimental, la Etapa III, para darles respuesta. 


\subsubsection{DISTRIBUCIÓN DE TENSIONES DE CONTACTO}

Tal y como se ha comentado en el apartado anterior, a raíz de la Fig.86, los resultados de los modelos de elementos finitos de la Etapa II presentan excentricidades o posiciones relativas de la resultante de tensiones de contacto de la zapata de medianería entre el $64 \%$ y el $71 \%$ del tamaño de la zapata de medianería, lo que coloca a dicha zapata en torno al límite de la distribución triangular de tensiones estricta.

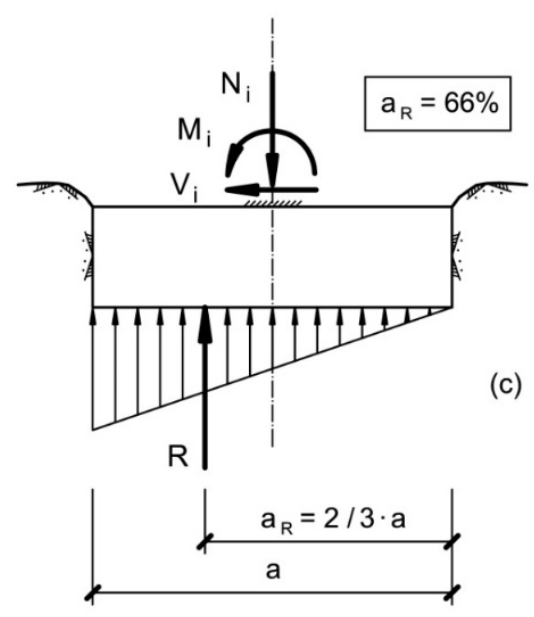

Fig.88. Distribución de tensiones triangular estricta

Una distribución triangular de tensiones, aunque sea límite y no llegue a producir despegues en la zapata, es una distribución más desfavorable que la distribución trapecial, por presentar una mayor punta de tensiones en el borde medianero y un peor comportamiento geotécnico.

$$
1,5: 1 \quad B+3 \quad L=7 m
$$

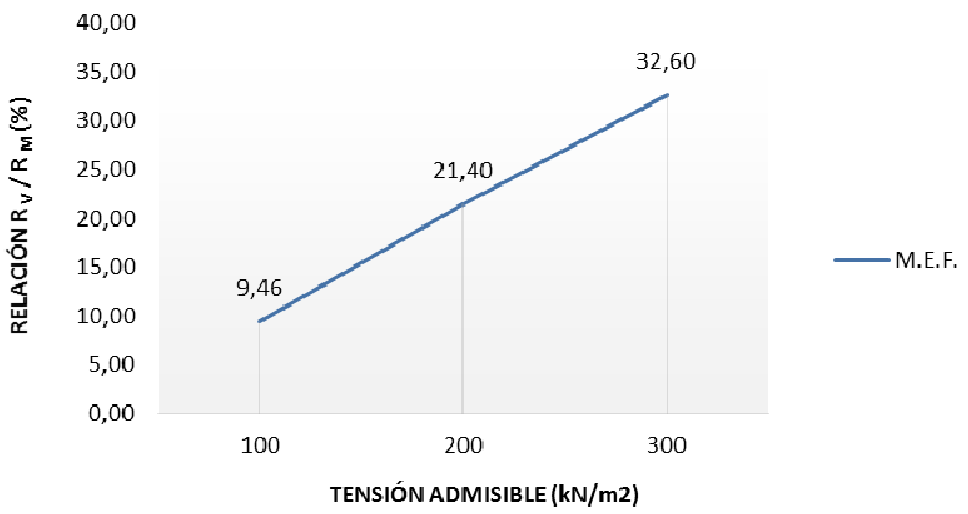

Fig.89. Relación resultante viga centradora - resultante zapata medianería. Etapa II

A ello se le une, en esta ocasión, otro efecto adicional igualmente desfavorable. Debido a la pérdida de rigidez de la viga centradora por la fisuración de la misma y al aumento de la deformación de la viga que ello genera, el contacto de la viga centradora con el terreno no es 
tan intenso, reduciéndose la colaboración portante de la viga centradora como viga de cimentación. En la Fig.89 se muestra la variación de la relación entre la resultante bajo la viga centradora y la resultante de la zapata de medianería, alcanzando tan solo un valor en torno al 35\% como máximo en la Etapa II, cuando en la Etapa I algunos casos alcanzaban hasta el $50 \%$.

$$
2: 1 \quad \sigma=200 \mathrm{kN} / \mathrm{m}^{2} \quad \mathrm{~B}+3
$$

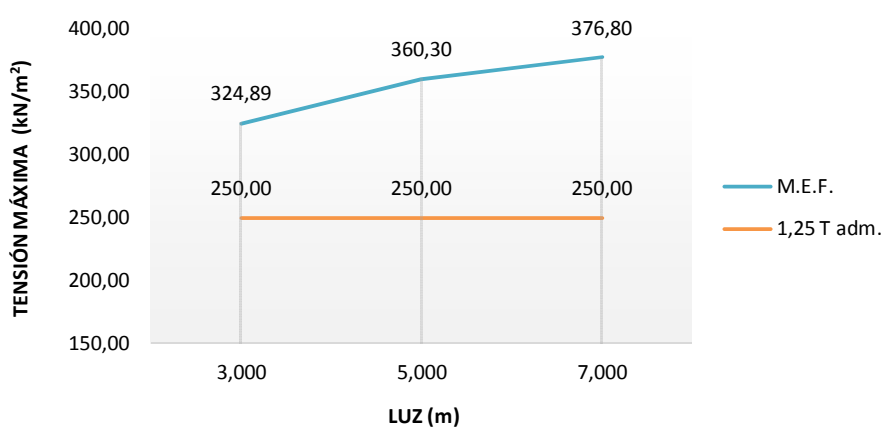

$2: 1 \quad \sigma=200 \mathrm{kN} / \mathrm{m}^{2} \quad \mathrm{~L}=5 \mathrm{~m}$

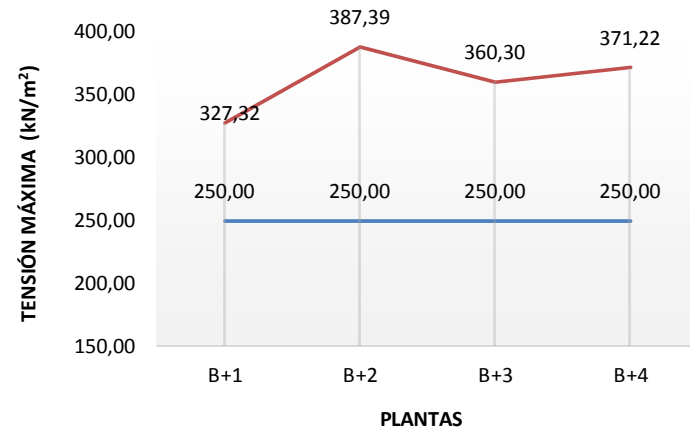

Fig.90. Verificación de tensiones de contacto. Etapa II

El incremento de tensión en punta del diagrama triangular, unido a la menor colaboración portante de la viga centradora, genera una situación muy problemática para la zapata de medianería en todos los modelos de elementos finitos de la Etapa II, ya que ninguno de ellos cumple la comprobación de tensiones de contacto, llegándose en ocasiones a superar en más de un $50 \%$ el valor límite establecido en $1,25 \cdot \sigma$ adm. (Fig.90).

Se llega así a un escenario contradictorio, con una viga centradora ineficaz (aparentemente sobredimensionada en su armado) incapaz de evitar el giro de una zapata de medianería que, por ello, resulta finalmente infradimensionada.

Estando la insuficiente rigidez de la viga centradora en el origen del problema, surgen dos posibles vías de solución. Por un lado, el incremento de la armadura de la propia viga centradora buscando minimizar el problema de la fisuración, que la debilita quitándole rigidez $y$, por otro, el aumento del canto de la viga centradora para incrementar su inercia y con ello su rigidez.

Estas dos nuevas cuestiones, junto con las dos anteriores, refuerzan la necesidad de una nueva etapa experimental, la Etapa III, para darles respuesta. 


\subsubsection{ESFUERZOS EN LA VIGA SUPERIOR}

Los resultados de los modelos de elementos finitos elaborados en la Etapa II (apartado 4.2, Tablas 45 a 56) vuelven a poner de manifiesto el trabajo a flexotracción de la viga de la primera planta (Fig.91 y 92 ).
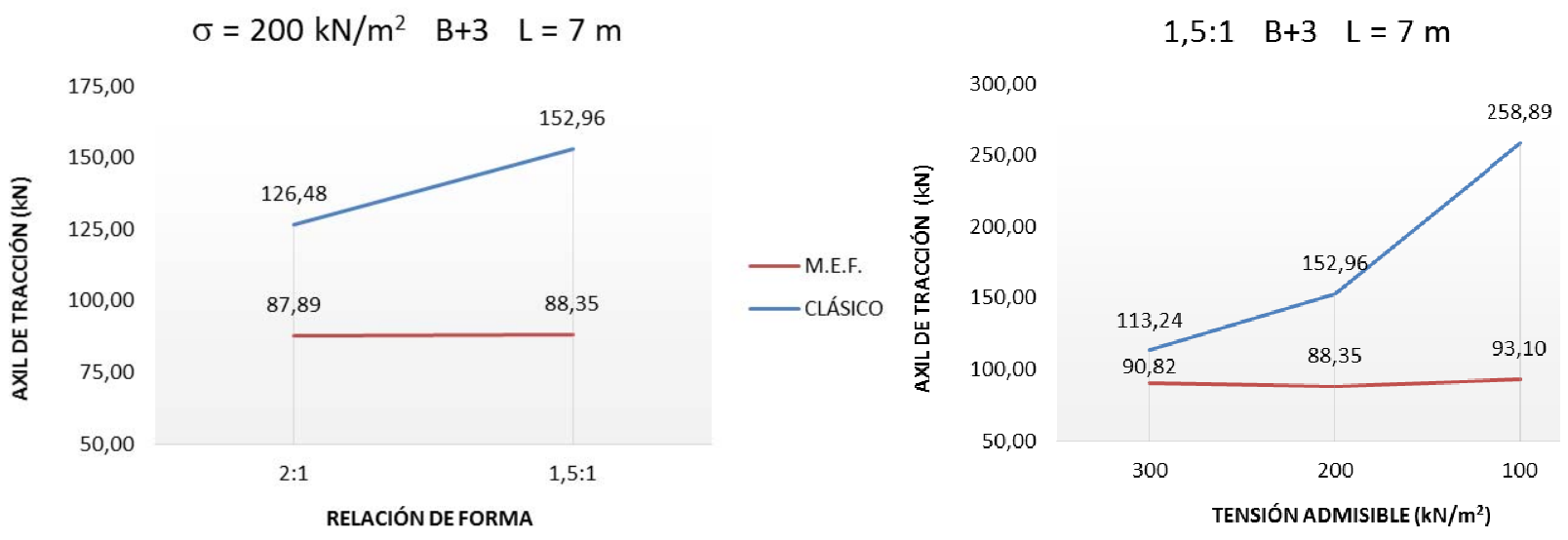

Fig.91. Contraste del esfuerzo axil en la viga superior en función de la relación de forma y de la tensión admisible del terreno
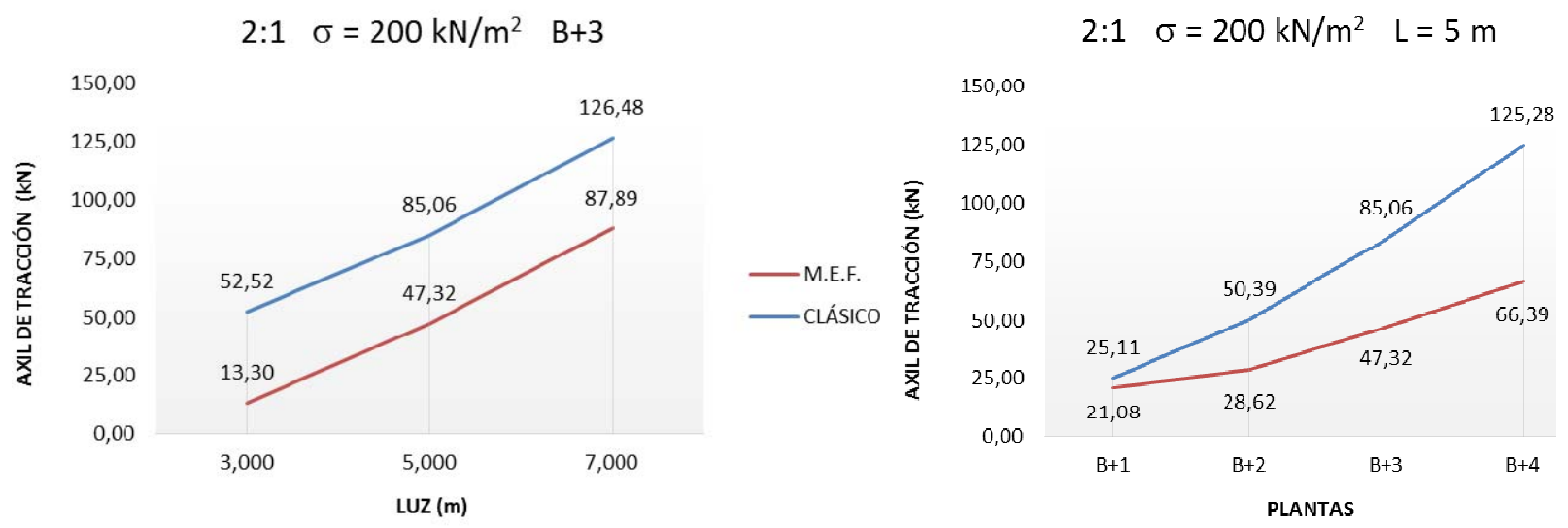

Fig.92. Contraste del axil en la viga superior en función de la luz y el número de plantas del pórtico

Al igual que en los resultados de la Etapa I, se comprueba (Fig.91) que las tracciones obtenidas presentan valores sensiblemente constantes respecto de la tensión admisible del terreno y la relación de forma del terreno no dependiendo, por ello, de ninguna de estas dos variables. En cambio, el contraste de resultados en función de las nuevas variables introducidas en la Etapa II, luz y número de plantas del pórtico (Fig.92), si muestra una influencia clara de estas variables, observándose un incremento del axil de tracción en la viga de la primera planta a medida que aumentan, tanto la luz como el número de plantas del pórtico, pero especialmente con el aumento de luz. 
Frente a los valores de axil de tracción obtenidos en los modelos de elementos finitos de la Etapa I, que permanecían sensiblemente constantes en torno a 40 - $50 \mathrm{kN}$, los resultados de la Etapa II muestran valores bastante superiores que llegan a alcanzar los $125 \mathrm{kN}$. Dichos resultados, ciertamente están lejos de las cotas de axil de tracción que ofrece el método convencional de viga centradora con colaboración exclusiva de la viga superior, pero suelen superar en muchos casos el $50 \%$ del axil proporcionado por el método convencional puro, lo cual ya es una cifra significativa.

Nuevamente el efecto de la fisuración del hormigón en los modelos de elementos finitos de la Etapa II se encuentra detrás el incremento de axil de tracción en la viga de la primera planta de los modelos de la Etapa II, frente a los modelos de la Etapa I. Dicho proceso de fisuración debilita la viga centradora, que pierde inercia y, por ello, rigidez. Al ser la viga centradora menos rígida, experimenta una mayor deformación al entrar en carga, permitiendo un mayor giro de la zapata de medianería, la cual, ante la pérdida de ayuda por parte de la viga centradora, necesita buscar apoyo en otros elementos recurriendo así a la colaboración de la viga de la primera planta como tirante a tracción. 


\subsection{ANÁLISIS Y DISCUSIÓN DE RESULTADOS. ETAPA III}

\subsubsection{AUMENTO DE ARMADURA DE LA VIGA CENTRADORA}

El análisis de los resultados de la Etapa II (apartado 5.2) pone de manifiesto una situación muy problemática en el comportamiento geotécnico de la zapata de medianería, con una importante excentricidad de la resultante de tensiones de contacto, que conduce a un diagrama de tensiones en el límite de las distribuciones triangulares, con inadmisibles tensiones en el borde medianero, incrementadas por la poca colaboración portante de la viga centradora como viga de cimentación.

Según el análisis realizado, en el origen del problema se encuentra la perdida de inercia y rigidez de la viga centradora debido a la fisuración y fractura del hormigón en la zona traccionada de la viga. El debilitamiento de la viga centradora por el proceso de fisuración produce una mayor deformación por flexión de la viga que permite giros excesivos de la zapata de medianería con las correspondientes consecuencias negativas sobre su comportamiento geotécnico.

Una de las posibles vías a plantear para solucionar el problema es reforzar la armadura de tracción de la viga centradora, intentando minimizar con ello el proceso de fisuración de la viga que desencadena su pérdida de rigidez.

En el apartado 3.1.3.3. se argumenta el criterio que fija el máximo nivel de refuerzo de armado que resultaría razonable, estableciéndose dicho nivel en un aumento de armadura tal que no llegue a generar una profundidad de la fibra neutra superior a 0,45 - d. Por su parte, en el apartado 4.3.3, Tabla 62, se ofrece la relación detallada de los refuerzos de armadura propuestos para los distintos casos estudiados, disponiéndose en todos los casos armaduras de tracción del orden de dos veces y media las armaduras de referencia de la Etapa II, lo cual supone un muy importante aumento de armadura.

Los resultados obtenidos en la Etapa III en los casos de incremento de armadura (apartado 4.3.3, Tablas 63 y 64) ciertamente muestran la efectividad conceptual de la medida, ya que todos los casos experimentan una reducción en la excentricidad de la resultante, un cierto aumento en la colaboración portante de la viga centradora y, por todo ello, una reducción en la tensión máxima en el borde de la zapata. Ahora bien, la eficacia real obtenida es mínima, dado que las excentricidades de la resultantes de la zapata de medianería se reducen solamente en tres puntos porcentuales (Fig.93), generando diagramas que se siguen 
situando al límite de las distribuciones triangulares y que las tensiones máximas en el borde de la zapata de medianería siguen siendo en todos los casos excesivas, a pesar de haberse reducido ligeramente (Fig.94).
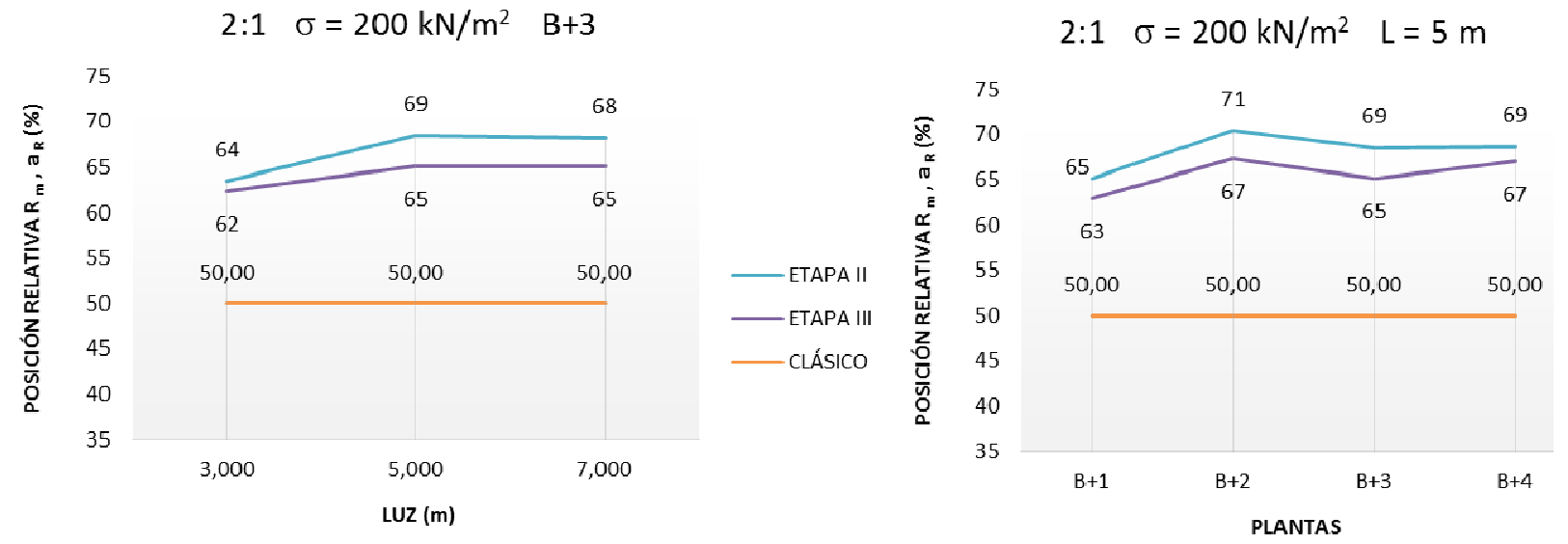

Fig.93. Excentricidades relativas de la resultante de la zapata de medianería con aumento de armadura. Contraste Etapa II - Etapa III

$2: 1 \quad \sigma=200 \mathrm{kN} / \mathrm{m}^{2} \quad \mathrm{~B}+3$

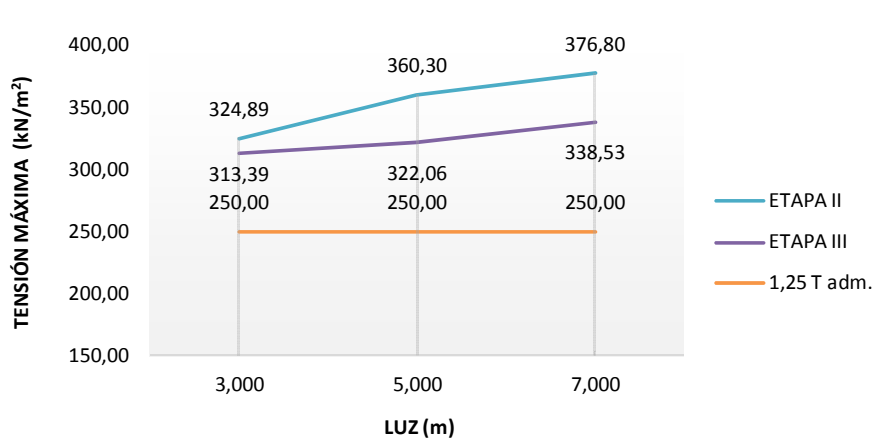

Fig.94. Verificación de tensiones de contacto con aumento de armadura.

Contraste Etapa II - Etapa III
$2: 1 \quad \sigma=200 \mathrm{kN} / \mathrm{m}^{2} \quad \mathrm{~L}=5 \mathrm{~m}$

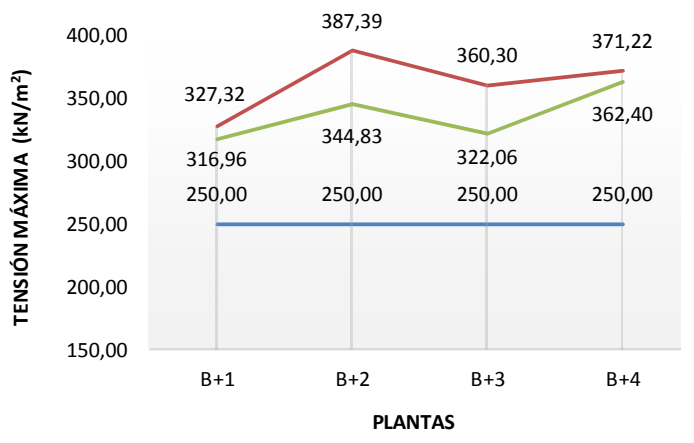

Resulta decepcionante disponer una armadura de tracción más de dos veces y media la original para obtener tan solo una reducción de tres puntos porcentuales en el control de la excentricidad. 


\subsubsection{REDUCCIÓN DE ARMADURA DE LA VIGA CENTRADORA}

El análisis de los resultados, tanto de la Etapa I (apartado 5.1) como de la Etapa II (apartado 5.2), pone de manifiesto la considerable disminución del valor del momento flector de la viga centradora de los modelos de elementos finitos respecto de los modelos convencionales.

Este hecho, junto con las consecuencias negativas que sobre el comportamiento geotécnico de la zapata de medianería tiene el proceso de fisuración de la viga centradora, conduce a dos ideas posiblemente contradictorias. Por un lado, la importante disminución del momento flector invita a una importante reducción del armado, acorde a los esfuerzos que realmente solicitan la viga centradora. Pero, por otro lado, surge el temor a que una reducción de la armadura acentúe el proceso de fisuración de la zona traccionada de la viga, incrementando la pérdida de rigidez de la misma, que a su vez conduciría a mayores giros de la cimentación que generarían todavía menores momentos en la viga centradora, demandando así aún una menor armadura, entrando en un posible bucle sin fin que terminaría con la práctica anulación de la viga centradora.

Resulta por ello obligado experimentar con la reducción de la armadura acorde con los momentos flectores que solicitan la viga centradora de acuerdo con los resultados de la Etapa II. En el apartado 4.3.1, Tabla 57, se ofrece la relación detallada de las armaduras empleadas en todos los casos con reducción de armadura, disponiéndose sección de armadura que llegan a ser inferiores al $40 \%$ de las armaduras de referencia de la Etapa II, lo cual supone una muy importante reducción de armadura.

Los resultados obtenidos en la Etapa III en los casos de reducción de armadura (apartado 4.3.1, Tablas 58 y 59) ciertamente confirman la influencia conceptual de la reducción de armadura sobre una mayor pérdida de rigidez de la viga centradora, que conduce a un mayor giro de la cimentación puesto de manifiesto en el incremento de la excentricidad de la resultante de tensiones de contacto de la zapata de medianería.

Ahora bien, de forma similar a como ocurría con los casos de incremento de armadura, las diferencias no son significativas, ya que se ha procedido a una drástica reducción de armado, llegando a casos con armadura inferior al $40 \%$ de la armadura original $y$, sin embargo, el incremento en la excentricidad de la resultante de la zapata de medianería es de tan solo dos puntos porcentuales (Fig 95). 

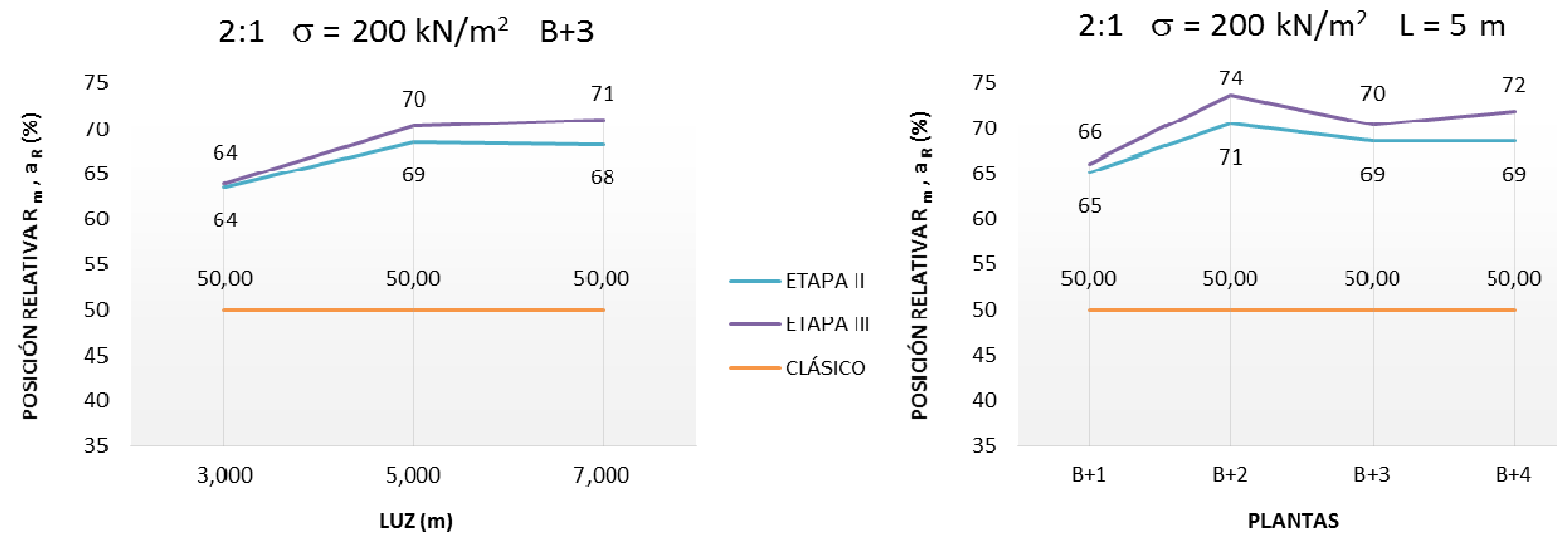

Fig.95. Excentricidades relativas de la resultante de la zapata de medianería con reducción de armadura. Contraste Etapa II - Etapa III

Por ello, puede afirmarse que ajustar la armadura a las solicitaciones reales de momento flector de la viga centradora no empeora significativamente el problema, ni conduce a bucles indefinidos que supongan la práctica anulación de la viga centradora.

Puede también afirmarse con lo analizado hasta este punto, que la viga centradora está demostrando poca eficacia en su función estabilizadora (centradora) de la zapata de medianería, pareciendo tener la armadura poca influencia sobre dicha eficacia, ya sea por exceso o por defecto de la misma. 


\subsubsection{ELIMINACIÓN DE LA VIGA CENTRADORA}

La experimentación de modelos de elementos finitos sin viga centradora tiene un doble objetivo, Por un lado, comprobar la eficacia real de la viga centradora, puesta en duda como consecuencia de los resultados obtenidos en etapas anteriores y, por otro, contrastar el modelo convencional de colaboración de viga superior sin viga centradora.

Los resultados obtenidos en la Etapa III para los casos sin viga centradora (apartado 4.3.2, Tablas 60 y 61) muestran un comportamiento geotécnico extremo para la zapata de medianería, con excentricidades del orden del $80 \%$, doce puntos porcentuales por encima de los resultados de la Etapa II, que conducen a la zapata de medianería hacia diagramas de distribución de tensiones netamente triangulares, altamente desfavorables y nada deseables (Fig.96).
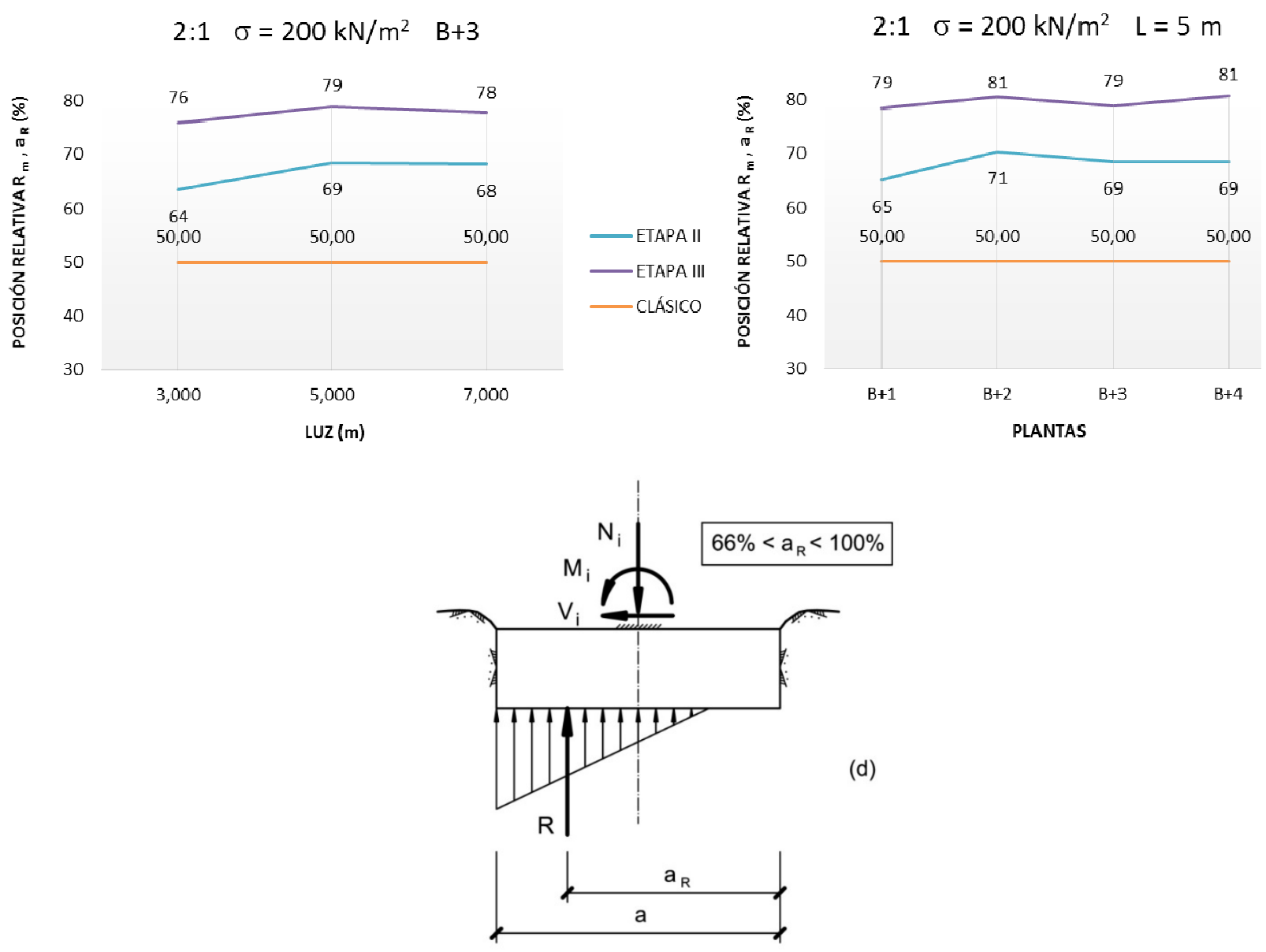

Fig.96. Excentricidades relativas de la resultante de la zapata de medianería sin viga centradora. Contraste Etapa II - Etapa III

Se trata, por tanto de un empeoramiento claramente significativo, muy diferente de los dos puntos porcentuales que suponía la reducción de armadura, que pone de manifiesto la 
eficacia de la viga centradora, no tanto por su armado, como por la viga en sí misma, mediante su propia geometría, definida por su escuadría y, especialmente por su canto.

Asimismo, los resultados mostrados en la Fig.96 indican lo alejado que se encuentra de la realidad el modelo convencional de colaboración de viga superior, que considera una distribución de tensiones uniformemente repartida en la zapata de medianería, totalmente opuesta a la realmente obtenida.

Finalmente, los modelos de elementos finitos sin viga centradora, permiten contrastar el trabajo a flexotracción de la viga de la primera planta en su doble función de viga y tirante. El contraste entre los valores de esfuerzo axil de tracción en la viga de la primera planta obtenidos tanto con los modelos de elementos finitos como con los modelos convencionales (Fig.97) muestra el incremento experimentado por el axil de tracción en la viga superior en os modelos de elementos finitos el eliminar la viga centradora, aun así siguen siendo menores los esfuerzos de tracción en los modelos de elementos finitos, debido a que al estar desplazada la resultante hacia el pilar medianero, el momento desestabilizante de la zapata de medianería es más pequeño y por ello se requiere una menor fuerza de tracción en la viga superior para equilibrarlo.

$2: 1 \quad \sigma=200 \mathrm{kN} / \mathrm{m}^{2} \quad \mathrm{~B}+3$

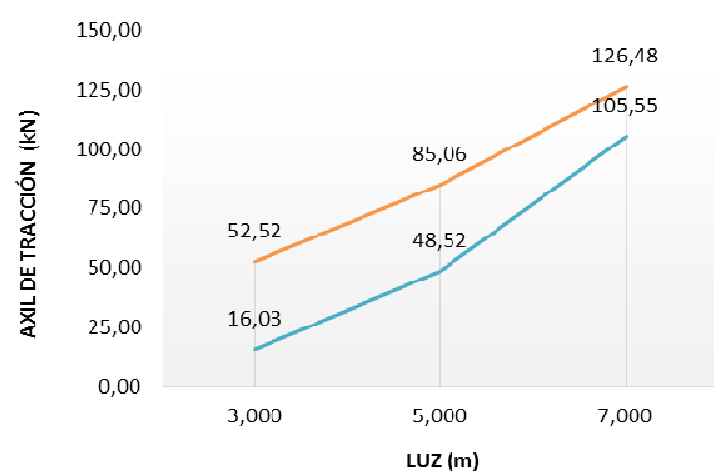

$2: 1 \quad \sigma=200 \mathrm{kN} / \mathrm{m}^{2} \quad \mathrm{~L}=5 \mathrm{~m}$

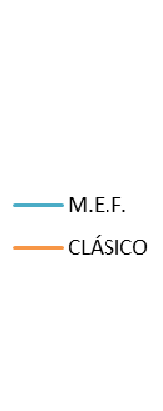

Fig.97. Contraste del axil en la viga superior en función de la luz y el número de plantas del pórtico 


\subsubsection{AUMENTO DEL CANTO DE LA VIGA CENTRADORA}

La segunda posible vía para aumentar la rigidez de la viga centradora es el aumento del canto de la viga centradora para lograr el correspondiente aumento en la inercia de la sección. Los casos desarrollados en la Etapa II están realizados con el mínimo canto compatible con la condición de anclaje de la armadura de los pilares. En la Etapa III, se ensayan tres niveles adicionales de rigidez que se obtienen incrementando dicho canto mínimo en un $25 \%, 50 \%$ y $75 \%$ respectivamente.

Los resultados obtenidos en la Etapa III en los casos de incremento de canto de la viga centradora (apartado 4.3.4, Tablas 65 a 70) muestran la clara eficacia de la medida de cara a conseguir una viga centradora suficientemente rígida, con reducida deformación y, por ello, con capacidad para controlar el giro de la zapata de medianería que, junto con el aumento de su capacidad portante como viga de cimentación conducen a un comportamiento geotécnico más apropiado de la zapata de medianería. Lógicamente el resultado es especialmente nítido en la propuesta de un $75 \%$ de aumento de canto que, frente a las llamativas propuestas realizadas con la variable aumento de armadura que conducían a armaduras dos veces y media la original, generan casos de no más de 1,250 m de canto que, siendo ligeramente elevado, resulta razonable y no especialmente llamativo.

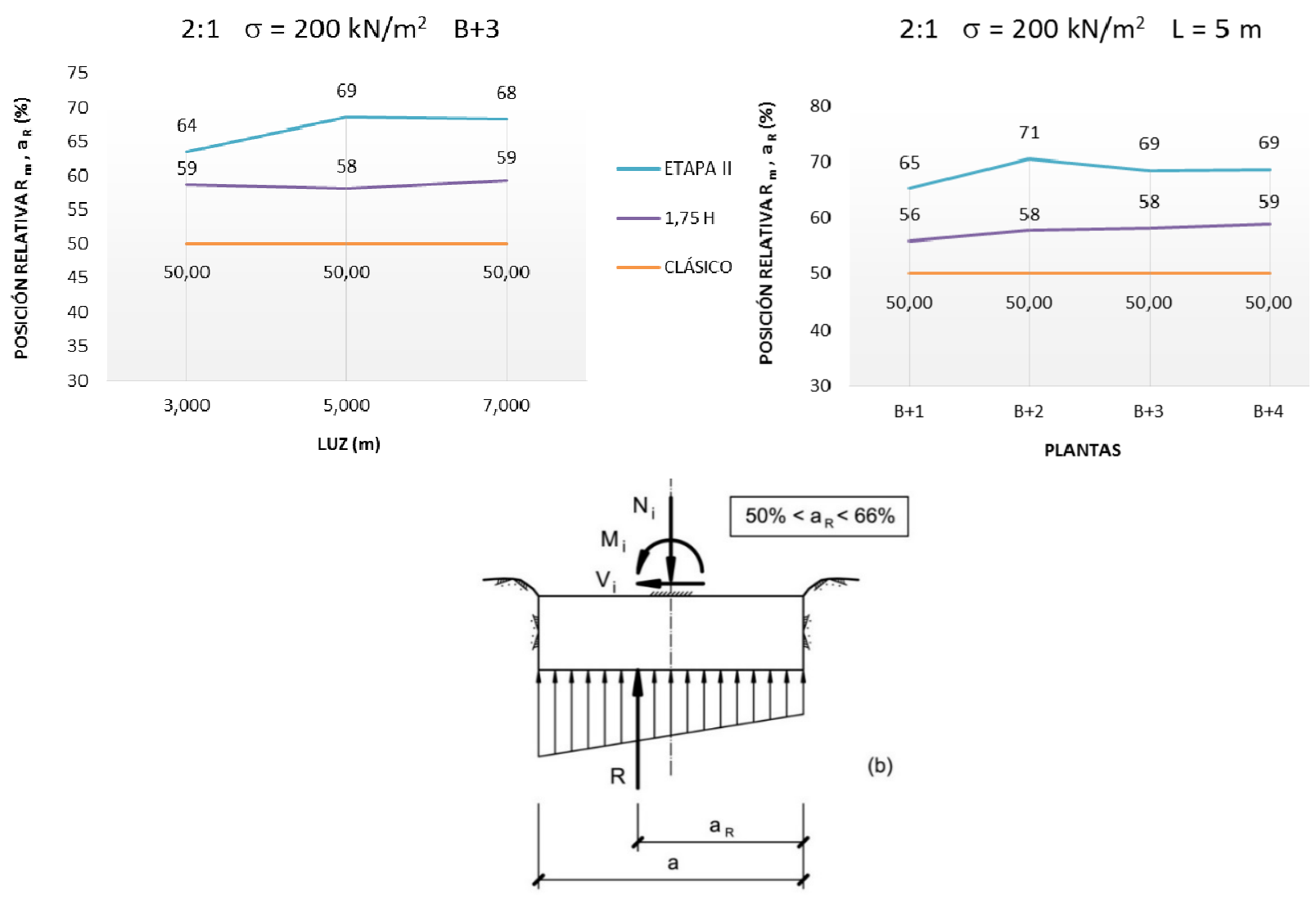

Fig.98. Excentricidades relativas de la resultante de la zapata de medianería. $H=1,75 \cdot H_{\text {min }}$ 
La Fig.98 muestra las excentricidades o posiciones relativas de la resultante de tensiones de contacto bajo la zapata de medianería que manifiestan haberse logrado un suficiente nivel de rigidez en la viga centradora pues se obtienen importantes reducciones, del orden de diez o doce puntos porcentuales respecto de los resultados de la Etapa II. Si bien alcanzar el centrado absoluto (50\% de posición relativa) resulta imposible pues requeriría un nivel de rigidez infinito, las excentricidades relativas obtenidas son muy satisfactorias, con valores en torno al $56 \%$ - $60 \%$ que generan diagramas netamente trapeciales.

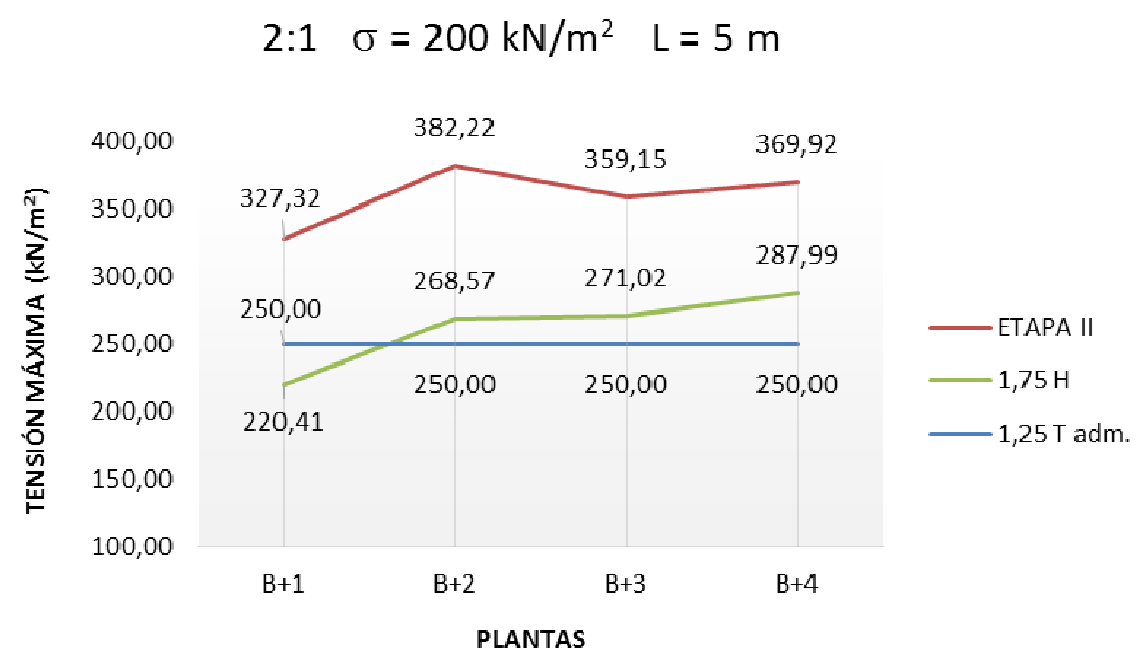

Fig.99. Verificación de tensiones de contacto. $\mathrm{H}=1,75 \cdot \mathrm{H}_{\min }$

La reducción en la excentricidad, unida a la recuperación del papel colaborador de la viga centradora como elemento transmisor de carga al terreno conducen a un razonable comportamiento geotécnico de las zapatas de medianería (Fig.99) donde, si bien hay casos que superan ligeramente el límite de tensión establecido en la comprobación de tensiones de contacto, hay otros que llegan a cumplir la verificación del E.L.U. de hundimiento a pesar de la punta de tensiones de los diagramas trapeciales.

Finalmente resulta muy llamativo el gráfico de la Fig.100 que muestra la comparación entre los momentos flectores obtenidos en la viga centradora con las distintas variables contempladas en el estudio. En dicha figura puede observarse que, cuando el nivel de rigidez de la viga centradora es suficiente, los momentos flectores vuelven a crecer considerablemente, pareciéndose mucho a los proporcionados por el método convencional, siendo del orden del $80 \%$ de éstos. 


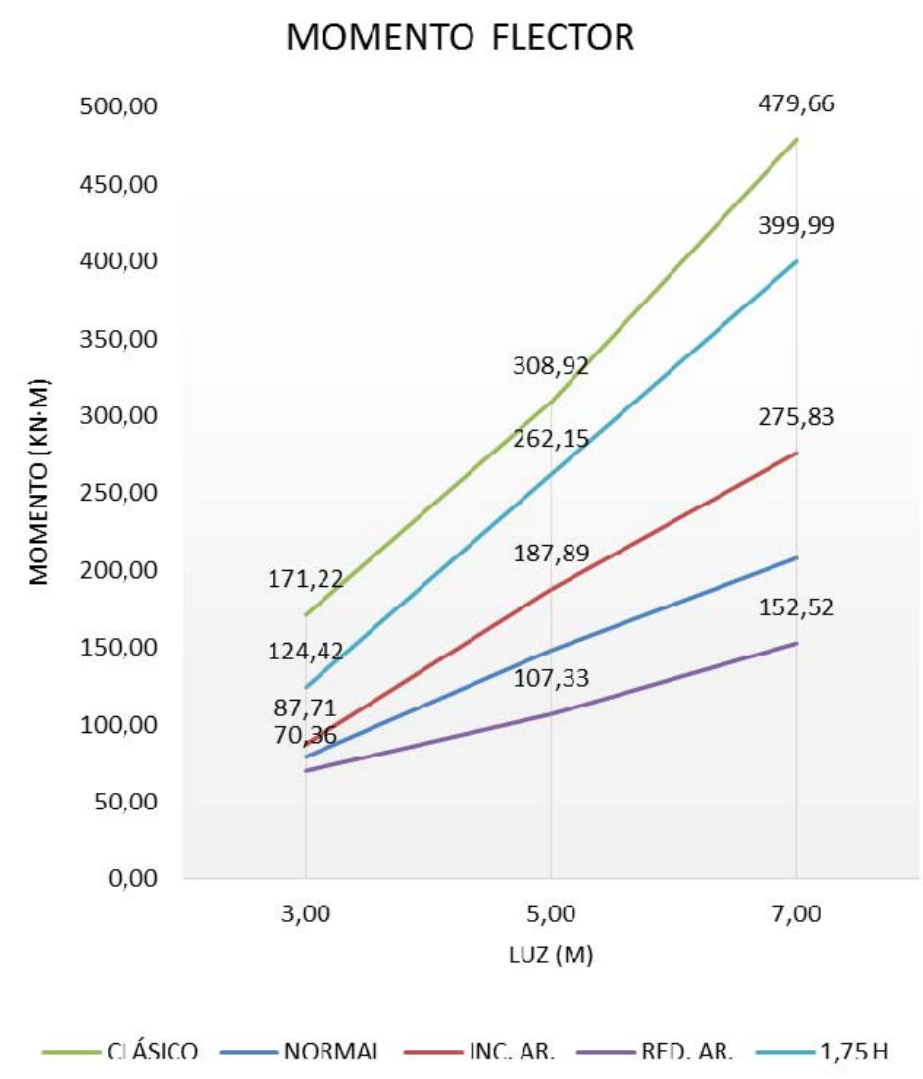

Fig.100. Contraste del valor del momento flector en la viga centradora

Podría concluirse que, al final, el método convencional parece no estar tan desencaminado, si bien el centrado absoluto de la zapata de medianería es imposible porque requeriría una rigidez infinita en la viga centradora. El auténtico problema en este tipo de cimentaciones es el giro de la zapata de medianería. Para evitarlo, la única solución claramente eficaz es disponer una viga centradora de suficiente rigidez, lo cual se logra únicamente con el aumento del canto de la misma. En dichas condiciones los momentos flectores en la viga centradora son también altos, si bien no hay ningún problema en ajustar la armadura al momento que realmente se produzca, ya que se ha comprobado que ligeras reducciones de armadura no se traducen en importantes incrementos de la excentricidad de la resultante de la zapata de medianería. 


\subsection{ANÁLISIS Y DISCUSIÓN DE RESULTADOS. ETAPA IV}

Concluido el estudio relativo a las zapatas de medianería, la Etapa IV constituye la aplicación del proceso a las zapatas de esquina con dos vigas centradoras, entendidas como caso particular de las anteriores. Dada la experiencia previa tras el trabajo realizado con las zapatas de medianería, solamente se ensaya la variable que ha demostrado tener influencia real sobre el problema, como es la variación en el canto de las vigas centradoras, aplicado todo ello a un conjunto de casos definido por las permutaciones de luces y número de plantas contempladas hasta ahora. Para el canto de la cimentación se estudian dos casos, el primero correspondiente al canto mínimo compatible con el anclaje de la armadura de los pilares y, el segundo, aplicando un incremento de un $75 \%$ sobre el canto mínimo.

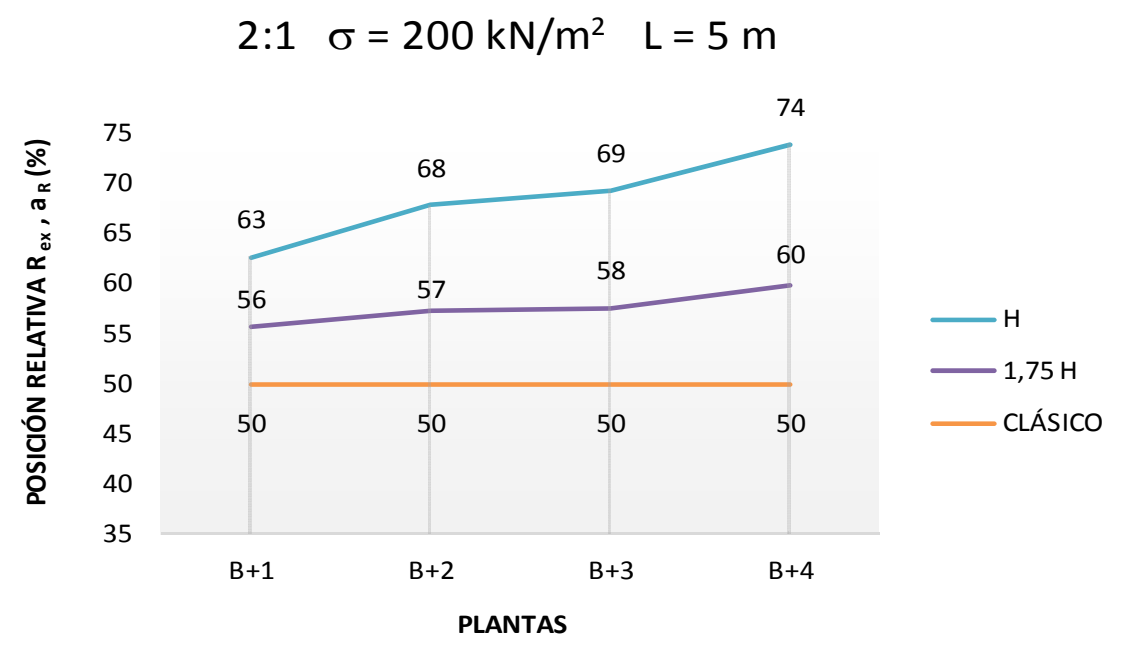

Fig.101. Excentricidades relativas de la resultante de la zapata de esquina

Los resultados obtenidos en la Etapa IV para la zapata de esquina (apartado 4.4, Tablas 71 a 77) muestran similitudes y diferencias con los resultados obtenidos para los casos equivalentes de zapata de medianería. Ciertamente, al igual que ocurría con las zapatas de medianería, las excentricidades generadas en la resultante de tensiones de contacto de la zapata de esquina dejan a ésta con diagramas de tensiones equivalentes al triangular en $3 \mathrm{D}$ para los casos de canto mínimo y diagramas equivalentes al trapecial para los casos de canto $1,75 \mathrm{H}_{\min }$ (Fig.101).

Ahora bien, la magnitud de las excentricidades obtenidas para los casos de zapata de esquina es superior a la de las obtenidas para los casos de zapata de medianería, lo cual señala a las zapatas de esquina como un caso más desfavorable que las zapatas de 
medianería. La explicación de este hecho puede encontrarse en la forma cuadrada de la zapata de esquina. Debido a la confluencia de dos medianerías, no es recomendable utilizar en este caso zapatas rectangulares, ya que una de las vigas centradoras se vería muy beneficiada por el lado corto del rectángulo, pero la otra se vería condenada por la mayor dimensión de la zapata que dejaría muy excéntrico el pilar respecto del centro de gravedad de la misma en esa dirección. La solución de zapata cuadrada pretende equilibrar ambas direcciones pero, como ya se comprobó en los casos de zapata de medianería, es una relación de forma desfavorable, que conduce a que la resultante de las tensiones de contacto se desplace más hacia el centro de las vigas centradoras, generando mayor flexión y deformación de las mismas.

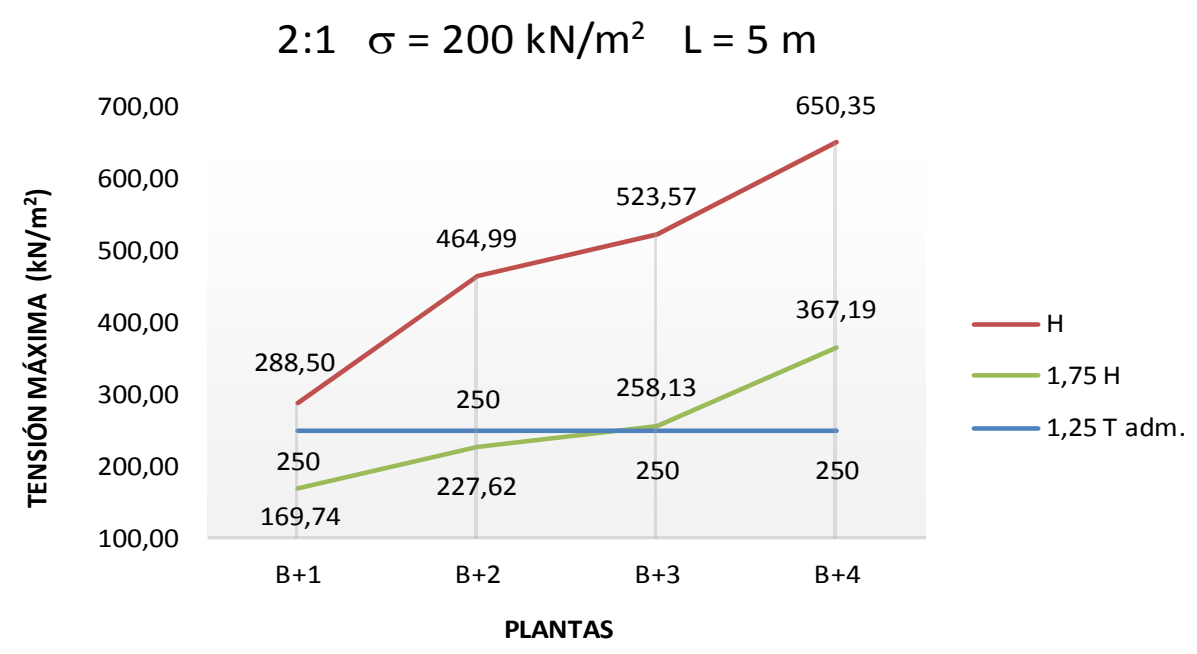

Fig.102. Verificación de tensiones de contacto en la zapata de esquina

Por su parte, se constata igualmente la situación problemática de la comprobación de tensiones de contacto en la zapata de esquina para los casos de canto mínimo (Fig.102), si bien el problema aparece en las zapatas de esquina de un modo más agudo que en las zapatas de medianería. La causa del agravamiento de la situación en las zapatas de esquina está, por un lado, en el aumento de las excentricidades comentado en el párrafo anterior y, por otro, en el hecho de tratarse de una situación de, podría decirse, flexión desviada, con una doble excentricidad simultanea que acentúa la cuestión de las tensiones de contacto.

Se comprueba, asimismo, el efecto claramente favorable del incremento de canto en las vigas centradoras, situándose en torno a la zona de cumplimiento los casos de canto $1,75 \mathrm{H}_{\text {min }}$ (Fig.102). Ahora bien, cabe indicar que las excentricidades obtenidas con este canto en los casos de zapata de esquina son, en general, ligeramente superiores a las obtenidas en los correspondientes casos de zapata de medianería, lo cual parece indicar la necesidad de un 
ligero incremento de canto adicional en las zapatas de esquina para alcanzar el mismo nivel de control de la excentricidad.

Señalar, por último, que también se comprueba en los casos de zapata de esquina una considerable reducción de momento flector de las vigas centradoras en los casos de canto mínimo y, por ello, reducida rigidez de las mismas obteniéndose, en cambio, momentos más próximos a los que genera el método convencional cuando de dota a las vigas centradoras de la suficiente rigidez (canto $1,75 \mathrm{H}_{\min }$ ) (Fig.103).

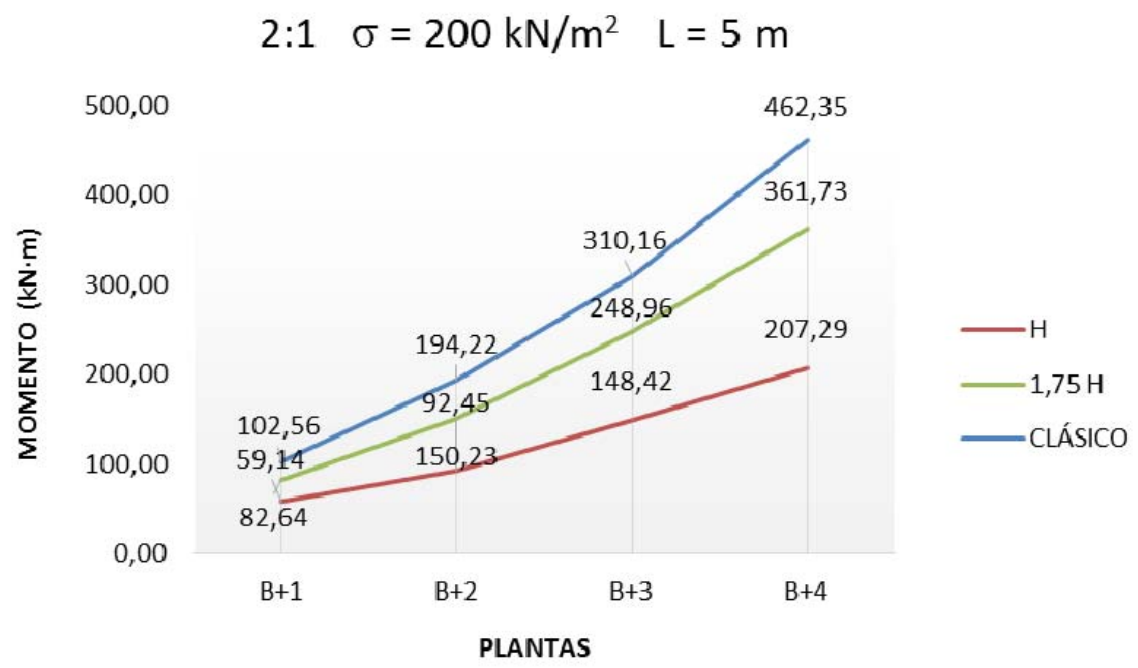

Fig.103. Contraste del valor del momento flector en las vigas centradoras

No obstante, es preciso matizar que los momentos de los casos $1,75 \mathrm{H}_{\min }$ obtenidos en las zapatas de esquina son, en proporción, algo inferiores a los obtenidos con zapata de medianería, lo cual pone de manifiesto la mayor flexión de las vigas centradoras en este caso y la necesidad de un ligero incremento del canto respecto de los casos de zapata de medianería. 


\subsection{PROPUESTA DE MEJORA DEL MÉTODO CONVENCIONAL}

\subsubsection{ZAPATA DE MEDIANERÍA CON VIGA CENTRADORA}

El método convencional para el cálculo de zapatas de medianería con viga centradora presenta la clara intención de buscar un esquema isostático fácilmente resoluble por medios manuales. Por ello, está planteado de tal modo que solo aparezcan dos incógnitas $R_{m}$ y $R_{i}$, cuya solución requiere solamente del empleo de dos ecuaciones, que se obtienen del equilibrio estático de momentos y de fuerzas verticales en el sólido representado en la Fig.104.a.
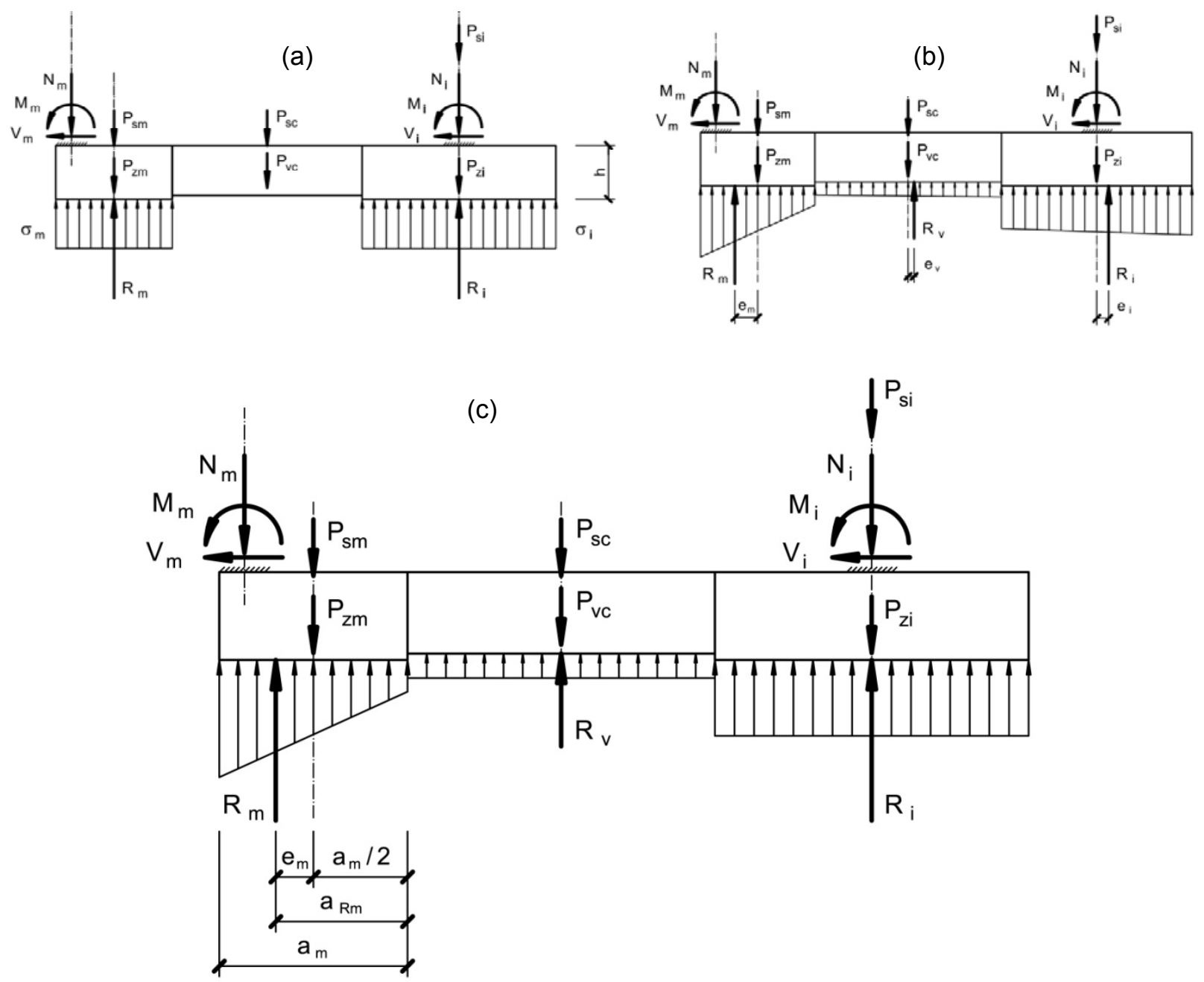

Fig.104. Comparación método convencional - resultados M.E.F.

Los resultados de los modelos de elementos finitos ponen de manifiesto, por un lado, la existencia de resultante por tensiones de contacto bajo la viga centradora y, por otro, la clara excentricidad de la resultante de la zapata de medianería. Por lo que respecta a las resultantes, tanto de la zapata interior como de la viga centradora, si bien es cierto que no 
están absolutamente centradas, las excentricidades que presentan suelen ser pequeñas especialmente cuando se expresan en términos relativos al tamaño total del correspondiente elemento (Fig.104.b), por lo cual no resulta especialmente problemático considerarlas en la práctica como reacciones centradas. Ello conduce a un total de cuatro incógnitas, tres resultantes más la excentricidad que permite localizar la posición de la resultante de la zapata de medianería (Fig.104.c).

Teniendo en cuenta que solo se dispone de dos ecuaciones de equilibrio estático, se necesitan dos nuevas ecuaciones para poder resolver el problema. En concreto, si se dispusiese de un algoritmo de cálculo que permitiese obtener la resultante bajo la viga centradora y otro para la excentricidad de la zapata de medianería, se tendrían las dos ecuaciones adicionales que permiten abordar el problema.

A ser posible, sería interesante que cada uno de los algoritmos indicados fuese particular y exclusivo de la correspondiente incógnita, de modo que se pudiesen ir resolviendo de forma secuencial sin necesidad de recurrir a la resolución de un sistema de cuatro ecuaciones con cuatro incógnitas, todo ello con el fin de proponer una alternativa metodológica más ajustada a la realidad, pero igualmente sencilla en su aplicación.

Dado que, gracias a los modelos de elementos finitos, se dispone de un conjunto amplio de valores correspondientes a las indicadas incógnitas, los algoritmos en cuestión pueden obtenerse mediante ajustes de regresión a partir de los resultados de los modelos de elementos finitos.

Se ofrece a continuación en las Tablas 75 a 78 una recopilación de las posiciones de la resultante de la zapata de medianería y del valor de las resultantes de la zapata de medianería y la viga centradora, correspondientes a los casos estudiados tanto en la Etapa II como en la Etapa III, exceptuando los casos de variación de armadura. La posición de la resultante se define respecto del extremo de la zapata y se expresa en tanto por ciento respecto del tamaño total de la misma. Se incluye también la relación luz - canto de cada caso y el porcentaje de área que representa la viga centradora respecto del área total del conjunto de cimentación definido por la zapata de medianería, la zapata interior y la viga centradora.

Posteriormente se procede a obtener los algoritmos indicados que permiten resolver las incógnitas sobrantes del esquema de la Fig.104.b, mediante ajustes de regresión a partir de los datos de las Tablas 75 a 78 . 


\begin{tabular}{|c|c|c|c|c|c|}
\hline & & \multicolumn{3}{|c|}{ RESULTADOS M.E.F. } & BAJA+1 \\
\hline & L/h & $\begin{array}{l}a_{R m} \\
(\%)\end{array}$ & $\begin{array}{c}R_{v} \\
(k N)\end{array}$ & $\begin{array}{l}R_{m} \\
(k N)\end{array}$ & $\begin{array}{l}A_{v} \\
(\%)\end{array}$ \\
\hline L3_1P $1,5: 1100$ & 6,0 & 61,3 & 19,28 & 348,61 & 4,0 \\
\hline L5_1P $1,5: 1100$ & 8,3 & 63,5 & 71,95 & 466,46 & 9,0 \\
\hline L7_1P 1,5:1100 & 10,0 & 66,7 & 128,88 & 602,24 & 9,8 \\
\hline L3_1P 1,5:1200 & 6,0 & 61,0 & 78,44 & 249,15 & 17,5 \\
\hline L5_1P $1,5: 1200$ & 8,3 & 67,5 & 120,21 & 350,16 & 21,6 \\
\hline L7_1P $1,5: 1200$ & 10,0 & 69,3 & 166,37 & 452,42 & 23,1 \\
\hline L3_1P $1,5: 1300$ & 6,0 & 62,5 & 115,81 & 205,76 & 27,2 \\
\hline L5_1P 1,5:1300 & 8,3 & 65,8 & 145,48 & 320,65 & 32,4 \\
\hline L7_1P 1,5:1300 & 10,0 & 68,1 & 192,64 & 423,09 & 34,1 \\
\hline L3_1P 2:1 100 & 6,0 & 61,1 & 28,08 & 329,09 & 5,0 \\
\hline L5_1P 2:1 100 & 8,3 & 64,8 & 77,50 & 444,16 & 8,2 \\
\hline L7_1P 2:1 100 & 10,0 & 68,3 & 156,91 & 569,46 & 11,0 \\
\hline L3_1P 2:1200 & 6,0 & 61,3 & 84,73 & 241,29 & 19,1 \\
\hline L5_1P 2:1200 & 8,3 & 65,0 & 134,82 & 342,39 & 23,3 \\
\hline L7_1P 2:1200 & 10,0 & 68,3 & 172,34 & 458,60 & 24,0 \\
\hline L3_1P 2:1300 & 6,0 & 61,6 & 112,20 & 204,31 & 28,1 \\
\hline L5_1P 2:1300 & 8,3 & 65,0 & 149,56 & 317,70 & 33,6 \\
\hline L7_1P 2:1300 & 10,0 & 66,7 & 205,00 & 413,96 & 35,0 \\
\hline L3_1P 2:1200 1,25 H & 4,8 & $\overline{59,5}$ & 90,71 & 229,01 & 19,1 \\
\hline L5_1P 2:1200 1,25 H & 6,7 & 60,0 & 176,97 & 329,30 & 23,3 \\
\hline L7_1P 2:12001,25 H & 8,0 & 63,5 & 220,74 & 462,54 & 24,0 \\
\hline L3_1P 2:1 $2001,50 \mathrm{H}$ & 4,0 & 58,5 & 94,59 & 243,45 & 19,1 \\
\hline L5_1P 2:1 $2001,50 \mathrm{H}$ & 5,6 & 57,0 & 201,60 & 319,92 & 23,3 \\
\hline L7_1P 2:1 $2001,50 \mathrm{H}$ & 6,7 & 59,6 & 284,37 & 435,37 & 24,0 \\
\hline L3_1P 2:1200 1,75 H & 3,4 & 58,2 & 97,36 & 263,68 & 19,1 \\
\hline L5_1P 2:1 $2001,75 \mathrm{H}$ & 4,8 & 56,0 & 217,48 & 324,44 & 23,3 \\
\hline L7_1P 2:1 $2001,75 \mathrm{H}$ & 5,7 & 57,8 & 324,48 & 420,18 & 24,0 \\
\hline
\end{tabular}

Tabla 75. Resultados M.E.F. Baja+1. Posición y Resultantes 


\begin{tabular}{|c|c|c|c|c|c|}
\hline & \multicolumn{4}{|c|}{ RESULTADOS M.E.F. } & $\mathrm{BAJA+2}$ \\
\hline & L/h & $\begin{array}{l}a_{R m} \\
(\%)\end{array}$ & $\begin{array}{c}R_{v} \\
(k N)\end{array}$ & $\begin{array}{c}R_{m} \\
(k N)\end{array}$ & $\begin{array}{l}A_{v} \\
(\%)\end{array}$ \\
\hline L3_2P 1,5:1 100 & & & & & \\
\hline L5_2P 1,5:1100 & 8,3 & 65,7 & 68,89 & 742,81 & 5,0 \\
\hline L7_2P 1,5:1100 & 10,0 & 67,7 & 129,93 & 961,70 & 7,2 \\
\hline L3_2P 1,5:1200 & 6,0 & 63,6 & 72,26 & 424,43 & 10,1 \\
\hline L5_2P 1,5:1200 & 8,3 & 69,3 & 138,28 & 543,45 & 16,1 \\
\hline L7_2P 1,5:1200 & 10,0 & 69,6 & 205,92 & 748,81 & 18,8 \\
\hline L3_2P $1,5: 1300$ & 6,0 & 64,0 & 113,54 & 363,29 & 19,2 \\
\hline L5_2P 1,5:1300 & 8,3 & 69,1 & 156,12 & 505,33 & 22,6 \\
\hline L7_2P 1,5:1300 & 10,0 & 67,0 & 268,44 & 665,87 & 30,2 \\
\hline L3_2P 2:1 100 & & & & & \\
\hline L5_2P 2:1100 & 8,3 & 66,0 & 76,55 & 718,03 & 5,5 \\
\hline L7_2P 2:1100 & 10,0 & 67,8 & 165,63 & 942,75 & 7,7 \\
\hline L3_2P 2:1200 & 6,0 & 63,3 & 76,27 & 414,86 & 11,1 \\
\hline L5_2P 2:1200 & 8,3 & 70,8 & 134,21 & 535,39 & 14,5 \\
\hline L7_2P 2:1200 & 10,0 & 70,0 & 227,74 & 719,91 & 20,4 \\
\hline L3_2P 2:1300 & 6,0 & 64,1 & 113,90 & 366,65 & 19,1 \\
\hline L5_2P 2:1300 & 8,3 & 68,0 & 158,89 & 505,03 & 23,3 \\
\hline L7_2P 2:1300 & 10,0 & 68,6 & 231,45 & 697,36 & 27,4 \\
\hline L3_2P 2:1 $2001,25 \mathrm{H}$ & 4,8 & 59,1 & 86,12 & 435,71 & 11,1 \\
\hline L5_2P 2:1 $2001,25 \mathrm{H}$ & 6,7 & 66,0 & 158,67 & 549,02 & 14,5 \\
\hline L7_2P 2:12001,25 H & 8,0 & 65,9 & 274,45 & 744,69 & 20,4 \\
\hline L3_2P 2:1 $2001,50 \mathrm{H}$ & 4,0 & 57,7 & 90,69 & 418,84 & 11,1 \\
\hline L5_2P 2:1 $2001,50 \mathrm{H}$ & 5,6 & 61,2 & 190,74 & 554,70 & 14,5 \\
\hline L7_2P 2:1 $2001,50 \mathrm{H}$ & 6,7 & 61,7 & 342,10 & 740,71 & 20,4 \\
\hline L3_2P 2:1 $2001,75 \mathrm{H}$ & 3,4 & 56,8 & 93,83 & 421,92 & 11,1 \\
\hline L5_2P 2:1200 1,75 H & 4,8 & 58,0 & 211,42 & 572,27 & 14,5 \\
\hline L7_2P 2:1200 1,75 H & 5,7 & 59,0 & 388,88 & 728,63 & 20,4 \\
\hline
\end{tabular}

Tabla 76. Resultados M.E.F. Baja+2. Posición y Resultantes 


\begin{tabular}{|c|c|c|c|c|c|}
\hline & \multicolumn{4}{|c|}{ RESULTADOS M.E.F. } & $\mathbf{B A J A + 3}$ \\
\hline & L/h & $\begin{array}{l}a_{\mathrm{Rm}} \\
(\%) \\
\end{array}$ & $\begin{array}{c}R_{v} \\
(\mathbf{k N})\end{array}$ & $\begin{array}{l}\mathbf{R}_{\mathrm{m}} \\
(\mathbf{k N}) \\
\end{array}$ & $\begin{array}{l}A_{v} \\
(\%)\end{array}$ \\
\hline L3_3P 1,5:1 100 & & & & & \\
\hline L5_3P $1,5: 1100$ & & & & & \\
\hline L7_3P 1,5:1100 & 10,0 & 66,9 & 130,84 & 1383,50 & 4,3 \\
\hline L3_3P $1,5: 1200$ & 6,0 & 62,9 & 40,35 & 640,06 & 6,0 \\
\hline L5_3P 1,5:1200 & 8,3 & 66,6 & 141,87 & 809,45 & 12,1 \\
\hline L7_3P 1,5:1200 & 10,0 & 68,5 & 223,60 & 1044,68 & 16,0 \\
\hline L3_3P $1,5: 1300$ & 6,0 & 65,1 & 101,55 & 529,58 & 14,3 \\
\hline L5_3P $1,5: 1300$ & 8,3 & 67,0 & 182,48 & 707,49 & 19,9 \\
\hline L7_3P 1,5:1300 & 10,0 & 67,7 & 301,49 & 924,94 & 26,1 \\
\hline L3_3P 2:1 100 & & & & & \\
\hline L5_3P 2:1100 & & & & & \\
\hline L7_3P 2:1100 & 10,0 & 67,0 & 168,32 & 1328,34 & 5,6 \\
\hline L3_3P 2:1200 & 6,0 & 63,8 & 71,40 & 606,28 & 6,7 \\
\hline L5_3P 2:1200 & 8,3 & 68,7 & 171,46 & 765,01 & 13,3 \\
\hline L7_3P 2:1200 & 10,0 & 68,2 & 256,91 & 1035,85 & 16,6 \\
\hline L3_3P 2:1300 & 6,0 & 64,0 & 109,48 & 527,88 & 14,1 \\
\hline L5_3P 2:1300 & 8,3 & 66,5 & 177,05 & 732,99 & 21,1 \\
\hline L7_3P 2:1300 & 10,0 & 67,8 & 267,57 & 984,01 & 23,9 \\
\hline L3_3P 2:1 $2001,25 \mathrm{H}$ & 4,8 & 61,5 & 65,27 & 613,96 & 6,7 \\
\hline L5_3P 2:1200 1,25 H & 6,7 & 64,7 & 184,28 & 775,83 & 13,3 \\
\hline L7_3P 2:1200 1,25 H & 8,0 & 66,5 & 298,16 & 1025,60 & 16,6 \\
\hline L3_3P 2:1 $2001,50 \mathrm{H}$ & 4,0 & 60,0 & 67,62 & 622,47 & 6,7 \\
\hline L5_3P 2:1 $2001,50 \mathrm{H}$ & 5,6 & 61,3 & 207,72 & 781,09 & 13,3 \\
\hline L7_3P 2:1200 1,50 H & 6,7 & 62,4 & 350,58 & 1043,26 & 16,6 \\
\hline L3_3P 2:1 $2001,75 \mathrm{H}$ & 3,4 & 58,5 & 69,21 & 621,71 & $\overline{6,7}$ \\
\hline L5_3P 2:1 $2001,75 \mathrm{H}$ & 4,8 & 58,0 & 224,21 & 821,46 & 13,3 \\
\hline L7_3P 2:1 $2001,75 \mathrm{H}$ & 5,7 & 59,4 & 402,64 & 1079,16 & 16,6 \\
\hline
\end{tabular}

Tabla 77. Resultados M.E.F. Baja+3. Posición y Resultantes 


\begin{tabular}{|c|c|c|c|c|c|}
\hline & \multicolumn{4}{|c|}{ RESULTADOS M.E.F. } & BAJA+4 \\
\hline & L/h & $\begin{array}{l}a_{\mathrm{Rm}} \\
(\%)\end{array}$ & $\begin{array}{c}R_{v} \\
(k N)\end{array}$ & $\begin{array}{c}R_{m} \\
(k N)\end{array}$ & $\begin{array}{l}A_{v} \\
(\%)\end{array}$ \\
\hline $\begin{array}{l}\text { L3_4P 1,5:1 } 100 \\
\text { L5_4P 1,5:1 } 100 \\
\text { L7_4P 1,5:1 } 100\end{array}$ & & & & & \\
\hline L3_4P 1,5:1200 & & & & & \\
\hline L5_4P 1,5:1200 & 8,3 & 67,0 & 142,14 & 1072,70 & 9,9 \\
\hline L7_4P 1,5:1200 & 10,0 & 68,7 & 247,02 & 1397,20 & 13,6 \\
\hline L3_4P 1,5:1300 & 6,0 & 60,4 & 99,19 & 729,88 & 10,4 \\
\hline L5_4P 1,5:1300 & 8,3 & 65,5 & 222,36 & 955,73 & 18,4 \\
\hline L7_4P 1,5:1300 & 10,0 & 67,2 & 289,68 & 1250,60 & 20,7 \\
\hline $\begin{array}{l}\text { L3_4P 2:1 } 100 \\
\text { L5_4P 2:1 } 100 \\
\text { L7_4P 2:1 } 100\end{array}$ & & & & & \\
\hline L3_4P 2:1200 & & & & & \\
\hline L5_4P 2:1200 & 8,3 & 68,8 & 167,30 & 1009,48 & 11,5 \\
\hline L7_4P 2:1200 & 10,0 & 70,0 & 272,68 & 1329,35 & 13,1 \\
\hline L3_4P 2:1300 & 6,0 & 60,4 & 71,16 & 708,03 & 11,3 \\
\hline L5_4P 2:1300 & 8,3 & 68,5 & 208,30 & 931,69 & 17,1 \\
\hline L7_4P 2:1300 & 10,0 & 68,7 & 310,77 & 1237,38 & 21,8 \\
\hline L3_4P 2:1200 1,25 H & & & & & \\
\hline L5_4P 2:1200 1,25 H & 6,7 & 64,7 & 174,51 & 1046,36 & 11,5 \\
\hline L7_4P 2:1 $2001,25 \mathrm{H}$ & 8,0 & 64,4 & 324,66 & 1425,86 & 13,1 \\
\hline L3_4P 2:1 $2001,50 \mathrm{H}$ & & & & & \\
\hline L5_4P 2:1 $2001,50 \mathrm{H}$ & 5,6 & 61,8 & 194,36 & 1037,48 & 11,5 \\
\hline L7_4P 2:1 $2001,50 \mathrm{H}$ & 6,7 & 63,3 & 370,95 & 1376,10 & 13,1 \\
\hline L3_4P 2:1 $2001,75 \mathrm{H}$ & & & & & \\
\hline L5_4P 2:1200 1,75 H & 4,8 & 58,8 & 212,19 & 1082,76 & 11,5 \\
\hline L7_4P 2:12001,75 H & 5,7 & 61,3 & 428,25 & 1389,21 & 13,1 \\
\hline
\end{tabular}

Tabla 78. Resultados M.E.F. Baja+4. Posición y Resultantes 


\section{POSICIÓN DE LA RESULTANTE DE LA ZAPATA DE MEDIANERÍA}

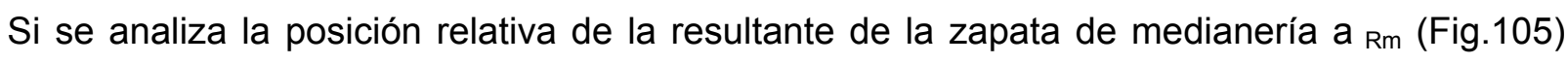
puede apreciarse que, para una determinada luz y un determinado canto de la viga centradora, dicha posición relativa arroja líneas sensiblemente constantes, que alcanzan una determinada cota de excentricidad en función, exclusivamente, de la rigidez de la viga centradora.

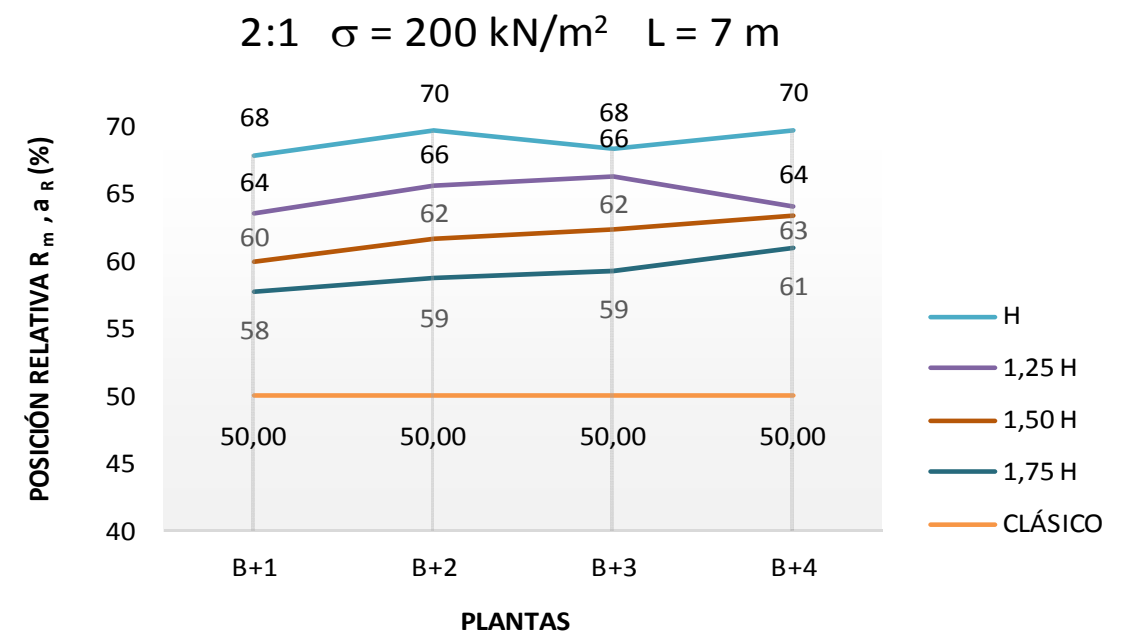

Fig.105. Posición de la resultante de la zapata de medianería en función de la rigidez

Por ello, y considerando como un buen indicador de la rigidez la relación luz - canto (L/h), se opta por ajustar la posición relativa de la resultante de la zapata de medianería mediante una expresión del tipo mostrado en la ec.64, en la que la que se propone una relación directamente proporcional entre ambos parámetros, ya que al aumentar la rigidez de la cimentación disminuye tanto la excentricidad de la resultante (valorada por a $\mathrm{Rm}$ ) como la relación $\mathrm{L} / \mathrm{h}$.

$$
\mathrm{a}_{\mathrm{Rm}}=\mathrm{k}_{1}+\mathrm{k}_{2} \cdot\left(\frac{\mathrm{L}}{\mathrm{h}}\right)^{\mathrm{k}_{3}}
$$

Siendo:

$a_{R m}$ : Posición de la resultante de la zapata de medianería respecto de un extremo de la misma en (\%)

$\mathrm{L}$ : $\quad$ Luz del pórtico en $(\mathrm{m})$

$\mathrm{h}$ : $\quad$ Canto de la viga centradora en $(\mathrm{m})$

Planteado el tipo de expresión a emplear se determinan los distintos coeficientes de la misma ajustándolos por el método de los mínimos cuadrados, obteniéndose el resultado mostrado en la Fig.106. 


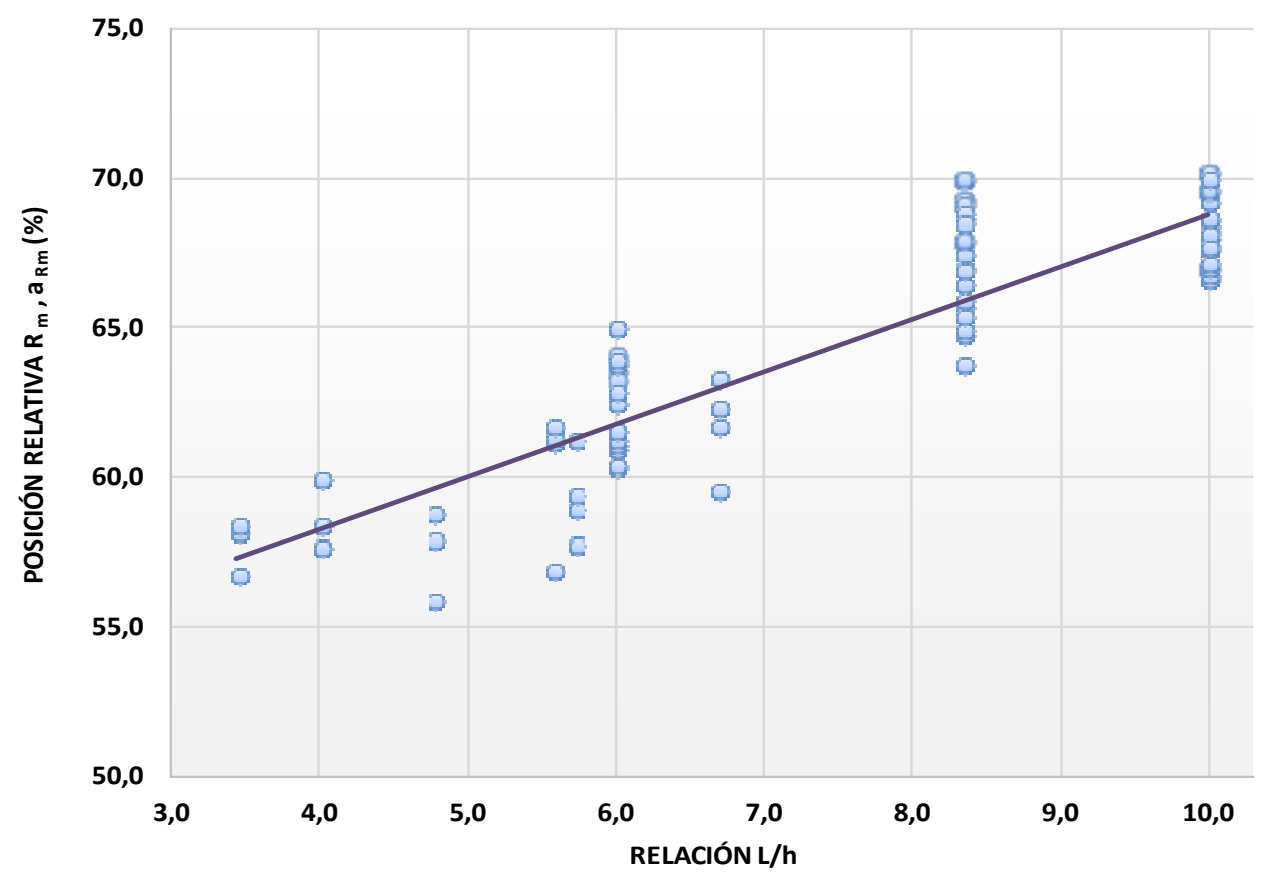

Fig.106. Gráfico de ajuste por mínimos cuadrados

En la Fig.106 se muestra el gráfico con el ajuste realizado, obteniéndose finalmente la expresión dada por la ec.65. A pesar de haber partido de un planteamiento inicial de carácter potencial, se ha obtenido finalmente un mejor ajuste dándole al coeficiente $\mathrm{k}_{3}$ valor 1 , lo cual convierte la expresión en un ajuste lineal.

$$
a_{R m}=51,339+1,741 \cdot\left(\frac{L}{h}\right)
$$

que presenta un coeficiente de correlación $R^{2}=0,81$ 


\section{RESULTANTE DE LA VIGA CENTRADORA}

La viga centradora, junto con la zapata de medianería y la zapata interior, forman un elemento de cimentación conjunto. La magnitud final de la carga transmitida al terreno por cada una de las partes depende del papel protagonista que desempeñe cada una de ellas en función de su geometría, siendo el porcentaje de área de cada parte respecto del área total del conjunto del elemento de cimentación un buen indicador para valorar dicho protagonismo.

La Fig.107 muestra la relación que existe, en los modelos de elementos finitos, entre la resultante de la zapata de medianería y la resultante de la viga centradora. En dichos gráficos se observa cómo al aumentar la luz del pórtico se incrementa la resultante de la viga centradora siguiendo el ritmo de crecimiento de la resultante de la zapata de medianería a un ritmo mayor que ésta última, llegando a superar el $30 \%$ del valor de la resultante de la zapata de medianería en casos de $7 \mathrm{~m}$ de luz. En cambio, al aumentar el número de plantas manteniendo la luz constante, se aprecia que la resultante de la viga centradora crece muy levemente, quedándose atrás del intenso ritmo de crecimiento de la resultante de la zapata de medianería.
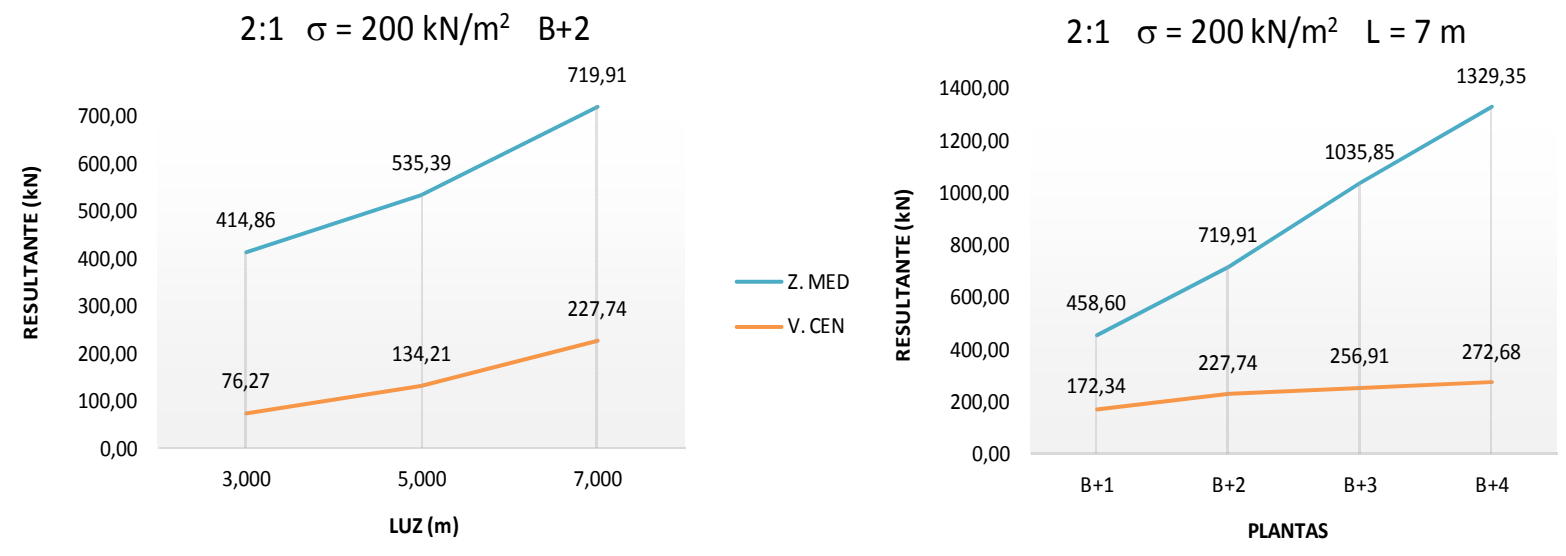

Fig.107. Resultantes de tensiones de contacto en zapata de medianería y viga centradora

La explicación se encuentra en los gráficos de la Fig.108 que representan la evolución del porcentaje del área de la viga centradora respecto del conjunto de cimentación. Efectivamente, al variar la luz con número de plantas constante, el tamaño de las zapatas tiende a estancarse creciendo en proporción el protagonismo de la viga centradora que llega a alcanzar el $20 \%$ del total del área. De este modo, a medida que aumenta el porcentaje de área de la viga centradora, su resultante empieza a crecer en porcentaje respecto de la resultante de la zapata de medianería. 
$2: 1 \quad \sigma=200 \mathrm{kN} / \mathrm{m}^{2} \quad \mathrm{~B}+2$

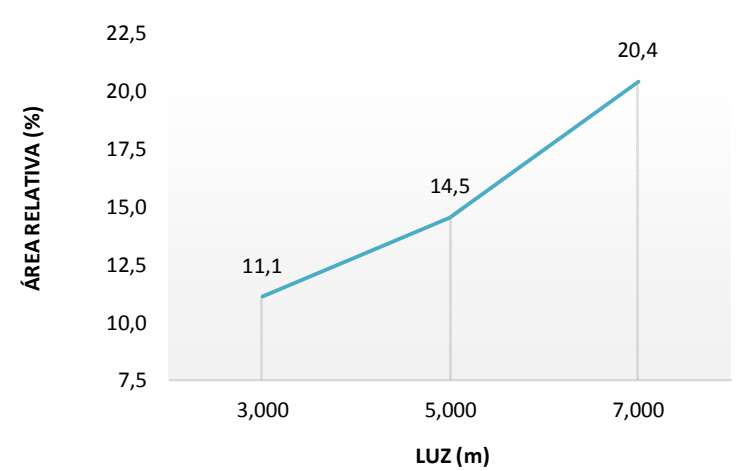

$2: 1 \quad \sigma=200 \mathrm{kN} / \mathrm{m}^{2} \quad \mathrm{~L}=7 \mathrm{~m}$

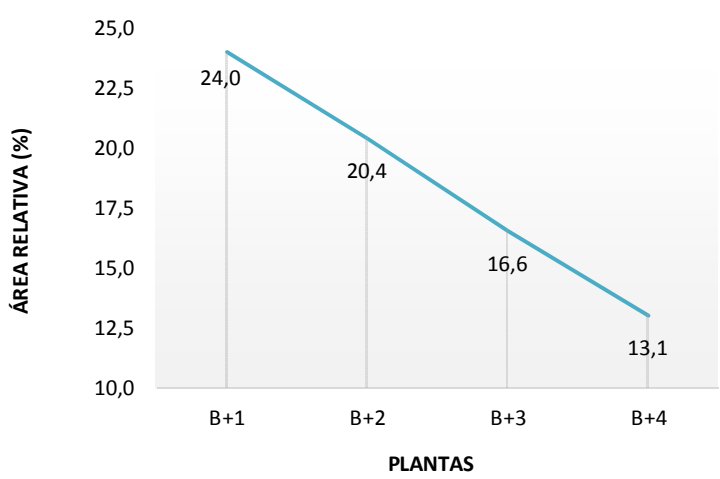

Fig.108. Evolución del porcentaje de área de la viga centradora

En cambio, al aumentar el número de plantas, el tamaño de las zapatas de los pilares crece, perdiendo la viga centradora protagonismo, al reducirse su porcentaje de área respecto del total, lo que conduce a que su resultante represente cada vez una proporción más pequeña respecto de la resultante de la zapata de medianería.

Otro factor que influye en la magnitud de la resultante de la viga centradora es la rigidez de la propia viga. Cuando las vigas centradoras tienen rigidez reducida, su deformación es elevada, tendiendo a perder contacto con el terreno. Por el contrario, con rigideces elevadas la deformación se limita y se intensifica el contacto con el terreno, aumentando así la resultante de la viga centradora. Puede observarse en el gráfico de la Fig.109 el incremento en la resultante de la viga centradora al aumentar la rigidez de la misma.

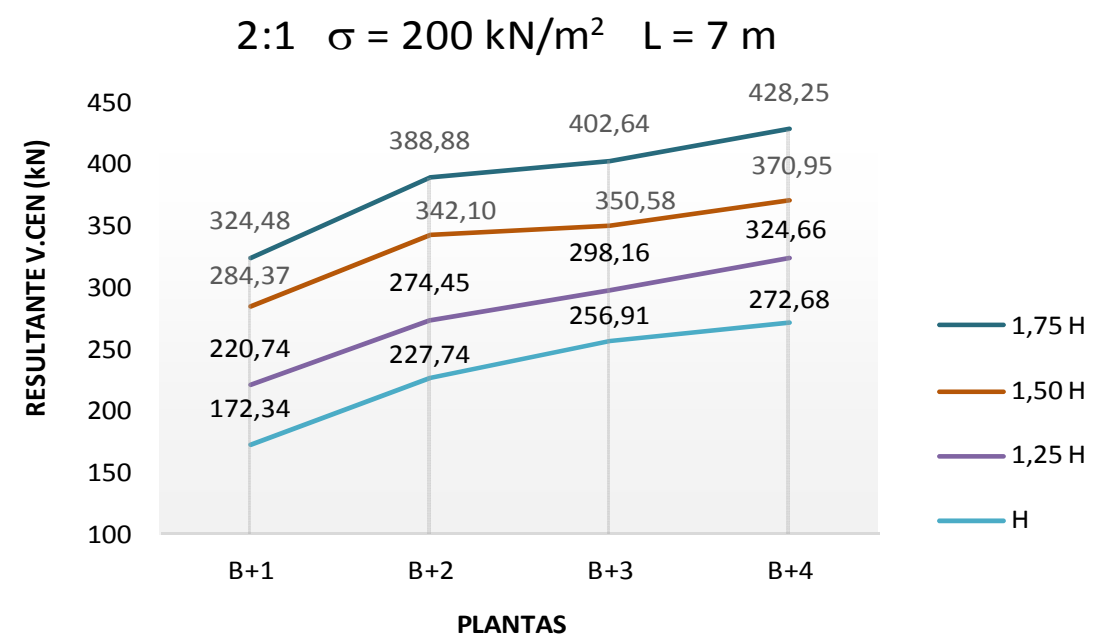

Fig.109. Resultante en la viga centradora en función de su rigidez

Así pues, son tres los factores a tener en cuenta a la hora de proponer una expresión para el valor de la resultante de la viga centradora. El primero, que la resultante de la viga centradora crece con la resultante de la zapata de medianería de forma directamente proporcional al 
porcentaje de área que representa la viga centradora. El segundo, que la resultante de la viga centradora es directamente proporcional a la rigidez de la viga y, por ello, inversamente proporcional al coeficiente de relación luz canto (L/h). Y, por último, en tercer lugar está la estrategia de la propuesta, que pretende expresar el valor de la resultante de la viga centradora como un porcentaje del valor de la resultante de la zapata de medianería para, de este modo, poder realizar un cambio de variable que permita eliminar fácilmente la incógnita resultante viga centradora.

Todo ello conduce a proponer el siguiente tipo de expresión para relacionar el valor de la resultante de la viga centradora con el valor de la resultante de la zapata de medianería:

$$
R_{v}=\frac{k_{1} \cdot A_{v}{ }^{k_{2}}}{k_{3} \cdot\left(\frac{L}{h}\right)^{k_{2}}} \cdot R_{m}
$$

Siendo:

$R_{v}$ : Resultante de tensiones de contacto de la viga centradora

$R_{m}$ : Resultante de tensiones de contacto de la zapata de medianería

$A_{v}$ : Proporción del área en planta de la viga centradora respecto del total del área en planta del conjunto zapata medianería - viga centradora - zapata interior en tanto por uno

$L$ : $\quad$ Luz del pórtico en

h : $\quad$ Canto de la viga centradora en

Planteado el tipo de expresión a emplear se determinan los distintos coeficientes de la misma ajustándolos por el método de los mínimos cuadrados, obteniéndose como resultado la siguiente expresión:

$$
R_{v}=\frac{1,979 \cdot A_{v}^{1,014}}{0,268 \cdot\left(\frac{L}{h}\right)^{0,729}} \cdot R_{m}
$$

Evidentemente, al tener cuatro variables implicadas en el ajuste, no es posible representar un gráfico con dicho ajuste. Ahora bien, puede realizarse una comprobación indirecta de la calidad del ajuste obtenido, correlacionando los valores de la resultante de la viga centradora proporcionados por los modelos de elementos finitos con los correspondientes valores obtenidos con la ec.67, obteniéndose una recta auxiliar de ajuste con un coeficiente de correlación $\mathrm{R}^{2}=0,80$ 


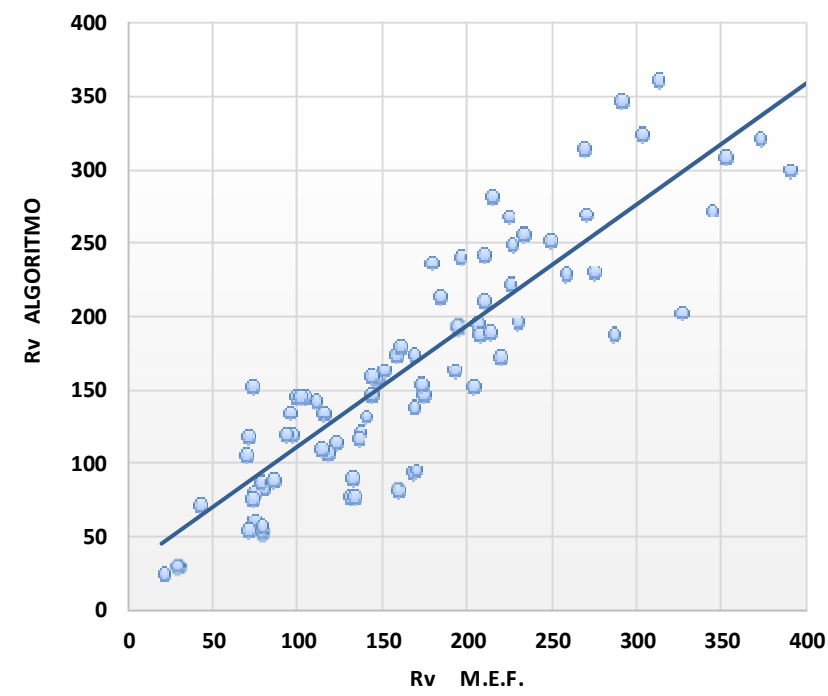

Fig.110. Correlación del ajuste de la resultante de la viga centradora

\section{MÉTODO OPERATIVO}

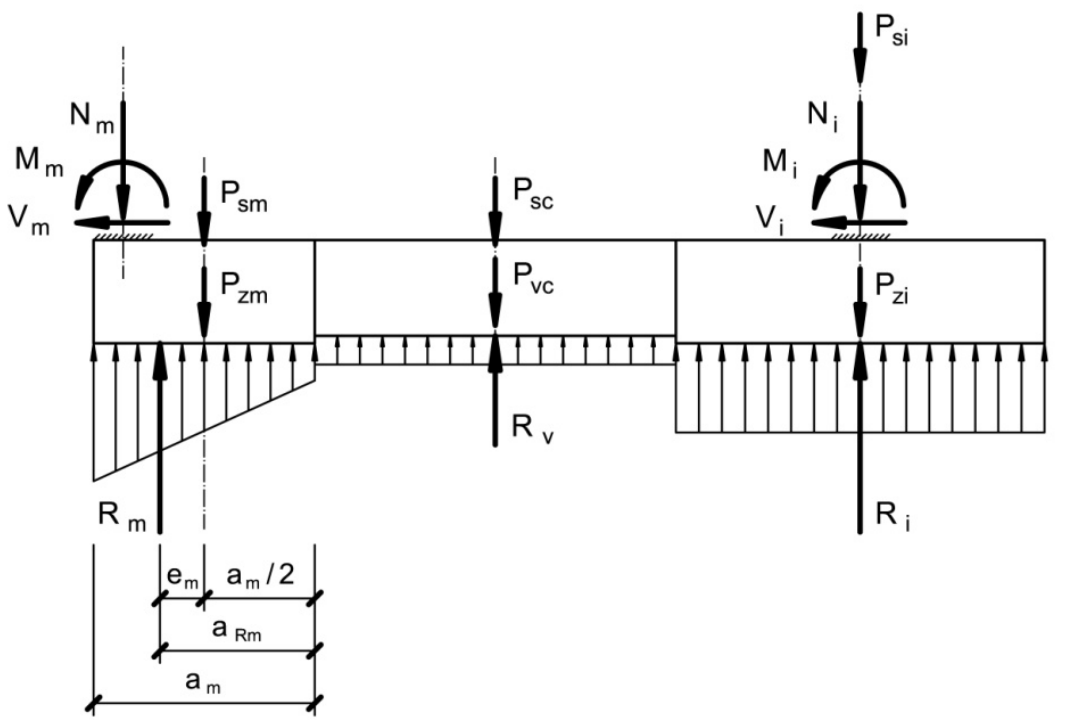

Fig.111. Método operativo

A modo de resumen, el modo de proceder en la práctica para resolver las cuatro incógnitas de la propuesta del modelo convencional modificado puede ser el siguiente. En primer lugar, empleando la expresión de la ec.65 se procede directamente al cálculo de la posición de la resultante de la zapata de medianería. En segundo lugar, empleando la ec.67, se plantea el cambio de variable que expresa el valor de la resultante de la viga centradora en función de la resultante de la zapata de medianería, el cual, una vez aplicado deja el esquema con solo dos incógnitas, $R_{m}$ y $R_{i}$. A continuación se resuelven estas dos incógnitas planteando las ecuaciones de equilibrio estático de momentos y de fuerzas verticales $y$, finalmente, se obtiene el valor de $\mathrm{R}_{\mathrm{v}}$ a partir de $\mathrm{R}_{\mathrm{m}}$ utilizando de nuevo la ec.67. 


\subsubsection{ZAPATA DE ESQUINA CON DOS VIGAS CENTRADORAS}

Una vez desarrollada la propuesta de modificación del método convencional para el caso de la zapata de medianería, la forma de proceder con el caso de zapata de esquina es la misma, con la diferencia de que en esta ocasión, al tratarse de un problema tridimensional, en lugar de una excentricidad de la zapata de medianería es preciso resolver dos excentricidades de la zapata de esquina a $\operatorname{Rex} y a_{\text {Rey }} y$, en lugar de una viga centradora, hay dos con sus respectivas resultantes $R_{c 1}$ y $R_{c 2}$. La argumentación que conduce a las expresiones necesarias para obtener las incógnitas indicadas es exactamente la misma que la empleada con las zapatas de medianería empleándose, por tanto, el mismo formato de ecuación, variando únicamente el valor de los coeficientes de las ecuaciones.

\begin{tabular}{|c|c|c|c|c|c|c|c|}
\hline & \multicolumn{7}{|c|}{ RESULTADOS M.E.F. ZAP. ESQUINA } \\
\hline & L/h & $\begin{array}{c}a_{R} \text { ex } \\
(\%)\end{array}$ & $\begin{array}{c}a_{R \text { ey }} \\
(\%)\end{array}$ & $\begin{array}{l}R_{e} \\
(k N)\end{array}$ & $\begin{array}{l}R_{\mathrm{c} 1} \\
(\mathrm{kN})\end{array}$ & $\begin{array}{l}\mathbf{R}_{\mathrm{c} 2} \\
(\%)\end{array}$ & $\begin{array}{l}A_{v} \\
(\%)\end{array}$ \\
\hline L3_1P 2:1200 H & 6,0 & 60,8 & 59,0 & 95,96 & 59,04 & 57,7 & 24,8 \\
\hline L5_1P 2:1200 H & 8,3 & 63,4 & 62,6 & 144,04 & 128,41 & 126,2 & 27,8 \\
\hline L7_1P 2:1200 H & 10,0 & 69,9 & 69,9 & 268,92 & 199,99 & 183,2 & 23,3 \\
\hline L3_2P 2:1200 H & 6,0 & 61,7 & 60,2 & 178,27 & 63,17 & 61,2 & 14,6 \\
\hline L5_2P 2:1200 H & 8,3 & 68,0 & 67,7 & 272,19 & 145,36 & 132,8 & 16,7 \\
\hline L7_2P 2:1200 H & 10,0 & 71,7 & 73,3 & 505,37 & 253,39 & 225,1 & 18,3 \\
\hline L3_3P 2:1200 H & 6,0 & 63,1 & 62,0 & 297,31 & 56,03 & 53,2 & 8,0 \\
\hline L5_3P 2:1200 H & 8,3 & 69,3 & 69,3 & 450,00 & 160,76 & 150,8 & 12,8 \\
\hline L7_3P 2:1200 H & 10,0 & 73,0 & 75,4 & 746,82 & 272,23 & 233,4 & 13,4 \\
\hline L5_4P 2:1200 H & 8,3 & 69,5 & 73,8 & 748,27 & 156,71 & 133,7 & 8,8 \\
\hline L7_4P 2:1200 H & 10,0 & 73,7 & 73,7 & 1026,53 & 251,33 & 229,2 & 8,4 \\
\hline L3_1P 2:1200 1,75 H & 3,4 & 57,2 & 55,7 & 102,97 & 66,22 & 65,4 & 24,8 \\
\hline L5_1P 2:12001,75 H & 4,8 & 56,2 & 55,6 & 143,19 & 156,21 & 156,0 & 27,8 \\
\hline L7_1P 2:1200 1,75 H & 5,7 & 58,1 & 58,3 & 253,91 & 256,37 & 249,6 & 23,3 \\
\hline L3_2P 2:1200 1,75 H & 3,4 & 57,7 & 56,4 & 192,70 & 68,87 & 67,3 & 14,6 \\
\hline L5_2P 2:12001,75 H & 4,8 & 57,2 & 56,5 & 280,94 & 170,12 & 166,5 & 16,7 \\
\hline L7_2P 2:12001,75 H & 5,7 & 58,3 & 59,7 & 491,96 & 332,21 & 315,8 & 18,3 \\
\hline L3_3P 2:1 $2001,75 \mathrm{H}$ & 3,4 & 59,0 & 57,9 & 325,15 & 57,84 & 56,6 & 8,0 \\
\hline L5_3P 2:1 $2001,75 \mathrm{H}$ & 4,8 & 57,6 & 57,3 & 492,88 & 184,62 & 181,7 & 12,8 \\
\hline L7_3P 2:12001,75 H & 5,7 & 59,5 & 60,4 & 806,01 & 359,25 & 329,4 & 13,4 \\
\hline L5_4P 2:12001,75 H & 4,8 & 59,7 & 61,7 & 778,10 & 166,13 & 158,2 & 8,8 \\
\hline L7_4P 2:12001,75 H & 5,7 & 61,5 & 61,2 & 1208,48 & 335,31 & 303,5 & 8,4 \\
\hline
\end{tabular}

Tabla 79. Resultados M.E.F. zapata de esquina. Posiciones y Resultantes 
Los citados coeficientes, al igual que en los casos de zapata de medianería, se obtienen por ajustes de regresión a partir de los resultados de los modelos de elemento finitos en función de la relación luz canto y del porcentaje de área en planta de la viga centradora.

\section{POSICIÓN DE LA RESULTANTE DE LA ZAPATA DE ESQUINA}

Las expresiones obtenidas tras el ajuste para las posiciones de la resultante de la zapata de esquina son las dadas por las ec.68 y 69, representándose en la Fig.112 los gráficos de los ajustes.
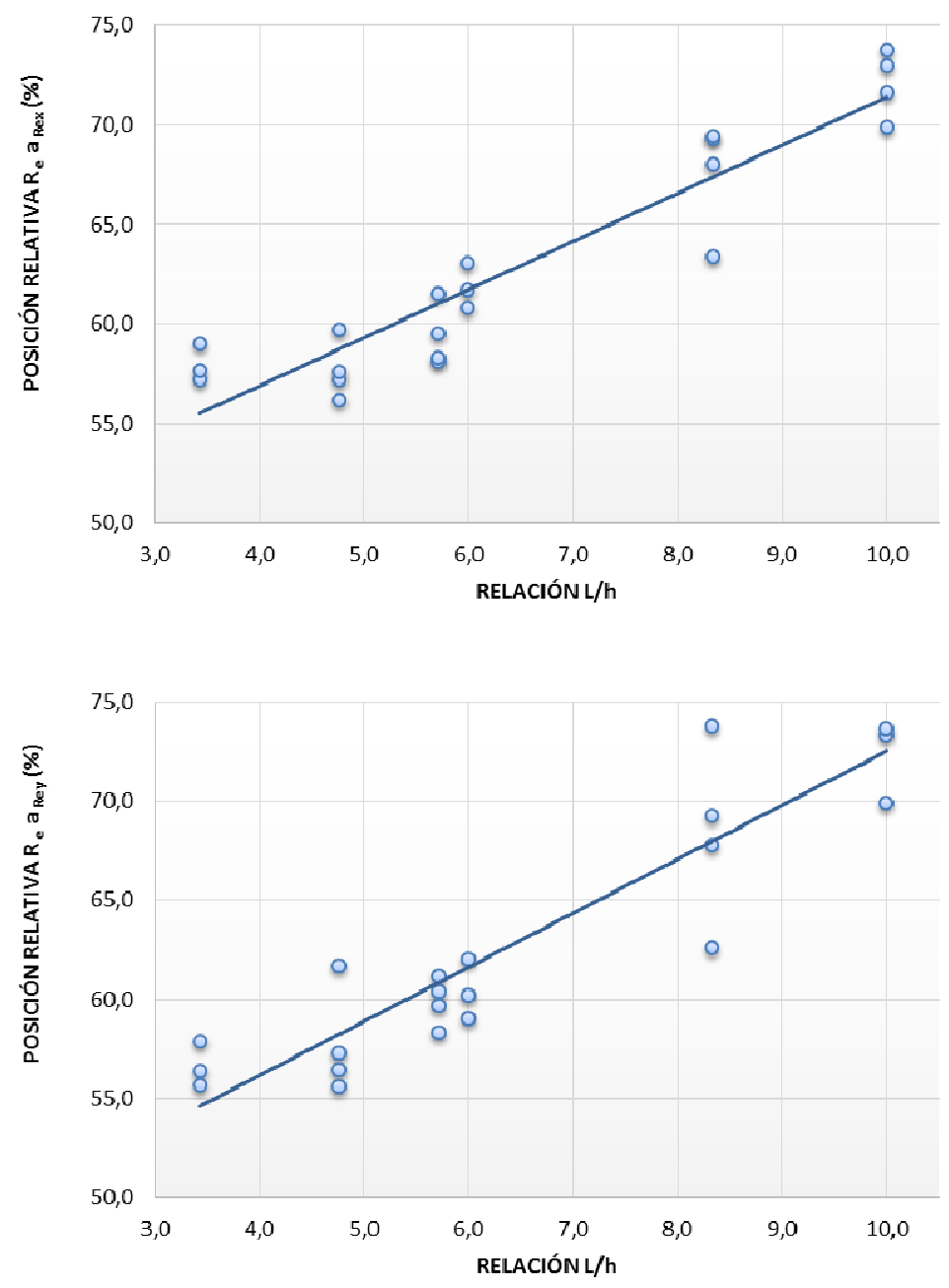

Fig.112. Gráficos de ajuste por mínimos cuadrados

$$
\begin{array}{ll}
a_{\operatorname{Rex}}=47,200+2,422 \cdot\left(\frac{L}{h}\right) & R^{2}=0,88 \\
a_{\text {Rey }}=45,304+2,723 \cdot\left(\frac{L}{h}\right) & R^{2}=0,85
\end{array}
$$




\section{RESULTANTES DE LA VIGAS CENTRADORAS}

Las expresiones obtenidas tras el ajuste para las resultantes de las vigas centradoras son las dadas por las ec.70 y 71, representándose en la Fig.113 los gráficos de los ajustes.
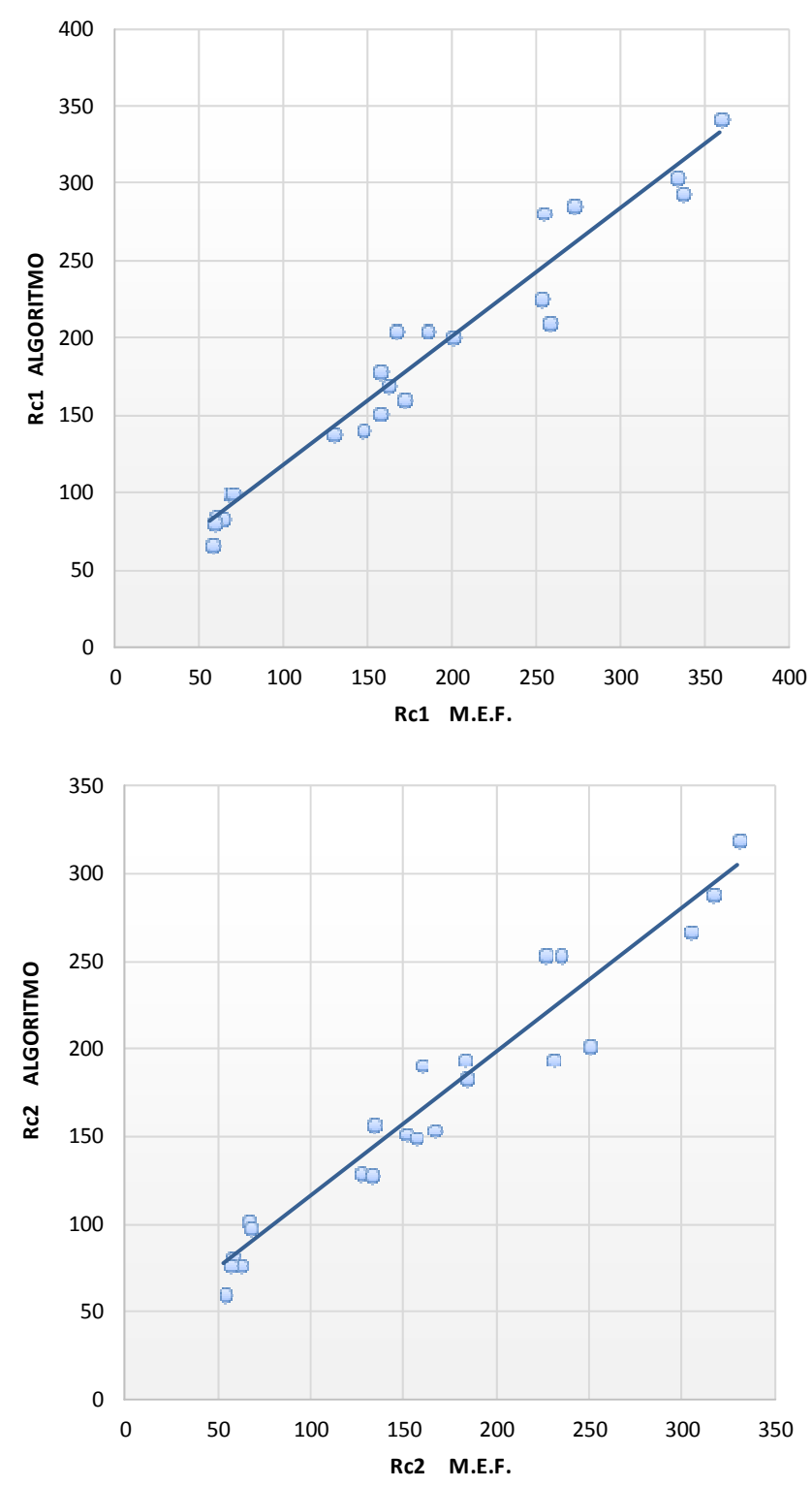

Fig.113. Correlación de los ajustes de las resultantes de las vigas centradoras

$$
\begin{array}{lll}
R_{c 1}=\frac{1,792 \cdot A_{v}{ }^{1,205}}{0,273 \cdot\left(\frac{L}{h}\right)^{0,182}} \cdot R_{e} & R^{2}=0,95 \\
R_{c 2}=\frac{2,049 \cdot A_{v}{ }^{1,261}}{0,254 \cdot\left(\frac{L}{h}\right)^{0,274}} \cdot R_{e} & R^{2}=0,94
\end{array}
$$




\subsection{RECOMENDACIONES DE RELACIÓN LUZ - CANTO}

A lo largo del desarrollo de la tesis ha quedado clara la importancia de la rigidez de la viga centradora en el comportamiento de este tipo de cimentaciones, siendo el canto de la viga centradora el parámetro que más influencia tiene sobre esta cuestión. Por ello, parece razonable, a la vista de los resultados obtenidos, dar unas referencias de cantos recomendables que conduzcan a un comportamiento adecuado de este tipo de cimentaciones.

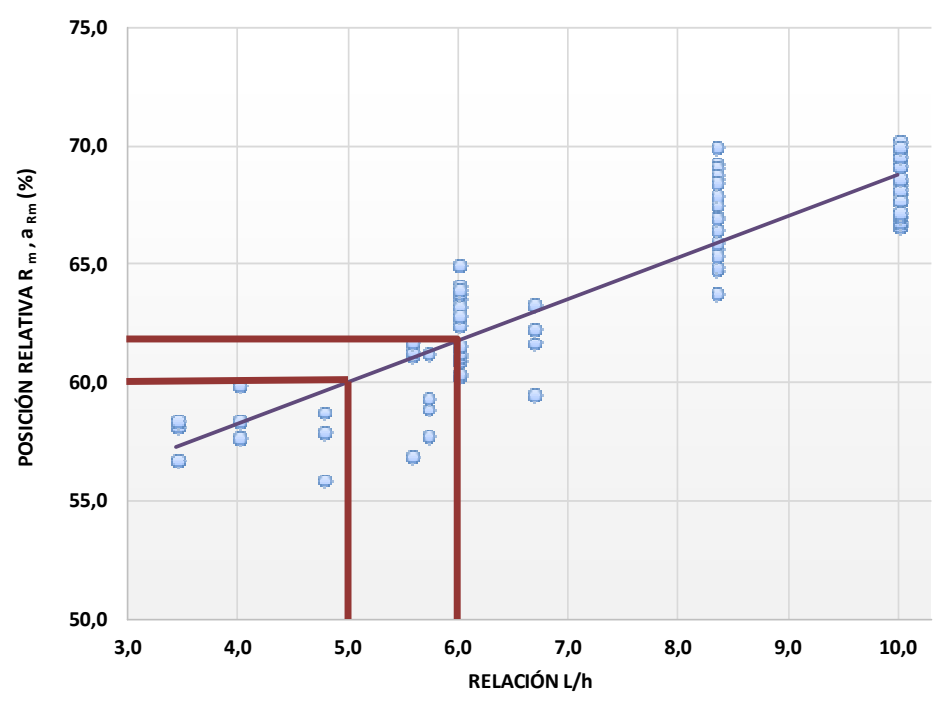

Fig.114. Recomendación de relación luz canto en zapatas de medianería

En el caso de las zapatas de medianería, ha quedado visto por medio de los resultados obtenidos, que el comportamiento geotécnico de las zapatas de medianería resulta adecuado, no generando especiales problemas de tensiones de contacto, cuando la excentricidad o posición relativa de la resultante de la zapata de medianería adopta valores inferiores al $60-62 \%$. Tal y como puede deducirse del gráfico de la Fig.114 que ofrece el gráfico de la expresión obtenida para dicho parámetro, esos valores de excentricidad requieren al menos un canto de la viga centradora entre L/6 y L/5.

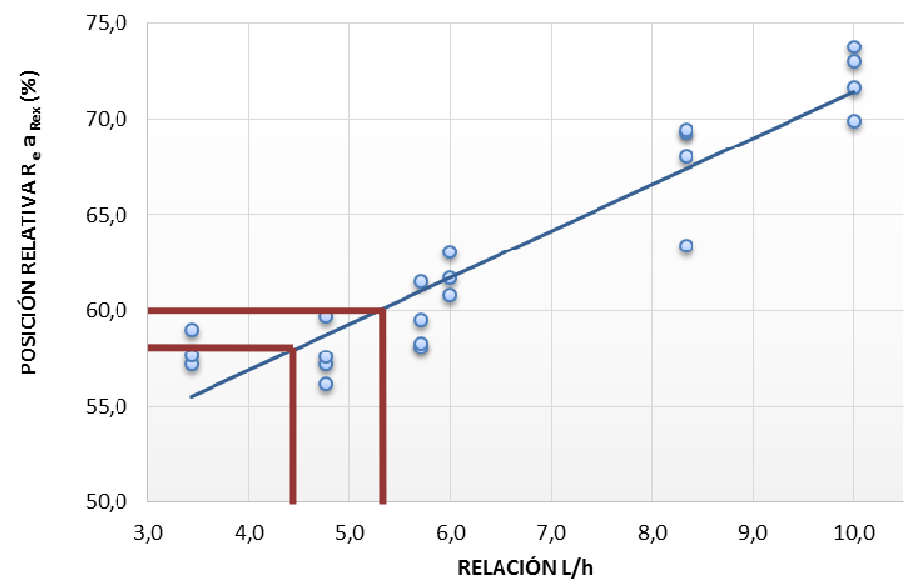

Fig.115. Recomendación de relación luz canto en zapatas de esquina 
Por su parte, también se ha visto que el caso de las zapatas de esquina resulta más desfavorable por su trabajo a flexión desviada con doble excentricidad. Ello conduce, en esta ocasión, a que el comportamiento geotécnico de las zapatas de esquina resulta adecuado, no generando especiales problemas de tensiones de contacto, cuando las excentricidades o posiciones relativas de su resultante adopta valores inferiores al 58 - 60\%. Tal y como puede deducirse del gráfico de la Fig.115 que ofrece el gráfico de la expresión obtenida para dichos parámetros, en la zapata de esquina es preciso ser algo más exigente, recomendando para sus vigas centradoras al menos un canto de L/5. 

CAPÍTULO 6

CONCLUSIONES Y FUTURAS LÍNEAS DE INVESTIGACIÓN 



\section{CONCLUSIONES Y FUTURAS LÍNEAS DE INVESTIGACIÓN}

\subsection{INTRODUCCIÓN}

Tras el trabajo de investigación, culminado con el análisis y discusión de los resultados obtenidos en las diferentes fases experimentales de la tesis, se ofrecen en este capítulo las conclusiones más relevantes derivadas del mismo. Dada la metodología seguida, con sucesivas etapas experimentales, con sus resultados y el correspondiente análisis y discusión de los mismos, parece coherente ordenar las conclusiones de la tesis doctoral según las sucesivas etapas de las que se extraen cada una de ellas.

Asimismo, tras la exposición de las conclusiones, se indican futuras líneas de investigación a desarrollar a raíz del trabajo realizado en la tesis doctoral.

\subsection{CONCLUSIONES}

Cabe destacar, como primera conclusión global de la tesis doctoral, las grandes posibilidades del Método de Elementos Finitos como herramienta de trabajo para desarrollar modelos de cálculo más ajustados a la realidad que los modelos convencionales, evitando así las simplificaciones que éstos últimos introducen debido a las limitaciones que les son propias.

\subsubsection{CONCLUSIONES DE LA ETAPA I}

La Etapa I, mediante el contraste realizado con los modelos de elementos finitos, pone de manifiesto una serie de discrepancias respecto del comportamiento de las zapatas de medianería con viga centradora descrito por los modelos convencionales. Las discrepancias más relevantes son las siguientes:

- El comportamiento, tanto de la zapata de medianería como de la zapata interior, no es el de un empotramiento perfecto. Al contrario, acompañando a la flexión de la viga centradora, experimentan giros que las convierten en empotramientos flexibles.

- La distribución de tensiones que se produce bajo la zapata de medianería es irregular y, debido al giro que experimenta la zapata, con tendencia a incrementar las tensiones hacia el pilar de medianería. Como consecuencia de ello, si se simplifica dicha distribución de tensiones mediante un esquema lineal equivalente, debería emplearse un esquema trapecial con tensión máxima bajo el pilar de medianería, no un esquema uniformemente repartido como hacen los modelos convencionales. 
- La distribución de tensiones trapecial conduce a resultantes excéntricas respecto del centro de la cara inferior de la zapata, con excentricidad creciente hacia el pilar de medianería a medida que se incrementa el porcentaje de luz de vano invadido por la zapata de medianería.

- La viga centradora, además de servir para estabilizar e intentar centrar el comportamiento de la zapata de medianería, trabaja como viga de cimentación o viga flotante, que colabora junto con la zapata de medianería y la zapata interior en la transmisión de cargas al terreno, formando globalmente un único elemento de cimentación. Como consecuencia de ello, la resultante de las tensiones de contacto bajo la viga centradora no es en absoluto despreciable, siendo mayor su importancia a medida que aumenta el tamaño relativo de la viga centradora respecto de la zapata de medianería.

- Como consecuencia de las cuestiones anteriores, el momento flector máximo en la viga centradora según el modelo de elementos finitos es considerablemente menor que el obtenido con modelos convencionales, pudiendo llegar dicha reducción a valores próximos al $50 \%$. Debido a ello, las armaduras de la viga centradora resultantes de los modelos convencionales parecen estar sobredimensionadas según los modelos de la Etapa I.

- Por el contrario, la viga de la primera planta situada sobre la viga centradora se encuentra solicitada a flexotracción, al combinar su función habitual de viga con la función de tirante que le induce la zapata de medianería. Si bien el valor del esfuerzo axil de tracción no es en la práctica tan elevado como el que indica el modelo convencional, ignorarlo puede conducir a infradimensionar la armadura de la citada viga.

- A pesar de la tendencia al incremento de tensiones en el borde medianero de las zapatas de medianería debido al giro de las mismas, el comportamiento geotécnico no resulta preocupante en los modelos elástico lineales de la Etapa I gracias a la colaboración de la viga centradora como elemento portante capaz de transmitir carga al terreno. 


\subsubsection{CONCLUSIONES DE LA ETAPA II}

El empleo de modelos de elementos finitos que contemplen un comportamiento del hormigón ajustado a la realidad, con diagrama tensión - deformación parabólico rectangular del hormigón y prácticamente nula resistencia a tracción del mismo conduce a resultados sustancialmente diferentes.

El proceso de fisuración que experimenta la viga centradora en su cara traccionada le induce una pérdida de inercia y, por ello, de rigidez que conduce a mayores deformaciones de la viga centradora por flexión al entrar en carga, lo cual permite mayores giros en la zapata de medianería, ya que una viga centradora debilitada se vuelve ineficaz a la hora de impedir o limitar los giros de la cimentación.

El incremento de deformación de la viga centradora en los modelos que contemplan la fisuración del hormigón y el giro excesivo de la cimentación en el escenario que se desencadena, traen consigo las siguientes consecuencias:

- La resultante de las tensiones de contacto con el terreno bajo la zapata de medianería incrementa su excentricidad, desplazándose hacia el pilar medianero, hasta un punto tal que genera distribuciones de tensiones al límite de los diagramas triangulares, con una clara tendencia al incremento de tensiones en el borde medianero.

- El aumento de deformación de la viga centradora reduce su capacidad portante para transmitir cargas al terreno, por lo cual, se reduce la colaboración de la viga centradora y se ve incrementada la resultante que le corresponde a la zapata de medianería.

- Los dos efectos anteriores colocan a la zapata de medianería en una problemática situación geotécnica, pasando a no verificarse convenientemente la comprobación de tensiones de contacto o E.L.U. de hundimiento.

- En este escenario, los momentos flectores que solicitan la viga centradora, debido al desplazamiento de la resultante de tensiones de la zapata de medianería hacia el borde medianero, son cada vez menores, partiendo incluso de unos valores ya de por sí pequeños en la Etapa I elástica lineal. Ello no debe interpretarse ya como un caso de sobredimensionamiento de armadura sino, más bien al contrario, como un síntoma de debilidad de la viga centradora que es preciso resolver. 


\subsubsection{CONCLUSIONES DE LA ETAPA III}

De las distintas medidas puestas en escena para lograr suficientes niveles de rigidez en la viga centradora, que permitan un eficaz control del giro de la cimentación, pueden exponerse las siguiente conclusiones:

- El aumento de la armadura de la viga centradora no es, en modo alguno, una solución eficaz para rigidizar la viga centradora. Se han llegado a ensayar casos con armaduras dos veces y media las originales que finalmente solo han conseguido reducir tres puntos porcentuales la excentricidad de la resultante de la zapata de medianería. Un incremente de armadura tan desproporcionado no queda justificado con un resultado tan pobre.

- Continuando en línea con lo anterior y, en contra del temor inicial, la reducción de la armadura de la viga centradora, ajustándola a los momentos que realmente la solicitan, no empeora drásticamente el comportamiento de la misma. Armaduras del orden del $40 \%$ de las originales solo generan pequeños incrementos de dos puntos porcentuales en la excentricidad de la resultante de la zapata de medianería. Conclusión, la cuantía de armado, tanto por exceso como por defecto, tiene muy poca influencia en la rigidez efectiva de la viga centradora.

- A pesar de la poca eficacia de la viga centradora en los primeros modelos de elementos finitos con fisuración del hormigón, su efecto siempre es positivo. En este sentido, los modelos de elementos finitos sin viga centradora ponen de manifiesto el mal funcionamiento de este modelo, con un comportamiento geotécnico extremo de la zapata de medianería. Estos modelos sin viga centradora, lógicamente, son los que arrojan axiles de tracción en la viga superior más próximos a los obtenido por el método convencional con colaboración de viga superior, si bien las tracciones de los modelos de elementos finitos son siempre inferiores a las de los modelos convencionales debido al desplazamiento de la resultante de la zapata de medianería hacia el pilar medianero.

- Finalmente, el canto de la viga centradora y de la cimentación en general, termina siendo el parámetro clave que sí incrementa eficazmente la rigidez de la misma. Se ha comprobado que para cantos de la viga centradora un $75 \%$ superiores a los cantos mínimos compatibles con la condición de anclaje de la armadura de los pilares, el comportamiento del conjunto del elemento de cimentación vuelve a ser correcto. Con dichos cantos (nada desproporcionados y bastante razonables), la viga 
centradora experimenta menor deformación y controla eficazmente el giro de la zapata de medianería, de modo que la excentricidad de la resultante de la viga centradora se reduce, pasando a dar diagramas netamente trapeciales, aumenta la capacidad portante de la viga centradora que ofrece mayor colaboración y se reducen las tensiones de borde que, o bien cumplen directamente, o bien conducen a valores poco preocupantes fáciles de resolver.

- Cuando se emplean vigas centradoras con suficiente canto, los momentos flectores en las mismas vuelven a ser importantes, del orden del $80 \%$ de los momentos proporcionados por los métodos convencionales. El ajuste de la armadura a la nueva situación no supone ningún peligro. Una reducción de la armadura de un $20 \%$ genera un aumento de excentricidad inapreciable en la zapata de medianería.

- Como conclusión final, la optimización de las cimentaciones de medianería con viga centradora puede resumirse en una doble línea de actuación, por un lado, inversión en hormigón para incrementar el canto de la viga centradora y, por otro lado, ahorro en armadura al ajustarla a unos momentos flectores solo ligeramente más pequeños. Ello probablemente no supone un ahorro global pero si un conjunto estructural más equilibrado, con niveles de seguridad similares en sus distintas partes.

\subsubsection{CONCLUSIONES DE LA ETAPA IV}

Los resultados de la cuarta fase experimental, dedicada a las zapatas de esquina, muestran, en términos generales, comportamientos y tendencias de la zapatas de esquina similares a las de la zapata de medianería, confirmando la idea de la zapata de esquina con dos vigas centradoras como caso particular de la zapata de medianería con viga centradora. Ahora bien, deben destacarse las siguientes diferencias por las precauciones de dimensionamiento a que pueden dar lugar:

- Al igual que en el caso de las zapatas de medianería, la distribución de tensiones en la zapata de esquina no es uniformemente repartida, por lo que su resultante no está centrad, presentando una cierta excentricidad. Ahora bien, la magnitud de las excentricidades obtenidas para los casos de zapata de esquina es superior a la de las obtenidas para los casos de zapata de medianería, lo cual señala a las zapatas de esquina como un caso más desfavorable que las zapatas de medianería. Ello es debido a la forma cuadrada habitualmente adoptada para este tipo de zapatas, en un 
intento de equilibrar el comportamiento de las dos medianerías que confluyen en la esquina. Si bien es posible que no haya otra opción mejor, la zapata de esquina cuadrada es una relación de forma desfavorable, que implica que la resultante de las tensiones de contacto se desplace más hacia el centro de las vigas centradoras, generando mayor flexión y deformación de las mismas.

- Asimismo, se constata igualmente la situación problemática de la comprobación de tensiones de contacto en la zapata de esquina para los casos de canto mínimo, si bien el problema aparece en las zapatas de esquina de un modo más agudo que en las zapatas de medianería. La causa del agravamiento de la situación en las zapatas de esquina está, por un lado, en el aumento de las excentricidades comentado en el párrafo anterior $\mathrm{y}$, por otro, en el hecho de tratarse de una situación de flexión desviada, con una doble excentricidad simultanea que acentúa la cuestión de las tensiones de contacto.

- Comprobado el efecto claramente favorable del incremento de canto en las vigas centradoras, cabe indicar que las excentricidades obtenidas en las zapatas de esquina son, en general, ligeramente superiores a las obtenidas en los correspondientes casos de zapata de medianería, a igualdad de canto, lo cual parece indicar la necesidad de un ligero incremento de canto adicional en las zapatas de esquina para alcanzar el mismo nivel de control de la excentricidad.

- Por último, es preciso matizar que los momentos obtenidos en las vigas centradoras de las zapatas de esquina son, en proporción, algo inferiores a los obtenidos con zapata de medianería, lo cual pone de manifiesto la mayor flexión de las vigas centradoras en este caso y refuerza la idea de la necesidad de un ligero incremento del canto respecto de los casos de zapata de medianería.

\subsubsection{PROPUESTA DE MEJORA DEL MÉTODO CONVENCIONAL}

A la vista del estudio realizado se concluye que podría mejorarse el método convencional de cálculo de este tipo de cimentaciones, conduciendo a resultados más ajustados a la realidad, si se ponen en escena, tanto la excentricidad de la resultante de tensiones de la zapata de medianería (o en su caso la de esquina), como la resultante de tensiones de contacto bajo la viga centradora (o en su caso vigas 
centradoras). Los resultados obtenidos a partir de los modelos de elementos finitos han permitido obtener las expresiones a las que responden los citados parámetros, que son las siguientes:

$$
\begin{aligned}
& a_{R m}=51,339+1,741 \cdot\left(\frac{L}{h}\right) \\
& a_{R e x}=47,200+2,422 \cdot\left(\frac{L}{h}\right) \\
& a_{R e y}=45,304+2,723 \cdot\left(\frac{L}{h}\right) \\
& R_{v}=\frac{1,979 \cdot A_{v}^{1,014}}{0,268 \cdot\left(\frac{L}{h}\right)^{0,729}} \cdot R_{m} \\
& R_{c 1}=\frac{1,792 \cdot A_{v}{ }^{1,205}}{0,273 \cdot\left(\frac{L^{2}}{h}\right)^{0,182}} \cdot R_{e} \\
& R_{c 2}=\frac{2,049 \cdot A_{v}^{1,261}}{0,254 \cdot\left(\frac{L}{h}\right)^{0,274}} \cdot R_{e}
\end{aligned}
$$

Siendo:

$a_{\mathrm{Rm}}$ : Posición de la resultante de la zapata de medianería respecto de un extremo de la misma en (\%)

$a_{\text {Rex }}$ : Posición de la resultante de la zapata de esquina respecto de un extremo de la misma en dirección $\mathrm{x}$ en (\%)

$a_{\text {Rey }}$ : Posición de la resultante de la zapata de esquina respecto de un extremo de la misma en dirección y en (\%)

$L$ : $\quad$ Luz del pórtico en $(m)$

h : $\quad$ Canto de la viga centradora en (m)

$R_{v}$ : Resultante de tensiones de contacto de la viga centradora

$R_{m}$ : Resultante de tensiones de contacto de la zapata de medianería

$R_{c 1}$ : Resultante de tensiones de contacto de la viga centradora 1

$R_{\mathrm{c} 2}$ : Resultante de tensiones de contacto de la viga centradora 2

$A_{v}$ : Proporción del área en planta de la viga centradora respecto del total del área en planta del conjunto zapata medianería - viga centradora - zapata interior en tanto por uno 


\subsubsection{RECOMENDACIONES DE RELACIÓN LUZ - CANTO}

A lo largo del desarrollo de la tesis ha quedado clara la importancia de la rigidez de la viga centradora en el comportamiento de este tipo de cimentaciones, siendo el canto de la viga centradora el parámetro fundamental que más influencia tiene sobre esta cuestión. Por ello, parece razonable, a la vista de los resultados obtenidos, dar unas referencias de cantos recomendables que conduzcan a un comportamiento adecuado de este tipo de cimentaciones.

En el caso de las zapatas de medianería, se comprueba que el comportamiento geotécnico de las mismas resulta adecuado, no generando especiales problemas de tensiones de contacto, cuando la excentricidad o posición relativa de la resultante de la zapata de medianería adopta valores inferiores al 60 - 62\%. Para lograr dichos valores de excentricidad se requiere, al menos, un canto de viga centradora comprendido entre L/6 y L/5.

Por su parte, en el caso de las zapatas de esquina, con una situación más desfavorable por su trabajo a flexión desviada con doble excentricidad, se comprueba que el comportamiento geotécnico de las mismas resulta adecuado, no generando especiales problemas de tensiones de contacto, cuando las excentricidades o posiciones relativas de su resultante adoptan valores inferiores al 58 - 60\%. Para lograr dichos valores de excentricidad es preciso ser algo más exigente, requiriendo, al menos, un canto de vigas centradoras de L/5. 


\subsection{FUTURAS LÍNEAS DE INVESTIGACIÓN}

Tras el trabajo de investigación desarrollado en la presente tesis doctoral pueden plantearse como futuras líneas de investigación las siguientes:

- Dentro del campo de las zapatas de medianería, el paso de los modelos de elementos finitos con planteamiento elástico lineal en todos los materiales implicados a modelos con un estudio del comportamiento del hormigón más ajustado a la realidad, ha supuesto cambios importantes en el estudio e interpretación del problema. En este sentido, queda otro material por abordar en profundidad, que es el terreno. El desarrollo de modelos de elementos finitos que contemplen la plastificación del terreno, especialmente en las zonas donde se producen puntas de tensión, junto con modelos de comportamiento más ajustados a la realidad de dicho material, puede abrir nuevos enfoques y puntos de vista del tema estudiado.

- El estudio de las zapatas de esquina se ha realizado con casos con igual luz que crujía y, por ello, zapata de esquina cuadrada. Resultaría interesante abrir el abanico de casos de estudio, con diferentes combinaciones de luces y crujías, con el fin de de alcanzar propuestas de aplicación más general.

- El método de los elementos finitos ha demostrado ser una valiosa herramienta para contrastar métodos de cálculo de carácter convencional, irremediablemente llenos de simplificaciones. Dentro de la amplia lista de posibles temas a estudiar, podría completarse el catálogo de cimentaciones directas habituales en edificación, con el estudio de las zapatas combinadas. 

BIBLIOGRAFÍA 



\section{BIBLIOGRAFÍA}

ACI 318 - 14 (2014). Building Code Requirements for Structural Concrete and Commentary. Ed. American Concrete Institute.

Ansys. (2012). Manual de Referencia ANSYS 12.0. Ed. ANSYS Inc.

Argüelles, R. (2015). Cálculo de Estructuras. Ed. Bellisco

Argüelles, R. (1992). Fundamentos de Elasticidad y su Programación por Elementos Finitos. Ed. Bellisco

Branson, D.E. (1977). Deformation of Concrete Structures. Ed. Mc Graw - Hill

Calavera, J. (2000). Cálculo de Estructuras de Cimentación. Ed. INTEMAC

Calavera, J. (2009). Proyecto y Cálculo de Estructuras de Hormigón. Ed. Intemac

CEB Task Group 2.2 (1998). Ductility of Reinforced Concrete Structures. CEB Bull. D'Information $n^{\circ} 242$

CEB Task Group 4.4. (2008). Practitioner's Guide to Finite Element Modelling of Reinforced Concrete Structures. Ed. CEB - FIB

Cervenka, V. (2002). Computer Simulation of Failure of Concrete Structures for Practice. 1st fib Congress 2002, Concrete Structures in 21 Century, Osaka, Japan

CTE (2006). Código Técnico de la Edificación. Ministerio de la Vivienda

EHE-08 (2008). Instrucción de Hormigón Estructural. Ministerio de la Presidencia

Galletero Montero, P. (2009). Estudio del Comportamiento de Zapatas de Medianería con Viga Centradora Mediante Modelos de Elementos Finitos. Trabajo de Investigación. Universidad Politécnica de Madrid.

García Meseguer, A. (2001). Hormigón Armado. Ed. U.N.E.D. Escuela de la Edificación García Valcarce, A. y otros. (2003). Mecánica de los Terrenos y Cimientos. Ed. Dossat 
Guaita Fernández, M y otros. (1999). Aplicación del Método de los Elemento Finitos a Problemas de Construcción Rural. Ed. Unicopia

Ingeciber. (2003). Curso de Teoría y Aplicación Práctica del Método de los Elementos Finitos y Simulación. Ed. U.N.E.D. E.T.S.I. Industriales

Jiménez Montoya, P. y otros. (2009). Hormigón Armado. Ed. Gustavo Gili

Jiménez Salas, J.A. (1981). Geotecnia y Cimientos. Ed. Rueda

Oñate, E. (1995). Cálculo de Estructuras por el Método de Elementos Finitos. Ed. Centro Internacional de Métodos Numéricos en Ingeniería

Perepérez, B.; Barberá, E. (2005). Manual del Hormigón Estructural. Ed. M.P.C.

Rodríguez, J. M.; Serra, J.; Oteo C. (1989). Curso Aplicado de Cimentaciones. Ed. Colegio Oficial de Arquitectos de Madrid

Zienkiewicz, O.C. (1994). El Método de los Elementos Finitos. Ed. Mc. Graw - Hill. 
ANEJO I

MODELO DE ELEMENTOS FINITOS 



\section{ANEJO I}

Se ofrece en el presente anejo un listado tipo con los comandos del lenguaje de programación APDL de ANSYS que permiten desarrollar el modelo de elementos finitos utilizado en la fase experimental virtual.

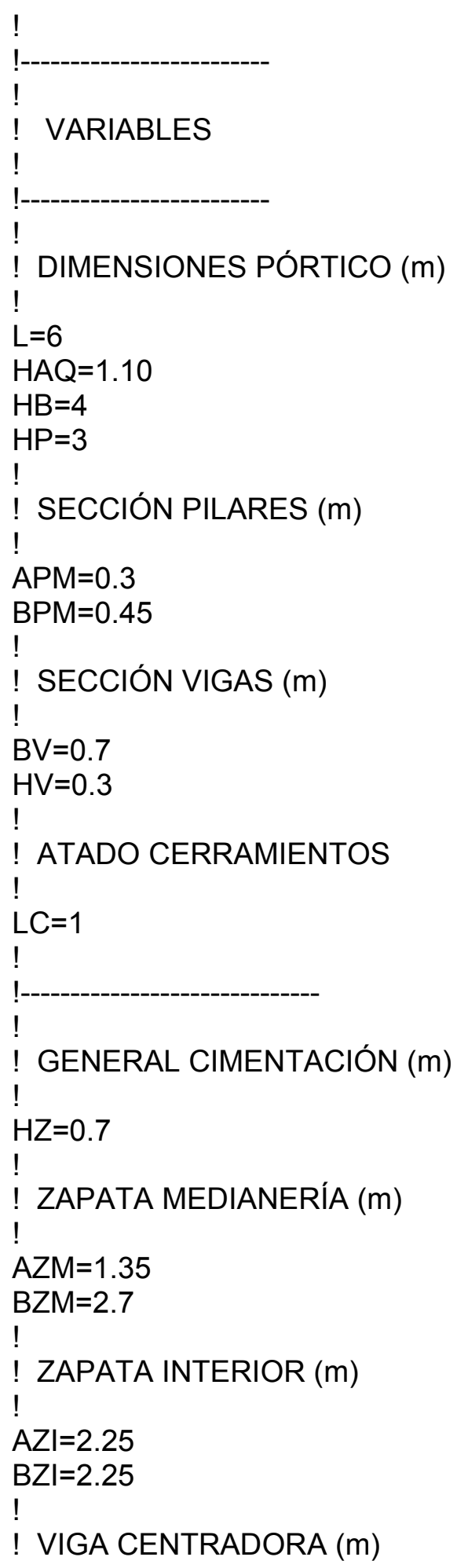




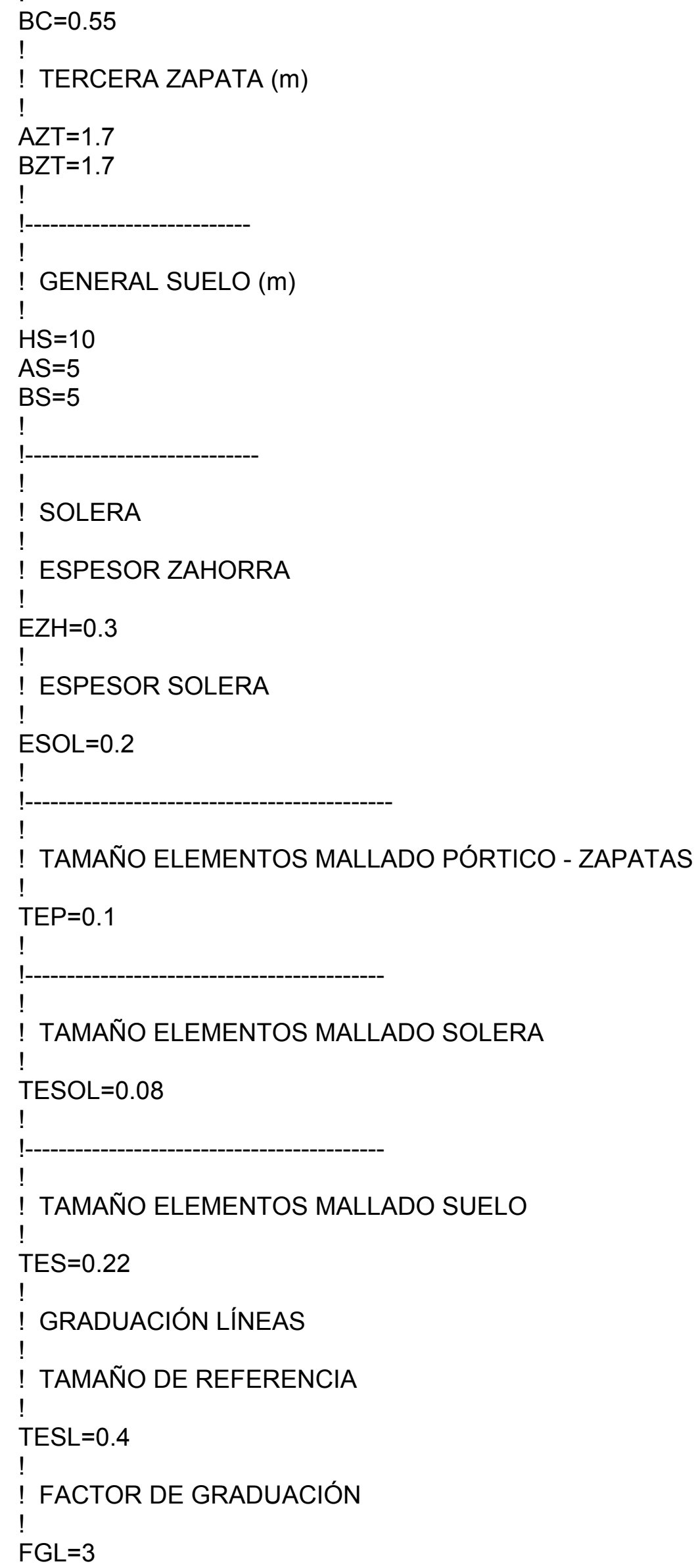




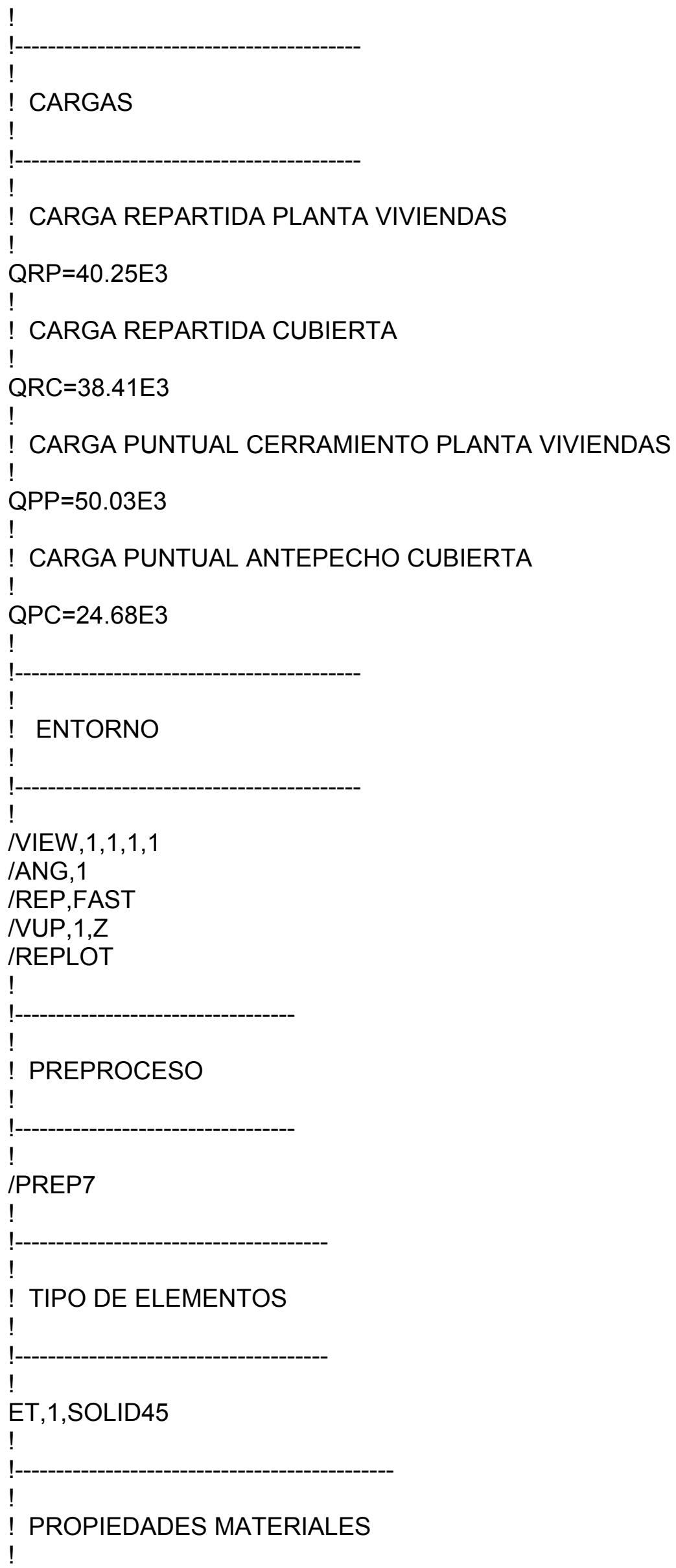




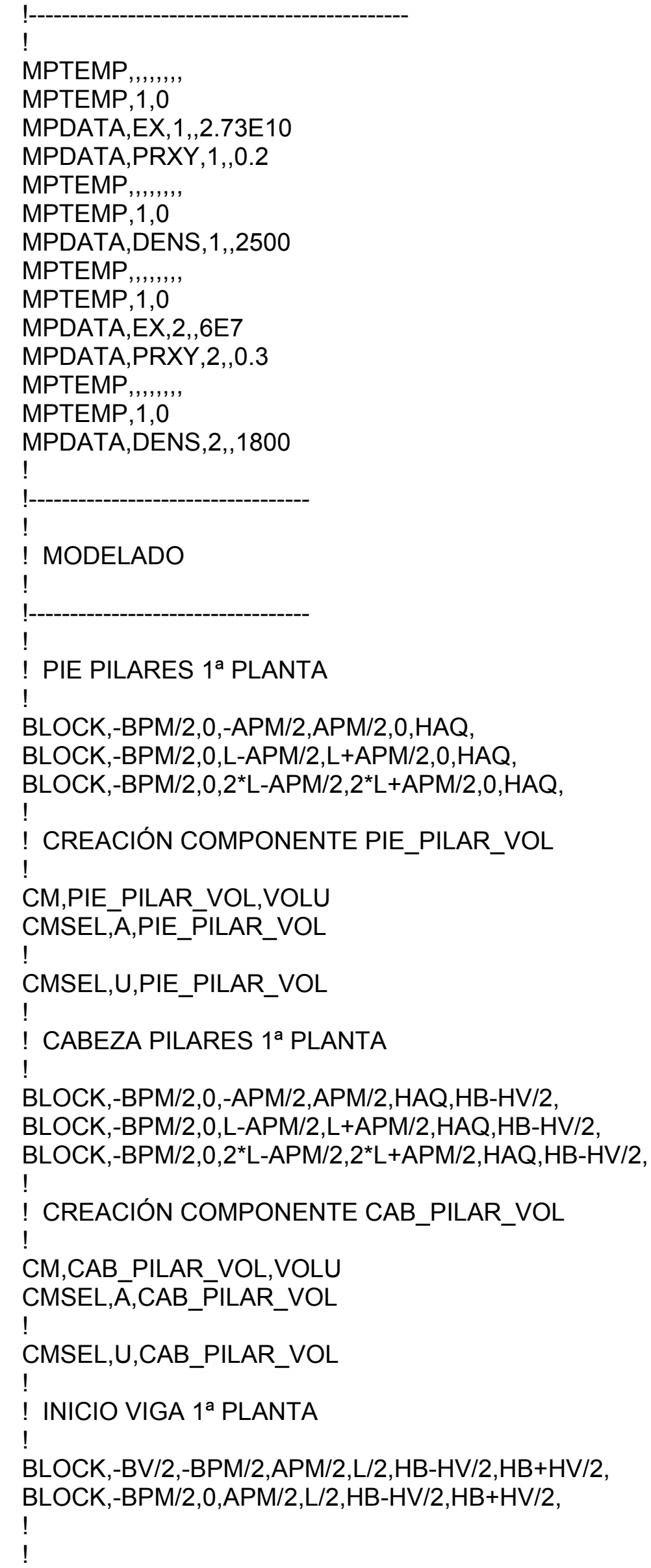


! CREACIÓN COMPONENTE INI_VIGA_VOL

!

CM,INI_VIGA_VOL,VOLU

CMSEL,A,INI_VIGA_VOL

!

CMSEL,U,INI_VIGA_VOL

!

! RESTO PILARES

!

BLOCK,-BPM/2,0,-APM/2,APM/2,HB+HV/2,HB+HP-HV/2,

$\mathrm{BLOCK},-\mathrm{BPM} / 2,0,-\mathrm{APM} / 2, \mathrm{APM} / 2, \mathrm{HB}+\mathrm{HP}+\mathrm{HV} / 2, \mathrm{HB}+2{ }^{*} \mathrm{HP}-\mathrm{HV} / 2$, !

BLOCK,-BPM/2,0,L-APM/2,L+APM/2,HB+HV/2,HB+HP-HV/2,

$\mathrm{BLOCK},-\mathrm{BPM} / 2,0, \mathrm{~L}-\mathrm{APM} / 2, \mathrm{~L}+\mathrm{APM} / 2, \mathrm{HB}+\mathrm{HP}+\mathrm{HV} / 2, \mathrm{HB}+2^{*} \mathrm{HP}-\mathrm{HV} / 2$, !

BLOCK,-BPM/2,0,2*L-APM/2,2*L+APM/2,HB+HV/2,HB+HP-HV/2,

$\mathrm{BLOCK},-\mathrm{BPM} / 2,0,2^{*} \mathrm{~L}-\mathrm{APM} / 2,2^{*} \mathrm{~L}+\mathrm{APM} / 2, \mathrm{HB}+\mathrm{HP}+\mathrm{HV} / 2, \mathrm{HB}+2^{*} \mathrm{HP}-$ $\mathrm{HV} / 2$,

!

! NUDOS

!

BLOCK,-BV/2,-BPM/2,-APM/2,APM/2,HB-HV/2,HB+HV/2,

BLOCK,-BPM/2,0,-APM/2,APM/2,HB-HV/2,HB+HV/2, !

BLOCK,-BV/2,-BPM/2,-APM/2,APM/2,HB+HP-HV/2,HB+HP+HV/2, BLOCK,-BPM/2,0,-APM/2,APM/2,HB+HP-HV/2,HB+HP+HV/2, !

BLOCK,-BV/2,-BPM/2,-APM/2,APM/2,HB+2*HP-HV/2,HB+2*HP+HV/2, BLOCK,-BPM/2,0,-APM/2,APM/2,HB+2*HP-HV/2,HB+2*HP+HV/2, !

BLOCK,-BV/2,-BPM/2,L-APM/2,L+APM/2,HB-HV/2,HB+HV/2, BLOCK,-BPM/2,0,L-APM/2,L+APM/2,HB-HV/2,HB+HV/2, !

BLOCK,-BV/2,-BPM/2,L-APM/2,L+APM/2,HB+HP-HV/2,HB+HP+HV/2, BLOCK,-BPM/2,0,L-APM/2,L+APM/2,HB+HP-HV/2,HB+HP+HV/2, !

BLOCK,-BV/2,-BPM/2,L-APM/2,L+APM/2,HB+2*HP-

$\mathrm{HV} / 2, \mathrm{HB}+2{ }^{*} \mathrm{HP}+\mathrm{HV} / 2$,

$\mathrm{BLOCK},-\mathrm{BPM} / 2,0, \mathrm{~L}-\mathrm{APM} / 2, \mathrm{~L}+\mathrm{APM} / 2, \mathrm{HB}+2^{*} \mathrm{HP}-\mathrm{HV} / 2, \mathrm{HB}+2^{*} \mathrm{HP}+\mathrm{HV} / 2$, !

BLOCK,-BV/2,-BPM/2,2*L-APM/2,2*L+APM/2,HB-HV/2,HB+HV/2,

BLOCK,-BPM/2,0,2*L-APM/2,2*L+APM/2,HB-HV/2,HB+HV/2, !

BLOCK,-BV/2,-BPM/2,2*L-APM/2,2*L+APM/2,HB+HP-

$\mathrm{HV} / 2, \mathrm{HB}+\mathrm{HP}+\mathrm{HV} / 2$,

BLOCK,-BPM/2,0,2*L-APM/2,2*L+APM/2,HB+HP-HV/2,HB+HP+HV/2, !

BLOCK,-BV/2,-BPM/2,2*L-APM/2,2*L+APM/2,HB+2*HP-

$\mathrm{HV} / 2, \mathrm{HB}+2{ }^{*} \mathrm{HP}+\mathrm{HV} / 2$,

BLOCK,-BPM/2,0,2*L-APM/2,2*L+APM/2,HB+2*HP-

$\mathrm{HV} / 2, \mathrm{HB}+2^{*} \mathrm{HP}+\mathrm{HV} / 2$,

!

! VIGAS

!

BLOCK,-BV/2,-BPM/2,L/2,L-APM/2,HB-HV/2,HB+HV/2, 


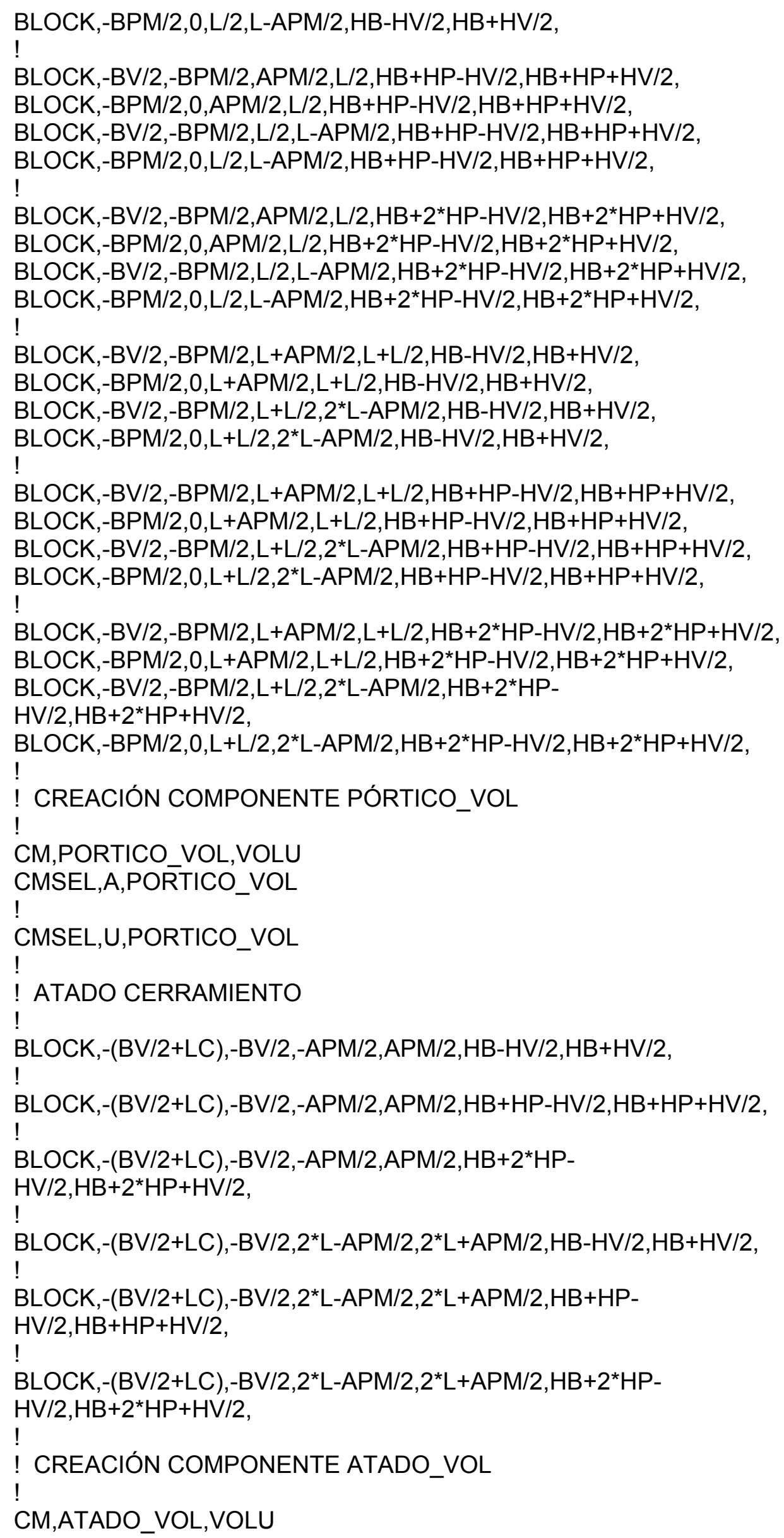




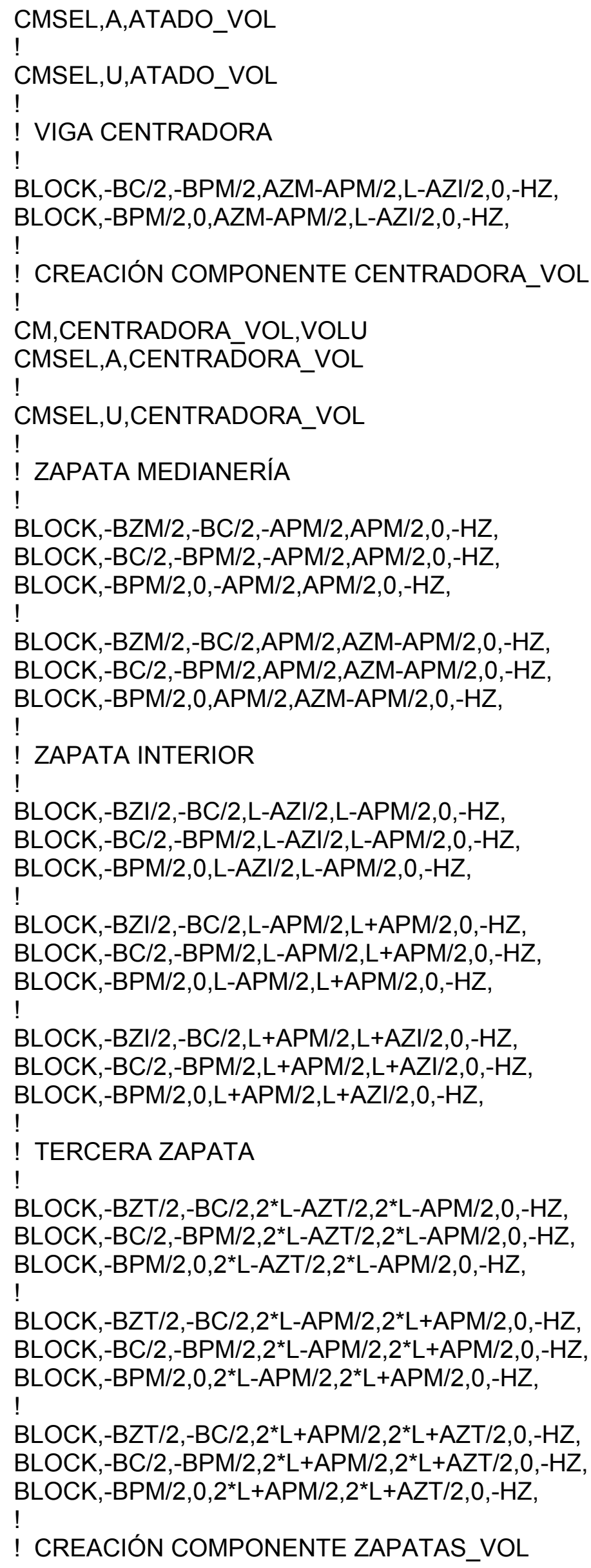




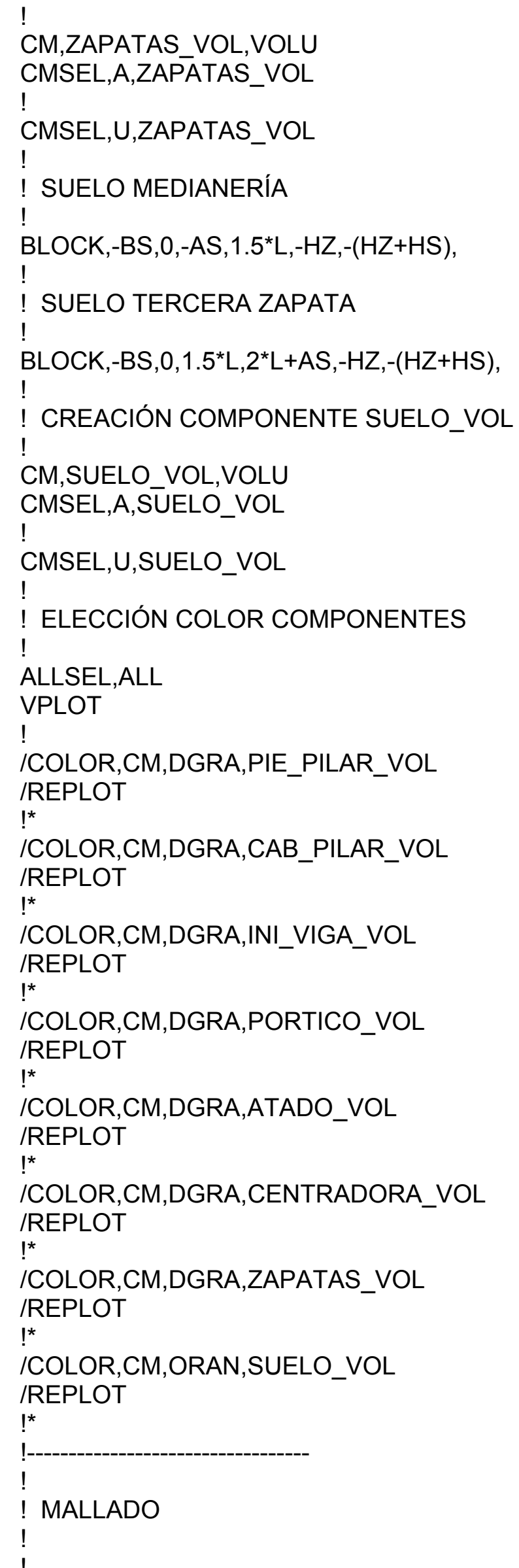




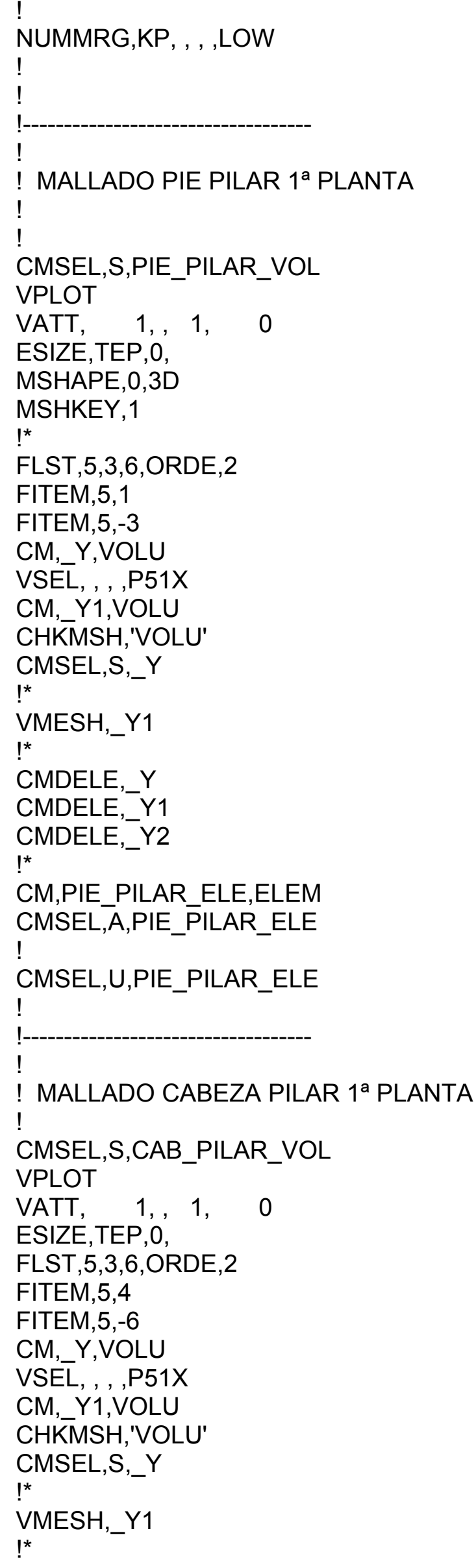




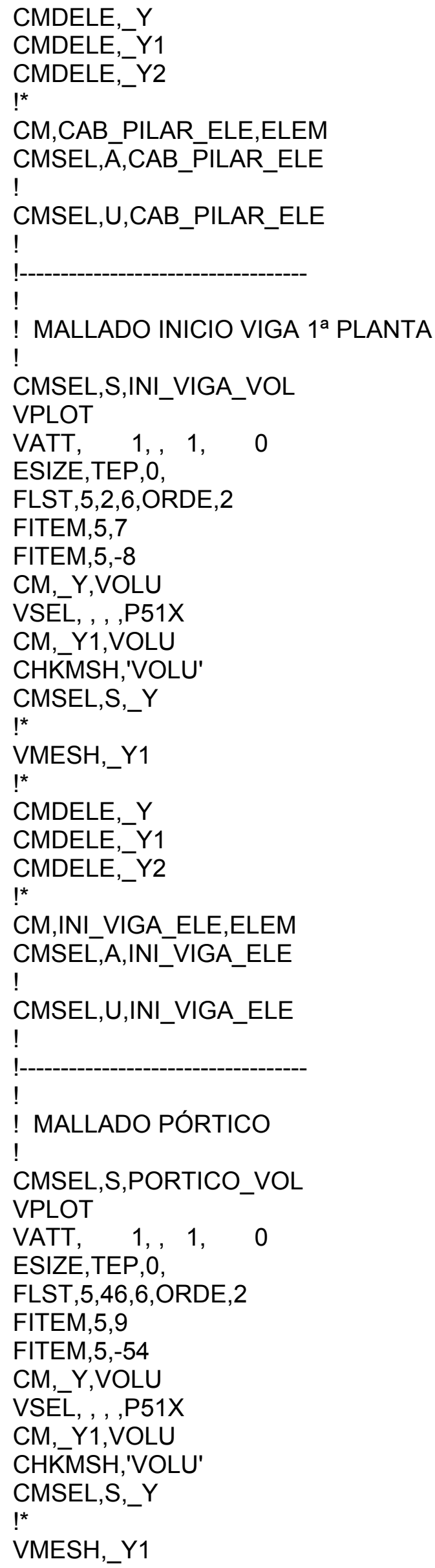




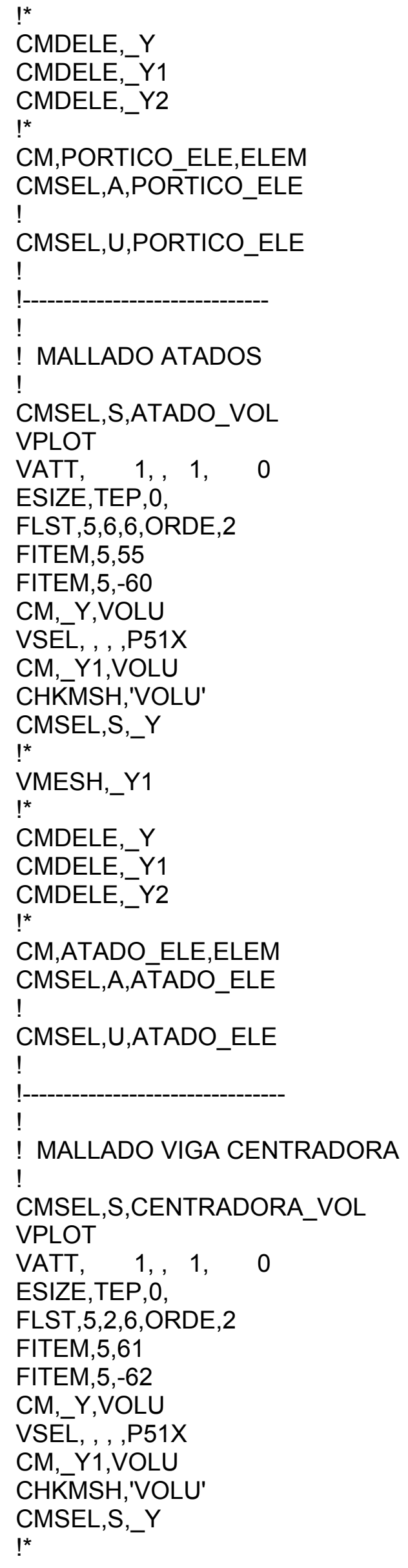




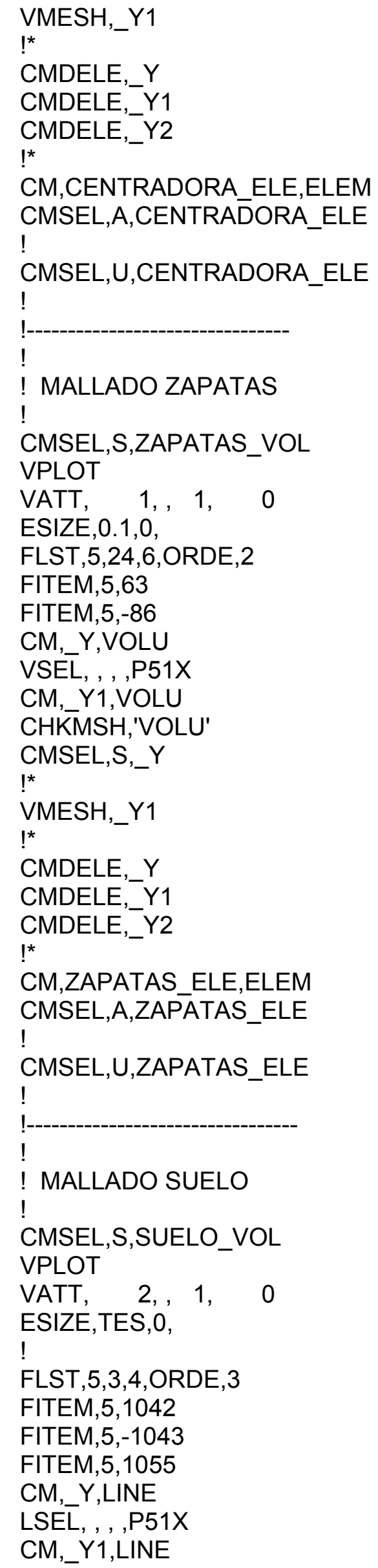




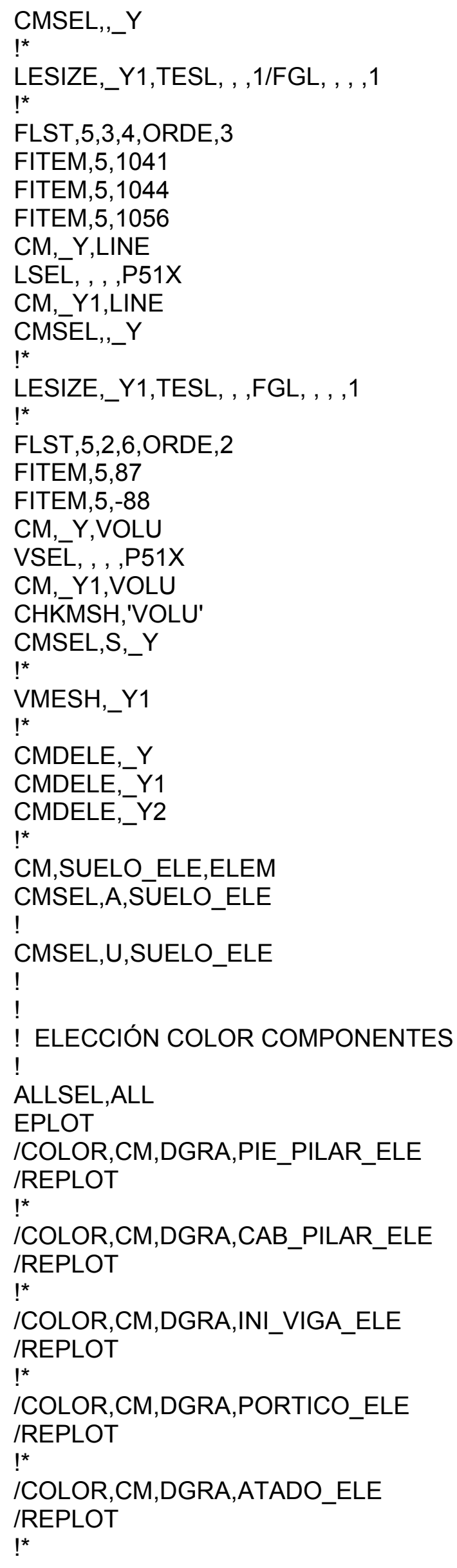




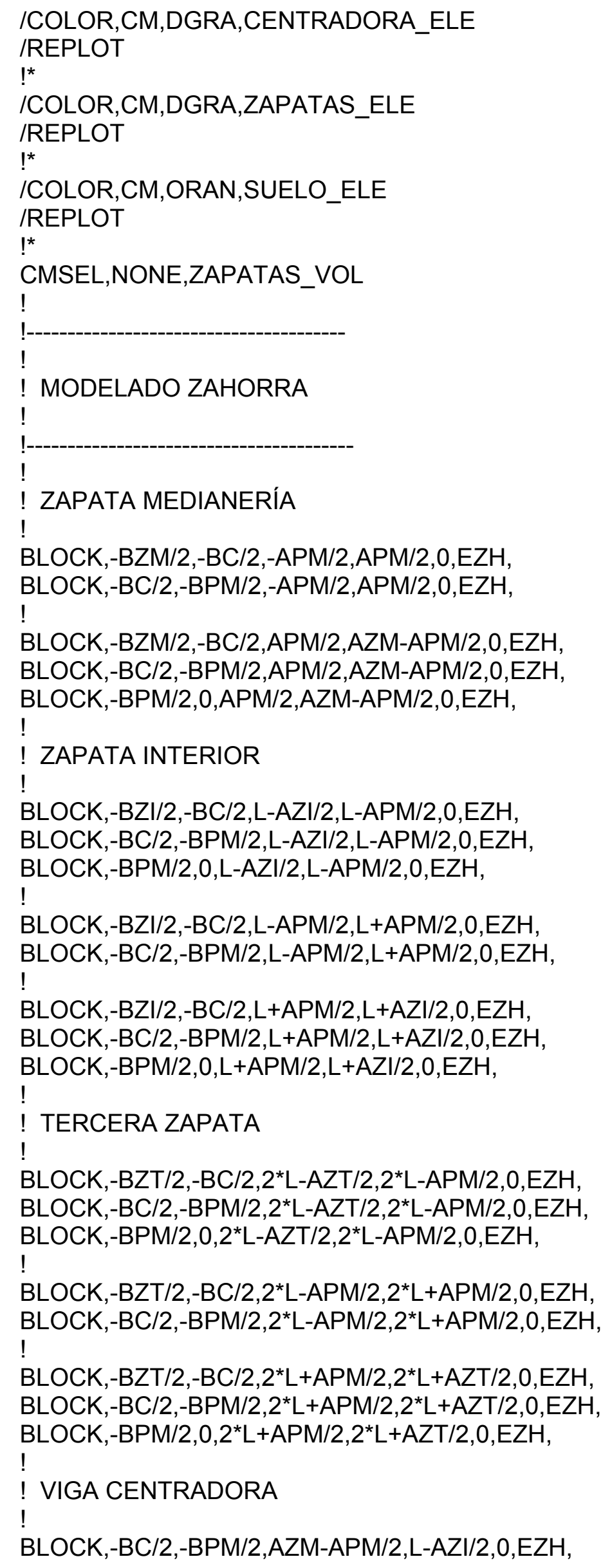




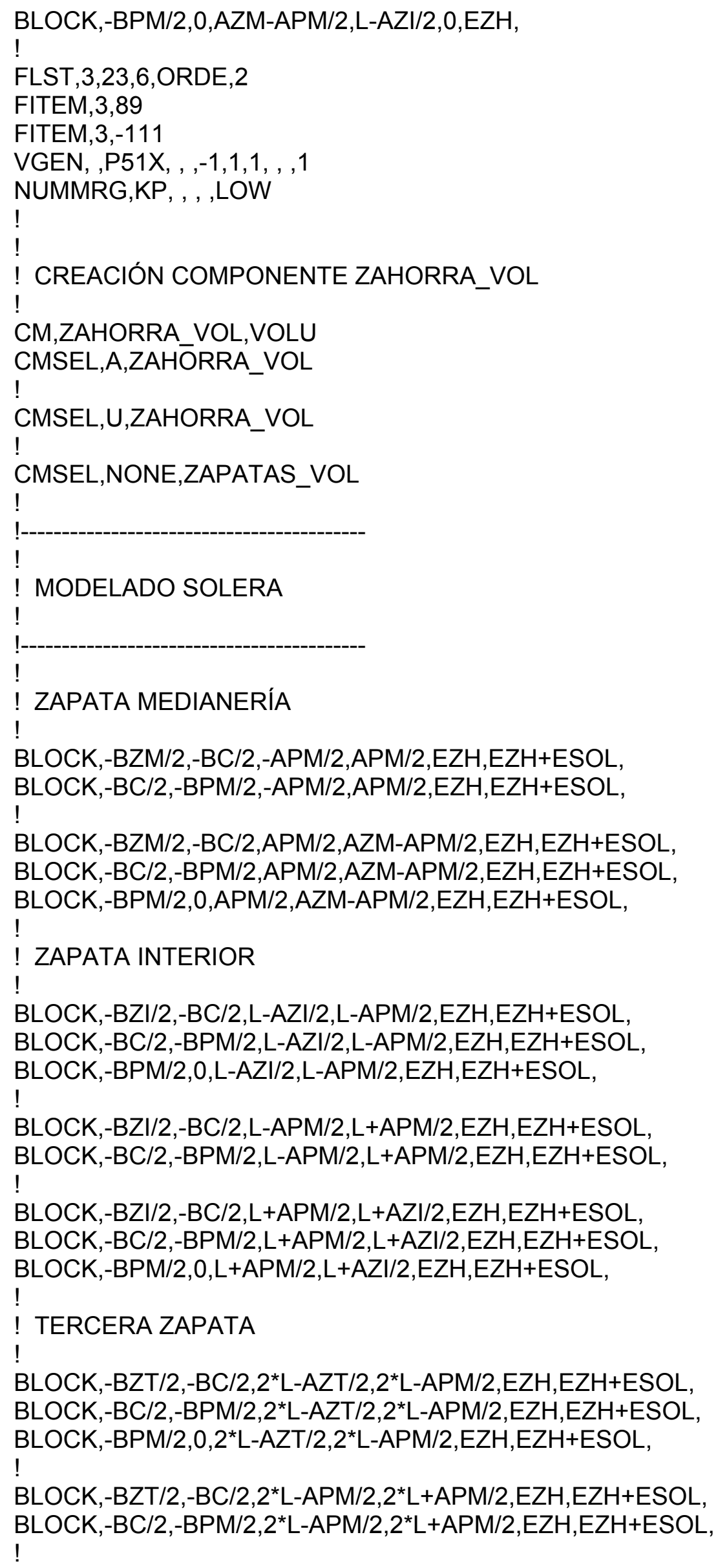




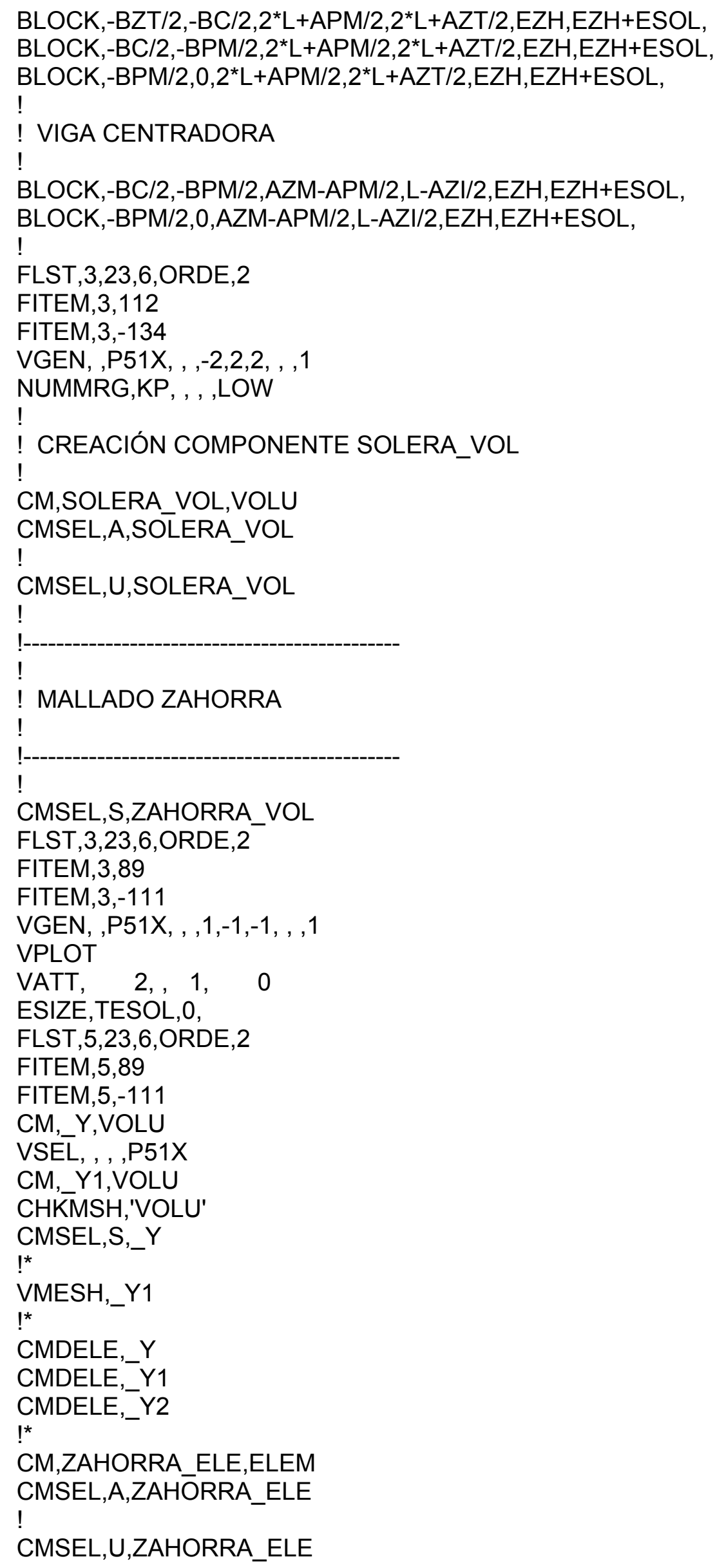




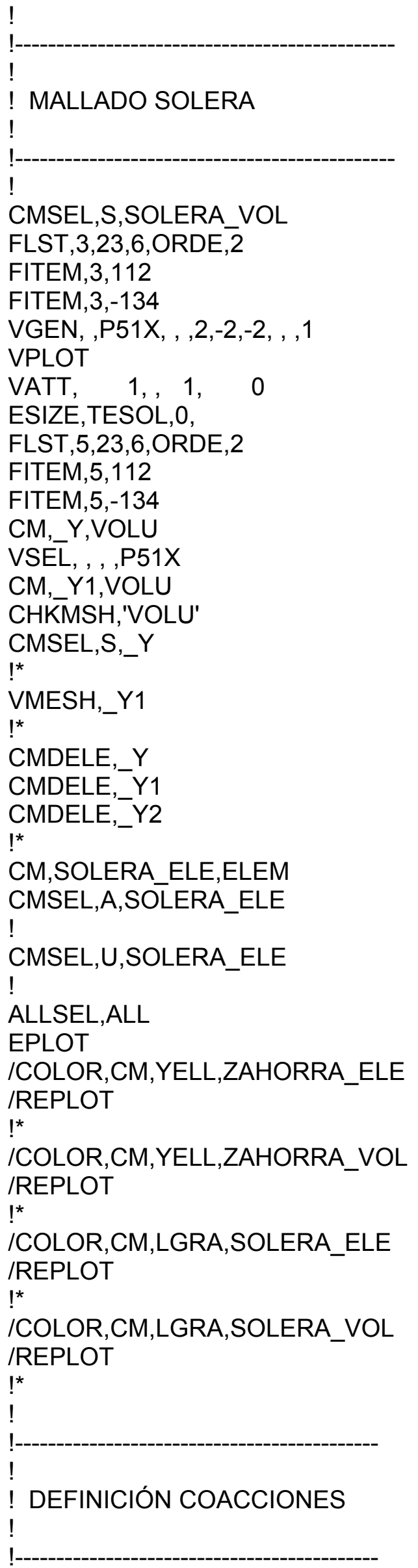




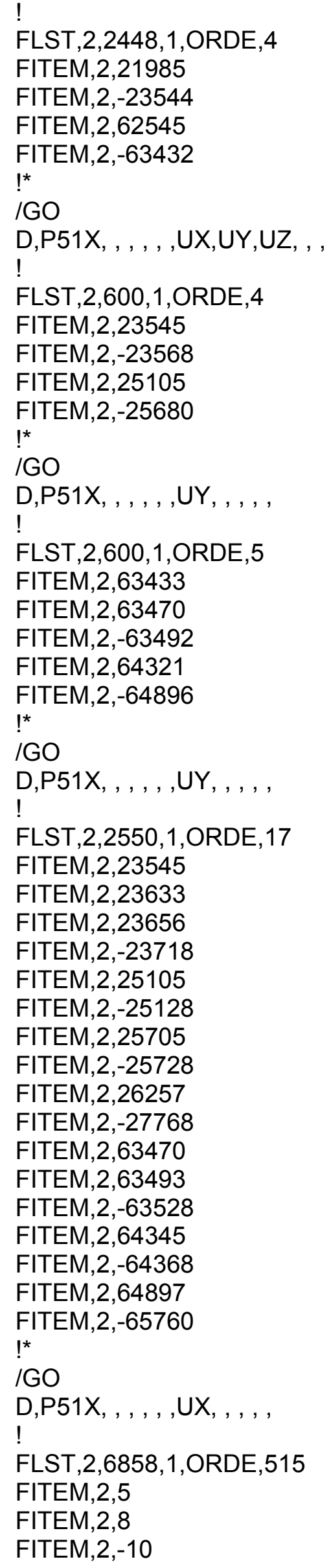


FITEM,2,18

FITEM,2,21

FITEM,2,-23

FITEM, 2,43

FITEM,2,-52

FITEM, 2,73

FITEM,2,-82

FITEM,2,133

FITEM,2,-152

FITEM,2,197

FITEM,2,200

FITEM,2,-202

FITEM,2,210

FITEM,2,213

FITEM,2,-215

FITEM,2,235

FITEM,2,-244

FITEM,2,265

FITEM,2,-274

FITEM,2,325

FITEM,2,-344

FITEM,2,389

FITEM,2,392

FITEM,2,-394

FITEM,2,402

FITEM,2,405

FITEM,2,-407

FITEM,2,427

FITEM,2,-436

FITEM,2,457

FITEM,2,-466

FITEM,2,517

FITEM,2,-536

FITEM,2,578

FITEM,2,581

FITEM,2,-583

FITEM,2,620

FITEM,2,-646

FITEM,2,701

FITEM,2,-727

FITEM,2,863

FITEM,2,-916

FITEM,2,1026

FITEM,2,1029

FITEM,2,-1031

FITEM,2,1068

FITEM,2,-1094

FITEM,2,1149

FITEM,2,-1175

FITEM,2,1311

FITEM,2,-1364

FITEM,2,1474

FITEM,2,1477

FITEM,2,-1479

FITEM,2,1516 
FITEM,2,-1542

FITEM,2,1597

FITEM,2,-1623

FITEM,2, 1759

FITEM,2,-1812

FITEM,2,2280

FITEM,2,2283

FITEM,2,-2310

FITEM,2,2367

FITEM, 2,2370

FITEM,2,-2398

FITEM,2,2457

FITEM,2,-2458

FITEM,2,2463

FITEM,2,-2464

FITEM,2,2469

FITEM,2,-2524

FITEM,2,2640

FITEM,2,-2642

FITEM,2,2650

FITEM,2,2653

FITEM,2,-2655

FITEM,2,2691

FITEM,2,-2716

FITEM,2,2769

FITEM,2,-2794

FITEM,2,2925

FITEM,2,-2976

FITEM,2,3085

FITEM,2,3088

FITEM,2,-3090

FITEM,2,3098

FITEM,2,3101

FITEM,2,-3103

FITEM,2,3139

FITEM,2,-3164

FITEM,2,3217

FITEM,2,-3242

FITEM, 2,3373

FITEM,2,-3424

FITEM,2,3533

FITEM,2,3536

FITEM,2,-3538

FITEM,2,3546

FITEM,2,3549

FITEM,2,-3551

FITEM,2,3587

FITEM,2,-3612

FITEM,2,3665

FITEM,2,-3690

FITEM,2,3821

FITEM,2,-3872

FITEM,2,3981

FITEM,2,3984

FITEM,2,-3986 
FITEM,2,3994

FITEM,2,3997

FITEM,2,-3999

FITEM,2,4035

FITEM,2,-4060

FITEM,2,4113

FITEM,2,-4138

FITEM,2,4269

FITEM,2,-4320

FITEM,2,4429

FITEM,2,4432

FITEM,2,-4434

FITEM, 2,4442

FITEM,2,4445

FITEM,2,-4447

FITEM, 2,4483

FITEM,2,-4508

FITEM,2,4561

FITEM,2,-4586

FITEM,2,4717

FITEM,2,-4768

FITEM,2,4877

FITEM, 2,4880

FITEM,2,-4882

FITEM,2,4890

FITEM,2,4893

FITEM,2,-4895

FITEM,2,4931

FITEM,2,-4956

FITEM,2,5009

FITEM,2,-5034

FITEM,2,5165

FITEM,2,-5216

FITEM,2,5351

FITEM,2,-5352

FITEM,2,5357

FITEM,2,-5360

FITEM,2,5409

FITEM,2,-5410

FITEM,2,5415

FITEM,2,-5416

FITEM,2,5421

FITEM,2,-5424

FITEM,2,5477

FITEM, 2,5480

FITEM,2,-5482

FITEM,2,5489

FITEM,2,-5490

FITEM,2,5495

FITEM,2,-5496

FITEM,2,5501

FITEM,2,-5504

FITEM,2,5553

FITEM,2,-5554

FITEM,2,5559 
FITEM,2,-5560

FITEM,2,5565

FITEM,2,-5568

FITEM,2,5617

FITEM,2,-5618

FITEM,2,5623

FITEM,2,-5624

FITEM,2,5629

FITEM,2,-5632

FITEM,2,5685

FITEM,2,5688

FITEM,2,-5690

FITEM,2,5697

FITEM,2,-5698

FITEM,2,5703

FITEM,2,-5704

FITEM,2,5709

FITEM,2,-5712

FITEM,2,5761

FITEM,2,-5762

FITEM,2,5767

FITEM,2,-5768

FITEM,2,5773

FITEM,2,-5776

FITEM,2,5825

FITEM,2,-5826

FITEM,2,5831

FITEM,2,-5832

FITEM,2,5837

FITEM,2,-5840

FITEM,2,5893

FITEM,2,5896

FITEM,2,-5898

FITEM,2,5905

FITEM,2,-5906

FITEM,2,5911

FITEM,2,-5912

FITEM,2,5917

FITEM,2,-5920

FITEM,2,6265

FITEM,2,-6292

FITEM,2,6349

FITEM,2,-6376

FITEM,2,6433

FITEM,2,-6488

FITEM,2,6949

FITEM,2,6952

FITEM,2,-6979

FITEM,2,7036

FITEM,2,-7064

FITEM,2,7123

FITEM,2,-7124

FITEM,2,7129

FITEM,2,-7184

FITEM,2,7633 
FITEM,2,-7660

FITEM, 2,7717

FITEM,2,-7744

FITEM,2,7801

FITEM,2,-7856

FITEM,2,8317

FITEM,2,8320

FITEM,2,-8347

FITEM, 2,8404

FITEM,2,-8432

FITEM,2,8491

FITEM,2,-8492

FITEM,2,8497

FITEM,2,-8552

FITEM,2,9001

FITEM,2,-9028

FITEM,2,9085

FITEM,2,-9112

FITEM,2,9169

FITEM,2,-9224

FITEM,2,9685

FITEM,2,9688

FITEM,2,-9715

FITEM,2,9772

FITEM,2,-9800

FITEM,2,9859

FITEM,2,-9860

FITEM,2,9865

FITEM,2,-9920

FITEM,2,10369

FITEM,2,-10396

FITEM,2,10453

FITEM,2,-10480

FITEM,2,10537

FITEM,2,-10592

FITEM,2,11053

FITEM,2,11056

FITEM,2,-11083

FITEM,2,11140

FITEM,2,-11168

FITEM,2,11227

FITEM,2,-11228

FITEM,2,11233

FITEM,2,-11288

FITEM,2,11737

FITEM,2,-11764

FITEM,2,11821

FITEM,2,-11848

FITEM,2,11905

FITEM,2,-11960

FITEM,2,12421

FITEM,2,12424

FITEM,2,-12451

FITEM,2,12508

FITEM,2,-12536 
FITEM,2,12595

FITEM,2,-12596

FITEM,2,12601

FITEM,2,-12656

FITEM,2,13105

FITEM,2,-13132

FITEM,2,13189

FITEM,2,-13216

FITEM,2,13273

FITEM,2,-13328

FITEM,2,15009

FITEM,2,15012

FITEM,2,-15048

FITEM,2,15123

FITEM,2,15126

FITEM,2,-15162

FITEM,2,15237

FITEM,2,-15242

FITEM,2,15255

FITEM,2,-15260

FITEM,2,15273

FITEM,2,-15488

FITEM,2,16333

FITEM,2,16336

FITEM,2,-16338

FITEM,2,16345

FITEM,2,-16350

FITEM,2,16363

FITEM,2,-16368

FITEM,2,16381

FITEM,2,-16392

FITEM,2,17545

FITEM,2,-17554

FITEM,2, 17575

FITEM,2,-17584

FITEM,2,17605

FITEM,2,-17664

FITEM,2,18736

FITEM,2,18739

FITEM,2,-18747

FITEM,2,18766

FITEM,2,-18774

FITEM,2,18793

FITEM,2,-18798

FITEM,2,18811

FITEM,2,-18864

FITEM,2,19234

FITEM,2,19237

FITEM,2,-19238

FITEM,2,19243

FITEM,2,-19248

FITEM,2,19261

FITEM,2,-19272

FITEM,2,20177

FITEM,2,20180 
FITEM,2,-20188

FITEM,2,20207

FITEM,2,-20216

FITEM,2,20237

FITEM,2,-20242

FITEM,2,20255

FITEM,2,-20308

FITEM,2,20928

FITEM,2,20931

FITEM,2,-20937

FITEM,2,20952

FITEM,2,20955

FITEM,2,-20960

FITEM,2,20973

FITEM,2,-20978

FITEM,2,20991

FITEM,2,-20996

FITEM,2,21009

FITEM,2,-21044

FITEM,2,21306

FITEM,2,21309

FITEM,2,-21310

FITEM,2,21315

FITEM,2,-21320

FITEM,2,21333

FITEM,2,-21344

FITEM,2,21817

FITEM,2,21820

FITEM,2,-21825

FITEM,2,21838

FITEM,2,-21844

FITEM,2,21859

FITEM,2,-21864

FITEM,2,21877

FITEM,2,-21912

FITEM,2,23546

FITEM,2,23569

FITEM,2,-23632

FITEM,2,25129

FITEM,2,-25152

FITEM,2,25681

FITEM,2,-25704

FITEM,2,27769

FITEM,2,-29280

FITEM,2,63433

FITEM,2,-63469

FITEM,2,64321

FITEM,2,-64344

FITEM,2,65761

FITEM,2,-66624

FITEM,2,87153

FITEM,2,87156

FITEM,2,-87169

FITEM,2,87198

FITEM,2,87201 
FITEM,2,-87214

FITEM,2,87243

FITEM,2,-87245

FITEM,2,87252

FITEM,2,-87254

FITEM,2,87261

FITEM,2,-87299

FITEM,2,88288

FITEM,2,88291

FITEM,2,-88303

FITEM,2,88330

FITEM,2,88333

FITEM,2,-88345

FITEM,2,88372

FITEM,2,-88374

FITEM,2,88381

FITEM,2,-88383

FITEM,2,88390

FITEM,2,-88425

FITEM,2,89603

FITEM,2,89606

FITEM,2,-89618

FITEM,2,89645

FITEM,2,89648

FITEM,2,-89660

FITEM,2,89687

FITEM,2,-89689

FITEM,2,89696

FITEM,2,-89698

FITEM,2,89705

FITEM,2,-89740

FITEM,2,90313

FITEM,2,90316

FITEM,2,-90324

FITEM,2,90343

FITEM,2,90346

FITEM,2,-90354

FITEM,2,90373

FITEM,2,-90375

FITEM,2,90382

FITEM,2,-90384

FITEM,2,90391

FITEM,2,-90414

FITEM,2,91113

FITEM,2,91116

FITEM,2,-91124

FITEM,2,91143

FITEM,2,91146

FITEM,2,-91154

FITEM,2,91173

FITEM,2,-91175

FITEM,2,91182

FITEM,2,-91184

FITEM,2,91191

FITEM,2,-91214 
FITEM,2,91713

FITEM,2,-91757

FITEM,2,91848

FITEM,2,-91892

FITEM,2,91983

FITEM,2,-92117

FITEM,2,93604

FITEM,2,93607

FITEM,2,-93620

FITEM,2,93649

FITEM,2,93652

FITEM,2,-93665

FITEM,2,93694

FITEM,2,-93695

FITEM,2,93700

FITEM,2,-93701

FITEM,2,93706

FITEM,2,-93731

FITEM,2,94512

FITEM,2,94515

FITEM,2,-94527

FITEM,2,94554

FITEM,2,94557

FITEM,2,-94569

FITEM,2,94596

FITEM,2,-94597

FITEM,2,94602

FITEM,2,-94603

FITEM,2,94608

FITEM,2,-94631

FITEM,2,95564

FITEM,2,95567

FITEM,2,-95579

FITEM,2,95606

FITEM,2,95609

FITEM,2,-95621

FITEM,2,95648

FITEM,2,-95649

FITEM,2,95654

FITEM,2,-95655

FITEM,2,95660

FITEM,2,-95683

FITEM,2,96132

FITEM,2,96135

FITEM,2,-96143

FITEM,2,96162

FITEM,2,96165

FITEM,2,-96173

FITEM,2,96192

FITEM,2,-96193

FITEM,2,96198

FITEM,2,-96199

FITEM,2,96204

FITEM,2,-96219

FITEM,2,96772 


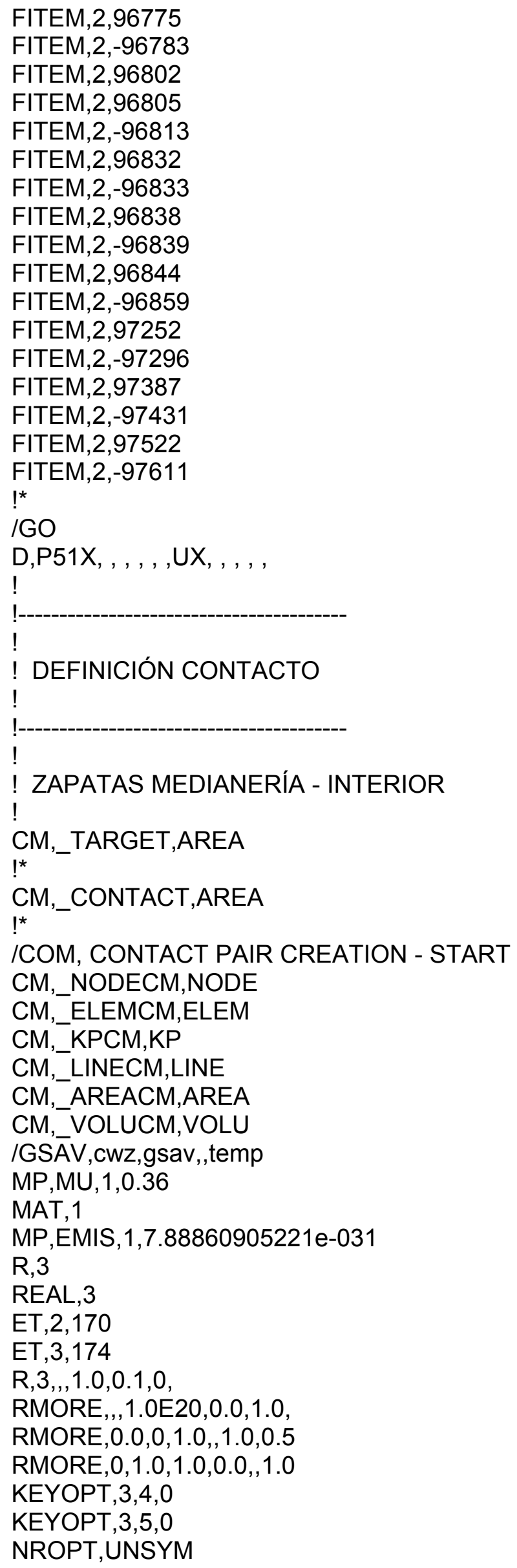


KEYOPT, $3,7,0$

KEYOPT, 3,8,0

KEYOPT, 3,9,0

KEYOPT,3,10,2

KEYOPT,3,11,0

KEYOPT, $3,12,0$

KEYOPT, 3,2,0

KEYOPT, 2,5,0

! Generate the target surface

ASEL,S, ,,517

ASEL,A,, ,518

ASEL,A,,, 519

ASEL,A,,,520

ASEL,A,,,521

ASEL,A,,,522

CM,_TARGET,AREA

TYPE, 2

NSLA,S, 1

ESLN,S,0

ESLL,U

ESEL,U,ENAME, ,188,189

ESURF

CMSEL,S, ELEMCM

! Generate the contact surface

ASEL,S,,,1

ASEL,A,,,7

ASEL,A,,,361

ASEL,A,,,362

ASEL,A,,,365

ASEL,A,,,367

ASEL,A,,,368

ASEL,A,,,372

ASEL,A,,,373

ASEL,A,,,374

ASEL,A,,,375

ASEL,A,,,377

ASEL,A,,,379

ASEL,A,,,380

ASEL,A,,,381

ASEL,A,,,385

ASEL,A,,,387

ASEL,A,,,390

ASEL,A,,,391

ASEL,A,,,392

ASEL,A,,,394

ASEL,A,,,395

ASEL,A,,,397

ASEL,A,, ,398

ASEL,A,,,403

ASEL,A,,,404

ASEL,A ,, ,408

ASEL,A,,,409

ASEL,A,,,410

ASEL, $A,,, 411$

ASEL,A,,,413 


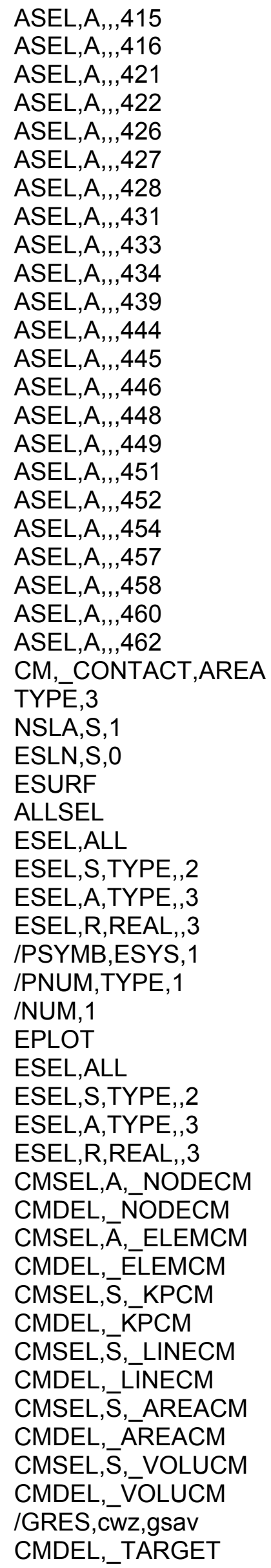




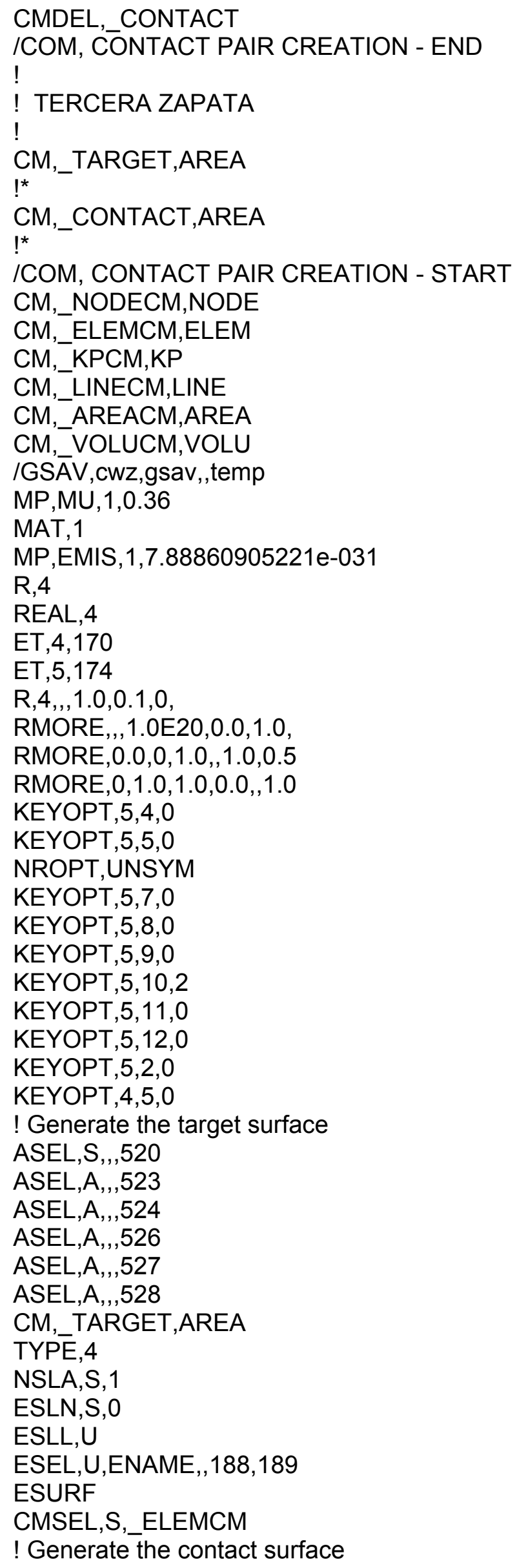




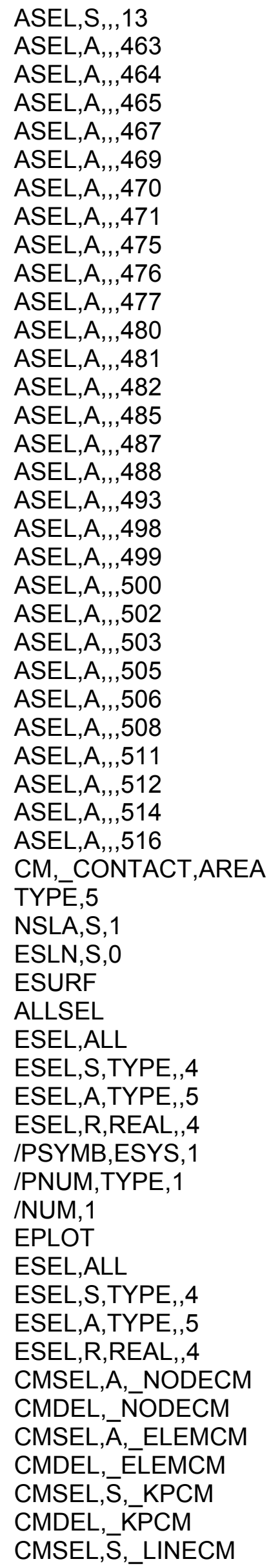




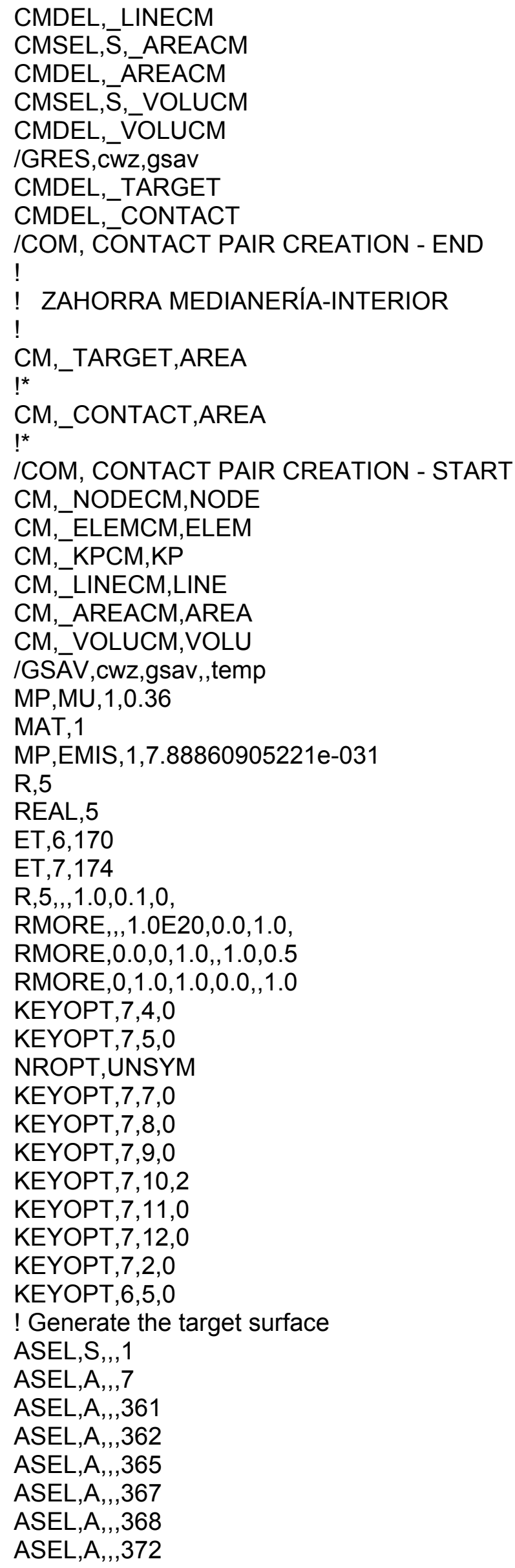




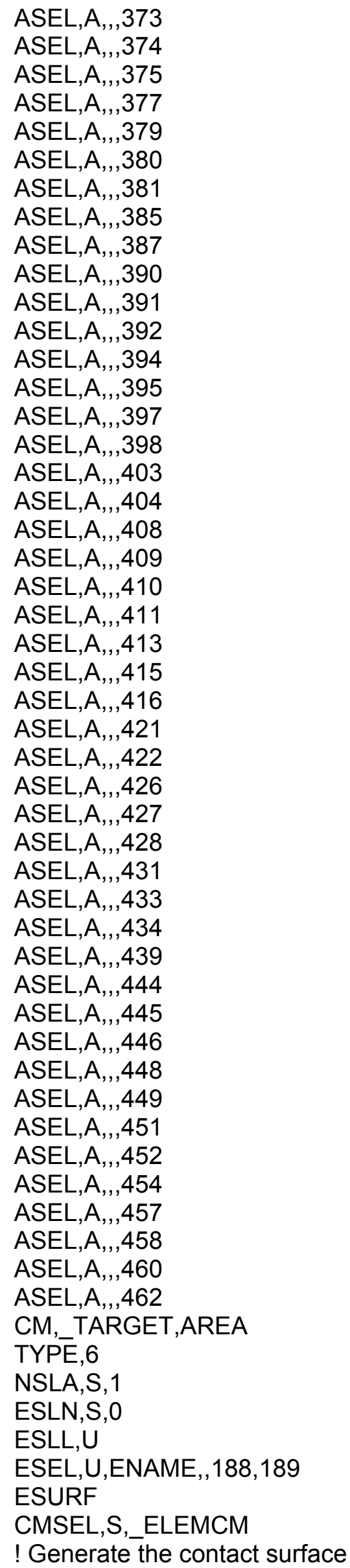


ASEL,S,,,19

ASEL,A,,,25

ASEL,A,,,31

ASEL,A,,,88

ASEL,A,,,92

ASEL,A,,,94

ASEL,A,,,95

ASEL,A,,,107

ASEL,A,,,115

ASEL,A,,,119

ASEL,A,,, 128

ASEL,A,,, 131

ASEL,A,,,140

ASEL,A,,,143

ASEL,A,,,167

ASEL,A,,,175

ASEL,A,,,176

ASEL,A,,,191

ASEL,A,,,195

ASEL,A,,,196

ASEL,A,,,201

ASEL,A,, ,203

ASEL,A,, ,213

ASEL,A,,.,215

ASEL,A,,,227

ASEL,A,,,231

ASEL,A,,,239

ASEL,A,,,244

ASEL,A,,,249

ASEL,A,,,250

ASEL,A,,,261

ASEL,A,,,267

ASEL,A,,,268

ASEL,A,,,279

ASEL,A,, ,285

ASEL,A,,,287

ASEL,A,,,292

ASEL,A,,,297

ASEL,A,,,299

ASEL,A,,,303

ASEL,A,,,311

ASEL,A,,,321

ASEL,A,, ,322

ASEL,A,,,323

ASEL,A,,,330

ASEL,A,,,342

ASEL,A,,,534

ASEL,A,,,535

ASEL,A, ,,538

ASEL,A,,,540

ASEL,A,,,541

ASEL,A,,,545

CM,_CONTACT,AREA

TYPE, 7

NSLA,S, 1 


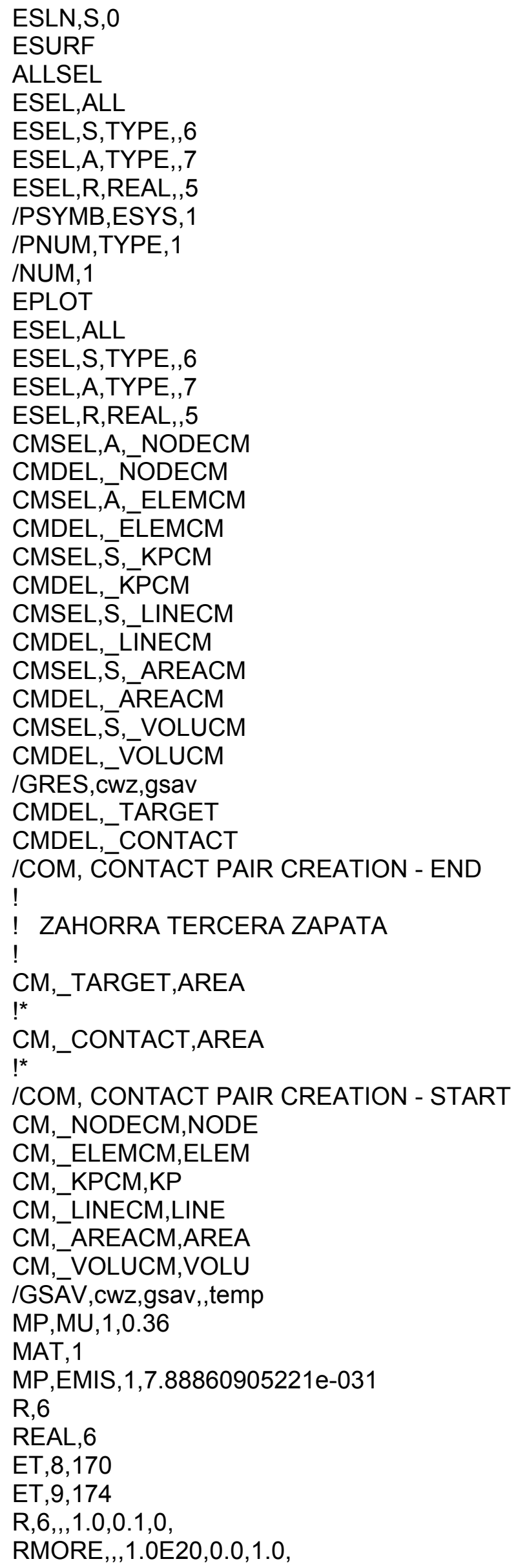


RMORE, 0.0,0,1.0, 1.0,0.5

RMORE,0,1.0,1.0,0.0, ,1.0

KEYOPT, $9,4,0$

KEYOPT, $9,5,0$

NROPT,UNSYM

KEYOPT, $9,7,0$

KEYOPT, $9,8,0$

KEYOPT, $9,9,0$

KEYOPT, 9,10,2

KEYOPT, $9,11,0$

KEYOPT, $9,12,0$

KEYOPT, $9,2,0$

KEYOPT, 8,5,0

! Generate the target surface

ASEL,S,,, 13

ASEL,A,,,463

ASEL,A,,,464

ASEL,A, ,,465

ASEL,A, ,,467

ASEL,A,,,469

ASEL,A,,,470

ASEL, $A,,, 471$

ASEL,A,, , 475

ASEL, $A,,, 476$

ASEL,A, , ,477

ASEL,A,,,480

ASEL,A, ,,481

ASEL,A,,,482

ASEL,A,,, 485

ASEL,A, ,,487

ASEL,A, ,,488

ASEL,A, ,,493

ASEL,A, ,, 498

ASEL,A,, ,499

ASEL,A, , ,500

ASEL,A,,,502

ASEL,A,,,503

ASEL,A,,,505

ASEL,A,,,506

ASEL,A, ,,508

ASEL,A, ,,511

ASEL,A,,,512

ASEL,A,,,514

ASEL,A,,,516

CM,_TARGET,AREA

TYPE, 8

NSLA,S, 1

ESLN,S,0

ESLL,U

ESEL,U,ENAME, $, 188,189$

ESURF

CMSEL,S,_ELEMCM

! Generate the contact surface

ASEL,S, ,,348

ASEL,A,,,354 


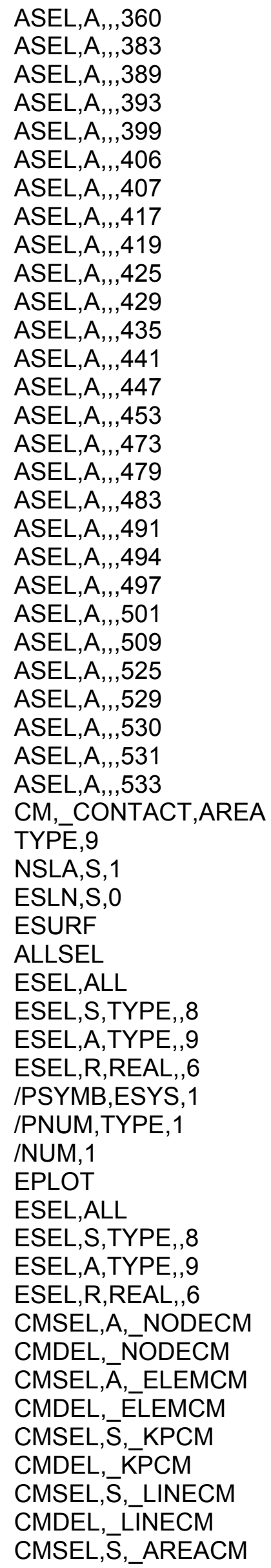




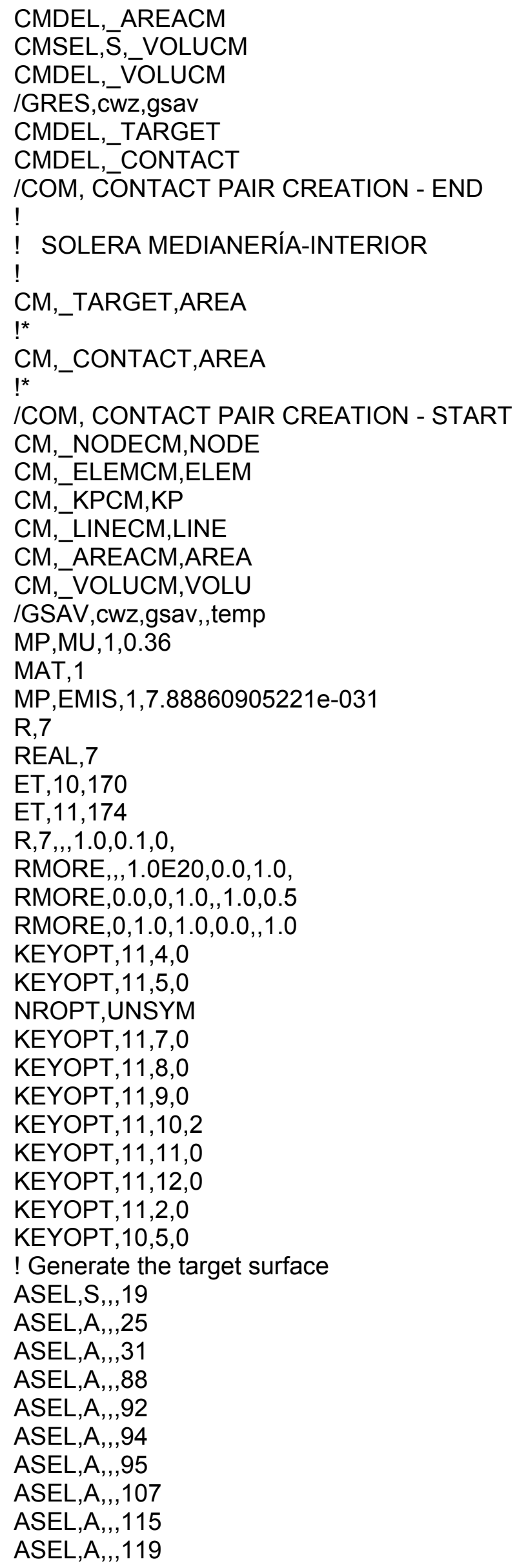




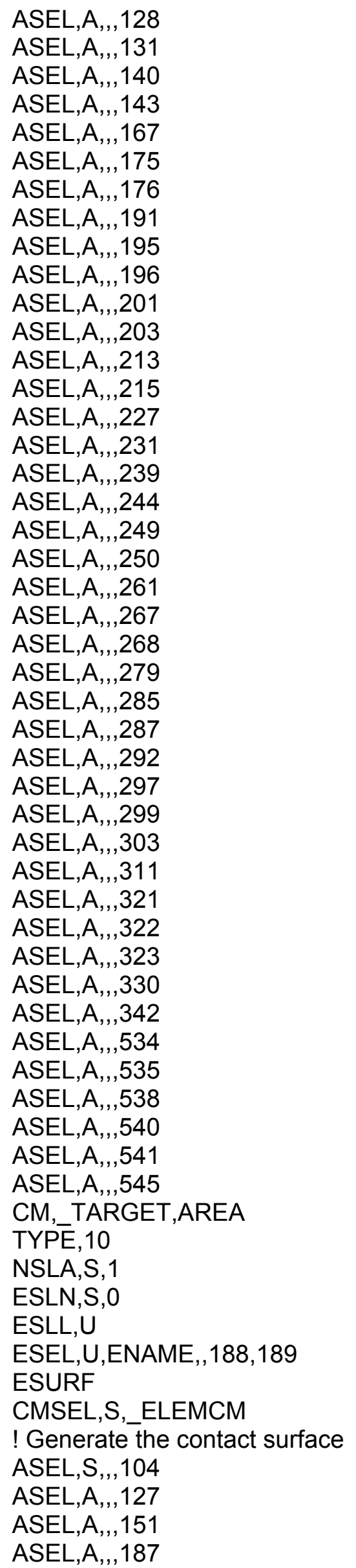




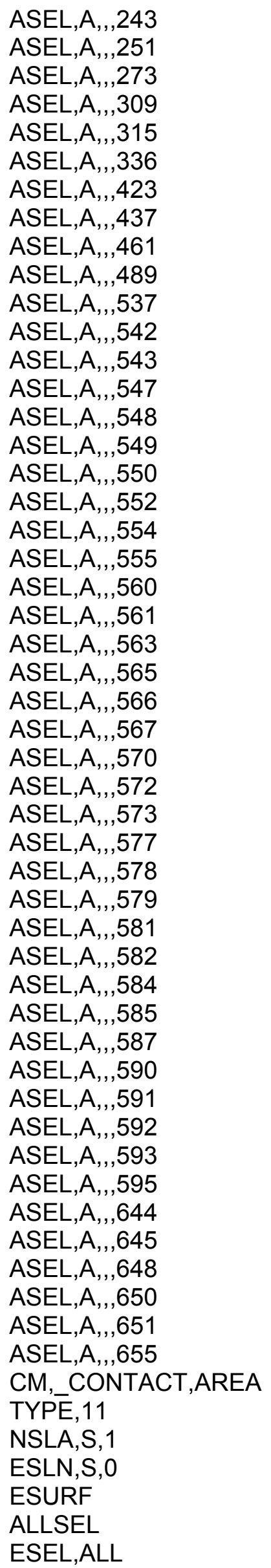




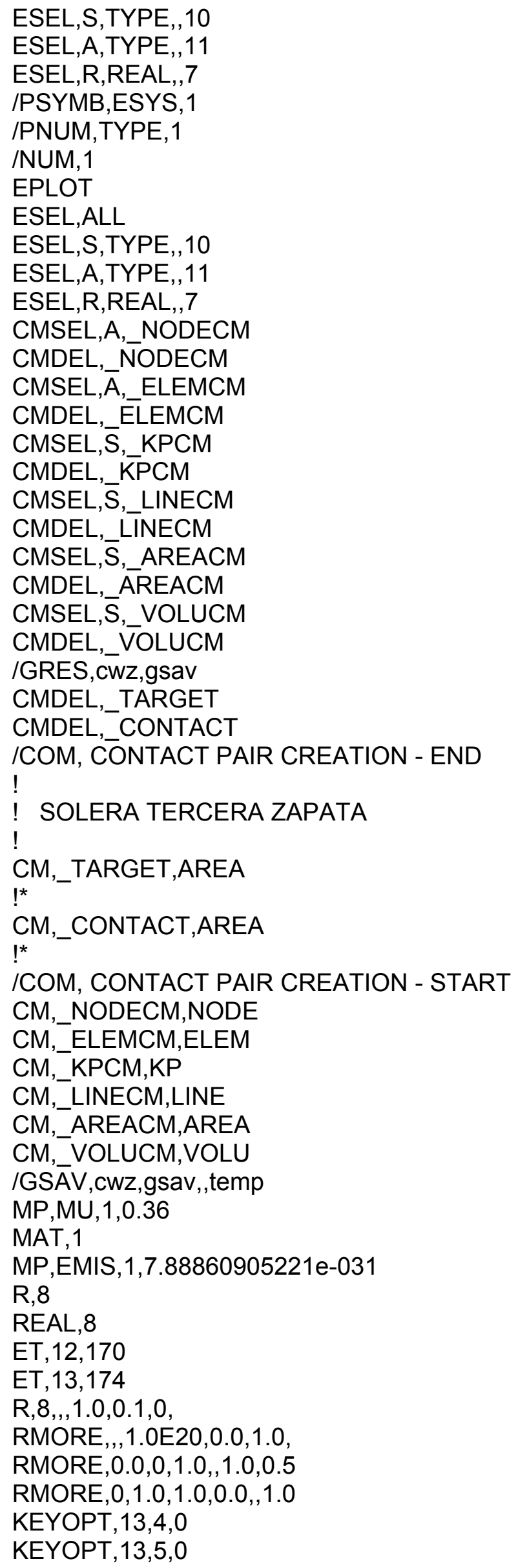




\section{NROPT,UNSYM \\ KEYOPT, 13,7,0 \\ KEYOPT,13,8,0 \\ KEYOPT,13,9,0 \\ KEYOPT,13,10,2 \\ KEYOPT,13,11,0 \\ KEYOPT,13,12,0 \\ KEYOPT,13,2,0 \\ KEYOPT,12,5,0}

! Generate the target surface

ASEL,S, ,,348

ASEL,A,,,354

ASEL,A,,,360

ASEL,A,,,383

ASEL,A,,,389

ASEL,A,,,393

ASEL,A,,,399

ASEL,A,,,406

ASEL,A,,,407

ASEL,A,,,417

ASEL,A,,,419

ASEL, $A,,, 425$

ASEL,A,, ,429

ASEL,A, , ,435

ASEL, $A,,, 441$

ASEL, $A,,, 447$

ASEL,A,,,453

ASEL,A, ,, 473

ASEL,A,,, 479

ASEL,A, ,,483

ASEL,A,,,491

ASEL,A, ,, 494

ASEL,A,,,497

ASEL,A,, ,501

ASEL,A,,, 509

ASEL,A,, ,525

ASEL,A,, ,529

ASEL,A,,,530

ASEL,A,,,531

ASEL,A,,,533

CM,_TARGET,AREA

TYPE, 12

NSLA,S, 1

ESLN,S,0

ESLL,U

ESEL,U,ENAME,,188,189

ESURF

CMSEL,S,_ELEMCM

! Generate the contact surface

ASEL,S, , ,596

ASEL,A,,, 597

ASEL,A, , ,598

ASEL,A,,,600

ASEL,A,,,602

ASEL,A,,,603 


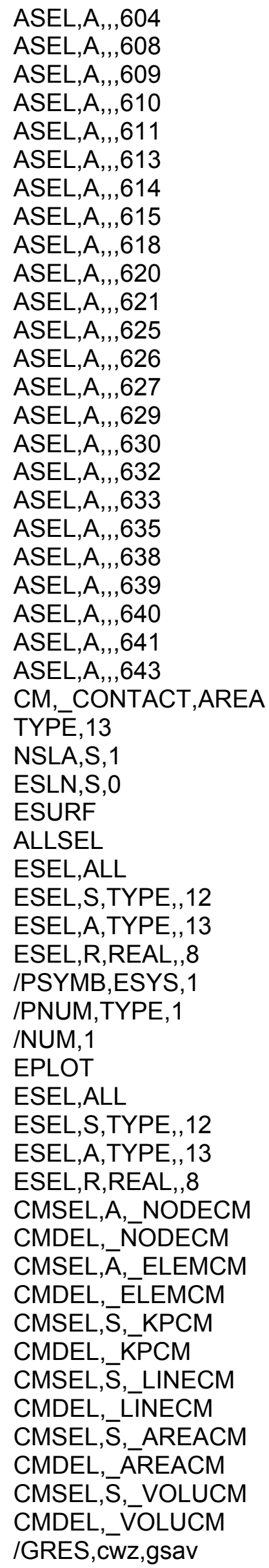




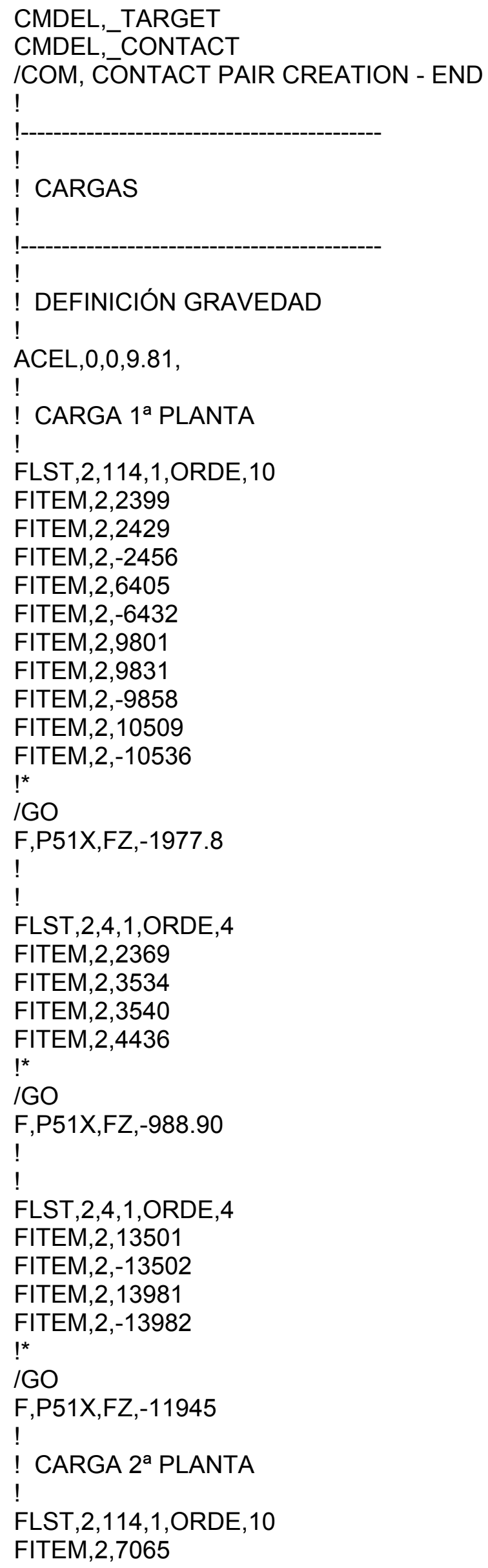




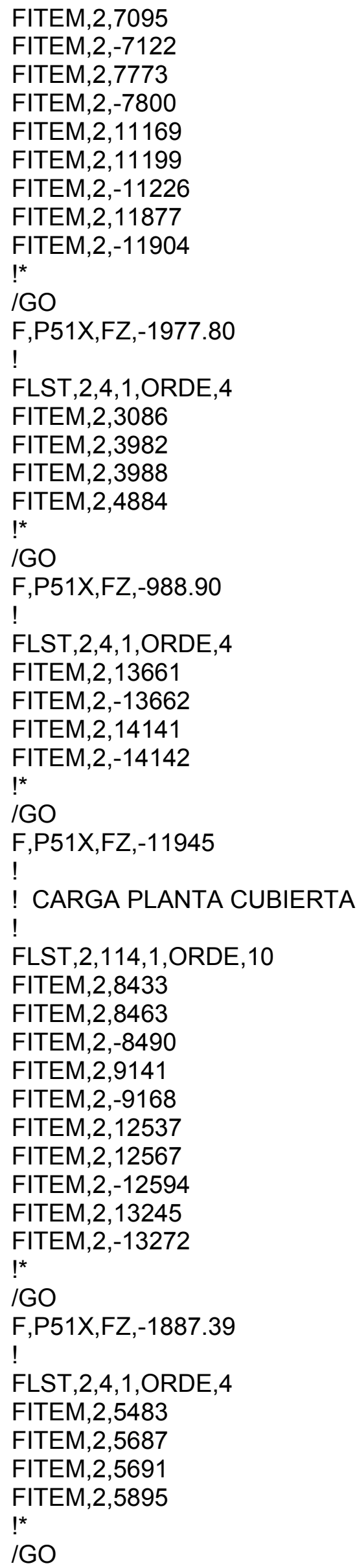


F,P51X,FZ,-943.69

!

FLST, 2,4, 1,ORDE,4

FITEM,2,13821

FITEM,2,-13822

FITEM,2,14301

FITEM,2,-14302

$!^{*}$

/GO

F,P51X,FZ,-5607.5

!

ALLSEL,ALL

EPLOT 

ANEJO II

\section{PARÁMETROS DE CONFIGURACIÓN DEL MATERIAL HORMIGÓN}





\section{ANEJO II}

! Active UNIT system in Workbench when this object was created: Metric $(\mathrm{m}, \mathrm{kg}, \mathrm{N}, \mathrm{s}, \mathrm{V}, \mathrm{A})$

! NOTE: Any data that requires units (such as mass) is assumed to be in the consistent

! solver unit system.

! See Solving Units in the help system for more information.

!

!

HORMIGÓN

!

ET,matid,SOLID65

!

KEYOPT, matid, 1,0

KEYOPT, matid, 3,2

KEYOPT, matid, 5,2

KEYOPT, matid,6,0

KEYOPT, matid, 7,1

KEYOPT, matid, 8,0

!

!

! DIAGRAMA TENSIÓN - DEFORMACIÓN

!

TB, KINH, matid, 1,5,0

TBTEMP,0

TBPT, $0.0005,1.094 \mathrm{E}+007$

TBPT, $0.001,1.875 \mathrm{E}+007$

TBPT,,0.0015,2.344E+007

TBPT, ,0.002,2.5E+007

TBPT, ,0.006,2.55E+007

!

!

!

! MODELO DE FRACTURA Y APLASTAMIENTO

!-

!

TB, CONC, matid, 1,9 ,

TBTEMP, 0

TBDATA, , 0.3,0.8,2.35E+006,2.5E+007, 0,0

TBDATA, ,0,0,0.2,,,

!

!

!

\section{! ADHERENCIA HORMIGÓN ARMADURA}

!

/prep7

allsel,all

cpintf,all,0.01

! 


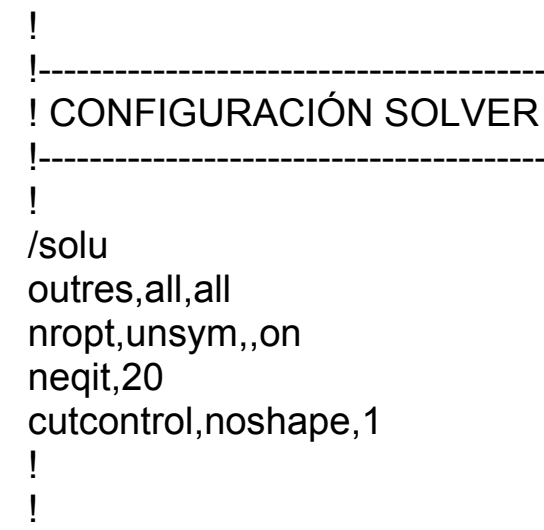

